
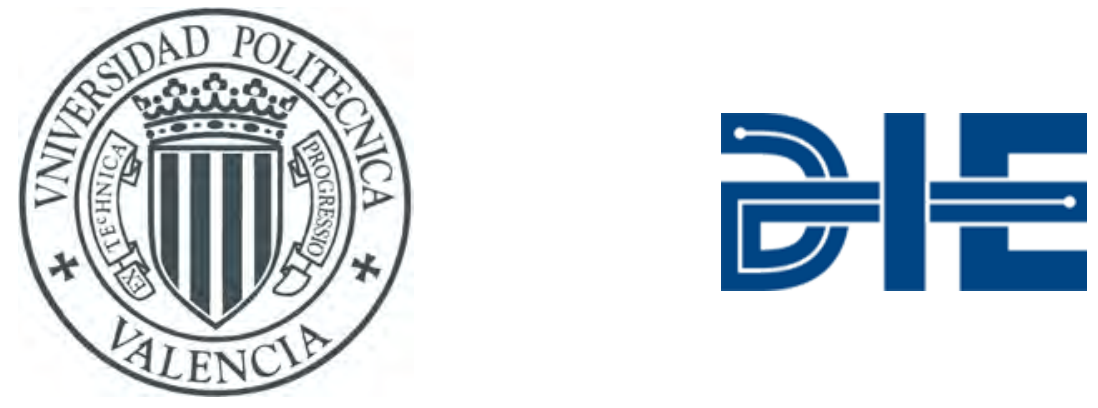

TESIS DOCTORAL

\title{
Requisitos técnicos para la aplicación de sensores de tecnología láser en sistemas inteligentes de transporte (ITS)
}

\author{
Autora: \\ Nieves GALLEGo RiPOLL \\ Director: \\ Dr. Antonio Mocholí S Alcedo
}

01 de Enero de 2010 

If we knew what it was we were doing, it would not be called research, would it?

Albert Einstein 



\section{Resumen}

La seguridad vial se convirtió en una preocupación global en abril de 2004, cuando la Organización Mundial de la Salud (OMS) y las Naciones Unidas publicaron conjuntamente el "Informe mundial sobre prevención de los traumatismos causados por el tráfico". Uno de los errores detectados fue la "insuficiente atención prestada hasta el momento al diseño de sistemas de tráfico”. Es este uno de los motivos que valida, confirma y justifica la investigación que se lleva a cabo en el diseño, desarrollo e implementación de sistemas de tráfico que ayuden a reducir el índice de accidentes de tráfico actuales.

Este conjunto de factores y circunstancias posiciona a la gestión de tráfico como uno de los sectores estratégicos más relevantes hoy en día. Los resultados del informe instaban a las autoridades competentes de tráfico a coordinar, gestionar y monitorizar el tráfico, centrándose en los problemas de Seguridad Vial. Los sistemas de transporte inteligentes, ITS (Intelligent Transportation Systems), se presentan como una solución a las demandas de seguridad vial, gestión de tráfico y movilidad ciudadana. El desarrollo y uso de diversas aplicaciones y tecnologías por parte de los sistemas ITS aumenta la seguridad vial mediante la incorporación de soluciones punteras en diferentes niveles de control y gestión.

En esta tesis se expone, discute y desarrolla una solución ITS eficaz, eficiente y polivalente que puede servir de apoyo a las entidades gestoras de las vías, proporcionándoles información fiel, precisa, exacta, clara y en tiempo real sobre la situación de las mismas. Esta solución está diseñada para ser compatible con cualquier equipo sensor comercial basado en el principio de detección de área, es decir, los láser escáner. 
Partiendo de los sensores y las necesidades del Centro de Gestión de Tráfico (CGT), la investigación desarrollada en esta tesis ha conseguido definir los requerimientos y la arquitectura del bloque intermedio que comunicará ambas áreas. Esto permite implementar y desarrollar las aplicaciones enmarcadas en el ámbito del eSafety tales como: peaje en sombra, información a los usuarios de la vía, ayuda en el control y gestión de tráfico, control de accesos, gestión de incidentes ...

En lo que al hardware se refiere, hay que indicar que se ha diseñado e implementado una plataforma multisensor, capaz de trabajar con diferentes equipos y formatos de información. Dicha unidad hardware realiza un pre-procesado de la señal recibida de modo que, únicamente, la información relevante a la detección de vehículos es enviada al CGT. Un depurado procesado software permite analizar la señal y resolver todos los inconvenientes inherentes a la naturaleza del sensor tales como vistas laterales o reflexiones perdidas.

La metodología seguida en la etapa de clasificación de vehículos se basa en técnicas de reconocimiento de patrones. En el proceso de aprendizaje se han extraído las características del grupo que permiten la discriminación entre clases en base a determinados parámetros predictivos. El éxito del proceso de clasificación se basa en una correcta selección de dichos parámetros. Al tratarse de un caso de aprendizaje supervisado mediante técnicas de modelado no paramétrico se ha recurrido a las técnicas de árboles de decisión, en primer lugar para definir los patrones de cada una de las categorías, y, en segundo, permitir la clasificación de nuevas muestras.

Finalmente, en el proceso de test, se ha usado la técnica de remuestreo adaptativo Bootstrap para el cálculo de los estimadores usados a la hora de evaluar la bondad del sistema de clasificación. Esta técnica es particularmente ventajosa cuando se usa en conjunción con árboles de decisión, ya que estos son relativamente eficientes en casos de muestras con varias dimensiones y tienden a tener una mayor varianza que otros métodos.

Como resultado de un sofisticado análisis de datos, la detección y clasificación de vehículos se efectúa con altos ratios de probabilidad de detección y extremadamente bajos valores de falsas alarmas. Las pruebas de campo han demostrado que el sistema presenta un ratio de 
detección del 97,89\%, con precisión del 99,69\% y exactitud del 97,60\%. El sistema desarrollado presenta un conjunto de: sensor, controlador, software y módulo de comunicaciones que permiten detectar y clasificar vehículos en tiempo real, a la vez que se adquiere y almacena su perfil e imagen 3D. Toda esta información es presentada en el CGT mediante una aplicación especial donde se muestran, además, importantes parámetros de tráfico, claves para la gestión de las vías, tales como: conteo, densidad, intensidad, flujo y ocupación. 



\section{Summary}

The road safety became a global concern with the release of the "World Report on Road Traffic Injury Prevention"” by the United Nations and the World Health Organization in April 2004. Some important mistakes were detected like "insufficient attention to the design of traffic systems". This statement confirms, validates and justifies research the reason to develop and design traffic monitoring systems to help reduce the actual traffic accidents rate.

In this situation, strategic traffic management is a key factor. This report encouraged traffic authorities to coordinate traffic management and monitoring focusing in Road Safety problems. The Intelligent Transport Systems (ITS) present a solution in traffic management and user mobility. The development and use of different applications and technologies in ITS systems increase road safety by incorporating breakthrough solutions in different levels of management and control.

In this thesis it is exposed, discussed and developed an effective, efficient and multipurpose ITS solution that would support the traffic authorities, providing plentiful, diverse, accurate and in real time information about the road situation. This solution is designed to be compatible with any commercial sensor that uses the area detection principle, this is, laser scanners.

The investigation developed in this thesis is based in ITS sensors and the traffic control center (TCC) needs. Therefore, it has been able to define the requirements and architecture of the intermediate block that will communicate both areas. This will help to implement and develop applications framed in the scope of eSafety such as: shadow tolls, travelers' information systems, highways monitoring and management systems, access controls, incidents management... 
Regarding the hardware, it was designed and implemented a multi-sensor platform, able to work with several commercial equipments and different information formats. The hardware unit carries out the signal pre-treatment, but only data captured by the sensor with information from vehicle detection is sent to the TCC. Effective signal-processing software analyzes the signal and treates undesired effects due to the nature of laser scanner, like, lateral views or lost reflections.

The methodology used for vehicle classification is described by means of pattern recognition techniques. In the learning process certain features from the vehicle silhouette are extracted. The selection of the features of the vehicle silhouette used in the discrimination has been key for success in the classification process. In the learning process are extracted the characteristics of the group that allow the discrimination between classes on the basis of certain predictive parameters. The success of the classification process is based on a correct selection of these parameters. Since this is a case of supervised learning solved by using nonparametric modelling techniques, classification trees have been used. This classification or decision trees define the basis of each one of the categories, and are used to classify new samples.

Finally, by means of the Bootstrappping technique adaptive resampling the estimators have calculated the goodness of the classification system. This technique is particularly advantageous when used in conjunction with decision trees. This is because decision tree algorithms are relatively efficient for samples with many dimensions; and decision trees tend to have larger variance components than other methods.

As a result of sophisticated data analysis, a highly accurate vehicle detection and classification is achieved with extremely low false alarm rates. Tests presented good results: namely, detection rates of $97.89 \%$, precision rates in detection of $99.694 \%$ and classification accuracy rates of $94.24 \%$. The system provides a set of sensor, controller, software, and communications modules for detecting and classifying vehicles in real time, acquiring and storing their silhouette and 3D image; as well as other important traffic parameters (density, flow rate, occupancy or traffic volume) shown in a frontend at the TCC. 
La seguretat viària es va convertir en una preocupació global a l'abril del 2004, quan l'Organització Mundial de la Salut (OMS) i les Nacions Unides van publicar conjuntament el "Informe mundial sobre prevenció dels traumatismes causats pel trànsit". Un dels errors detectats va ser la "insuficient atenció prestada fins al moment al disseny de sistemes de trànsit". És este un dels motius que valida, confirma i justifica la investigació que es du a terme en el disseny, desenrotllament i implementació de sistemes de trànsit que ajuden a reduir l'índex d'accidents de trànsit actuals.

Este conjunt de factors i circumstàncies posiciona a la gestió de trànsit com un dels sectors estratègics més rellevants hui en dia. Els resultats de l'informe instaven a les autoritats competents de trànsit a coordinar, gestionar i monitoritzar el trànsit, centrant-se en els problemes de Seguretat Viària. Els sistemes de transport intel-ligents, ITS (Intelligent Transportation Systems), es presenten com una solució a les demandes de seguretat viària, gestió de trànsit i mobilitat ciutadana. El desenrotllament i ús de diverses aplicacions i tecnologies per part dels sistemes ITS augmenta la seguretat viària per mitjà de la incorporació de solucions punteres en diferents nivells de control i gestió.

En esta tesi s'exposa, discutix i desenrotlla una solució ITS eficaç, eficient i polivalent que pot servir de suport a les entitats gestores de les vies, proporcionant-los informació fidel, precisa, exacta, clara i en temps real sobre la situació de les mateixes. Esta solució està dissenyada per a ser compatible amb qualsevol equip sensor comercial basat en el principi de detecció d'àrea, és a dir, els làser escàner. 
Partint dels sensors i les necessitats del Centre de Gestió de Trànsit (CGT), la investigació desenrotllada en esta tesi ha aconseguit definir els requeriments i l'arquitectura del bloc intermedi que comunicarà ambdós àrees. Açò permet implementar i desenrotllar les aplicacions emmarcades en l'àmbit de l'eSafety com ara: peatge en ombra, informació als usuaris de la via, ajuda en el control i gestió de trànsit, control d'accessos, gestió d'incidents ...

Referent al maquinari, cal indicar que s'ha dissenyat i implementat una plataforma multisensor, capaç de treballar amb diferents equips i formats d'informació. Aquesta unitat realitza un preprocessat del senyal rebut de manera que, únicament, la informació rellevant a la detecció de vehicles és enviada al CGT. Un depurat processat programari permet analitzar el senyal i resoldre tots els inconvenients inherents a la naturalesa del sensor com ara vistes laterals o reflexions perdudes.

La metodologia seguida en l'etapa de classificació de vehicles es basa en tècniques de reconeixement de patrons. En el procés d'aprenentatge s'han extret les característiques del grup que permeten la discriminació entre classes basant-se en determinats paràmetres predictius. L'èxit del procés de classificació es basa en una correcta selecció dels paràmetres. Al tractarse d'un cas d'aprenentatge supervisat per mitjà de tècniques de modelatge no paramètric s'ha recorregut a les tècniques d'arbres de decisió, en primer lloc per a definir els patrons de cada una de les categories, i, en segon, permetre la classificació de noves mostres.

Finalment, en el procés de test, s'ha usat la tècnica de remostratge adaptatiu Bootstrap per al càlcul dels estimadors usats a l'hora d'avaluar la bondat del sistema de classificació. Esta tècnica és particularment avantatjosa quan s'usa en conjunció amb arbres de decisió, ja que estos són relativament eficients en casos de mostres amb diverses dimensions i tendixen a tindre una major variança que altres mètodes.

Com resultat d'una sofisticada anàlisi de dades, la detecció i classificació de vehicles s'efectua amb alts ràtios de probabilitat de detecció i extremadament baixos valors de falses alarmes. Les proves de camp han demostrat que el sistema presenta un ràtio de detecció del 97,89\%, amb precisió del 99,69\% i exactitud del 97,60\%. El sistema desenrotllat presenta un conjunt de: sensor, controlador, programari i mòdul de comunicacions que permeten detectar i classificar 
vehicles en temps real, al mateix temps que s'adquirix i emmagatzema el seu perfil i imatge 3D. Tota esta informació és presentada en el CGT per mitjà d'una aplicació especial on es mostren, a més, importants paràmetres de trànsit, claus per a la gestió de les vies, com ara: conteo, densitat, intensitat, flux i ocupació. 



\section{Agradecimientos}

Me gustaría agradecer en primer lugar a la persona que confió en mí para esta investigación, me ha asesorado a lo largo de todo el proceso con sus conocimientos y experiencia, y me ha indicado el camino que me ha llevado hasta aquí, el Dr. Antonio Mocholí.

A los compañeros del grupo de investigación SCT (Sistemas de Control de Tráfico), del Instituto de Investigación ITACA, con los que he colaborado en este periodo, que que me han solventado dudas, han cooperado conmigo y me han animado a seguir en los momentos bajos. Todos ellos han contribuido al resultado final presente en este documento.

A todas las personas que indirectamente han participado en esta tesis contribuyendo con sus aportaciones, de las que he aprendido y de las que espero seguir aprendiendo.

A mi "dies irae" y a mi "chica de letras" por acompañarme siempre, sabiendo estar a mi lado y nunca delante o detrás, por alentar mis sueños desde el principio, confiar ciega e inquebrantablemente en mí, porque soy quien soy gracias a ellos y porque me quiere sin condiciones.

Y a mi piloto. Por las horas perdidas, los abrazos reconfortantes y los desvelos compartidos. 



\section{Índice general}

Índice de figuras

XXV

Índice de tablas $\quad$ xxxi

I Introducción $\quad 1$

1. Introducción 3

1.1. La Seguridad Vial: un problema del siglo XXI . . . . . . . . . . . . 3

1.2. ITS: ¿La solución? . . . . . . . . . . . . . . . . . . . . 7

1.3. La importancia de la información . . . . . . . . . . . . . . . . 10

1.4. Estructura y contenido de la tesis . . . . . . . . . . . . . . . . 12

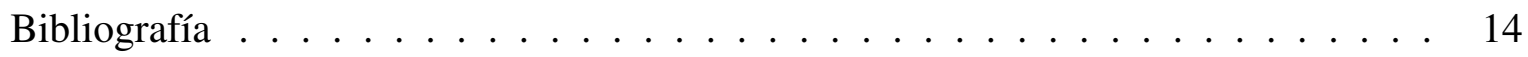

II Estado del Arte $\quad 19$

2. El láser escáner en aplicaciones ITS $\quad 21$

2.1. Tecnologías usadas en ITS . . . . . . . . . . . . . . . . . . 21

2.2. Sensores de Infrarrojo: detectores activos . . . . . . . . . . . . . 26

2.3. Láser Escáner: el porqué ． . . . . . . . . . . . . . . . . . . 27

2.4. Láser Escáner: Antecedentes y trabajos actuales . . . . . . . . . . . . . . . 32

2.5. Láser Escáner: Equipos comerciales . . . . . . . . . . . . . . . 35

2.5.1. SICK: LMS 221-30206 . . . . . . . . . . . . . . . . . . 38 
2.5.2. ACUITY: AccuRange $4000 \ldots \ldots$. . . . . . . . . . . . . 39

2.5.3. OSI LaserScan: AutoSense 800 . . . . . . . . . . . . . . . . . . . 40

2.5.4. ASIM: TT-293 . . . . . . . . . . . . . . . 42

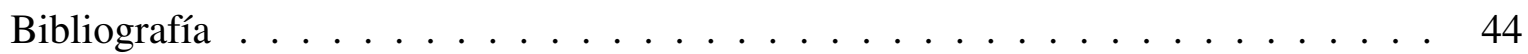

3. Centros de Gestión de Tráfico - CGT 49

3.1. Centros de Gestión de Tráfico Urbano . . . . . . . . . . . . . . . . . . 51

3.2. Arquitectura de un CGT . . . . . . . . . . . . . . . . 53

3.2.1. Sistemas de sensorización y monitorización . . . . . . . . . . . . . . 54

3.2.2. Sistemas de señalización variable . . . . . . . . . . . 55

3.2.3. Sistemas de información de tráfico . . . . . . . . . . . . . . 57

3.2.4. Infraestructuras de comunicaciones $\ldots \ldots \ldots . \ldots 58$

3.3. Parámetros de tráfico necesarios en un CGT . . . . . . . . . . . . . . . . 59

3.3.1. Relación entre los parámetros de tráfico . . . . . . . . . . . . . 61

3.4. Investigación en el sector de tráfico: el caso americano y el caso europeo . . . . 64

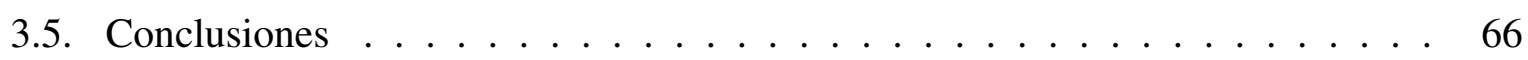

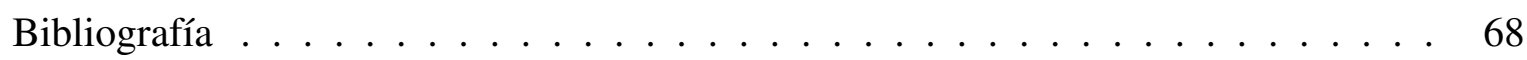

III Hipótesis de partida, Objetivos y Desarrollo 73

$\begin{array}{ll}\text { 4. Objetivos } & 75\end{array}$

$\begin{array}{ll}\text { 5. Materiales y Metodología } & 77\end{array}$

5.1. Metodología . . . . . . . . . . . . . . . . . . . 77

5.2. Programas Desarrollados y Software . . . . . . . . . . . . . 78

5.3. Equipos e Instrumentación . . . . . . . . . . . . . . . . . . . 79

$\begin{array}{ll}\text { 6. Arquitectura Hardware } & 81\end{array}$

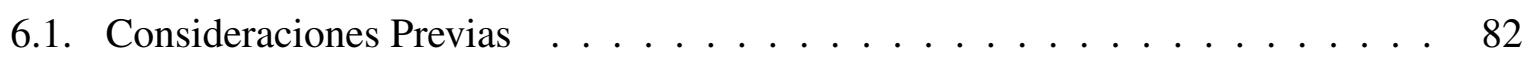

6.1.1. Principio de Operación . . . . . . . . . . . . . . . . . . 82 
6.2. Estudio del caso del equipo comercial SICK LMS 221-30206 . . . . . . . . . 85

6.2.1. Configuración de las comunicaciones . . . . . . . . . . . 85

6.2.2. Conectores del Equipo . . . . . . . . . . . . . . . . . . 88

6.3. Diseño de la placa de circuito impreso . . . . . . . . . . . . . . . . . . 89

6.3.1. Etapas Conversoras . . . . . . . . . . . . . . . . 90

6.3.2. Microprocesador .......................... 92

6.3.3. Alimentación y Otros . . . . . . . . . . . . . . . 95

6.3.4. Comunicaciones . . . . . . . . . . . . . . 97

6.4. Pruebas y validación de la Arquitectura Hardware . . . . . . . . . . . . . . 97

6.4.1. Pruebas de Comunicación Serie . . . . . . . . . . . . . . . . 98

6.4.2. Pruebas de Comunicación Serie mediante una tarjeta PC Card . . . . . 99

6.5. Conclusiones . . . . . . . . . . . . . . . . . 103

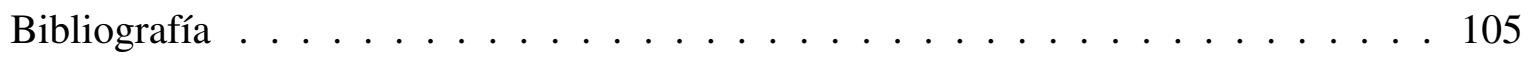

$\begin{array}{ll}\text { 7. Arquitectura Software } & 107\end{array}$

7.1. Firmware DSC . . . . . . . . . . . . . . . . . 108

7.1.1. Generación del baudrate de la UART . . . . . . . . . . . . . . . . 110

7.1.2. Configuración del equipo y normalización de la trama . . . . . . . . . 112

7.1.2.1. Corrección del efecto de ángulo . . . . . . . . . . . . . . 114

7.1.2.2. Detección y eliminación de objetos estáticos sobre la vía . 116

7.1.2.3. Detección de vehículos y envío de información al ordenador . 120

7.2. Software de Procesado realizado en el ordenador . . . . . . . . . . . . . . 122

7.2.1. Reconstrucción de los vehículos . . . . . . . . . . . . . . 123

7.2.1.1. Recepción y tratamiento de las tramas . . . . . . . . . . . 124

7.2.1.2. Distribución de las tramas en vehículos . . . . . . . . . . 125

7.2.1.3. Reconstrucción del vehículo según la posición de escaneo . . 133

7.2.2. Tratamiento de los datos . . . . . . . . . . . . . . . . . . 134

7.2.2.1. Eliminación de las Vistas Laterales . . . . . . . . . . . 135

7.2.2.2. Tratamiento de Reflexiones Perdidas . . . . . . . . . . . . . 139 
7.2.2.3. Técnicas de Interpolación y Diezmado . . . . . . . . . . . 142

7.3. Interfaz Gráfica de Usuario . . . . . . . . . . . . . . . . . . . . . . . . . 144

7.3.1. Bloques Principales . . . . . . . . . . . . . . . . . . 146

7.3.1.1. Representación de la vía y del vehículo . . . . . . . . . . . 146

7.3.1.2. Datos estadísticos . . . . . . . . . . . . . . . 148

7.3.2. Opciones del Interfaz . . . . . . . . . . . . . . . . . . . . 149

7.4. Conclusiones . . . . . . . . . . . . . . . . . 151

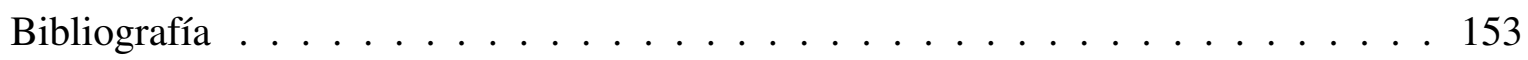

8. Proceso de Clasificación: enfoque y metodología 155

8.1. Técnicas de Reconocimiento de Patrones . . . . . . . . . . . . . . 155

8.1.1. Árboles de decisión . . . . . . . . . . . . . . . . . . . 158

8.1.2. Técnicas de Bootstrap . . . . . . . . . . . . . . . . 161

8.2. Medidas de la investigación . . . . . . . . . . . . . . . . . . . 164

8.2.1. Definiciones de las clases de vehículos . . . . . . . . . . . . . . . 164

8.2.2. Estándares de clasificación . . . . . . . . . . . . . . . . . 166

8.3. Recopilación de datos y creación de la base de datos . . . . . . . . . . . . . 169

8.4. Método de muestreo . . . . . . . . . . . . . . . . . . . . . . 172

8.4.1. Tamaño muestral . . . . . . . . . . . . . . . . . . . 174

8.4.1.1. Cálculo de la afijación . . . . . . . . . . . . . 175

8.4.1.2. Cálculo del tamaño de la muestra . . . . . . . . . . . . 176

8.4.1.3. Cálculo de los tamaños muestrales de cada una de las categorías 177

8.4.1.4. Parque de vehículos: datos proporcionados por la DGT . . 178

8.4.2. Conclusiones . . . . . . . . . . . . . . . . . . . 179

8.5. Proceso Aprendizaje . . . . . . . . . . . . . . . . . . . 182

8.5.1. Parámetros seleccionados . . . . . . . . . . . . . . 182

8.5.2. Definición de patrones: Árboles de clasificación . . . . . . . . . . . . . 184

8.5.2.1. Primera Discriminación . . . . . . . . . . . . . 187

8.5.2.2. Segunda Discriminación . . . . . . . . . . . . . . . . 189 
8.5.2.3. Tercera Discriminación . . . . . . . . . . . . . . 191

8.5.2.4. Cuarta Discriminación . . . . . . . . . . . . . 193

8.5.2.5. Sexta Discriminación . . . . . . . . . . . . . 195

8.5.3. Conclusiones . . . . . . . . . . . . . . . . . 197

8.6. Proceso de Test . . . . . . . . . . . . . . . . . . . . . . 199

8.6.1. Primera Discriminación . . . . . . . . . . . . . . . . 202

8.6.2. Segunda Discriminación . . . . . . . . . . . . . . 203

8.6.3. Tercera Discriminación . . . . . . . . . . . . . . . . . 204

8.6.4. Cuarta Discriminación . . . . . . . . . . . . . . . . . 207

8.6.5. Sexta Discriminación . . . . . . . . . . . . . . . . . . . 209

8.6.6. Conclusiones . . . . . . . . . . . . . . . . 210

8.7. Conclusiones . . . . . . . . . . . . . . . . . 212

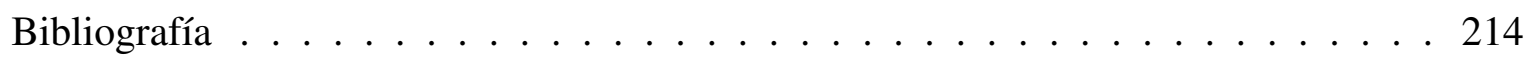

IV Resultados y Evaluación $\quad 219$

9. Resultados y Discusión 221

9.1. Instalación del equipo en la vía . . . . . . . . . . . . . . . . . . 221

9.1.1. Emplazamiento del sistema . . . . . . . . . . . . . . 221

9.1.2. Equipos: conexiones y características . . . . . . . . . . . . 222

9.1.3. Características de la captura de datos . . . . . . . . . . 223

9.2. Detección de vehículos: evaluación . . . . . . . . . . . . . . 225

9.2.1. Pruebas de Laboratorio . . . . . . . . . . . . . . . . . 226

9.2.2. Pruebas de Campo . . . . . . . . . . . . . . . . . . 227

9.3. Clasificación de vehículos: evaluación . . . . . . . . . . . . . . . . . . 229

9.3.1. Pruebas de Laboratorio . . . . . . . . . . . . . . . . . . . . . . 229

9.3.2. Pruebas de Campo . . . . . . . . . . . . . . . . 230

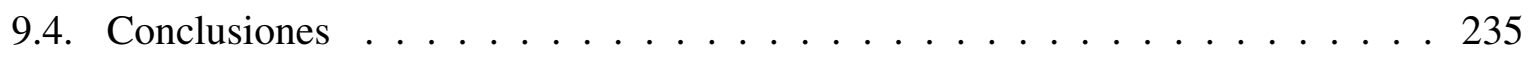




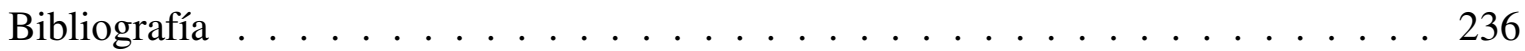

$\begin{array}{lll}\text { V Conclusiones y Trabajo Futuro } & 237\end{array}$

$\begin{array}{ll}\text { 10. Conclusiones } & 239\end{array}$

11. Líneas Futuras de Investigación 249

12. Aportaciones 253

12.1. Trabajos colaterales desarrollados . . . . . . . . . . . . 253

12.1.1. Sensores Inteligentes: Proyecto TRACKSS . . . . . . . . . . . . . 253

12.1.1.1. Arquitectura Operacional . . . . . . . . . . . 255

12.1.1.2. Arquitectura Funcional . . . . . . . . . . . . 257

12.1.1.3. Validación de resultados: Colaboraciones . . . . . . . . . 258

12.1.1.4. Conclusión . . . . . . . . . . . . . . . 261

12.1.2. Estudio del caso del equipo comercial Acuity Accurange 4000 . . . . . 262

12.1.2.1. Arquitectura Hardware . . . . . . . . . . . . . 263

12.1.2.2. Arquitectura Software . . . . . . . . . . . . 266

12.1.2.3. Validación de resultados . . . . . . . . . . . . . . . 268

12.1.2.4. Conclusiones . . . . . . . . . . . . . . . . 269

12.2. Publicaciones . . . . . . . . . . . . . . . . . 270

12.2.1. Artículos en Congresos Nacionales . . . . . . . . . . . . . . 270

12.2.2. Artículos en Congresos Internacionales . . . . . . . . . . . . . 272

12.2.3. Artículos en Revistas . . . . . . . . . . . . . . . . . . . . . . 273

12.2.4. Proyecto Europeo TRACKSS - 7PM . . . . . . . . . . . . . 273

12.2.5. Otros Artículos en el área ITS . . . . . . . . . . . . . . . . . 274

Bibliografía . . . . . . . . . . . . . . . . . 275 
VI Anexos

A. Imágenes de vehículos por clases 279

A.1. Clase Motocicletas . . . . . . . . . . . . . . . . . . . . . . 279

A.2. Clase Tipo Turismo . . . . . . . . . . . . . . . . . . . . . 280

A.3. Clase Furgonetas . . . . . . . . . . . . . . . . . . . 283

A.4. Clase Camiones . . . . . . . . . . . . . . . . . . . 285

A.5. Clase Camiones con tráiler . . . . . . . . . . . . . . . . . . 288

A.6. Clase Autobuses . . . . . . . . . . . . . . . . . . . . . . . . 290

B. Código programa para la extracción de características: ClasiCoche 291

C. Código programa para diseño de los árboles de decisión: Generar_arboles

D. Código programa para el análisis mediante la técnica Bootstrap: GruposTest

Lista de acrónimos y símbolos 



\section{Índice de figuras}

1.1. Logotipo de la Semana Mundial para la Seguridad Vial . . . . . . . . . . 5

1.2. Diferentes organizaciones de ITS en el mundo . . . . . . . . . . . . . 10

2.1. Diferentes tipos de sensores intrusivos . . . . . . . . . . . . 23

2.2. Diferentes tipos de sensores no intrusivos . . . . . . . . . . . . . . 24

2.3. Sistema Láser Escáner empleado por H. Cheng et al. . . . . . . . . . . . . 33

2.4. Sistema Láser Escáner empleado por S.A. Ahmned et al. . . . . . . . . . . . 33

2.5. Sistema Láser Escáner empleado por C. Harlow . . . . . . . . . . . . . . . . 34

2.6. Sistema Láser Escáner empleado por J. Pehkonen . . . . . . . . . . . . . . 35

2.7. Principio de operación del LMS 221-30206 . . . . . . . . . . . . . . . 39

2.8. Tecnología de medida de distancias aplicada en el AR4000 . . . . . . . . . 40

2.9. Principio de operación del equipo AutoSense $800 \ldots \ldots$. . . . . . . . . . 41

2.10. Zonas de detección del equipo TT-293 . . . . . . . . . . . . . . . . . . 42

3.1. Arquitectura de un CGT Urbano . . . . . . . . . . . . . . . . . 53

3.2. Sistemas de monitorización mediante cámaras . . . . . . . . . . . 55

3.3. Sistemas de señalización variable . . . . . . . . . . . . . . . 56

3.4. Sistemas de información de tráfico . . . . . . . . . . . . . . 58

3.5. Relaciones generalizadas entre los parámetros de intensidad, densidad y velocidad en tráfico continuo $\ldots \ldots \ldots$. . . . . . . . . . . . . 63

6.1. Principio de operación $\ldots \ldots \ldots \ldots$. . . . . . . . . . 83

6.2. Medida de alturas . . . . . . . . . . . . . . . . . 83 
6.3. Captura de la trama de inicio . . . . . . . . . . . . . . . . 87

6.4. Conexiones traseras del sensor LMS . . . . . . . . . . . . . . . . . 88

6.5. Conector Serie del sensor LMS . . . . . . . . . . . . . . . . . . . . . . . . 88

6.6. Diseño de la PCB . . . . . . . . . . . . . . . . . . . . . . . . . . . . 89

6.7. Esquemático Conversor Serie-USB . . . . . . . . . . . . . . . . . . . . 91

6.8. Esquemático Conversores Varios . . . . . . . . . . . . . . . . . . 91

6.9. PCB: Etapas Conversoras . . . . . . . . . . . . . . . . . . . . . . . 92

6.10. Esquemático Microprocesador . . . . . . . . . . . . . . . . . 93

6.11. Esquemático Oscilador Externo _. . . . . . . . . . . . . . . . . 93

6.12. DSC modelo dsPIC30F4011 . . . . . . . . . . . . . . . 95

6.13. Esquemático Alimentación . . . . . . . . . . . . . . . . . . . 96

6.14. PCB: Etapas varias . . . . . . . . . . . . . . . . . . 96

6.15. Comunicaciones en la PCB . . . . . . . . . . . . . . . . . . 98

6.16. Prueba de comunicaciones serie: prototipo . . . . . . . . . . . . . . 99

6.17. Prueba de comunicaciones serie: captura de pantalla . . . . . . . . . . . 100

6.18. Prueba de comunicaciones serie via PC Card . . . . . . . . . . . . . . . 102

6.19. Prueba de comunicaciones serie: captura de pantalla . . . . . . . . . . . . . 102

6.20. Hardware diseñado e implementado . . . . . . . . . . . . . . . . . 103

7.1. Arquitectura general del sistema . . . . . . . . . . . . . . . 108

7.2. Tareas del DSC . . . . . . . . . . . . . . . . . 110

7.3. Diagrama de flujo del Firmware . . . . . . . . . . . . . . . 113

7.4. Vector "datos_escaneados" . . . . . . . . . . . . . . . . . . 114

7.5. Vector "vector_ángulo" . . . . . . . . . . . . . . . . 115

7.6. Vector "valores_medidos" . . . . . . . . . . . . . . . . . . 116

7.7. "Vector_Offset" . . . . . . . . . . . . . . . . 117

7.8. "Vector_Offset" corregido . . . . . . . . . . . . . . . . 117

7.9. Vehículos detectados sobre la vía . . . . . . . . . . . . . . 118

7.10. Cálculo del valor medido . . . . . . . . . . . . . . . . . . . . . . . 119 
7.11. Zoom realizado sobre la representación de la vía en ausencia de vehículos . . 119

7.12. Representación de la vía en ausencia de vehículos . . . . . . . . . . . . . 120

7.13. Procesado llevado a cabo en el ordenador . . . . . . . . . . . . . . . 123

7.14. Vía: planta . . . . . . . . . . . . . . . . . . . . . . . . 124

7.15. Vía: vista $3 \mathrm{D} \ldots \ldots \ldots \ldots$. . . . . . . . . . . . . . . . 124

7.16. Diagrama de Flujo del algoritmo de distribución de las tramas . . . . . . . . 128

7.17. Diferentes escaneos realizados sobre la vía . . . . . . . . . . . . . 131

7.18. Vehículos detectados . . . . . . . . . . . . . . . . . 134

7.19. Casos reales de vistas laterales . . . . . . . . . . . . . . . 136

7.20. Vistas Laterales . . . . . . . . . . . . . . . . . . . . 137

7.21. Matriz con información de autobús y turismo . . . . . . . . . . . . 137

7.22. Matrices de los vehículos tras el tratamiento de vistas laterales . . . . . . . 139

7.23. Turismo que presenta casos de reflexiones perdidas . . . . . . . . . . 140

7.24. Turismo tras la eliminación de reflexiones perdidas . . . . . . . . . . . 141

7.25. Vehículos con reflexiones perdidas: antes y después . . . . . . . . . . . . . 142

7.26. Casos extremos de reflexiones perdidas: antes y después $\ldots$. . . . . . . . 143

7.27. Interpolación y Diezmado: antes y después . . . . . . . . . . . . . . . . . . 144

7.28. Interfaz Gráfico de Usuario: Bloques . . . . . . . . . . . . . . . . . 146

7.29. GUI: Representación de la vía . . . . . . . . . . . . . . . . . . . . 147

7.30. GUI: Representación del vehículo . . . . . . . . . . . . . . . . . . . 148

7.31. GUI: Clases de Vehículos . . . . . . . . . . . . . . . . . . . . . . . . . 148

7.32. GUI: Estadísticos ． . . . . . . . . . . . . . . . . . . . 149

7.33. GUI: Opciones . . . . . . . . . . . . . . . . . 150

7.34. GUI: Configuración del sensor . . . . . . . . . . . . . . . . . 151

7.35. Requerimientos Software . . . . . . . . . . . . . . . . 151

8.1. Arquitectura de Reconocimiento de Patrones . . . . . . . . . . . . . . . . 157

8.2. Estándar AUSTROADS Fuente: www.austroads.com.au $\ldots \ldots$. . . . . . . . . 167

8.3. Estándar FHWA Fuente: www.fhwa.dot.gov . . . . . . . . . . . . . . . . . . . 168 
8.4. Diseño de la base de datos . . . . . . . . . . . . . . . . . . . 172

8.5. Aspecto de la base de datos . . . . . . . . . . . . . . . . . . 173

8.6. Árbol de clasificación . . . . . . . . . . . . . . . . . . . . . . . 185

8.7. Primera Discriminación: árbol de clasificación . . . . . . . . . . . . . . . . 188

8.8. Primera Discriminación: Tamaño óptimo del árbol . . . . . . . . . . . . . . . 188

8.9. Segunda Discriminación: árbol de clasificación . . . . . . . . . . . . . . . . 189

8.10. Segunda Discriminación: Tamaño óptimo del árbol ～. . . . . . . . . . . . . 190

8.11. Tercera Discriminación: árbol de clasificación . . . . . . . . . . . . . . . . . 192

8.12. Tercera Discriminación: Tamaño óptimo del árbol . . . . . . . . . . . . . . 193

8.13. Cuarta Discriminación: árbol de clasificación . . . . . . . . . . . . . . . . 194

8.14. Cuarta Discriminación: Tamaño óptimo del árbol . . . . . . . . . . . . . . 195

8.15. Sexta Discriminación: árbol de clasificación . . . . . . . . . . . . . . 196

8.16. Sexta Discriminación: Tamaño óptimo del árbol ․ . . . . . . . . . . . . . 197

8.17. Programa para la obtención de los parámetros . . . . . . . . . . . . . . 198

8.18. Flujo del Proceso de Aprendizaje . . . . . . . . . . . . . . . . . . . . 199

8.19. Diagrama de dispersión . . . . . . . . . . . . . . . . . . . 202

8.20. Histograma de la exactitud en la segunda discriminación _ . . . . . . . . . 204

8.21. Histograma de la segunda discriminación por clases . . . . . . . . . . . 205

8.22. Histograma de la exactitud en la tercera discriminación . . . . . . . . . . 206

8.23. Histograma de la tercera discriminación por clases _ . . . . . . . . . . 207

8.24. Histograma de la exactitud en la cuarta discriminación . . . . . . . . . . 208

8.25. Histograma de la cuarta discriminación por clases _ . . . . . . . . . . . 209

8.26. Histograma de la exactitud en la sexta discriminación . . . . . . . . . . 210

8.27. Histograma de la sexta discriminación por clases _ . . . . . . . . . . 211

8.28. Flujo del Proceso de Test . . . . . . . . . . . . . . . . . . . 211

8.29. Programa para la generación de los grupos de test . . . . . . . . . . . . 212

9.1. Emplazamiento del sistema . . . . . . . . . . . . . . . . . . 222

9.2. Cruce bajo estudio . . . . . . . . . . . . . . . . . 223 
9.3. Instalación en la vía . . . . . . . . . . . . . . . . . . . . . . . . . 224

9.4. Vehículos de la clase Turismo: Todoterrenos . . . . . . . . . . . . . . . 232

9.5. Vehículos de la clase Camión . . . . . . . . . . . . . . . . . 233

9.6. Camión grúa . . . . . . . . . . . . . . . . . . . . 233

9.7. Vehículos de la clase Furgoneta . . . . . . . . . . . . . . . . . . . 234

10.1. Implementación de la Arquitectura Hardware . . . . . . . . . . . . . . 240

10.2. Diferentes Programas Desarrollados . . . . . . . . . . . . . . . 242

10.3. Árbol de clasificación . . . . . . . . . . . . . . . . . . . . . . . . 244

10.4. Esquema de la tesis . . . . . . . . . . . . . . . . . . 248

12.1. Cronograma del proyecto TRACKSS . . . . . . . . . . . . 255

12.2. Arquitectura del KSS Láser Escáner . . . . . . . . . . . . . . . . 256

12.3. Interacción: anuncio-subscripción-publicación . . . . . . . . . . . . . 258

12.4. Modificación de los sensores afectados por la intensidad luminosa en la vía . . 260

12.5. Restricción de la entrada de vehículos al centro urbano . . . . . . . . . . . . 261

12.6. Modelo Accurange y AccuRange Line Scanner . . . . . . . . . . . . . . 263

12.7. Conectores: modelo comercial Acuity . . . . . . . . . . . . . . 265

12.8. Montaje realizado con el modelo comercial Acuity . . . . . . . . . 266

12.9. Arquitectura general del sistema: modelo comercial Acuity . . . . . . . . . . 266

12.10Test Laboratorio: imagen 3D Equipo Acuity . . . . . . . . . . . . . . 269

12.11.Test Laboratorio Equipo Acuity . . . . . . . . . . . . . . . . . . 269

A.1. Vehículos de la categoría: Motocicleta . . . . . . . . . . . . . . 280

A.2. Vehículos de la categoría: Tipo Turismo . . . . . . . . . . . . . 283

A.3. Vehículos de la categoría: Furgoneta . . . . . . . . . . . . . . . . 284

A.4. Vehículos de la categoría: Camión . . . . . . . . . . . . . . . 288

A.5. Vehículos de la categoría: Camión con tráiler . . . . . . . . . . . . . . . . 289

A.6. Vehículos de la categoría: Autobús . . . . . . . . . . . . . . . . . 290 



\section{Índice de tablas}

2.1. Comparativa de las tecnologías usadas en ITS . . . . . . . . . . . . . 25

2.2. Tecnologías: Información proporcionada y coste del equipo [MK07] . . . . . . 30

2.3. Comparativa de equipos comerciales . . . . . . . . . . . . . . . 37

6.1. Bytes que miden la distancia $\ldots \ldots \ldots \ldots$. . . . . . . . . . . 84

6.2. Rangos de medidas . . . . . . . . . . . . . . . . . 85

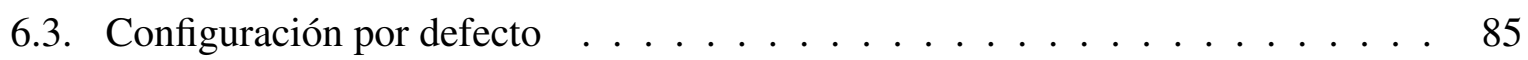

6.4. Datos capturados ASCII-Hexadecimal . . . . . . . . . . . . . . . . 88

6.5. Valores de Badurate de la PC Card . . . . . . . . . . . . . . . . . 101

6.6. Requerimientos Hardware . . . . . . . . . . . . . . . . . . . . 104

7.1. Generador del baudrate con el oscilador a $7,5 \mathrm{MHz}$. . . . . . . . . . . . 111

7.2. Generador del baudrate con el oscilador a $6 \mathrm{MHz}$. . . . . . . . . . . . . . 112

7.3. Número de valores del “vector_ángulo” para cada una de las posibles combinaciones . . . . . . . . . . . . . . . . . . 115

7.4. Formato de la trama . . . . . . . . . . . . . . . . . . . 121

8.1. Estándar TLS de clasificación de vehículos . . . . . . . . . . . . . . . 170

8.2. Número de vehículos presentes en la base de datos y por procesos . . . . . . 172

8.3. Valores de la afijación para cada una de las categorías . . . . . . . . . . 176

8.4. Valores de los tamaños de la muestra para cada una de las categorías . . . . . . 178

8.5. Cálculo del tamaño de las categorías. Parque de vehículos provincia de Valencia

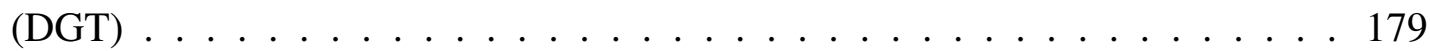


8.6. Cálculo del tamaño de las categorías. Parque de vehículos nacional (DGT) . . . 179

8.7. Comparativa tamaños muestrales por categorías . . . . . . . . . . . . 180

8.8. Porcentaje por categorías respecto a al población total . . . . . . . . . . . . . 181

8.9. Parámetros de la Primera Discriminación . . . . . . . . . . . . . . . . . . 189

8.10. Parámetros de la Segunda Discriminación . . . . . . . . . . . . . . . . 191

8.11. Parámetros de la Tercera Discriminación . . . . . . . . . . . . . . . . 193

8.12. Parámetros de la Cuarta Discriminación . . . . . . . . . . . . . . . . 195

8.13. Parámetros de la Sexta Discriminación . . . . . . . . . . . . . . . . . . 197

8.14. Matriz de Confusión _. . . . . . . . . . . . . . . . . . . 200

8.15. Matriz de Confusión de la Primera discriminación . . . . . . . . . . . . . . 202

8.16. Matriz de Confusión de la Segunda discriminación . . . . . . . . . . . 203

8.17. Matriz de Confusión de la Tercera Discriminación . . . . . . . . . . . . . 205

8.18. Matriz de Confusión de la Cuarta Discriminación . . . . . . . . . . . . 208

8.19. Matriz de Confusión de la Sexta Discriminación . . . . . . . . . . . . . . . 210

9.1. Equipos instalados y características . . . . . . . . . . . . . . . . . 224

9.2. Test de Laboratorio - Detección de Vehículos . . . . . . . . . . . . . . . . 226

9.3. Test Experimental - Detección de Vehículos . . . . . . . . . . . . . . . . 228

9.4. Test Experimental - Clasificación de vehículos: Matriz de confusión . . . . . 230

9.5. Test Experimental - Clasificación de vehículos: Evaluación . . . . . . . . . 231

10.1. Requerimientos Funcionales . . . . . . . . . . . . . . . . . . . . 247

12.1. Configuración por defecto . . . . . . . . . . . . . . . . . 264

12.2. Formato de la trama: modelo comercial Acuity . . . . . . . . . . . . 267 


\section{Parte I}

\section{Introducción}





\section{Capítulo 1}

\section{Introducción}

\subsection{La Seguridad Vial: un problema del siglo XXI}

Es un hecho incuestionable que las necesidades de los ciudadanos han cambiado a lo largo de los últimos tiempos. Objetos, bienes, cualidades y situaciones que antes nos eran indiferentes actualmente ocupan una elevada posición en nuestra escala de valores. Un ejemplo de ello es la seguridad que en la sociedad en la que vivimos es un activo en alza que está alcanzando cotas muy importantes. Su interés se ve reflejado en el hecho de que para la mayoría de ciudadanos poseer este valor se ha vuelto casi una exigencia. Necesitamos sentirnos seguros y esa exigencia se ve reflejada en todos los ámbitos de nuestra vida: seguridad en el trabajo, seguridad jurídica, seguridad ciudadana, seguridad en el hogar, seguridad vial, seguridad informática ...

Hoy en día, todos los trabajadores exigen que las empresas en las que desarrollan su labor posean unas mínimas normas de seguridad; los ciudadanos que viven en zonas más inseguras de las ciudades exigen a las autoridades responsables mejoras en la seguridad ciudadana de su barrio; exigimos que se protejan nuestra información personal de las miles de bases de datos gubernamentales; la lista sería interminable. Cualquier tema que abarque estas áreas adquiere rápidamente un gran valor social. Ese es el caso de la Seguridad Vial, tema que nos va a ocupar en esta tesis.

La seguridad vial se convirtió en una preocupación global en abril de 2004, cuando la Asamblea General de la Organización de las Naciones Unidas (ONU) aprobó una resolución en la que instaba a la mejora de la seguridad vial en el mundo [ONU04]. Para lo cual, invitó 
a la Organización Mundial de la Salud a que coordinara las cuestiones de seguridad vial en el sistema de las Naciones Unidas. Dicha resolución dio lugar a la aparición del "Grupo de colaboración de las Naciones Unidas para la Seguridad Vial" (UN Road Safety Collaboration) con representantes de más de 42 organizaciones.

Ese mismo año, la Organización Mundial de la Salud (OMS) y el Banco Mundial publicaron conjuntamente el "Informe mundial sobre prevención de los traumatismos causados por el tráfico" $\left[\mathrm{PSS}^{+} 04\right]$. En este informe se exponían datos tan preocupantes como: "De todos los sistemas con los que las personas han de enfrentarse cada día, los del tráfico son los más complejos y peligrosos. Se estima que, cada año, en el mundo mueren 1,2 millones de personas por causa de choques en la vía pública y hasta 50 millones resultan heridas. Las proyecciones indican que, sin un renovado compromiso con la prevención, estas cifras aumentarán en torno al $65 \%$ en los próximos 20 años.”

En dicho informe se destacaba "la preocupación de ambos organismos por el hecho de que los sistemas de tráfico inseguros estén dañando gravemente la salud pública y el desarrollo mundiales". Una de las medidas correctivas que se presentaban como remedio y solución era "disponer de la capacidad de realizar investigaciones científicas en los propios sistemas de tráfico y determinar las tecnologías conocidas que podrían ser adecuadas y las adaptaciones que se necesitarían. Además, las características particulares del tránsito nacional y local probablemente exijan desarrollar nuevas tecnologías." $\left[\mathrm{PSS}^{+} 04\right]$. Es este uno de los motivos que valida, confirma y justifica la investigación que se lleva a cabo en el diseño, desarrollo e implementación de sistemas de tráfico que ayuden a reducir el índice de accidentes de tráfico actuales.

El "Grupo de colaboración de las Naciones Unidas para la Seguridad Vial”, además de desarrollar una serie de manuales de buenas prácticas y libros blancos o realizar el seguimiento de las legislaciones a nivel mundial en materia de seguridad vial, entre otros, llevó a cabo del 23 al 29 de abril del 2007 la primera semana de las Naciones Unidas para la Seguridad Vial [ONU07], cuyo logotipo se representa en la figura 1.1. Este evento demostró la importancia que a nivel 
mundial había adquirido la seguridad vial y la necesidad de aunar recursos e investigación en esta línea de trabajo.
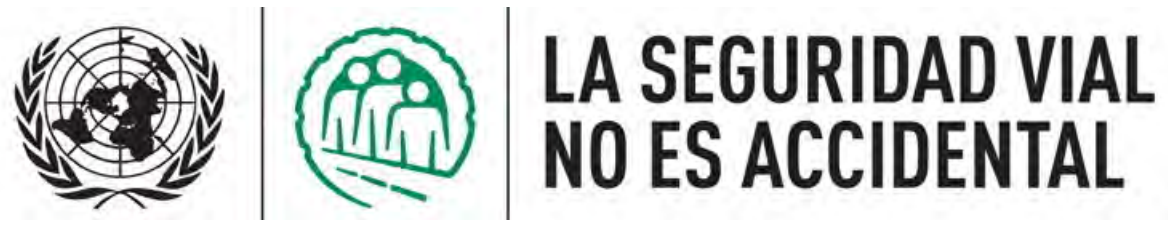

Figura 1.1 - Logotipo de la Semana Mundial para la Seguridad Vial

Las resoluciones más importantes llevadas a cabo por Naciones Unidas en relación a la Seguridad Vial se pueden resumir en:

- Mayo 2003 - Asamblea General ONU: Global Road Safety crisis. Llamamiento a los Gobiernos y la sociedad civil para incrementar la sensibilización y hacer respetar la legislación existente respecto a seguridad vial [UN03b].

- Noviembre 2003 - Asamblea General ONU: Global Road Safety crisis. Se formaliza el punto "Mejoras en la Seguridad Vial" en la agenda de la Sexagésima Sesión de la Asamblea General [UN03a].

- Mayo 2004 - Asamblea General ONU: Improving Road Safety. Se hace mención al lanzamiento del "Informe mundial sobre prevención de los traumatismos causados por el tráfico" [UN04].

- Mayo 2004 - Asamblea de la OMS: Road Safety and Health. Llamamiento para fomentar la investigación de propuestas basadas en la evidencia para la prevención de lesiones causadas por el tráfico y la reducción de sus consecuencias [WHA04].

- Octubre 2005 - Asamblea General ONU: Improving Global Road Safety. Llamamiento para animar a la comunidad internacional a liderar el apoyo financiero, técnico y político para mejorar la seguridad vial [UN05].

- Marzo 2008 - Asamblea General ONU: Improving Global Road Safety. Llamamiento al sector público y privado a implementar políticas que reduzcan el riesgo de accidente para los ocupantes de vehículos y otros usuarios de la vía [UN08].

Los días 19 y 20 de noviembre de 2009 ha tenido lugar en Moscú la primera conferencia global de ministros sobre Seguridad Vial, solicitada por la Asamblea General de la ONU. En ella 
han participado diferentes personalidades como: ministros de sanidad, transporte, educación y asuntos exteriores, representantes de las agencias de Naciones Unidas, líderes de organizaciones no gubernamentales y de la sociedad civil, representantes de empresas privadas, y diversos expertos mundiales en el campo de la seguridad vial [ONU09]. Los resultados de esta conferencia han servido para la elaboración del informe "Una década de acción en la seguridad vial" que será aprobado por la Asamblea General de la ONU en 2010.

Todas estas actuaciones por parte de la ONU vienen avaladas por otras similares tanto a nivel europeo como nacional. La Unión Europea, dentro de su "Programa europeo de acción en seguridad vial 2003-2010" [EC03], promovió la iniciativa eSafety con la que se pretendía formular recomendaciones y proponer una serie de medidas a escala comunitaria, además de reforzar las actividades de investigación en el ámbito de la seguridad vial, en particular, en el contexto del sexto programa marco de investigación.

El mismo programa invitaba a los estados miembros a "aumentar su cooperación e intercambiar sus experiencias en materia de prevención y análisis de los accidentes, gracias a instrumentos comunes desarrollados a partir de la base de datos CARE o mediante la creación de un observatorio europeo de la seguridad vial, que reunirá todas las actividades de apoyo, tanto para los expertos de la seguridad vial como para el público en general" (Programa de Acción Europeo de seguridad vial [EC03] 2003:41 y Libro blanco "Política Europea de Transportes de cara al 2010: la hora de la verdad" [EU02] 2002:77). Estas acciones derivaron en la creación del "Observatorio Europeo para la Seguridad Vial" (European Road Safety Observatory) en el año 2003 financiado mediante el IP SafetyNet dentro del sexto programa marco de investigación. Otra iniciativa más por parte de la Comisión Europea ha llevado a establecer el día Europeo de las Seguridad Vial. En el año 2008 se celebró su segunda y, por ahora, última edición el día 13 de octubre en París [EC08].

Dentro del marco español, ya en el año 1979 se promulgó el primer "Plan nacional de Seguridad Vial” [DGT03]. El Real Decreto 1544/1997, de 3 de octubre de 1997, modificado posteriormente en el Real Decreto 1947/2000, del 1 de diciembre de 2000 [BOE00], creó la Comisión Interministerial de Seguridad Vial para lograr una mayor eficacia en la lucha contra 
los accidentes de circulación en las vías públicas. Más tarde, el 14 de marzo, mediante el Real Decreto 317/2003 [BOE03], se reguló la organización y funcionamiento del Consejo Superior de Tráfico y Seguridad de la Circulación Vial. Se trata de un órgano colegiado de carácter consultivo para el impulso y mejora del tráfico y la seguridad vial tanto en el ámbito urbano como interurbano, adscrito al Ministerio del Interior [BOE03]. Finalmente, el 2 de julio de 2004, mediante el Real Decreto 1599/2004 [BOE04] se creó el Observatorio Nacional de Seguridad Vial dependiente de la Dirección General de Tráfico (DGT) y con funciones dentro de los ámbitos de la seguridad vial como: el impulso de políticas, apoyo a la investigación, y análisis de datos y estadísticas.

En el “Plan Estratégico de Seguridad Vial: 2005-2008” [DGT06b] la DGT presentaba diferentes acciones a llevar a cabo para "disminuir tanto los accidentes de tráfico como la gravedad de los mismos” ([DGT06b] 2006:30). La implantación de dicho plan ha logrado la reducción del número de fallecidos en accidentes de tráfico, por lo que España ha recibido en el año 2009 el "Premio a la Seguridad Vial 2009" otorgado por el Consejo Europeo para la Seguridad en el Transporte (ETSC, acrónimo del inglés European Transport Safety Council) "por ser uno de los países que más ha progresado en la reducción de fallecidos en carretera” [DGT09b]. Actualmente se encuentra en vigor el "Programa de acción europeo de seguridad vial (20032010)".

Entre las actuales actividades de la DGT destaca la creación de un "Portal de Educación Vial" en el año 2009, donde se define esta como "parte de la educación social, siendo una eficaz base de actuación ciudadana, dado que trata de crear hábitos y actitudes positivas de convivencia, de calidad de vida, calidad medioambiental y la SEGURIDAD VIAL.” [DGT09a], fijando la atención así en la importancia de la Seguridad Vial a todos los niveles.

\subsection{ITS: ¿La solución?}

El escenario planteado manifiesta la importancia a nivel global que ha adquirido la seguridad vial, así como la preocupación desde todas las esferas de gobierno (ONU, UE, Gobierno de 
España ...) por este tema. El principal objetivo de todas las políticas y planes de seguridad vial se centran actualmente en la reducción de muertes en carretera ([DGT06a] 2006:6 y [EU02] 2002:79). Las estadísticas de accidentes de tráfico reflejan que buena parte de ellos son ocasionados por exceso de velocidad, condiciones climatológicas adversas o la presencia de obstáculos en la calzada [Nor06, DGT06a].

Para reducir la siniestralidad y mejorar con ello la seguridad vial hay que trabajar en dos líneas principales:

- Información - Trabajar en ampliar y mejorar la información de que se dispone. No solo las características de las vías y velocidad a la que se desplazan los vehículos, sino también todos los parámetros que se puedan medir, resulten indicativos de las condiciones de la vía y aporten información útil y susceptible de ser administrada por los centros de gestión de tráfico (CGT) [DGT06b, Oda07, $\mathrm{CBU}^{+}$97].

- Comunicaciones - Facilitar las comunicaciones y el intercambio de información entre los diferentes actores de las vías. Impulsar las comunicaciones entre vehículos (V2V, acrónimo del inglés vehicle to vehicle), entre infraestructuras (I2I, acrónimo del inglés infrastructure to infrastructure) y entre vehículos e infraestructuras (V2I, acrónimo del inglés vehicle to infrastructure) [SGSSA08, JMS07, STY04]. Un ejemplo de este tipo de comunicaciones, muy usado hoy en día, es el de paneles de mensaje variable (PMV) que presentan información a los usuarios de las vías sobre las condiciones de la misma o cualquier otro tipo de dato que resulte relevante y pueda influir en las condiciones de circulación.

Uno de los escenarios donde se pone de manifiesto de forma más evidente y clara el problema de la seguridad vial y el objetivo de reducción de víctimas por accidentes de tráfico es el entorno urbano y metropolitano. Las Naciones Unidas en su informe "Estado de la población mundial 2007” [UNF07, introducción p.1] declaraba: “En 2008, por primera vez, más de la mitad de la población mundial residirá en zonas urbanas. Alrededor del año 2030, los pueblos y ciudades albergarán al menos a 5 mil millones de personas”. Superado el umbral del 2008 
se ha podido comprobar que dicho crecimiento tanto en ciudades como en habitantes ha sido el esperado, a la par que han crecido las demandas y requisitos de movilidad ciudadana.

Este conjunto de factores y circunstancias posiciona a la gestión de tráfico como uno de los factores estratégicos más relevantes hoy en día. Asimismo, implica a diversos sectores tales como el económico (dependencia de los combustibles), el ambiental (contaminación, ruido, emisión de gases de efecto invernadero ...), la seguridad (de usuarios de la vía, tanto conductores, como peatones) y la salud (problemas respiratorios, circulatorios ....).

Los sistemas de transporte inteligentes, ITS (acrónimo del inglés Intelligent Transportation Systems), presentan una solución a las demandas de seguridad vial, gestión de tráfico y movilidad ciudadana, gracias al desarrollo y al uso de diversas aplicaciones y tecnologías [ITS08a, ITS08b]. Los sistemas y los servicios ITS aúnan una gran variedad de sectores y de áreas que no tenían previamente conexión directa entre ellas, sectores tales como automoción, transporte, tecnologías de la información y comunicaciones (TIC), etc.

La irrupción de los sistemas, soluciones y tecnologías ITS en el marco económico, tecnológico y social mundial ha adquirido una gran relevancia. Su impacto se ve plasmado en diferentes acciones que han derivado, entre otras, en:

- Creación de diferentes organizaciones ITS a nivel mundial con sus respectivas delegaciones a nivel: europeo (Ertico); americano (ITS USA); y zona asia-pacífico (ITS Japan) [ITS08b, ITS09b, ITS09a], (ver figura 1.2).

- Congresos con identidad propia que agrupan sectores muy diversos relacionados con ITS: fabricantes de vehículos, administraciones, institutos de investigación, proveedores de servicios, empresas privadas y públicas ... Por ejemplo: ITS World Congress cuya última edición se celebró en septiembre de 2009 en Estocolmo (Suecia).

- Creación de una rama de IEEE dedicada en exclusiva al sector ITS (ITS Society) que organiza sus propios congresos y eventos [Soc09].

- Llamadas especiales en el séptimo programa marco de la Unión Europea dedicadas al transporte. 


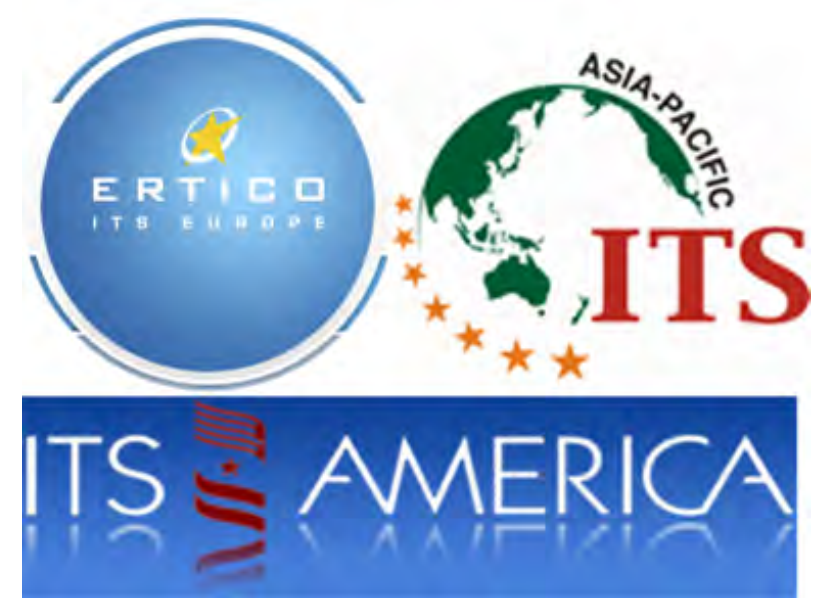

Figura 1.2 - Diferentes organizaciones de ITS en el mundo

Los sistemas ITS aumentan la eficacia del tráfico incorporando tecnologías punteras y novedosas en diversos niveles del control y gestión de la circulación, orientados hacia el uso de sistemas cooperativos e inteligentes mediante la integración de tecnologías de la información y comunicaciones con las infraestructuras, vehículos y usuarios. Compartiendo esta información vital, las tecnologías ITS permiten a los usuarios obtener mayores beneficios de las redes de transporte, aumentando su seguridad vial con un menor impacto en el entorno [ITS08a, ITS08b].

\subsection{La importancia de la información}

A simple vista, los sistemas ITS presentan la solución perfecta a los problemas de Seguridad Vial ya que integran todas las necesidades de información y comunicación. Aún así, queda todavía mucho camino a la hora de integrar los sistemas sensores que se han venido utilizando hasta ahora en las modernas redes y sistemas ITS [TWM06, MHC05]. Las redes de sensores inteligentes capaces de comunicarse entre ellos reciben el nombre de sistemas cooperativos de transporte (CTS, acrónimo del inglés Cooperative Transport Systems) y en ellas la interactuación entre sensores es vital.

El laboratorio del tráfico de Utah (UTL, acrónimo del inglés Utah Traffic Laboratory) en su informe "Evaluación de la tecnología detectora" realizado en noviembre de 2003 especifica: "Los datos recogidos deben ser abundantes, diversos, y exactos. Estos complejos requisitos de 
los datos presentan un desafío para los sistemas detectores de tráfico” ([MFW03] 2003:1). Esta afirmación evidencia la importancia de la información detectada. La calidad de los parámetros recibidos es decisiva para poder llevar a cabo una correcta y eficiente supervisión y gestión del tráfico [MFW03, Gar00].

No se trata únicamente de recibir y recoger datos de la vía, sino que estos tengan una determinada calidad que permita de forma certera conocer qué pasa en la zona bajo estudio. Todas las aplicaciones ITS (sistemas de información a viajeros, sistemas de monitorización y gestión de carreteras y autopistas, gestión de incidencias, detección de peatones ...) dependen de los parámetros del tráfico proporcionados por los diferentes sensores que miden en tiempo real la situación en las vías.

Desde la década de los 90, se dispone de múltiples tecnologías para la detección de vehículos [Kle01, SBM04]. Atendiendo a su forma de instalación se pueden distinguir dos grandes familias de detectores de vehículos [MSJ97, MKM99]:

- Intrusivos - son aquellos que se instalan en la propia calzada, por debajo o en la superficie del asfalto. Estos traen asociadas dos dificultades: requieren interrumpir el tráfico durante su instalación, y su reparación es muy complicada al estar enterrados o cubiertos por resinas o selladores. Entre este tipo de sistemas se encuentran: espiras magnéticas, sensores piezoeléctricos, sondas de presión o magnetómetros.

- No intrusivos [Mic01] - son aquellos que se instalan fuera de la calzada, sobre postes, báculos, señales, semáforos, puentes o incluso en edificios. Su mayor ventaja es que no requieren cortes de circulación para su instalación o reparación. En este grupo podemos destacar: sistemas láser escáner, infrarrojo pasivo, radares de microondas y visión artificial.

De entre toda la gama de detectores mencionada, esta tesis centra su atención en los sistemas láser escáner. Este tipo de detectores utiliza la tecnología láser para la detección y clasificación de vehículos [GGM05, Góm05]. El láser estima la distancia a un objeto mediante la medida del tiempo de vuelo (ToF, acrónimo del inglés time of flight), es decir, calcula la distancia midiendo 
el tiempo que transcurre desde que se emite un pulso láser hasta que es detectada la señal reflejada por el objeto.

\subsection{Estructura y contenido de la tesis}

La motivación que ha dado origen a la presente tesis no ha sido sino el de exponer, discutir y desarrollar una solución ITS eficaz, eficiente y polivalente que sirva de apoyo a las entidades gestoras de las vías, proporcionándoles información fiel, precisa, exacta, clara y en tiempo real sobre la situación de las vías, apoyando de este modo a la toma de decisiones y el diseño de los planes de mejora de la seguridad vial.

La presente tesis consta de 12 capítulos estructurados en cinco secciones: Introducción, Estado del Arte, Hipótesis de partida, Objetivos y Desarrollo, Resultados y Evaluación y Conclusiones y Trabajo Futuro.

La sección sobre el estado del arte la componen dos capítulos en los que se habla de: tecnologías ITS, equipos comerciales y centros de gestión de tráfico. Solo una visión global permite detectar la pieza que falta. Así, para poder presentar y justificar la selección de la tecnología láser es necesario estudiar los antecedentes, tecnologías usadas en ITS, equipos comerciales disponibles en el mercado y necesidades de los centros de gestión de tráfico (CGT). Este es el objetivo del primer bloque de la presente tesis.

El grueso de la investigación se presenta en la sección Hipótesis de partida, Objetivos y Desarrollo donde, una vez seleccionada la tecnología, se definen las especificaciones hardware y software de diseño además de la metodología para la clasificación. De este modo, estos capítulos versan sobre la metodología a seguir para convertir los datos sin procesar provenientes de los sensores en verdadera información que pueda utilizarse en los CGT. Las especificaciones permitirán adaptar cualquier sistema láser a la aplicación ITS de detección y clasificación de vehículos. El último capítulo de esta sección trata sobre las técnicas de reconocimiento de patrones y los procesos de aprendizaje y test. También, se presenta un exhaustivo estudio estadístico sobre los resultados del proceso que evalúan la validez del mismo. 
La discusión sobre los resultados logrados tras la evaluación estadística y su análisis es el objeto de la sección Resultados y Evaluación. Por último, la sección Conclusiones y Trabajo Futuro presenta las conclusiones extraídas del estudio realizado, las líneas futuras en las que poder seguir trabajando en próximas investigaciones que puedan derivar de la iniciada en este momento y las aportaciones científicas a las que ha dado lugar este trabajo. 


\section{Bibliografía}

[BOE00] BOE, Real Decreto 1947/2000, tomo 289, págs. 42.291-42.292. Boletín Oficial del Estado, 1 de Diciembre 2000.

[BOE03] BOE, Real Decreto 317/2003, tomo 80, págs. 12.847-12.851. Boletín Oficial del Estado. Ministerio de Administraciones Públicas, 3 de abril 2003.

[BOE04] BOE, Real Decreto 1599/2004, tomo 160, págs. 24.646-24.657. Boletín Oficial del Estado. Ministerio de Administraciones Públicas, 2 de Julio 2004.

[CBU ${ }^{+97] ~ C a r v e l l, ~ J . D . ~ e t ~ a l ., ~ F r e e w a y ~ M a n a g e m e n t ~ H a n d b o o k . ~ I n f o r m e ~ t e ́ c n i c o, ~ U S ~}$ Department of Transportation. Federal Highway Transportation, Texas, August 1997. Report Number: FHWA-SA-97-064.

[DGT03] DGT, Seguridad Vial en España: Informe 2003. Dirección General de Tráfico, 2003. NIPO: 128-05-122-1. ISSN: 1576-8708.

[DGT06a] DGT, Las principales cifras de la siniestralidad vial. Dirección General de Tráfico. Observatorio Nacional de la Seguridad Vial, 2006. NIPO: 128-06-083-4.

[DGT06b] DGT, Plan Estratégico de Seguridad Vial 2005-2008. Dirección General de Tráfico, 2006. NIPO: 128-06-012-6.

[DGT09a] DGT, Portal de educación vial. Dirección General de Tráfico, Junio 2009, URL http://www.dgt.es/educacionvial/DGT_Home_Buscar_.html.

[DGT09b] DGT, Resultados del programa pin sobre seguridad vial. Dirección General de Tráfico, Junio 2009.

[EC03] EC, Programa de acción europeo de seguridad vial. Comunicación de la Comisión. Comisión de las Comunidades Europeas, 2 de Junio 2003. $\operatorname{COM}(2003) 311$ Final.

[EC08] EC, European road safety day 2008. Comisión de las Comunidades Europeas, 2008, URL http://ec.europa.eu/transport/roadsafety/road_ safety_days/index_2008_en.htm. [Online: Último acceso Julio 2008].

[EU02] EU, Libro Blanco: Política Europea de Transportes de cara al 2010: la hora de la verdad. Luxemburgo: Comisión Europea. Oficina de Publicaciones Oficiales de las Comunidades Europeas, 2002, ISBN 92-894-0337-3.

[Gar00] García, L.A., Diseño e implementación de una arquitectura multiagente para la ayuda a la toma de decisiones en un sistema de control de tráfico urbano. Tesis Doctoral, Departamento de Informática. Universidad Jaime I, Castellón de la Plana. España, 2000. Director: Dr. Francisco Toledo Lobo.

[GGM05] Gallego, N., Gómez, L.E. y Mocholí, A., Sistema láser para detección y clasificación de vehículos en múltiples carriles. XII Seminario Anual de Automática, Electrónica Industrial e Instrumentación (SAAEI),2005. Congreso en., Septiembre 2005. 
[Góm05] Gómez, L.E., Contribución al diseño e implementación de un sistema de detección y clasificación de vehículos con tecnología láser, mediante método estadístico y redes neuronales. Tesis Doctoral, Departamento de Ingeniería Electrónica. Universidad Politécnica de Valencia, Valencia. España, 2005. Directores: Antonio Mocholí y José Millet.

[ITS08a] ITS. ITS España. Ministerio de Ciencia y Tecnología, 2008, URL http: / / www . itsspain. com/itsspain/. [Online: Último acceso Agosto 2009].

[ITS08b] ITS. Ertico. ITS Europe, 2008, URL http://www.ertico.com/. [Online: Último acceso Octubre 2009].

[ITS09a] ITS. ITS Japan, 2009, URL http://www.its-jp.org/english/. [Online: Último acceso Noviembre 2009].

[ITS09b] ITSA. Intelligent Transportation Society of America, 2009, URL http:// http: / / www. itsa .org/. [Online: Último acceso Noviembre 2009].

[JMS07] Jerbi, M., Marlier, P. y Senouci, S.M., Experimental assessment of V2V and V2I communications. Mobile Adhoc and Sensor Systems, 2007. MASS 2007. IEEE Internatonal Conference on, págs. 1-6, October 2007, doi:10.1109/MOBHOC. 2007.4428739 .

[Kle01] Klein, L.A., Sensor technologies and data requirements for ITS, capítulo Traffic Flow Sensor Technologies: 5. London: Artech House, 2001, ISBN 1-58053-077$\mathrm{X}$.

[MFW03] Martin, P.T., Feng, Y. y Wang, X., Detector Technology Evaluation. Technical report, Department of Civil and Environmental Engineering University of Utah Traffic Lab, November 2003, URL http: / / www . mountain-plains . org/ pubs/html/mpc-03-154/. MPC Report number 03-154. Last Access November 2008.

[MHC05] Meier, R., Harrington, A. y Cahill, V., Framework for integrating existing and novel intelligent transportation systems. Intelligent Transportation Systems, 2005. Proceedings. 2005 IEEE, págs. 154-159, September 2005, doi:10.1109/ITSC. 2005.1520124.

[Mic01] Michalopoulos, P., Review of non-intrusive advanced sensor devices for advanced traffic management systems and recent advances in video detection. Proceedings of the Institution of Mechanical Engineers. Proceedings part L, Journal of materials, design and applications, tomo 215 (4): págs. 345-355, 2001, ISSN 1464-4207.

[MKM99] Matsuo, T., Kaneko, Y. y Matano, M., Introduction of intelligent vehicle detection sensors. Intelligent Transportation Systems, 1999. International Conference on IEEE/IEEEJ/JSAI, págs. 709-713, 1999, doi:10.1109/ITSC.2005.1520124.

[MSJ97] Middlenton, D., Shaffer, M. y Jasek, D., Initial Evaluation of the Existing Technologies for Vehicle Detection. Informe técnico, Texas Transportation Institute, College Station, Texas, TX, October 1997. Report Number: FHWA/TX99/1715-1. 
[Nor06] Norma, N., El exceso de velocidad duplica la mortalidad. Tráfico y Seguridad Vial, tomo año XXII (177): págs. 24-25, Marzo-Abril 2006, ISSN 1886-3566.

[Oda07] Oda, T., Signal control by successive updating of control parameters based on prediction of traffic flow. Electrical Engineering in Japan, tomo 161 (3): págs. 4957, July 2007, ISSN 1520-6416.

[ONU04] ONU, Resolución aprobada por la asamblea general en la $84^{a}$ sesión plenaria. Organización de Naciones Unidas, 11 de Mayo 2004. A/RES/58/289.

[ONU07] ONU, Primera semana mundial de las naciones unidas para la seguridad vial. Organización de Naciones Unidas, 23-29 de Abril 2007, URL http: / /www . who. int/roadsafety/week/es/. [Online: Último acceso Julio 2008].

[ONU09] ONU, Primera conferencia global de ministros sobre seguridad vial. Organización de Naciones Unidas, 19-20 de Noviembre 2009, URL http://www. who. int/roadsafety/ministerial_conference/en/index.html.

[Online: Último acceso Noviembre 2009].

$\left[\mathrm{PSS}^{+} 04\right]$ Peden, M. et al., World Report on Road Traffic Injury Prevention. Geneva, Switzerland: World Health Organization, 1a edición, 2004, ISBN 92-4-156260-9.

[SBM04] Sun, Z., Bebis, G. y Miller, R., On-road vehicle detection using optical sensors: A review. Intelligent Transportation Systems, 2004. Proceedings. The $7^{\text {th }}$ th International IEEE Conference on, págs. 585-590, October 2004, doi:10.1109/ ITSC.2004.1398966.

[SGSSA08] Santa, J., Gómez-Skarmeta, A.F. y Sánchez-Artigas, M., Architecture and evaluation of a unified $\mathrm{V} 2 \mathrm{~V}$ and $\mathrm{V} 2 \mathrm{I}$ communication system based on cellular networks. Computer Communications, tomo 13 (12): págs. 2.850-2.861, July 2008, doi:10.1016/j.comcom.2007.12.008, URL http://www.sciencedirect.com/science/article/ B6TYP-4RDS 43D-2/2/2cfb740205958d1b85df688b90429835.

[Online: Último acceso Julio 2008].

[Soc09] Society, I.T.S. IEEE, 2009, URL http://www.ewh.ieee.org/tc/its/ index. html. [Online: Último acceso Noviembre 2009].

[STY04] Sawant, H., Tan, J. y Yang, Q., A sensor networked approach for intelligent transportation systems. Intelligent Robots and Systems, 2004. (IROS 2004). Proceedings. 2004 IEEE/RSJ International Conference on, tomo 2: págs. 17961801, September-2 October 2004, doi:10.1109/IROS.2004.1389657.

[TWM06] Tang, S., Wang, F.Y. y Miao, Q., Itsc '05: Current issues and research trends. IEEE Computer Science, págs. 96-102, March/April 2006.

[UN03a] UN, Resolution adopted by the general assembly: Global road safety crisis. $56^{\text {th }}$ plenary meeting. United Nations, 19 November 2003. A/RES/58/9.

[UN03b] UN, Resolution adopted by the general assembly: Global road safety crisis. $86^{\text {th }}$ plenary meeting. United Nations, 29 May 2003. A/RES/57/309. 
[UN04] UN, Resolution adopted by the general assembly: Improving road safety. $84^{\text {th }}$ plenary meeting. United Nations, 11 May 2004. A/RES/58/289.

[UN05] UN, Resolution adopted by the general assembly: Improving global road safety. $38^{\text {th }}$ plenary meeting. World Health Assembly, 26 October 2005. A/RES/60/5.

[UN08] UN, Resolution adopted by the general assembly: Improving global road safety. $87^{\text {th }}$ plenary meeting. World Health Assembly, 31 March 2008. A/RES/62/244.

[UNF07] UNFPA, State of world population 2007.unleashing the potential of urban growth. United Nations Population Fund, 2007.

[WHA04] WHA, Resolution adopted by the 57th assembly: Road safety and health. World Health Assembly, 22 May 2004. WHA57.10. 



\section{Parte II}

\section{Estado del Arte}





\section{Capítulo 2}

\section{El láser escáner en aplicaciones ITS}

A lo largo del presente capítulo se estudian y presentan las tecnologías más frecuentemente usadas hoy en día en el sector ITS. Se realiza un estudio exhaustivo de todas ellas para justificar la selección del láser escáner como una de las tecnologías más prometedoras en este sector. Se concluye con una comparativa entre diferentes equipos comerciales de láser escáner, analizando sus prestaciones y especificaciones.

\subsection{Tecnologías usadas en ITS}

Los sensores de tráfico perciben, detectan y recogen diferentes parámetros que son utilizados en algoritmos, programas de gestión de tráfico o cualquier otro tipo de sistema ITS, para su procesado y evaluación. No debemos olvidar que el control del tráfico urbano depende de la cantidad, tipo y calidad de los parámetros recibidos [MFW03, Gar00, VAVBB93]. Esta información permite estudiar el comportamiento del tráfico pasado para poder predecir el tráfico futuro gracias a los históricos elaborados en función del escenario de aplicación. Dependiendo de la información obtenida, se adoptará una u otra estrategia de control y gestión desde el centro de gestión de tráfico (CGT) [Kle01]. De ahí la importancia de seleccionar el sensor adecuado para cada aplicación. De ahora en adelante se referirá a estos tipos de sensores como sensores ITS.

Gracias a la sinergia de diferentes sectores y a la necesidad de mejores sistemas detectores han surgido los llamados sensores inteligentes. Los sensores ITS deben poseer una característica 
muy importante: ser inteligentes. Se trata de dar el salto de simples puntos de medida a sensores capaces de comunicarse, interactuar y cooperar entre ellos.

Esta nueva familia de sensores inteligentes se divide en dos grandes grupos: sensores instalados en los vehículos y en las infraestructuras $\left[\mathrm{GMA}^{+}\right.$07, TA00]. División realizada debido a que se trata de dos sectores bien diferenciados, como son el de automoción y el de infraestructuras, cuya gestión recae en el ámbito privado y la administración pública generalmente. En ambos casos las características de los sensores, su diseño, y su forma de enviar los parámetros son diferentes. El tipo de sistemas considerados en esta tesis corresponden al tipo de sensores ITS instalados en las infraestructuras y desarrollados mediante tecnología IR.

Si bien en términos de capacidad cualquier tecnología puede ser aplicada en sistemas ITS, existen ciertas de ellas que han sobresalido al resultar sus aplicaciones las más idóneas. Las tecnologías usadas en sistemas y aplicaciones ITS más importantes son: espiras magnéticas, sensores magnéticos, piezoeléctricos, radar de microondas, visión artificial, láser escáner, y detectores acústicos y ultrasónicos. Las tres primeras tecnologías abarcan el grupo de sensores intrusivos, o instalados en la vía, mientras el resto dan lugar al grupo de no intrusivos, encontrándose instalados en puentes, postes o arcos puestos al efecto.

Desde su introducción a principio de los años 60, las espiras magnéticas han sido los sistemas ITS más utilizados [WN03]. Se trata de una tecnología intrusiva, es decir, necesita realizar obra civil en la vía en la que se va a instalar con el consiguiente cierre de la misma y las desventajas que ello ocasiona. Su gran ventaja es que una vez instalados pueden funcionar durante años sin presentar fallos ni malos funcionamientos. Las líneas de investigación actuales abiertas en el área de las espiras magnéticas se centran en nuevos diseños que permitan con una simple espira medir valores de velocidad [WN03]. La falta de habilidad de las espiras para la detección de bicicletas es la segunda gran línea de investigación actual [Gib08], proponiendo su uso en carriles bici para el control semafórico de dichos carriles.

Los sensores magnéticos, conocidos también como magnetómetros, son sistemas pasivos que utilizan variaciones en el campo magnético debidas a elementos metálicos tales como vehículos. Aunque esta tecnología no encontró una amplia aceptación y su uso no ha sido muy 


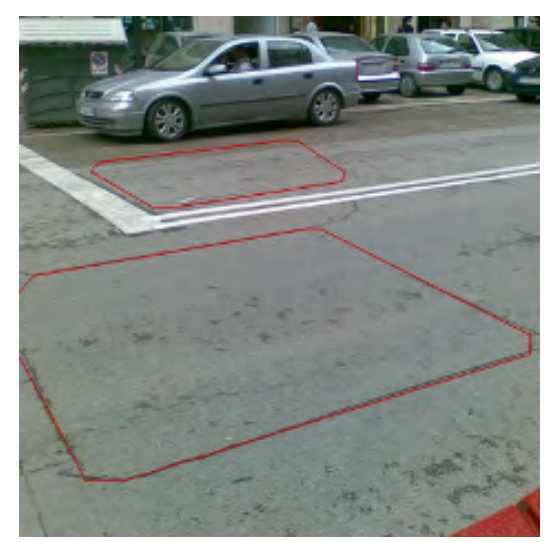

(a) Espiras magnéticas

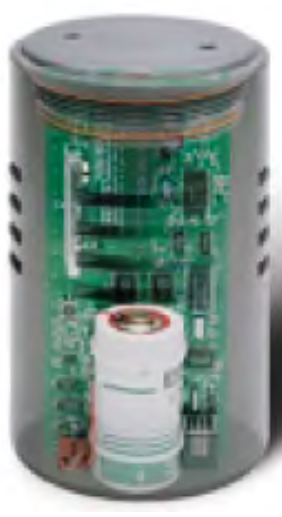

(b) Sensores Magnéticos

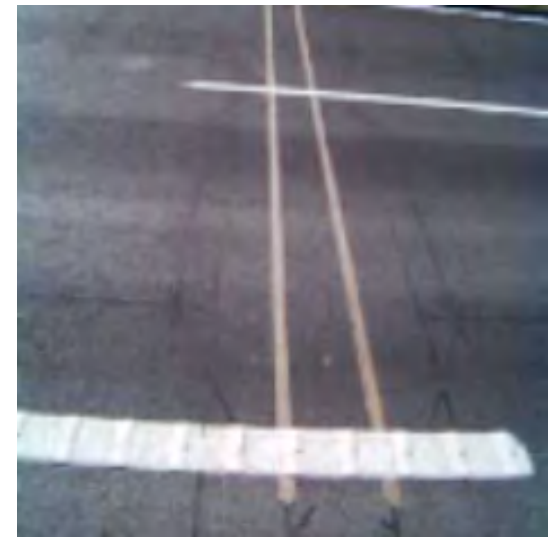

(c) Piezoeléctricos

Figura 2.1 - Diferentes tipos de sensores intrusivos

extendido, se pueden encontrar todavía diseños de redes wireless ITS que utilizan este tipo de sensores. Los sensores piezoeléctricos suelen ser muy utilizados en nuevas vías como sistemas de uso temporal [YSJ07].

El efecto Doppler es aprovechado en los radares de microondas, que son los sistemas no intrusivos más generalizados. El principal problema de este tipo de sensores es que no detecta vehículos parados o circulando a bajas velocidades. Para resolver este problema los radares emiten una onda modulada en frecuencia [FMZW07].

La visión artificial, no puede considerarse estrictamente una tecnología sensora pero es una tecnología ampliamente utilizada en sistemas ITS. Gracias a la madurez de dicha tecnología, la rápida reducción de los precios en este tipo de sistemas y la experiencia adquirida con el tiempo, se trata de una opción muy apreciada principalmente por las entidades gestoras de las 
vías [MFW03]. Los esfuerzos en este área se centran en la mejora del tratamiento de la imagen y el diseño de nuevos algoritmos [GMMP02].

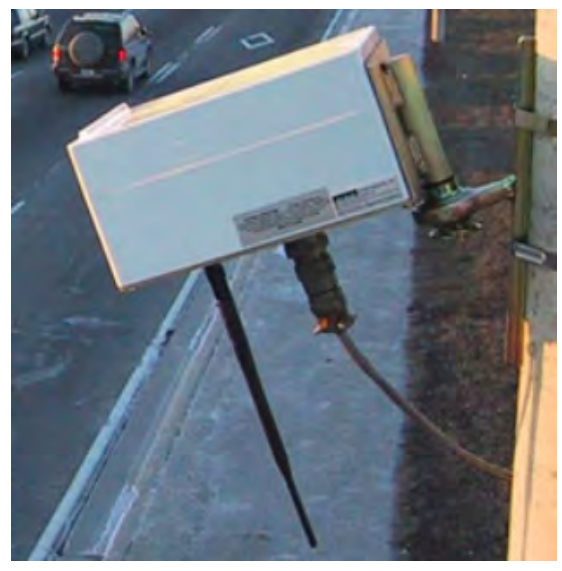

(a) Radar de microondas

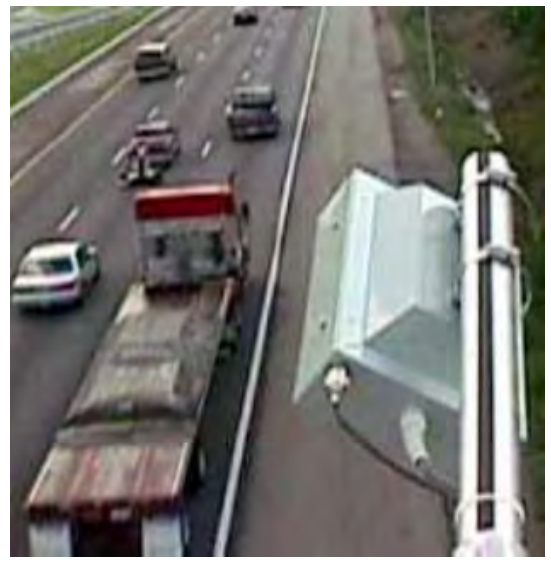

(b) Sensor acústico

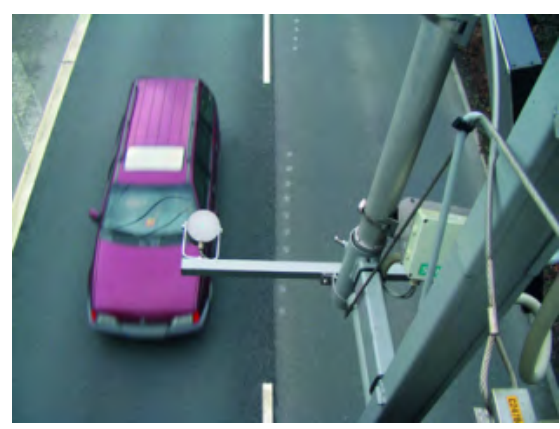

(c) Visión artificial

Figura 2.2 - Diferentes tipos de sensores no intrusivos

Los sensores acústicos y ultrasónicos no son estables en ambientes ruidosos. Los sensores pasivos acústicos pueden detectar volumen, presencia, flujo y clasificación. Los ultrasónicos no son más que sensores acústicos activos que transmiten una serie de pulsos [MFW03].

Si bien se trata de tecnologías maduras en aplicaciones de gestión de tráfico, no todas ellas son aplicables del mismo modo ante distintas situaciones o en distintas aplicaciones finales. Habrá que tener en cuenta tanto las necesidades de la vía, como las de las entidades gestoras, los costes, la duración de la aplicación, la finalidad... La selección de una u otra tecnología necesita partir de un vasto y profundo conocimiento de cada una de las tecnologías y sus características, para poder elegir correctamente la que mejor se ajuste a cada uno de los casos de uso y aplicaciones. La finalidad de la tabla 2.1 es mostrar de forma concisa las ventajas e inconvenientes que presenta cada una de las distintas tecnologías para facilitar una visión global 


\begin{tabular}{|c|c|c|}
\hline TECNOLOGÍA & VENTAJAS & INCONVENIENTES \\
\hline $\begin{array}{l}\text { Espiras } \\
\text { Magnéticas }\end{array}$ & $\begin{array}{l}\text { Diseño flexible a cada aplicación } \\
\text { Tecnología madura y muy estudiada } \\
\text { Proporciona parámetros básicos (volumen presencia, } \\
\text { flujo, velocidad ...) } \\
\text { Insensible a las inclemencias meteorológicas, como: } \\
\text { lluvia, niebla y nieve } \\
\text { Proporciona mejor precisión en el conteo de vehículos } \\
\text { que otros sensores }\end{array}$ & $\begin{array}{l}\text { La instalación requiere realizar cortes en el pavimento } \\
\text { Instalaciones defectuosas disminuyen la vida del pavi- } \\
\text { mento } \\
\text { La instalación y mantenimiento requiere cerrar la vía al } \\
\text { tráfico } \\
\text { Sistemas sometido a fatiga por el tráfico y la temperatura } \\
\text { Si se instalan múltiples espiras se necesitan controlar } \\
\text { simultáneamente }\end{array}$ \\
\hline $\begin{array}{l}\text { Sensores } \\
\text { Magnéticos }\end{array}$ & $\begin{array}{l}\text { Menos susceptible que las espiras a las fatigas del tráfico } \\
\text { Algunos modelos envían la información de forma } \\
\text { inalámbrica } \\
\text { Pueden utilizarse donde las espiras no se pueden instalar } \\
\text { Insensible a las inclemencias meteorológicas, como: } \\
\text { lluvia, niebla y nieve }\end{array}$ & $\begin{array}{l}\text { La instalación requiere realizar cortes en el pavimento } \\
\text { Instalaciones defectuosas disminuyen la vida del pavi- } \\
\text { mento } \\
\text { La instalación y mantenimiento requiere cerrar la vía al } \\
\text { tráfico } \\
\text { No puede detectar vehículos parados sin el uso de SW y } \\
\text { HW especial }\end{array}$ \\
\hline Piezoeléctricos & $\begin{array}{l}\text { Es una de las tecnologías más baratas } \\
\text { No sufren fatiga con el tráfico } \\
\text { Tecnología madura y muy estudiada }\end{array}$ & $\begin{array}{l}\text { La instalación requiere realizar cortes en el pavimento } \\
\text { Instalaciones defectuosas disminuyen la vida del pavi- } \\
\text { mento } \\
\text { Sensibles a variaciones de temperatura }\end{array}$ \\
\hline $\begin{array}{l}\text { Radar de } \\
\text { Microondas }\end{array}$ & $\begin{array}{l}\text { Proporciona medidas directas de velocidad } \\
\text { Puede trabajar en varios carriles a la vez } \\
\text { Tecnología madura en detección de vehículos y cálculo } \\
\text { de velocidad }\end{array}$ & $\begin{array}{l}\text { Los sensores que emiten onda continua no detectan } \\
\text { vehículos parados } \\
\text { Tecnología no apta para clasificación de vehículos }\end{array}$ \\
\hline Visión Artificial & $\begin{array}{l}\text { Controla y detecta múltiples carriles o zonas } \\
\text { Facilidad en modificar/añadir carriles o zonas } \\
\text { Proporciona multitud de información } \\
\text { Proporciona detección de amplia área cuando se juntan } \\
\text { varias cámaras }\end{array}$ & $\begin{array}{l}\text { Requiere mantenimiento periódico de las lentes } \\
\text { Sensible a las inclemencias meteorológicas, como: lluvia, } \\
\text { niebla y nieve } \\
\text { Durante las horas de oscuridad necesita iluminación en } \\
\text { las vías } \\
\text { Da lugar a fallos si se produce movimiento en las cámaras } \\
\text { debido al viento o vibraciones del soporte }\end{array}$ \\
\hline $\begin{array}{l}\text { Sensores } \\
\text { Acústicos }\end{array}$ & $\begin{array}{l}\text { Detectores pasivos } \\
\text { Insensible a las precipitaciones } \\
\text { Algunos modelos pueden detectar múltiples carriles }\end{array}$ & $\begin{array}{l}\text { Bajas temperaturas pueden afectar a la precisión en el } \\
\text { conteo de vehículos } \\
\text { Algunos modelos no son recomendados en el caso de } \\
\text { tráfico lento o incluso parado }\end{array}$ \\
\hline $\begin{array}{l}\text { Sensores } \\
\text { Ultrasónicos }\end{array}$ & $\begin{array}{l}\text { Detecta en múltiples carriles } \\
\text { Sistemas capaces de detectar vehículos pesados }\end{array}$ & $\begin{array}{l}\text { Sensible a cambios de temperatura y turbulencias } \\
\text { Si los sensores trabajan con pulsos de periodo muy largo } \\
\text { pueden producir errores en las medidas si los vehículos } \\
\text { circulan a altas velocidades }\end{array}$ \\
\hline $\begin{array}{l}\text { Sensores IR } \\
\text { Pasivos }\end{array}$ & $\begin{array}{l}\text { Proporcionan medidas de velocidad utilizados en modo } \\
\text { multizona } \\
\text { Sistemas capaces de detectar bicicletas }\end{array}$ & $\begin{array}{l}\text { Pueden ver reducida su sensibilidad ante fuertes lluvias o } \\
\text { nevadas } \\
\text { Necesita varios sensores para detección de velocidad }\end{array}$ \\
\hline $\begin{array}{l}\text { Sensores IR } \\
\text { Activos }\end{array}$ & $\begin{array}{l}\text { Medidas muy precisas de detección y clasificación de } \\
\text { vehículos } \\
\text { Sistemas capaces de cubrir varios carriles }\end{array}$ & $\begin{array}{l}\text { Su funcionamiento se ve afectado antes cambios bruscos } \\
\text { de intensidad luminosa en la vía } \\
\text { Pueden requerir mantenimiento periódico de las lentes }\end{array}$ \\
\hline
\end{tabular}

Tabla 2.1 - Comparativa de las tecnologías usadas en ITS 
de todas ellas ya que la selección se realiza orientada a la aplicación final [FMZW07, KMG06, MFW03, TA00].

\subsection{Sensores de Infrarrojo: detectores activos}

Los sistemas infrarrojos se encuentran dentro del grupo de dispositivos optoelectrónicos y, como tales, se han clasificado tradicionalmente en dos grandes grupos: emisores y receptores. Los emisores, también llamados fotoemisores, son dispositivos capaces de generar luz a partir de una señal eléctrica; mientras que los receptores, o fotodetectores, son capaces de transformar una señal luminosa en una señal eléctrica. A grandes rasgos podemos decir que el grupo de fotoemisores está formado básicamente por: diodos LED (acrónimo del inglés Light Emitting Diode), lámparas y láseres. Por otra parte, el grupo de fotodetectores está formado por dos grandes familias: térmicos y fotónicos [WZ85].

A medida que las aplicaciones de los sensores de IR se extendían empezó a hablarse de sensores activos y pasivos. Se hace esta distinción en función de que el sensor disponga o no una fuente propia de iluminación. Así, los sensores pasivos, conocidos también como PIR (acrónimo del inglés Passive Infrared Detectors), abarcarían el grupo de los fotodetectores. Mientras que los activos corresponderían a la combinación de un fotoemisor y un fotodetector dentro del mismo sensor. Los sensores activos de infrarrojo son capaces de emitir cierta radiación infrarroja y detectar la reflexión producida [KKMKS02, BMBL90]. En este caso se utiliza generalmente como fotoemisor un LED de infrarrojo (ILED, acrónimo del inglés Infrared LED) y como fotodetector un PIR, como es el caso del láser escáner.

Durante la última década del siglo XX las aplicaciones comerciales de los sistemas IR han presentado un gran auge debido en gran parte a su aplicación en sistemas remotos. Destacan aplicaciones médicas (termografía), medioambientales (control de zonas forestales mediante imágenes IR de satélite), domóticas (control de temperatura y/o acceso) y en el campo de la automoción (aplicaciones de seguridad). La demanda actual de la tecnología IR se centra en las siguientes aplicaciones: vigilancia de la contaminación medioambiental y el cambio 
climático, astronomía IR, ayuda a la conducción segura, cámaras de IR, robótica e imágenes IR en diagnóstico médico [ZGBW07, Mat04, RC02].

El láser escáner, en concreto, se utilizan principalmente en dos grandes áreas: domótica y robótica. Las aplicaciones en el área de robótica se centran en dos campos: detección y reconocimiento de obstáculos [IJR04, KEW94], y rastreo y posicionamiento [KHY05, FEZM05]. En el campo de la domótica su uso está muy extendido debido sobre todo a la introducción de un alto nivel de sensorización en los hogares. El campo de aplicación de estos sensores es inmenso. En concreto los sensores activos de infrarrojo cubren aplicaciones como: detectores de gas o fuego [Won06], detectores de presencia [Zam06] ... La incursión de sensorización en el hogar ha dado lugar a nuevas aplicaciones como las del cuidado de personas mayores y de movilidad reducida en el hogar, donde el uso de sensores activos infrarrojos también ha sido importante $\left[\mathrm{SCB}^{+}\right.$06, IRK02, $\left.\mathrm{VCK}^{+} 00\right]$. En nuestro caso, las aplicación de tráfico se semejan a las del área de la robótica ya que se basan en la detección de objetos y cálculo de distancias.

\subsection{Láser Escáner: el porqué}

Si en el apartado anterior, El láser escáner en aplicaciones ITS, ya se presentaron las principales ventajas e inconvenientes de cada una de las tecnologías, en el presente se muestran los diferentes parámetros proporcionados por cada tecnología hasta encontrarnos en posición de justificar la elección de la tecnología seleccionada en la tesis.

Las tendencias y esfuerzos actuales en el área de sensores se centran en el continuo desarrollo de algunas de estas tecnologías: espiras magnéticas, radar de microondas, visión artificial y láser escáner, con el fin de [KMG06]:

- dotarlos de capacidad de medida de nuevos parámetros de tráfico,

- realizar seguimiento de vehículos,

- mejorar la resolución espacial,

- o comunicar diferentes sensores. 
En la tabla comparativa 2.2, se han incluido los siguientes parámetros: detección, conteo, tiempo de ocupación, velocidad (individual e instantánea) y clasificación. Parámetros como son: aforo, densidad, intensidad o volumen, se obtienen indirectamente de los parámetros anteriores. El conteo nos permite obtener el aforo de tráfico. Del mismo modo, si se determina un periodo de tiempo sobre el que calcularlo se obtiene la intensidad de tráfico y el volumen o flujo. La densidad puede estimarse a partir de la ocupación si se acepta que los vehículos tienen longitudes uniformes [Ni07].

Es importante, llegados a este punto, remarcar el hecho de que la calidad de un sensor no depende de la cantidad de parámetros que sea capaz de proporcionar sino de la exactitud de los mismos. No se debe caer en el error de considerar, en una primera selección, como mejor el equipo que proporcione mayor información. Es necesario analizar todos los detalles y seleccionar el capaz de proporcionar una mayor fiabilidad orientado a la aplicación final.

Los costes indicados en la tabla comparativa 2.2 se refieren únicamente al precio del equipo en el mercado, sin incluir en algunos casos el hw y/o sw asociado necesario para la obtención directa de los parámetros que se trata de un dato decisivo a la hora de analizar los costes presentados. Por ejemplo en el caso de las espiras magnéticas, si bien a simple vista parece el equipo más barato, necesita el hw de procesado de la señal para poder obtener los parámetros. Mientras en el caso de visión artificial y sensores IR activos, se trata del caso opuesto: el coste de los equipos que puede parecer elevado a simple vista incluye generalmente el hw asociado.

Para poder obtener una aproximación lo más realista posible acerca del verdadero coste final del sistema deberían tenerse en cuenta costes como: formación, instalación, operación, mantenimiento y reparación. Es importante no confundir el coste de operación con el de mantenimiento. El primero se refiere a los costes derivados del funcionamiento diario de los sistemas, por ejemplo: salarios, costes de comunicación, etc. Los costes de mantenimiento, por otra parte, son los costes necesarios para la conservación de los sensores, sistemas y subsistemas.

A la hora de calcular los costes de formación es necesario considerar el nivel de experiencia y conocimiento requerido para realizar una correcta instalación y calibración del equipo. Otra consideración que debe analizarse a la hora de hablar de los costes es el caso de detección en 
múltiples carriles, donde es necesario en determinadas tecnologías el uso de dos o más equipos sensores con lo cual su coste final aumentará.

En esta comparativa no se ha tenido en cuenta la tasa de transferencia ya que la mayoría de equipos comerciales hoy en día disponen de interfaces de alta velocidad dada la necesidad de transmitir la información en tiempo real entre los equipos y los controladores o CGT. Es notable, asimismo, el hecho de que cada vez son más los equipos sensores que se venden acompañados de un software especial desarrollado por el fabricante que permite desde la configuración del mismo hasta la adquisición y procesado de la información proveniente del equipo sensor. La desventaja reside en que las licencias deben ser adquiridas periódicamente para que dicho software pueda seguirse utilizando.

Por ejemplo, en el caso particular del equipo AccuRange 4000 de la empresa Acuity, del cual se dispone de un presupuesto de marzo de 2008, cabe destacar que el software proporcionado por el fabricante con la licencia supone el $28 \%$ del coste del sensor en sí y la tarjeta de adquisición de alta velocidad de transferencia de datos alcanza el $42 \%$ del coste del sensor.

A primera vista, queda en evidencia el grupo de sensores más adecuados para el desarrollo de nuevas aplicaciones ITS. Se desprende de la tabla que de los dos grandes grupos de sensores ITS: intrusivos y no intrusivos, (ver apartados 1.2 y 2.1), el que proporciona un mayor número de parámetros es el grupo de los no intrusivos, además de las ventajas inherentes a este grupo cuyo principal valor radica en que no requiere de cortes en la vía para su instalación, ni detenciones o interrupciones del tráfico.

Analizando la información presentada en la tabla 2.2 se extraen las siguientes conclusiones:

- Existen ciertos parámetros considerados básicos ya que son proporcionados por todos los sensores. Estos son: conteo, detección y tiempo de ocupación.

- La medida de la velocidad se realiza de forma directa únicamente mediante tres tecnologías: radares, visión artificial y sensores acústicos. Otras tecnologías necesitan el uso de dos sensores (como las espiras magnéticas en el caso de la trampa de velocidad), o de equipos especiales de detección en múltiples carriles (caso de los sensores de IR, tanto activos como pasivos) lo que incrementa su coste. 

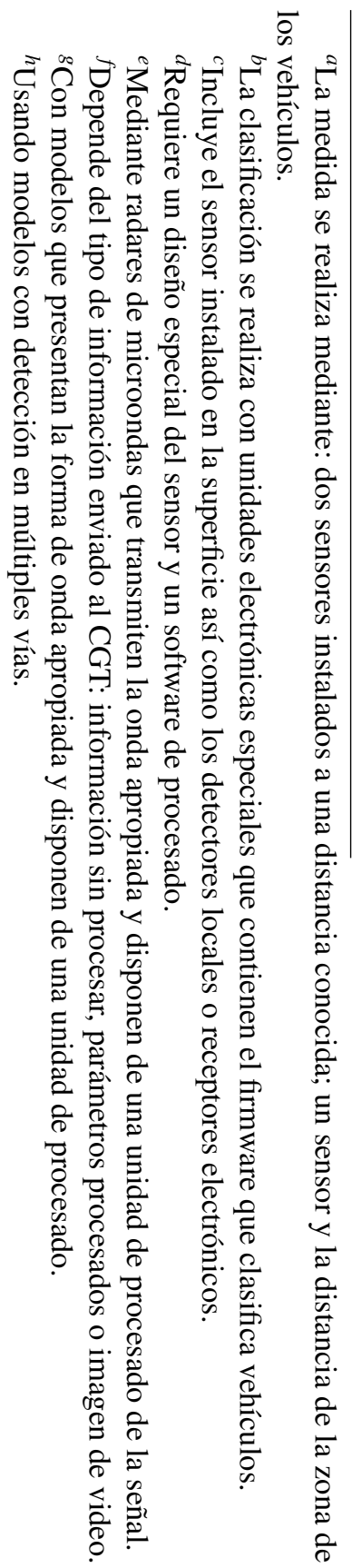

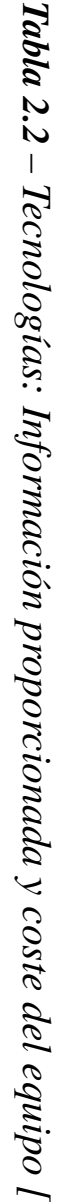

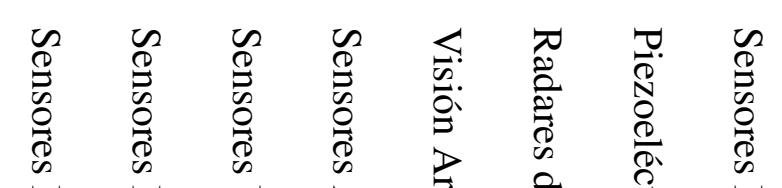

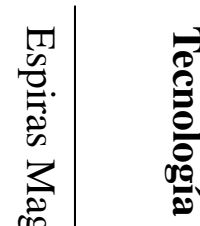

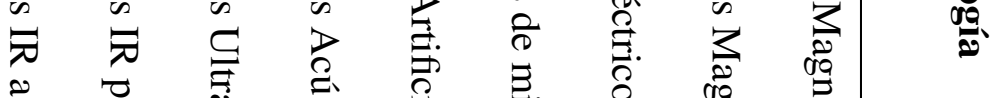

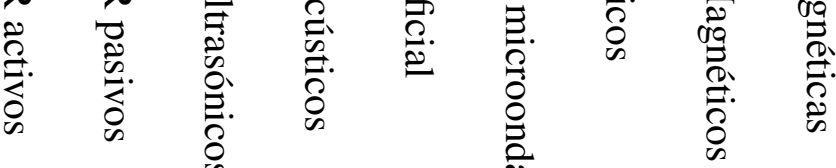

$\leq x<<<<<\frac{2}{2}$

$<<<<<<<<\frac{\wp}{\overparen{\delta}}$

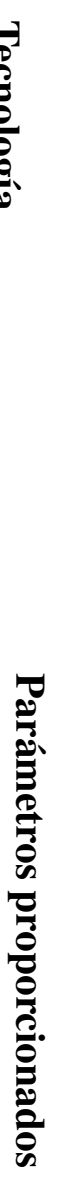

$x \quad x<x<x<x<\frac{\rho}{\mathscr{0}}$

:

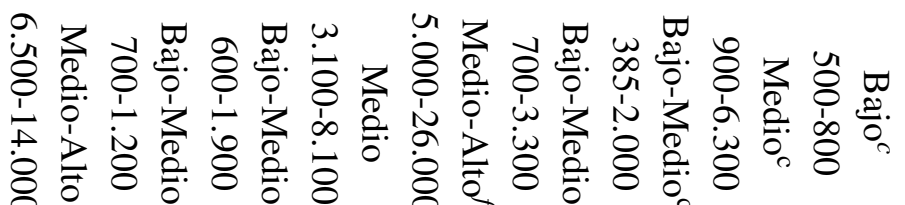

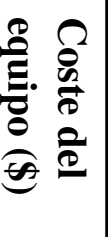


- La clasificación de vehículos se realiza usando unidades electrónicas externas que analizan la información proporcionada por los sensores. En el caso de las espiras magnéticas se analiza la huella magnética, por ejemplo, mientras que en el caso del láser escáner se analiza la imagen 3D de la zona de detección.

- La detección en múltiples carriles es necesaria dadas las dimensiones de las vías actuales, y solo es posible directamente en el caso de: visión artificial y láser escáner. Por ello, los equipos basados en estas tecnologías resultan más rentables.

Aunque los resultados anteriores son válidos en condiciones ideales, hay que tener en cuenta también las condiciones del tráfico y factores medioambientales como: viento, lluvia, temperatura ..., para completar un estudio lo más minucioso posible de las tecnologías detectoras. Las condiciones del tráfico afectan a todas y cada una de las tecnologías sin excepción, tanto el alto como el bajo volumen de tráfico [MFW03]. Sin embargo, las condiciones medioambientales en general tienen un impacto mínimo sobre las tecnologías detectoras [Góm06, MFW03].

Resultados derivados de otros estudios nos permiten afirmar que los efectos más generalizados debidos a factores medioambientales son [MFW03, Góm06]:

- El viento puede modificar la instalación de los sensores y con ellos su zona de detección.

- El viento, además, puede producir vibraciones en los sensores especialmente si están situados cerca del fin de los mástiles de instalación o a elevadas alturas.

- La lluvia y la nieve pueden reducir la visibilidad y ocultar la detección.

- Extremadamente altas o bajas temperaturas pueden reducir la precisión en la detección.

A vista de los resultados presentados, el láser escáner se presenta como la tecnología más adecuada para proporcionar al CGT los parámetros básicos que ayuden en la correcta gestión del tráfico. Pese a que sean necesarios dos equipos para detectar velocidad, se trata de una de las tecnologías menos afectadas por factores medioambientales y posibilitan la detección en múltiples carriles. 


\subsection{Láser Escáner: Antecedentes y trabajos actuales}

La literatura actual en el área de láser escáner en aplicaciones ITS es muy diversa. Se podría agrupar el trabajo de los distintos autores en tres grandes grupos:

- Autores centrados en la tecnología: desarrollan los sensores y el hardware necesario.

- Autores centrados en la aplicación: hacen uso de equipos comerciales y se centran en el tratamiento de la señal adquirida.

- Autores que centran sus investigaciones en mejorar la tecnología de medida de distancias (ToF).

El grupo de autores que desarrollan sus propios sensores, así como el hardware relacionado y necesario, es el minoritario y centra su trabajo en la tecnología: sensores puntuales y telémetros $\left[\mathrm{CSP}^{+}\right.$05, $\mathrm{CSP}^{+}$01, AHS94, HSA93]. En el caso de H. Cheng et al. $\left[\mathrm{CSP}^{+}\right.$05, $\mathrm{CSP}^{+}$01] utiliza como sistema dos pares de sensor-láser. El láser utilizado como emisor es un diodo láser IR pulsado, mientras que como receptor emplea diversos tipos de lentes y un array de fotodiodos de avalancha (APD, acrónimo del inglés Avalanche Photodiodes), encargados de transformar la señal reflejada en señal recibida. El sistema se sitúa sobre la vía bajo estudio como se representa en la figura 2.3 y emite dos rayos sobre la vía lo que le permite realizar medidas de velocidad, además de presencia y longitud de los vehículos que circulan por la zona de detección o carril.

Los resultados presentan un sistema de detección de vehículos de "gran exactitud", pero sin llegar a dar valores de los resultados obtenidos. Entre las pruebas experimentales realizadas destaca una evaluación durante más de 24 horas con el sistema instalado en una autopista, con lo cual las condiciones medioambientales se modifican a lo largo del día aunque ligeramente. Estas modificaciones en las condiciones medioambientales no se reflejan en los resultados.

Sin poder cuantificar objetivamente la exactitud lograda y sin haberse llevado a cabo un análisis detallado bajo diferentes condiciones medioambientales (lluvia, niebla, nieve ...) no estamos en posición de poder ni evaluar, ni valuar el sistema.

En la misma línea del anterior, S.A. Ahmed et al. [AHS94] presenta un trabajo en el que se ha desarrollado un sistema ITS usando tanto sistemas de IR activos como pasivos. En el 


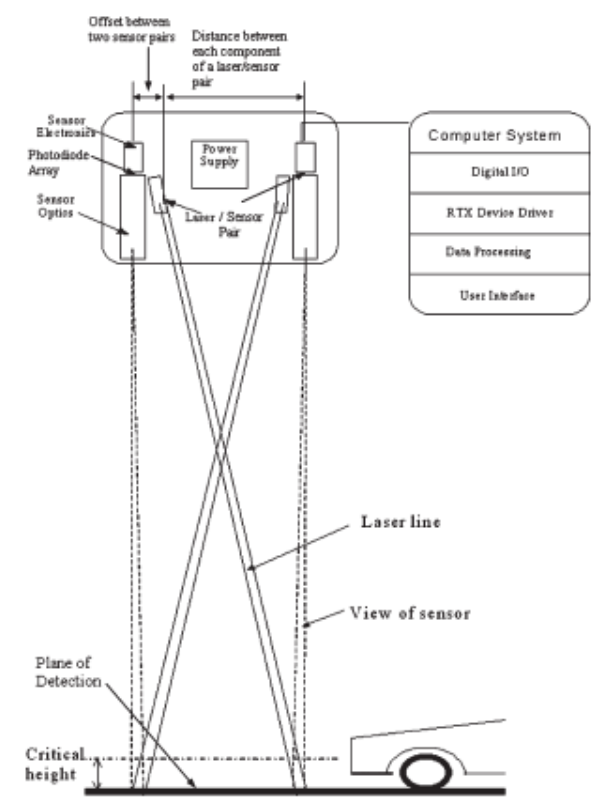

Figura 2.3 - Sistema Láser Escáner empleado por H. Cheng et al.

caso de los detectores pasivos se utilizan detectores IR térmicos (piroeléctricos) que detectan variaciones en la intensidad de la radiación térmica de los vehículos que circulan sobre la vía para poder detectarlos. Se utiliza una línea de varios de estos sensores por carril. Los sistemas activos utilizan emisores láser y fotodetectores, sin entrar en más detalle o especificar sus características. Mediante el sistema desarrollado, (ver figura 2.4), se detectan los siguientes parámetros: presencia, longitud, velocidad de los vehículos y densidad de tráfico, siempre trabajando en un único carril. Como conclusiones del estudio se habla de un "sistema rentable" sin entrar en ratios o porcentajes, y sin detectar un sistema, activo o pasivo, más ventajoso que el otro.

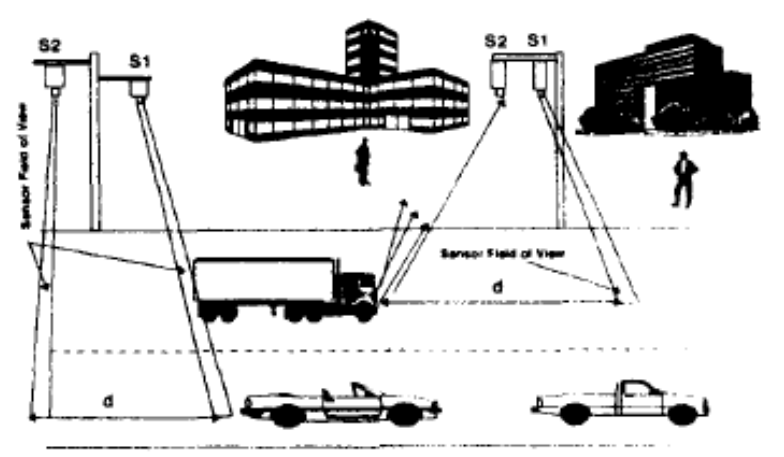

Figura 2.4 - Sistema Láser Escáner empleado por S.A. Ahmned et al. 
Los autores que trabajan con equipos comerciales dedican sus investigaciones a mejorar la adquisición y tratamiento de la señal, profundizando en la velocidad de procesado y transmisión, pero sin entrar en detalle en la tecnología sensora. Este grupo se centra en la aplicación y es el mayoritario actualmente [GMA ${ }^{+}$07, HM05, FD04, Har01, AHG01, Wan95].

Algunos de estos estudios se centran en sensores instalados en vehículos, como el caso de K. Fuerstenberg y K. Dietmayer [FD04]. Estos autores hacen uso generalmente del equipo comercial ALASCAde la empresa IBEO Automobile Sensor GmbH. Al tratarse de sensores instalados en vehículos, las aplicaciones ITS difieren de las presentadas con anterioridad y las que son objetivo de esta tesis, por ello no se entra en mayor detalle.

En el caso de C. Harlow [Har01] el equipo usado es el Autosense II de la empresa Schwartz Electro-Optics actualmente absorbida por OSI LaserScan. El trabajo desarrolla diferentes métodos de clasificación para caracterizar el vehículo usando el Autosense II. El equipo usado genera dos líneas de barrido separadas $10^{\circ}$ y se sitúa sobre la vía como muestra la figura 2.5. Aunque el uso de dos barridos láser sirve para realizar cálculos de velocidad, los autores no realizan un estudio al respecto ni presentan resultados experimentales. Los métodos desarrollados presentan resultados muy dispares en la clasificación; desde valores de un $98 \%$ de clasificaciones correctas de vehículos de pasajeros o un $92 \%$ en camionetas, hasta un $33 \%$ en el caso de los autobuses.
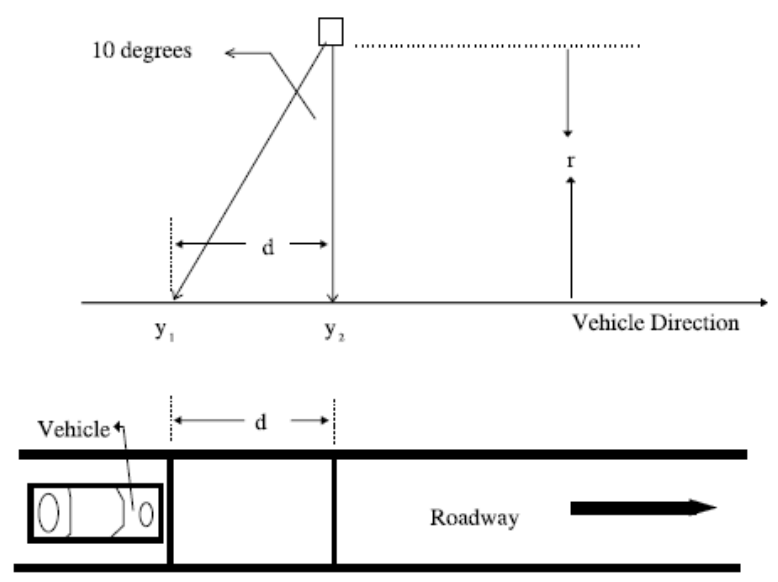

Figura 2.5 - Sistema Láser Escáner empleado por C. Harlow 
El trabajo de K.F. Hussain [HM05, AHG01] presenta un sistema final (autodenominado AVCSLII) sin distinguir entre el sensor y el software usado para el tratamiento. Estos autores desarrollan un algoritmo de clasificación basado en redes neuronales. Aunque este sistema utiliza un láser escáner, no usa medidas de distancia sino imágenes 3D en escala de grises. Los resultados experimentales presentan una clasificación en cinco clases sobre una base de datos de 4.995 vehículos. El error en clasificación de vehículos de pasajeros es de un 10,52 \% y en motocicletas de un $40 \%$. Todas estas pruebas experimentales se han realizado off-line, es decir, procesando las imágenes previamente obtenidas con el sensor y almacenadas posteriormente.

Finalmente, se encuentra el grupo de autores que basan sus esfuerzos en las mejoras de la tecnología usada entrando en detalle en la medidas de distancias que realizan los láser escáner [PPK06, PRK05, NPK03, CZYH03]. Entre este grupo cabe destacar los trabajos realizados por el grupo de J. Kostamovaara de la universidad de Oulu en Helsinki. Cuentan con numerosas publicaciones al respecto desde el año 1989, en el que publicaron su primer trabajo "A CMOS ASIC time-to-digital converter for short time interval measurements" [RKS89]. Han optimizado y evolucionado los integrados y sistemas hardware encargados de realizar la medida del tiempo de vuelo, ToF, diseñando los receptores usando tecnología BiCMOS. El diagrama de bloques del receptor del láser escáner desarrollado se representa en el figura 2.6.

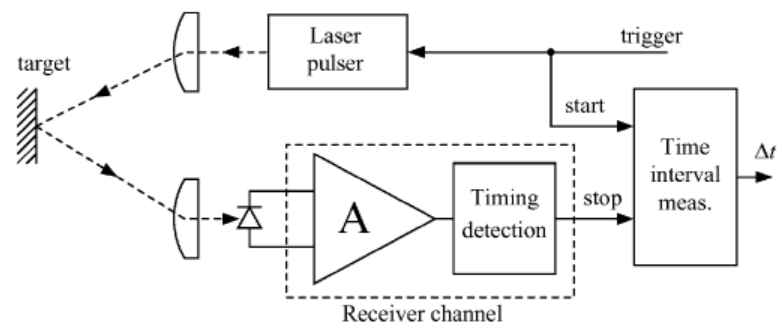

Figura 2.6 - Sistema Láser Escáner empleado por J. Pehkonen

\subsection{Láser Escáner: Equipos comerciales}

El presente estudio se enmarca dentro del grupo de autores que desarrollan las técnicas de tratamiento de la señal y hacen uso de equipos comerciales. Así, es necesario realizar un estudio 
y una comparativa de los equipos actuales usados en aplicaciones ITS con el fin de conocer las bondades y carencias de cada uno de ellos. Una vez se tenga una visión general se puede elegir el equipo óptimo, que más se aproxime a las necesidades del actual trabajo así como de la aplicación final.

La elección entre los equipos comerciales que se ofertan hoy en día en el mercado se ha realizado en base a su presencia en sistemas ITS. Se han seleccionado equipos usados por distintos autores y con presencia en distintas comparativas como son el AutoSense [MK07, KMG06, MFW03, Har01], el LMS-221 [Góm05, AJ99] y el AccuRange [AJ99]. Finalmente, se presenta también un sistema multisensor ya que actualmente se trata de un tipo de equipos muy solicitados, se trata del modelo TT-293 [MK07, KMG06, MFW03].

En resumen, los equipos bajo estudio son:

- LMS 221-30206 de la compañía SICK AG. - Se trata de un equipo muy extendido tanto en aplicaciones ITS para detección de vehículos, como en robótica para ayuda en la navegación y detección de obstáculos [Ind02].

- AccuRange de la compañía Acuity - Se trata en realidad de dos equipos independientes. Por un lado está el AccuRange 4000 que es el sensor láser escáner en sí mismo, mientras que por otro lado se encuentra el AccuRange Line Scanner que está formado por el motor y el espejo giratorio que hará posible el barrido [Inc00].

- AutoSense 800 de la compañía OSI LaserScan - Este equipo, utilizado en aplicaciones ITS como se ha comentado con anterioridad, posee la particularidad de realizar dos barridos consecutivos sobre la vía separados por un ángulo de $10^{\circ}$ con lo que permite realizar medidas de velocidad [Las06].

- TT 293 de la compañía ASIM - Se trata de un sistema multisensor que incluye: un radar Doppler que realiza medidas de velocidad; sensores de ultrasonidos usados en la detección y clasificación de vehículos; y un sensor PIR que en forma de cortina realiza diferentes medidas sobre el carril y dispara el sensor de ultrasonido [Ame05].

En la tabla 2.3 se muestran los parámetros más importantes de los equipos comerciales estudiados obtenidos de sus correspondientes catálogos de fabricante. Para una mejor compren- 


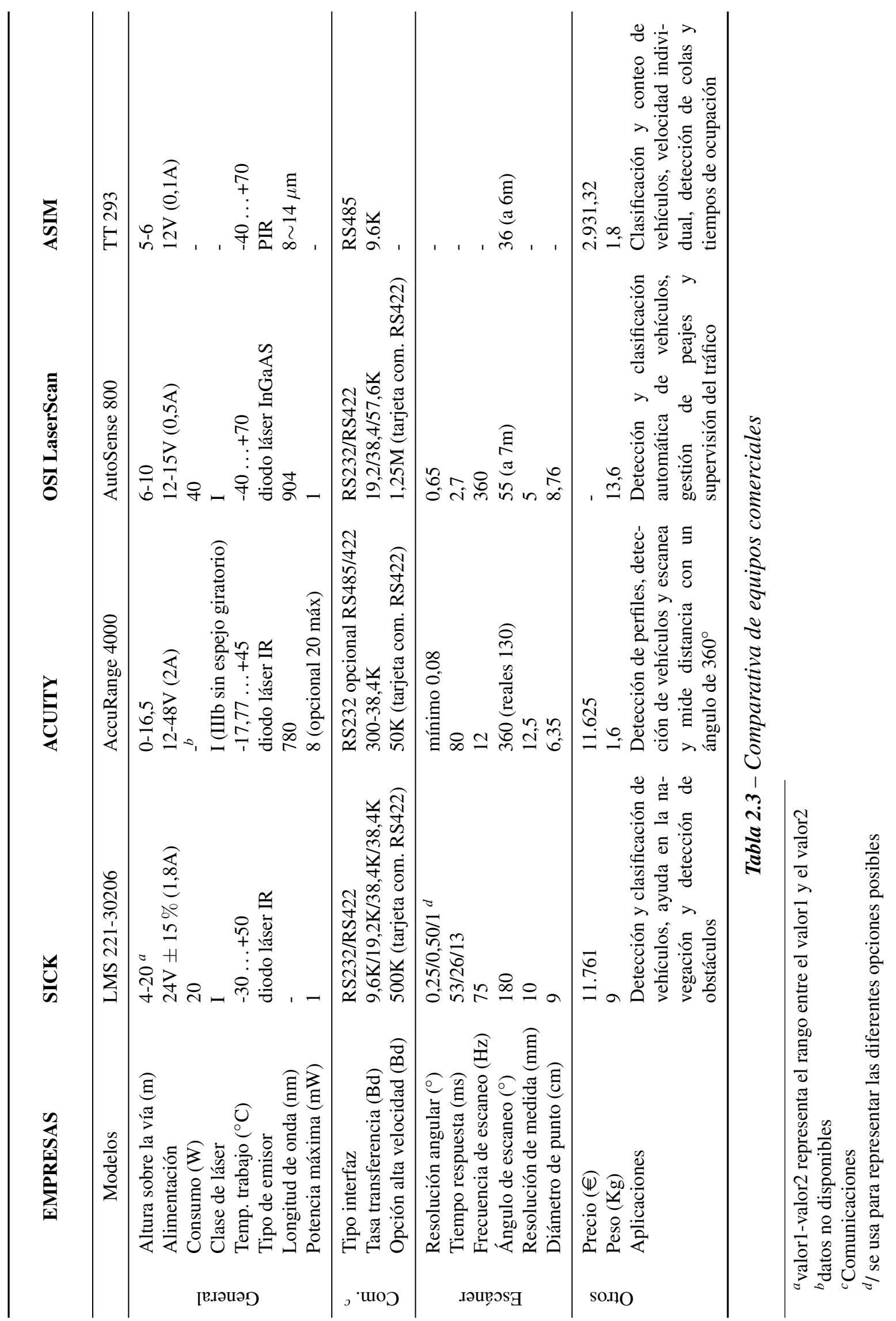


sión de los mismos se han agrupado bajo cuatro conceptos: general, comunicaciones, escáner y otros. El grupo de escáner abarca los datos más relevantes a la hora de seleccionar un equipo u otro en función de la aplicación que se le quiera dar al mismo. Los precios han sido proporcionados por los fabricantes de los equipos tras varias consultas realizadas durante el año 2008. En los siguientes subapartados se comenta brevemente cada uno de los equipos, su modo de funcionamiento y sus particularidades.

\subsubsection{SICK: LMS 221-30206}

El equipo de la compañía SICK LMS 221-30206 ha servido como base de una tesis anterior en nuestro grupo de investigación, y dada su disponibilidad ha servido de inicio del presente estudio. Se trata de un equipo bien conocido en la literatura, como demuestra su aparición en varias comparativas entre equipos. Evidentemente, la empresa SICK ha ido realizando sucesivas mejoras al equipo desde la primera versión del año 1999. Se trata de un sensor de altas prestaciones que permite realizar barridos sobre una vía de varios carriles ya que puede cubrir un ángulo sobre la vía de hasta $180^{\circ}$. Trabajos anteriores han demostrado la capacidad del equipo de trabajar en vías de hasta cuatro carriles.

El equipo emite un haz procedente de un diodo láser sobre la vía, la reflexión difusa será recibida por un fotodiodo. Para realizar el barrido se utiliza un espejo giratorio accionado por un motor paso a paso. La figura 2.7 muestra el principio de operación del LMS 221. Instalado sobre la vía a una distancia de entre 4 y 20 metros realiza barridos perpendiculares a la misma localizando a los vehículos que circulan por la zona de detección independientemente del sentido de circulación. Así, se puede utilizar en vías con vehículos circulando en dos direcciones sin que ello afecte a la medida.

Este equipo presenta además la posibilidad de seleccionar: la frecuencia de escaneo, la resolución angular, el tiempo de respuesta e incluso la tasa de transferencia. Si se requiere una transferencia de datos más elevada de la disponible en las opciones básicas, la empresa ofrece la posibilidad de adquirir una tarjeta de alta velocidad (500 KBd). Todas estas características hacen que el equipo pueda trabajar en aplicaciones de detección y clasificación de vehículos. 


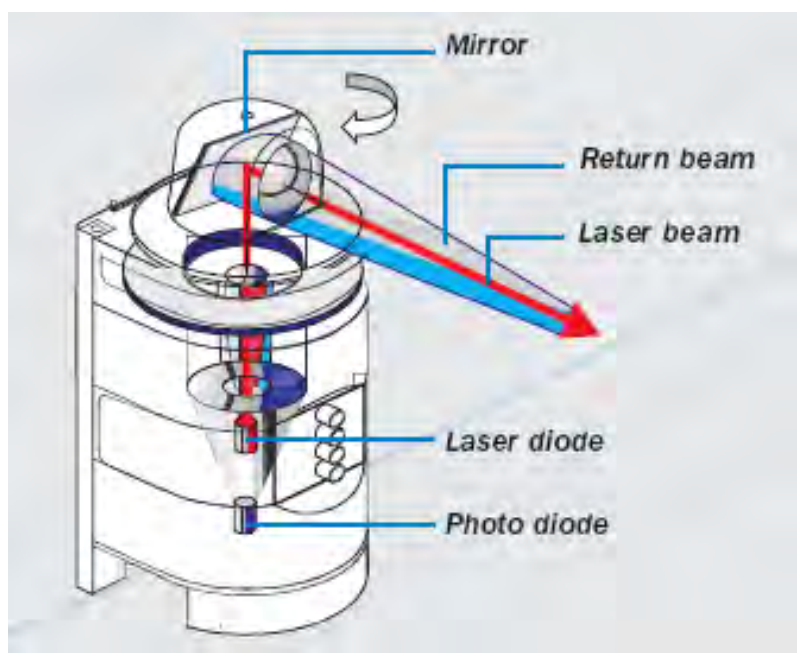

Figura 2.7 - Principio de operación del LMS 221-30206

\subsubsection{ACUITY: AccuRange 4000}

En el caso de la empresa Acuity ofrece dos equipos independientes. Para aplicaciones de láser trabajando como telémetro puntual ofertan el modelo AccuRange 4000, se trata de un sensor láser que mide las distancias. Mientras que para realizar el barrido necesario sobre la vía hay que adquirir el equipo AccuRange Line Scanner que incluye un espejo y un motor de continua. Lo más importante a destacar de este equipo es que se trata de un láser escáner de clase IIIb, es decir, se trata de un equipo que comporta ciertos riesgos: puede causar daños oculares o cutáneos agudos si se entra en contacto directo con el haz láser. En el caso de acoplar este equipo con el AccuRange Line Scanner este riesgo se evita al tratarse en este caso de un equipo de clase I que no supone riesgo alguno para los usuarios de la vía.

El AccuRange 4000 funciona mediante un diodo láser que trabaja en el rango de infrarrojo cercano (NIR) a una longitud de onda de $780 \mathrm{~nm}$. La característica más importante de este equipo es la forma en la que detecta la señal reflejada para calcular el tiempo de vuelo. El diodo láser se sitúa en el centro de unas lentes concéntricas, emite un haz de luz colimada y la reflexión difusa es detectada por un fotodiodo APD que se sitúa en el centro de las lentes. Esta tecnología para medir las distancias está patentada (US patent 5.309.212) y su funcionamiento puede verse en la figura 2.8 . 


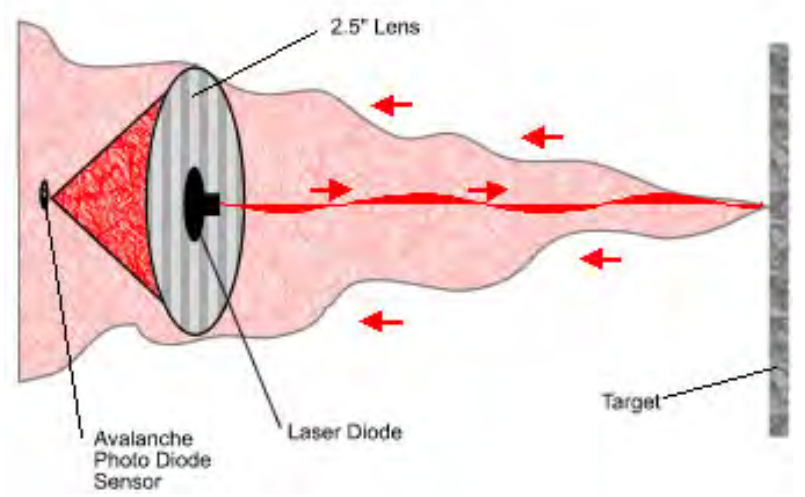

Figura 2.8 - Tecnología de medida de distancias aplicada en el AR4000

Uno de los parámetros dados por el catálogo que puede dar lugar a confusiones es el del ángulo de barrido, que según el catálogo es de $360^{\circ}$. Evidentemente, no corresponde con el efectivo en aplicaciones ITS. Es decir, al situar el equipo sobre la vía, a unos 7 metros, el sistema cubre la vía con un ángulo de $130^{\circ}$ y no los $360^{\circ}$ citados por catálogo. En otras aplicaciones puede que sea necesario o aplicable este valor, pero en aplicaciones ITS dadas sus características de instalación este valor nunca se cumplirá.

El principal inconveniente de este equipo radica en que la necesidad de trabajar con el line scanner reduce considerablemente las ventajas del telémetro como tal. El telémetro posee unas características de muestreo superiores a otros equipos como el SICK, pero al tener que añadirle un motor de continua para realizar el barrido sobre la superficie, la vía en nuestro caso, la velocidad de muestreo se ve reducida debido al encoder usado en el motor.

\subsubsection{OSI LaserScan: AutoSense 800}

El equipo AutoSense de la empresa OSI LaserScan es uno de los equipos comerciales más empleados en sistemas ITS, ya desde las primeras versiones de este modelo: AutoSense I y II cuando todavía pertenecían a la empresa Schwartz Electro-Optics. Este equipo, a diferencia de los anteriores, realiza dos barridos sobre la vía con un ángulo de $10^{\circ}$ de diferencia entre ellos. Por ello, es necesario duplicar tanto las etapas emisoras y receptora como el driver del láser que controla el disparo del diodo láser. Cada unos de los haces láser emitidos se reflejan en un 
polígono controlado por un motor para realizar cada unos de los barridos, como se muestra en la figura 2.9 .

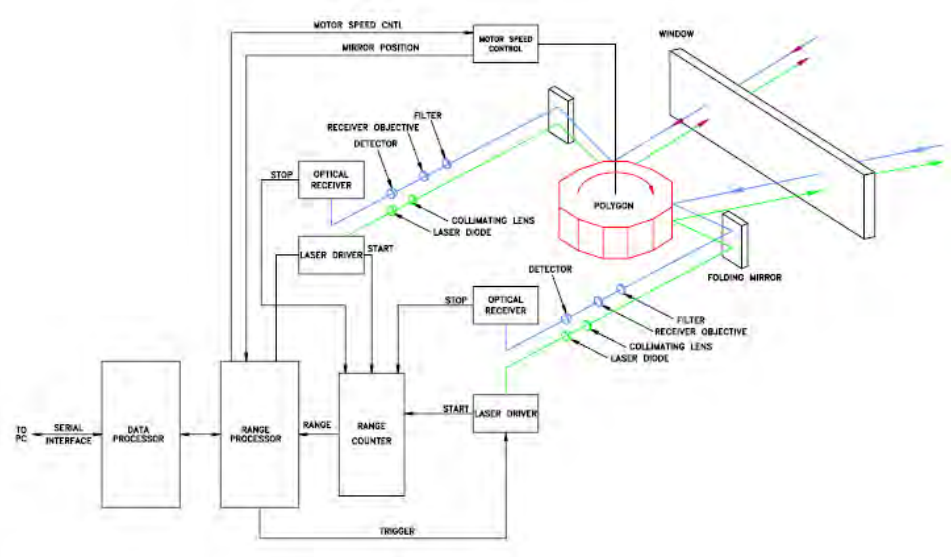

Figura 2.9 - Principio de operación del equipo AutoSense 800

Su ventaja principal reside en que al realizar dos barridos a un ángulo conocido es capaz de medir velocidades considerando que la aceleración es nula en la zona de detección. Por otra parte su desventaja reside en su pequeño ángulo de escaneo que se reduce a $55^{\circ}$ cuando el láser se sitúa a 7 metros sobre la vía, lo que hace que cubra sólo 7,28 metros de la vía. Este pequeño valor permite cubrir únicamente un carril, o dos como máximo si se sitúa en el centro de los mismos y se espera que los vehículos circulen centrados por cada uno de sus respectivos carriles. En caso contrario, las detecciones no se realizarán de forma adecuada, con lo que no se permitirá clasificar los vehículos correctamente ni conocer su velocidad.

Este equipo proporciona información sobre: detección, posición, velocidad y clasificación, según las especificaciones del fabricante. Cabe destacar que la clasificación se realiza en 11 clases sin seguir ningún estándar de clasificación de los utilizados comúnmente en aplicaciones de ITS como pueden ser el alemán TLS (definido por el instituto federal de investigaciones de carreteras, Bundesanstalt für Straßenwesen) [BAS08] o el FHWA americano (Federal Highway Administration) [FHW08]. 


\subsubsection{ASIM: TT-293}

El equipo TT-293 de la empresa ASIM es un detector diseñado expresamente para aplicaciones ITS, que incluye tres tecnologías sensoras: radar Doppler, ultrasonidos y PIR. El equipo es capaz de proporcionar información sobre: detección y clasificación de vehículos, conteo, volumen, velocidad, presencia y detección de colas y tiempo de ocupación. Toda esta información es relativa a un solo carril de la vía.

Tras esta primera aproximación a los datos dados por el catálogo, podría parecer que se trata del mejor equipo entre todos los presentados hasta el momento teniendo en cuenta sus prestaciones y su coste. Pero hay que entrar en detalle en ciertos aspectos para poder conocer su auténtico potencial. Para la clasificación de vehículos utiliza la longitud y forma del mismo, lo que no resulta uno de los mejores métodos de clasificación. La clasificación se realiza siguiendo el estándar alemán TLS [BAS08], y dependiendo del modelo del equipo esta clasificación se realiza en un mayor o menor número de clases (el modelo 293 clasifica en 2+1 clases, el modelo 295 en $5+1$ y el modelo 298 en $8+1)$.

En el caso del modelo 293 se trata de una clasificación 2+1, es decir, distingue en dos grupos (pequeños vehículos y vehículos pesados) más un grupo de "no identificado". Esta clasificación resulta insuficiente en la mayoría de aplicaciones ITS, sobre todo en el caso urbano ya que el volumen de camiones representa un número muy pequeño del tráfico total, y es necesario poder distinguir como mínimo entre turismos, motocicletas y furgonetas.

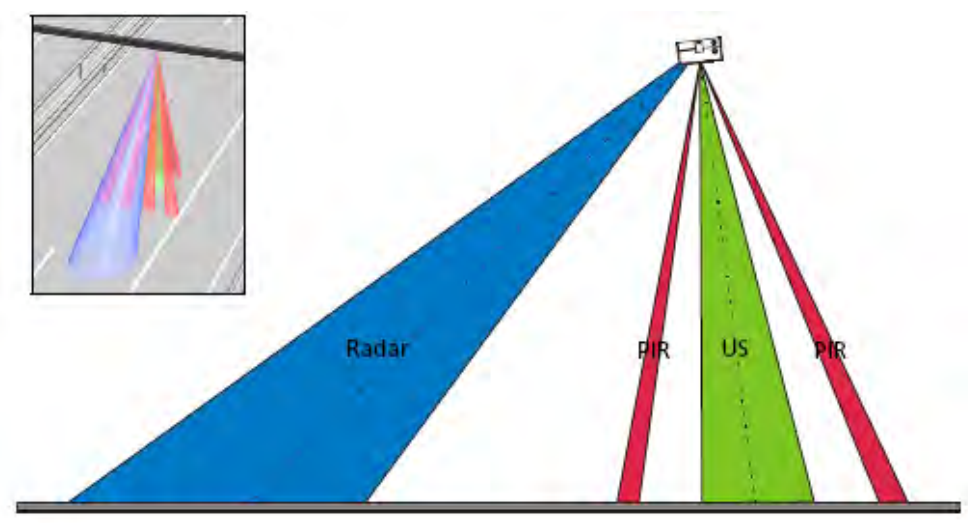

Figura 2.10 - Zonas de detección del equipo TT-293 
Si bien es cierto que el uso de múltiples sensores mejora la cantidad de información (parámetros) proporcionada por el equipo, en el caso de mal funcionamiento o fallo de uno de ellos se pierde gran parte de su potencial ya que la información se obtiene gracias a la combinación de varios de estos sensores. La figura 2.10 muestra las diferentes zonas de detección de cada uno de los sensores. El buen funcionamiento del equipo está altamente vinculado con la correcta instalación de los sensores que deben estar dirigidos hacia la vía en un determinado ángulo. 


\section{Bibliografía}

[AHG01] Abdelbaki, H., Hussain, K. y Gelenbe, E., A laser intensity image based automatic vehicle classification system. Intelligent Transportation Systems, 2001. Proceedings. 2001 IEEE, págs. 460-465, 2001, doi:10.1109/ITSC.2001.948701.

[AHS94] Ahmed, S.A., Hussain, T.M. y Saadawi, T.N., Active and passive infrared sensors for vehicular traffic control. Proceedings of IEEE Vehicular Technology Conference (VTC) VETEC-94, págs. 1393-1397, 1994.

[AJ99] Angelopoulou, E. y Jr., J.R.W., Laser Scanner Technology. Technical Report (CIS) MS-CIS-99-16, University of Pennsylvania. Department of computer and information science, 1999.

[Ame05] America, S.O.N., Installation Manual Tri-Tech TT 293, TT 295, TT 298. ASIM Technologies, Inc., 2005, URL http://www.asim-technologies. com/. Publication No. 19479800.

[BAS08] BAST, Description of the vehicle categories with code according to the tls. Bundesanstalt für Straßenwesen, 2008, URL http://www.bast.de/nn_ $43710 / \mathrm{EN} / \mathrm{e}-\mathrm{Home} / \mathrm{e}$-homepage_node.html? _nnn=true. [Online: Último acceso Octubre 2008].

[BMBL90] Butler, M.J.A. et al., Aplicación de la tecnología de percepción remota a las pesquerías marinas: manual introductorio. Documentos técnicos de pesca - T295 T0355/S, FAO, 1990. 9253026944.

$\left[\mathrm{CSP}^{+} 01\right] \quad$ Cheng, $\mathrm{H}$. et al., A real-time laser-based detection system for measurement of delineations of moving vehicles. Mechatronics, IEEE/ASME Transactions on, tomo 6 (2): págs. 170-187, Jun 2001, ISSN 1083-4435, doi:10.1109/3516. 928732 .

[CSP $\left.{ }^{+} 05\right] \quad$ Cheng, H.H. et al., Development and field test of a laser-based nonintrusive detection system for identification of vehicles on the highway. Intelligent transportation systems, IEEE Transactions on, tomo 6 (2): págs. 147-155, 2005.

[CZYH03] Chen, Q. et al., Self-triggering pulsed time-of-flight laser range-finding method. Optical Engineering, tomo 42 (12): págs. 3608-3611, 2003, doi:10.1117/1. 1621407.

[FD04] Fuerstenberg, K. y Dietmayer, K., Object tracking and classification for multiple active safety and comfort applications using a multilayer laser scanner. Intelligent Vehicles Symposium, 2004 IEEE, págs. 802-807, June 2004, doi: 10.1109/IVS.2004.1336487.

[FEZM05] Floreano, D. et al., Evolution of spiking neural circuits in autonomous mobile robots. International Journal of Intelligent Systems, tomo XX: págs. 100-123, February 2005. 
[FHW08] FHWA, Fhwa vehicle types. Federal HighWay Administration, 2008, URL http://www. fhwa.dot.gov/policy/ohpi/vehclass.htm. [Online: Último acceso Octubre 2008].

[FMZW07] Fang, J. et al., A low-cost vehicle detection and classification system based on unmodulated continuous-wave radar. Intelligent Transportation Systems Conference, 2007. ITSC 2007. IEEE, págs. 715-720, 30 October 2007, doi: 10.1109/ITSC.2007.4357739.

[Gar00] García, L.A., Diseño e implementación de una arquitectura multiagente para la ayuda a la toma de decisiones en un sistema de control de tráfico urbano. Tesis Doctoral, Departamento de Informática. Universidad Jaime I, Castellón de la Plana. España, 2000. Director: Dr. Francisco Toledo Lobo.

[Gib08] Gibson, D., Making signal systems work for cyclists. Public roads, tomo 71 (6), May/June 2008, URL http://www.tfhrc.gov/pubrds/08may/02. htm. [Online: Último acceso Septiembre 2008].

[Góm05] Gómez, L.E., Contribución al diseño e implementación de un sistema de detección y clasificación de vehículos con tecnología láser, mediante método estadístico y redes neuronales. Tesis Doctoral, Departamento de Ingeniería Electrónica. Universidad Politécnica de Valencia, Valencia. España, 2005. Directores: Dr. Antonio Mocholí y Dr. José Millet.

[Góm06] Gómez, N.R., Evaluación del uso de Autoscope para conteos automáticos de vehículos en intersecciones. Master en ingeniería, Universidad de Puerto Rico, Mayagüez, 2006.

[GMA $\left.{ }^{+} 07\right]$ Gallego, N. et al., Explotación de las infraestructuras actuales en entornos urbanos para aplicaciones its. VII congreso español en Sistemas de Inteligentes de Transporte, Valencia., 18-20 Septiembre 2007.

[GMMP02] Gupte, S. et al., Detection and classification of vehicles. Intelligent Transportation Systems, IEEE Transactions on, tomo 3 (1): págs. 37-47, March 2002, ISSN 1524-9050, doi:10.1109/6979.994794.

[Har01] Harlow, C., Automatic vehicle classification system with range sensors. Transportation research. Part C: Emerging Technologies, tomo 9 (4): págs. 231247, August 2001.

[HM05] Hussain, K. y Moussa, G., Automatic vehicle classification system using range sensor. Information Technology: Coding and Computing, 2005. ITCC 2005. International Conference on, tomo 2: págs. 107-112, April 2005, doi:10.1109/ ITCC.2005.96.

[HSA93] Hussain, T., Saadawi, T. y Ahmed, S., Overhead infrared sensor for monitoring vehicular traffic. Vehicular Technology, IEEE Transactions on, tomo 42 (4): págs. 477-483, November 1993, ISSN 0018-9545, doi:10.1109/25.260764. 
[IJR04] Iske, B., Jager, B. y Ruckert, U., A ray-tracing approach for simulating recognition abilities of active infrared sensor arrays. Sensors Journal, IEEE, tomo 4 (2): págs. 237-247, April 2004, ISSN 1530-437X.

[Inc00] Incorporated, A.R., AccuRange 4000. User's manual. Acuity Research Incorporated, 2000, URL http://www.acuitylaser.com/spanish. htm. [Online: Último acceso Octubre 2008].

[Ind02] Indent, D.A., LMS 221. Laser Measurement Systems. Technical Description. SICK AG., Reute, Germany, 2002, URL http://www.sick.com/home/ en.html. 8008 970/01 2002 WU.Sm.

[IRK02] Ivanov, B., Ruser, H. y Kellner, M., Presence detection and person identification in smart homes. International Conference in Sensors and Systems. St. Petersburg, 2002.

[KEW94] Korba, L., Elgazzar, S. y Welch, T., Active infrared sensors for mobile robots. Instrumentation and Measurement, IEEE Transactions on, tomo 43 (2): págs. 283-287, April 1994, ISSN 0018-9456.

[KHY05] Kuo, C.H., Huang, F.C. y Yang, F.C., Development of active ir-based surgical marker tracking and positioning systems. Systems, Man and Cybernetics, 2005 IEEE International Conference on, tomo 3: págs. 2443-2448, October 2005.

[KKMKS02] Keßel, A. et al., A concept for coupling empirical data and microscopic simulation of pedestrian flows. Monitoring and management of Visitor Flows in Recreational and Protected Areas. Conference on, págs. 199-204, 2002. Bodenkultur University, Vienna, Austria.

[Kle01] Klein, L.A., Sensor technologies and data requirements for ITS, capítulo Sensors in modern Traffic Management Systems:1. London: Artech House, 2001, ISBN $1-58053-077-X$.

[KMG06] Klein, L.A., Mills, M.K. y Gibson, D.R., Traffic Detector Handbook. Informe técnico, US Department of Transportation. Federal Highway Transportation, October 2006. Publication No. FHWA-HRT-06-108.

[Las06] LaserScan, O., Autosense AS800. Series User guide. OSI LaserScan, Orlando, FL, USA., 2006, URL http://www.osi-ls.com/. Publication No. 19479800.

[Mat04] Matthews, S.J., Thermal imaging on the rise. Laser Focus World, tomo 40 (3): págs. 105-109, March 2004, ISSN 1043-8092.

[MFW03] Martin, P.T., Feng, Y. y Wang, X., Detector Technology Evaluation. Technical report, Department of Civil and Environmental Engineering University of Utah Traffic Lab, November 2003, URL http://www.mountain-plains. org/pubs/html/mpc-03-154/. MPC Report number 03-154. 
[MK07] Mimbela, L.E. y Klein, L.A., A Summary of Vehicle Detection and Surveillance Technologies used in Intelligent Transportation Systems. Informe técnico, The Vehicle Detector Clearinghouse and US Department of Transportation. Federal Highway Transportation, August 2007.

[Ni07] Ni, D., Determining traffic-flow characteristics by definition for application in its. Intelligent Transportation Systems, IEEE Transactions on, tomo 8 (2): págs. 181-187, June 2007, ISSN 1524-9050, doi:10.1109/TITS.2006.888621.

[NPK03] Nissinen, J., Palojarviand, P. y Kostamovaara, J., A cmos receiver for a pulsed time-of-flight laser rangefinder. Solid-State Circuits Conference, 2003. ESSCIRC '03. Proceedings of the $29^{\text {th }}$ European, págs. 325-328, September 2003, doi:10.1109/ESSCIRC.2003.1257138.

[PPK06] Pehkonen, J., Palojarvi, P. y Kostamovaara, J., Receiver channel with resonancebased timing detection for a laser range finder. Circuits and Systems I: Regular Papers, IEEE Transactions on, tomo 53 (3): págs. 569-577, March 2006, ISSN 1549-8328, doi:10.1109/TCSI.2005.858758.

[PRK05] Palojarvi, P., Ruotsalainen, T. y Kostamovaara, J., A 250-mhz bicmos receiver channel with leading edge timing discriminator for a pulsed time-of-flight laser rangefinder. Solid-State Circuits, IEEE Journal of, tomo 40 (6): págs. 13411349, June 2005, ISSN 0018-9200, doi:10.1109/JSSC.2005.848022.

[RC02] Rogalski, A. y Chrzanowski, K., Infrared devices and techniques. Opto-Electron. Rev., tomo 10 (2): págs. 111-136, 2002.

[RKS89] Rahkonen, T., Kostamovaara, J. y Saynajakangas, S., A cmos asic time-to-digital converter for short time interval measurements. Circuits and Systems, 1989., IEEE International Symposium on, tomo 3: págs. 2092-2095, May 1989, doi: 10.1109/ISCAS.1989.100787.

[SCB $\left.{ }^{+} 06\right]$ Scanaill, C.N. et al., A review of approaches to mobility telemonitoring of the elderly in their living environment. Annals of Biomedical Engineering, tomo 34 (4): págs. 547-563, April 2006, doi:10.1007/s10439-005-9068-2.

[TA00] Turner, J.D. y Austin, L., A review of current sensor technologies and applications within automotive and traffic control systems. Institute of the Mechanical Engineers, 2000. Proceedings IMechE 2000, tomo 214 (D): págs. 589-614, 2000.

[VAVBB93] Van Arem, B. et al., Demonstration of a general european road data information exchange network - GERDIEN. Vehicle Navigation and Information Systems Conference, 1993., Proceedings of the IEEE-IEE, págs. 163-168, October 1993, doi:10.1109/VNIS.1993.585608.

[VCK $\left.{ }^{+} 00\right] \quad V a l, T$. et al., Using télédomotis interface for a new multiservice network applied to monitoring the elderly. Universal Multiservice Networks, 2000. ECUMN 2000. $1^{\text {st }}$ European Conference on, págs. 433-438, 2000, doi:10.1109/ECUMN. 2000.880795 . 
[Wan95] Wangler, R., Laser vehicle detector-classifier. Idea project - final report, Transportation Research Board. National Research Council, November 1995.

[WN03] Wang, Y. y Nihan, N.L., Can single-loop detectors do the work of dual-loop detectors? Journal of Transportation Engineering, tomo 129 (2): págs. 169-176, March/April 2003, doi:10.1061/(ASCE)0733-947X(2003)129:2(169).

[Won06] Wong, J.Y., Ultra low power ndir gas sensor fire detector. US Patent and Trademark Office, 2006. Patent number: 7335885. Filing date: 3 March 2006. Issue date: 26 February 2008.

[WZ85] Wolfe, W.L. y Zissis, G.J., The infrared handbook. Arlington: Office of Naval Research, Department of the Navy, 1985, edited by Wolfe, William L.; Zissis, George J., 1985.

[YSJ07] Yoo, J.J., Sung, K.B. y Jang, J.A., Intelligent non-signalized intersections based on magnetic sensor networks. Intelligent Sensors, Sensor Networks and Information, 2007. ISSNIP 2007. $3^{\text {rd }}$ International Conference on, págs. 275280, December 2007, doi:10.1109/ISSNIP.2007.4496856.

[Zam06] Zambon, A., Thermally sensitive array device for presence detection around automatic doors. EPO, European Patent Office, 2006. European Patent number: EP1619342. United States Patent number: 7362224. Filing date: 22 July 2004. Publication date: 25 January 2006. Bulletin 2006/04.

[ZGBW07] Zhang, Z. et al., Moving targets detection and localization in passive infrared sensor networks. Information Fusion, $200710^{\text {th }}$ International Conference on, págs. 1-6, July 2007, doi:10.1109/ICIF.2007.4408178. 


\section{Capítulo 3}

\section{Centros de Gestión de Tráfico - CGT}

La densidad de tráfico tanto urbano como interurbano ha sufrido a lo largo del último siglo un gran crecimiento [GMMA08]. Uno de los múltiples datos que sustenta esta afirmación es el aumento del parque de vehículos español, que en los últimos diez años ha crecido un $38 \%$ según datos de la DGT relativos al año 2008 [DGT08c]. El actual crecimiento vertiginoso no se ha producido a la par que el desarrollo de las infraestructuras de tráfico dando lugar, entre otras situaciones, a importantes congestiones de tráfico diarias en la mayoría de las grandes ciudades. Estas congestiones no solo producen pérdidas en tiempo de espera para los conductores y un elevado coste económico, sino que además aumentan la probabilidad de accidentes y producen un impacto negativo en el medio ambiente [FR08].

Según datos del Observatorio Nacional de Seguridad Vial [DGT09], los accidentes de tráfico con víctimas en zona urbana representaron en el año 2008 el $53 \%$ del total de accidentes de tráfico con víctimas, aunque su número se ha reducido un $6 \%$ entre el año 2003 y el año 2008. A lo largo del mismo periodo, el número de víctimas mortales en carretera ha descendido un $45 \%$ mientras que en zona urbana solo se han reducido un $31 \%$.

Por lo tanto, los esfuerzos de las entidades administradoras de las vías se han alineado en la mejora de los CGTs. Se han invertido cantidades considerables de dinero para lograr el progreso esperado de la gestión, control e información del tráfico urbano [FR08, DGT09], que logre reducir la siniestralidad, incrementando así la seguridad vial. Es precisamente en el "Plan de actuaciones de Seguridad Vial - 2008" de la DGT [DGT08b] donde se señala como una de las áreas estratégicas clave: Infraestructura, gestión e información del tráfico. Esta línea de 
actuación promueve, entre otros objetivos, "el despliegue de los ITS para la implantación de sistemas avanzados de gestión del tráfico" íntimamente ligado con uno de los objetivo de esta tesis como es la mejora de la captura de datos y servicios de monitorización, potenciando los sistemas ya existentes e investigando nuevas soluciones.

Los centros de gestión de tráfico se pueden definir genéricamente como los lugares desde los que se realiza la gestión y control del tráfico, tanto urbano como interurbano, en base a la información que reciben en tiempo real de los distintos equipos sensores instalados en la vía. Sin embargo, la labor de los CGT va mucho más allá, abarcando, entre otras, las siguientes funciones [BOE08, DGT08a]:

- Reducción de la siniestralidad:

- Investigación de las condiciones de la vía.

- Coordinación de las operaciones de auxilio en caso de accidente o incidente.

- Gestión de incidencias meteorológicas.

- Autorización de obras, transporte de mercancías peligrosas, pruebas deportivas, etc.

- Colaboración en los planes de actuación en materia de protección civil.

- Elaboración de normativa y reglamentación relacionada con la circulación (restricciones de circulación).

- Proporcionar información y asistencia a los usuarios de la red viaria:

- Red de postes de auxilio SOS para comunicación de accidentes, averías, cortes de vía, etc.

- Recopilación de toda la información que puede ser de interés para la gestión del tráfico (meteorología, estado de las carreteras, incidencias, restricciones ... ).

○ Difusión de información (radio, televisión, teléfono, sistemas telemáticos ...).

- Gestión y control del tráfico interurbano:

- Mejorar la fluidez del tráfico.

- Gestión del tráfico en los accesos a las grandes ciudades (>600 Km controlados y otros $500 \mathrm{Km}$ monitorizados).

○ Actuaciones en operaciones especiales (puentes, vacaciones, ... ). 
○ Información de rutas alternativas y situación de la red viaria.

- Carriles reversibles y BUS-VAO (acrónimo del inglés Vehículos de Alta Ocupación).

- Coordinación con los medios de comunicación (prensa, radio y televisión).

- Promover la investigación y realización de estudios en materia de seguridad vial.

- Elaboración de estadísticas de accidentes, intensidades de tráfico, velocidad, llamadas atendidas, etc.

- Participación en grupos de trabajo dentro de la Unión Europea.

○ Financiación de proyectos de investigación y desarrollo.

- Cooperación con otros organismos de la Administración, Instituto de Estudios Turísticos, Ministerio de Fomento, Consorcio de Transportes, etc.

Además de los grandes CGTs a nivel nacional e incluso a nivel autonómico no hay que olvidar los CGT urbanos instalados en la mayoría de las principales ciudades del territorio nacional, destacando: Madrid, Zaragoza, Barcelona, Málaga, Sevilla y Valencia, por su larga trayectoria. En el esta tesis interesan precisamente estos CGTs urbanos ya que el trabajo elaborado está enmarcado en dicho ámbito, y son a los que se dedica el presente capítulo donde se explican: sus atribuciones, los sistemas con los que cuentan, los parámetros que controlan ...

\subsection{Centros de Gestión de Tráfico Urbano}

"Los CGTs urbanos pretenden ser el punto de unión entre todos los agentes implicados en el tráfico urbano de la ciudad: peatones, vehículos privados, transporte colectivo, policía local .... y desde él se realiza la gestión integral del tráfico con el objetivo de optimizar las condiciones generales de la circulación para todos los usuarios de la vía pública.”, [AYT08]. Los CGTs deben conocer la demandas de tráfico de la forma más exacta posible para poder satisfacerla adaptando los planes de tráfico y haciendo que las vías operen en sus óptimas condiciones de capacidad y seguridad [Arr08]. Pero también deben anticiparse a estas demandas elaborando modelos predictivos de la situación futura del tráfico [BP01].

Las atribuciones de un CGT urbano se podrían resumir en las siguientes [GV07]: 
- Supervisión, mediante monitorización en tiempo real, del estado de la circulación y el tráfico urbano.

- Recogida, clasificación y análisis de los parámetros que caractericen el tráfico, así como las variables atmosféricas y de contaminación que afecten al mismo.

- Activación de los planes de gestión de tráfico aprobados.

- Detección y pronta respuesta a los incidentes de tráfico en las vías urbanas.

- Adopción de las estrategias y medidas de ordenación y regulación del tráfico adecuadas en cada momento para prevenir la congestión circulatoria y garantizar su movilidad y seguridad, gestionando para ello las posibilidades técnicas que, en su caso, ofrezca el sistema de gestión de tráfico urbano.

- Adopción de las estrategias y medidas de ordenación y regulación del tráfico y eventos especiales como la celebración de pruebas deportivas, periodos festivos, operaciones de salidas y entradas de los períodos vacacionales ..., de conformidad con lo que dispongan los planes de gestión del tráfico previstos al efecto.

- Establecer, en cada caso, los usos y mensajes de los paneles de mensaje variable (PMV).

- Orientación a la ciudadanía en la conducción de sus vehículos, informándoles sobre el estado de la red viaria y el uso más eficiente de las posibles alternativas de circulación y desplazamiento, utilizando para ello la emisión de recomendaciones a través de los PMV, o la difusión de boletines informativos a través de los medios de comunicación y las tecnologías de la información más apropiadas.

- Procurar la conexión y el intercambio informativo con otros centros de gestión de tráfico urbanos y con los de otras administraciones encargadas del tráfico y la circulación vial.

- Poner en conocimiento de las autoridades competentes aquellos hechos de los que tengan conocimiento que pudieran constituir infracción a la normativa de tráfico, circulación de vehículos a motor y seguridad vial, y disposiciones complementarias. 


\subsection{Arquitectura de un CGT}

Los sistemas de tráfico urbano son un caso típico de sistemas geográficamente distribuidos con un centro o núcleo radicado en el CGT. De este modo, el CGT comprende no solo las instalaciones y equipos instalados en el propio centro que lo alberga, sino también los diferentes equipos instalados a lo largo de la red vial que permiten conocer en tiempo real el estado del tráfico y sus parámetros, (ver figura 3.1).

La arquitectura se estructura en niveles jerárquicos, cada uno de los cuales realiza unas funciones determinadas dependiendo de su posición [Bui08]. El uso de niveles jerárquicos proporciona una elevada seguridad salvaguardando el funcionamiento del sistema aunque este se encuentre dañado, ya que cada nivel puede tomar el control de forma aislada e independiente.

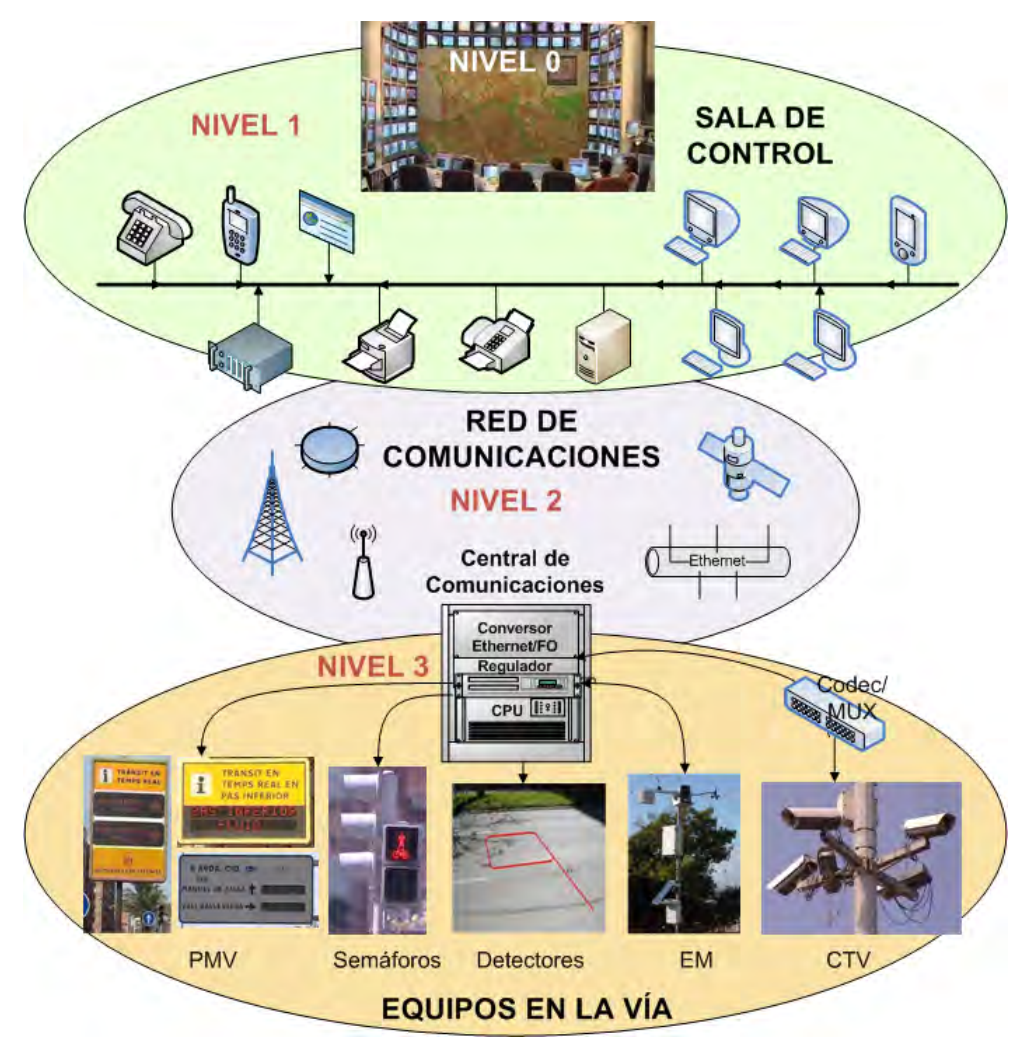

Figura 3.1 - Arquitectura de un CGT Urbano

Los sistemas jerárquicos suelen estar formados por cuatro niveles que corresponden a las zonas de la figura 3.1. El Nivel 0 es la cúpula de la dirección operativa y de toma de decisiones formada por los operarios del CGT. El Nivel 1 está constituido por los sistemas ubicados en la 
sala de control donde se realizan las funciones de control táctico y estratégico. El Nivel 2 corresponde a la etapa de comunicación e interfaz entre los niveles precedente y posterior. Incluye concentradores de comunicaciones, conmutadores y centrales de comunicaciones. Finalmente el Nivel 3 realiza las funciones de control de la señalización y toma de datos, estando formado por: reguladores, equipos sensores, PMV, semáforos, cámaras ...

\subsubsection{Sistemas de sensorización y monitorización}

Ya en el capítulo de introducción, en el apartado 1.3, Introducción, se constató la importancia de que los parámetros proporcionados fueran abundantes, diversos y exactos. Esta exactitud es esencial a la hora de proporcionar información a los usuarios, así como de explotar y gestionar eficazmente los datos recibidos en el CGT [SYOC08]. Los sistemas de sensorización y monitorización permiten conocer en tiempo real el estado del tráfico y sus variables, siendo los detectores más utilizados a lo largo de los últimos tiempos las espiras magnéticas.

Los detectores basados en espiras magnéticas fueron instalados de forma masiva sobre todo durante la década de los 90 [JLLM08, Ulz98], aunque gracias a la evolución de los sistemas y sensores ITS se han ido introduciendo otros detectores entre los que destacan: visión artificial, radares de microondas y piezoeléctricos [MK07, KMG06, MFW03]. Actualmente se están instalando estaciones meteorológicas y de detección de gases contaminantes para analizar la polución producida por el tráfico. Por otra parte, las cámaras son otro de los sistemas de monitorización más generalizados. Forman parte de circuitos cerrados de televisión (CCTV) controlados desde los CGT.

En el caso de la ciudad de Valencia, hay un total de 3.170 detectores instalados en las vías que miden la intensidad de circulación (número de vehículos), el tiempo de ocupación y la velocidad media de circulación. El CCTV permite controlar más de 100 intersecciones, y 17 pasos inferiores y accesos a la ciudad. Se suelen instalar grupos de cámaras de número variable. En el caso de las intersecciones se instalan cámaras orientadas a cada uno de los accesos más una cámara móvil. En total, la red cuenta con 660 cámaras controladas desde el CGT, ver figura 3.2. 
Las imágenes detectadas por las cámaras se usan también en sistemas de detección automática de incidentes mediante aplicaciones de visión artificial [AYT08].

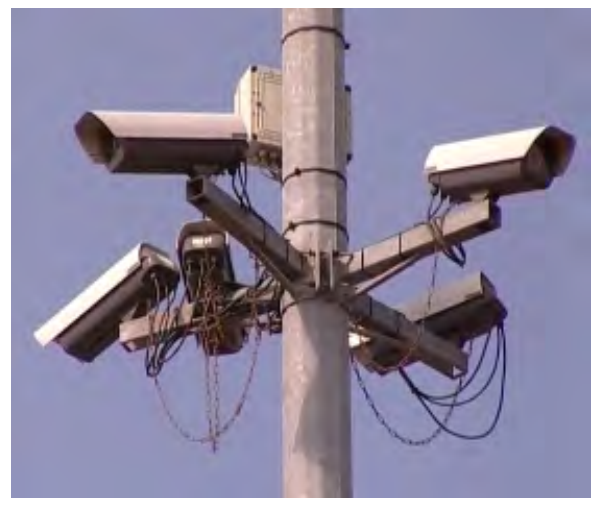

(a) Grupo de cámaras

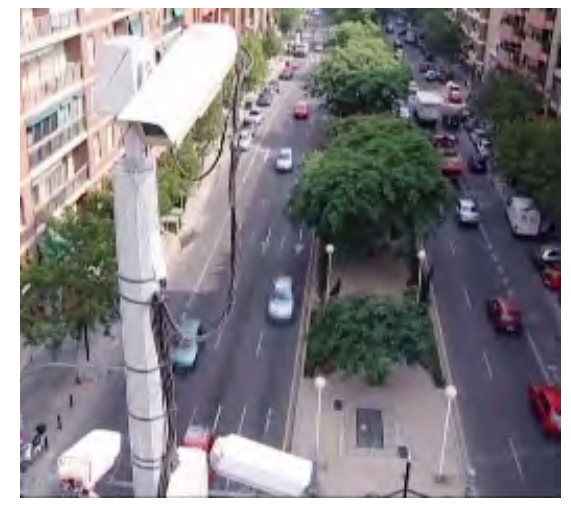

(b) Cámara móvil

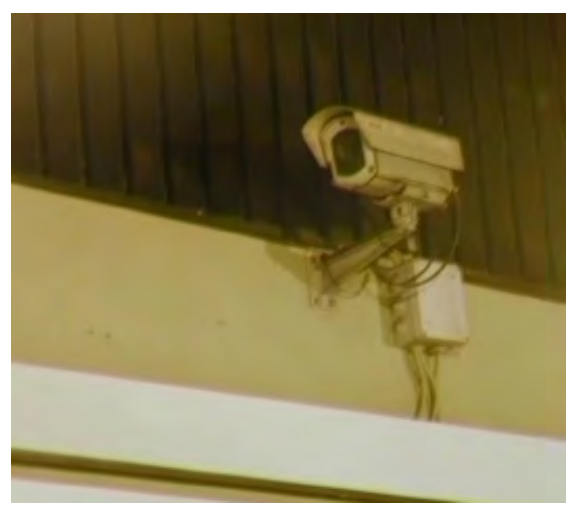

(c) Cámara en túnel

Figura 3.2 - Sistemas de monitorización mediante cámaras

\subsubsection{Sistemas de señalización variable}

Los sistemas de señalización variable están compuestos por los PMV situados en puntos estratégicos de la vía pública, cuyo objetivo es informar a los conductores de la vía sobre el estado de la misma con el objetivo de lograr su uso efectivo. Estos sistemas de señalización pueden ser preventivos, restrictivos o informativos. Pudiendo ser estos últimos: de identificación, de destino, de recomendación, generales y de servicios, y turísticas [MCG98]. Por consiguiente, los conductores están informados de los problemas que se puede encontrar en las vías por las que circulan y de posibles alternativas, así como información general que ayude a la conducción.

Mediante paneles alfanuméricos y gráficos gestionados desde el CGT se informa a los conductores de: 
- estado del tráfico,

- tiempos de recorridos,

- itinerarios alternativos,

- incidencias en la vía pública: accidentes, obras, cortes de calles ...,

- velocidad de circulación recomendada,

- e incluso el estado de los aparcamientos de la ciudad.

Toda esta información debe llegar en tiempo real al conductor para mejorar la situación del tráfico en cada momento. En la ciudad de Valencia hay instalados: 25 paneles de itinerarios alternativos, 76 paneles informativos alfanuméricos que permiten representar pictogramas, 8 paneles de recorridos de tiempos urbanos, 2 paneles generales de información de la circulación en toda la ciudad instalados en dos de las vías principales de acceso a la ciudad y 26 paneles informativos de plazas libres en aparcamientos, (ver figura 3.3).

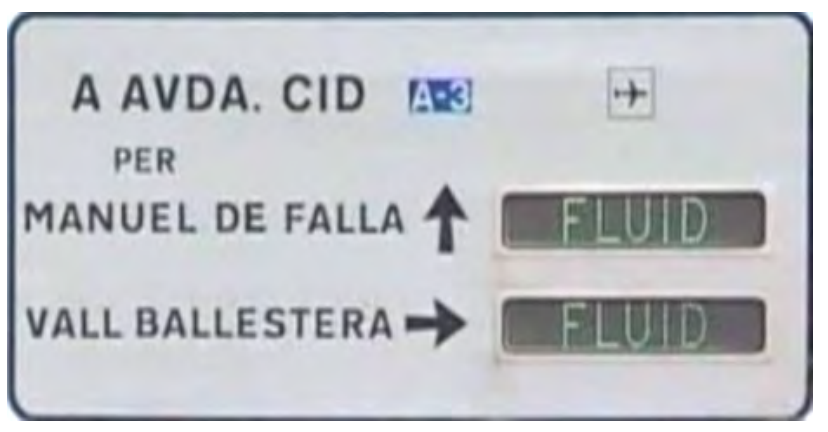

(a) PMV itinerarios

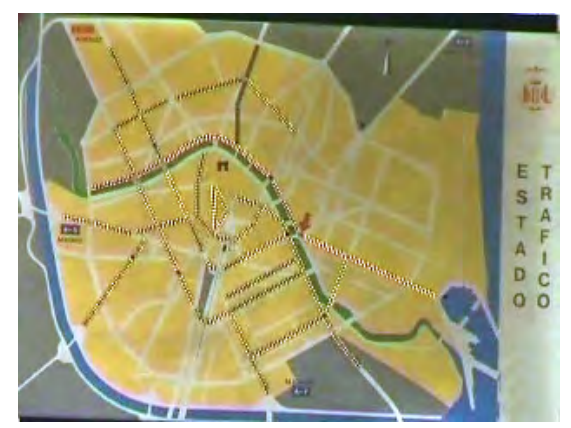

(b) Paneles de la ciudad

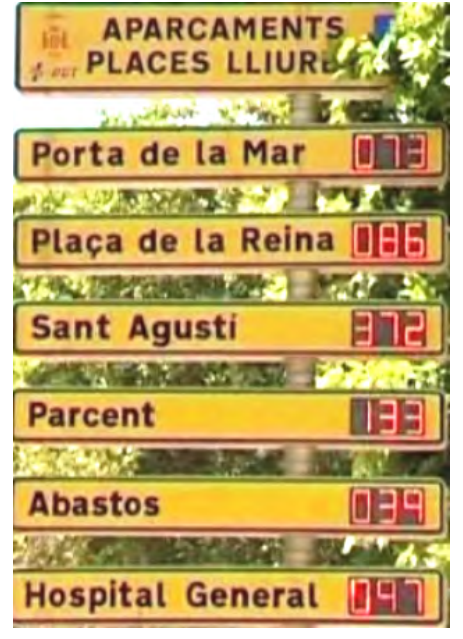

(c) Paneles de aparcamientos

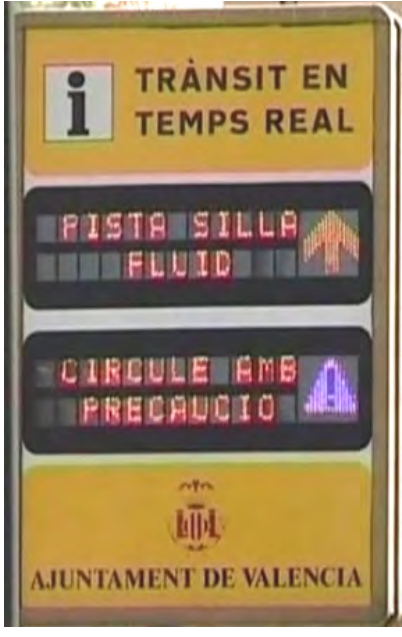

(d) PMV alfanumérico

Figura 3.3 - Sistemas de señalización variable 


\subsubsection{Sistemas de información de tráfico}

Una vez los datos son recibidos y analizados en el CGT se ponen a disposición de los usuarios finales de la vía a través de diferentes tecnologías y herramientas, entre las que destacan [Rod03, GV04]:

- Televisión - Información sobre el estado de las carreteas en tiempo real, previsiones e incidencias mediante conexiones directas con varias televisiones, tanto a nivel nacional como regional, e información mediante el teletexto, sistema cada vez más en desuso.

- Radio.

- Conexiones diarias con las grandes emisoras de ámbito nacional, regional y local. Se realizaron un total de 85.157 conexiones de emisoras de radio en 2002 [Rod03].

- RDS (acrónimo del inglés Radio Data Systems) - Los datos se envían utilizando el canal de mensajes de tráfico codificado TMC-TA que envía información sobre tráfico únicamente en modo continuo, no bajo petición.

- DAB (acrónimo del inglés Digital Audio Broadcasting) - Tecnología en desarrollo para la difusión de audio en formato digital.

- Telefonía básica, RDSI, gracias a la existencia de números de teléfono de información (línea 900). Informan sobre el estado de las carreteras, incidencias, ayuda y asistencias, y trámites administrativos. El número de usuarios de este servicio en 2002 fue de 1.935.515.

- Telefonía móvil.

- Información sobre el estado de las carreteras mediante telefonía móvil usando generalmente GSM para el envío de mensajes cortos de texto, SMS, aunque se está introduciendo cada vez más la tecnología UMTS y 3G. La mayor empresa nacional que ofrece este tipo de servicios, calculó que en el año 2001 el número de usuarios fue de 2.434.023.

- Además de información de las carreteras se puede consultar trámites y noticias mediante tecnología WIFI, principalmente mediante el protocolo de aplicación WAP. 
- Internet - Mediante la información proporcionada desde las páginas de las entidades gestoras del tráfico se proporciona información tanto de tráfico como administrativa y de legislación. Se registraron 30.620.663 de usuarios en el año 2002.

- Otros.

- Paneles de mensaje variable - Informan sobre las incidencias y recomendaciones del tramo por el que se circula (retenciones, problemas meteorológicos, obras ...).

- Postes SOS - Sirven para pedir ayuda y asistencia en carretera. A lo largo del año 2002 se recibieron 38.667 llamadas a través de este servicio.

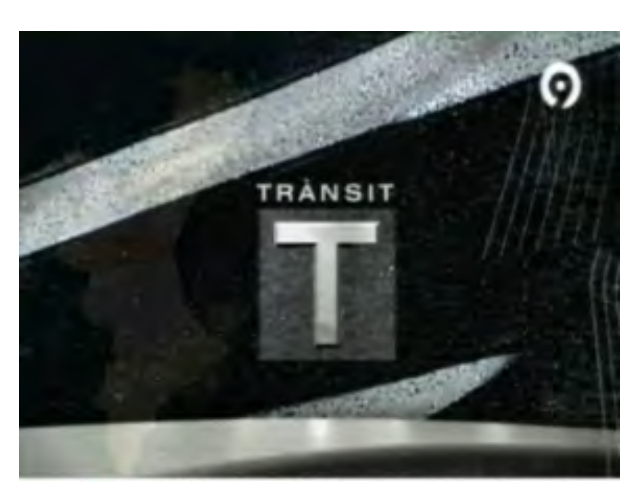

Teléfono Infovoz: 963626250

(a) Televisión autonómica

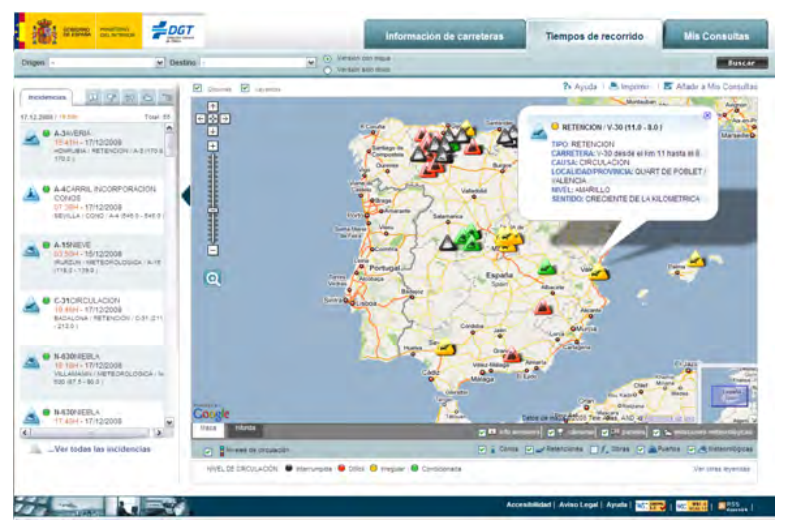

(b) Internet: web DGT

Figura 3.4 - Sistemas de información de tráfico

\subsubsection{Infraestructuras de comunicaciones}

La red de comunicaciones está formada por el conjunto de infraestructuras y equipamientos de telecomunicaciones que permiten interconectar los equipos telemáticos y de sensorización ubicados en las carreteras con el CGT. Los requisitos que debe cumplir los sistemas de comunicaciones son [Ulz02]:

- Permitir comunicaciones en tiempo real.

- Integrar distintos formatos de información (datos, audio, video).

- Posibilitar distancias de transmisión variables desde unos pocos kilómetros hasta cientos de ellos.

- Proporcionar un elevado número de canales para CCTV. 
- Deben ser: seguros, redundantes y tolerantes a fallos.

- Usar estándares homologados por la UIT-T, comité de normalización de las telecomunicaciones dentro de la UIT (acrónimo del inglés Unión Internacional de Telecomunicaciones).

El flujo de información comienza con la toma de parámetros desde los distintos sistemas de sensorización y monitorización, estos datos son transmitidos a través de diferentes tipos de redes (fibra óptica, GPRS, RDSI, WIFI, WIMAX ... ) normalmente propietarias y de uso exclusivo. Al CGT llega la información que es tratada, analizada y posteriormente difundida a los usuarios finales de la vía mediante PMV, internet, radios y televisiones, etc.

En el continente Americano, al tener que cubrir elevadas distancias y ser las infraestructuras muy costosas, se utilizan sistemas inalámbricos de radioenlaces. En el caso Europeo y Asiático se ha apostado por el uso de redes IP sobre fibra óptica, utilizando jerarquía digital síncrona (SDH) para transmisión de formatos de datos, audio y vídeo codificado y otra red independiente como seguridad y apoyo para transmisión de vídeo analógico y/o digital en tiempo real [Ulz02]. Tanto los sistemas de sensorización y monitorización como los sistemas de información variable utilizan el interfaz RS232 o similar para enviar la información a la ERU o regulador, donde ya utilizan protocolos normalizados bajo el estándar TCP/IP.

\subsection{Parámetros de tráfico necesarios en un CGT}

Dependiendo del tipo de centro de control: nacional, regional, extraurbano o urbano, y de las aplicaciones de tráfico llevadas a cabo en el mismo, los parámetros de tráfico que necesita variarán tanto en el tipo como en la frecuencia en la que tienen que ser proporcionados. Es decir, no todos los centros de gestión del tráfico tienen las mismas necesidades de información. Aun así, existen una serie de parámetros esenciales y necesarios en todo centro de control para disponer de una información básica sobre la situación del tráfico que permita tomar las acciones adecuadas en cada caso y posibilite anticiparse a las situaciones críticas e incidencias. 
En primer lugar, hay que definir correctamente cada uno de los parámetros involucrados en la gestión de tráfico. Debido a la diversidad de definiciones y para evitar posibles errores o confusiones se ha aceptado a lo largo de la presente tesis la terminología aceptada por la Asociación Mundial de la carretera (PIARC) y recopilada en su "Diccionario Técnico Vial" (octava edición de septiembre de 2007)[PIA07]:

- Aforo de tráfico (Traffic census) - Censo de circulación.

- Clasificación de vehículos (Vehicle classification) - Distribución de vehículos por clases en función de ciertos parámetros como el peso, longitud, uso, tipo de motor, número de ejes o de pasajeros, etc.

- Conteo (Counting) - Información sobre el número de vehículos que circulan en el área de detección en un determinado periodo de tiempo.

- Densidad o concentración de tráfico (Concentration or Density) - Número de vehículos por unidad de longitud, de una vía o carretera o parte de ella en un instante dado, excluyendo los vehículos estacionados.

- Intensidad de tráfico (Flow rate) - Número de vehículos que pasan por una sección transversal dada de una vía o carretera en la unidad de tiempo. Se mide en vehículos/hora o vehículos/día. Cuando se emplea como unidad los vehículos/hora se habla de intensidad horaria, y cuando se utilizan los vehículos/día se habla de intensidad diaria.

- Ocupación (Occupancy) - Porcentaje de tiempo durante el cual una sección transversal o longitudinal dada de una vía o carretera, durante un cierto período de tiempo, está ocupada por algún vehículo, en algún punto de la sección.

- Velocidad individual instantánea de un vehículo (Individual spot speed) - Velocidad de un vehículo en el instante en que atraviesa una determinada sección transversal de una vía o carretera. La media aritmética de las velocidades individuales instantáneas de una serie de vehículos se denomina "velocidad media en el tiempo".

- Volumen o Flujo (Traffic volume or Flow) - Número de vehículos que pasan por una sección transversal dada de una vía o carretera en el transcurso de un período de tiempo dado. 
La intensidad de tráfico es la característica más importante y para medirla se realizan aforos en determinadas secciones de la carretera [BKPS95]. Se trata de un parámetro continuamente variable condicionado por la demanda, que cambia considerablemente en función del tramo de red vial [Val88]. Así, la intensidad depende del tiempo, es distinta en cada momento siguiendo ciclos periódicos. Desde el punto de vista de la Ingeniería del Tráfico son especialmente interesantes dos situaciones concretas [BKPS95, Val88]: la intensidad media diaria (IMD) anual y la intensidad horaria punta.

La intensidad media diaria anual es la magnitud más utilizada para caracterizar la intensidad en las carreteras, se define como el número de vehículos que pasan por una sección transversal dada de una vía o carretera durante un año dividido por 365. Se trata de la intensidad de tráfico que corresponde al día medio del año. La intensidad horaria punta representa el número de vehículos que pasan por una sección transversal dada de una vía o carretera durante la hora que se considera representativa de las condiciones de mayor circulación, determinando el correcto dimensionado de la misma. La IMD es fundamental desde el punto de vista del planeamiento (clasificación de vías, cálculos de índices de accidentes, tendencias de uso, determinación de las características geométricas de las vías ... ). Mientras que la intensidad horaria es más interesante desde el punto de vista del proyecto y de la ordenación (capacidad de las vías, control de tráfico, ordenación de la circulación ... ) [Val88].

La densidad de tráfico, dada su dependencia de la intensidad, tiene un interés más teórico que práctico [BKPS95]. Su valor máximo se alcanza cuando todos los vehículos se encuentran parados en la vía sin la posibilidad de moverse, ni aunque sea a bajas velocidades. Esta densidad máxima es igual a la inversa de la longitud media de los vehículos por el número de carriles.

\subsubsection{Relación entre los parámetros de tráfico}

Como puede apreciarse de las definiciones anteriores algunos de estos parámetros se obtienen por medida directa mientras que otros se calculan indirectamente de los anteriores, como son: aforo, densidad y volumen. En Ingeniería de Tráfico se estudian las relaciones que vienen dadas entre intensidad, densidad y velocidad. 
Una vez determinada la intensidad de tráfico que circula por una vía, se puede estimar la velocidad de los vehículos que circulan por ella. No obstante, la velocidad a su vez depende de otros parámetros dependientes de la vía y/o de otros agentes externos como los factores medioambientales. Ello no impide que se pueda determinar que, ante un aumento de intensidad, corresponde una reducción de la velocidad media, hasta llegar a un punto de densidad crítica que corresponde a la máxima intensidad. A partir de este punto decrecen ambas: velocidad e intensidad [BKPS95, Val88].

La relación densidad-velocidad es similar a la anterior. La velocidad media es función de la densidad y alcanza su valor máximo cuando la densidad es cero, disminuyendo constantemente al aumentar la densidad hasta llegar a anularse cuando la densidad de tráfico alcanza su valor máximo. Se trata de parámetros inversamente proporcionales. En un estudio realizado en la Universidad de Yale, se llegó a la conclusión de que la intensidad de tráfico puede encontrarse en tres situaciones distintas: circulación normal, inestable y forzada, pudiendo definirse cada zona en términos de probabilidad. La densidad define así el grado de inestabilidad del tráfico [Val88].

La relación entre todos estos parámetros, en condiciones normales de tráfico, viene definida por la siguiente ecuación [TRB00]:

$$
I=\bar{V}_{e} \cdot D
$$

donde,

$I$ es la intensidad de tráfico $(\mathrm{veh} / \mathrm{h})$,

$\bar{V}_{e}$ es la velocidad media espacial $(\mathrm{Km} / \mathrm{h})$,

y $D$ la densidad de tráfico (veh/km).

La ecuación 3.1 establece la relación entre los tres parámetros más importantes que describen situaciones de tráfico continuo e ininterrumpido. Aunque dicha ecuación puede producir, para una determinada intensidad, infinitos casos combinando valores de velocidad y densidad 
en una determinada vía, existen relaciones adicionales que restringen la variedad de condiciones de intensidad en una vía [TRB00].
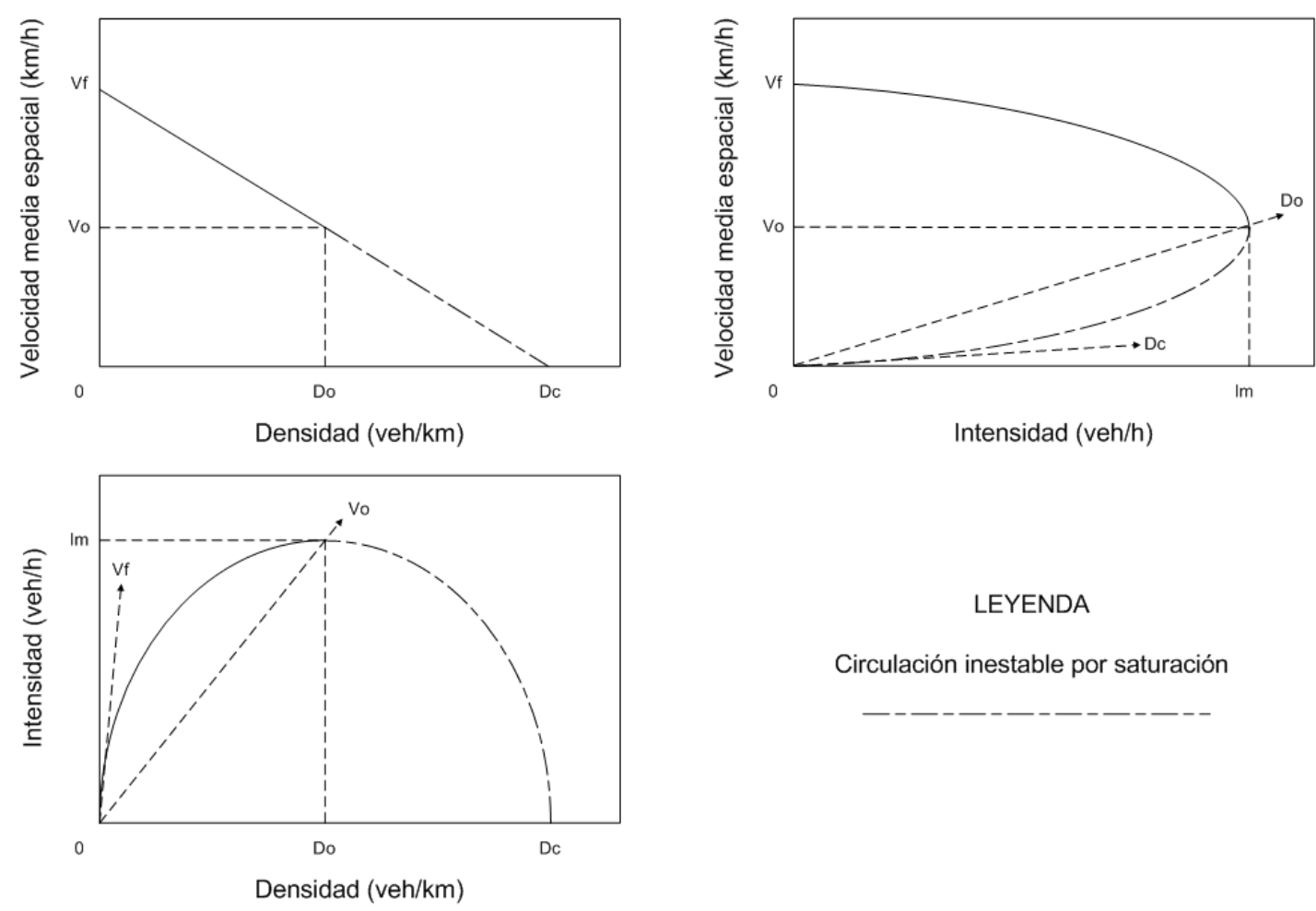

LEYENDA

Circulación inestable por saturación

Figura 3.5 - Relaciones generalizadas entre los parámetros de intensidad, densidad y velocidad en tráfico continuo

Una representación gráfica y generalizada de las relaciones entre estos parámetros puede observarse en la figura 3.5 que representa las bases para poder analizar una situación de tráfico continuo e ininterrumpido. La función intensidad/densidad se sitúa debajo de la función velocidad/densidad ya que comparten el eje horizontal. En el caso de las funciones velocidad/densidad y velocidad/intensidad comparten en eje vertical. Estas funciones dependen del tráfico predominante y las condiciones de la vía bajo estudio. Aunque en la figura 3.5 se han representado curvas continuas es poco probable que se den todo el rango de las funciones en una determinada localización. En condiciones normales, los datos recogidos mostraran discontinuidades con parte de las curvas ausente.

Se puede dar el caso de intensidad cero bajo dos condiciones distintas: que no haya vehículos en la vía (densidad=0) o que haya tantos vehículos que estos se encuentren parados (veloci- 
dad=0). En el primer caso la velocidad es teórica y vendría establecida por el primer conductor, esta velocidad se representa por $V_{f}$ en las gráficas. Mientras que la densidad que produce la segunda situación, denominada densidad de congestión, se representa por $D_{c}$. Cuando la intensidad aumenta desde cero, también lo hace la densidad al haber más vehículos circulando en la vía. En este momento, el aumento de vehículos produce una disminución de la velocidad. Esta disminución es insignificante para densidades e intensidades de valores medios y bajos.

A medida que la densidad crece, estas curvas generalizadas sugieren que la velocidad decrece significativamente antes de alcanzar la capacidad de la vía que corresponde al valor máximo de la intensidad. En este momento se produce la velocidad óptima, $V_{o}$, llamada velocidad crítica; la densidad óptima, $D_{o}$, llamada densidad crítica; y la máxima intensidad, $I_{m}$.

La densidad se representa en la gráfica velocidad/intensidad mediante la pendiente de la recta que une el origen con el punto que se desee medir, basándose en la ecuación 3.1. De modo análogo sucede en la gráfica intensidad/densidad, la pendiente de la recta que une el origen con el punto a medir informa sobre su velocidad. Las tres gráficas proporcionan información redundante, ya que conociendo una relación las otras dos están definidas de forma única. La gráfica intensidad/densidad es la más importante y usada, conociéndose como diagrama fundamental del tráfico [BKPS95].

\subsection{Investigación en el sector de tráfico: el caso americano y el caso europeo}

En Estados Unidos se han realizado diferentes estudios relativos a las tecnologías detectoras y los parámetros necesarios en el control de tráfico. Un estudio llevado a cabo por el Departamento de Transporte de Minesota y la consultora SRF [MnD97], define como parámetros básicos: conteo, velocidad, clasificación, detección y pesado de vehículos de varios ejes. Otro estudio realizado por el Departamento de Transporte de Utah [MFW03] se centra en diferentes tecnologías detectoras y en los parámetros proporcionados por cada una de ellas, obteniendo como parámetros importantes: ocupación, presencia, conteo y velocidad. 
No se debe olvidar el hecho de que cada una de las estrategias de control de tráfico en tiempo real necesita un tipo diferente de información, formato, índices, precisión y ancho de banda de transmisión [KMG06]. Por ejemplo, en la gestión de tráfico en autopistas, para detectar incidentes automáticamente en tiempo real se necesitan como mínimo los siguientes parámetros: volumen o flujo, ocupación y velocidad en intervalos entre 20 y 30 segundos. La información de volumen y ocupación permiten detectar congestión y alertar al personal de control sobre incidentes. Por su parte, la información de velocidad permite estimar los retardos en el tiempo de viaje y el nivel de servicio, parámetros usados en los algoritmos de detección de incidentes [KMG06].

El caso europeo podría asemejarse al norteamericano en el hecho de que los países tienen la misma labor que los Departamentos de Transporte de los diferentes estados norteamericanos. En Europa, cada uno de los países cuenta con organismos responsables del tráfico y los esfuerzos comunes se centran en las aplicaciones, auspiciadas generalmente dentro de las acciones de I $+\mathrm{D}+\mathrm{i}$ promovidas por la Comisión Europea. Esta, ha potenciado la investigación en el área de sistemas de transporte inteligente ya desde su $4^{\circ}$ Programa Marco (1994-1998) [CE94] y hasta el vigente, $7^{\circ}$ Programa Marco (2007-2013) [CE07] con numerosos proyectos desarrollados en diversas áreas temáticas, entre ellas ITS. El listado de proyectos desarrollados en este área a lo largo de dicho periodo sería interminable, por lo que nos vamos a limitar a citar solo algunos de ellos agrupados según su aplicación y el hecho de que estén más relacionados con esta tesis $\left[\mathrm{MKH}^{+} 06\right]$ :

- Gestión y control del tráfico urbano - Proyectos: Eurocor, desarrollo e implementación de modelos y estrategias de control para el tráfico urbano; Icaros Net, desarrollo de un entorno que permite la toma de decisiones críticas, y Smart Nets, estado del arte del control de tráfico urbano en tiempo real.

- Monitorización del tráfico urbano - Efect, medida y predicción de la contaminación debida al tráfico para implementar estrategias de tráfico más eficaces.

- Arquitecturas ITS - Gerdien, desarrollo de un marco para la recolección e intercambio de datos entre sistemas ITS; Cometa, desarrollo de una arquitectura telemática y electrónica 
para vehículos comerciales, y Quartet, desarrollo de un entorno de vías de transporte integrado.

- Comunicaciones vehículo-infraestructura (V2I) - Cvis, sistemas inteligentes cooperativos para comunicaciones V2I y V2V, [CVI06]; Safespot, prevención de accidentes de tráfico mediante el estudio y desarrollo de sistemas ITS, [SAF06]; Coopers, desarrollo de aplicaciones telemáticas para obtener una gestión de tráfico cooperativa, [COO06], y Trackss, desarrollo de sensores inteligentes para mejorar el transporte por carretera, [TRA06].

- Comunicaciones entre vehículos (V2V) - Cvis, sistemas inteligentes cooperativos para comunicaciones V2I y V2V, y Safespot, prevención de accidentes de tráfico mediante el estudio y desarrollo de sistemas ITS.

- Comunicaciones infraestructura CCT - Cvis, sistemas inteligentes cooperativos para comunicaciones V2I y V2V, y Coopers, desarrollo de aplicaciones telemáticas para obtener una gestión de tráfico cooperativa.

El proyecto GERDIEN (General European Road Information Exchange Network) supuso el primer proyecto en el que se destacaba la importancia de los parámetros recibidos por el CCT: "From a functional point of view Dynamic Traffic Management, DTM, is based on the giving of real time information about the traffic and the road network status. This requires coherent information exchange between the main subsystems in DTM.” [VAVBB93] 1993:164. Pero más allá de esta mención, en la Unión Europea no se han desarrollado proyectos o estudios enfocados a los parámetros de tráfico únicamente sino a aplicaciones finales, como se acaba de exponer.

\subsection{Conclusiones}

A lo largo del presente capítulo se ha manifestado la importancia de los centros de gestión de tráfico como nexo de unión entre todos los agentes implicados en el tráfico urbano. Estos, deben proporcionar información sobre el estado del tráfico en tiempo real, así como prever las situaciones futuras del mismo. Necesitan, para realizar esta labor, basarse en datos fiables 
proporcionados en tiempo real por los sensores instalados en las vías, de los que se extraerán los parámetros de tráfico.

Los parámetros de tráfico pese a su manifiesta relevancia no han sido objeto de estudio en detalle y de forma aislada sino en aplicaciones concretas. Aún así, son tres los parámetros imprescindibles para los ingenieros de tráfico a la hora de realizar modelos predictivos y planes de tráfico desde el CGT. Estos son:

- Densidad,

- Intensidad,

- y Velocidad.

Fuentes de la sala de control de tráfico de la ciudad de Valencia consultadas han confirmado que actualmente los parámetros que se reciben desde los sistemas de sensorización y monitorización instalados en las vías son: intensidad y tiempo de ocupación por ciclo, además de alarmas e imágenes. De este modo los nuevos sistemas que se incluyan en la arquitectura del CGT deben ser capaces de proporcionar información relevante, de calidad y que al menos cubra los parámetros con los que se trabaja actualmente. 


\section{Bibliografía}

[Arr08] Arranz, A., La gestión del tráfico. Jornada sobre la optimización en la gestión de carreteras, PROINTEC, 7 de Noviembre 2008.

[AYT08] AYTO, Sala de control de tráfico. Ajuntament de València. Regidoria de circulació, transports e infraestructures del transport, 2008, URL http://www.valencia.es/ayuntamiento2/ndprincipal.nsf/ frtraficoc? openframeset. [Online: Último acceso Diciembre 2008].

[BKPS95] Balaguer, E. et al., Elementos de Ingeniería de Tráfico. Cátedra de Caminos y aeropuertos. Escuela Técnica Superior de Ingeniería de Caminos, Canales y Puertos. Universidad Politécnica de Madrid, 5- edición, 1995, ISBN $847493091 X$.

[BOE08] BOE, Real Decreto 11811/2008, tomo 171, págs. 31.041-31.054. Boletín Oficial del Estado, 11 de Julio 2008.

[BP01] Bargiela, A. y Peytchev, E., Intelligent transportation systems-towards integrated framework for traffic/transport telematics applications. Vehicular Technology Conference, 2001. VTC 2001 Fall. IEEE VTS 54 ${ }^{\text {th }}$, tomo 2: págs. 713-717 vol.2, 2001, doi:10.1109/VTC.2001.956863.

[Bui08] Buira, C., Los sistemas de gestión para la movilidad urbana. Boletic, págs. 61-65, Junio 2008.

[CE94] CE, The fourth framework program 1994-98. Comisión Europea, 1994, URL http: / / ec .europa.eu/research/specpr.html. [Online: Último acceso Noviembre 2008].

[CE07] CE, The seventh framework program 2007-13. Comisión Europea, 2007, URL http: / / cordis.europa.eu/fp7/home_en.html. [Online: Último acceso Noviembre 2008].

[COO06] COOPERS, Cooperative systems for intelligent road safety. European Commission. DG Information Society and Media. Esafety, February 2006, URL http: //www. coopers-ip.eu/. [Online: Último acceso Enero 2009].

[CVI06] CVIS, Cooperative vehicle-infrastructure systems. European Commission. DG Information Society and Media. Esafety, January 2006, URL http://www . cvisproject. org//. [Online: Último acceso Enero 2009].

[DGT08a] DGT, Centros de gestión de tráfico. Dirección General de Tráfico, 2008, URL http://www.dgt.es/portal/es/la_dgt/estructura_ organica/centros_gestion/funciones_cgt.htm. [Online: Último acceso Diciembre 2008].

[DGT08b] DGT, Plan de actuaciones de seguridad vial, 2008. Dirección General de Tráfico, Diciembre 2008, URL http://www.dgt.es/portal/es/seguridad_ vial/planes_seg_vial/. [Online: Último acceso Diciembre 2008]. 
[DGT08c] DGT, Series históricas: Parque de vehículos. Dirección General de Tráfico, Diciembre 2008, URL http://www.dgt.es/portal/es/seguridad_ vial/estadistica/parque_vehiculos/series_historicas_ parque/. [Online: Último acceso Noviembre 2009].

[DGT09] DGT, Accidentes de tráfico en zona urbana en españa, 2008. Dirección General de Tráfico. Observatorio Nacional de Seguridad Vial, 2009, URL http://www.dgt.es/was6/portal/contenidos/ documentos/seguridad_vial/estudios_informes/Informe_ accidentalidad_urbana_2008.pdf. [Online: Último acceso Noviembre 2009].

[FR08] Fink, A. y Rothlauf, F., eds., Advances in Computational Intelligence in Transport, Logistics, and Supply Chain Management, tomo 144 de Studies in Computational Intelligence, capítulo Real time identification of road traffic control measures: I-4. Berlin: Springer, 1ํㅡㄹ edición, 2008, ISBN 978-3-540-69024-5.

[GMMA08] Gallego, N. et al., Sensores inteligentes cooperativos aplicados al sector de tráfico: el láser escáner. Ciencia y Tecnología en la frontera, págs. 166-174, 2008, ISSN 1665-9775.

[GV04] Gobierno-Vasco, Sistema de gestión de tráfico interurbano y cgt de euskadi. Departamento de Interior, 2004, URL http://www9.euskadi.net/ o82 / o82WebServlet?accion=10\&id=24\&ident=168\&tag= PagDescProyecto. [Online: Último acceso Diciembre 2008].

[GV07] Gobierno-Vasco. Departamento de Interior, 2007, URL http://www . trafikoa.net/public/wps/portal/trafico. [Online: Último acceso Diciembre 2008].

[JLLM08] Jung, S. et al., Development of wireless interface signal control system for dynamic and optimal management based on dsrc. Networked Computing and Advanced Information Management, 2008. NCM '08. Fourth International Conference on, tomo 2: págs. 389-393, September 2008, doi:10.1109/NCM.2008.109.

[KMG06] Klein, L.A., Mills, M.K. y Gibson, D.R., Traffic Detector Handbook. Informe técnico, US Department of Transportation. Federal Highway Transportation, October 2006. Publication No. FHWA-HRT-06-108.

[MCG98] Cal-y Mayor, R. y Cárdenas Grisales, J., Ingeniería de Tránsito: Fundamento y aplicaciones. México: Alfaomega, 7- edición, Octubre 1998, ISBN 958-682-103$\mathrm{X}$.

[MFW03] Martin, P.T., Feng, Y. y Wang, X., Detector Technology Evaluation. Technical report, Department of Civil and Environmental Engineering University of Utah Traffic Lab, November 2003, URL http: / / www . mountain-plains . org/ pubs / html/mpc-03-154/. MPC Report number 03-154. 
[MK07] Mimbela, L.E. y Klein, L.A., A Summary of Vehicle Detection and Surveillance Technologies used in Intelligent Transportation Systems. Informe técnico, The Vehicle Detector Clearinghouse and US Department of Transportation. Federal Highway Transportation, August 2007.

$\left[\mathrm{MKH}^{+} 06\right]$ McDonald, M. et al., Intelligent Transport Systems in Europe: Opportunities for Future Research. Singapore: World Scientific Publishing Co. Ltd., October 2006, ISBN 978-981-270-082-7.

[MnD97] MnDoT, Field Test of monitoring of urban vehicle operations using non-intrusive technologies. Technical Report FHWA-PL-97-018, Minnesota Department of Transportation and SRF Consulting Group, Inc. (SRF), May 1997.

[PIA07] PIARC, Technical dictionary of road terms, validated by the members of the technical and terminology committee sf piarc. World Road Association (PIARC), September 2007, URL http://termino.piarc.org/. [Online: Último acceso Octubre 2008].

[Rod03] Rodríguez, J.I., Cómo ser un conductor bien informado. Tráfico y Seguridad Vial, tomo año XIX (158): págs. 38-39, Enero-Febrero 2003, ISSN 1886-3566.

[SAF06] SAFESPOT, Cooperative vehicles and road infrastructure for road safety. European Commission. DG Information Society and Media. Esafety, February 2006, URL http: / / www . safespot-eu.org/pages/page.php. [Online: Último acceso Enero 2009].

[SYOC08] Seo, G. et al., An approach for data collection and traffic signal control in the futuristic city. Advanced Communication Technology, 2008. ICACT 2008. 10 International Conference on, tomo 1: págs. 667-672, February 2008, ISSN 17389445, doi:10.1109/ICACT.2008.4493849.

[TRA06] TRACKSS, Technologies for road advanced cooperative knowledge sharing sensors. European Commission. DG Information Society Technologies. Esafety, January 2006, URL http: / /www.trackss. net/. [Online: Último acceso Enero 2009].

[TRB00] TRB, ed., Higway Capacity Manual, tomo II, capítulo Traffic Flow Parameters: 7. Washington, D.C.: National Research Council: Transportation Research Board, 2000, ISBN 0-309-06681-6.

[Ulz98] de Ulzurrum, J.D., Sistemas de control de accesos a valencia. Revista de Obras Públicas, págs. 55-70, Mayo 1998.

[Ulz02] de Ulzurrum, J.D., Red de transporte para los sistemas de gestión de tráfico de la dirección general de tráfico. BIT, tomo Especial: Sistemas de telecontrol (133), Junio 2002.

[Val88] Valdés, A., Ingeniería de Tráfico. Madrid: Bellisco, 3- edición, 1988, ISBN 8485198-22-0. 
[VAVBB93] Van Arem, B. et al., Demonstration of a general european road data information exchange network - GERDIEN. Vehicle Navigation and Information Systems Conference, 1993., Proceedings of the IEEE-IEE, págs. 163-168, October 1993, doi:10.1109/VNIS.1993.585608. 



\title{
Parte III
}

\section{Hipótesis de partida, Objetivos y}

\author{
Desarrollo
}





\section{Capítulo 4}

\section{Objetivos}

Tanto el perfil de las ciudades como las necesidades de movilidad ciudadanas se han modificado a lo largo de las últimas décadas. Los sistemas de transporte inteligente (ITS) aparecen en escena como una herramienta capaz de ayudar tanto en la gestión del tráfico como en la movilidad, la vigilancia o la seguridad vial, gracias al desarrollo y utilización de diferentes aplicaciones y tecnologías.

Para que las necesidades de los centros de control se vean cubiertas se precisa en primer lugar conocerlas, y en segundo lugar proporcionar las herramientas capaces de satisfacerlas. Ese espacio existente entre "la demanda" de información y "la oferta" de los equipos sensores sirve de punto de partida para este trabajo.

La importancia de las aplicaciones ITS no se limita a los elementos que los integran: sistemas de sensorización y monitorización, los sistemas de señalización, de información o las infraestructuras de comunicaciones, sino que se extiende a la calidad, cantidad y precisión de los parámetros que sea capaz de aportar. Actualmente, ningún sensor por si mismo proporciona información ya tratada. Todos los equipos comerciales vienen acompañados de software de adquisición y procesado de los datos para proporcionar la información que se necesita en cada una de las aplicaciones.

Esta investigación persigue la definición de los requisitos funcionales necesarios para que un sensor láser escáner sea capaz de usarse en sistemas ITS salvando las distancias actuales existentes entre oferta y demanda. Aunque a primera vista parezca un tema trivial, alcanzar di- 
cho propósito es una tarea muy ambiciosa a la que llegar mediante la consecución de diferentes objetivos hasta su resolución final.

Los objetivos perseguidos en esta tesis son:

- Definir los requerimientos funcionales mínimos que debe tener un sensor de tecnología láser escáner para su aplicación en el área ITS.

- Especificar la arquitectura hardware en la que se basa la adquisición y pretratamiento de la señal proveniente de los sensores láser escáner.

- Implementar la arquitectura hardware y validarla mediante diferentes modelos comerciales de sensores láser escáner con el objetivo de certificar su independencia del equipo usado, es decir, su condición de sistema multisensor.

- Especificar y detallar los requerimientos de la arquitectura software, es decir, los algoritmos necesarios para su correcto funcionamiento que deben ser íntegramente descritos:

○ Algoritmo de recepción y adecuación de la señal proveniente del sensor.

- Algoritmo de tratamiento de la señal hasta la obtención del perfil del vehículo detectado.

- Crear una base de datos donde se guarde y recopile toda la información para su posterior análisis o uso en futuras aplicaciones.

- Determinar el enfoque y metodología a seguir en el proceso de aprendizaje y clasificación:

- Método de muestreo a seguir.

- Procedimiento de extracción de características.

- Definición de patrones.

○ Análisis de los resultados.

- Sistema de clasificación.

- Comunicar con el centro de gestión de tráfico para enviar la información procesada.

- Presentar la información obtenida de forma accesible, inteligible y fácil.

- Garantizar que la información proporcionada sea: cuantiosa, precisa, fiable y en tiempo real.

- Posibilitar las futuras aplicaciones V2I o I2I. 


\section{Capítulo 5}

\section{Materiales y Metodología}

Este capítulo está dedicado a la descripción de los materiales utilizados y de la metodología seguida para abordar el trabajo planteado. La naturaleza de la tecnología seleccionada en esta tesis, el láser escáner, y de la aplicación a la que van destinadas (sistemas de información de tráfico en tiempo real), hace que los materiales y equipos utilizados deban ofrecer unas grandes prestaciones, al tener que trabajar a altas velocidades para poder cumplir con las especificaciones marcadas. Además se trata de equipos que deben ser instalados en exteriores, a la intemperie, hecho que debe influir en la selección de los materiales a usar seleccionando los más robustos y resistentes.

En primer lugar se presenta la metodología que se sigue en el diseño de la arquitectura y las especificaciones que necesitan este tipo de sistemas. Más adelante, se repasan los programas software usados que han conformado el entorno en el que se han desarrollo las diversas aplicaciones en la tesis. Finalmente se listan los equipos y la instrumentación utilizados y que deben servir para reproducir cada uno de los pasos definidos.

\subsection{Metodología}

La metodología determinada y definida en esta tesis sigue los siguientes pasos:

- Arquitectura Hardware - En primer lugar se debe conocer el sensor a utilizar: su principio de operación, conectores de entrada y salida, formato de la información ... En segundo lugar se diseñará el prototipo PCB utilizado como etapa de pre tratamiento y adecuación 
de los datos entre el sensor y las posteriores etapas de adquisición y tratamiento de datos. Finalmente es necesaria una validación tanto del diseño como de las comunicaciones.

- Arquitectura Software - Se centra en dos etapas: programación del firmware y de la etapa de tratamiento de la señal. Tras este procesado se obtiene el perfil del vehículo que será analizado para su clasificación. Sería interesante desarrollar una aplicación gráfica a modo de interfaz que presente los resultados.

- Análisis Estadístico - Requiere de la superación de diferentes etapas: definición del método de muestreo, captura y recopilación de datos y cálculo del tamaño muestral que permita inferir conclusiones de la población total.

- Proceso de Aprendizaje - También llamado de entrenamiento, en el se considera la existencia de un grupo de datos de los que, a priori, se conoce la clase a la que pertenecen y sirven para entrenar al sistema, se trata del grupo de aprendizaje. Se trata de definir y encontrar características y patrones útiles que sean fáciles de calcular y mantengan información para la discriminación en clases. Esta estrategia se denomina aprendizaje supervisado ya que se conocen a priori los patrones.

- Proceso de Test - Etapa de clasificación o reconocimiento de nuevos datos, es la encargada de calcular los parámetros y características definidos en el proceso de aprendizaje que permiten la discriminación en clases. Este procedimiento se realiza con el grupo de test.

- Evaluación de los datos obtenidos - Cálculo de estimadores que permitan realizar afirmaciones sobre la bondad del modelo diseñado. También se estudian los posibles errores y fallos del sistema y se presentan soluciones correctoras.

\subsection{Programas Desarrollados y Software}

- Orcad Family Release 9.2. Diseño de los esquemáticos (esquemas eléctricos), mediante la aplicación Capture; y de la placa de circuito impreso, mediante la aplicación Layout Plus. 
- MPLAB IDE Editor version 7.6. Editor de la empresa Microchip para la programación de sus DSCs, dsPIC20F4011 en nuestro caso. El programador y depurador usado es el mismo, y se trata del Hardware Development Tools: MPLAB IDE Debugging - MPLAB ICD2. Finalmente compilador de C es el MPLAB C18 v.3.02.

- Microsoft Visual Studio 2005 Professional Edition. Entorno de desarrollo integrado para el diseño de aplicaciones para la plataforma win32, y con la posibilidad de utilizar varios lenguajes de programación y compilado. Usado en cuatro ocasiones diferentes para el diseño de los siguientes programas: Procesado Sensor Láser, GUI, ClasiCoche y GruposTest.

- Microsoft Office Access 2007 Programa de base de datos escogido por: facilidad y versatilidad que presenta a la hora de introducción de datos; permite la creación de todo tipo de informes relativos a la información incluida en la base de datos; permite acceder desde cualquier punto de forma remota a dicha base de datos, y finalmente no se necesita poseer amplios conocimientos sobre bases de datos para realizar su gestión.

- MATLAB versión R2008a. Se ha usado el paquete estadístico y en concreto la clase classregtree para el diseño de los árboles de clasificación en el proceso de aprendizaje. Mientras, en el proceso de test se ha usado para el cálculo de estimadores, dibujo de gráficas e histogramas mediante la herramienta dfittool.

\subsection{Equipos e Instrumentación}

- Láser Escáner SICK 221-30206. Sensor de altas prestaciones que permite realizar barridos sobre una vía de varios carriles ya que puede cubrir un ángulo sobre la vía de $180^{\circ}$. El equipo emite un haz láser haciendo uso de un diodo láser que emite la señal sobre la vía cuya reflexión difusa es recibida por un fotodiodo. Para realizar el barrido utiliza un espejo giratorio accionado por un motor paso a paso. Este equipo presenta además la posibilidad de seleccionar: la frecuencia de escaneo, la resolución angular, el tiempo de respuesta e incluso la tasa de transferencia. 
- Láser Escáner Acuity Accurange 4000 y Line Scanner. Sensor similar al equipo comercial de la empresa SICK, con la diferencia de trabajar con un motor de continua, que en base a un encoder informa sobre la posición en la que se ha realizado la medida. Se trata de un equipo de clase I que no supone riesgo alguno para los usuarios de la vía.

- PCMCIA SIO. Tarjeta PC Card o PCMCIA (acrónimo del inglés Personal Computer Memory Card International Association) de adquisición de datos. Proporcionada por la empresa SICK por si se requiere realizar una transferencia de datos a velocidades más elevadas de las permitidas en el rango de las opciones básicas. En este caso posibilita el envío de información desde el sensor a velocidades de 500KBd.

- Analizador Lógico. Modelo PM 3.580 de 100 MHz de la compañía Philips. Con 2 conectores que proporcionan un total de 32 canales de entrada.

- Osciloscopio Portátil Digital. El modelo empleado fue el 199 Scopemeter de $200 \mathrm{MHz}$ de la compañía Fluke. La principal ventaja y motivo de uso de este osciloscopio reside en su portabilidad, necesario a la hora de realizar pruebas de campo.

- Fuente de alimentación. De la marca PROMAX modelo FACC-662B, con dos canales independientes de 0-30 V DC 1 A y canal de salida fijo 5 V 2 A, regulación de intensidad y displays de visualización de voltaje e intensidad para la alimentación del sistema.

- Generador de funciones. SONY-Tektronix modelo AFG320. Antes de disponer del sensor láser se realizaron las pruebas iniciales con estos generadores simulando, mediante formas de onda, las señales que más tarde proporcionará dicho sensor. Evidentemente en este punto la velocidad no era la final, sino que correspondía simplemente a una aproximación al funcionamiento del sistema a desarrollar. 


\section{Capítulo 6}

\section{Arquitectura Hardware}

A lo largo del capítulo2, El láser escáner en aplicaciones ITS, se realizó el estudio previo de los diferentes equipos comerciales que permitió, de entre todos ellos, seleccionar uno para su uso a lo largo de la presente tesis. Se buscó y seleccionó el que presentaba mejores características en general y el que mejor se ajustaba a la aplicación que se iba a desarrollar: desarrollo de sensores de tecnología láser en entornos urbanos.

Aunque a primera vista pudiera parecer que el equipo Autosense 800 presentaba las mayores prestaciones en velocidad (opción de alta velocidad de hasta 1,25 MBd, o MBps, y tiempo de respuesta de $2,7 \mathrm{~ms}$ ) estas se deben a que presenta un reducido ángulo de escaneo que no le hacen apto para trabajar en vías urbanas de hasta 4 carriles como las deseadas. Los modelos LMS 221-30206 y AccuRange 4000 presentan características similares, pero la frecuencia de escaneo y la opción de alta velocidad mayores en el caso del LMS, llevó a decantarse por este último, (Ver tabla 2.3).

La arquitectura hardware consiste en dos bloques principales: el equipo en sí mismo y la PCB (acrónimo del inglés Printed Circuit Board) diseñada. La especificación de los requerimientos es, evidentemente, independiente del equipo sensor usado. Aunque se ha de utilizar un equipo sensor comercial (LMS en esta primera aproximación) este no ha definido el diseño en absoluto. La PCB permite, entre otras acciones, adecuar las señales recibidas del sensor a una trama estándar para eliminar la posible dependencia del equipo sensor. A lo largo del presente capítulo se entra en detalle en cada una de las partes hardware que conforman la arquitectura a definir. 


\subsection{Consideraciones Previas}

Es una premisa de diseño que la selección de un equipo concreto no modifique el diseño

final, pero aún así se deben tener en cuenta ciertas consideraciones previas sobre el funcionamiento concreto del mismo para poder justificar en un futuro las operaciones realizadas. De este modo, es necesario empezar este capítulo presentando, aunque sea de forma somera, el principio de operación del sensor al ser este similar en todos los posibles equipos láser escáner comerciales basados en la medida del ToF que se puedan utilizar en un futuro.

\subsubsection{Principio de Operación}

El equipo se basa en un detector láser de área, dispositivo que funciona midiendo el tiempo de vuelo un haz láser. Un diodo láser pulsado emite un rayo hacia la zona de detección, la vía en este caso, y su reflexión difusa es registrada por el receptor del sensor. Se determina la distancia mediante la medición del tiempo transcurrido entre el envío del haz y la detección de la reflexión al ser este directamente proporcional a la distancia entre el sensor y el vehículo que circula sobre la vía. Conociendo la distancia a la misma en ausencia de vehículos, se puede precisar la altura de los objetos que pasan por la zona de detección del sistema. Los sensores suelen trabajar en el espectro infrarrojo (con una longitud de onda aproximada de $0,9 \mu \mathrm{m}$ ) evitando posibles distracciones a los conductores o peatones que se encuentran cerca de la zona de detección.

El láser escáner funciona realizando sucesivos escaneos, o barridos a lo largo de la vía, perpendiculares a la vía, con un determinado ángulo de escaneo y resolución angular. Los sensores cuentan con un elemento móvil que es el que permite realizar el movimiento de barrido y definirá la frecuencia de escaneo y el tiempo de respuesta. Se define la frecuencia de escaneo como el tiempo que tarda el sensor en realizar un escaneo completo sobre la vía. En la figura 6.1 se representa la zona de detección y el escaneo que se realiza sobre la misma. El ángulo de escaneo, $\alpha$, o ángulo de visión, se refiere a la abertura total con la que se realiza el escaneo sobre la vía y viene determinado, además de por las propiedades del sensor, por la anchura de la vía y la altura a la que se instale el sensor. Finalmente, la resolución angular se refiere al paso existente 
entre cada uno de los puntos de medida, en este caso sera cada $0,5^{\circ}$. Ambos parámetros son seleccionables desde la configuración inicial del sensor, manteniéndose constantes para todas las medidas realizadas hasta que se reinicie el sensor o se modifiquen manualmente [SIC06].
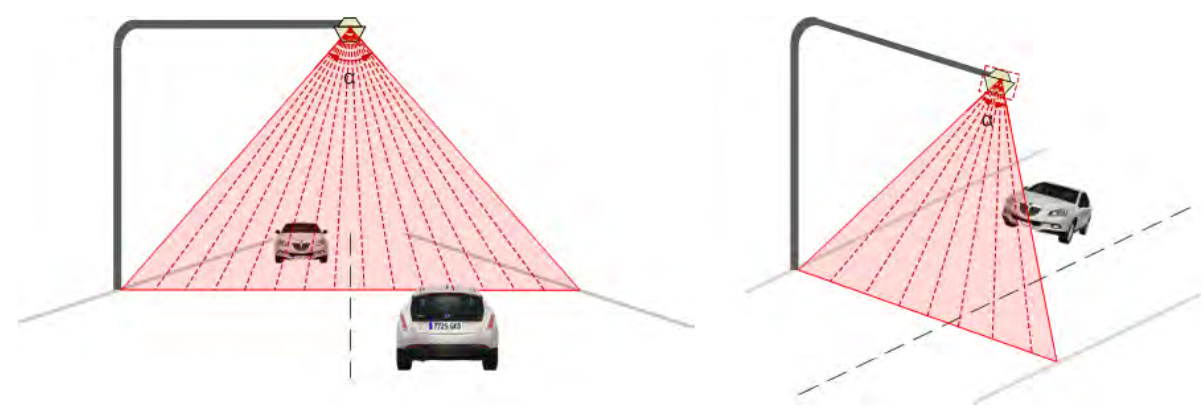

Figura 6.1 - Principio de operación

Realmente el equipo no mide alturas directamente, sino que mide distancias que existen desde su posición a la superficie sobre la que se enfoque, medida $A$ de la figura 6.2. Con lo cual, para obtener las alturas hay que realizar simples cálculos trigonométricos. En primer lugar, se realiza un escaneo inicial sobre la vía en ausencia de vehículos con el objetivo de generar un vector de referencia o de offset. Es decir, se almacenan las distancias del láser a cada unos de los puntos de la vía en ausencia de vehículos, valores $B$ de la figura 6.2. Cada una de estas distancias se miden con un ángulo de escaneo determinado, efecto denominado de ángulo, con lo que es necesario conocer el ángulo que corresponde a cada una de las medidas a la hora de calcular los valores de altura.

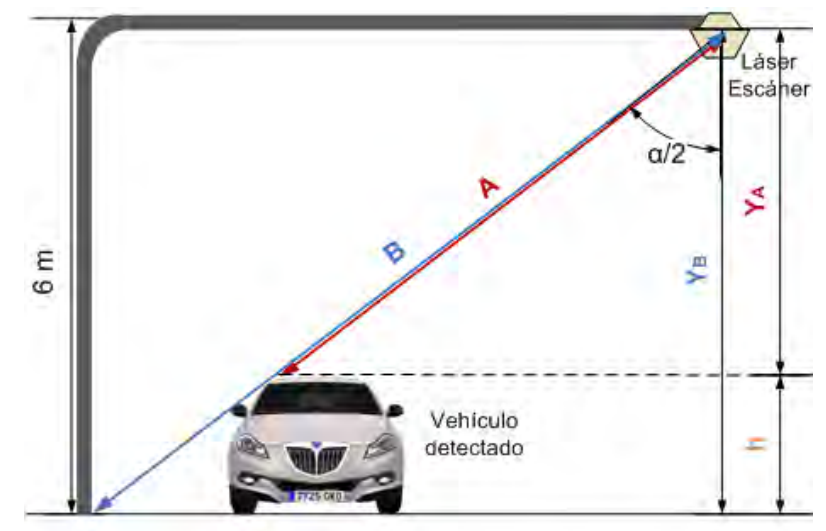

Figura 6.2 - Medida de alturas

Por simple trigonometría se pueden obtener los valores de las alturas de cada uno de los puntos, es decir, $Y_{B}$ de la figura. Cuando se obtiene este valor ya se ha eliminado el efecto 
del ángulo de escaneo. A esta operación se le llama cálculo del efecto del ángulo y se obtiene multiplicando el valor de $B$ por el coseno del ángulo $\alpha$ que le corresponde (en este caso $\alpha / 2$ ) obteniendo de este modo el valor $Y_{B}$. Tras estas operaciones se genera un segundo vector de offset linealizado. Este vector contiene las alturas, o distancia existente, desde cada uno de los puntos de la vía hasta la horizontal que pasa por el equipo.

En condiciones ideales todos los valores de este vector debieran ser iguales, pero hay que tener en cuenta tanto posibles irregularidades del asfalto como objetos estáticos situados sobre la vía que harán que esta situación no sea la de condiciones normales de medida. Ambos vectores (vector de offset y vector de offset linealizado) se almacenan en la configuración del equipo, y a no ser que existan cambios en la superficie de la vía o se modifique la instalación del equipo no será necesario volver a medirlos.

En el caso de la detección de un vehículo las operaciones a realizar son similares. En este caso, el valor medido corresponde al valor $A$ de la figura 6.2, y calculando el efecto de ángulo se obtiene el valor $Y_{A}$. Por último, para obtener la altura del vehículo detectado bastará con restar el valor de offset linealizado en dicho punto, $Y_{B}$, y valor actual, $Y_{A}$ para obtener el valor de altura, $h$.

En el caso específico del equipo utilizado las distancias medidas se codifican en dos bytes. En configuración estándar, es decir, usando rangos de medida de hasta 8 metros, los bits en el rango 0-12 se usan para representar la distancia y los bits del rango 13-15 no se utilizan [SIC06]. La tabla 6.1 muestra el significado de los dos bytes que miden distancia:

\begin{tabular}{lcccccccccccccccc}
\hline & \multicolumn{1}{c}{ Byte más significativo } & \multicolumn{1}{c}{ Byte menos significativo } \\
\hline Número de bit & 15 & 14 & 13 & 12 & 11 & 10 & 9 & 8 & 7 & 6 & 5 & 4 & 3 & 2 & 1 & 0 \\
\hline Valor binario & $2^{15}$ & $2^{14}$ & $2^{13}$ & $2^{12}$ & $2^{11}$ & $2^{10}$ & $2^{9}$ & $2^{8}$ & $2^{7}$ & $2^{6}$ & $2^{5}$ & $2^{4}$ & $2^{3}$ & $2^{2}$ & $2^{1}$ & $2^{0}$ \\
\hline Valor hexadecimal & \multicolumn{1}{c}{ De 00 a FF } \\
\hline Valor decimal & \multicolumn{1}{c}{ De 00 a FF } \\
\hline
\end{tabular}

Tabla 6.1 - Bytes que miden la distancia

La configuración estándar es la que se usa en este trabajo al estar el equipo situado a $6 \mathrm{~m}$ sobre la vía, por lo que se usan 13 bits para codificar la información de distancia. Estos 13 bits permiten representar valores hasta $2^{13}-1=8.191$, que al trabajar en resolución de mm se 
convierten en $8.191 \mathrm{~mm}$. O lo que es lo mismo, es posible representar todas las distancias hasta 8,191 m de altura. Dependiendo del rango de medidas se usarán los siguientes bits:

\begin{tabular}{cccc} 
Rango de medida(m) & Bits usados & Máximo valor hexadecimal & Máximo valor medido(m) \\
\hline 8 & 13 & $1 \mathrm{FF} 7 \mathrm{~h}$ & 8,183 \\
16 & 14 & $3 \mathrm{FF} 7 \mathrm{~h}$ & 16,385 \\
32 & 15 & $7 \mathrm{FF} 7 \mathrm{~h}$ & 32,759 \\
80 & 13 & $1 \mathrm{FF7h}$ & 81,83 \\
\hline
\end{tabular}

Tabla 6.2-Rangos de medidas

\subsection{Estudio del caso del equipo comercial SICK LMS 221- 30206}

\subsubsection{Configuración de las comunicaciones}

Las comunicaciones con el equipo se realizan a través de los llamados telegramas. Se trata de una serie de instrucciones predefinidas por el fabricante que permiten realizar diferentes operaciones, entre ellas las que corresponden a la configuración del sistema. El equipo presenta la configuración por defecto [SIC06] que se muestra en la tabla 6.3.

\begin{tabular}{cc}
\hline Parámetro & Sensor LMS 221 \\
\hline Baudrate & $9.600 \mathrm{Bd}$ \\
Ángulo de Escaneo & $180^{\circ}$ \\
Resolución Angular & $0,5^{\circ}$ \\
Rango de medida & $80 \mathrm{~m}$ \\
Resolución de medida & $10 \mathrm{~mm}$ \\
\hline
\end{tabular}

Tabla 6.3 - Configuración por defecto

La configuración del equipo debe seguir una secuencia definida y fija que selecciona paso a paso cada uno de los parámetros regulables. El flujo de configuración es el siguiente: configuración de baudrate $\left(9.600,38.400\right.$ o $500 \mathrm{~KB}$.), configuración de rango $\left(100^{\circ}\right.$ o $\left.180^{\circ}\right)$, configuración de la resolución angular $\left(1^{\circ}, 0,5^{\circ}\right.$ o $\left.0,25^{\circ}\right)$ y finalmente la configuración de las unidades de medida (cm o mm). 
Para la realización de cada uno de estos pasos se debe enviar un telegrama diferente al equipo que no corresponde explicar aquí, para más detalle acudir al manual de la propia compañía [SIC06]. A continuación se listan determinadas características de la comunicación de datos importantes y a tener en cuenta a la hora del correcto funcionamiento del equipo:

- El formato de los datos enviados por el equipo es 8N1, es decir, 8 bits de información, No parity bit, one stop bit.

- Los datos proporcionados por el equipo se envían en pasos angulares crecientes. El paso utilizado en cada medida no se envía en sí mismos, sólo se envían los datos de distancia.

- La configuración se realiza mediante comandos predefinidos que se envían y se reciben del equipo mediante telegramas.

- Cada telegrama representa un único comando, y cada telegrama de respuesta corresponde a un único comando de respuesta.

- Cada telegrama termina con un CRC (acrónimo del inglés Cyclic Redundancy Checks), y no con un ETX (acrónimo del inglés End of Text) como sería de esperar.

- Si el telegrama es recibido correctamente por el equipo, este envía un Acknowledge (ACK 06h) como respuesta, o en el caso de ser incorrecto el telegrama se enviará Not Acknowledge (NAK 15h).

- El máximo tiempo de respuesta del láser para NAK o ACK es de 60 ms.

- Una vez recibido un NAK, se debe esperar al menos $30 \mathrm{~ms}$ antes de enviar un nuevo telegrama.

La primera vez que se trabaja con algunos equipos comerciales, como es el caso del LMS, es necesario configurarlos. Esta tarea se realizará todas las veces que se necesite modificar la configuración del mismo, lo que no significa que tenga que realizarse todas las veces que se conecta. Es más, dado que cada una de estas configuraciones se graba en la EEPROM (acrónimo del inglés Erasable Programmable Read-Only Memory) interna que poseen y este tiene un número limitado de escrituras no es recomendable modificarla cada vez [SIC06]. En nuestro caso se realizaron modificaciones únicamente en la etapa de prueba de comunicaciones, manteniendo a lo largo de las etapas de toma de datos y validación la misma configuración. Así, 
tras una configuración inicial no se volvió a realizar esta tarea. De todas formas se prevé que a lo largo del periodo de vida del equipo el número de ciclos de escritura sea el suficiente para permitir las modificaciones que se realicen.

$\mathrm{Al}$ encender el equipo, se envía una trama de inicio en hexadecimal a 9.600 Bd vía el puerto serie. Así, lo primero que se debe comprobar es que la trama de inicio es enviada correctamente. Por ello, una vez conocidos los terminales del cable serie proveniente del equipo (ver figura 6.4), se realiza la comprobación mediante lecturas en el analizador lógico. La figura 6.3 presenta las capturas realizadas que verifican que la trama es enviada correctamente.

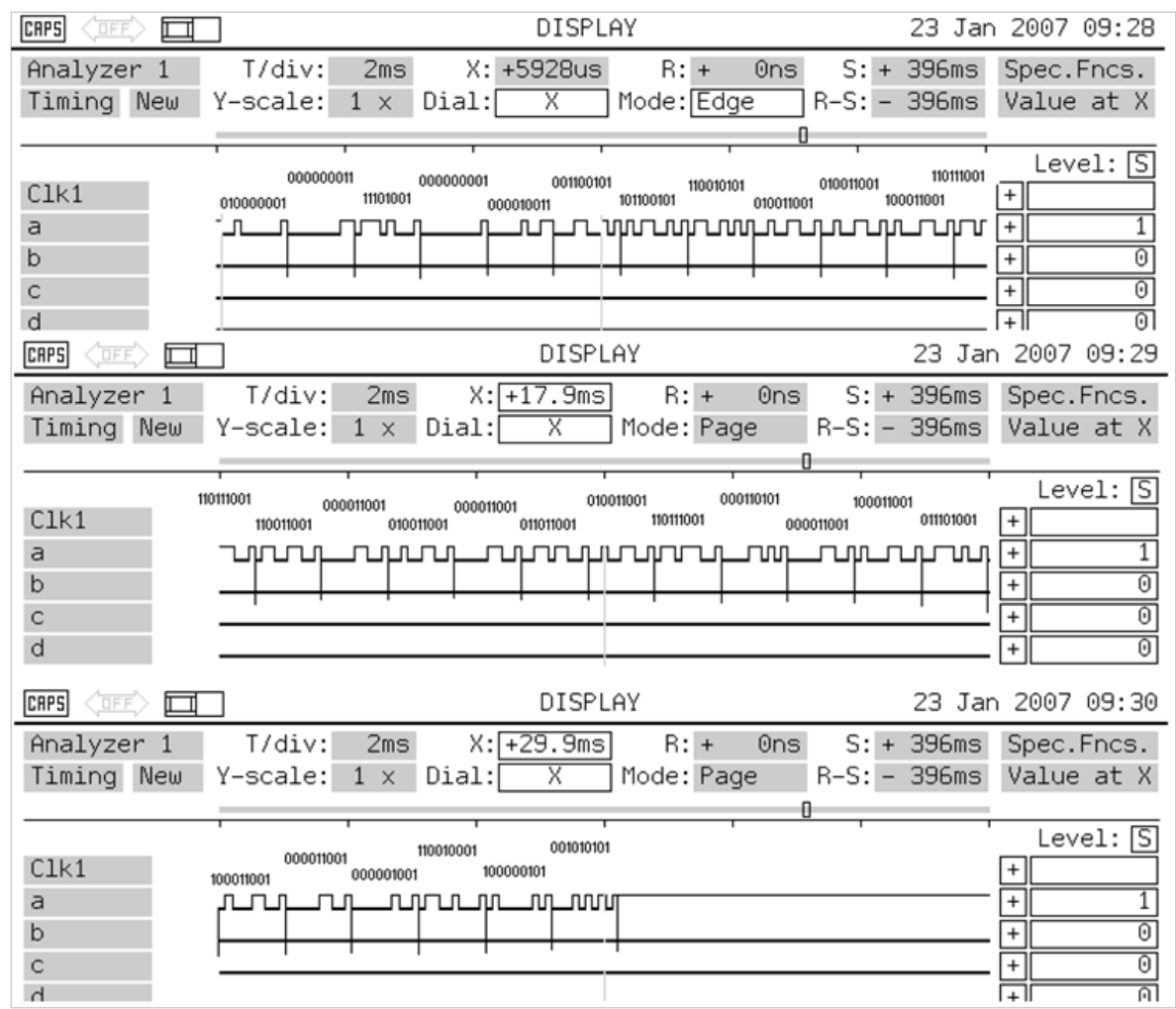

Figura 6.3 - Captura de la trama de inicio

Esta trama corresponde en hexadecimal a:’02 801700 90 4C 4D 533232 31 3B 333032 303632 3B 583031 2E 3130201341 54", que es el telegrama de bienvenida del sensor. Cabe recordar que el envío de los bits se realiza desde el menos significativo hasta el más significativo. En el listado de telegramas ([SIC06] 2003:29) se observa que corresponde al telegrama enviado por el láser una vez encendido.

Los datos capturados corresponde en la codificación ASCII a: 


$\begin{array}{ccccccccccccccccccccc}4 \mathrm{C} & 4 \mathrm{D} & 53 & 32 & 32 & 31 & 3 \mathrm{~B} & 33 & 30 & 32 & 30 & 36 & 32 & 3 \mathrm{~B} & 58 & 30 & 31 & 2 \mathrm{E} & 31 & 30 & 20\end{array}$

Tabla 6.4 - Datos capturados ASCII-Hexadecimal

\subsubsection{Conectores del Equipo}

La figura 6.4 muestra las conexiones de la parte trasera del láser SICK modelo LMS 221. En el manual se establece que para este modelo los pines 3 y 11 están conectados internamente mediante un jumper, lo que hace que la conexión serie que se establezca sea del tipo RS422 [SIC02a, SIC02b].
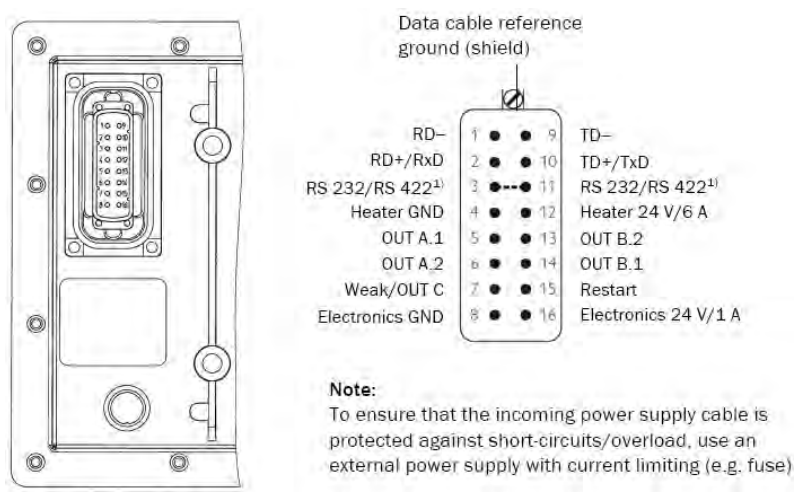

Figura 6.4 - Conexiones traseras del sensor LMS

El conector que muestra la figura 6.5 es el que se conecta a esta parte trasera y presenta dos terminales: uno que se conecta a la fuente de alimentación y otro que es un cable DE9 hembra para la comunicación serie. En concreto, este modelo, trabaja con alimentación de 24 V y máximo $1,8 \mathrm{~A}$.

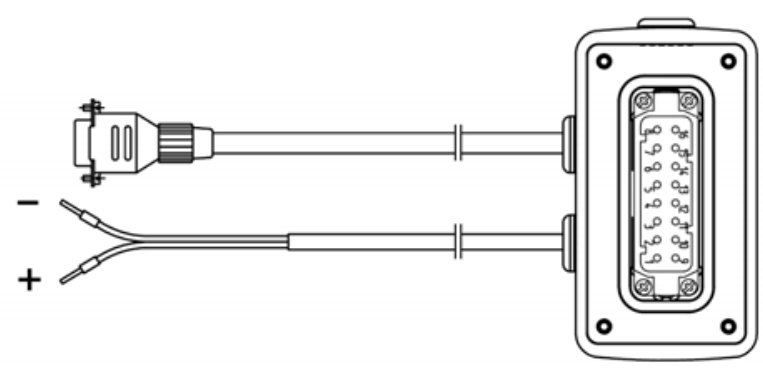

Figura 6.5 - Conector Serie del sensor LMS 
Aunque a primera vista puede parecer que el conocimiento de los conectores no es relevante, el hecho que estos definan el tipo de comunicación que establece el equipo hace que su conocimiento sea de vital importancia para un correcto funcionamiento del sistema completo.

\subsection{Diseño de la placa de circuito impreso}

La placa de circuito impreso, $\mathrm{PCB}$, se diseña tras adquirir un cierto conocimiento del equipo así como de su funcionamiento. El objetivo de la misma es servir de interfaz entre cualquier equipo comercial de sensor láser escáner y el ordenador, aunque por motivos evidentes las pruebas preliminares se han realizado usando el equipo LMS.

Básicamente, la PCB comprende tres grandes bloques: etapas conversoras, microprocesador y alimentación. A continuación, se procede a detallar cada una de ellas por separado. La figura 6.6 muestra la PCB diseñada con cada uno de sus componentes.

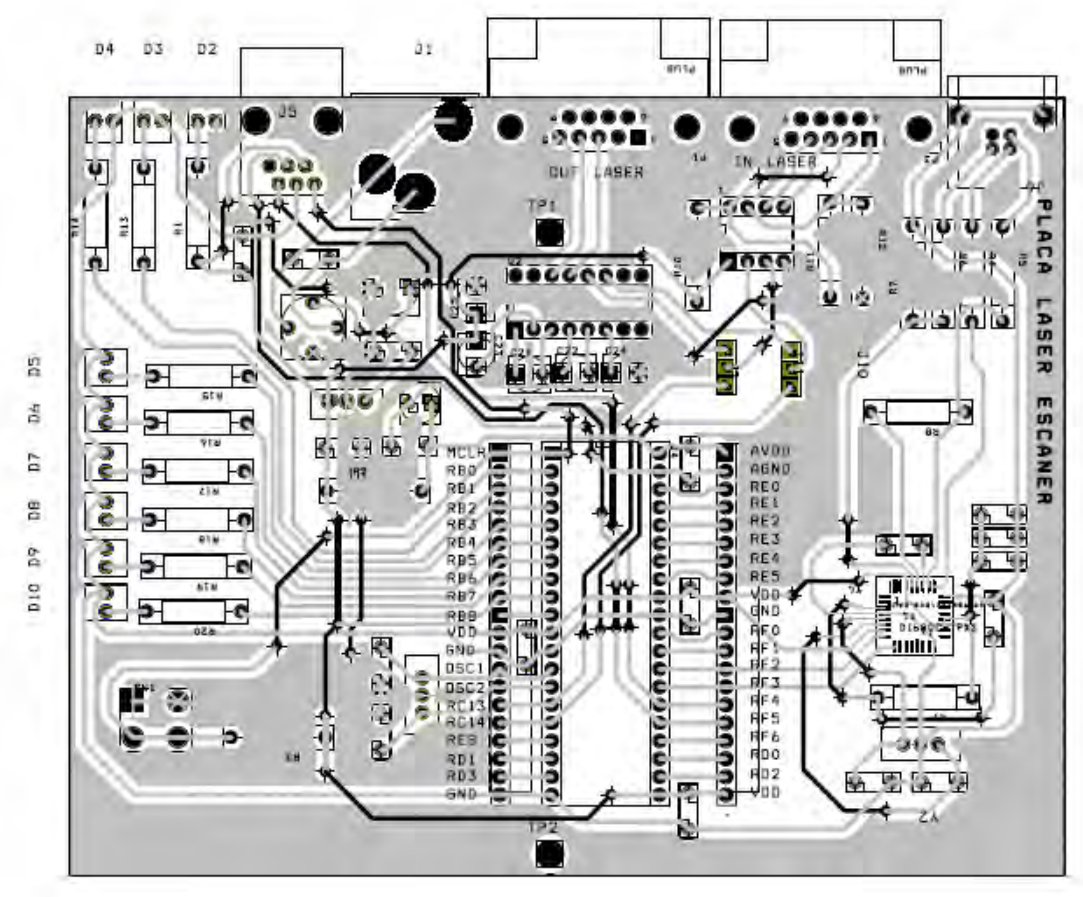

Figura 6.6 - Diseño de la PCB 


\subsubsection{Etapas Conversoras}

El equipo transmite las señales usando el estándar internacional ITU-T V.11 (acrónimo del inglés International Telecommunication Union - Telecommunication Standardization Sector) o su equivalente americano TIA/EIA-422-B (RS422) (acrónimo del inglés Telecommunications Industry Association/Electronic Industries Alliance [ITU96]). El estándar define el interfaz serie diferencial RS-422 que se utiliza para la transmisión de datos de alta velocidad (hasta 10 MBps) a grandes distancias $(1.200 \mathrm{~m})$. Permite un emisor y hasta 10 receptores simultáneos. La diferencia de tensión entre las líneas le proporciona mayor inmunidad al ruido. Otros de los interfaces utilizados son el RS-232 definido por el estándar de comunicaciones internacional ITU-T V.24 o su equivalente americano TIA/EIA-232 [ITU00] y el estándar USB (2.0) (acrónimo del inglés Universal Serial Bus) [For00].

A la hora de enviar los datos capturados por el equipo directamente al ordenador es necesario realizar varias conversiones previas:

- De niveles TIA/EIA-422 (que es como se recibe la información del equipo), a niveles 5V. TTL/CMOS(acrónimo del inglés Transistor-Transistor Logic y Complementary Metal Oxide Semiconductor) para lo cual se usa el integrado SN75179 de la compañía Texas Instruments, (ver figura 6.9(a)).

- De niveles 5V TTL/CMOS (que es la tecnología usada en el diseño digital), a TIA/EIA232 correspondiente al interfaz del puerto serie del ordenador, mediante un MAX232 de la compañía Texas Instruments, (ver figura 6.9(b)).

- De USB-B a comunicación serie mediante el integrado FT232BL, de la compañía FTDI, (ver figura 6.9(c) y 6.9(d)).

Los esquemas eléctricos de estas etapas conversoras se muestran en las figuras 6.7, esquema del componente FT2323BL, y 6.8, esquema de los componentes MAX232 y SN75179.

Debido a la generalización en el uso de los integrados SN75179 y MAX232 no es necesario dar más detalles sobre los mismos pasando directamente a comentar las características del FT232BL que es el dispositivo más novedoso. Se trata de un convertidor USB - Serie 


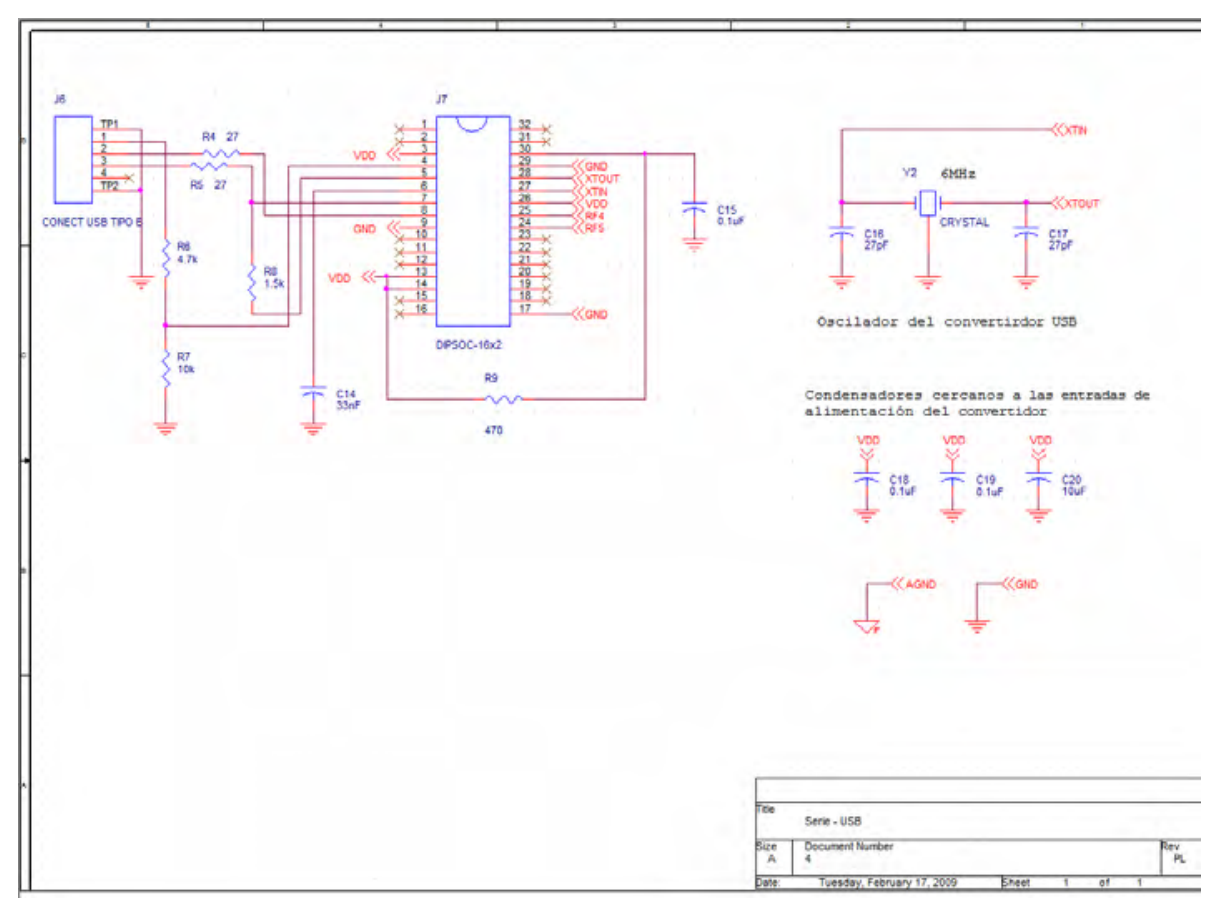

Figura 6.7 - Esquemático Conversor Serie-USB

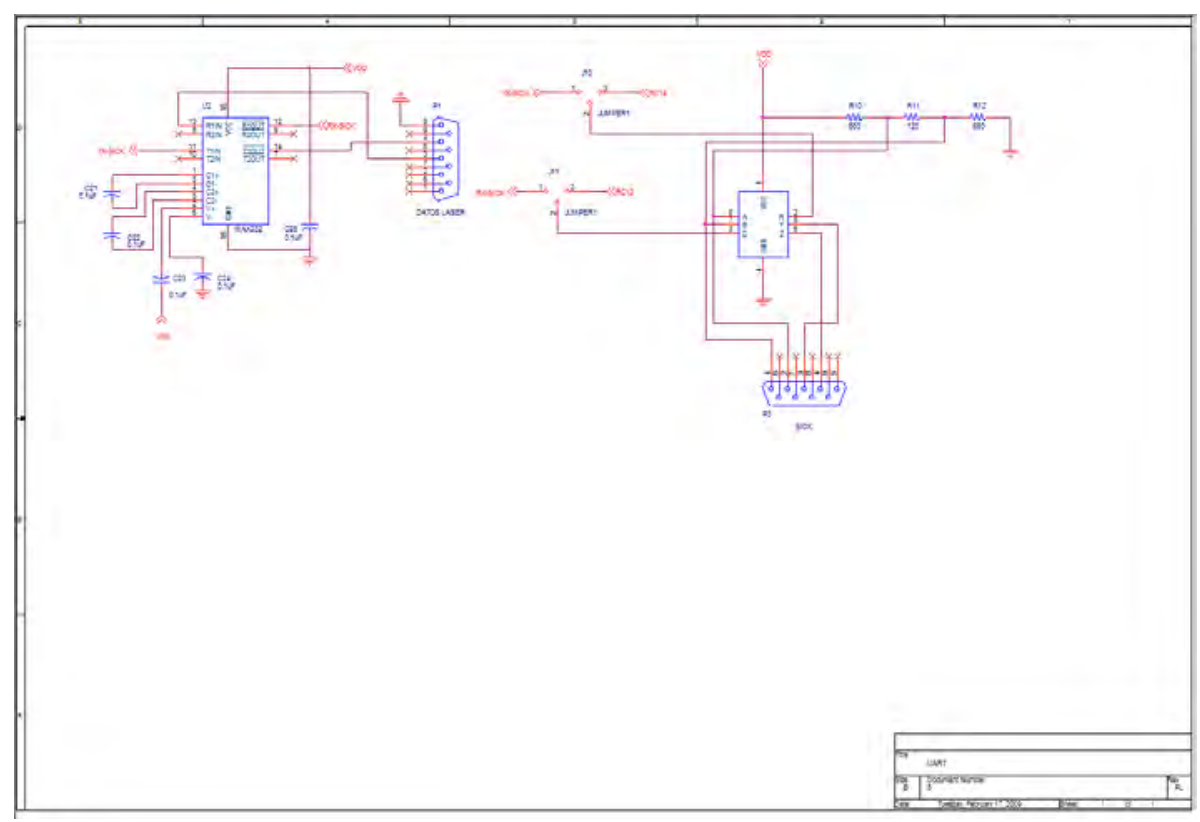

Figura 6.8 - Esquemático Conversores Varios

(Asynchronous Serial Data Transfer) con un ratio de transferencia de 3 MBd o 1 MBd según se trate de niveles de 5V TTL/CMOS y RS-422/485 o RS-232. Este dispositivo trabaja con un oscilador externo de $6 \mathrm{MHz}$.

La idea inicial era comunicar el equipo con la PCB y esta a su vez con el ordenador mediante comunicación serie. Sin embargo, en la etapa de especificaciones de la arquitectura, dada la 
generalización del estándar USB en los ordenadores actuales en detrimento de los puertos serie, se ha decidido modificar la salida de la PCB hacia el exterior haciendo posible la transmisión de datos mediante un puerto USB-B.

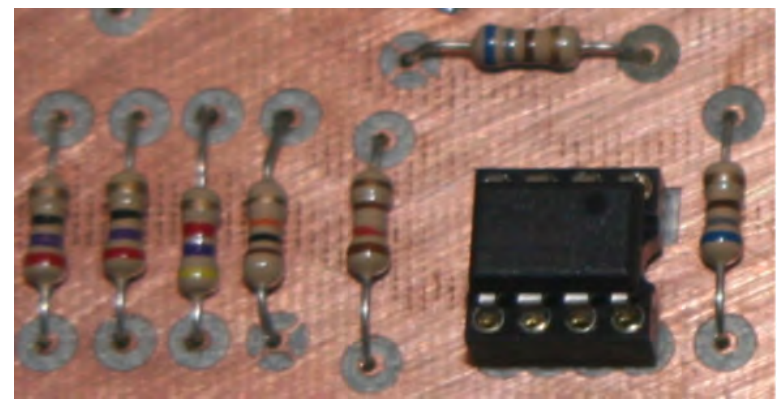

(a) SN75179

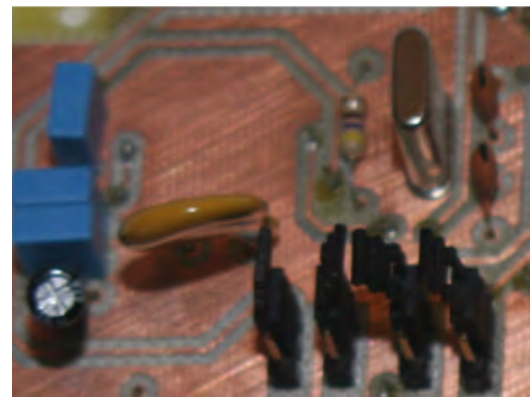

(c) FTB232BL

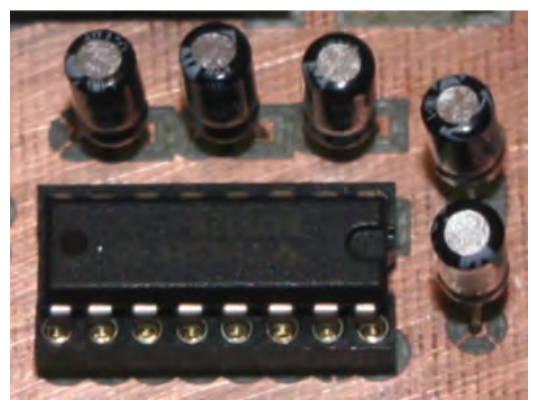

(b) MAX232

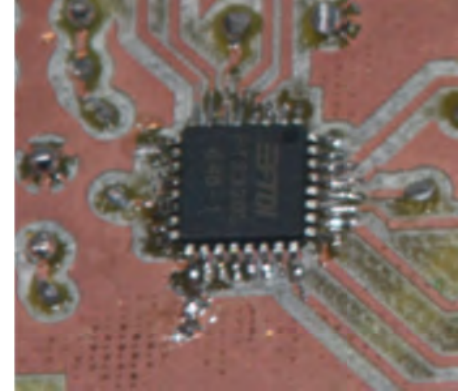

(d) FTB232BL trasero

Figura 6.9-PCB: Etapas Conversoras

\subsubsection{Microprocesador}

El microprocesador se utiliza para la adquisición y el pretratamiento de la señal previo a su envío al ordenador, su tarea principal es la de detección de vehículos. Para evitar el envío de información no relevante al ordenador, es decir, momentos en los que no se detecten vehículos sobre la vía, se ha decidido que únicamente cuando se detecten vehículos el microprocesador enviará la señal, el resto es descartado. Así se evita que durante los largos periodos en los que no existe prácticamente circulación, por ejemplo en periodos nocturnos, se sature el canal de información con datos no relevantes. Esta premisa introduce una mejora en el sistema de envío de datos. 
La figura 6.10 representa el esquema eléctrico de la etapa correspondiente al microprocesador. Muestra además los leds conectados a las salidas programables del mismo y el conector RJ11 necesrio para su programación. La figura 6.11 muestra el oscilador externo y el reset.

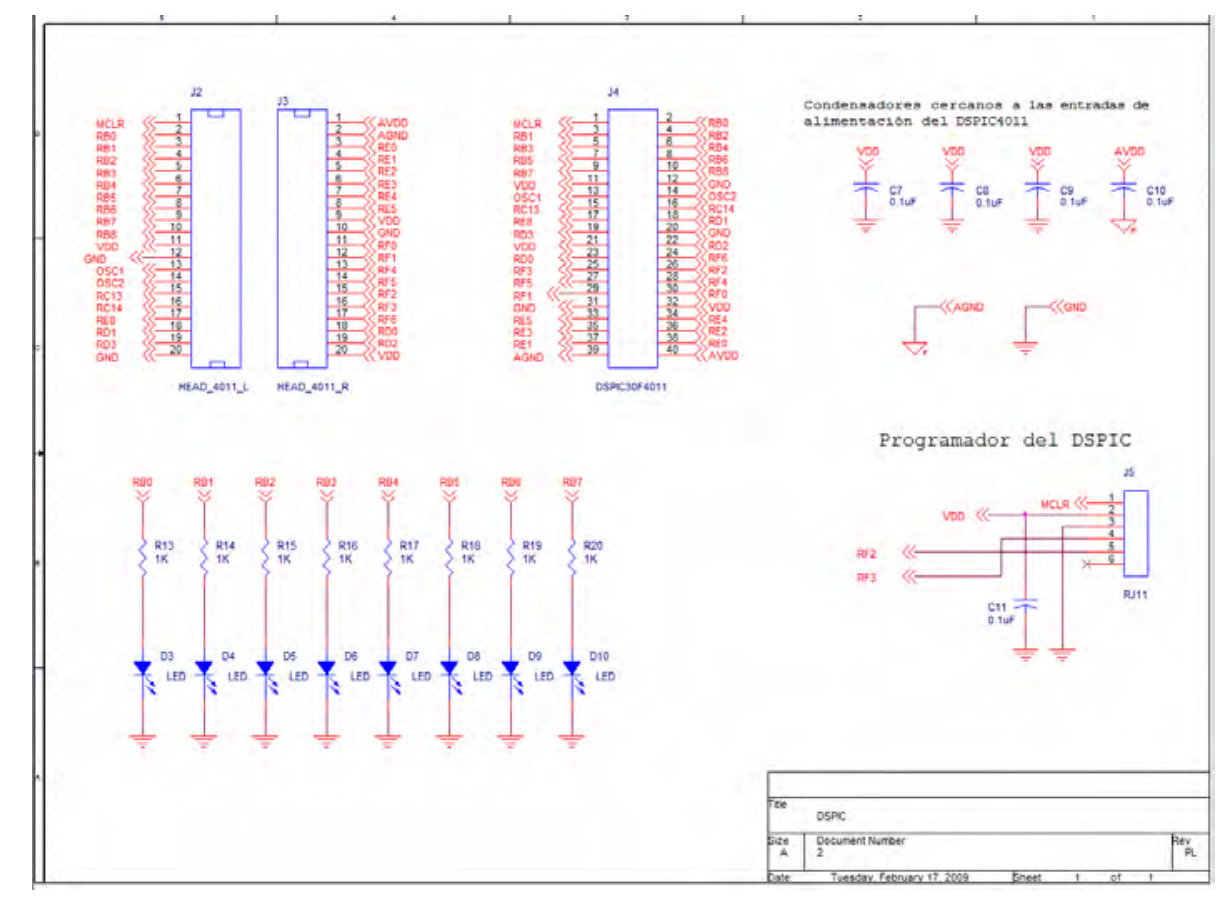

Figura 6.10 - Esquemático Microprocesador

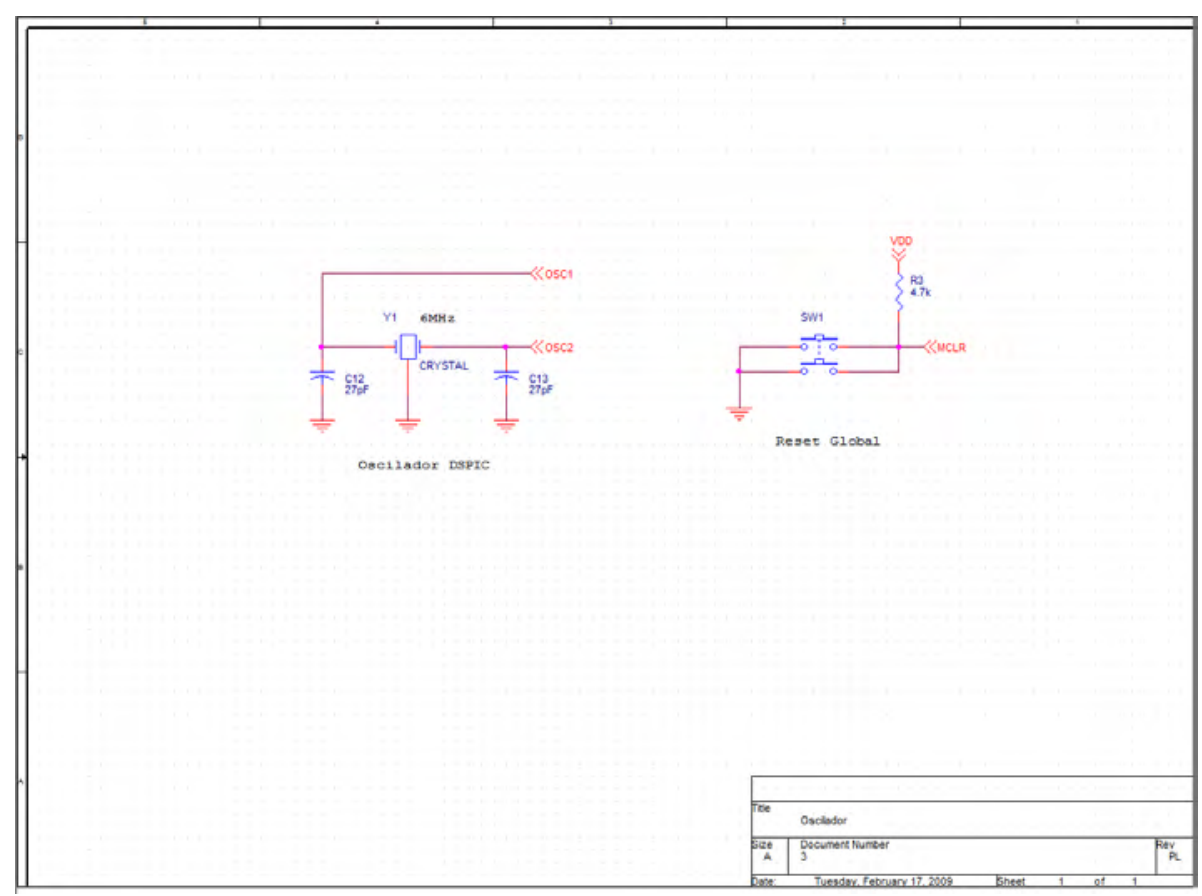

Figura 6.11 - Esquemático Oscilador Externo 
El tratamiento de la señal se realiza en dos etapas y en dos localizaciones físicamente separadas del sistema final. El flujo de información es el siguiente: el equipo envía los datos detectados al microprocesador de la $\mathrm{PCB}$, este analiza la información recibida y envía únicamente la que contiene información relativa a la detección de vehículos al ordenador donde se procede a su clasificación.

El microprocesador realiza las siguientes funciones, aunque se entrará en detalle más adelante en estos aspectos cuando se hable del firmware (ver capitulo 7):

- Configuración del láser escáner (baudrate, ángulo de escaneado, resolución...)

- Normalización de la trama del láser.

- Corrección del efecto de ángulo: se trata de la obtención del vector de referencia o de offset (explicado con anterioridad en el apartado 6.1.1).

- Detección y eliminación de elementos estáticos sobre la vía: se realiza restando dos vectores de offset sucesivos.

- Envío de la información al ordenador: se trata del vector que contiene los valores de las alturas (ver apartado 6.1.1).

El microprocesador seleccionado ha sido un DSC (acrónimo del inglés Digital Signal Controller), ya que a las funcionalidades de un procesador digital de señal (DSP, acrónimo del inglés Digital Signal Processor) le añade las de un microcontrolador de altas prestaciones de 16 bits (MCU, acrónimo del inglés Microcontroller Unit). En concreto, el modelo seleccionado fue el dsPIC-30F4011 de la compañía Microchip por el conocimiento previo que se tenía del mismo y las altas prestaciones que ofrece. Se trata de un dispositivo programable, normalmente en lenguaje de programación C, lo que presenta dos importantes ventajas. La primera y principal es permitir modificar, comprobar y depurar el diseño y sus funcionalidades sin que ello afecte a la arquitectura hardware. La segunda ventaja es que permite su reutilización al final del proyecto. Dada esta versatilidad, se ha incluido en el diseño de la PCB un conector para la programación del DSC.

En la figura 6.12 se muestra el DSC utilizado con la electrónica asociada y necesaria para su correcto funcionamiento. Este dispositivo necesita un oscilador externo, formado por un 


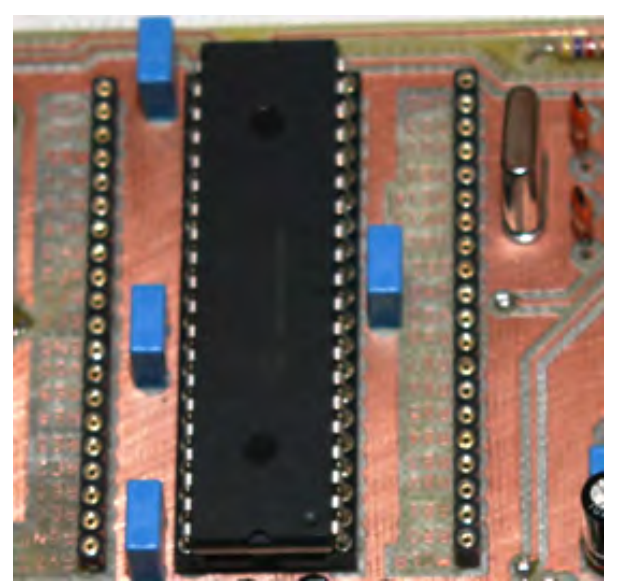

Figura 6.12 - DSC modelo dsPIC30F4011

cristal de $6 \mathrm{MHz}$ y diversos condensadores. También, incorpora una serie de condensadores para el filtrado de las señales de alimentación. Se ha añadido además un pulsador, unido al pin del reset del DSC, con lo que se habilita la posibilidad de reiniciar todo el sistema en cualquier momento. Finalmente, para conseguir una mayor funcionalidad y comodidad a la hora de realizar determinadas pruebas se han añadido unas tiras de pines para facilitar el acceso a los pines del dsPIC.

\subsubsection{Alimentación y Otros}

Los componentes de la PCB funcionan con tensiones de $5 \mathrm{~V}$ con lo que es necesaria una etapa de adaptación. Dicha etapa de adaptación de la alimentación está compuesta por diversos componentes discretos: rectificadores de onda completa, reguladores de tensión, condensadores... Toda esta circuitería permite:

- proteger al circuito frente a variaciones de tensión, descargas eléctricas y ruido existente;

- filtrar la señal evitando posibles fuentes de ruido debidas al rizado,

- y sobre todo obtener la tensión constante de salida necesaria, $5 \mathrm{~V}$.

Para una comprobación visual rápida del correcto funcionamiento de la etapa de alimentación se ha añadido un LED indicador, (ver figura 6.14(a)).

El esquemático de la etapa de alimentación se muestra en la figura 6.13. 


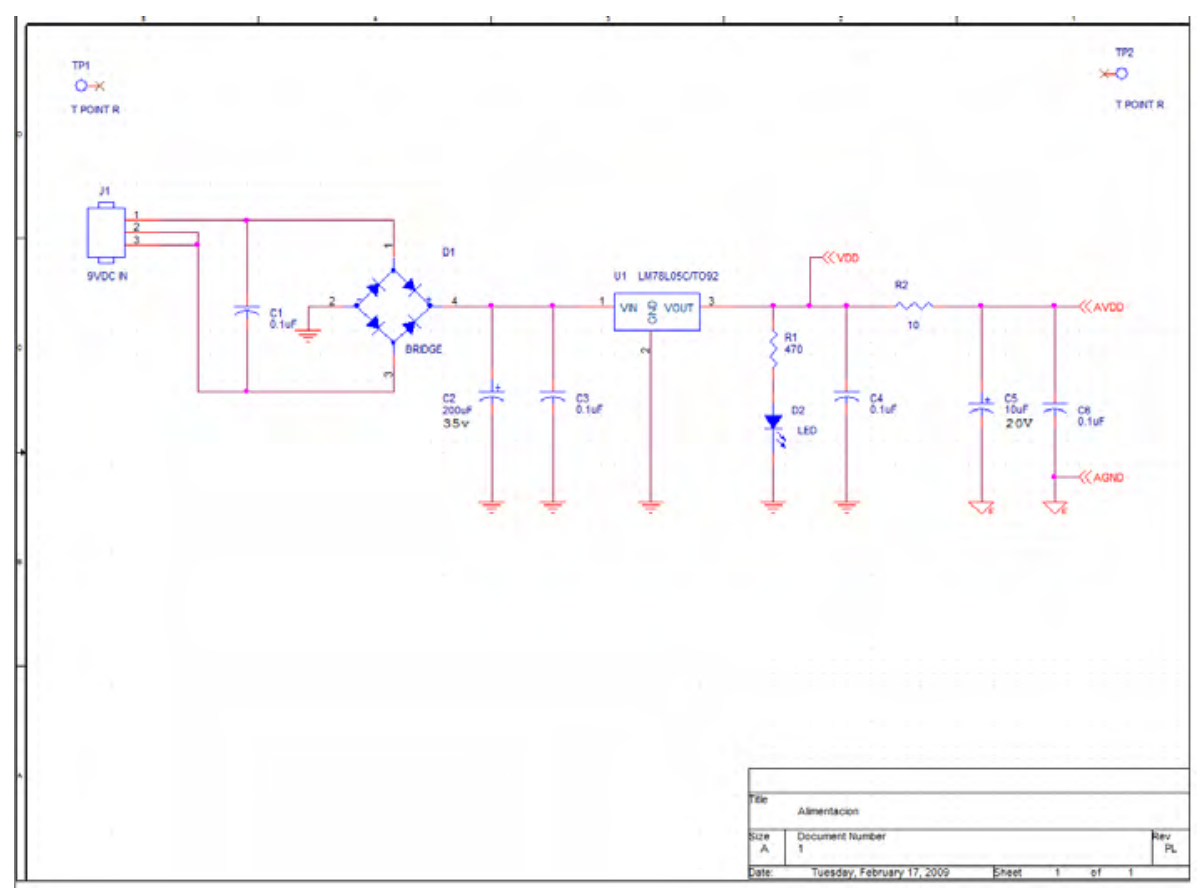

Figura 6.13 - Esquemático Alimentación

Si bien en el primer diseño solo se incluía el led mencionado, se consideró interesante añadir un mayor número de indicadores conectados a determinadas señales de salida programables del DSC. En le etapa de pruebas y verificación estos indicadores permiten una fácil y rápida visualización puntual de resultados, lo que facilita la revisión y detección de errores. En la figura 6.14(b) se aprecia, además de dichos indicadores LEDs, el pulsador de reset del DSC.

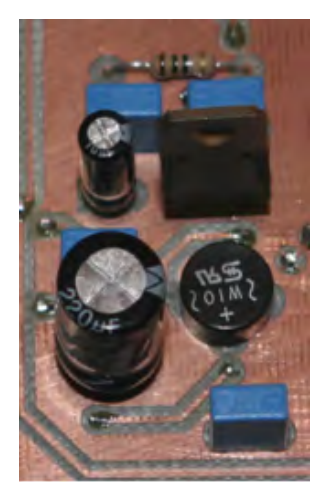

(a) Alimentación

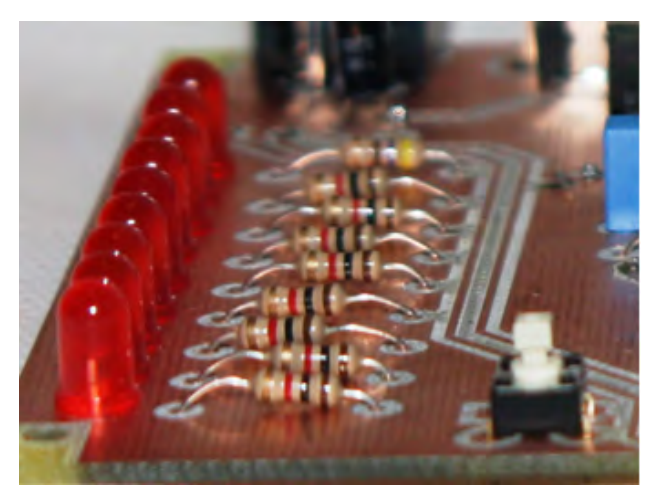

(b) Leds y Reset

Figura 6.14-PCB: Etapas varias 


\subsubsection{Comunicaciones}

Al tratarse de un prototipo es necesario dotarlo de la mayor versatilidad posible, permitiendo el uso de diversos tipos de dispositivos con diferentes estándares de comunicación. Es por ello que la PCB dispone de diversos conectores eléctricos: DE9 tanto macho como hembra para las comunicaciones serie, conectores USB-B, conector de alimentación y conector RJ-11 para programación, pruebas y verificación del DSC.

La arquitectura y especificaciones definidas permiten una amplia posibilidad de combinaciones a la hora de tratar los datos. La información detectada por el equipo es enviada mediante un interfaz RS-422 a la PCB diseñada donde se transforma a niveles 5V TTL/CMOS. Una vez en la PCB y en función de diferentes combinaciones de jumpers el flujo de datos puede ser el siguiente:

- Comunicación Equipo-Serie. Enviar los datos al conversor TTL-RS232, y directamente al ordenador para el procesado directamente en este.

- Comunicación Equipo-DSC. Los datos pueden enviarse al DSC para su preprocesado; convertirlos a niveles RS-232, mediante el conversor TTL/RS-232; y finalmente enviarse al ordenador a través del puerto serie del mismo.

- Comunicación Equipo-DSC. Los datos tras ser pretratados en el DSC y transformados a niveles RS-232 y posteriormente USB, pueden ser enviados al ordenador a través del puerto USB del mismo.

Esta diversificación es la que confiere una gran versatilidad a nuestra arquitectura permitiendo que se adapte con facilidad y rapidez a cada una de las situaciones a las que se puede enfrentar. En la figura 6.15 se han marcado en diferentes colores cada una de estas posibles combinaciones.

\subsection{Pruebas y validación de la Arquitectura Hardware}

La arquitectura hardware diseñada requiere ser implementada con el fin de poder demostrar y validar el buen funcionamiento del diseño. Para ellos se realizan diversas pruebas de comu- 


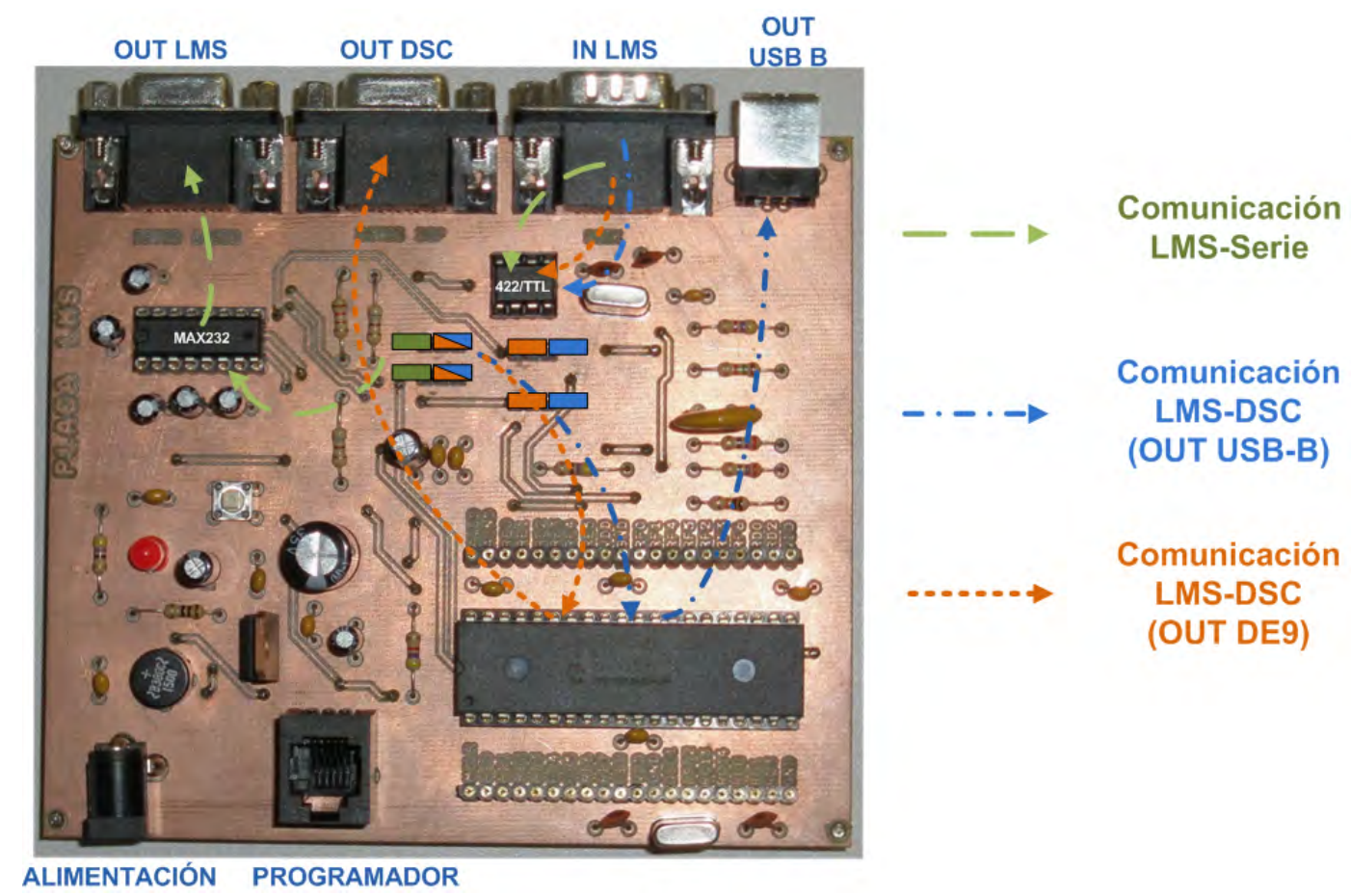

Figura 6.15 - Comunicaciones en la PCB

nicaciones entre el equipo, la PCB y el ordenador utilizando comunicación serie y la tarjeta de adquisición SIO directamente al ordenador.

\subsubsection{Pruebas de Comunicación Serie}

Las primeras pruebas de comunicación realizadas han servido para comprobar el correcto funcionamiento del canal bidireccional de comunicaciones entre el equipo y el puerto serie del ordenador, directamente y sin utilizar la PCB diseñada. En este caso se ha diseñado el siguiente protocolo de test:

- Configuración del puerto serie a 9.600 Bd 8N1 (8 bits, No parity, 1 stop).

- Espera hasta la recepción del telegrama de bienvenida del equipo.

- Comprobación de la codificación ASCII recibida.

- Envío de la trama de inicio, telegrama PING.

- Presentación en hexadecimal de la respuesta al mismo.

El sistema en este caso está configurado de la siguiente manera: el cable proveniente del equipo se conecta al ordenador a través de la electrónica necesaria para la adecuación de niveles. 
En la figura 6.16 se muestra el primer prototipo utilizado, aunque tras el diseño de la PCB ya no se ha utilizado mas esta electrónica.

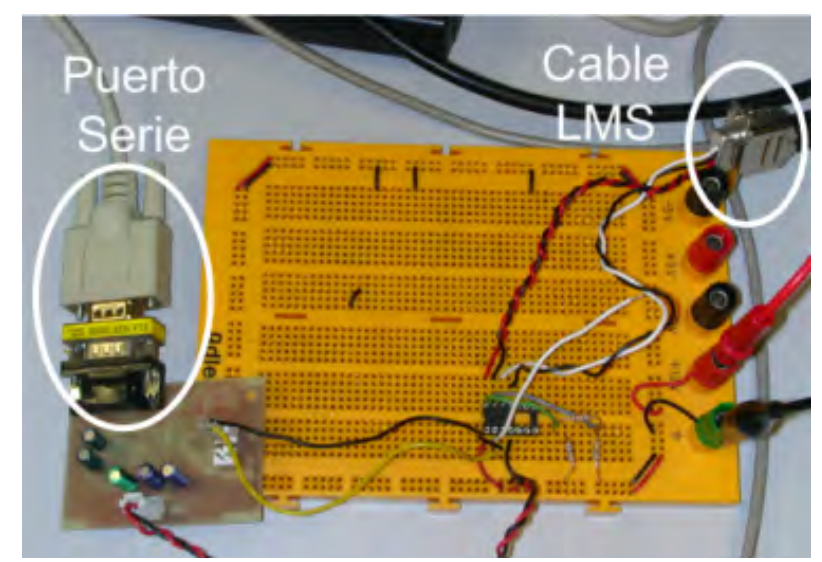

Figura 6.16 - Prueba de comunicaciones serie: prototipo

A la hora de realizar las verificaciones y comprobar que la comunicación se establecía correctamente la opción más sencilla era capturar el tráfico del puerto serie mediante el programa hyperterminal del ordenador. Tras varias pruebas se pudo constatar que este programa no interpretaba bien los datos. Este hecho se debe a que aunque interpreta en codificación ASCII la información que recibe desde el equipo, no todos los bits que recibe se pueden codificar en ASCII como datos validos en nuestro caso, como por ejemplo los comandos de control.

La solución fue desarrollar diferentes scripts en lenguaje Python para realizar dicha tarea. En el momento de ejecución de los script es necesario que el puerto serie no esté en uso ya que el mismo se encarga de abrirlo. Finalmente, se muestra por pantalla los datos recibidos para proceder a una comprobación visual de la correcta recepción.

Todos estos pasos se han realizado correctamente verificando de este modo: el buen funcionamiento de la comunicación directa entre el equipo y el ordenador, y el correcto diseño de las etapas conversoras. La comunicación se realizó a 9.600 Bd. La figura 6.17 muestra la captura de la pantalla tras la realización del test.

\subsubsection{Pruebas de Comunicación Serie mediante una tarjeta PC Card}

Tras la comprobación del correcto envío de la trama de inicio desde el equipo al ordenador, el paso siguiente consiste en la comprobación, mediante la tarjeta PC Card o PCMCIA de la 


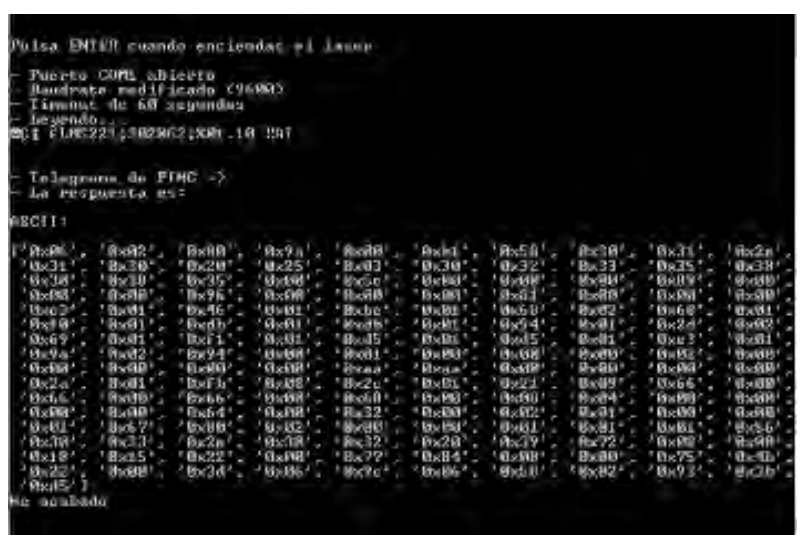

Figura 6.17 - Prueba de comunicaciones serie: captura de pantalla

compañía SIO, proporcionada por la empresa SICK, de la posibilidad de envío de información a velocidades de $500 \mathrm{KBd}$.

En este caso, la conexión se realizó directamente desde el equipo al ordenador haciendo uso de dicha tarjeta de comunicaciones. El problema principal en esta etapa ha residido en la escasa información que se disponía de la tarjeta PC Card y de su conector. Ya que la empresa la proporcionaba pero sin aportar ningún manual, ni mayor información al respecto. En esta situación el primer paso fue la comprobación de los pines de transmisión/recepción y su correcto funcionamiento.

Para comprobar los pines de transmisión se ha utilizado un script que mandaba reiteradamente la cadena en hexadecimal $0 x A A$, es decir una secuencia de " 0 " y " 1 ", por el puerto serie del ordenador al que estaba conectada la PC Card. De este modo, un simple análisis de de la información que se tienen por cada uno de los pines, usando el analizador lógico, fue suficiente para detectar, sin lugar a errores, los pines de transmisión y recepción buscados.

Generalmente, los conceptos de baudio y bps (acrónimo de bits por segundo) se intercambian dándoles a ambos el mismo significado aunque realmente no deben confundirse. Los baudios representan el número de cambios de estado que se producen cada segundo durante la transferencia de datos. Mientras que los bps representan el número de bits enviados por segundo. La velocidad de transferencia se puede medir en baudios o bps. Sólo cuando cada cambio de estado transporta un solo bit coinciden la velocidad de transmisión de datos en baudios y en 
bps. Normalmente, las señales binarias tienen la tasa de bit igual a la tasa de símbolos $\left(r_{b}=r_{s}\right)$, con lo cual la duración de símbolo y la duración de bit son también iguales $\left(T_{s}=T_{b}\right)$.

En el caso de la PC Card esta distinción ha supuesto un inconveniente al ser la tasa de bit diferente a la tasa de símbolo, con lo que los bps que se configuraban en el hiperterminal no coincidían con la velocidad a la que realmente se quería configurar la transmisión. Es decir, la PC Card trabaja con un baudrate no estándar. Para poder utilizar los valores estándar normalizados se debe configurar la PC Card con los valores que se muestran en la tabla 6.5, [SIC02b] 2002:20 y [SIC02a] 2002:17.

\begin{tabular}{cc}
\hline Baudrate (bps) & Baudios \\
\hline 9.600 & 2.150 \\
19.200 & 4.301 \\
38.400 & 8.602 \\
500.00 & 115.000 \\
\hline
\end{tabular}

Tabla 6.5 - Valores de Badurate de la PC Card

Una vez se ha tenido en cuenta este importante detalle, se probaron los modos de funcionamiento a distintas velocidades, usando el software proporcionado por la compañía, con las siguientes opciones de configuración: puerto (COM seleccionado en el ordenador), tipo de puerto (PCMCIA hasta 500KBd.) y baudrate (valor seleccionado). Se han realizado diversas pruebas del modo de funcionamiento de dicho conector, lo que permitió diseñar el cable necesario para unir correctamente el conector DE9 proveniente del equipo a la tarjeta PC Card (ver figura 6.18), ya que la conexión no era directa y este conector no era proporcionado por la compañía a la par que la tarjeta PC Card.

El mismo protocolo diseñado para las pruebas de comunicación serie se utilizó en este caso y se obtuvieron resultados positivos, al igual que con anterioridad, (ver figura 6.19). Es decir, la comunicación realmente se llevaba a cabo entre el equipo y el ordenador a la velocidad de 500 Kbps.

Si bien los resultados de las pruebas mediante la tarjeta PC Card y el script desarrollado fueron los esperados, en un primer momento no fue posible verificarlo usando el software proporcionado por la empresa SICK para tal efecto, "MST 200 Demo Application v2.01". Tras 


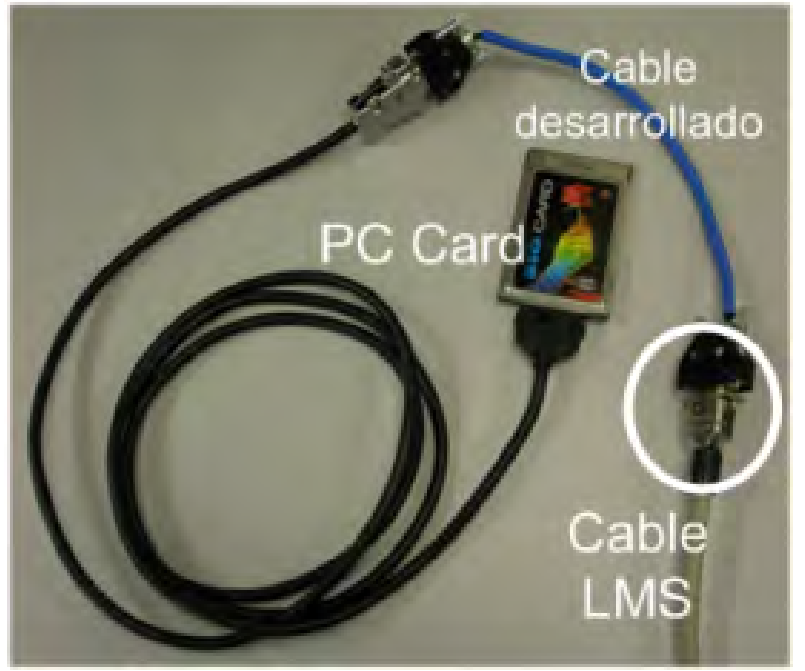

Figura 6.18 - Prueba de comunicaciones serie via PC Card

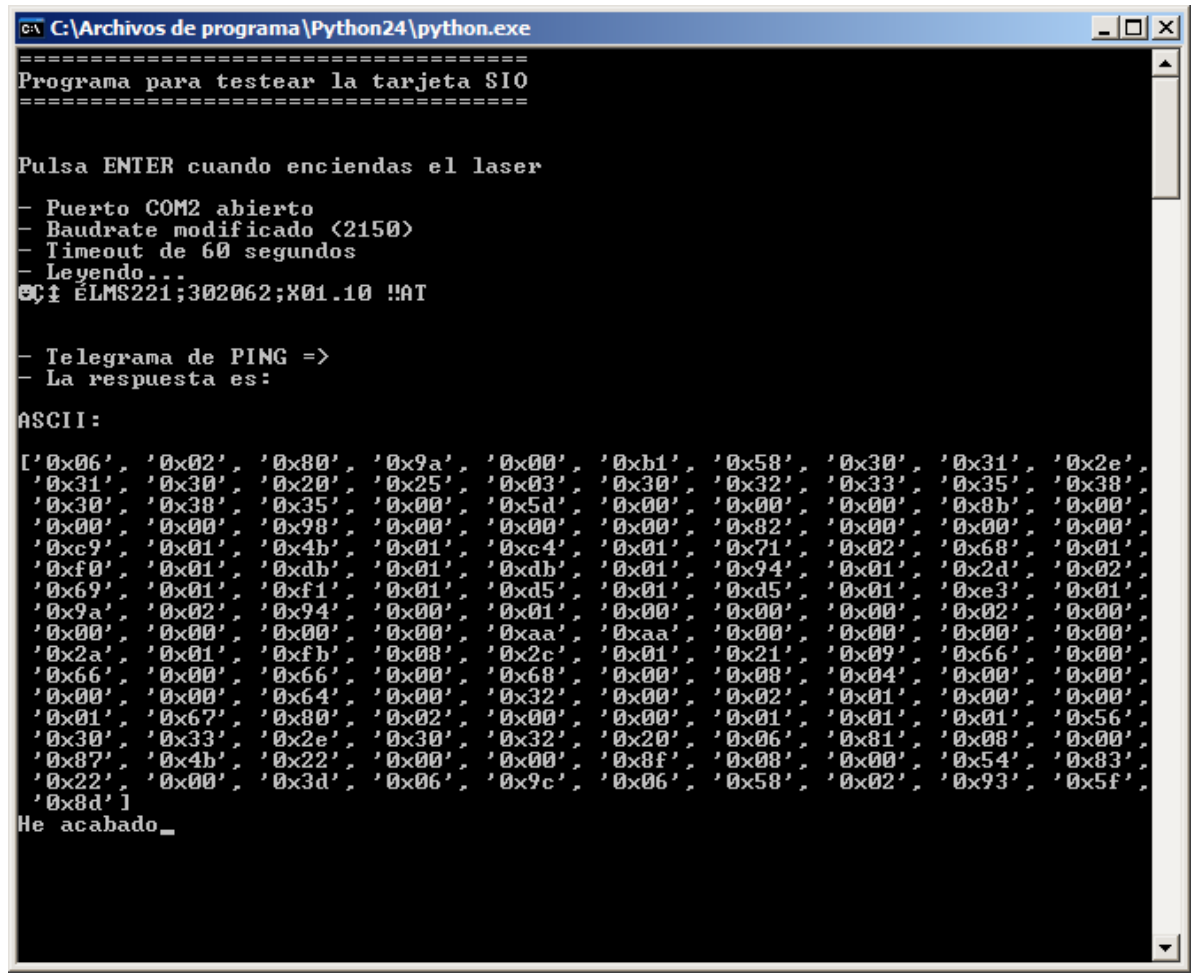

Figura 6.19 - Prueba de comunicaciones serie: captura de pantalla

diferentes pruebas y ensayos, se han obtenido la representación por pantalla de los resultados haciendo uso del software mencionado. 


\subsection{Conclusiones}

La etapa de especificación de la arquitectura hardware se ha completado con éxito destacando los siguientes hitos:

- Conocimiento del principio de operación que rige los sensores láser escáner.

- Establecimiento de las etapas de comunicación entre el equipo sensor y el ordenador.

- Diseño del hardware necesario.

- Implementación del primer prototipo.

- Pruebas y validación del hardware multisensor diseñado.

Las figuras 6.20 muestran no solo la PCB definitiva diseñada con el objeto de verificar los requerimientos establecidos, sino también el diseño definitivo presentado en el interior de una caja.
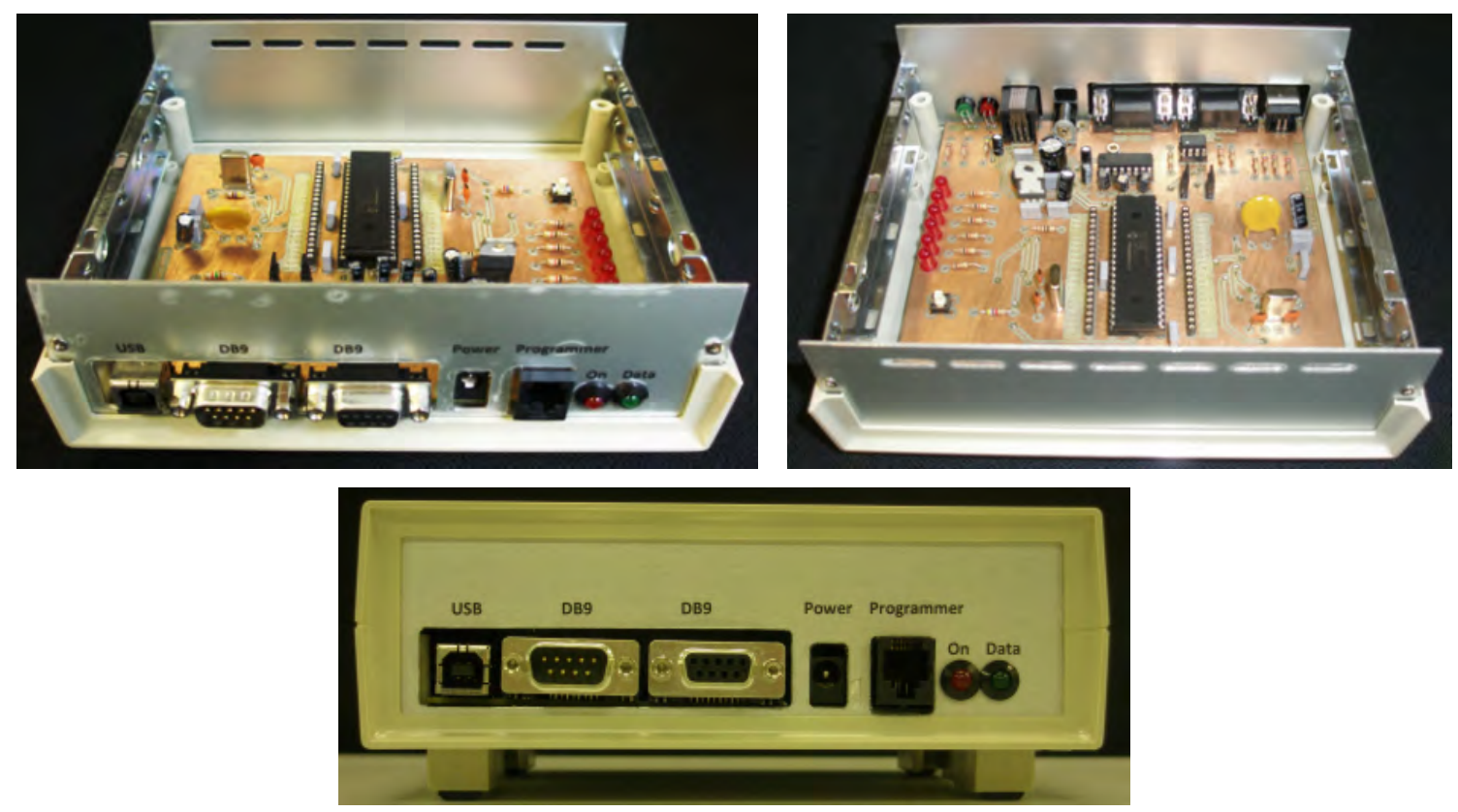

Figura 6.20 - Hardware diseñado e implementado

Gracias a la consecución de todos los hitos anteriores se han podido definir los requerimientos hardware, como se pretendía en este capítulo, y que aparecen resumidos en la tabla 6.6. 


\section{Requerimientos Hardware}

\begin{tabular}{|c|c|}
\hline \multicolumn{2}{|l|}{ General } \\
\hline Altura mínima sobre la vía (m) & 5 \\
\hline Consumo máximo (W) & 40 \\
\hline Clase de láser & I (seguro) \\
\hline Tipo de emisor & diodo láser IR \\
\hline \multicolumn{2}{|l|}{ Comunicaciones } \\
\hline Tipo interfaz & RS232 opcional RS485/422 \\
\hline Baudrate, tasa de transferencia (KBd) & $9,6-500$ \\
\hline Opción alta velocidad (MBd) & 1,5 \\
\hline \multicolumn{2}{|l|}{ Escáner } \\
\hline Frecuencia de escaneo $(\mathrm{Hz})$ & $15-100$ \\
\hline Tiempo respuesta (ms) & $53-10$ \\
\hline Ángulo de Escaneo & $100^{\circ}-180^{\circ}$ \\
\hline Resolución Angular & $0,25^{\circ}-1^{\circ}$ \\
\hline \multicolumn{2}{|l|}{ Especificaciones } \\
\hline \multicolumn{2}{|c|}{$\begin{array}{l}\text { El sistema debe ser capaz de detectar los vehículos que circulan por la zona de } \\
\text { detección. }\end{array}$} \\
\hline \multicolumn{2}{|c|}{$\begin{array}{l}\text { El sistema debe adquirir y almacenar los datos provenientes de los vehículos } \\
\text { detectados. }\end{array}$} \\
\hline \multicolumn{2}{|c|}{$\begin{array}{l}\text { El equipo debe situarse en la perpendicular de la vía con visión directa a la } \\
\text { misma. }\end{array}$} \\
\hline \multicolumn{2}{|c|}{$\begin{array}{l}\text { La comunicación entre el equipo sensor y la arquitectura hardware debe } \\
\text { realizarse via RS } 232 \text { o USB. }\end{array}$} \\
\hline \multicolumn{2}{|c|}{$\begin{array}{l}\text { La comunicación entre la arquitectura hardware y el ordenador debe realizarse } \\
\text { via USB. }\end{array}$} \\
\hline
\end{tabular}

Tabla 6.6 - Requerimientos Hardware 


\section{Bibliografía}

[For00] Forum, U.I., Universal Serial Bus Specification. Recomendación USB Revision 2.0, Compaq Computer Corporation, Hewlett-Packard Company, Intel Corporation, Lucent Technologies Inc, Microsoft Corporation, NEC Corporation, Koninklijke Philips Electronics N.V., Abril 2000, URL http: / / www . usb . org/developers / docs /. [Online: Último acceso Marzo 2009].

[Ins98] Instruments, T., Data Sheet: SN75179B. Texas Instruments Incorporated, Post Office Box 655303, Dallas, Texas 75265, review edición, June 1998.

[Ins04] Instruments, T., Data Sheet: MAX232. Texas Instruments Incorporated, Post Office Box 655303, Dallas, Texas 75265, review edición, March 2004.

[ITU96] ITU, V.11 - Características eléctricas de los circuitos de enlace simétricos de doble corriente que funcionan con velocidades binarias de hasta $10 \mathrm{Mbit} / \mathrm{s}$. Recomendación UIT-T v.11 Serie V: Comunicación de datos por la red telefónica, Union Internacional de Telecomunicaciones. Sector de Normalización de las Telecomunicaciones, October 1996, URL http: / / www.itu.int/rec/ T-REC-V.11-199303-S/es. [Online: Último acceso Marzo 2009].

[ITU00] ITU, V.24 - Lista de definiciones para los circuitos de enlace entre el equipo terminal de datos y el equipo de terminación del circuito de datos. Recomendación UIT-T v.24 Serie V: Comunicación de datos por la red telefónica, Union Internacional de Telecomunicaciones. Sector de Normalización de las Telecomunicaciones, February 2000, URL http: / / www. itu. int/rec/ T-REC-V.24-200002-I/es. [Online: Último acceso Marzo 2009].

[Mic05] Microchip, Data Sheet: dsPIC30F4011/4012. Microchip Technology Inc., 2355 West Chandler Blvd., Chandler, AZ 85224-6199, preliminary edición, 2005.

[SIC02a] SICK, Quick Manual for LMS Communication Setup - Hardware setup and measurement mode configuration. Auto Indent. SICK AG, version 1.1 edición, March 2002.

[SIC02b] SICK, Quick Manual for MST Demo Setup - Software setup and configuration. Division Auto Indent. SICK AG, version 1.0 edición, August 2002. 8007 954/0000/04-04-2003.

[SIC02c] SICK, Technical Description: LMS 200/211/220/221/291. Laser Measurement Systems. Auto Indent. SICK AG, version 1.1 edición, January 2002. 8008 970/012002.

[SIC06] SICK, Telegrams for Configuring and Operating the LMS 2xx. Laser Measurement Systems. Firmware Version v2.30/X1.27. Division Auto Indent. SICK AG, 2006. 8 007 954/Q501/2006-08-01.

[Tec05] Technology, F., Data Sheet: FT245BL USB FIFO. Future Technology Devices Intl. Ltd., 373 Scotland Street, Glasgow G5 8QB, United Kingdom, version 1.7 edición, 2005. 



\section{Capítulo 7}

\section{Arquitectura Software}

Antes de iniciar este capítulo es importante realizar ciertas reflexiones sobre la naturaleza del firmware. A la hora de introducir la explicación relativa al DSC en la arquitectura hardware surgió una duda sobre dónde tratar la parte del firmware o la programación del DSC y cuál era su correcta ubicación dentro del marco de este estudio.

El firmware se encuentra en esa zona dudosa que delimita el hardware y el software. Se trata de un bloque de instrucciones de programa con propósitos específicos que establece la lógica de más bajo nivel que controla los circuitos electrónicos de un dispositivo de cualquier tipo. Funcionalmente, se considera el interfaz entre las instrucciones externas que recibe el dispositivo y su electrónica, donde se ejecutan [Wik09]. Al estar integrado en la electrónica del dispositivo se trata en parte de hardware y así lo consideran muchos autores como Jack Ganssle en su libro The Firmware Handbook [Gan04]. Mientras otros autores, como Tammy Noergaard [Noe08], lo consideran parte del software ya que proporciona lógica y se programa mediante algún tipo de lenguaje, normalmente en $\mathrm{C}$.

En los últimos años se ha generalizado el perfil de ingeniero firmware como programador del hardware y nexo de unión entre los ingenieros hardware que poseen el conocimiento de los dispositivos y los ingenieros software o programadores [Sut02]. En nuestro caso, no se le dedica un capítulo especial sino que se incluye en el actual ya que se ha considerado más apropiado que hacerlo en el capítulo previo de arquitectura hardware.

Tras las consideraciones precedentes, se procede a la descripción de los requerimientos definidos y el diseño implementado. El procesado de los datos tiene lugar en dos ubicaciones 
diferentes del sistema. A grandes rasgos se puede decir que la detección se realiza en el DSC, mientras que la clasificación se realizará en el ordenador. Antes de entrar en detalles sobre la etapa software se considera conveniente que esta especificación, que marcará el resto del diseño, quede suficientemente clara, definida y patente. La figura 7.1 representa el flujo llevado a cabo en el procesado de los datos.

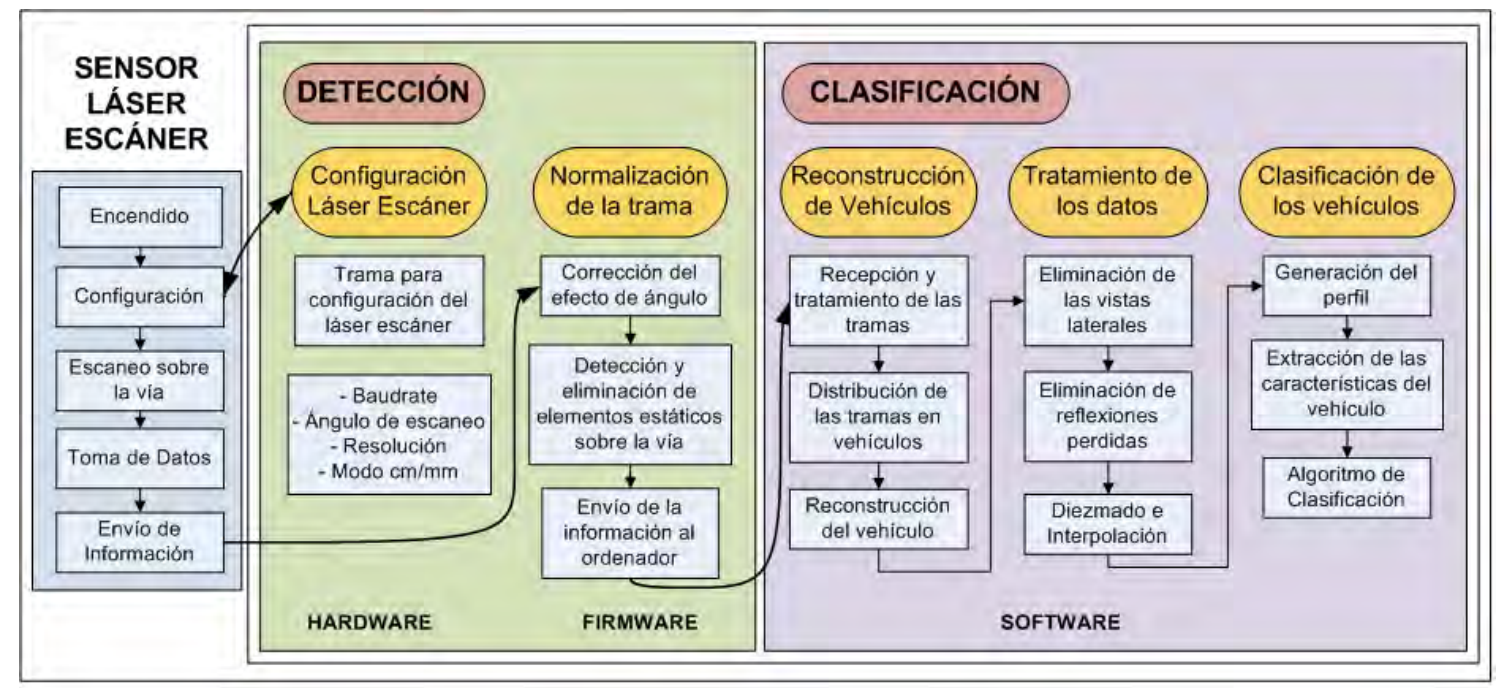

Figura 7.1 - Arquitectura general del sistema

El DSC es el dispositivo encargado de configurar el sensor y realizar el pretratamiento de la señal, (ver capítulo Arquitectura Hardware). Una vez se obtiene la información procesada, es enviada al ordenador para su posterior análisis. En este capítulo se analiza y entra en detalle sobre cada una de estas etapas por separado, que darán lugar a las Especificaciones Software del sistema.

\subsection{Firmware DSC}

El DSC seleccionado fue el dsPIC30F4011 de la compañía Microchip, y por ello se usó el entorno de desarrollo MPLAB IDE versión 7.6. de la misma compañía, que permite editar, compilar y depurar los programas diseñados. La programación del firmware se realizó en lenguaje de programación C. El programador y depurador usado es el mismo, y se trata del Hardware Development Tools: MPLAB IDE Debugging - MPLAB ICD2, mientras que el compilador de C 
es el MPLAB C30. El programa desarrollado para la configuración del sensor y normalización de los datos se integra en el proyecto llamado FirmwareLS, dentro del entorno de trabajo del mismo nombre.

El término DSC fue inicialmente introducido por la compañía Microchip en el año 2002 con su serie 6000 [Tec09]. Fue rápidamente adoptado por la mayoría de fabricantes como Freescale [Fre09, Ban01] y Texas Instruments. El dsPIC30F4011 es un híbrido entre un DSP y un microprocesador de 16 bits especializado en el procesado digital de la señal. Posee tres tipos de de memorias internas: memoria Flash de $48 \mathrm{~KB}$, memoria RAM de $2 \mathrm{~KB}$ y finalmente una EPROM de 1KB. Tiene 30 puertos I/O, pudiendo operar hasta 30 MIPS [Mic05]. Dispone de diferentes módulos, entre los que cabe destacar los de comunicaciones y el convertidor A/D, al ser estos los usados en esta investigación. Aunque además posee otros como:

- Módulo $\mathrm{I}^{2} \mathrm{C}$ (acrónimo del inglés Inter-Integrated Circuit), para comunicaciones serie de 16 bits.

- Módulo SPI (acrónimo del inglés Serial Peripheral Interface), para comunicaciones serie entre diferentes periféricos: EEPROMS, convertidores A/D, registros de desplazamiento e incluso otros microcontroladores.

- Módulo UART, dispone de dos UART para comunicación serie. Una de ellas se programa para realizar las tareas de transmisión/recepción con el sensor y otra para transmitir los resultados al ordenador.

- Módulo CAN, para comunicaciones serie entre otros módulos CAN u otros microcontroladores.

- Módulo convertidor A/D de 10 bits de resolución y 9 canales.

El DSC realiza dos tareas bien diferenciadas: configuración del sensor y normalización de los datos que recibe, (ver figura 7.2). El firmware programado contempla estas dos tareas como dos opciones dentro del mismo programa. En función de un bit externo, configurado como una de las entradas del DSC, se puede seleccionar entrar en modo de configuración o en modo de detección. A lo largo de los siguientes apartados se explica en detalle cada una de estas etapas. 


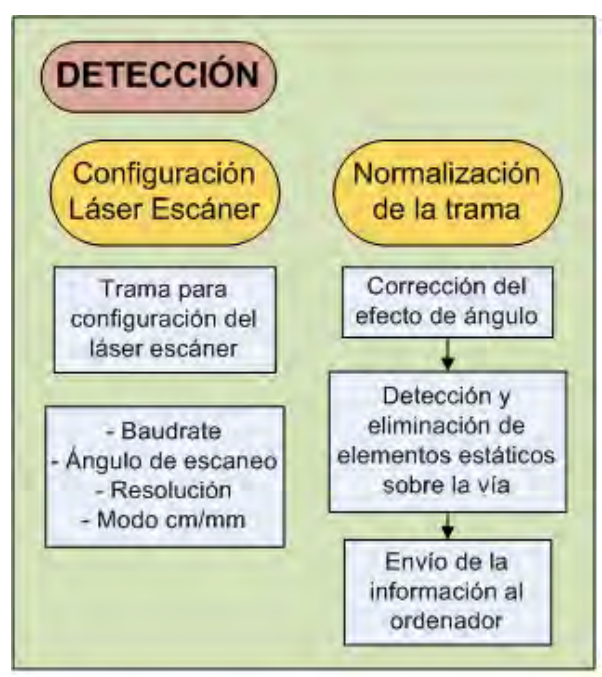

Figura 7.2 - Tareas del DSC

\subsubsection{Generación del baudrate de la UART}

La UART es el módulo serie I/O del DSC. Se trata de un sistema asíncrono full-duplex que puede comunicar diversos periféricos como, por ejemplo, distintos ordenadores. La velocidad de trabajo de este dispositivo se define mediante el módulo baud rate generator de 16 bits. El baudrate se genera en función de la ecuación 7.1 [Mic05] (2005:117):

$$
\text { Baudrate }=F_{C Y} /(16 *(B R G+1))
$$

donde,

$F_{C Y}$ es el ratio de instrucciones por ciclo de reloj.

$B R G$ es el valor almacenado en el registro de baudrate.

El reloj utilizado en el dsPIC está compuesto por un oscilador externo, un cristal de $4 \mathrm{MHz}$ a $10 \mathrm{MHz}$, y un PLL activo, que multiplica la señal del reloj, generada por dicho oscilador, por diversos valores: 4x, 8x, 16x [Mic05] 2005:143. De esta manera, el parámetro $F_{C Y}$ está relacionado, a su vez, con el oscilador y el PLL, según la ecuación 7.2.

$$
F_{C Y}=X T_{F R E Q} * P L L M O D E / 4
$$


donde,

$X T_{F R E Q}$ es la frecuencia del cristal usado.

El mayor rango de frecuencias de salida del PLL se produce, como era de esperar, utilizando el multiplicador x16. En este caso el rango de frecuencias de entrada es [4 MHz - 7,5 MHz] [Mic05] 2005:145. Todas estas características del dsPIC llevaron a realizar una primera prueba trabajando a la máxima velocidad posible del reloj, es decir, usando un oscilador de 7,75 MHz y el PLL x16, con lo que según la ecuación 7.2 proporciona un valor de $F_{C Y}$ de 31 MIPS.

Veamos un ejemplo de cómo se calcularía el baudrate. Por ejemplo, si el baudrate deseado fuera 9.600 bps, aplicando la ecuación 7.1 se obtiene un valor de registro o BRG 194,31. Después de truncar este valor el entero que se obtiene es 194. Si se calcula ahora el valor del baudrate mediante la misma ecuación se obtiene un baudrate de 9.615,38 bps. Es decir tenemos una desviación respecto a la deseada, 9.600, de un 0,16\%. Si se repite la misma operación para los valores de baudrate con los que se trabaja se obtienen las relaciones mostradas en la tabla 7.1.

\begin{tabular}{cccccc}
\hline Baudrate(bps) & F $_{C Y}($ MIPS) & BRG & BRG(integer) & Baudrate obtenido(bps) & Desviación( $\%$ ) \\
\hline 9.600 & 30 & 194,31 & 194 & $9.615,38$ & 0,16 \\
38.400 & 30 & 47,83 & 47 & $39.062,50$ & 1,73 \\
$500 \mathrm{~K}$ & 30 & 2,75 & 2 & $625.000,00$ & 25,00 \\
\hline
\end{tabular}

Tabla 7.1 - Generador del baudrate con el oscilador a 7,5 $\mathrm{MHz}$

Cabe recordar, que el baudrate con el que se trabaja es un parámetro definido por el hardware, en nuestro caso por el equipo, y explicado anteriormente en el apartado 6.2.1 del capítulo Arquitectura Hardware, página 85.

El baudrate y la desviación, como ha quedado demostrado en la tabla 7.1, son altamente dependientes del reloj externo que se use y con ello del ciclo de instrucciones $F_{C Y}$. En el caso de usar el oscilador a 7,5 MHz trabajando al máximo baudrate se produce una desviación del valor deseado del $25 \%$, lo cual deriva en errores de sincronismo. Se puede concluir que no es posible utilizar dicho oscilador si se desea trabajar con baudrates máximos de 500 Kbps. 
Analizando las ecuaciones 7.1 y 7.2 se observa como el único parámetro que se puede modificar es el de instrucciones por ciclo de reloj, $F_{C Y}$, que evidentemente se modifica mediante el reloj. Esta situación hizo que el oscilador se modificara por uno de $6 \mathrm{MHz}$ para poder trabajar al baudrate deseado. En este caso los valores proporcionados por el generador de baudrate ofrecen desviaciones mínimas de 0,16\% llegando incluso a no presentar desviaciones en el caso de $500 \mathrm{Kbps}$, (ver tabla 7.2).

\begin{tabular}{cccccc}
\hline Baudrate(bps) & F $_{C Y}$ (MIPS) & BRG & BRG(integer) & Baudrate obtenido(bps) & Desviación(\%) \\
\hline 9.600 & 24 & 155,25 & 155 & $9.615,38$ & 0,16 \\
38.400 & 24 & 38,06 & 38 & $38.461,54$ & 0,16 \\
$500 \mathrm{~K}$ & 24 & 2,00 & 2 & $500.000,00$ & 0,00 \\
\hline
\end{tabular}

Tabla 7.2 - Generador del baudrate con el oscilador a $6 \mathrm{MHz}$

Finalmente, a la vista de estos resultados el oscilador seleccionado fue el de $6 \mathrm{MHZ}$ que permite trabajar al baudrate deseado de $500 \mathrm{KBd}$.

\subsubsection{Configuración del equipo y normalización de la trama}

El diagrama de flujo de datos que define esta parte del firmware es la representada en la figura 7.3, formada por la configuración del sensor y la normalización de la trama, entendiendo por normalización la obtención directa de las medidas de alturas de los vehículos detectados.

El equipo, desde el momento de su puesta en marcha se encuentra ya configurado, bien porque mantiene la configuración por defecto o bien porque se haya configurado con anterioridad. En cualquiera de los dos casos el primer paso consiste en determinar el baudrate al que se encuentra trabajando. El procedimiento seguido para determinar el baudrate consiste en enviar diferentes telegramas al sensor a diferente baudrates hasta que en una de ellas se obtenga el telegrama de recepción correcta por el mismo (ACK, 06h).

Una vez detectado el baudrate se está en posición de iniciar las comunicaciones con el sensor, permitiendo así realizar los pasos necesarios para su configuración. La secuencia de operación consta de las siguientes etapas, configuración de: ángulo de escaneo, resolución angular y finalmente modo de medida $(\mathrm{mm} / \mathrm{cm})$. En nuestro caso se selecciona: 


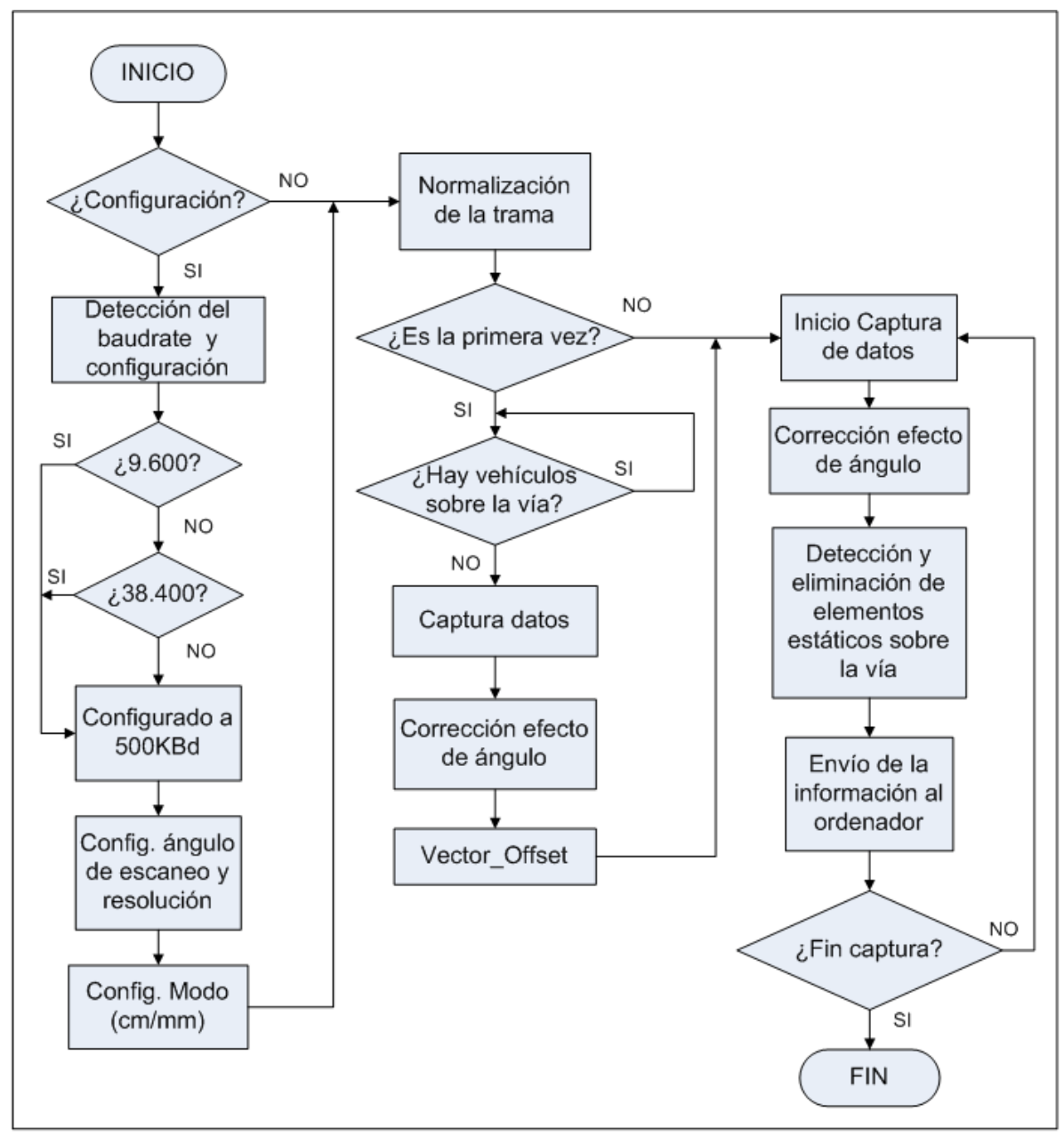

Figura 7.3 - Diagrama de flujo del Firmware

- Baudrate - La comunicación con el sensor siempre se realiza a la máxima velocidad posible $(500 \mathrm{KBd})$, así la primera etapa consiste en modificar este valor mediante el telegrama correspondiente ya que por defecto el equipo no está configurado a este valor.

- Ángulo de escaneo y resolución angular - Se trabaja en un rango de $180^{\circ}$ e incrementos de $0,5^{\circ}$.

- Modo de medida - Se selecciona

La tarea de normalización constituye un preprocesado de la señal. En este caso, las funciones que debe realizar el firmware del DSC son: corrección del efecto de ángulo y detección y eliminación de objetos estáticos sobre la vía mediante el vector de offset. 


\subsubsection{Corrección del efecto de ángulo}

Las distancias medidas por el sensor láser escáner no son medidas perpendiculares a la vía sino que están definidas por un determinado ángulo. Este efecto se puede corregir fácilmente mediante simples ecuaciones trigonométricas, (ver apartado 6.1.1 del capítulo Arquitectura Hardware, página 82).

Cada uno de los barridos o escaneos que se realiza sobre la vía da lugar a un vector formado por los valores que corresponde a las distancias medidas por el equipo. Este vector recibe el nombre “datos_escaneados”. De este modo, si se limitara a representar los valores de estas medidas sin tener en cuenta el efecto del ángulo correspondiente a cada una de ellas se obtendría una representación gráfica en forma de catenaria o curvatura como se representa en la figura 7.4.

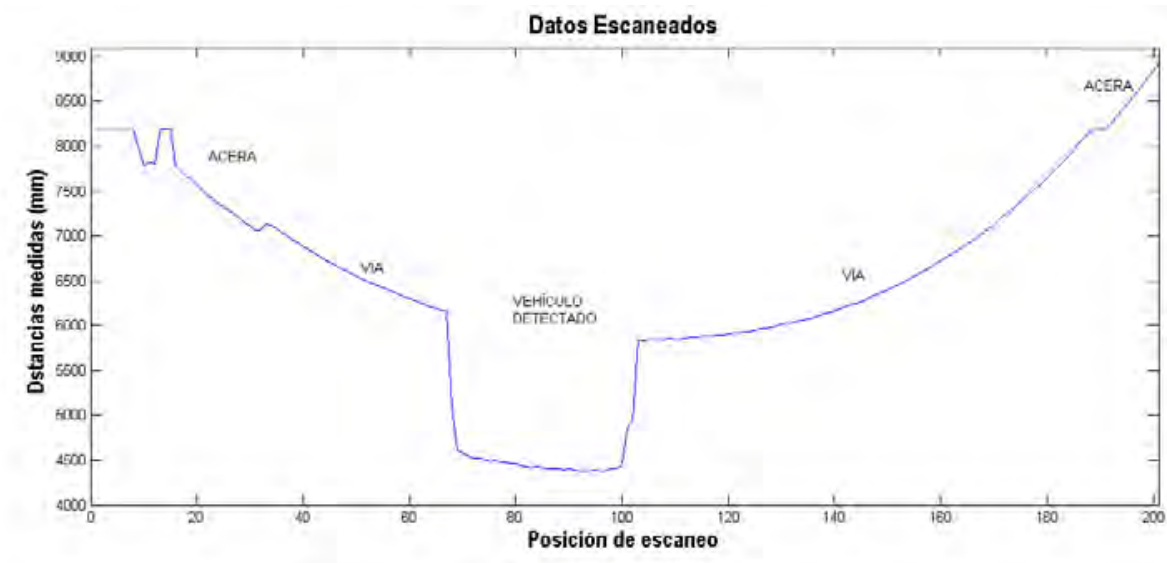

Figura 7.4 - Vector “datos_escaneados”

La figura 7.4 muestra uno de los escaneos que realiza el sensor sobre la vía, donde se aprecian: las aceras, la vía y un vehículo detectado. A vista de esta figura es importante explicar la asimetría existente entre las dos detecciones de las aceras debido a la propia instalación del sensor que no se encuentra centrado sobre la vía. Así, las aceras tampoco se encuentran centradas en la detección de la vía representada en la figura 7.4, aunque, a parte de a efectos puramente estéticos, no afecta en absoluto a las medidas.

La configuración inicial del equipo determina tanto el ángulo de escaneo como la resolución angular, definiendo el número de puntos de medida que se toman y a que ángulo corresponde cada uno de ellos. Con estos datos se crea un “vector_ángulo”, que contiene todos los pasos del 
sensor, para su posterior asociación con los datos medidos. Por ejemplo, en caso de la configuración utilizada (ángulo de escaneo $100^{\circ}$ y resolución angular de $0,5^{\circ}$ ) el “vector_ángulo” está formado por 201 valores que corresponden a los valores: $\left[\begin{array}{lllllll}50 & 49,5 & 49 & 48,5 & \ldots & \ldots\end{array} \quad\right.$. 4949,5 50]. La gráfica 7.5 representa el “vector_ángulo” en el caso de los 201 valores anteriores.

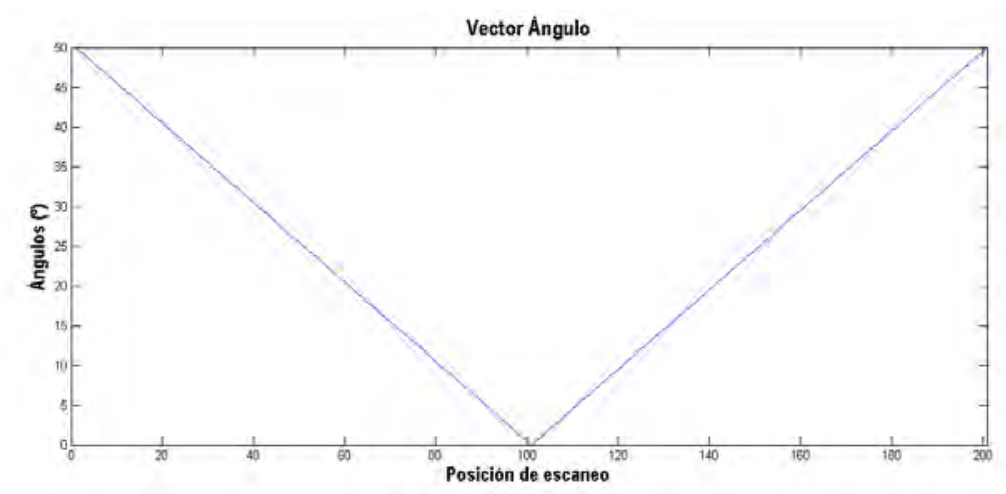

Figura 7.5 - Vector “vector_ángulo”

Como se aprecia en la figura 7.5, este vector presenta una forma simétrica definida por el funcionamiento en sí del equipo. Esta forma se justifica ya que en cada uno de los escaneos los ángulos se miden desde el centro de la vía, o ángulo cero, aumentando los valores cuando nos movemos tanto hacia la derecha como hacia la izquierda. Estos vectores realmente no se calculan cada vez, sino que se almacenan en diferentes constantes en función del ángulo y resolución angular seleccionada inicialmente. La tabla 7.3 muestra las posibles combinaciones de ángulo de escaneo y resolución angular, y el número de valores que tendrá el “vector_ángulo” para cada una de ellas.

\begin{tabular}{ccc}
\hline Ángulo de escaneo $\left({ }^{\circ}\right)$ & Resolución angular $^{\circ}{ }^{\circ}$ & Valores del vector \\
\hline 100 & 1 & 101 \\
100 & 0,5 & 201 \\
100 & 0,25 & 401 \\
\hline 180 & 1 & 181 \\
180 & 0,5 & 361 \\
180 & 0,25 & 721 \\
\hline
\end{tabular}

Tabla 7.3 - Número de valores del “vector_ángulo" para cada una de las posibles combinaciones 
Para corregir el efecto de ángulo se necesita calcular el coseno de cada uno de los valores del “vector_ángulo" y almacenarlos en el vector "vector_coseno”. Finalmente, se multiplica el vector “datos_escaneados” por este último valor. Siguiendo este procedimiento se obtiene un vector, llamado “valores_medidos”, que contiene todas las distancias medidas por el equipo una vez corregido el efecto de ángulo, (ver figura 7.6). Esta corrección se tiene que efectuar en cada uno de los escaneos realizados sobre la vía sin excepción.

$$
\text { Valores_medidos }=\sum_{i=0}^{n-1}[(\text { vector_coseno })[i] \cdot(\text { datos_escaneados })[i]]
$$

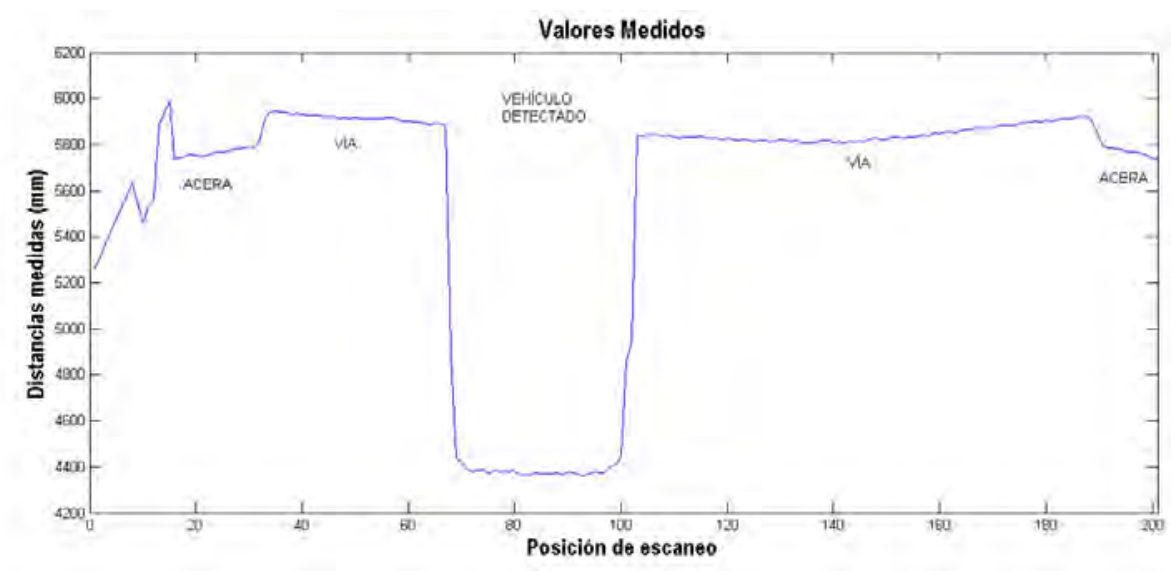

Figura 7.6 - Vector "valores_medidos"

Evidentemente, la figura 7.6 muestra las distancias desde el equipo a la vía con lo que la imagen final no corresponde con los verdaderos valores de altura de los vehículos que circulan por la vía. Para obtenerlos se tiene que trabajar con un nivel base u offset sobre el que realizar la detección.

\subsubsection{Detección y eliminación de objetos estáticos sobre la vía}

El uso normal de la vía y la propia circulación de vehículos produce irregularidades en la superficie de la misma. Estas irregularidades, así como la posible presencia de objetos estáticos sobre ella, pueden falsear los datos que se reciben del equipo, por lo que es necesario almacenar una trama de offset que defina un nivel base sobre el que realizar la detección. No obstante, al ser la resolución en medida de altura del sensor de $10 \mathrm{~mm}$., cualquier objeto que se encuentre 
en la vía y sea inferior a esa altura no será detectado. Este valor es suficientemente pequeño como para no afectar a las medidas.

El “vector_offset” contiene una medida sobre vía en ausencia de vehículos, (ver figura 7.7).

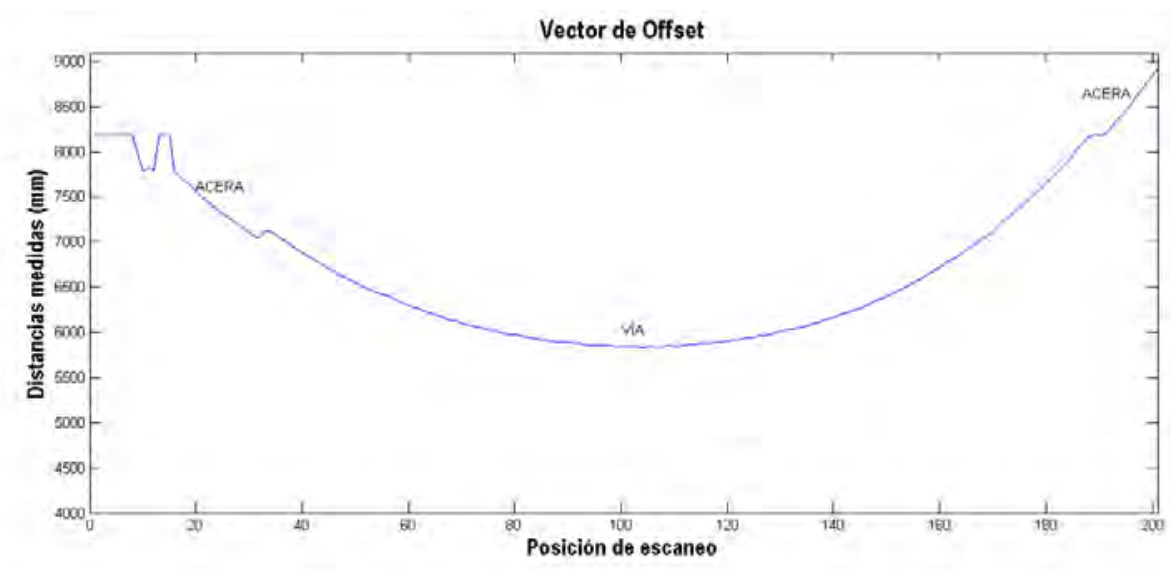

Figura 7.7 - "Vector_Offset"

Evidentemente es necesario realizar sobre el mismo la debida corrección del efecto de ángulo lo que da lugar a la figura 7.8.

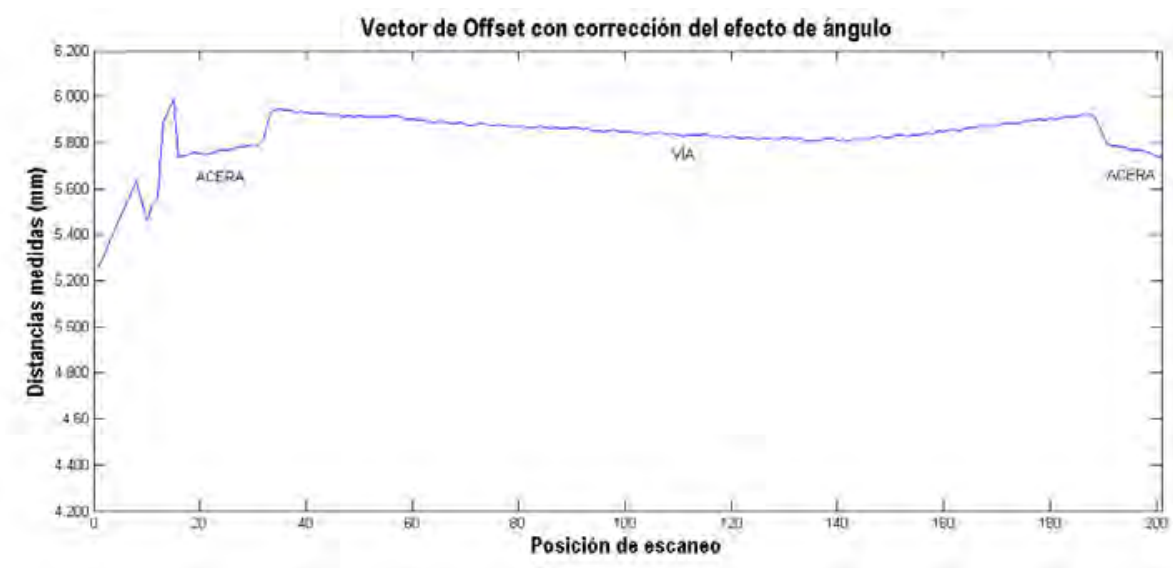

Figura 7.8 - "Vector_Offset" corregido

El proceso de eliminación de estas irregularidades es sencillo y se limita a restar el "vector_offset" con cada uno de los vectores “valores_medidos”. Este procedimiento permite obtener directamente un vector que contiene las alturas de todos los vehículos que circulan por la vía, así como de cualquier objeto que pase por la zona de detección, y viene definido por la ecuación 7.4. 


$$
\text { Valores_medidos_def }=\sum_{i=0}^{n-1}[(\text { vector_offset })[i]-(\text { valores_medidos })[i]]
$$

Finalmente se obtiene el valor de la altura de los vehículos detectados sobre la vía como se muestra en la figura 7.9, donde se representa el vector “valores_medidos_definitivos”.

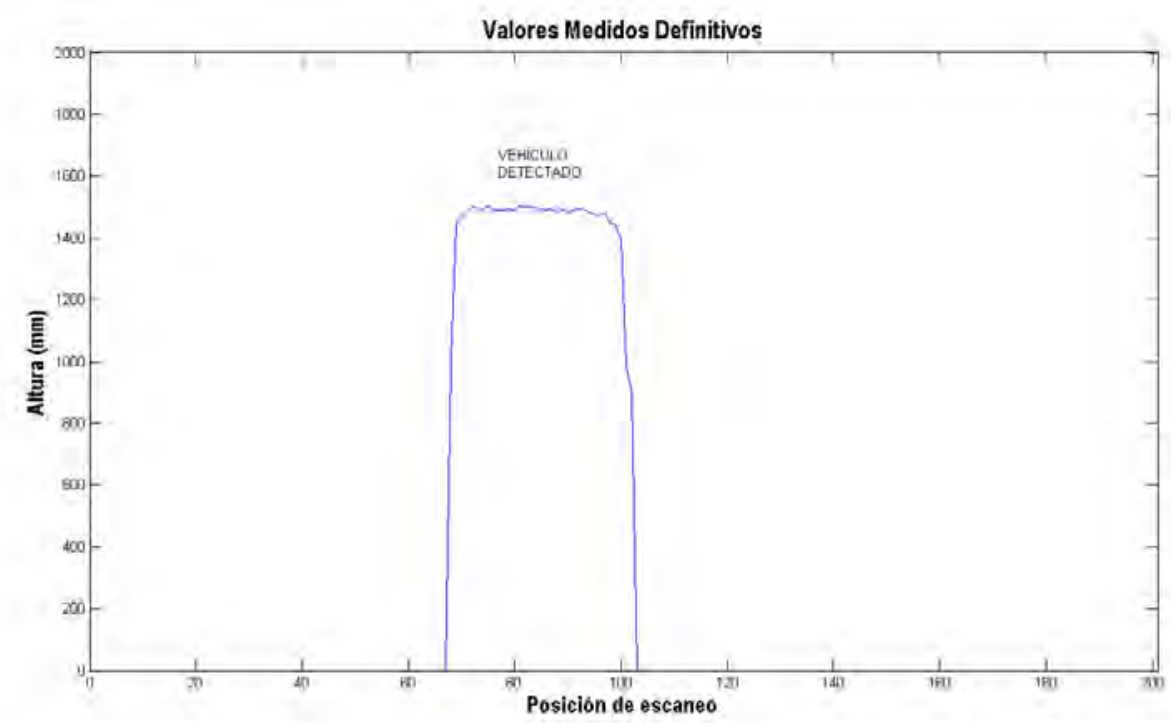

Figura 7.9 - Vehículos detectados sobre la vía

Este proceso presenta una ligera inexactitud que aunque afecta a la medida no afecta al resultado final de forma apreciable. Cuando se realiza la resta entre el vector de offset y el vector de los valores medidos, se están restando realmente valores obtenidos respecto al mismo ángulo pero que no tienen porqué coincidir respecto a su posición horizontal, y de hecho no lo hacen. El efecto que producido se muestra gráficamente en la figura 7.10. En este caso, siguiendo el proceso explicado con anterioridad, el valor medido corresponderia con la resta de los valores $\mathrm{Y}_{B}$ e $\mathrm{Y}_{A}$. Para que el efecto de irregularidades sobre la vía fuera realmente eliminado debería tenerse en cuenta además las posiciones $\mathrm{X}_{A} \mathrm{y} \mathrm{X}_{B}$, ya que aunque se realice la resta en función del mismo ángulo de escaneo debería realizarse en función de la misma posición en el eje horizontal.

Aunque a primera vista pueda parecer que esta forma de operar introduce errores significativamente altos, veamos como no es así. En primer lugar la diferencia de alturas a lo largo de 


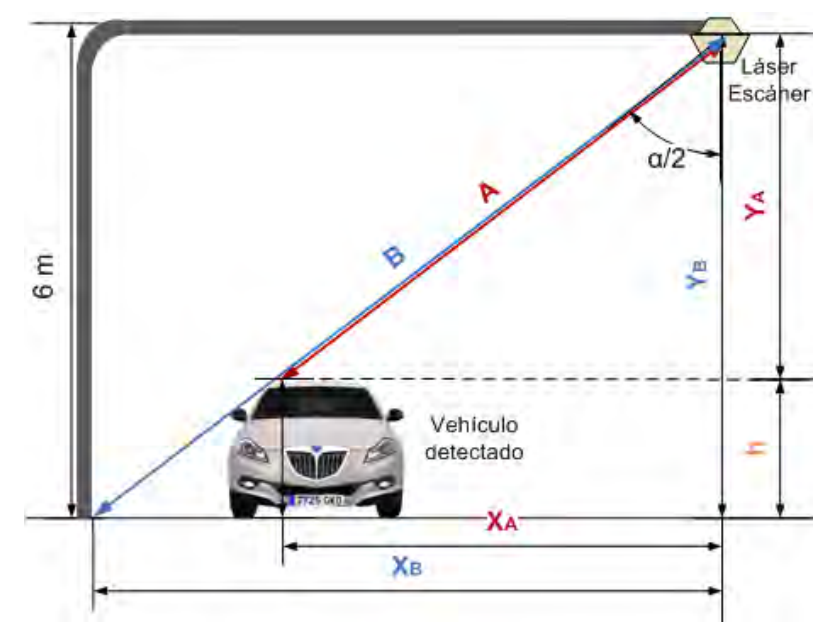

Figura 7.10 - Cálculo del valor medido

la sección de la calzada no es muy elevada. En la figura 7.11 se muestra la vía en ausencia de vehículos en referencia a la posición horizontal en las que se realizan las medidas. Así el punto cero corresponde a la perpendicular del láser, mientras que a derecha e izquierda se sitúan los diferentes carriles de la vía. En la figura 7.12 se realiza un zoom sobre la figura anterior, de manera que muestra únicamente el tramo que corresponde a la vía donde circulan vehículos. En esta segunda figura se aprecia como la diferencia máxima existente entre dos puntos de la vía, en ausencia de vehículos, es de 133,88 mm. Cálculos y pruebas realizadas han demostrado que este valor no afecta considerablemente a los valores finales, ni modifica de forma significativa los valores medidos.

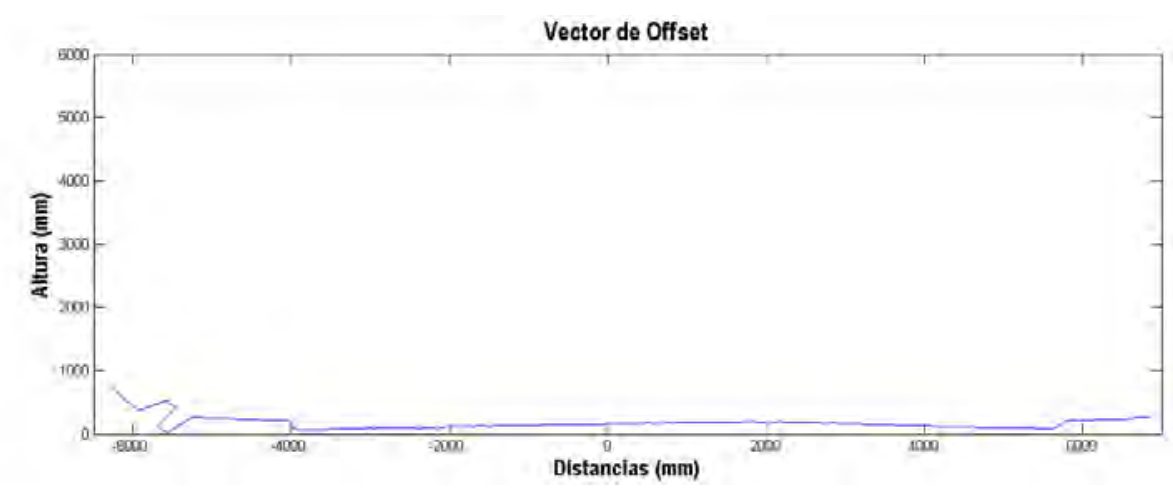

Figura 7.11 - Zoom realizado sobre la representación de la vía en ausencia de vehículos

En segundo lugar, tener que calcular las posiciones horizontales para proceder a su resta de forma precisa supone un elevado proceso de cálculo. Este proceso no podría llevarse a cabo en el DSPIC y debería desplazarse al ordenador. Así una de las grandes ventajas del hardware 


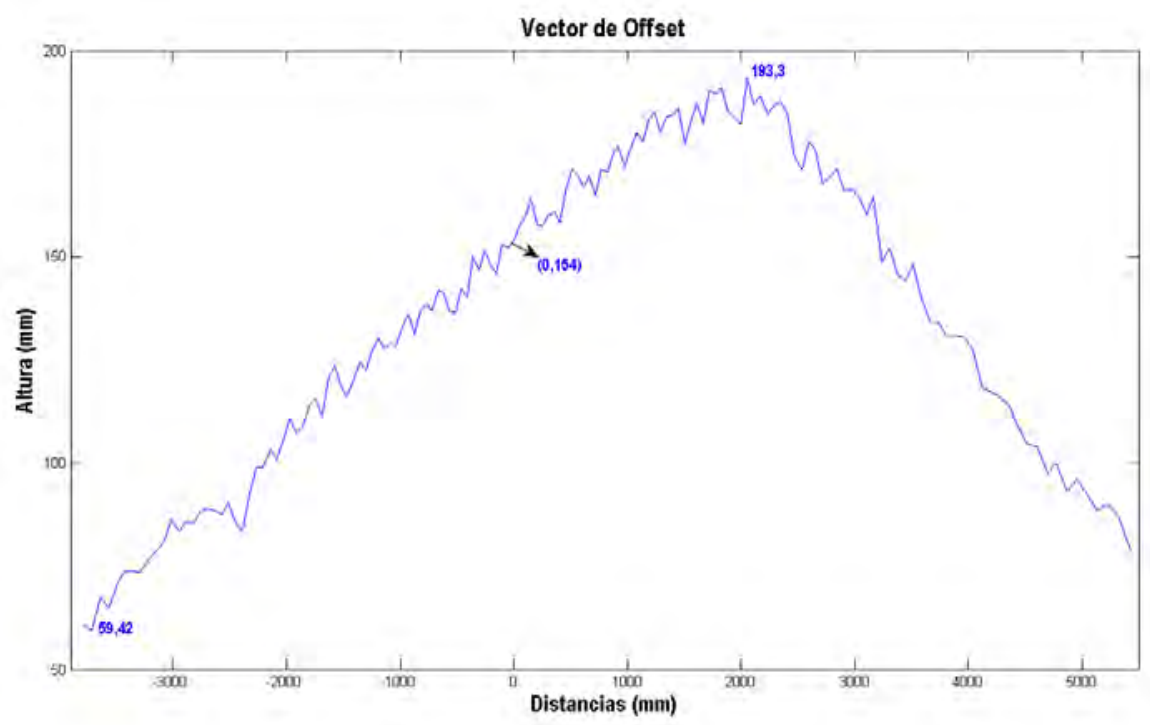

Figura 7.12 - Representación de la vía en ausencia de vehículos

desarrollado, como es el envío únicamente de datos que contienen información se perdería. Y no solo eso, el software de procesado realizado en el ordenador sería mucho más costoso computacionalmente ya que no se trabajaría con las 201 posiciones de escaneo, sino con cerca de las 9.000 posiciones horizontales en $\mathrm{mm}$ en las que se divide la vía. Esta diferencia de magnitud afectaría a todo el procesado haciendo que fuera casi inviable su tratamiento.

Queda así justificado el proceso realizado respecto a la resta del offset. De todos modos, es importante remarcar que este hecho no afecta ni en la obtención del perfil de los vehículos, ni en el cálculo de los parámetros utilizados en la clasificación. El único parámetro para el que sí se realiza la conversión de posición de escaneo a posición horizontal es, evidentemente, en el ancho del vehículo. Precisamente, el formato de la trama, como se presenta más adelante, incluye la posición en la que se detecta el vehículo dentro de un barrido respecto a la posición horizontal, es decir, medida en mm.

\subsubsection{Detección de vehículos y envío de información al ordenador}

Tras la configuración y normalización de cada uno de los vectores “datos_escaneados”, y la obtención del vector “valores_medidos_definitivos" se está en disposición de iniciar el procesado de los datos. Para optimizar el trabajo de procesado, que se lleva a cabo en el 
ordenador, únicamente la parte que corresponde a datos con información es enviada desde el DSC. Con ello se evita que en periodos de escasa o nula circulación se realice un constante procesado en el ordenador consumiendo recursos innecesarios, como ya se explicó en el capítulo anterior. En este caso se han considerado como "datos con información" cada uno de los diferentes vectores de datos escaneados que contienen valores de detección.

Cada vez que un escaneo sobre la vía detecta un vehículo, su información ha de ser enviada desde el DSC al ordenador. Para que esta información siga una estructura comprensible y capaz de ser analizada se han definido, por convenio, las especificaciones de la trama del modo siguiente:

\begin{tabular}{|c|c|c|c|c|c|c|c|c|c|c|}
\hline \multirow{2}{*}{$0 x F F$} & \multirow{2}{*}{$0 x F F$} & \multicolumn{2}{|c|}{ Índice } & \multicolumn{2}{|c|}{ Posición Inicial $\left(\mathrm{X}_{i n i}\right)$} & \multirow{2}{*}{ Datos } & \multicolumn{2}{|c|}{ Anchura (D) } & \multirow{2}{*}{$0 x F F$} & \multirow{2}{*}{$0 x E F$} \\
\hline & & low & high & low & high & & low & high & & \\
\hline
\end{tabular}

Tabla 7.4 - Formato de la trama

Cada uno de los bytes que definen la trama se pueden definir por separado de la siguiente manera:

- Los dos primeros bytes 0xFF 0xFF indican inicio de trama.

- Índice - representa mediante dos bytes la posición de escaneo en la cual se ha detectado el vehículo. Su valor se encuentra entre 0 y 201 que son el número de valores medidos.

- Primera posición $\left(X_{i n i}\right)$ - representa con dos bytes la posición en el eje X del valor en el que se ha detectado el vehículo y que corresponde con el ángulo de barrido. Sus unidades son $\mathrm{cm}$.

- Datos - corresponde a todos los valores correlativos detectados, que corresponden a un mismo vehículo.

- Anchura - representa en dos bytes la última posición de escaneo en la que se detecta el vehículo.

- Finalmente los dos últimos bytes corresponden a 0xFF 0xEF que define el final de trama.

A la hora de elegir las series de bytes que definen inicio $(0 \mathrm{xFF} 0 \mathrm{xFF})$ y fin de trama $(0 \mathrm{xFF}$ 0xEF) se han escogido combinaciones que no puedan darse como medidas válidas de alturas. Es decir, son valores que nunca pueden dar lugar a confusión con posibles valores medidos. 
Cada uno de los escaneos que se realiza sobre la vía pueden contener o no información de detección. Además, en el caso de detección pueden detectarse uno o más vehículos. Fácilmente se puede determinar si se ha detectado uno o más vehículos mediante un estudio de la posición en la que se encuentran los datos y si entre ellos existen zonas en las que no ha habido detección. Resumiendo, dentro de un escaneo se pueden dar dos casos:

- Se detecta un solo vehículo, con lo que para cerrar la trama se envían los bytes de fin de barrido: 0xFF 0xEF.

- Se detectan varios vehículos, en cuyo caso se envía el terminador 0xFF 0xFF después de cada vehículo detectado a excepción del último vehículo, en cuyo caso se envía el terminador de fin de barrido: 0xFF 0xEF.

Es decir dentro de una trama existirán tantas combinaciones de bytes 0xFF 0xFF como número de vehículos más uno se detecten. Solo al final de la trama se enviará la combinación 0xFF 0xEF. Estas dos combinaciones son llamadas valores de control.

Cada vez que se detecte un vehículo sobre la vía, se codifica en la trama correspondiente y se envía al ordenador vía USB a una velocidad de 1,5 MBd.

\subsection{Software de Procesado realizado en el ordenador}

La información que recibe el ordenador está compuesta por diferentes tramas conteniendo la información del vehículo adquirida en cada uno de los escaneos que se ha realizado sobre la vía. Es decir, el ordenador no recibe más que diferentes tramas correspondientes a los escaneos llevados a cabo por el sensor. La primera tarea que se debe realizar consiste en el tratamiento de todas estas tramas "independientes" hasta llegar a aislar en matrices individuales los diferentes vehículos detectados. Esta etapa se llama reconstrucción de vehículos.

En la posterior etapa de tratamiento de los datos se realiza un procesado de las matrices hasta obtener una representación 3D, lo más parecida posible a la realidad, donde se han eliminado probables errores introducidos tanto por la naturaleza del láser escáner en sí, como por la detección. 
A partir de dicha imagen se obtiene el perfil del vehículo del que se extraen las características necesarias para proceder a la última etapa, la de clasificación del vehículo.

La figura 7.13 muestra cada uno de los pasos a seguir en las diferentes etapas de procesado llevadas a cabo en el ordenador, y que, genéricamente, se ha denominado clasificación, al ser este su fin último.

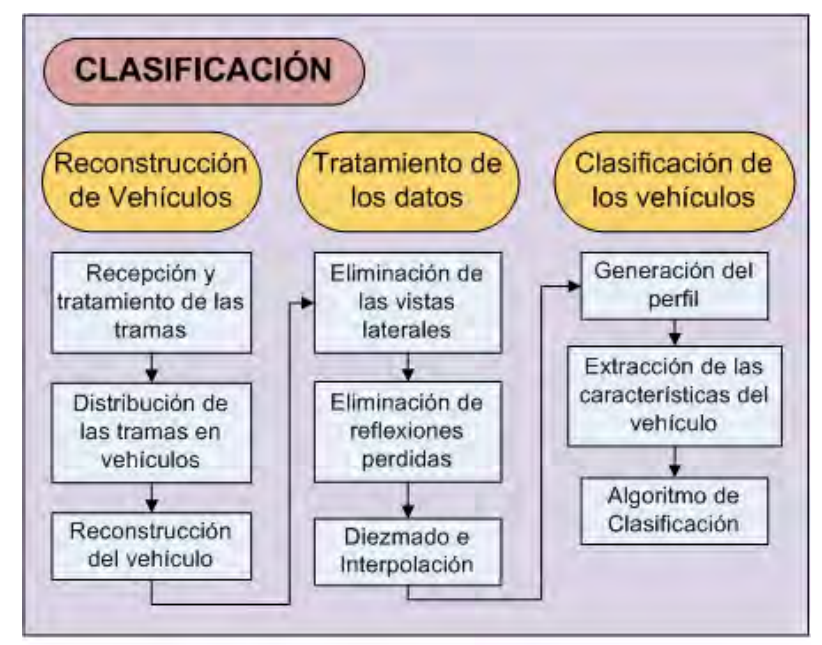

Figura 7.13 - Procesado llevado a cabo en el ordenador

El procesado se ha realizado mediante un programa diseñado y desarrollado usando Microsoft Visual Studio llamado Procesado Sensor Láser. Este programa es el que realiza todos y cada uno de los pasos que se muestran en la figura 7.13.

\subsubsection{Reconstrucción de los vehículos}

Por reconstruir un vehículo se entiende extraer la información del mismo a partir de todas las tramas correspondientes y unirlas de modo que se obtenga una representación 3D del vehículo, tras los sucesivos escaneos. A la hora de realizar dicha reconstrucción hay que analizar cada una de las tramas recibidas y la información que contienen.

La figura 7.14 muestra la información después de que el sensor realice un determinado número de escaneos sucesivos sobre la vía y se les aplique a todos ellos las correcciones del efecto de ángulo en el DSC. Así mismo, la figura 7.15 muestra la vista 3D de la vía. En este 


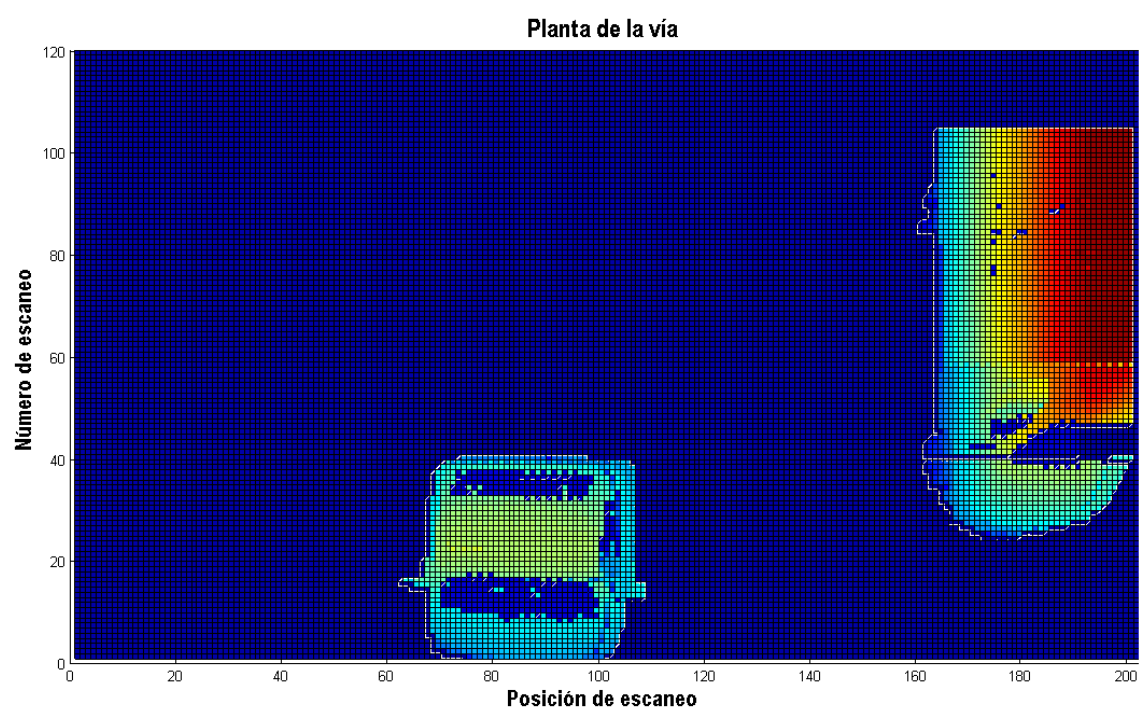

Figura 7.14 - Vía: planta

caso concreto se puede apreciar como sobre la vía circulan dos vehículos: un camión y un turismo. Se toma este ejemplo para explicar la reconstrucción de los vehículos.

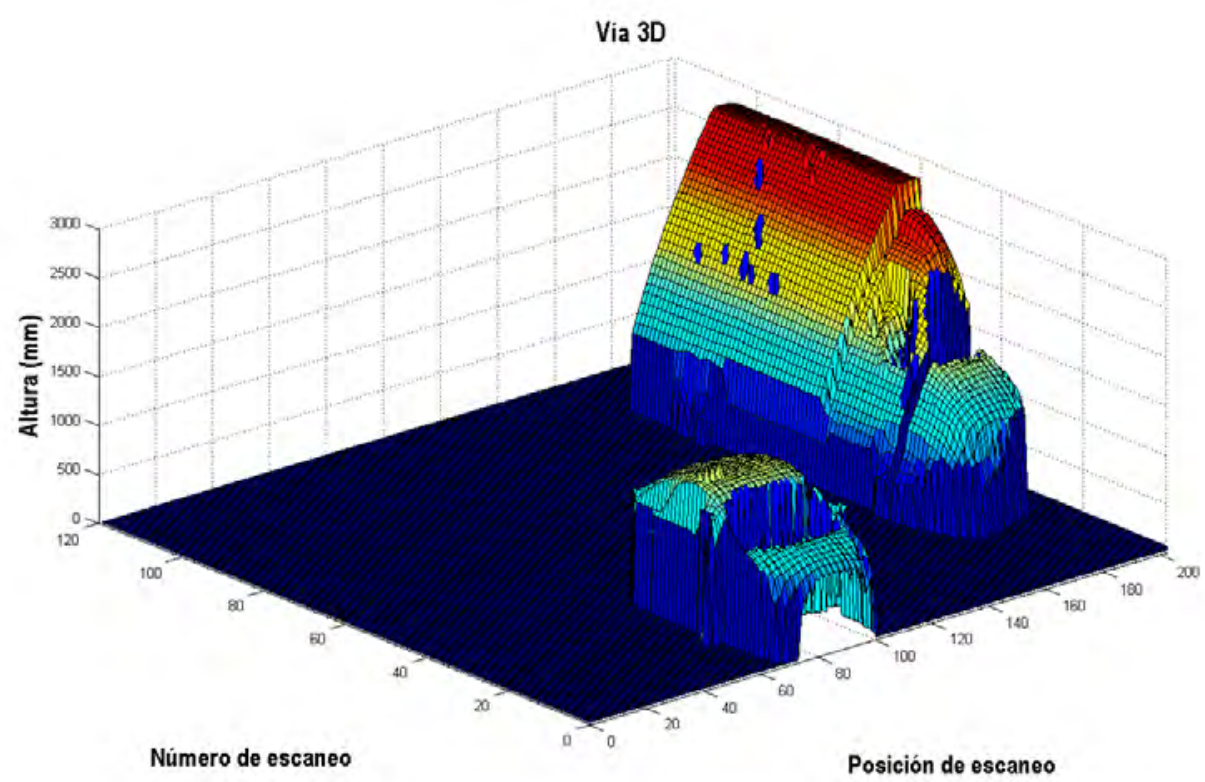

Figura 7.15 - Vía: vista $3 D$

\subsubsection{Recepción y tratamiento de las tramas}

Todas las tramas que se reciben contienen información que, generalmente, va a corresponder a datos de vehículos detectados. En ausencia de vehículos y teniendo en cuenta que el sensor 
está situado a 6 metros de la vía, la resolución de medida horizontal se encuentra en el rango [5,24 cm - 12,54 cm], o lo que es lo mismo la distancia mínima y máxima posible entre dos posiciones de escaneo.

Teniendo en cuenta esta resolución y el ancho menor detectable correspondiente a la rueda de una motocicleta, se ha definido un número de datos mínimos que debe contener la trama para considerarlos válidos. De este modo, se define un umbral de 3 datos, por debajo del cual no se considera que haya habido detección, los datos no son validos y no se realiza su procesado, simplemente son descartados.

Tras esta primera eliminación y selección de datos, se procede a comprobar el número de vehículos que se han detectado en cada una de las tramas y a separarlos según su índice. El índice indica la posición de barrido y sirve de referencia a la hora de conocer la posición del vehículo sobre la vía y su situación. Este valor es de especial importancia ya que su análisis permite "agrupar" los diferentes escaneos realizados sobre un vehículo y obtener su representación $3 \mathrm{D}$.

\subsubsection{Distribución de las tramas en vehículos}

El equipo realiza escaneos o cortes transversales de los vehículos al cruzar la zona de detección. Durante el tiempo de paso por la zona de detección el vehículo generalmente no realiza un desplazamiento lateral considerable sobre la vía, lo que permite que todos los escaneos que se realicen sobre un mismo vehículo presenten índices de valores similares.

La distribución de las tramas recibidas en distintos vehículos se hace comparando el índice y la anchura de cada una de las tramas los valores recibidos en el escaneo anterior. Para que la distribución entre los vehículos sea eficaz, la comparación entre los índices se debe realizar considerando un cierto margen dentro del cual se asume que se trata del mismo vehículo. La definición de este margen se ha realizado tomando los dos casos críticos que se pueden dar, ya que son los que delimitarán los valores superior e inferior que pude tener el margen.

El caso más crítico a la hora de distribuir las tramas, se produce cuando los vehículos realizan desplazamientos laterales importantes y/o bruscos sobre la vía. Se supone, por ejemplo, 
el caso de un vehículo que sortea un obstáculo que ha aparecido de forma abrupta sobre la vía como un balón de unos niños que están jugando en la acera. Esta posibilidad existe, y aunque su casuística sea muy baja hay que tenerla en cuenta.

El otro caso crítico puede darse cuando motocicletas adelantan a otro tipo de vehículos y se mantienen muy cerca de ellos. Puede existir el problema de que el margen entre ambos vehículos sea demasiado estrecho y a la hora de detectar ambos vehículos no se sea capaz de separarlos, agrupándose así como uno solo. En este caso, la situación que se plantea es justo la contraria a la anterior, hay que asegurar un margen suficientemente estrecho como para no confundir vehículos. Hay que llegar a una situación de compromiso entre ambos casos que de lugar a una distancia adecuada para ambos. Este caso es similar al que se produce cuando un vehículo grande (autobús) obstruye total o parcialmente la visión de otro más pequeño.

Las primeras simulaciones llevadas a cabo en el laboratorio para determinar el margen adecuado no fructificaron debido a los problemas de escala que surgieron cuando se quiso reproducir los vehículos, la vía y el sensor láser escáner a escala. Consiguientemente, se esperó hasta obtener los primeros datos de test reales para poder delimitar el margen de modo correcto. Con estos datos se comprobó que:

- la distancia menor que se detectó entre dos vehículos circulando en condiciones normales fue de 20 posiciones de escaneo o índices,

- la mayor diferencia que existía entre los índices de dos tramas consecutivas del mismo vehículo era de 8 posiciones de escaneo o índices.

Con estos resultados se estimó oportuno definir el margen en un rango de \pm 15 valores de índices, es decir, medidas con índices 15 posiciones mayores o menores que la anterior eran consideradas pertenecientes al mismo vehículo. Los resultados de aplicar esta hipótesis no fueron todo lo satisfactorios que se esperaba al obtenerse un $5 \%$ de errores en la distribución de las tramas. Es decir, se agruparon incorrectamente determinados vehículos debido al margen considerado. Un estudio individual de estos casos permitió descubrir que estos errores se producían en los casos en los que un mismo vehículo había dado lugar a diferentes detecciones de 
datos dentro de la trama, es decir, se habían recibido dos grupos de valores como si fueran dos vehículos diferentes cuando en realidad no lo eran.

Estos resultados llevaron a ir depurando el margen establecido hasta obtener valores óptimos. Tras diferentes pruebas esta situación se produjo al definir el margen en \pm 10 valores de índices, donde se consiguió distribuir todas las tramas de modo correcto. Después de realizar diversos test en casos reales de detecciones sobre la vía, ha quedado demostrada la bondad del margen definido. Se puede concluir que el margen es suficiente como para distribuir correctamente todas las tramas recibidas en vehículos, habiendo tenido en cuenta los dos casos más críticos que podían limitar el margen tanto por exceso como por defecto.

El procesado realizado en cada una de las tramas supone la extracción de la información que contienen: valores de control, índice, anchura y posición inicial. A grandes rasgos se puede decir que se delimita el vehículo detectado por ambos laterales, no se puede hablar de izquierda y derecha ya que ello depende del sentido de circulación de los vehículos y en el caso estudiado se trata de una vía con dos carriles circulando en ambos sentidos. Una vez delimitado el ancho del vehículo, las sucesivas tramas medidas se comparan con los laterales para comprobar si se trata del mismo vehículo o de un vehículo diferente.

En el caso de la distribución de las tramas se trabaja comparando, en primer lugar los índices, es decir, el primer lateral del vehículo. En caso de que esta primera discriminación no resulte satisfactoria se recurre a la anchura, para obtener el índice del lateral contrario del vehículo, a este índice se le denomina índice máximo.

La distribución de las tramas se realiza en base al siguiente algoritmo, cuyo diagrama del flujo está representado en la figura 7.16:

- Tras la recepción de la primera trama, trama[i], su índice se guarda en una lista, llamada LISTA, para realizar su comparación con las sucesivas, este valor se llamará indice_inicial. Así mismo se guarda en memoria el índice_máximo, que es el resultado de sumar la primera posición de la trama $\left(\mathrm{X}_{i n i}\right)$ mas la anchura. 


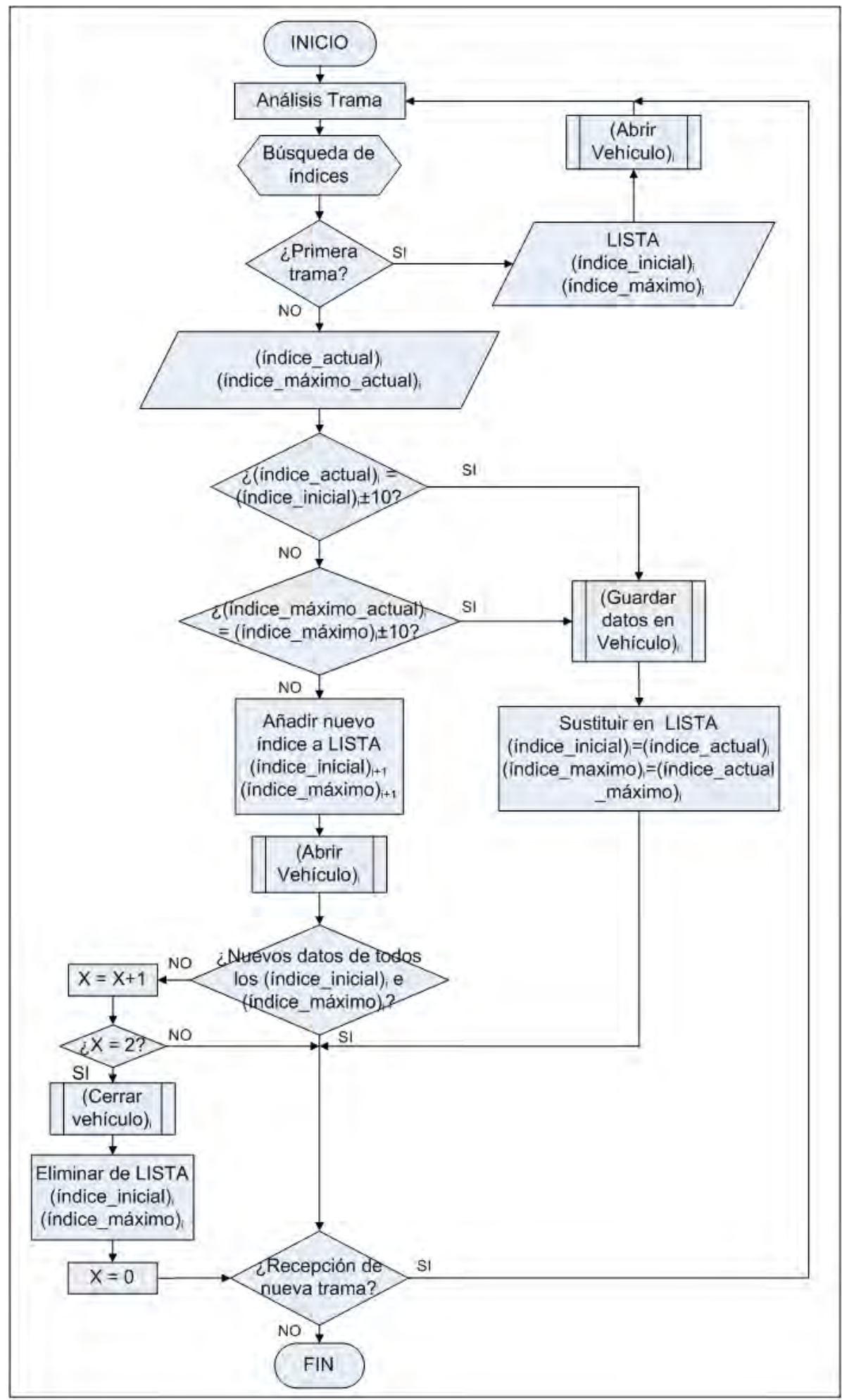

Figura 7.16 - Diagrama de Flujo del algoritmo de distribución de las tramas

- Si es la primera iteración, este índice da lugar a la acción abrir_vehículo. Esta acción crea una matriz en la que van almacenando todas y cada una de las detecciones del mismo vehículo, es decir, los datos. 
- Si en la misma trama[i] se recibe mas de un índice se almacenan cada uno de ellos, así como su anchura, como (índice_inicial) $)_{i}$ e (índice_máximo) ${ }_{i}$ en LISTA, aumentando en cada uno de ellos el valor del subíndice i. Cada uno de estos valores da lugar a la acción de abrir vehículo. Se acaba de analizar la trama[i].

- En la siguiente trama, trama[i+1], se busca el primer índice y se memoriza bajo el nombre índice_actual, así como su anchura, llamado del mismo modo índice_máximo_actual.

- Se procede a comparar el valor del índice_actual con el valor del índice_inicial.

- Si el valor del índice_actual coincide con el valor del índice_inicial los nuevos datos se añaden a los anteriores con coincidencia de índice, ya que corresponden al mismo vehículo. Esta acción se llama guardar_datos_vehículo. En este momento se guarda en memoria el valor de índice_actual en índice_inicial y se guarda en LISTA.

- Si el valor del índice_actual se encuentra dentro del margen definido como $[-10,+10]$ del valor de índice_inicial, se considera que también pertenece al mismo vehículo con lo cual se ejecuta la acción guardar_datos_vehículo. En este momento se guarda en memoria el valor de índice_actual en índice_inicial y se guarda en LISTA.

- Si el valor del índice_actual no coincide con ninguno de los anteriores, ni se encuentra dentro del margen definido, se inicia de nuevo este bucle realizando la comparación entre índice_actual e (índice inicial) ${ }_{i}$ hasta terminar la comparación con todos ellos.

- Si la comparación de valores de índices ha resultado exitosa y se ha encontrado el vehículo al que pertenece el índice actual de la trama[i+1], se inicia de nuevo el algoritmo con el siguiente índice detectado de la misma trama[i+1].

- Si no se ha obtenido resultado mediante la comparación de valores del índice se procede a comparar los valores de índice_máximo:

- Si el valor de la índice_máximo_actual coincide con el valor de índice_máximo los nuevos datos se añaden a los anteriores con coincidencia de índice mediante la acción guardar_datos_vehículo. En este momento se guarda en memoria el valor de índice_máximo_actual en índice_máximo y se guarda en LISTA. 
- Si el valor del índice_máximo_actual se encuentra dentro del margen definido como $[-10,+10]$ del valor de índice_máximo, se considera que también pertenece al mismo vehículo con lo cual los nuevos datos se añaden a los anteriores mediante la acción guardar_datos_vehículo. En este momento se guarda en memoria el valor de índice_máximo_actual en índice_máximo y se guarda en LISTA.

- Si el valor de índice_máximo_actual no coincide con ninguno de los anteriores, ni se encuentra dentro del margen definido, se repite este bucle realizando la comparación con el siguiente valor de (índice_máximo) ${ }_{i}$ hasta terminar la comparación con todos ellos.

- Si la comparación de valores de índices máximos no ha resultado exitosa estamos ante un caso de un nuevo vehículo detectado. En esta situación se añaden los valores de los índices en LISTA para añadirlos a las comparaciones que se realizarán y se realiza la acción de abrir vehículo.

- Se inicia el algoritmo con el siguiente índice detectado de la misma trama[i+1].

- Si tras dos tramas sucesivas no se reciben datos de un índice anterior, se considera que no existen más datos relativos al vehículo y se procede a guardar la información relativa al mismo. Esta acción se denomina cerrar_vehículo. En este caso se elimina el valor del índice de la LISTA.

- Se repite el proceso tantas veces como tramas se reciban.

Resumiendo, se comparan los índices de cada uno de los escaneos con los índices de la trama precedente para ver si corresponde a alguno de los vehículos anteriores. Se compara el vehículo tanto por un lateral como por el otro para evitar que pérdidas de valores den lugar a errores. A lo largo del proceso de comparación se almacena la información en matrices diferentes, cada una de ellas correspondiente a cada uno de los vehículos detectados. Cuando la comparación entre índices no da lugar a ningún resultado, y este proceso se repite en dos tramas sucesivas, se considera que ya se ha detectado completamente el vehículo y se procede a su almacenamiento como tal. 
Veamos un ejemplo de ejecución del algoritmo en base a la figura 7.14 que representa datos reales. En este caso, desde el inicio de toma de medidas (escaneo 1) se detecta un único vehículo. Pero, a partir de un determinado número de escaneo (en concreto a partir del número 25) y en lo sucesivo, se empiezan a detectar de forma simultánea dos vehículos en cada uno de los escaneos.
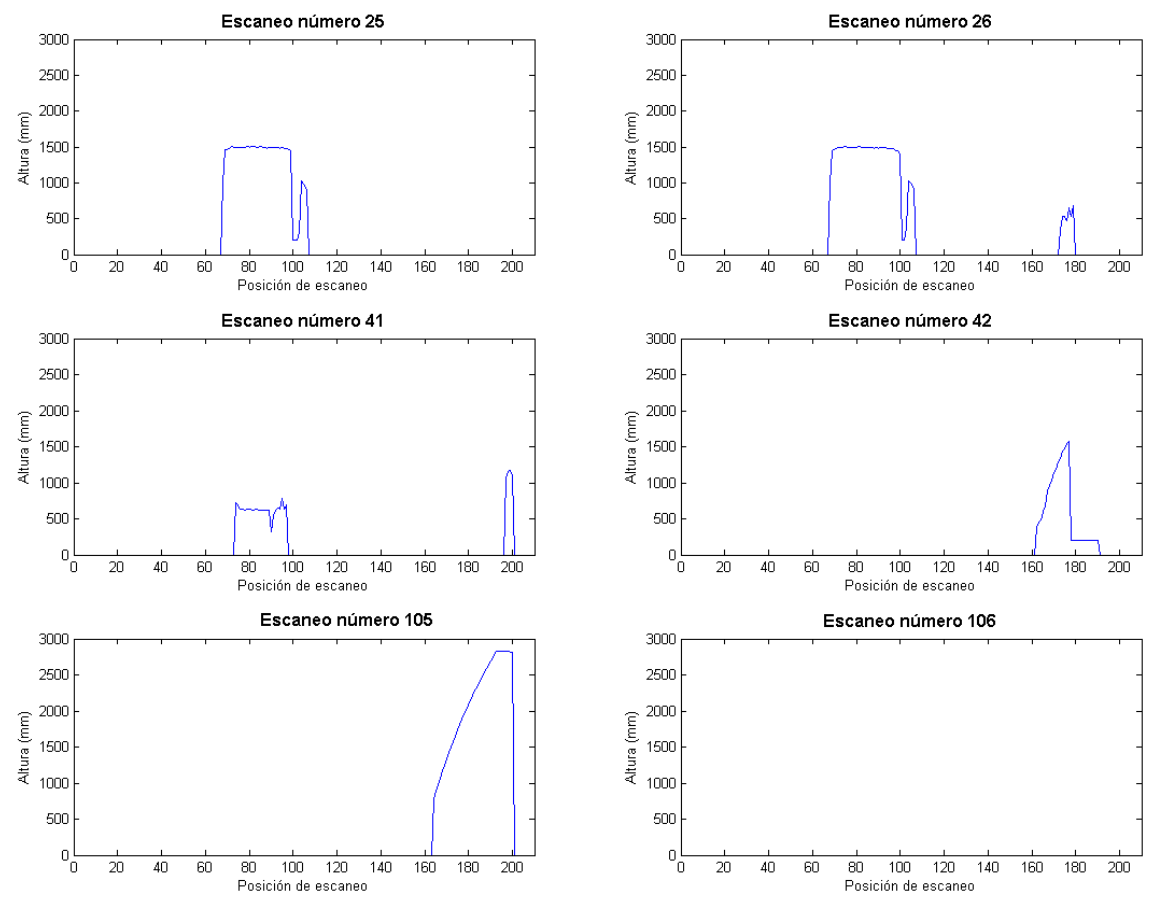

Figura 7.17 - Diferentes escaneos realizados sobre la vía

La figura 7.17 representa los escaneos número 25, 26, 41, 42, 105 y 106. Desde el escaneo 1 hasta el 25 se detecta un único vehículo; en el escaneo 26 es la primera vez que se detectan los dos vehículos a la vez; hasta el escaneo 41 se siguen detectando los dos vehículos a la vez; desde el escaneo 42 hasta el 105 se detecta solo un vehículo; y finalmente en el escaneo 106 ya no se detecta ningún vehículo.

A modo de ejemplo se realiza el procesado de las tramas tal y como se ejecutaría en el programa desarrollado para ilustrar su funcionamiento. Los pasos que se realizarían serían los siguientes:

- La primera trama detectada, trama 1, presenta un único índice. Índice_inicial=75.

- Al ser el primer barrido se ejecuta la acción de abrir vehículo. 
- Se guarda en LISTA el valor índice_inicial=75 e índice_máximo=100.

- Se continúa con la trama 2. En este caso índice_actual=71 e índice_máximo_actual=102.

- El valor índice_actual está en el margen [65,85], así que:

- Los nuevos datos se añaden al del vehículo abierto anteriormente,

- Se cambian los valores de LISTA por: índice_inicial=71 e índice_máximo=102.

- Este proceso se repetirá hasta la trama 25 con el mismo resultado. Así, los índices detectados en cada trama corresponden al mismo vehículo. En ninguno de los casos ha sido necesario realizar la comparación por anchura ya que los valores de los índices han dado resultados positivos.

- La trama 25 presenta un primer índice de valor 68 que coincide con el del vehículo que ya se ha detectado. Así que esos datos se añaden al del vehículo abierto anteriormente.

- Se cambian los valores de LISTA por: Índice_inicial=68 e índice_máximo=107.

- El segundo índice detectado es (índice_actual $)_{2}=173$ e (índice_máximo_actual $)_{2}=179$.

- En este caso ni el índice actual ni el índice máximo actual coinciden ni son comparables con índice inicial e índice máximo. Por ello:

○ Se añaden a la lista los valores: $(\text { índice_inicial })_{2}=173$ y (indice_maximo $)_{2}=179$.

- Se ejecuta la acción de abrir vehículo .

- La trama 26 presenta de nuevo dos índices 68 y 171. Al comparar estos valores con los anteriores se comprueba que mientras el primer índice pertenece al primer vehículo detectado, el segundo índice pertenece al segundo.

- La trama 27 presenta de nuevo dos índices: 68 y 169. Sucede el mismo caso que con la trama 26.

- El proceso se repite hasta que en los escaneos número 41 y 42 no se encuentran ya tramas de índice_actual con lo que se ejecuta la acción cerrar vehículo.

- En los escaneos 105 y 106 sucederá lo mismo con el segundo vehículo detectado, ya que no se detectarán más tramas correspondientes al índice (índice_actual) ${ }_{2}$ con lo cual se procede a cerrar el vehículo . $_{\text {. }}$ 


\subsubsection{Reconstrucción del vehículo según la posición de escaneo}

El algoritmo anterior ha permitido separar la información correspondiente a cada uno de los vehículos detectados en diferentes matrices. Pero las tramas se almacenan sin tener en cuenta la posición del vehículo en cada una de ellas, es decir, su índice. Se pretende en este paso almacenar la información convenientemente. Para ello, partiendo de una matriz de ceros se situarán los datos en el lugar correcto en función de su índice.

Tomando como punto de partida uno de los vehículos separados anteriormente, el proceso a realizar es el siguiente:

- De todos los índices de un mismo vehículo se busca el valor menor.

- Este valor se considera como la posición cero para situar un vehículo.

- Una vez conocido el índice que se considera posición 0, se analizan cada uno de ellos desde el primero hasta al último y se sitúan en su lugar relativo correspondiente dentro de la matriz.

Repitiendo este procedimiento en cada uno de los vehículos detectados, separados y almacenados en el apartado anterior, se obtienen dos matrices que contienen la información 3D de los dos vehículos detectados y que, si se representan, dan lugar a la figura 7.18. Hay que tener en cuenta que estos datos son directamente los recibidos por el sensor sin que se haya realizado ningún tratamiento en los mismos. Es por ello que la forma del segundo vehículo detectado, el camión, refleja el escaneo detectado en el lateral del mismo. Será necesario ajustar cada una de las posiciones de escaneo a las posiciones en el eje x para poder obtener una vista real del camión.

Tras el procedimiento de reconstrucción de vehículos se ha logrado:

- detectar vehículos que circulan sobre la vía,

- distribuir cada una de las tramas recibidas en el vehículo correspondiente,

- reconstruir los vehículos detectados según su posición de escaneo,

- y finalmente, almacenar cada uno de ellos en diferentes matrices.

Después de este procesado y llegados a este punto, es posible iniciar el tratamiento de las diferentes matrices que contienen la información de los vehículos detectados. 


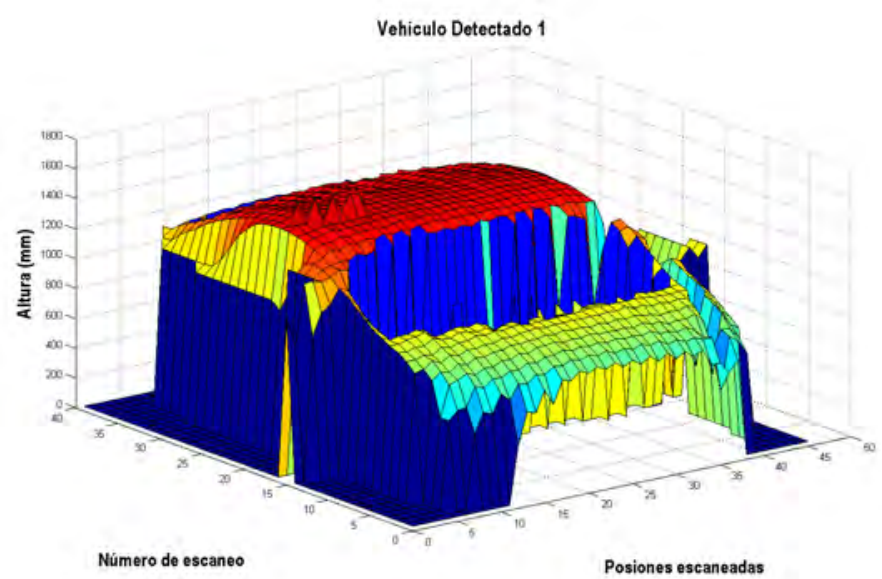

(a) Vehículo detectado 1 - Turismo

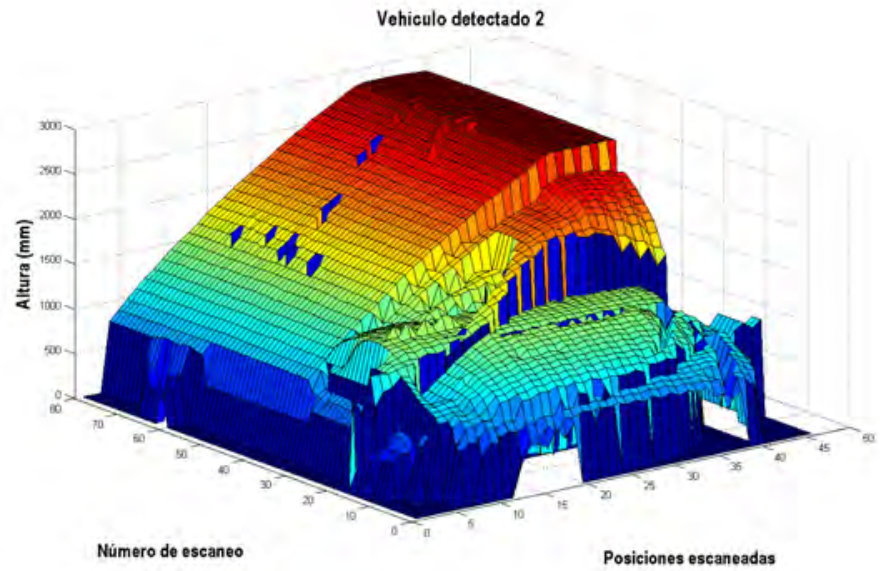

(b) Vehículo detectado 2 - Camión

Figura 7.18 - Vehículos detectados

\subsubsection{Tratamiento de los datos}

Una vez se han aislado los datos de cada uno de los vehículos detectados en diferentes matrices se puede iniciar su procesado. El procesado se realiza de forma individual para cada uno de los vehículos, y el objetivo del mismo es corregir los efectos no deseados introducidos en el momento del escaneo, debido sobre todo a la naturaleza y al funcionamiento del sensor láser escáner.

Los pasos a seguir para un correcto tratamiento de las tramas es:

- Eliminación de las vistas laterales.

- Tratamiento de reflexiones perdidas.

- Interpolado y diezmado. 
A lo largo de los siguiente subapartados se explican en detalle todas y cada una de las anomalías detectadas y el procesado llevado a cabo para su tratamiento y eliminación.

\subsubsection{Eliminación de las Vistas Laterales}

Las vistas laterales son solapamientos producidos cuando un vehículo de mayor tamaño oculta a otro de menor tamaño que circula más alejado del centro de la vía. En este caso la información de ambos vehículos se superpone y se detecta como uno único. La eliminación de vistas laterales permite solucionar los problemas producidos por solapamiento de vehículos.

La peculiaridad de las vistas laterales consiste en que la situación real de la vía no corresponde exactamente con lo capturado por el sensor en cada uno de sus escaneos, aún siendo cierta la información capturada por el sensor. Es decir, aunque los vehículos circulen con la correcta separación entre ellos, su posición respecto al sensor puede derivar en que en un mismo escaneo sobre la vía se solapen las medidas de ambos. Al estar todos los datos capturados de forma consecutiva y sin interrupción entre ellos, se detecta como un único vehículo. La figura 7.19 muestra dos imágenes tomadas en la vía, en la zona de medidas, donde se produce un caso de vistas laterales entre un autobús que bloquea la visión de un turismo en primer lugar, y una furgoneta después. Se aprecia en las imágenes que los vehículos circulan cumpliendo la separación mínima entre ellos. Más adelante, en la figura 7.21 se muestra el resultado de los escaneos sobre la vía.

Este evento sucede en vías de más de dos carriles y cuando circulan dos vehículos por carriles contiguos. Además, el vehículo de mayor altura debe circular por el carril más cercano a la perpendicular del sensor, mientras que el de menor tamaño circula por los carriles más alejados. En esta situación, el vehículo más cercano al centro de la vía, el de mayor tamaño, es detectado correctamente, pero no así el que circula por el carril contiguo y más alejado. En el caso de este último vehículo, únicamente se detecta una parte limitada del lateral y además la información del mismo se solapa con la del vehículo de mayor altura.

El escaneo se realiza de derecha a izquierda de la figura 7.20, así que la primera detección es la medida $A$ que corresponde al autobús mediante las detección de distancias $x_{a}$ y altura $h_{a}$. Las 


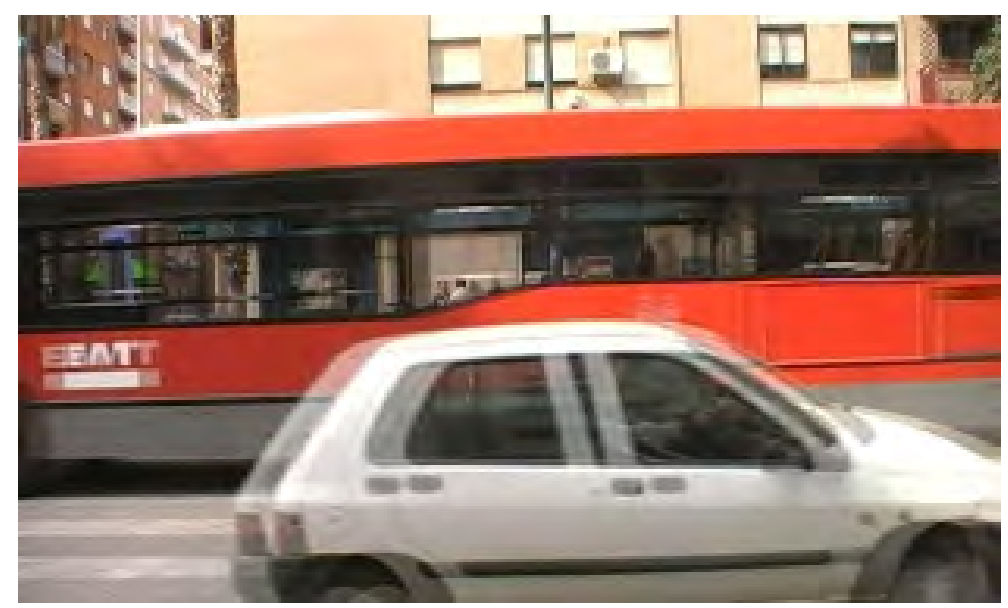

(a) Caso vista lateral: turismo-autobús

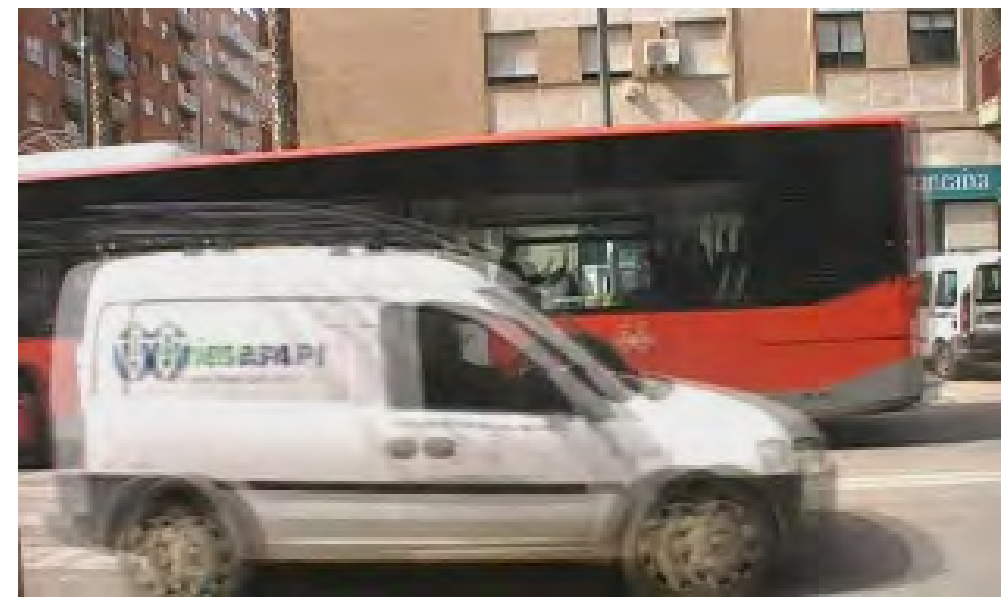

(b) Caso vista lateral: furgoneta-autobús

Figura 7.19 - Casos reales de vistas laterales

sucesivas medidas que se toman del vehículo corresponden a realizar un corte transversal del autobús, hasta detectar el borde izquierdo superior del autobús momento en el que la siguiente medida es la medida $B$ correspondiente al turismo. Si no estuviera el turismo, ya se habría acabado de detectar el autobús. Como esta detección se produce en la mitad del techo del turismo, la parte del turismo anterior a ese punto no se ha detectado. El escaneo continua tomando las medidas de modo consecutivo hasta llegar a la última, medida $B^{\prime}$.

Estas situaciones no se pueden resolver mediante el algoritmo de distribución de tramas ya que los datos que se reciben son continuos, por lo cual no se pueden separar al no existir datos nulos entre ellos. Es decir, el primer índice detectado en este caso correspondería a índice ${ }_{a}$ y este contendría todos los datos recibidos en el escaneo desde ese punto hasta la última detección 


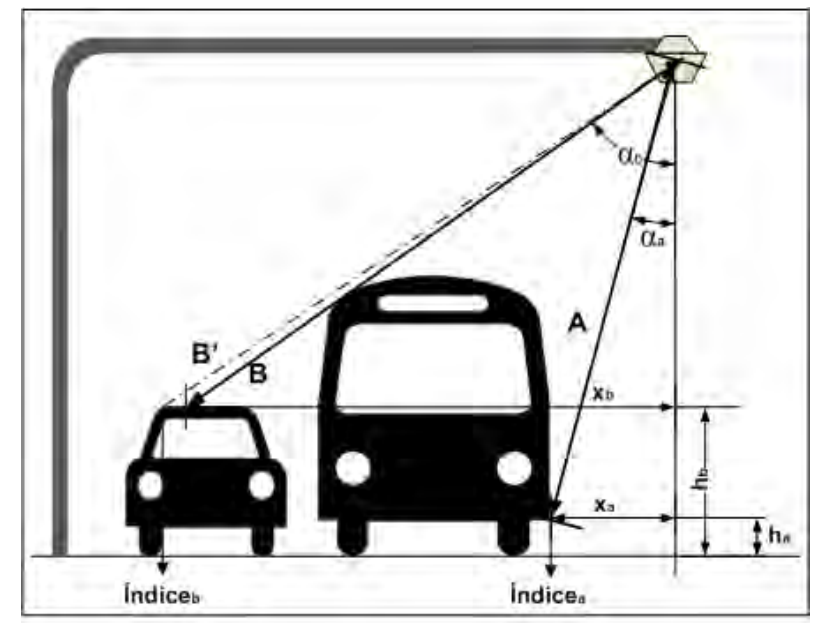

Figura 7.20 - Vistas Laterales

correspondiente a la medida $B^{\prime}$ con índice ${ }_{b}$. El algoritmo de distribución de las tramas trata a toda ella como un único vehículo y almacena los datos en la misma matriz como se puede apreciar en la figura 7.21.

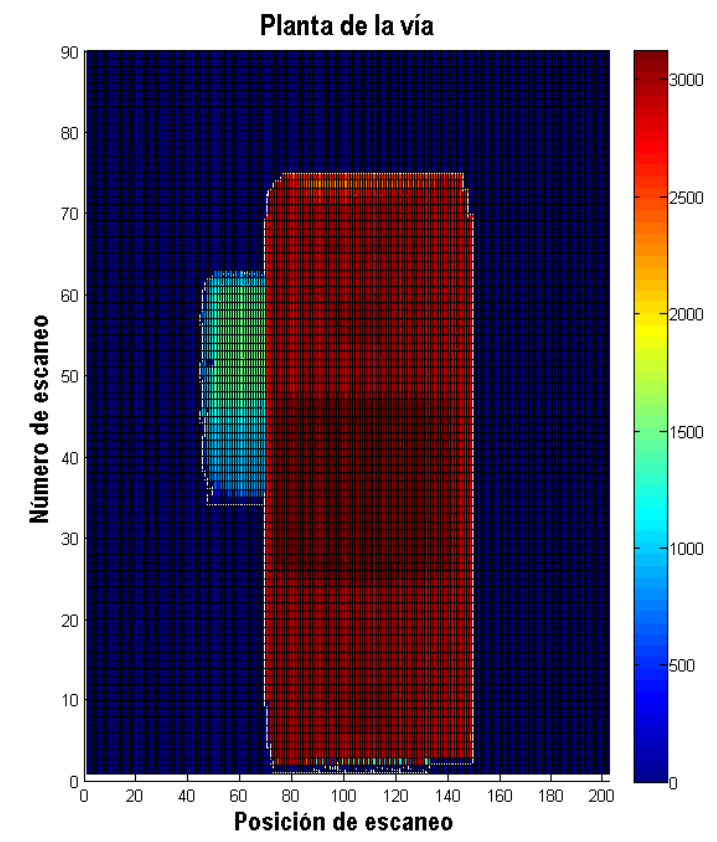

Figura 7.21 - Matriz con información de autobús y turismo

En cuanto al funcionamiento del algoritmo de eliminación de vistas laterales, este se inicia con la detección de un vehículo cuya anchura sea mayor de 2,5 m. Se ha elegido este valor ya que corresponde a la anchura del vehículo más grande considerado que es un camión con tráiler. 
Así, como se aprecia claramente en la figura 7.21, al ser las posiciones de escaneo contiguas es necesario otro parámetro para realizar una correcta discriminación entre ambos vehículos. En este caso se analizan las lecturas de cada escaneo para estudiar la resolución horizontal entre dos lecturas consecutivas.

La resolución horizontal es la distancia existente en el eje x entre dos medidas consecutivas dentro de un mismo escaneo. Dicha resolución no es constante, sino directamente proporcional al valor del ángulo de escaneo. A medida que el valor del ángulo crece lo mismo sucede con la resolución horizontal. El valor de la resolución horizontal se encuentra en el rango [5,24 cm 12,54 cm], (ver página 124).

Cuando el algoritmo de eliminación de vistas laterales detecta vehículos con anchura mayor a 2,5 m busca incrementos en el eje x mayores a $15 \mathrm{~cm}$. En este punto del procesado, la información que se tiene es la relativa a la altura de los vehículos $\left(h_{a} \mathrm{y} h_{b}\right)$ y el ángulo de escaneo $\left(\alpha_{a} \mathrm{y} \alpha_{b}\right)$, (ver figura 7.20). Teniendo en cuenta estos datos y por trigonometría se obtienen los incrementos en el eje x mediante la ecuación 7.5. En esta ecuación el valor 6 hace referencia a la altura a la que está situado el láser escáner.

$$
\Delta_{x}=\left|\left[\left(6-h_{x}\right) * \tan \left(\alpha_{x}\right)-\left(6-h_{x-1}\right) * \tan \left(\alpha_{x-1}\right)\right]\right|
$$

En el caso de encontrar un valor de $\Delta_{x}$ mayor de $15 \mathrm{~cm}$ en un escaneo se revisan las mismas posiciones de escaneos sucesivos para ver si en todos ellos se produce la misma situación. De ser así, se confirma la hipótesis inicial relativa al solapamiento de vehículos y la existencia de vistas laterales. Para eliminar dicho efecto se recurre a usar la posición detectada como límite entre los dos vehículos, y a partir de ella se separa la información convenientemente en dos matrices diferentes.

Tras esta operación las matrices que contienen a los vehículos por separado corresponden a las representadas en la figura 7.22. Como se aprecia en la figura del turismo, se ha perdido parte de la información del mismo al quedar ocultada por el autobús. Este hecho no afecta a su detección como acabamos de comprobar, ni a su posterior clasificación ya que para la misma se recurre al perfil del vehículo, y en los casos de vistas laterales el perfil no se ve modificado. 


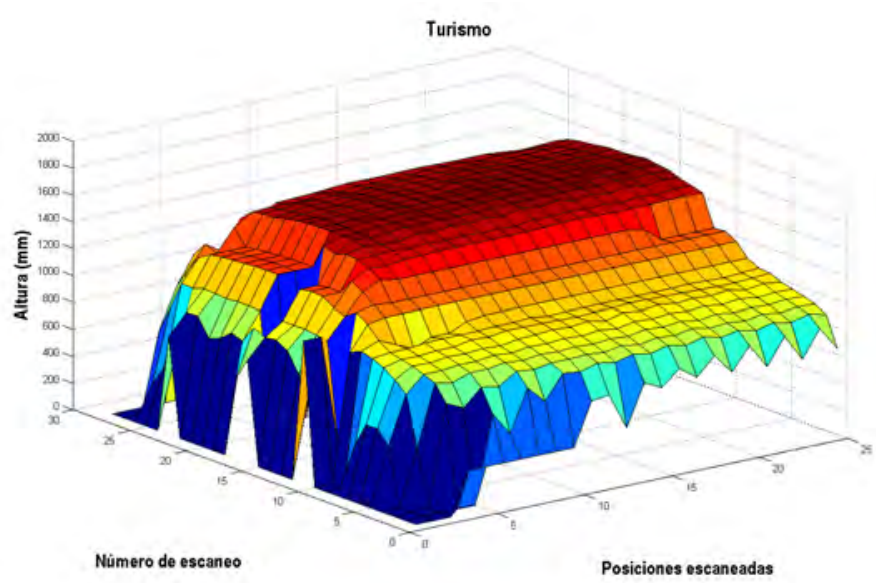

(a) Turismo

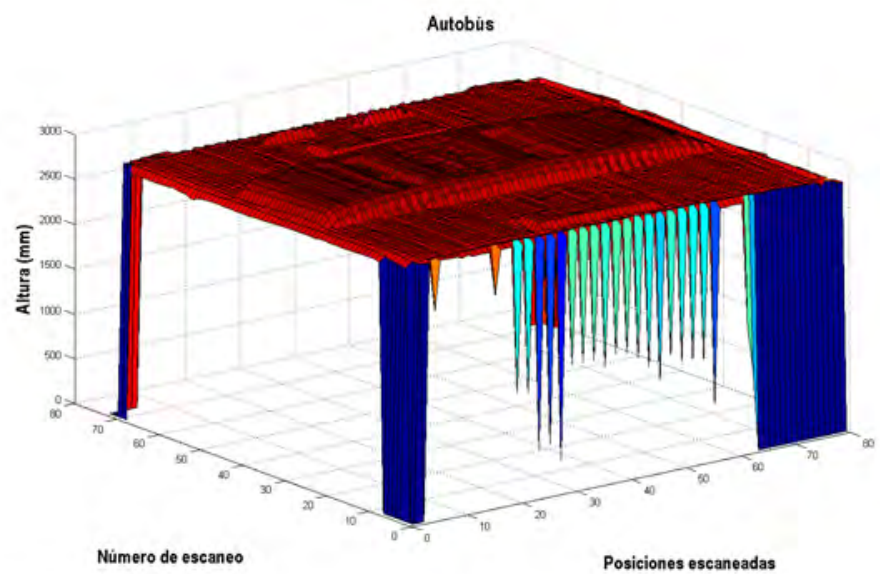

(b) Autobús

Figura 7.22 - Matrices de los vehículos tras el tratamiento de vistas laterales

\subsubsection{Tratamiento de Reflexiones Perdidas}

El principio de operación del sensor láser escáner se basa en la medición de los ToF, o lo que es lo mismo el tiempo que se tarda en recibir la reflexión en la superficie de medición de un pulso láser desde que este es emitido por el sensor. Si estas reflexiones son demasiado débiles y no se reciben dentro del tiempo de detección máxima que define el sensor se denominan reflexiones perdidas. Este efecto es característico de las partes más reflectivas del vehículo, como pueden ser las lunas delantera y trasera, ya que la luz del pulso láser emitido sufre una reflexión directa en un ángulo que no coincide con la posición de detector, no produciéndose la reflexión difusa en todas direcciones que es lo que se aprovecha para la detección. 
La figura 7.23 muestra la imagen de un vehículo que presenta casos de reflexiones perdidas. Como se puede apreciar en la figura, tanto el cristal delantero como los laterales presentan valores de altura de entre 0 y $200 \mathrm{~mm}$, correspondiente al color azul. En el caso del cristal delantero, se puede comprobar como lo esperado es recibir valores crecientes entre 1.000 y $1.400 \mathrm{~mm}$, mientras lo que se recibe son valores muy inferiores debido a las reflexiones perdidas.

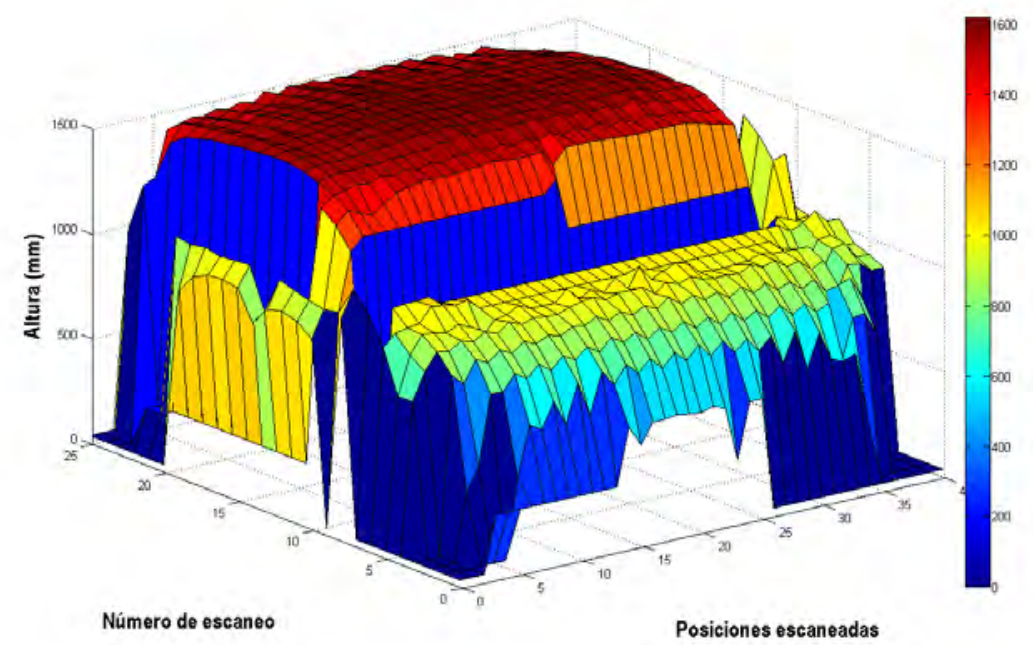

Figura 7.23 - Turismo que presenta casos de reflexiones perdidas

Para poder corregir estos errores debidos a la naturaleza intrínseca del funcionamiento del sensor es necesario realizar una revisión de los valores detectados. Los casos de reflexiones perdidas son fácilmente detectables en la matriz que contiene los datos de los vehículos, ya que presentan valores anormales como pueden ser valores negativos o demasiado elevados.

El procesado a realizar consiste en buscar valores negativos o mayores a la altura máxima definida en 4 m y cambiar su valor por -1, valor definido por convenio. De ahora en adelante estos valores negativos serán considerados datos no válidos o desconocidos. El siguiente paso consiste en modificar estos valores y sustituirlos por los que presentan los puntos situados en su entorno mediante el siguiente procedimiento:

- Se inicia el proceso revisando cada una de las filas de la matriz, o cada uno de los escaneos, en busca de datos cuyo valor sea -1 , es decir, posiciones en las que existan casos de reflexiones perdidas. 
- Si el/los valores desconocidos se encuentran entre dos valores conocidos, se reemplazan con el valor mayor de entre los dos conocidos.

- Si el/los valores desconocidos se encuentran al inicio o al final de la fila, se reemplaza su valor por el del primer dato válido que se encuentre.

- En el caso de que exista solamente un dato válido en toda la fila se copia ese dato al resto de posiciones.

- Se ignora la fila que solo contiene valores de reflexiones perdidas, -1 .

- Se repite el proceso mientras existan filas.

- Tras el procesado de las filas se repite el proceso para cada una de las columnas.

Aplicando el procedimiento anterior se consigue eliminar las reflexiones perdidas que aparecían en la figura 7.23 y obtener como resultado la figura 7.24.

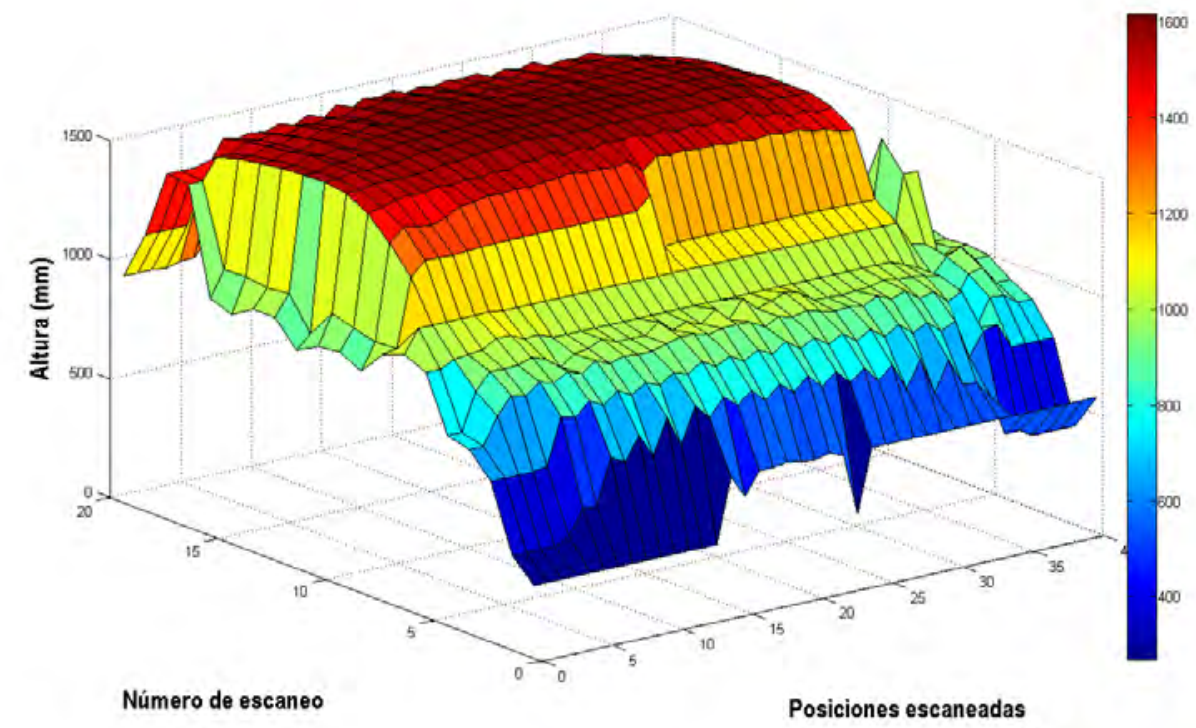

Figura 7.24 - Turismo tras la eliminación de reflexiones perdidas

La figura 7.25 muestra ejemplos de vehículos antes y después de ser tratados de reflexiones perdidas. La fila superior muestra los vehículos antes del procesado, donde se observa que la figura 1 es la que presenta un mayor número de datos no válidos debidos a reflexiones perdidas. La fila inferior muestra los vehículos tras el tratamiento de las reflexiones perdidas, comprobándose como la mayor parte de las mismas han sido eliminadas. 


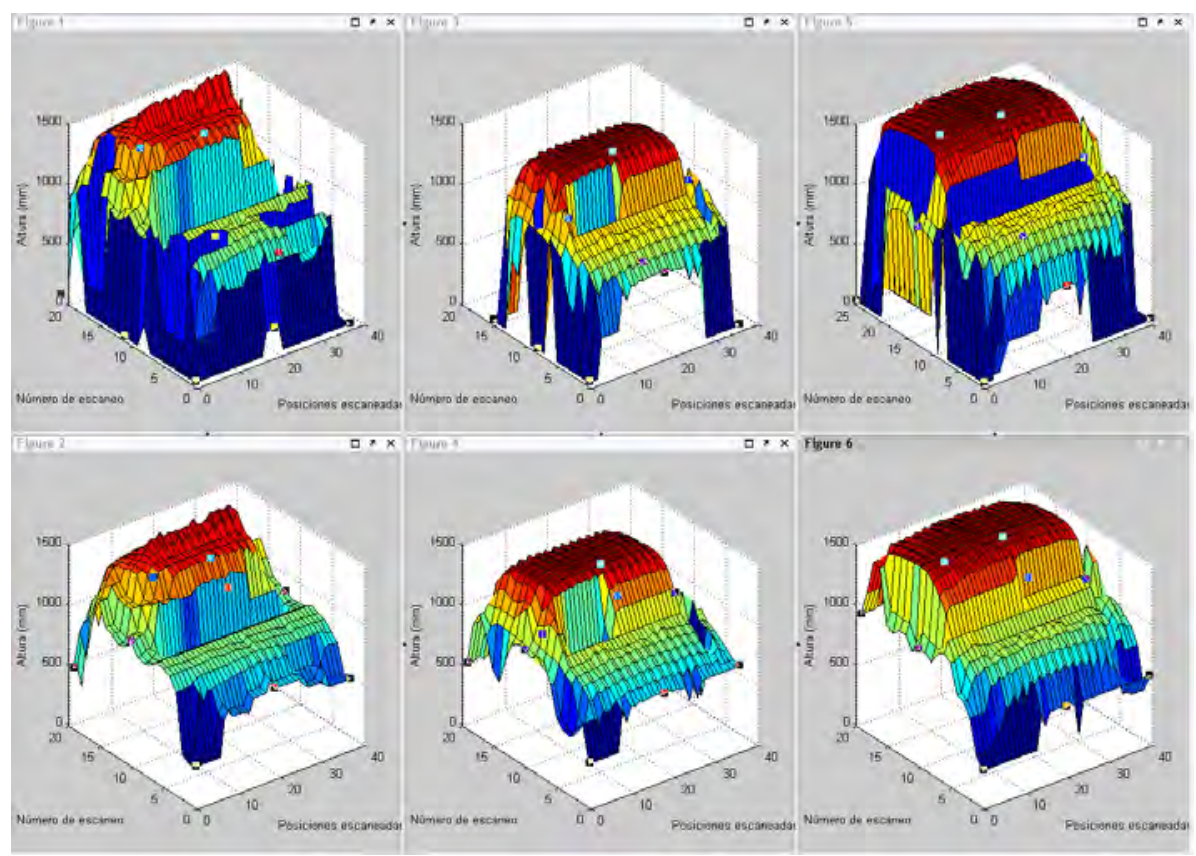

Figura 7.25 - Vehículos con reflexiones perdidas: antes y después

También existen casos extremos en los que las reflexiones perdidas hacen que sea prácticamente imposible reconocer el vehículo detectado. En estos casos, solo un buen tratamiento de la señal como el descrito permite reconstruir el vehículo de modo satisfactorio. Las imágenes de la figura 7.26 muestran algunos de estos casos, verificando la validez del algoritmo definido.

\subsubsection{Técnicas de Interpolación y Diezmado}

Evidentemente, no todos los vehículos circulan a la misma velocidad sobre la vía. Esta situación deriva en que cada una de las matrices de los vehículos tenga un número diferente de escaneos, a mayor velocidad de circulación menos escaneos o cortes transversales se pueden realizar del vehículo y viceversa. Para que la velocidad de circulación no afecte al perfil de los vehículos y con ello a los parámetros calculados para su clasificación, se utilizan técnicas de interpolación y diezmado. Al no poder ajustar la frecuencia de muestreo del sensor para cada uno de los vehículos, estas técnicas persiguen, sin modificar la frecuencia del sensor modificar la frecuencia a la que se muestrea el vehículo a posteriori.

Modelos comerciales actuales de sensores láser escáner han modificado su funcionamiento para permitir cálculos de velocidades en detrimento de la frecuencia de trabajo. Uno de estos 

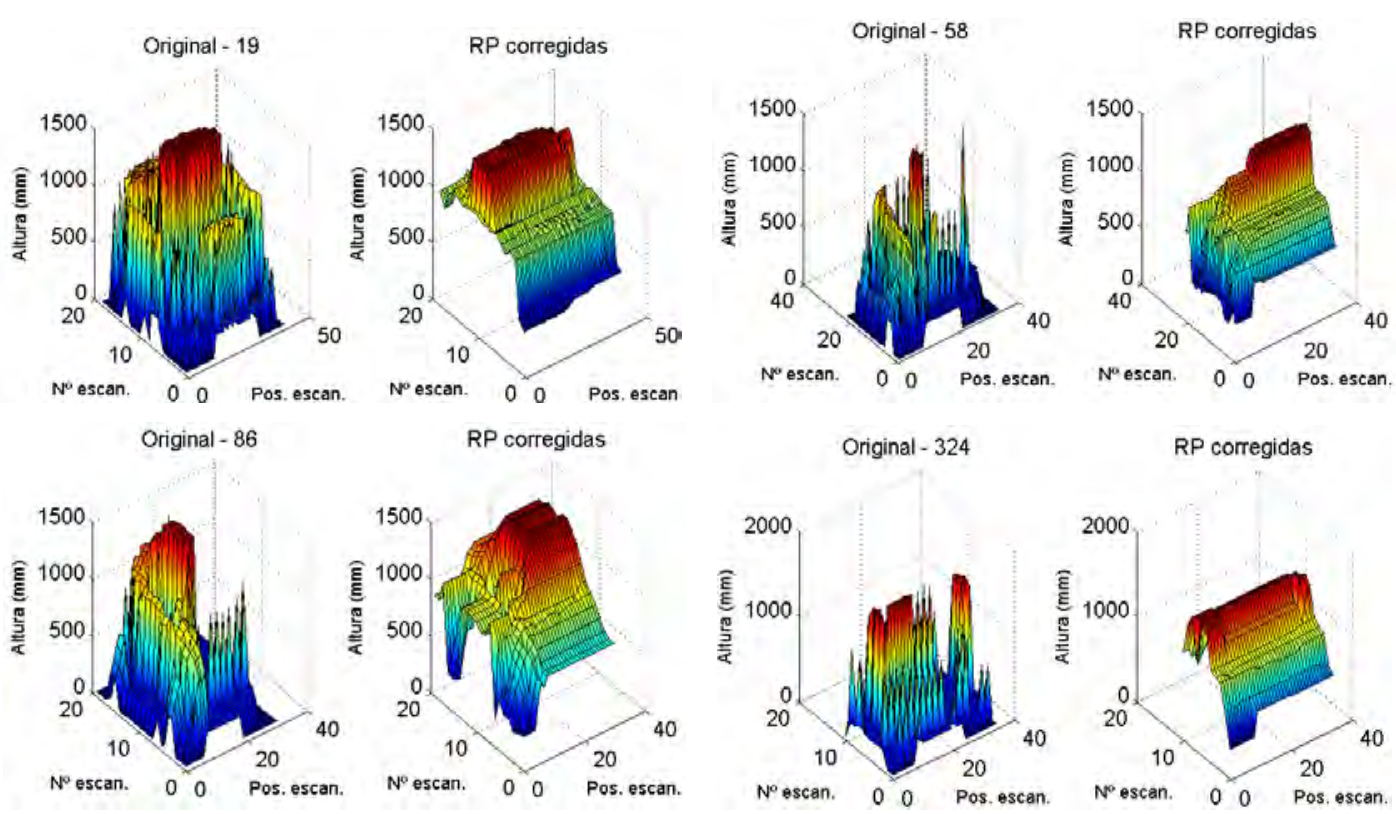

Figura 7.26 - Casos extremos de reflexiones perdidas: antes y después

equipos, en concreto el modelo Ibeo Lux, de la compañía Ibeo Automobile Sensor GmbH [Ibe09], trabaja con cuatro haces que realizan barridos sobre la superficie pero a una frecuencia de $12 \mathrm{~Hz}$, lo que para el sistema propuesto aquí resulta totalmente insuficiente. Este equipo es utilizado en aplicaciones ITS de Sistemas Avanzados de Asistencia al conductor, ADAS (acrónimo del inglés Advanced Driver Assistance Systems). Su instalación en motocicletas, por ejemplo, permite conocer la situación de la vía ante el vehículo y detectar situaciones de peligro y escenarios de accidentes [KR09].

Mediante interpolación y diezmado se consigue homogeneizar las matrices de todos los vehículos. . En nuestro caso se ha seleccionado para trabajar un número de 20 filas. Es decir, todos los vehículos presentan un número de 20 escaneos. Este valor se ha tomado como válido tras demostrar, tesis anteriores, que representa un número de escaneos suficiente como para permitir clasificar los vehículos correctamente [Góm05].

Las figuras 7.27 presentan casos de interpolación y diezmado, donde se muestra el vehículo tras el tratamiento de reflexiones perdidas y después tras interpolación y diezmado. En el eje $y$, que representa el número de escaneos, se puede apreciar como se ajusta a un valor de 20 en cada una de las figuras. 

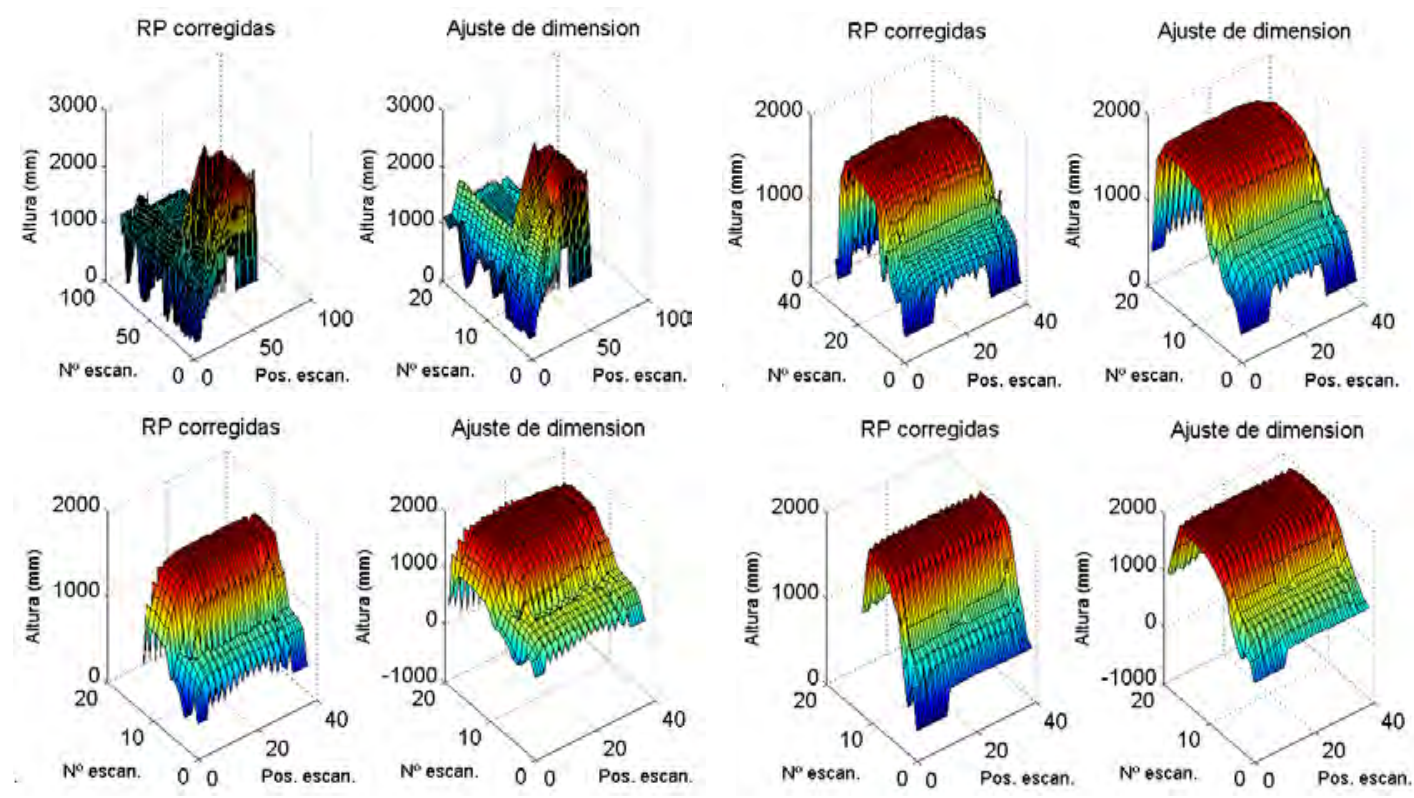

Figura 7.27 - Interpolación y Diezmado: antes y después

\subsection{Interfaz Gráfica de Usuario}

El interfaz gráfico de usuario, o GUI (acrónimo del inglés Graphical User Interface), permite visualizar de forma gráfica y numérica la información del estado del tráfico en tiempo real mediante una serie de parámetros que son enviados de forma automática tras el procesado de la información. El programa diseñado usando Microsoft Visual Studio, llamado GUI, además de informar acerca de la detección y clasificación de vehículos, envía información relativa a diferentes parámetros de tráfico interesantes para el CGT como pueden ser el volumen o la densidad.

Los requerimientos de diseño que se establecieron inicialmente fueron dos: minimizar el tiempo de adaptación al sistema por parte del personal de los CGT y proporcionar la información del estado del tráfico en tiempo real.

Minimizar el tiempo necesario para la adaptación del personal del CGT ante nuevas aplicaciones de visualización y control es vital si se quiere que la aplicación tenga éxito y sea útil. Es necesario diseñar un interfaz similar al de otras aplicaciones ya conocidas por el usuario, por lo tanto se recomienda respetar la estructura que siguen las aplicaciones de la plataforma Windows, al ser estas las más conocidas y usadas [Mic09]. Por otra parte, un factor que reduce 
el tiempo de aprendizaje consiste en facilitar al usuario la tarea de lectura de la información reduciendo al máximo el número de acciones necesarias para controlar la aplicación.

Es importante conocer, además de qué debe hacer la aplicación, dónde se va a instalar y bajo qué condiciones debe funcionar. Así, en este caso la aplicación debe compartir la máquina con otras tareas, requiriendo un uso mínimo de recursos y celeridad a la hora de mostrar la información. A continuación se comentan algunas de las alternativas de lenguajes de programación existentes en el mercado y las características que favorecen o limitan su uso en esta aplicación.

Los lenguajes de alto nivel, como Java o $\mathrm{C} \sharp$, hacen que la programación sea más rápida y fácil, abstrayendo al programador de los elementos de bajo nivel, pero dependen de una máquina virtual que realice la interpretación de un código objeto generado al desarrollar el programa. Esta dependencia produce un aumento excesivo de los requerimientos de sistema necesarios para poder ejecutar la aplicación, además de un aumento del consumo de recursos.

Para minimizar dicho consumo se ha elegido un lenguaje que puede funcionar de forma autónoma sin dependencia de elementos extras para la ejecución del mismo. De los lenguajes C y $\mathrm{C}++$, que son los que se encuentran dentro de esta categoría, se ha elegido $\mathrm{C}++$ al permitir usar estructuras de $\mathrm{C}$ y funcionar con el paradigma de programación orientada a objetos. Además, $\mathrm{C}++$ no puede trabajar directamente con los elementos que forman un interfaz de usuario (botones, imágenes ...) de forma nativa siendo necesario el uso de librerías externas para la realización esta labor.

Los CGT trabajan con el sistema operativo Windows, por esta razón se han analizado las librerías gráficas usadas en esta plataforma que pueden utilizarse en el desarrollo de la aplicación. Se trata de las librerías: MFC, GTK o wxWidgets. Mientras que MFC solo funciona en la plataforma Windows, las dos últimas pueden trabajar también en GNU/Linux, a costa de aumentar el tiempo de desarrollo del interfaz. De este modo, para reducir tiempos de desarrollo se ha elegido la librería MFC, que además, al ser nativa del sistema, puede integrarse con el entorno de desarrollo y facilitar su uso en el entorno de programación Visual Studio de Microsoft lo que permite acelerar el desarrollo. 


\subsubsection{Bloques Principales}

La figura 7.28 muestra la ventana principal del interfaz de usuario que ha sido dividida en varios bloques según estén relacionados con la visualización de la vía y los vehículos, el cálculo de estadísticos o la configuración. El primer bloque, parte izquierda del interfaz, está formado por la visualización en planta de la vía (2D) y la imagen 3D del vehículo que ha pasado por la zona de detección. En el segundo bloque, parte superior derecha, se muestran diferentes valores estadísticos: densidad de tráfico en la vía, clasificación de vehículos por tipos, volumen ... El último bloque, esquina inferior derecha, es el relacionado con el de las opciones del interfaz.

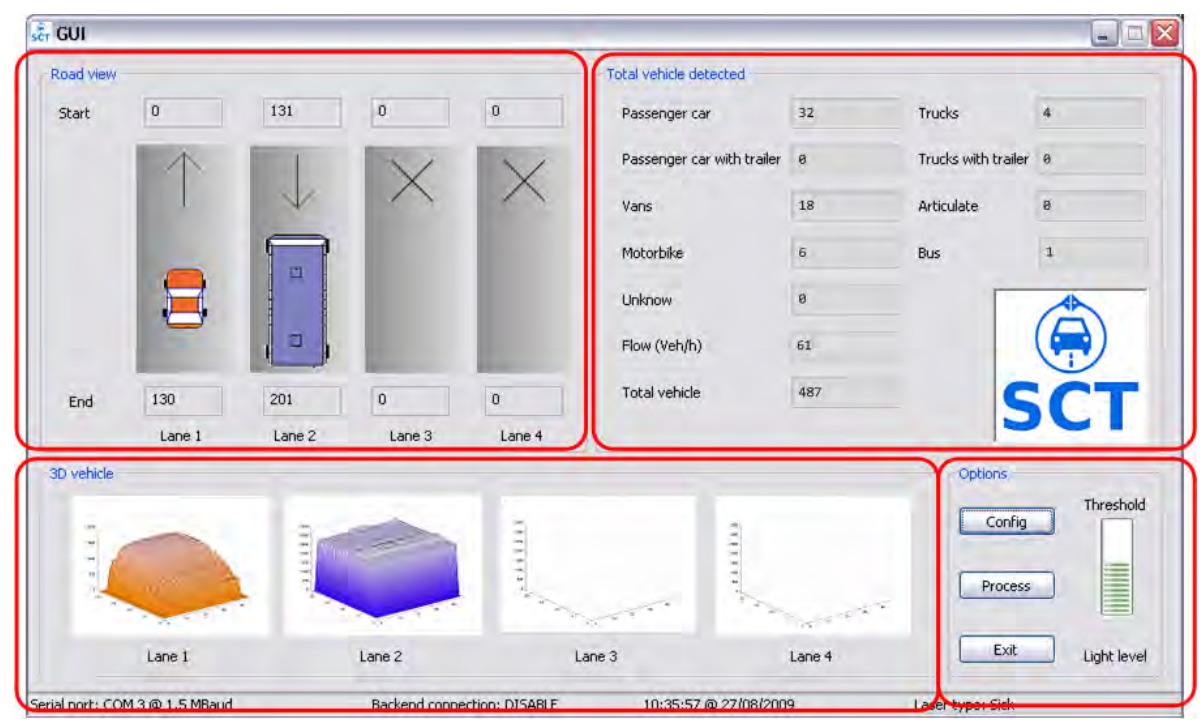

Figura 7.28 - Interfaz Gráfico de Usuario: Bloques

Con el fin de independizar la entrada de los datos al interfaz de una aplicación de procesado que puede estar escrita en cualquier lenguaje y/o funcionando en otra máquina, se ha trabajado con sockets para abstraer la recepción de la información y su visualización. A continuación se explican en detalle cada uno de los bloques con sus características más importantes.

\subsubsection{Representación de la vía y del vehículo}

Corresponde a la parte principal del interfaz, donde se visualiza en tiempo real la clase de vehículo que es detectado por el equipo. Ya que la aplicación ha sido diseñada para entornos urbanos se ha supuesto un número máximo de cuatro carriles por vía, si bien puede modificarse 
esta estructura en función de la aplicación mediante la configuración del programa. Por defecto se trabaja con dos carriles por sentido. También se ha contemplado la posibilidad de que el sentido de los carriles varíe dependiendo de diversos factores como obras o desvíos de tráfico. Es decir, el interfaz presenta total flexibilidad a la hora de definir tanto los carriles como su sentido de circulación.

La aplicación puede usarse en vías con diferentes estructuras: medianas centrales, carriles de diferentes tamaños, carriles especiales VAO ... Este factor debe ser considerado a la hora de definir las características de la vía, siendo necesario que, además de la representación gráfica de los carriles, se pueda definir el ancho, o rango, de cada uno de los mismos de forma independiente. Esta posibilidad ha sido contemplada permitiendo la introducción de estos datos manualmente en el bloque de opciones/configuración, y reflejando estas dimensiones en el bloque de la vía arriba y debajo de cada carril.

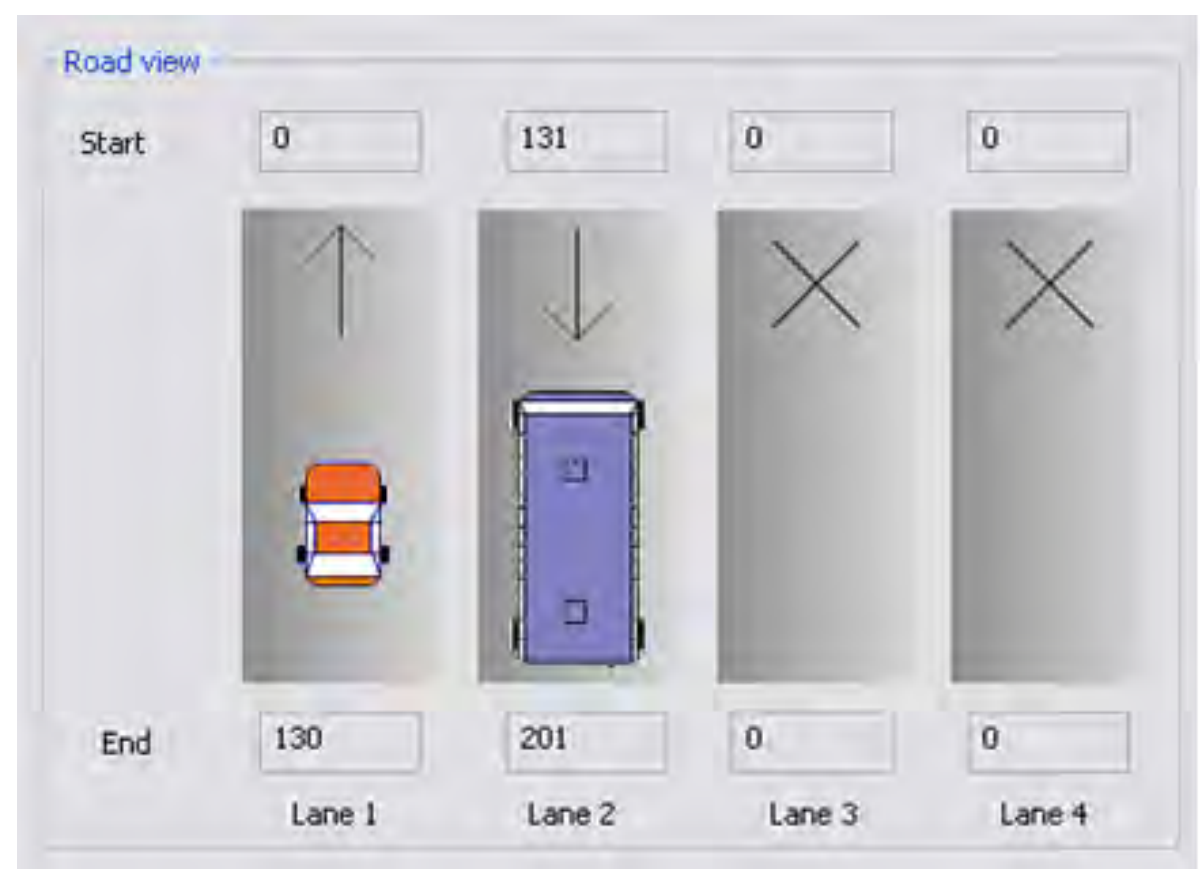

Figura 7.29 - GUI: Representación de la vía

Una vez que la tipología de la vía (dirección, sentido del carril y dimensiones) ha sido definida en el bloque de configuración, esta aparece reflejada en el interfaz. La figura 7.29 muestra el resultado en el interfaz de las opciones seleccionadas. Como se observa, los carriles que muestran una $\mathrm{X}$ son los que se encuentran deshabilitados. En la parte superior e inferior de 
cada uno de los dos carriles se muestran las dimensiones del mismo, en las casillas señaladas como start y end.

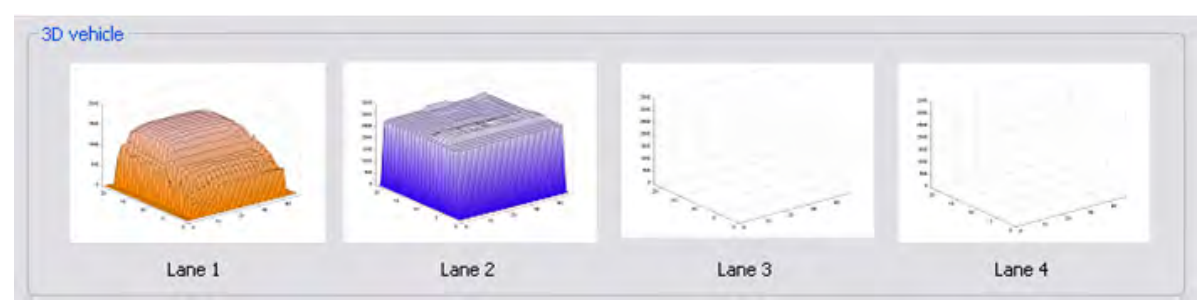

Figura 7.30 - GUI: Representación del vehículo

Cuando se detecta un vehículo en cada uno de los carriles, se muestra su imagen 3D en la ventana inferior a la de la vía, (ver figura 7.30). Como requerimiento del sistema se propuso que cada una de las clases se representara en colores diferentes, ya que esto facilitaría su rápida identificación. Así por ejemplo, los turismos se representan en color naranja.

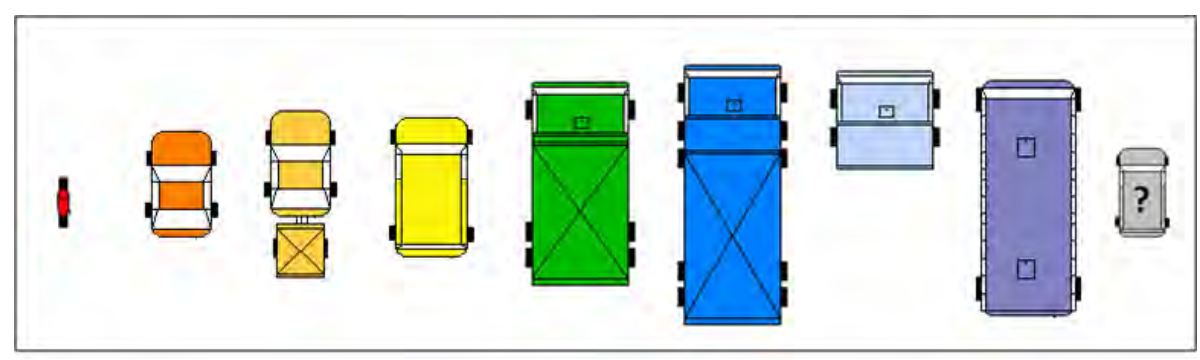

Figura 7.31 - GUI: Clases de Vehículos

La figura 7.31 muestra las categorías o clases de vehículos consideradas actualmente, con los colores usados en su representación. Como el interfaz relaciona la imagen de un vehículo con un código único (ID), para añadir una nueva clase de vehículos solo hace falta generar la imagen y asignarle un ID que no esté siendo usado.

\subsubsection{Datos estadísticos}

Según el tipo de equipo y la aplicación final, puede mostrarse en el interfaz diferente información y estadísticos. Esta información es importante a la hora de comprobar en tiempo real las acciones tomadas respecto al tráfico desde el CGT, o realizar nuevas acciones. Por ejemplo, si se decidiera modificar los tiempos de verde de los semáforos se podría comprobar, en tiempo real, el efecto producido en la circulación de la zona. Estas acciones sobre el tráfico 
pueden ayudar a resolver incidencias puntuales y/o problemáticas como pueden ser atascos, obras llevadas a cabo en la vía, cortes de circulación ...

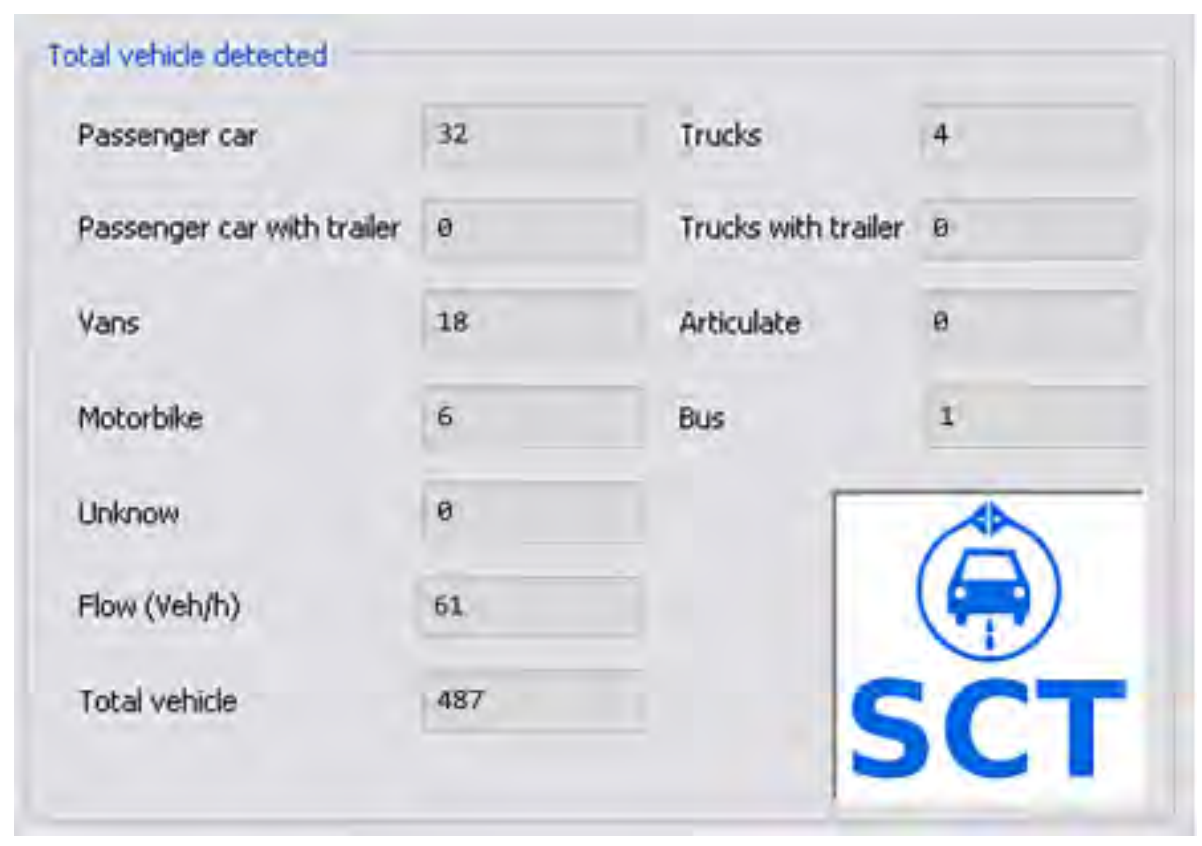

Figura 7.32 - GUI: Estadísticos

En el caso de la aplicación para un sensor láser escáner se informa en tiempo real sobre el número de vehículos de cada clase que circula, intensidad de tráfico (veh/h) y la densidad de tráfico o número total del vehículos, (ver figura 7.32). La información sobre los vehículos detectados por clase se actualiza instantáneamente al detectar un nuevo vehículo, pero su valor se reinicia cada hora. De este modo, el valor de intensidad de tráfico corresponde a la suma de cada una de las clases, mientras que el valor de la densidad de tráfico va acumulando todo el número de vehículos detectados a lo largo del periodo considerado. Evidentemente, toda la información recibida es almacenada, además de visualizada, para la realización de estadísticos, estudios anuales e históricos y simulaciones sobre la circulación en la zona.

\subsubsection{Opciones del Interfaz}

Finalmente, resta el bloque de opciones desde el cual se realizan tres acciones principalmente: configuración del sensor, procesado de los datos y salida de la aplicación. Este bloque muestra también la intensidad luminosa en la vía en forma de barra de nivel, (ver figura 7.33). 


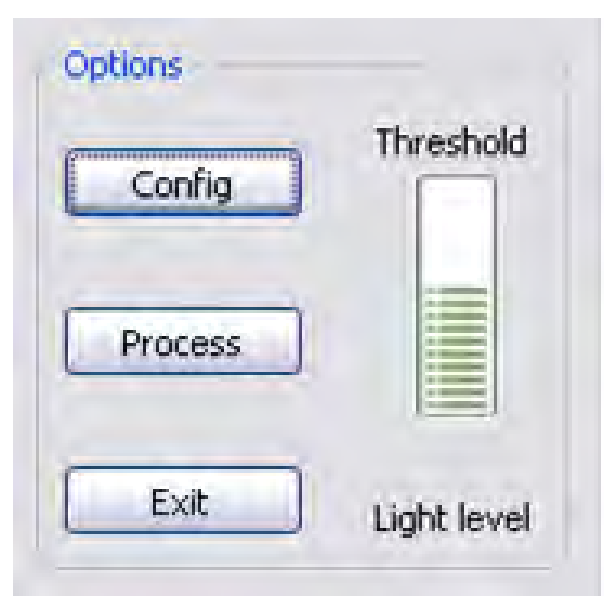

Figura 7.33 - GUI: Opciones

La figura 7.34 muestra la ventana de configuración del sensor donde se puede: configurar la vía, establecer los puertos de comunicaciones y elegir el modelo de equipo que se está utilizando. En este ejemplo de configuración de la vía se han seleccionado dos carriles de circulación en sentidos opuestos y los otros dos han sido deshabilitados. No obstante, para introducir estos valores es necesario realizar una primera calibración del sensor tras su instalación. El interfaz guarda esta información para el resto de usos hasta que se modifique su ubicación. Una vez realizada esta calibración se podrán introducir manualmente los valores, definiendo los rangos que abarca la zona de detección en la que se consideran los datos relevantes.

Otro de los aspectos considerados en el bloque es el relativo a los puertos del ordenador por donde se recibe la información del sensor. Cuando el programa se ejecute desde el CGT el interfaz se tiene que adaptar a los puertos usados en la comunicación. Así, la configuración permite la selección del puerto serie por el que llegan los datos así como su baudrate.

El interfaz es completamente configurable por parte de los usuarios tanto en lo que respecta a la geometría de la vía como a los sistemas informáticos utilizados. Finalmente, la opción de "procesado" inician el interfaz, y la de "salida" lo cierra. 


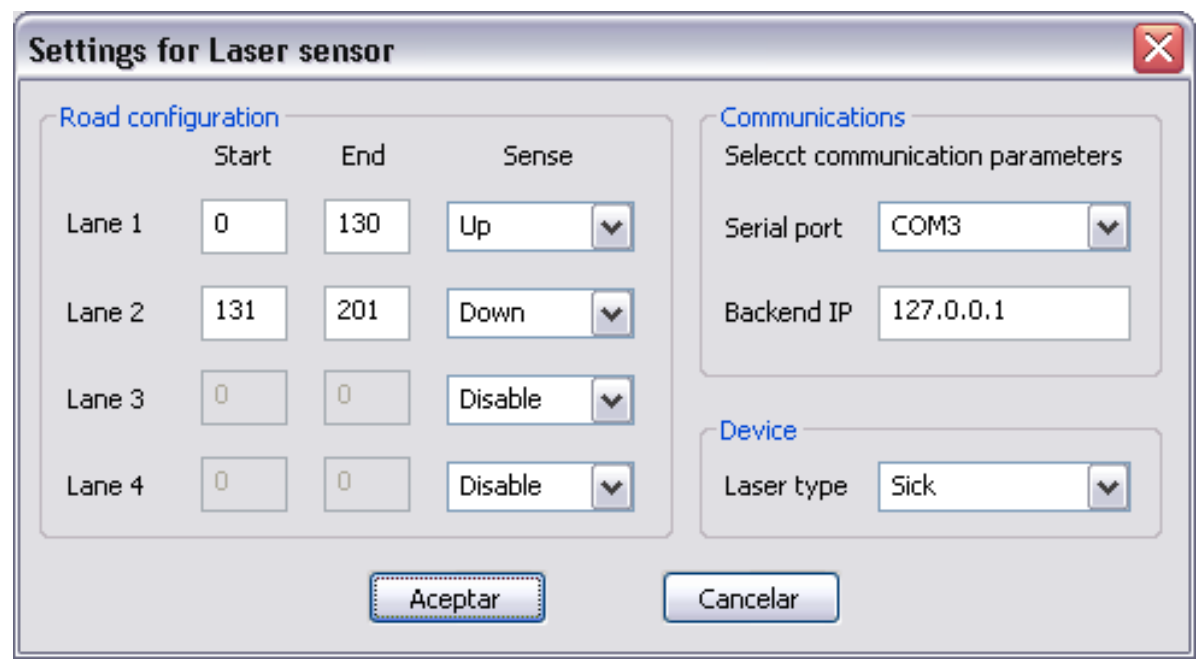

Figura 7.34 - GUI: Configuración del sensor

\subsection{Conclusiones}

Los requerimientos software han sido el objetivo del presente capítulo, desde las etapas de configuración del sensor hasta las de procesado de la señal para su correcto tratamiento, (ver figura 7.35).

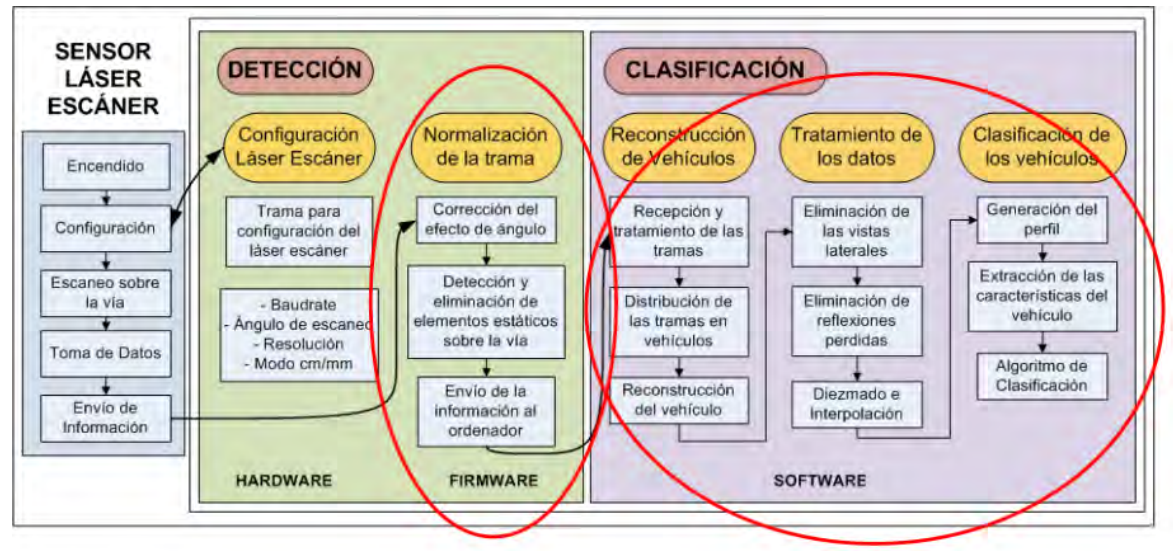

Figura 7.35 - Requerimientos Software

De este modo, los requerimientos software definidos son:

- Adquisición de la señal: Firmware.

- El sistema debe ser capaz de realizar el correcto tratamiento de la trama recibida del sensor láser escáner. 
- El firmware programado en el DSP debe corregir los fenómenos producidos por el efecto de ángulo, así como detectar y eliminar los objetos estáticos que se encuentren sobre la vía, estableciendo una línea de offset de medida.

- El firmware, tras la correcta detección de la señal y una vez realizado el pretratamiento, debe enviar dicha información al ordenador vía USB a una velocidad de 1,5 MBd para su procesado.

- Tratamiento de los datos: Software.

- La información recibida ha de ser correctamente tratada para la obtención de los parámetros que se enviarán al CGT.

- Tras este proceso se debe obtener la siguiente información: detección de vehículos, asignación a una clase de los mismos y todos los estadísticos y valores que se puedan inferir de ellos: intensidad del tráfico (veh/h) y densidad principalmente.

○ El procesado de la señal debe seguir los algoritmos definidos de tratamiento de las tramas (recepción y distribución) y reconstrucción de vehículos (eliminación vistas laterales, tratamiento de reflexiones perdidas y modificación de la frecuencia de muestreo).

- La información proporcionada tras estos procedimientos debe ser fiable e inteligible. 


\section{Bibliografía}

[AH05] Anant, V. y Hutchings, B., Digital signal controller applications. DSP-FPGA.com Product Resource Guide, págs. 8-9, May 2005.

[Ban01] Bannatyne, R., The evolution of the digital signal controller. Embedded System Engineering, September 2001, URL http://www2. electronicproducts.com/The_evolution_of_the_digital_ signal_controller-article-sepmot1-sep2001.aspx.

[Fre09] Freescale, Digital signal controller products. Freescale Semiconductor, 2009, URL http://www. freescale.com/webapp/sps/site/overview. jsp? $\mathrm{code}=\mathrm{GS}-\mathrm{MCUPRODOVDSC} \& \mathrm{f} \mathrm{s} r \mathrm{ch}=1$. [Online: Último acceso Febrero 2009].

[Gan04] Ganssle, J., The Firmware Handbook. Embedded Technology, Elsevier, 2004, ISBN 0-75067-606-X.

[Góm05] Gómez, L.E., Contribución al diseño e implementación de un sistema de detección y clasificación de vehículos con tecnología láser, mediante método estadístico y redes neuronales. Tesis Doctoral, Departamento de Ingeniería Electrónica. Universidad Politécnica de Valencia, Valencia. España, 2005. Directores: Dr. Antonio Mocholí y Dr. José Millet.

[Ibe09] Ibeo, Ibeo lux. Ibeo Automobile Sensor, 2009, URL http: / /www. ibeo-as. com/english/products_ibeolux.asp. [Online: Último acceso Abril 2009].

[KR09] Kauvo, K. y Roessler, B., Laserscanner data processing for motorcycle adas. $6^{\text {th }}$ International Workshop on Intelligent Transportation, 2009. Proceedings. WIT 2009, págs. 39-44, 24-25 March 2009.

[MGM08a] Menéndez, M., Gallego, N. y Mocholí, A., Frontend para aplicaciones de sistemas its: Interfaz gráfico. XV Seminario Anual de Automática, Electrónica Industrial e Instrumentación. SAAEI 08. Actas del SAAEI 2008, September 2008.

[MGM08b] Menéndez, M., Gallego, N. y Mocholí, A., Frontend para aplicaciones de sistemas its: Interfaz gráfico. I Congreso Internacional de Mecatrónica y II Congreso Nacional de Universidades Politécnicas. Actas del congreso, Abril 2008, ISSN ISSN: 1665-9775.

[MGM09] Menéndez, M., Gallego, N. y Mocholí, A., Software de procesado y clasificación en tiempo real de un sensor láser para la detección y clasificación de vehículos. IX Congreso ITS Español (ITS 09), junio 2009.

[Mic05] Microchip, Data Sheet: dsPIC30F4011/4012. Microchip Technology Inc., 2355 West Chandler Blvd., Chandler, AZ 85224-6199, preliminary edición, 2005.

[Mic09] Microsoft, Msdn library: Guidelines for applications. MSDN, 2009, URL http: //msdn.microsoft.com/en-us/library/aa373651.aspx. [Online: Último acceso Marzo 2009]. 
[Noe08] Noergaard, T., Embedded board buses and i/o. Embedded Hardware: Know it all, capítulo 4, pág. 770, Amsterdam: Elsevier/Newnes, 2008, ISBN 0-75068-583-2.

[Sut02] Sutter, E., Embedded Systems Firmware Demystified. Embedded Technology, Kansas: CMP Books, 2002, ISBN 1-57820-099-7.

[Tec09] Technology, M., Dsc product tree. Microchip Technology Inc., 2009, URL http: / / www. microchip.com/. [Online: Último acceso Febrero 2009].

[Wik09] Wikipedia, Firmware definition. Wikipedia, 2009, URL http://es. wikipedia.org/wiki/Firmware. [Online: Último acceso Febrero 2009]. 


\section{Capítulo 8}

\section{Proceso de Clasificación: enfoque y}

\section{metodología}

A lo largo del presente capítulo se desarrolla la metodología a seguir para obtener las ecuaciones de clasificación en cada una de las diferentes categorías. Las técnicas de reconocimiento de patrones se usan para definir los patrones o ecuaciones usadas en la clasificación, que se lleva a cabo posteriormente mediante árboles de decisión. La clasificación asocia cada uno de los vehículos detectados a uno de los 9 grupos distintos establecidos (clasificación 8+1) en base al estándar TLS.

El proceso de elaboración de un sistema de clasificación comprende las siguientes etapas:

- Recopilación de información y creación de la base de datos.

- Proceso de Aprendizaje.

- Proceso de Test.

\subsection{Técnicas de Reconocimiento de Patrones}

El reconocimiento de patrones es el estudio de como las máquinas pueden observar el entorno, aprender a distinguir patrones de interés y tomar decisiones sólidas y razonables sobre la categoría del patrón [JDJ00]. El reconocimiento, la descripción, la clasificación, y la agrupación automática de patrones son problemas muy importantes en diferentes ramas de la ingeniería y 
en disciplinas científicas tales como biología, psicología, medicina, comercialización, visión artificial, inteligencia artificial, y teledetección [JDJ00].

El objetivo principal de estas técnicas es clasificar patrones en base a un conocimiento a priori o información estadística extraída de los mismos. O dicho de otra manera: "el campo de reconocimiento de patrones está relacionado con el reconocimiento automático de regularidades en datos mediante el uso de algoritmos computacionales. Dichas regularidades sirven para tomar diferentes acciones como clasificar datos en diferentes categorías" [Bis06].

El rápido crecimiento del poder de cómputo de los ordenadores en los últimos tiempos ha permitido el uso de métodos de análisis de datos y clasificación más elaborados y variados. Asimismo, los requerimientos de los sistemas de reconocimiento de patrones automáticos están creciendo enormemente debido a la disponibilidad de extensas bases de datos y rigurosos requisitos de funcionamiento. Así, en la mayoría de las aplicaciones emergentes no existe un método de clasificación óptimo, por lo que se recurre a múltiples métodos y enfoques [JDJ00].

Las técnicas clásicas de reconocimiento y clasificación de patrones pueden ser paramétricas (bayesianas, discriminantes lineales, máquinas de vectores soporte ...) o no paramétricas (histogramas, K vecinos más cercanos, árboles de decisión ... ). Ya desde los años 90 se vienen empleando, además, técnicas basadas en redes neuronales artificiales. En el área de tráfico las redes neuronales han sido utilizadas habitualmente en el caso de visión artificial, contando incluso con importantes congresos de IEEE dedicados al tema. Los congresos sobre "Computer vision and Pattern Recognition” vienen celebrándose ya desde el año 1985. En el año 2009 se ha celebrado su última edición, estando prevista la próxima para Junio de 2010 en la ciudad de San Francisco, Estados Unidos [CVP08]. También se ha utilizado la correspondencia multinomial de patrones [KM06], en la detección de vehículos mediante sensores IR o acústicos [CCM07, CGSC07].

La figura 8.1 muestra la arquitectura genérica definida en un proceso de reconocimiento de patrones. Tras la recopilación de datos, la primera etapa en el reconocimiento de patrones es la de aprendizaje o entrenamiento. En esta fase se considera la existencia de un grupo de datos de los que, a priori, se conoce la clase a la que pertenecen y sirven para entrenar al sistema. Esta 


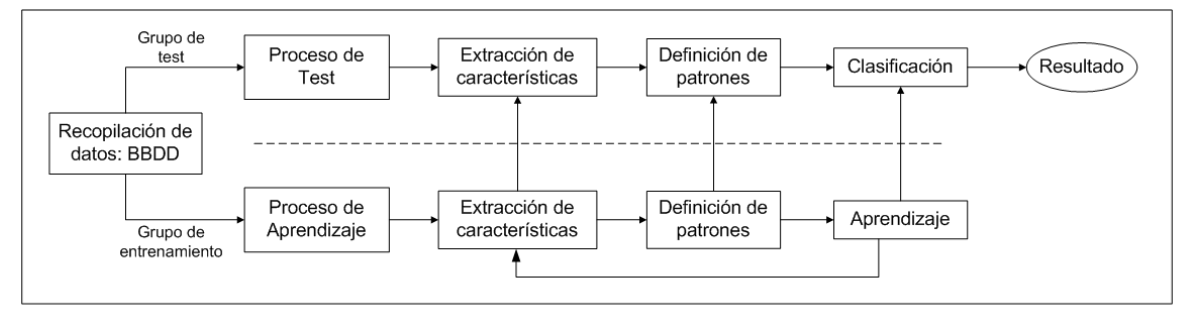

Figura 8.1 - Arquitectura de Reconocimiento de Patrones

estrategia se denomina aprendizaje supervisado, al conocerse los patrones; si no se conocieran se trataría de aprendizaje no supervisado [FK99, Rip97].

En los casos de aprendizaje supervisado se pueden dar dos situaciones: que el objetivo sea asignar cada valor de entrada a una de un número finito de categorías discretas, lo que se llama problema de clasificación; o que el objetivo sea asignar una o más variables continuas, tratándose entonces de regresión. Los casos de aprendizaje no supervisado pueden tener diferentes objetivos: detectar grupos de ejemplos similares dentro de los datos, clustering; determinar la distribución de los datos en el espacio de entrada, estimación de densidad; o proyectar los datos en espacios de menor dimensión para visualizarlos [Bis06].

El grupo de datos conocido como grupo de entrenamiento, define los patrones correspondientes a cada una de las categorías que se desea clasificar, y permite determinar la función que será usada para la clasificación [Bis06]. Cuanto mejor sea el grupo de entrenamiento, mejores patrones definirán y mejores discriminaciones permitirán llevar a cabo [JDJ00]. Las categorías empleadas en esta tesis se basan en el estándar de clasificación TLS que será explicado más adelante en el apartado Proceso de Clasificación: enfoque y metodología.

Una vez que el modelo ha sido entrenado se inicia la segunda y última etapa que es la de clasificación o reconocimiento de nuevos datos. Este procedimiento se realiza con el grupo de test. En algunas aplicaciones prácticas donde los datos son complejos, se preprocesan para transformarlos en un nuevo espacio de variables, de modo que el problema de reconocimiento de patrones sea más fácil de resolver. Esta etapa de preprocesado también es llamada de extracción de características, su finalidad es encontrar características útiles que sean fáciles de calcular y que mantengan información para la discriminación en clases. Es decir, se encarga de extraer un conjunto o vector de características que situará los datos en puntos del espacio n-dimensional de 
clasificación. En este caso el vector de características es utilizado como entrada del algoritmo de reconocimiento de patrones [sR08, Bis06]. El preprocesado también se realiza si se desea aumentar la velocidad de cálculo en aplicaciones de tiempo real [Bis06].

\subsection{1. Árboles de decisión}

Uno de los enfoques más prácticos e intuitivos para realizar una clasificación son los árboles de decisión [Pha06] 2006:617. Los árboles de decisión, también denominados árboles de clasificación o de identificación, sirven para resolver problemas de clasificación con datos categóricos [Mat09]. Son estructuras arborescentes jerárquicas que clasifican basándose en una serie de preguntas, o de reglas, sobre las cualidades de la clase [Tek09]. Dados unos datos de cualidades junto con sus clases, un árbol de decisión produce una secuencia de reglas, o una serie de preguntas, que se puedan utilizar para reconocer la clase [Tek09].

En este tipo de estructuras el objetivo es obtener un método o procedimiento sistemático que permita predecir, dado un conjunto de medidas, a que categoría pertenece cada una de ellas [BFOS84]. Se trata de una alternativa no paramétrica de modelización frente a otros modelos paramétricos como análisis discriminantes lineales [Mat09].

La construcción de árboles de decisión es el método de aprendizaje inductivo supervisado más utilizado. Su dominio de aplicación no está restringido a un ámbito concreto sino que pueden ser utilizados en diversas áreas, desde aplicaciones de diagnóstico médico hasta juegos como el ajedrez o sistemas de predicción meteorológica [Día07].

Las características más importantes de los árboles de decisión son [Alu09, Ye04]:

- Sencillez, jerarquización y flexibilidad.

- Representación intuitiva.

- Técnica no paramétrica.

- Relativamente rápidos comparados con otros métodos.

- Precisión en la clasificación comparable a la de otros métodos.

- Eficientes computacionalmente. 
Un árbol de decisión lleva a cabo un test a medida que este se recorre hacia las hojas para alcanzar así una decisión. El árbol de decisión contiene: un nodo raíz que representa a toda la población; nodos hojas o nodos terminales que representan la partición final; nodos intermedios; nodos de probabilidad y arcos. Un nodo intermedio contiene un test o pregunta sobre algún atributo concreto teniendo un hijo por cada respuesta posible. Un nodo de probabilidad indica que debe ocurrir un evento aleatorio de acuerdo a la naturaleza del problema. Este tipo de nodos son redondos, los demás son cuadrados. Un nodo hoja representa el valor que devolverá el árbol de decisión y representa cada una de las clasificaciones. Finalmente, las ramas brindan los posibles caminos que existen de acuerdo a la decisión tomada [Vil06, BFOS84].

Este tipo de árboles puede usarse para clasificar un caso comenzando desde su raíz y siguiendo el camino determinado por las respuestas a las preguntas de los nodos internos, hasta que se encuentre un nodo terminal. Esta forma de construir los árboles es denominada TDIDT (acrónimo del inglés Top-Down Induction on Decision Trees) citeDIA07, para hacer referencia a la familia de algoritmos de construcción de árboles de decisión. La inducción topdown procede de acuerdo a la estrategia divide y vencerás, donde el conjunto de entrenamiento se va dividiendo en subconjuntos y el algoritmo se aplica recursivamente sobre cada uno de ellos [Ni196].

Los árboles de decisión presentan varias ventajas como [Alu09, Día07, BFOS84]:

- No precisan hipótesis iniciales, ni asumen que los conjuntos de datos son homogéneos.

- Se trata de sistemas especialmente buenos en el caso de grandes conjuntos de datos y elevada dimensionalidad, al producir resultados útiles con pocas variables importantes.

- La adquisición del conocimiento a partir de ejemplos preclasificados (grupo de entrenamiento) salva el obstáculo que representa adquirir el conocimiento mediante la intervención de un experto humano en el área.

- Llevan a cabo la clasificación a través de una secuencia de preguntas simples, fáciles de entender, cuya semántica es intuitivamente clara tanto para los expertos en el área como para los que no lo son. 
- Minimizan el pretratamiento, pudiendo trabajar con un cierto nivel de ruido y de datos perdidos.

- Los métodos basados en árboles son exploratorios en lugar de inferenciales. Al no realizarse hipótesis sobre el modelo y la distribución de los datos, los árboles pueden modelizar un amplio rango de distribuciones de datos.

- La descomposición jerárquica supone un mejor uso de las características disponibles y una mayor eficiencia computacional en la clasificación.

- Pueden trabajar de la misma manera con datos unimodales y multimodales, al contrario que algunos métodos estadísticos.

- Pueden usarse con la misma facilidad en problemas deterministas, donde la variable dependiente puede determinarse perfectamente a partir de las variables independientes, como en problemas incompletos.

En cualquier caso, se debe tener cuidado con descartar información que sea importante para obtener la solución del problema ya que en este caso la precisión de todo el sistema puede verse comprometida. Otras de las desventajas que presenta este tipo de estructuras son [Tek09, BFOS84]:

- La estructura final puede dar lugar a resultados engañosos: enmascarando variables y dando lugar a interpretaciones erróneas.

- Los árboles de clasificación estándar pueden dar problemas en casos de estructuras lineales. Esta situación se resuelve incorporando decisiones de combinaciones lineales en cada nodo del árbol.

- Pueden producirse casos de sobre-ajuste (overfitting).

- Es necesario obtener el tamaño correcto del árbol. Un árbol con un grado de ramificación elevado no deriva en una mejor clasificación.

Los árboles de decisión se construyen recursivamente hasta que no se encuentre un parámetro mediante el que seguir ramificando, o se cumpla alguna condición de parada. En estos casos el árbol no se expande más. Las reglas de parada, denominadas originalmente reglas de 
pre-poda, tratan de predecir si merece la pena seguir construyendo el árbol o no. Ejemplos de este tipo de reglas son: pureza del nodo, cota de profundidad o mínimo de casos.

El método recursivo de construcción de árboles de decisión continúa dividiendo el conjunto de casos de entrenamiento hasta que encuentra un nodo puro o no puede aplicar más test. El resultado suele ser un árbol muy complejo, más de lo deseable, que sobre-ajusta los datos del conjunto de entrenamiento. Este sobre-ajuste debido a un sobre-aprendizaje es un problema bastante importante ya que limita considerablemente la aplicabilidad del modelo de clasificación aprendido [BFOS84].

Los árboles de clasificación se ajustan perfectamente, como era de esperar, a los datos del grupo de aprendizaje, pero puede que realicen predicciones no muy acertadas en el caso de valores nuevos. Las ramas inferiores, especialmente, pueden verse fuertemente afectadas por valores atípicos. Árboles más simples pueden ofrecer a menudo mejores resultados evitando sobre-ajustes [Mat09].

Una vez construido completamente el árbol de decisión, las reglas de poda (o post-poda) intentan eliminar los subárboles que no contribuyen significativamente a la precisión de la clasificación. La poda se suele aplicar después de construir el árbol completo ya que la correcta estimación a priori, del beneficio obtenido al simplificar un árbol durante su construcción, es muy difícil. Se realiza en función de algún estimador no sesgado del error de clasificación del árbol de decisión, y se selecciona aquel que optimiza alguno de los criterios de calidad [SS08]. Algunos de los métodos de poda de árboles de decisión más comunes son: la poda por estimación del error, la poda por coste-complejidad y la poda pesimista. Siendo el de costecomplejidad el más usado.

\subsubsection{Técnicas de Bootstrap}

A la hora de comprobar la exactitud de una regla de clasificación, las tasas de error tienden a estar sesgadas si se estiman usando el mismo grupo de test que ha sido utilizado como grupo de aprendizaje para la construcción de las normas [MST94]. Los métodos usados para poder 
corregir este sesgo se basan en la diferenciación de dos grupos: uno de aprendizaje y otro de test.

La técnica de bootstrap es un método de remuestreo que fue propuesto por Bradley Efron en 1979. Se utiliza para aproximar la distribución en el muestreo de un estadístico. Se usa frecuentemente para aproximar el sesgo o la varianza de un estadístico, así como para construir intervalos de confianza o realizar contrastes de hipótesis sobre parámetros de interés [Mat09, Cor04, SS99].

El bootstrap y los procedimientos de remuestreo en general, comenzaron a ser relevantes a partir de la década de los 80, cuando la gran potencia de cálculo de los ordenadores facilitó la aplicabilidad de este método permitiendo la simulación de un número elevado de muestras. A finales de esta década, la utilización del método bootstrap para el contraste de hipótesis empezaba a ser considerada una alternativa a los test paramétricos y no paramétricos convencionales [Gil05].

La aplicación del enfoque bootstrap permite obtener estimaciones de medidas de precisión así como la realización de contrastes de hipótesis en aquellas situaciones en las que no se dispone de información acerca de las distribución muestral de un estadístico, o en casos en los que la distribución muestral depende de parámetros desconocidos [LE04].

Esta técnica es particularmente ventajosa cuando se utiliza junto a árboles de decisión, debido a dos razones principales: los algoritmos del árbol de decisión son relativamente eficientes para muestras de muchas dimensiones, y los árboles de decisión tienden a tener un componente de variación más grande que otros métodos como: $\mathrm{k}$ vecinos más cercanos o redes neuronales [ADW98]. Se utiliza además para reducir el sobre-optimismo de los estimadores calculados sobre el grupo de aprendizaje, tales como el error debido a clasificaciones erróneas [BFOS84].

La idea subyacente al bootstrap es simple: los datos muestrales son tratados como si constituyesen los datos de toda la población, es decir se utilizan como el universo del que se extraerán muestras con reemplazo. Para cada remuestreo se calculará el valor del estimador bootstrap que se utilizará para estimar la variabilidad muestral [Pha06, LE04, Cor04]. Por tanto, la adecuación de este método será tanto mayor cuanta más información aporte la muestra sobre la población. 
Una consecuencia directa es que a medida que aumenta el tamaño de la muestra mejor será la estimación que podemos hacer sobre la distribución muestral de un estadístico [Gil05].

Este procedimiento implica escoger muestras al azar con reemplazo de un conjunto de datos, grupo de test, y analizar cada muestra de la misma manera. El muestreo con reemplazo significa que cada muestra es devuelta al conjunto de datos después de muestrear [Mat09]. Si se tiene una muestra de tamaño $\mathrm{N}$, por ejemplo, se debe generar un gran número de muestras de tamaño $\mathrm{N}$ mediante dicho muestreo con reemplazo. Como se explica en los estudios teóricos, debido al reemplazo se espera que en cada nueva muestra exista un 63,2\% de valores únicos pertenecientes a la muestra inicial o grupo de test [ADW98]. Después, en esa muestra se calcula el valor del parámetro que se está estimando. Este proceso se repite un gran número de veces, normalmente alrededor de 10.000 o más, con lo que se obtiene una distribución de valores para el parámetro en la que ya se puede calcular su dispersión, análogo al error estándar, y determinar unos límites de confianza utilizando dicha distribución.

Todo esto se puede resumir en los siguientes pasos:

- A partir de la muestra original $X_{1}, X_{2}, \ldots, X_{n}$, se extrae una nueva muestra $X_{1}^{*}, X_{2}^{*}, \ldots$, $X_{n}^{*}$ mediante muestro con reemplazo.

- Para la muestra obtenida se calcula el valor de un determinado estadístico $\hat{\theta}$ que se utiliza como estimador del parámetro poblacional $\theta$, en cuyo estudio se está interesado.

- Se repiten los dos pasos anteriores $n$ veces hasta obtener un elevado número de estimaciones $\hat{\theta}^{*}$.

- Se construye una distribución empírica del estadístico $\hat{\theta}$, que representa una buena aproximación a la verdadera distribución de probabilidad para ese estadístico.

De este modo queda definida la distribución muestral de un estadístico sin haber hecho suposiciones sobre la distribución teórica a la que este se ajusta, ni utilizar fórmulas analíticas para determinar los correspondientes parámetros de esa distribución [Gil05].

El estimador bootstrap para la media muestral de tamaño $n$ se define como la media de los valores estadísticos calculados en las $n$ muestras de bootstrap, (ver ecuación 8.1). 


$$
\overline{\hat{\theta}^{*}}=\frac{1}{n} \sum_{i=1}^{n} \hat{\theta}_{i}
$$

Por otra parte el estimador del error estándar de las muestras bootstrap se define según la ecuación 8.2.

$$
s_{\hat{\theta}}=\sqrt{\frac{1}{n-1} \sum_{i=1}^{n}\left(\hat{\theta}_{i}-\overline{\hat{\theta}^{*}}\right)^{2}}
$$

\subsection{Medidas de la investigación}

Esta investigación tiene como objetivo realizar una clasificación de vehículos. Así que la población bajo estudio son los vehículos existentes en una determinada zona, es decir, el parque de vehículos. Antes de iniciar un estudio hay que conocer las características de la población. Consecuentemente, este apartado presenta los tipos de vehículos y los estándares actuales más usados en clasificación de los mismos.

En primer lugar se presentan algunas definiciones dadas por el instituto estadounidense de estándares y el Ayuntamiento de Valencia sobre los tipos de vehículos. Al trabajar con el parque de vehículos de dicha ciudad, se han aceptado las definiciones dadas por esta última administración. Tras este repaso, se explican en detalle diferentes estándares de clasificación de vehículos haciendo especial hincapié en la clasificación TLS usada en la presente investigación.

\subsubsection{Definiciones de las clases de vehículos}

El instituto estadounidense de estándares, ANSI (acrónimo del inglés American National Standards Institute), define es su normativa D16.1-1996 los vehículos en los siguientes tipos [Ame96]:

- Motocicleta. Cualquier vehículo de motor de no más de tres ruedas que tiene un asiento o silla de montar para el conductor, y está diseñado para viajar. 
- Automóvil. Vehículo con motor, con excepción de una motocicleta o de un vehículo utilitario, diseñado para transportar hasta un máximo de 10 personas. Los automóviles se pueden clasificar por tamaño, peso o ambos.

- Furgoneta. Vehículo de motor de peso no superior a las 10.000 libras. Se trata básicamente de una "caja con ruedas" que es identificable por su área común de pasajero y/o de carga, piso elevado y capó relativamente corto o inexistente.

- Camión. Vehículo de motor diseñado principalmente para el transporte. Puede constar de un único módulo o varios, con la excepción de tractores.

- Autobús. Vehículo de motor diseñado para el transporte de más de diez personas.

- Tráiler. Vehículo diseñado para ser arrastrado por un vehículo de motor.

Además de estas clases, se definen otras o subdividen estas llegando a diferenciar entre cuatro subtipos de motocicletas y tres de furgonetas, entre otras muchas divisiones.

Por otra parte, el Ayuntamiento de Valencia es su "Anuario 2008" define las categorías de vehículos como [Ayu08]:

- Motocicleta. Vehículo de dos o tres ruedas, provisto de un motor de cilindrada superior a $50 \mathrm{~cm}^{3}$, si es de combustión interna, y/o con una velocidad máxima por construcción superior a $45 \mathrm{~km} / \mathrm{h}$.

- Ciclomotor. Vehículo de dos o tres ruedas, provisto de un motor de cilindrada no superior a $50 \mathrm{~cm}^{3}$, si es de combustión interna, y con una velocidad máxima por construcción no superior a $45 \mathrm{Km} / \mathrm{h}$.

- Turismo. Automóvil destinado al transporte de personas que tenga, por lo menos, cuatro ruedas y, además del asiento del conductor, ocho plazas como máximo.

- Autobús. Automóvil que tenga más de 9 plazas incluida la del conductor; destinado, por su construcción y acondicionamiento, al transporte de personas y sus equipajes.

- Camión. Automóvil con cuatro ruedas o más, concebido y construido para el transporte de mercancías, cuya cabina no está integrada en el resto de la carrocería y con un máximo de 9 plazas, incluido el conductor. 
- Tractor. Vehículo especial autopropulsado, de dos o más ejes, concebido y construido para efectuar trabajos diversos.

- Remolque. Vehículo no autopropulsado diseñado y concebido para ser remolcado por un vehículo de motor.

\subsubsection{Estándares de clasificación}

Actualmente, existen diferentes estándares usados para la clasificación de vehículos en ITS. Normalmente, son las administraciones nacionales las que aplican y definen los estándares a seguir y estos varían dependiendo del área geográfica. De este modo se ajustan a las tres grandes regiones de ITS mundiales: América, Europa y Asia-Pacífico, y en consecuencia cada una de ellas define un estándar diferente.

Generalmente, los estándares relativos a clasificación de vehículos no tienen entidad por sí mismos, sino que se incluyen y forman parte de normativas más extensas sobre sistemas ITS [MGR02]. El Departamento de transporte estadounidense, mediante la familia de estándares NTCIP (acrónimo del inglés National Transportation Communication for ITS Protocol) ha definido los protocolos de comunicación y el vocabulario necesario para permitir la interoperabilidad entre equipos comerciales de control de tráfico de diferentes fabricantes [NTC09]. El estándar NTCIP 1209 versa sobre los sensores de tráfico. Es en este estándar donde se incluirá todo lo relativo a detección, conteo y clasificación de vehículos. En Europa, se han desarrollado diferentes estándares para equipos de captura de datos, pero a nivel nacional, en países como: Francia, Holanda y Alemania [MGR02].

La región asiático-pacífica sigue generalmente las normativas de la "Asociación de las autoridades de tráfico y transporte terrestre" de Australia y Nueva Zelanda (Austroads) que fija el estándar definido en el proyecto n.rum.9812. [RPA00]. Este estándar permite clasificar hasta en 12 grupos diferentes, dando una especial relevancia al número de ejes con los que cuentan los vehículos. Así, hasta 10 de las 12 clases se diferencian en función de dicho número de ejes. Algunos de los proyectos realizados en el sector ITS que trabajan con este tipo de clasificación 
son: "Development of a Mobile Vehicle Classification System" [Ott06] y "Automated vehicle classification system using advanced noise reduction technology” [ $\left.\mathrm{XOW}^{+} 07\right]$.

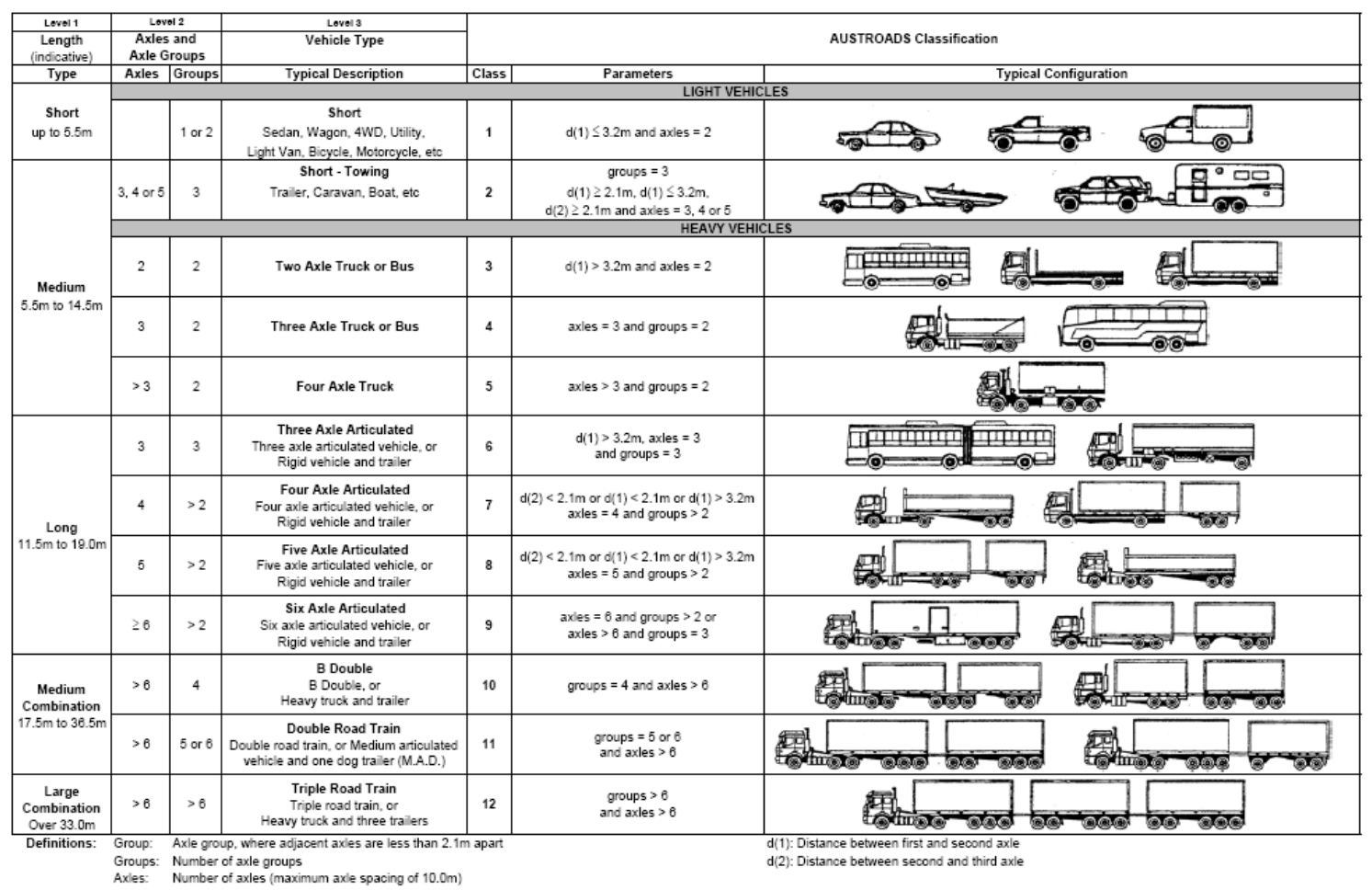

Figura 8.2 - Estándar AUSTROADS Fuente: www.austroads.com.au

El número de ejes de los vehículos pesados es también la base del estándar americano definido por la FHWA (acrónimo del inglés Federal Highway Administration) dependiente del Departamento Americano de Transporte [FHW08]. La FHWA en su informe "Traffic Monitoring Guide” [FHW01, sección 4] afirma: "para muchos de los análisis llevados a cabo por las agencias de tráfico los esquemas simples de tres grupos (vehículos de pasajeros, camiones de una unidad y camiones articulados) son válidos, pero otras veces se requiere una clasificación más sofisticada”.

Actualmente son pocos los estados norteamericanos que usan íntegramente la clasificación en 13 grupos definida por la FHWA, si bien utilizan variaciones de la misma dependiendo del parque de vehículos que circule por cada uno de los estados. Además, la mayoría de los fabricantes estadounidenses de equipos comerciales ya proporcionan la clasificación de vehículos en las categorías definidas por la FHWA. Por ejemplo, el software de procesado Traffic Executive de la compañía MetroCount [MET09]. 
El estándar estadounidense está enfocado hacia una clasificación centrada en camiones, ya que de las 15 clases que define 6 de ellas se basan en camiones con y sin tráiler y con diversos ejes, como se puede apreciar en la figura 8.3.

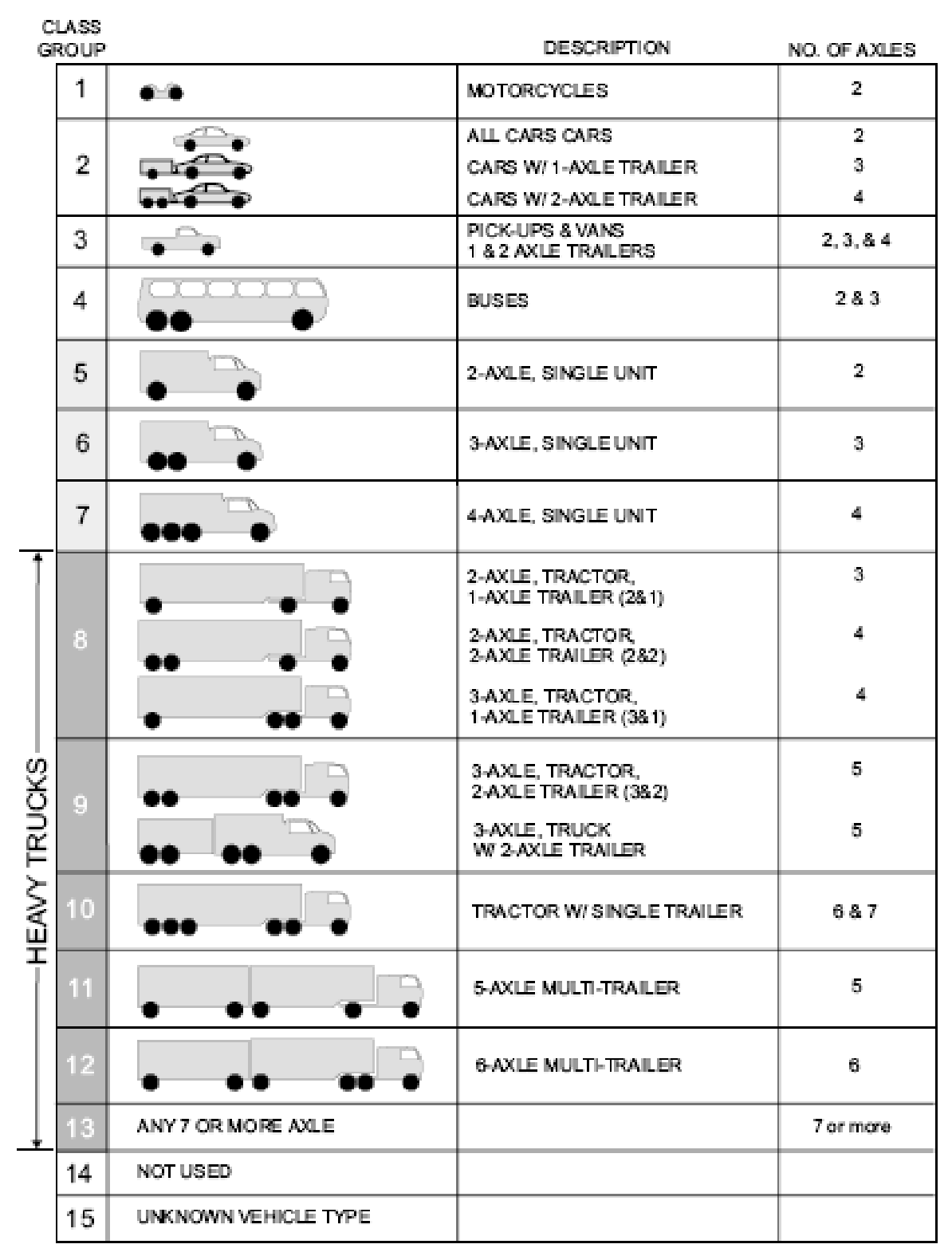

Figura 8.3 - Estándar FHWA Fuente: www.fhwa.dot.gov

Finalmente, en Europa una gran parte de los equipos aforadores y sistemas de clasificación comerciales están basados en el estándar alemán TLS (definido por el instituto federal de investigaciones de carreteras, Bundesanstalt für Straßenwesen) [BAS08]. Al igual que sucedía en el caso estadounidense, las empresas más importantes del sector también han adoptado este estándar. Un ejemplo de ello son: Weiss Electronics con modelos como el MC2024 [Ele09]; 
Efkon con modelos como el AE TITAN 3000 [EFK09]; y Xtralis con modelos como el DT 350 o TT290 [Xtr09]. Así mismo, proyectos europeos del VII Programa Marco como el proyecto TRACKSS [TRA06], utilizan el mismo estándar a la hora de realizar aplicaciones de clasificación de vehículos.

Aunque estas clasificaciones de vehículos son las usadas por la administración, existen otras que no se basan en aplicaciones ITS. Es el caso de las empresas automovilísticas, que realizan diferentes clasificaciones de sus modelos en clases tipo: microcar, sedan, station wagon, sport cars, grand tourers ... Existen, así mismo, las famosas clasificaciones de seguridad Euro NCAP (acrónimo del inglés European New Car Assessment Programme) que agrupan a los vehículos entre otros en: supermini, family car, executive, MPV, 4x4 ... [Eur09].

La unión europea ha iniciado los primeros pasos para definir un estándar de clasificación de vehículos a nivel europeo. La directiva europea 2004/52/EC de interoperabilidad de sistemas de peaje electrónico, EETS (acrónimo del inglés European Electronic Toll Service) fue adoptada formalmente por el Parlamento Europeo en Abril de 2004 y pretendía homogeneizar los servicios de peaje electrónico a nivel europeo [EU04]. Una de sus iniciativas pretendía, por lo tanto, definir un estándar común de clasificación de vehículos. Aunque el grupo de expertos II trabajó en clasificación de vehículos para establecer unas recomendaciones a nivel europeo, nunca se llegaron a establecer unas categorías detallándose únicamente unas recomendaciones a cerca de los parámetros que se deben medir para la clasificación de vehículos.

En vista del estado del arte actual respecto a los estándares de clasificación de vehículos se ha optado en esta tesis por usar el estándar alemán TLS. Dicho estándar se ajusta mejor a la variedad del parque automovilístico europeo, permitiendo diferentes tipos de clasificación como se muestra en la tabla 8.1.

\subsection{Recopilación de datos y creación de la base de datos}

La información que se recoge en cada una de las muestras son:

- tipo de vehículo, 


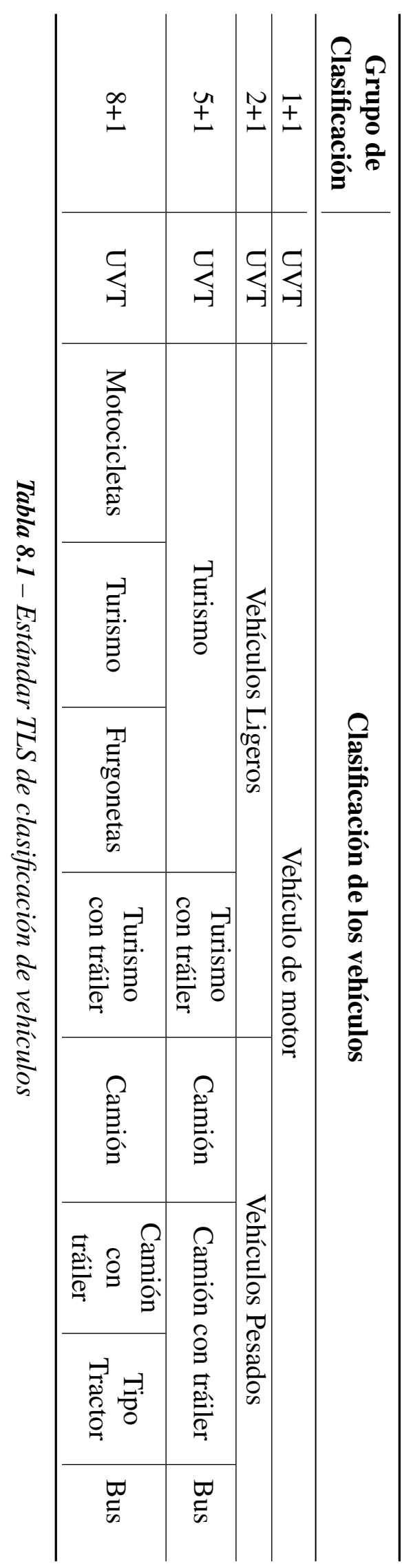


- anchura,

- perfil,

- matriz 3D,

- e imagen.

A medida que los datos recogidos iban creciendo, crecía la complejidad de la estructura de carpetas para su almacenamiento. Llegados a este punto, y dada la elevada cantidad de vehículos ya guardados, alrededor de 1.000 , se consideró oportuno diseñar una base de datos donde almacenar toda la información.

Tras barajar diferentes opciones se consideró que el programa Microsoft Office Access 2007 reunía las características que se buscaban, destacando la facilidad de introducción de datos y la creación de todo tipo de informes relativos a la información incluida en la base de datos. También era importante poder acceder desde cualquier punto a la base de datos, y no necesitar amplios conocimientos sobre bases de datos para poder gestionarla.

Además, se ha diseñado un interfaz para facilitar la introducción de la información. En la figura 8.4 se muestra el diseño realizado.

En la base de datos, además de la información almacenada de cada una de las muestras se adjunta: fecha de captura, número de medida, número de ID, categoría: aprendizaje o test, y una nota. El aspecto general que muestra la base de datos una vez introducidos los valores de cada una de las muestras se puede apreciar en la figura 8.5.

La información capturada ha dado lugar a una base de datos que contiene diferentes tipos vehículos. La información recopilada en la base de datos ha sido dividida aleatoriamente en dos grupos para su posterior estudio: grupo de aprendizaje y de test. Cada uno de ellos estará involucrado en los procesos de aprendizaje y clasificación respectivamente. La tabla 8.2 presenta los datos usados en cada uno de los procesos. 


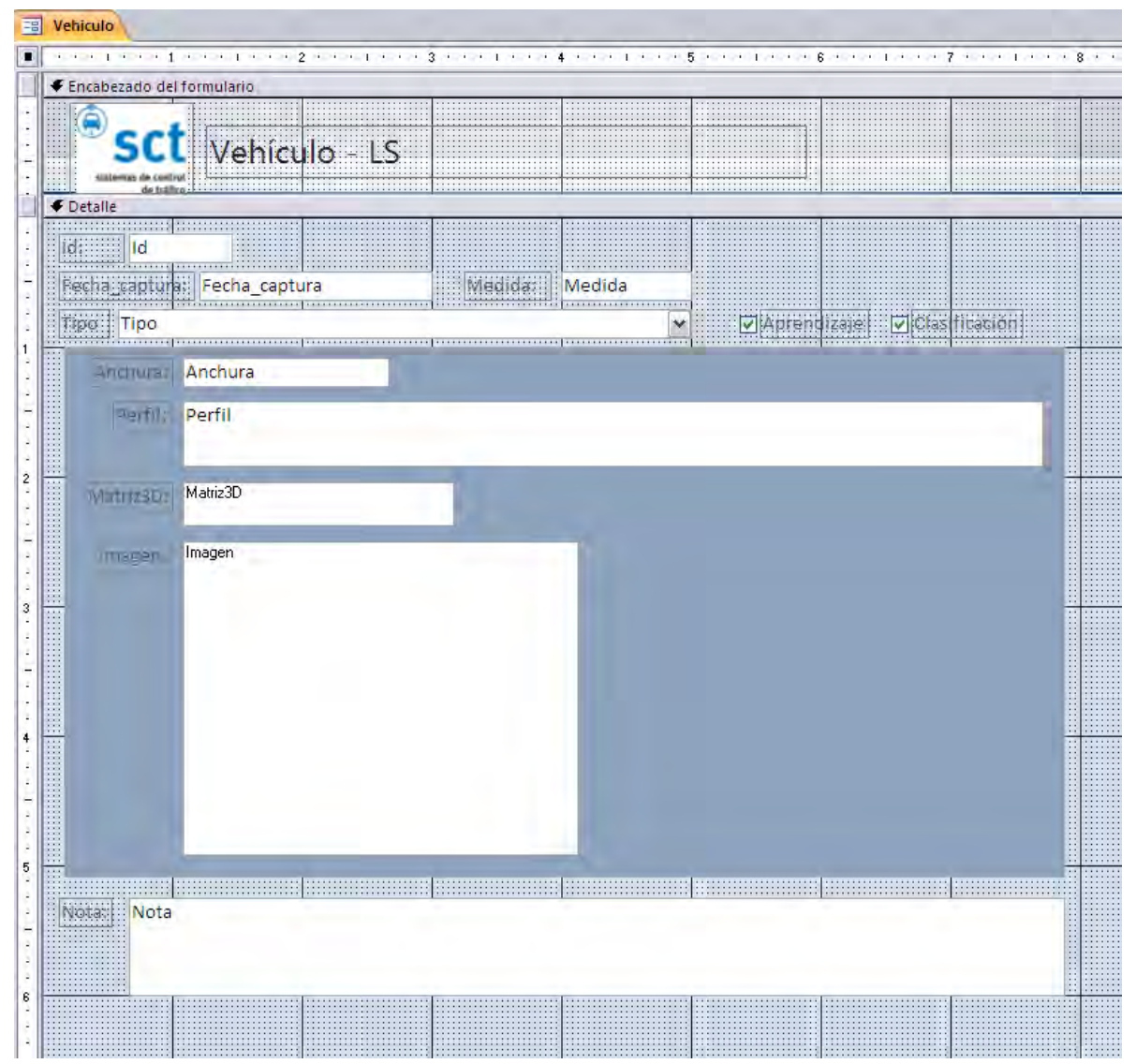

Figura 8.4 - Diseño de la base de datos

Tabla 8.2 - Número de vehículos presentes en la base de datos y por procesos

\begin{tabular}{cccc}
\hline Tipo & TOTAL & $\begin{array}{c}\text { Grupo } \\
\text { Aprendizaje }\end{array}$ & $\begin{array}{c}\text { Grupo } \\
\text { Test }\end{array}$ \\
\hline Motocicletas & 102 & 51 & 51 \\
Turismos & 1.350 & 675 & 675 \\
Furgonetas & 357 & 179 & 178 \\
Camiones & 75 & 38 & 37 \\
Camiones con tráiler & 14 & 7 & 7 \\
Autobús & 49 & 25 & 24 \\
\hline TOTAL & 1.947 & 975 & 972 \\
\hline
\end{tabular}

\subsection{Método de muestreo}

Muestrear consiste en seleccionar una parte de la población para su observación de modo que puedan obtenerse estimaciones sobre determinados parámetros o comportamientos de la población completa [Tho02]. Se considera población al conjunto de individuos o elementos que 


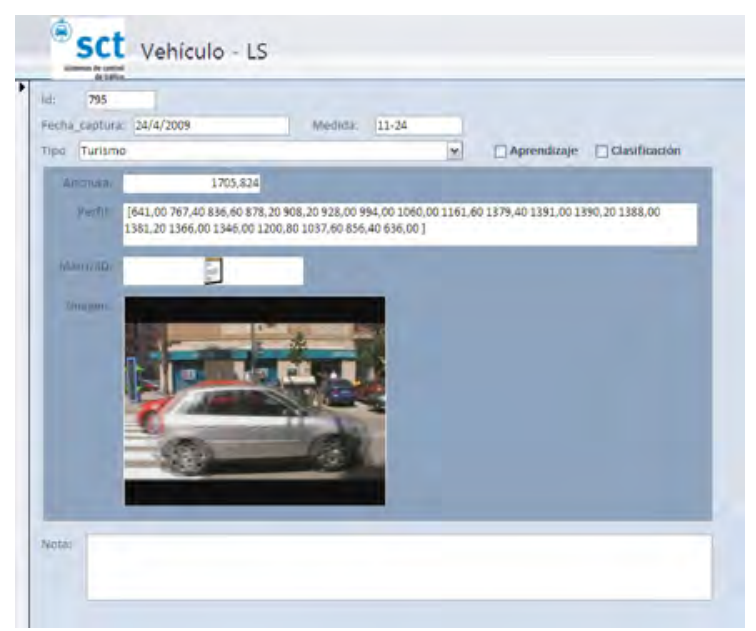

(a) Turismo

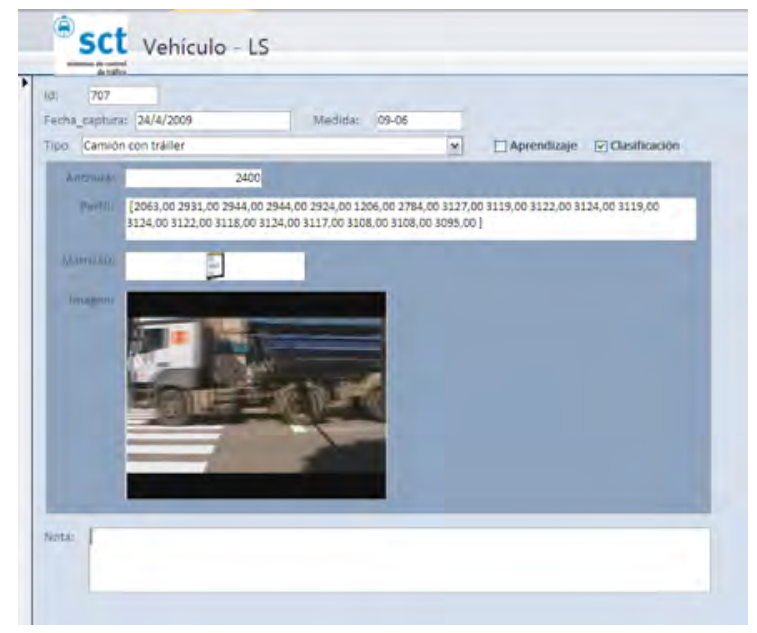

(c) Camión con tráiler

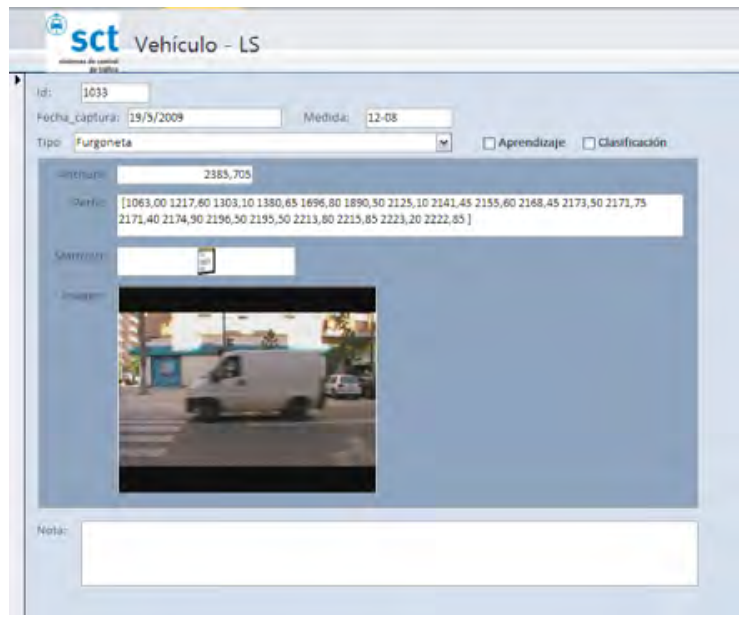

(b) Furgoneta

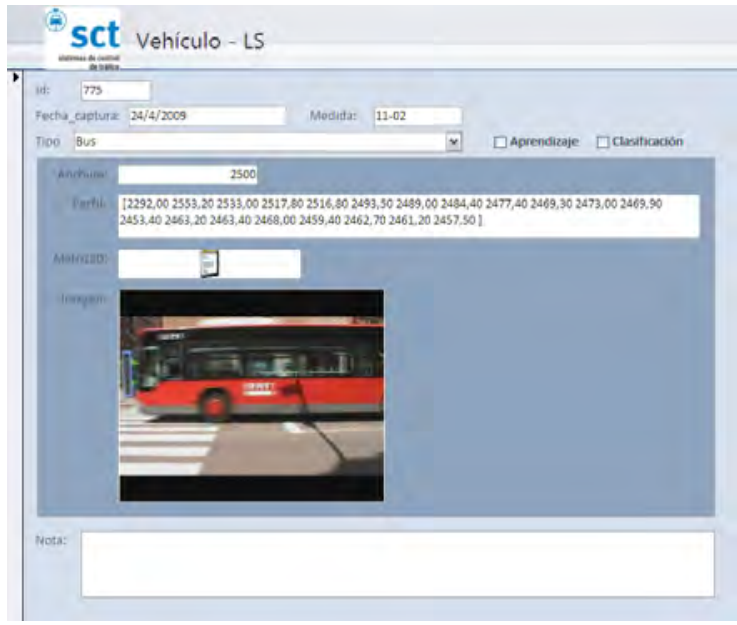

(d) Autobús

Figura 8.5 - Aspecto de la base de datos

se pueden observar y su tamaño es la cantidad de elementos de esta. Las dificultades a la hora de realizar estudios de una población radican en la posibilidad de que su tamaño no sea finito, sus elementos se destruyan, sufran daños al ser medidos o estén muy dispersos [Sán09, Tho02].

Una solución a este problema consiste en medir solo una parte de la población llamada muestra y tomar en ella un estimador medio como una aproximación al verdadero valor del estimador medio de la población. El tamaño de la muestra es la cantidad de elementos de la misma y sus poblaciones pueden ser finitas e infinitas. La muestra debe comprender toda la información deseada para tener la posibilidad de extraerla. Aunque esto sólo se puede lograr con una buena selección de la muestra y un trabajo muy cuidadosos y de alta calidad en la recogida de los datos [Sán09, Kis65]. 
El proceso de muestreo consta de dos etapas importantes: la selección del método de muestreo y el proceso de estimación. La selección del método de muestreo incluye las reglas y operaciones que definirán qué elementos de la población se incluyen en la muestra y porqué. El proceso de estimación se basa en cómo obtener la muestra de forma que represente, del mejor modo posible, a la totalidad de la población, esto es, definir su tamaño [Tho02, Kis65, Coc77].

A la hora de muestrear se ha empleado un método de muestreo probabilístico. De entre la multitud de métodos de muestro probabilístico existentes, cuatro de ellos son los más utilizados: el muestreo aleatorio simple, el muestro sistemático, el muestreo estratificado y el muestro por conglomerados [Tro06, Coc77]. Cuando no basta con que cada uno de los elementos muestrales tengan la misma probabilidad de ser escogidos, sino que además es necesario dividir la muestra en relación a estratos o categorías que se presentan en la población, y que además son relevantes para los objetivos del estudio, se diseña una muestra probabilística estratificada [Sán09]. La estratificación aumenta la precisión de la muestra e implica el uso deliberado de diferentes tamaños de muestra para cada estrato, "a fin de lograr reducir la varianza de cada unidad muestral"[Kis65].

El muestreo estratificado es el que mejor se ajusta al caso tratado en esta tesis, teniendo en cuenta el conocimiento previo que se posee de la clasificación al dividirse la población, vehículos, en base a una característica, tipo, que hace que pertenezcan a cada uno de los estratos o categorías de clasificación. A la hora de evitar el sesgo o error que aparece en los casos de estratificación hay que intentar que la muestra contenga las mismas proporciones de individuos con características comunes; de este modo las proporciones de individuos en las muestras serán las mismas que en la población global [Gil09]. Es decir, para que se pueda considerar un muestreo estratificado proporcional, se debe mantener en la muestra un número de individuos de cada categoría en proporción al peso de la misma dentro de la población final [Coc77].

\subsubsection{Tamaño muestral}

La decisión sobre el tamaño muestral necesario para que un estudio sea estadísticamente válido es uno de los pasos más importantes a la hora de definir una metodología de diseño de 
evaluación. La respuesta no es sencilla y depende de múltiples parámetros: el diseño muestral usado, la información disponible, el parámetro a considerar ... El problema de la determinación del tamaño de las muestras es muy complejo y no siempre tiene solución, ya que con frecuencia no se dispone de información suficiente acerca de la población para poder determinar la solución óptima [MMP04].

Sea el espacio muestral $X$ el que contiene todas las medidas vehículo. En el caso que nos ocupa $X$ es un espacio de 33 dimensiones cuyas coordenadas se corresponden con los parámetros utilizados en el estudio de cada uno de los vehículos, (ver página 182). Es decir, cada una de las medidas realizadas del tipo vehículo forman un vector de 33 valores. Lo importante es que cualquier definición de vehículos tiene la propiedad de poder ser clasificada dentro del espacio $X$ [BFOS84].

Se pretende calcular el tamaño de la muestra, $n$, de una población $N$, dividida en 6 estratos o categorías de tamaños $N_{h}, h=1, \ldots, 6$. Los datos del "Anuario 2008: Parque de vehículos" editado por la oficina de estadística del Ayuntamiento de Valencia [Ayu08] han sido usados como base de este estudio que permite definir el tamaño muestral, conocidos los tamaños de los estratos $N_{h}$. Si bien no todas las clases que se usarán posteriormente en la clasificación están presentes en dicho informe, los resultados sirven como base estadística que se extrapolará al caso bajo estudio.

Para determinar el tamaño muestral en muestreo estratificado proporcional los pasos a seguir son [MMP04]:

- especificar el tipo de afijación a seguir y calcularlo,

- determinar el tamaño de la muestra según el parámetro a estimar, en este caso se trata de una proporción,

- y cálculo de los tamaños muestrales de cada una de las categorías o estratos.

\subsubsection{Cálculo de la afijación}

La afijación es el criterio de reparto de unidades de muestra a cada categoría. En este caso se utiliza la afijación proporcional ya que no existe información sobre los costes de analizar 
una unidad en cada categoría, ni se dispone de buenas aproximaciones para las varianzas poblacionales en cada categoría. La afijación proporcional distribuye la muestra entre las categorías proporcionalmente al peso de estas según la ecuación 8.3.

$$
w_{h}=\frac{N_{h}}{N}
$$

donde,

$N_{h}$ es el tamaño de cada categoría,

y $N$ es el tamaño de la población.

Los valores en este caso para la afijación de cada uno de los estratos, o categorías, sustituyendo en la ecuación 8.3, se muestra en la tabla 8.3.

Tabla 8.3 - Valores de la afijación para cada una de las categorías

\begin{tabular}{ccc}
\hline Estrato & Tamaño del estrato & $\begin{array}{c}\text { Afijación Proporcional } \\
w_{h}(\%)\end{array}$ \\
Categoría & $N_{h}$ & 15,60 \\
Motocicletas & 79.080 & 74,87 \\
Turismos & 379.425 & 6,48 \\
Camión & 32.839 & 1,68 \\
Tractor & 8.494 & 0,20 \\
Autobús & 1.023 & 1,17 \\
Otros & 5.915 &, \\
\hline
\end{tabular}

\subsubsection{Cálculo del tamaño de la muestra}

Una vez obtenido el tipo de afijación se calcula el tamaño de muestra según el parámetro a estimar, en este caso una proporción, según la ecuación 8.4.

$$
n=\frac{\sum \frac{N_{h}^{3} P_{h}\left(1-P_{h}\right)}{N^{2}\left(N_{h}-1\right) w_{h}}}{a^{2}+\sum \frac{N_{h}^{2} P_{h}\left(1-P_{h}\right)}{N^{2}\left(N_{h}-1\right)}}
$$

donde,

$a=\frac{e}{z_{\alpha / 2}}$, si se fija el error máximo admisible, e, y el nivel de confianza, 1- $\alpha$,

y $P_{h}$ son las proporciones poblacionales dentro de cada categoría. 
El error máximo admisible, $e$, es una cota para definir la diferencia entre el parámetro y su estimación $|\theta-\hat{\theta}| \leq e$. Las aplicaciones prácticas no pueden garantizar un $100 \%$ de acierto entre el parámetro y su estimación $(\hat{\theta}-e<\theta<\hat{\theta}+e)$. Con lo que lo más habitual es fijar el nivel de confianza, $1-\alpha$, del $95 \%$, o lo que es lo mismo esperar que el suceso anterior ocurra un $95 \%$ de las veces. La precisión aumenta disminuyendo el error máximo admisible [MMP04]. Utilizando las tablas de áreas en una distribución normal Z y con niveles de confianza de 95\%, $z$ vale 1,96 [Mar07].

Si se sustituyen los valores conocidos en la ecuación 8.4, se obtiene un valor de $n$ igual a $248,85 \simeq 249$. Es decir, se requerirán al menos 249 vehículos para poder tener un nivel de confianza del $95 \%$, valor usado en la mayoría de estudios [MMP04]

\subsubsection{Cálculo de los tamaños muestrales de cada una de las categorías}

Una vez definida la afijación y calculado el tamaño de la muestra, solo resta calcular los tamaños muestrales de cada una de las categorías según la ecuación 8.5.

$$
n_{h}=\frac{n}{w_{h}}
$$

donde,

$n$ es es tamaño de la muestra,

y $w_{h}$ es la afijación proporcional.

Sustituyendo en la ecuación 8.5 los valores conocidos se obtiene para cada una de las categorías los valores de tamaño representados en la tabla 8.4.

En el caso de los autobuses, el tamaño muestral obtenido es 1. Esta circunstancia hace que la categoría de autobuses pueda presentar problemas en la fase de estimación de los errores del muestreo. Una de las posibles soluciones a este problema es aumentar en una unidad todas las submuestras de las categorías que presentan este problema [MMP04]. Aplicando esta solución, el tamaño muestral de la categoría de autobuses queda en 2. Dicha consideración se tiene en cuenta siempre que se repite la misma situación. 
Tabla 8.4 - Valores de los tamaños de la muestra para cada una de las categorías

\begin{tabular}{ccc}
\hline Estrato & \multicolumn{2}{c}{ Tamaño de la muestra } \\
Categoría & $n_{h}$ & Núm. vehículos \\
\hline Motocicletas & 39,7267 & 40 \\
Turismos & 190,6080 & 191 \\
Camión & 16,4970 & 17 \\
Tractor & 4,2670 & 5 \\
Autobús & 0,5139 & 1 \\
Otros & 2,9715 & 3 \\
\hline TOTAL & & 257 \\
\hline
\end{tabular}

\subsubsection{Parque de vehículos: datos proporcionados por la DGT}

Si bien los cálculos anteriores se han realizado con arreglo a la base de datos del parque de vehículos presentada por el Ayuntamiento de Valencia, existe otra base de datos que puede servir de referencia. Se trata de las publicaciones "Series históricas: Parque de Vehículos" presentada anualmente por la DGT. Los datos con los que se trabaja son los correspondientes al 2007, ya que a fecha de realización de esta tesis eran los últimos datos disponibles [DGT07]. Dicho informe baraja tanto valores a nivel nacional como regional, así se decidió realizar el mismo estudio tanto a nivel nacional como de la provincia de Valencia, ya que estos últimos son los que mejor se ajustan a la realidad del estudio.

En este caso, así como en el anterior, las categorías no se ajustan al $100 \%$ con las correspondientes al estándar TLS. El informe presenta las siguientes categorías: motocicletas, turismos, camionetas y furgonetas, autobuses, tractores industriales y otros vehículos. Aún así, los valores que se obtengan de estos estudios son extrapolables a nuestro estudio.

Los valores calculados se presentan a continuación. En el caso de estudio de la provincia de Valencia, se obtiene un valor de tamaño de muestra de $n=267,052 \simeq 268$. A partir de este valor se obtienen los tamaños de las categorías reflejados en la tabla 8.5. En el caso de estudio a nivel nacional, el valor de $n$ es de $269,583 \simeq 270$, los resultados se muestran en este caso en la tabla 8.6. 
Tabla 8.5 - Cálculo del tamaño de las categorías. Parque de vehículos provincia de Valencia $(D G T)$

\begin{tabular}{ccccc}
\hline Estrato & Tamaño del estrato & $\begin{array}{c}\text { Afijación Proporcional } \\
w_{h}(\%)\end{array}$ & \multicolumn{2}{c}{ Tamaño de la muestra } \\
Categoría & $N_{h}$ & 8,71 & 23,2526 & Núm. vehículos \\
\hline Motocicletas & 146.470 & 71,71 & 191,5050 & 192 \\
Turismos & 1.206 .303 & 15,61 & 41,6754 & 42 \\
Cam.+ Furg. & 262.516 & 1,03 & 2,7404 & 3 \\
Tractor & 17.262 & 0,15 & 0,4097 & 2 \\
Autobús & 2.581 & 2,80 & 7,4690 & 8 \\
Otros & 47.048 & & & 271 \\
\hline TOTAL & 1.682 .180 & & & \\
\hline
\end{tabular}

Tabla 8.6 - Cálculo del tamaño de las categorías. Parque de vehículos nacional (DGT)

\begin{tabular}{ccccc}
\hline Estrato & Tamaño del estrato & $\begin{array}{c}\text { Afijación Proporcional } \\
w_{h}(\%)\end{array}$ & \multicolumn{2}{c}{ Tamaño de la muestra } \\
Categoría & $N_{h}$ & 7,62 & 20,5517 & Núm. vehículos \\
\hline Motocicletas & 2.311 .346 & 71,77 & 193,4846 & 21 \\
Turismos & 21.760 .174 & 16,96 & 45,7085 & 46 \\
Cam.+ Furg. & 5.140 .586 & 0,70 & 1,8912 & 2 \\
Tractor & 212.697 & 0,20 & 0,5427 & 2 \\
Autobús & 61.039 & 2,75 & 7,4033 & 8 \\
Otros & 832.615 & & & 273 \\
\hline TOTAL & 30.318 .457 & &
\end{tabular}

\subsubsection{Conclusiones}

El objetivo de este procedimiento es validar estadísticamente el tamaño muestral usado en esta tesis. A modo de resumen, se van a presentar los resultados obtenidos anteriormente tras los cálculos llevados a cabo. La tabla 8.7 presenta: todos los vehículos con los que se cuenta en la base de datos diseñada; una comparativa de los resultados obtenidos anteriormente, mostrando los diferentes tamaños muestrales de las categorías adoptadas en esta tesis basadas en el estándar TLS; y las categorías definidas en los diferentes informes utilizados para el cálculo del tamaño muestral. La primera columna de la tabla refleja el número de vehículos totales por categorías con los que se ha trabajado en la tesis y que son el objetivo de la validación.

En vista de los resultados presentes en la tabla 8.7 se observa como en todos los casos el número de vehículos utilizados en la tesis es mayor que el necesario para que el estudio sea 
Tabla 8.7 - Comparativa tamaños muestrales por categorías

\begin{tabular}{ccccc}
\hline $\begin{array}{c}\text { Estrato } \\
\text { Categoría }\end{array}$ & Tesis & $\begin{array}{c}\text { Ayto Valencia } \\
\text { Local }\end{array}$ & $\begin{array}{c}\text { DGT } \\
\text { Provincia }\end{array}$ & $\begin{array}{c}\text { DGT } \\
\text { Nacional }\end{array}$ \\
\hline Motocicletas & 102 & 40 & 24 & 21 \\
Turismos & 1.350 & 191 & 192 & 194 \\
Furgonetas & 357 & - & 42 & 46 \\
Camiones & 75 & 17 & 3 & 2 \\
Camiones con tráiler & 14 & 5 & 2 & 2 \\
Autobuses & 49 & 2 & 8 & 8 \\
Otros & 0 & 3 & 271 & 273 \\
\hline TOTAL & 1.947 & 258 & &
\end{tabular}

significativo estadísticamente, ya que presenta tamaños muestrales superiores a los definidos en el peor caso, que es el de los datos relativos al parque de vehículos de la ciudad de Valencia.

Otro tema interesante, y tenido en cuenta, es el de las proporciones que representan cada categoría. Se pretende que una vez validado el tamaño de las muestras de las diferentes categoría, el porcentaje de individuos de cada una de ellas respecto a la población total sea lo más parecido posible a la realidad. La situación en este caso es análoga a la anteriormente presentada en el parque de vehículos, la disparidad de datos hace que no se tenga un patrón que seguir sino que haya que estudiar los distintos datos pertenecientes tanto al ayuntamiento de Valencia como a la DGT. Además, en este caso hay que tener en cuenta el hecho importante de que el emplazamiento seleccionado para realizar las medidas no puede representar a la totalidad de la población de un modo exacto, sino que puede presentar ciertas particularidades en función del tipo de tráfico de la zona, aunque sin que esto suponga una gran discrepancia con los datos que corresponderían al parque total de vehículos.

Si se analiza la tabla 8.8 se aprecia que una de las mayores diferencias de porcentajes es la presentada por los autobuses que pasa de una media de $0,75 \%$ en los datos oficiales a un 2,52\% en la presente tesis. Este hecho era de esperar al tratarse de una zona urbana que se encuentra dentro del recorrido de varias líneas de autobuses de la empresa municipal de transporte. Con lo cual, la circulación de este tipo de vehículos es normal que supere a la media del parque de vehículos. Aún así es importante destacar el hecho de que esta discrepancia, aún siendo la 
Tabla 8.8 - Porcentaje por categorías respecto a al población total

\begin{tabular}{ccccc}
\hline $\begin{array}{c}\text { Estrato } \\
\text { Categoría }\end{array}$ & Tesis & $\begin{array}{c}\text { Ayto Valencia } \\
\text { Local }\end{array}$ & $\begin{array}{c}\text { DGT } \\
\text { Provincia }\end{array}$ & $\begin{array}{c}\text { DGT } \\
\text { Nacional }\end{array}$ \\
\hline Motocicletas & $5,24 \%$ & $15,50 \%$ & $8,86 \%$ & $7,69 \%$ \\
Turismos & $69,34 \%$ & $74,03 \%$ & $70,85 \%$ & $71,06 \%$ \\
Furgonetas & $18,34 \%$ & - & & \\
Camiones & $3,85 \%$ & $6,59 \%$ & $15,50 \%$ & $16,85 \%$ \\
Camiones con tráiler & $0,72 \%$ & $1,94 \%$ & $1,11 \%$ & $0,73 \%$ \\
Autobuses & $2,52 \%$ & $0,78 \%$ & $0,74 \%$ & $0,73 \%$ \\
Otros & $0 \%$ & $1,16 \%$ & $2,95 \%$ & $2,93 \%$ \\
\hline
\end{tabular}

mayor de todas las clases, no representa un valor importante con lo que puede ser aceptado y no suponer mayores errores por ello.

Aunque parezca que la categoría de turismos presenta un porcentaje menor que el obtenido a partir de los datos oficiales, hay que realizar un estudio más detallado de los datos para ver que esta afirmación no es del todo correcta. Al no contemplarse el caso de furgonetas en los datos proporcionados por el ayuntamiento, no estamos en disposición de afirmar en qué grupo han sido incluidos los vehículos de este tipo. Aunque es posible conjeturar sin riesgo a incurrir en un número elevado de fallos, que aunque la mayoría de ellas deben haberse incluido como camiones las más pequeñas, de reparto, es más que probable que se hayan computado como turismos. Si esta hipótesis pudiera verificarse los porcentajes presentes en la tesis se acercarían aún más a la realidad del parque de vehículos.

En base a los datos sobre furgonetas y camiones presentados por la DGT, los porcentajes del ambos grupos son menores que los presentes en la tesis, un $16,85 \%$ frente a un $22,19 \%$. De nuevo es necesario fijarse en el emplazamiento real del sistema. Al tratase de una zona urbana y haberse tomado las medidas durante días laborables mayoritariamente, el número de furgonetas de reparto es elevado, haciendo que el porcentaje aumente.

Finalmente es importante remarcar que se trata de datos de difícil comparación ya que el número de categorías, ni es similar, ni reproduce el mismo tipo de vehículos. Incluso ante esta dificultad, los porcentajes presentados no muestran desviaciones considerables, pudiendo 
asumirse los valores tomados de cada una de las $8+1$ categorías como representativos de la población total.

\subsection{Proceso Aprendizaje}

La primera etapa de reconocimiento de patrones tras la recopilación de datos es la correspondiente al proceso de aprendizaje, como se ha explicado en el apartado Proceso de Clasificación: enfoque y metodología, (ver figura 8.1). En esta etapa se deben realizar diferentes tareas:

- Obtención de los parámetros que se usarán en la clasificación (Extracción de características).

- Definición de los patrones de cada discriminación mediante los árboles de clasificación.

\subsubsection{Parámetros seleccionados}

Tras la detección de los vehículos y su posterior procesado se obtiene una imagen 3D de los mismos, además del valor de la anchura. A partir de esta imagen 3D se obtiene el perfil de los vehículos, que es la información que se utiliza para calcular los parámetros usados en la discriminación por categorías. Toda esta información es almacenada en la base de datos y empleada para obtener los distintos parámetros usados en el proceso de aprendizaje y test.

La selección de los parámetros correctos es uno de los puntos claves del éxito de la clasificación. Decidir los parámetros que pueden resultar útiles para el estudio de los vehículos no es tarea sencilla ya que de la bondad de los mismos dependerán los resultados de la clasificación. Si se hubieran seleccionado parámetros diferentes es posible y probable que se hubieran obtenido resultados diferentes, aunque en este estudio se ha trabajado con el objetivo de obtener la mejor combinación posible. Estos parámetros se obtuvieron tras la realización de un estudio individualizado para cada una de las categorías, que ha permitido definir los parámetros que se consideran más representativos de cada una de ellas y que sirven como base para realizar las discriminaciones. 
Inicialmente, en base a la experiencia de estudios anteriores [Góm05], se consideraron más de 50 parámetros diferentes que podían definir características del vehículo susceptibles de ser discriminatorias en el proceso de clasificación. De estos, se eliminaron 17 que no ofrecieron resultados positivos en los procesos de discriminación. Los 33 parámetros que quedaron son los que se utilizaron finalmente en el proceso de aprendizaje. Estos parámetros también se pueden llamar parámetros predictivos, al ser los usados en la clasificación por categorías [Pha06]. A continuación se enumeran los parámetros con una breve descripción de los mismos.

- Anchura - Valor de la anchura de cada uno de los vehículos.

- Altura - Valor máximo del perfil.

- RatioXCF - Número de valores entre el centro del vehículo y el final que presentan un valor mayor de $\mathrm{X} \%$ del máximo del perfil. En este grupo hay cinco parámetros: Ratio50CF, Ratio60CF, Ratio70CF, Ratio80CF y Ratio90CF, que representan respectivamente al $50 \%, 60 \%, 70 \%, 80 \%$ y $90 \%$ del valor máximo del perfil o altura.

- RatioXIC - Número de valores entre el inicio y el centro del vehículo que presentan un valor mayor de X \% del máximo del perfil. En este grupo hay cinco parámetros: Ratio50IC, Ratio60IC, Ratio70IC, Ratio80IC y Ratio90IC, que representan respectivamente al 50\%, $60 \%, 70 \%, 80 \%$ y $90 \%$ del valor máximo del perfil o altura.

- RatioIC100_125 - Número de valores entre el inicio del vehículo y el centro del mismo que presenta valores entre 1,000 y $1,250 \mathrm{~m}$.

- Valor3XY - Tras dividir el perfil del vehículo en 2 partes (mediante 3 líneas: principio, centro y final) este valor muestra el número resultante de dividir el valor del perfil en la línea X entre el valor del perfil en la línea Y. En este grupo se encuentran los parámetros: Valor321 y Valor332.

- Valor5XY - Tras dividir el perfil del vehículo en 4 partes (mediante 5 líneas, siendo la primera la correspondiente al principio del vehículo y la última correspondiente al final) este valor muestra el número resultante de dividir el valor del perfil en la línea X entre el valor del perfil en la línea Y. En este grupo se encuentran los parámetros: Valor532 y Valor543. 
- Valor7XY - Tras dividir el perfil del vehículo en 6 partes (mediante 7 líneas, siendo la primera la correspondiente al principio del vehículo y la última correspondiente al final) este valor muestra el número resultante de dividir el valor del perfil en la línea $\mathrm{X}$ entre el valor del perfil en la línea Y. En este grupo se encuentran los parámetros: Valor724, Valor734, Valor754 y Valor764

- DerI50 - Cálculo de la derivada del perfil entre el valor inicial y el central del perfil del vehículo.

- Der50F - Cálculo de la derivada del perfil entre el valor central y el final del perfil del vehículo.

- RangoX_Y - Número de datos del perfil que se encuentran entre X e Y centímetros. Así, el parámetro Rango0_100 representa el número de datos del perfil que se encuentran entre 0 y 1 metros; Rango50_100 es el número de datos del perfil que se encuentran entre 0,50 y 1 metros; y así sucesivamente. En este grupo hay nueve parámetros: Rango0_100, Rango50_100, Rango100_125, Rango100_150, Rango150_175, Rango150_200, Rango200_250 y Rango250_300.

- Rango 300 - Número de datos del perfil mayores de 3 metros.

No todos los parámetros anteriores son usados en todas las discriminaciones ya que, evidentemente, en cada una de ellas los vehículos a clasificar presentan características diferentes. De hecho tras el análisis de cada una de las discriminaciones individualmente se han encontrado parámetros que no aportan información relevante a dicha discriminación y por lo tanto no han sido utilizados. Buena cuenta de cada uno de ellos se presenta más adelante cuando se expliquen las discriminaciones por separado.

\subsubsection{Definición de patrones: Árboles de clasificación}

El árbol de decisión usado, (ver figura 8.6), es binario ya que cada nodo interno contiene únicamente dos hijos o ramificaciones [Día07]. La estructura de condición y ramificación de un árbol de decisión es idónea para el caso de clasificación que nos ocupa. El árbol de clasificación se ha dividido hasta dar lugar a las diferentes discriminaciones, como puede apreciarse en la 
figura 8.6. Es importante no confundir este árbol de clasificación, desarrollado con el fin de clasificar los vehículos y diseñado en base al estándar TLS, con los árboles de clasificación que se han diseñado en cada una de las siete discriminaciones presentes en dicho árbol en base a los resultados del proceso de aprendizaje y la definición de patrones. Es decir, no se presentan ecuaciones ni fórmulas en las que sustituyendo los parámetros del vehículo se obtenga la clase a la que pertenece; sino que se utiliza un árbol de clasificación en cada una de las discriminaciones. Además, a estos árboles se les aplica las técnicas de poda hasta la obtención de los óptimos.

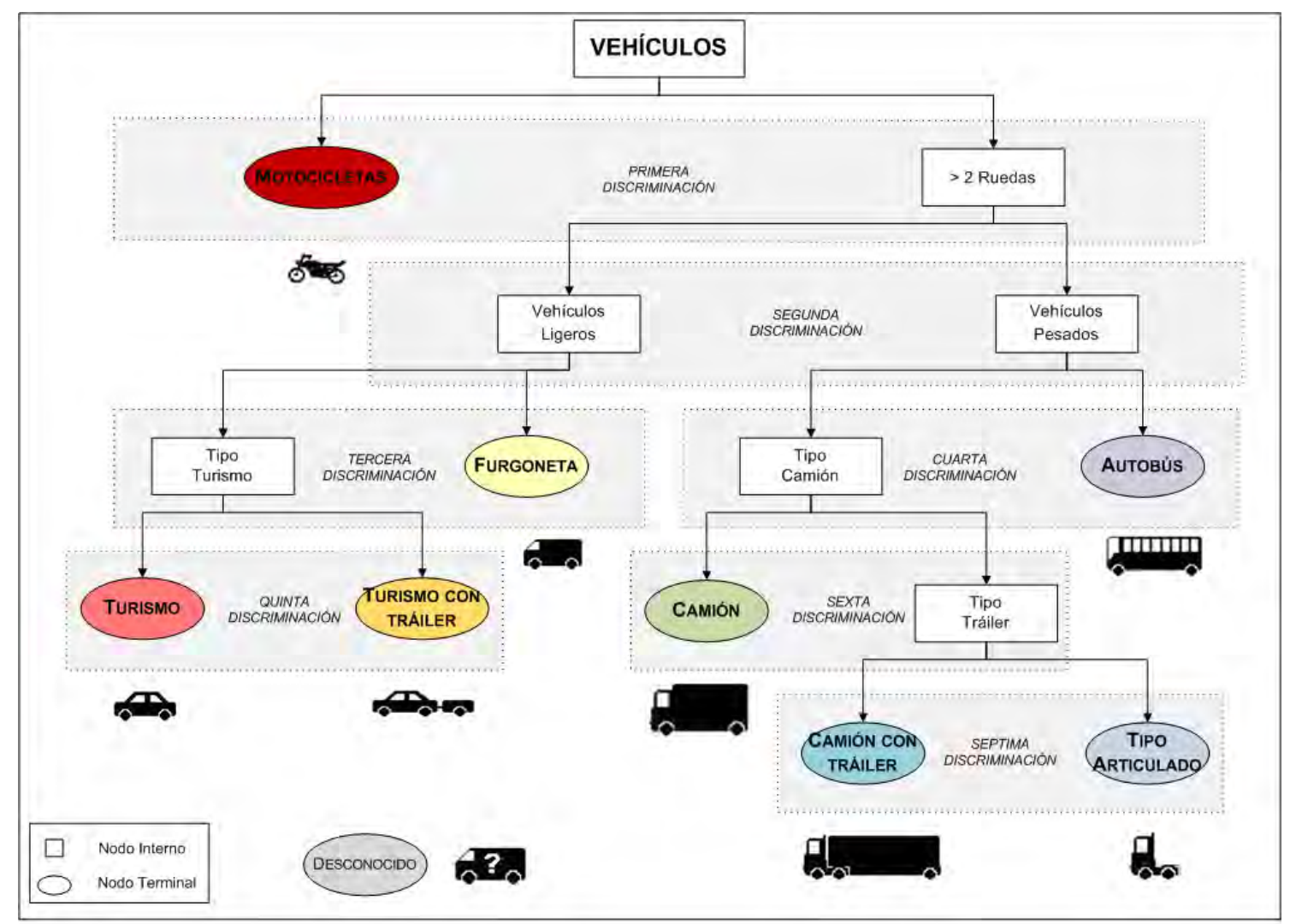

Figura 8.6 - Árbol de clasificación

La base de datos ha sido dividida en dos grupos: aprendizaje y test. El grupo de aprendizaje es el que ha servido de base para el diseño de la topología del árbol y las discriminaciones. Para realizar la discriminación entre clases se ha usado el paquete estadístico, concretamente la clase classregtree, [Mat09] del programa MATLAB en su versión R2008a, con el que se ha diseñado el programa Generar_Arboles. El algoritmo usado para árboles de clasificación y regresión por 
el paquete estadístico de MATLAB se basa en los propuestos por Breiman et al. en su libro "Classification and Regression Trees" [BFOS84].

A lo largo del presente capítulo se exponen los árboles de decisión que dan lugar a cada una de las discriminaciones del árbol 8.6. Asimismo, se describen los tipos de vehículos considerados en cada una de las categorías y los parámetros usados en cada uno de los árboles de clasificación. También se presentan algunos valores importantes a la hora de diseñar el árbol de clasificación como son: la proporción de clase en cada uno de los nodos, para evitar casos de sobre-ajuste, y el valor de los errores de clasificación, usado para realizar la posterior poda. Los árboles de clasificación han sido optimizados mediante técnicas de poda para no dar lugar a problemas de sobre-ajuste debido a un sobre-aprendizaje, al ser muy específicos para el grupo de aprendizaje.

A la hora de definir la proporción de una clase se considera que la clasificación se realiza en $Y$ clases que toman los valores $[1,2, \ldots, K]$ en función de $p$ parámetros de discriminación o predicción $\left[X_{1}, X_{2}, \ldots, X_{P}\right]$. En el nodo $m$, que contiene un subconjunto de observaciones $N_{m}$, la proporción de una clase $k$ cumple la ecuación 8.6.

$$
\hat{p}_{m}=\frac{1}{N_{m}} \sum_{i=1}^{N_{m}} I\left(y_{i}=k\right) \quad, \mathrm{k}=1, \ldots, \mathrm{K}
$$

donde,

$I(A)$ vale 1 cuando se cumple la condición $\mathrm{A}$, sino vale 0 .

El coste de clasificaciones erróneas en el nodo $m$ para la clase $k, r_{k}(m)$, se define según la ecuación 8.7.

$$
r_{k}(m)=\sum_{j} c(k \mid j) \pi_{m}(j)
$$

donde,

$\pi_{m}(j)$ es la probabilidad de que el nodo $\mathrm{m}$ sea de la clase $\mathrm{k}$,

y $c(i \mid j)$ es el coste de clasificar las clases $i$ y $j$ que cumple $c(i \mid j) \geq 0$ si $\mathrm{i} \neq \mathrm{j}$ y

$$
c(i \mid j)=0 \text { si } \mathbf{i}=\mathbf{j} .
$$


Finalmente, el error debido a clasificaciones erróneas se define en la ecuación 8.8.

$$
i_{m}(k)=\frac{1}{N_{m}} \sum_{i=1}^{N_{m}} I\left[y_{i} \neq k(m)\right]
$$

En cada una de las discriminaciones, explicadas en los apartados siguientes, se presentan los valores de: proporción de la clase definida en el nodo, coste de clasificaciones erróneas y error debido a las clasificaciones erróneas. Estos estimadores, calculados sobre el grupo de aprendizaje, permiten hacernos una idea de la bondad del árbol de discriminación construido [BFOS84].

\subsubsection{Primera Discriminación}

Se trata de la primera discriminación del árbol de decisión tras el nodo raíz, basada en la discriminación entre las categorías motocicletas y vehículos de más de dos ruedas. Esta discriminación da lugar a: un nodo interno que permite seguir distinguiendo entre categorías y un nodo terminal que da lugar a la primera categoría de vehículos: "motocicletas", (ver figura 8.6). El nodo de vehículos mayores de 2 ruedas da lugar al resto de categorías: turismo, turismo con tráiler, furgoneta, camión, camión con tráiler, tipo articulado y autobús.

El árbol de clasificación de la primera discriminación obtenido se representa en la figura 8.7, donde se ha utilizado únicamente el parámetro anchura para realizar la discriminación entre las categorías: motocicletas y vehículos mayores de dos ruedas.

Como se aprecia en la figura 8.7, este árbol muestra una estructura muy simple, donde del nodo raíz se llega directamente a los nodos terminales. Aunque las bicicletas no se han tenido en cuenta en este trabajo, se ha comprobado que cuando se ha detectado alguna de ellas han sido clasificadas correctamente como motocicletas.

Evidentemente, dado el árbol de clasificación obtenido no es necesaria la realización de una poda sobre el mismo para poder optimizarlo. De todas maneras, la gráfica 8.8 demuestra también que los niveles del árbol son los óptimos, ya que en el caso de dos nodos terminales el coste de errores de clasificación para el árbol es de 0. Por lo cual, la proporción de clasificacio- 


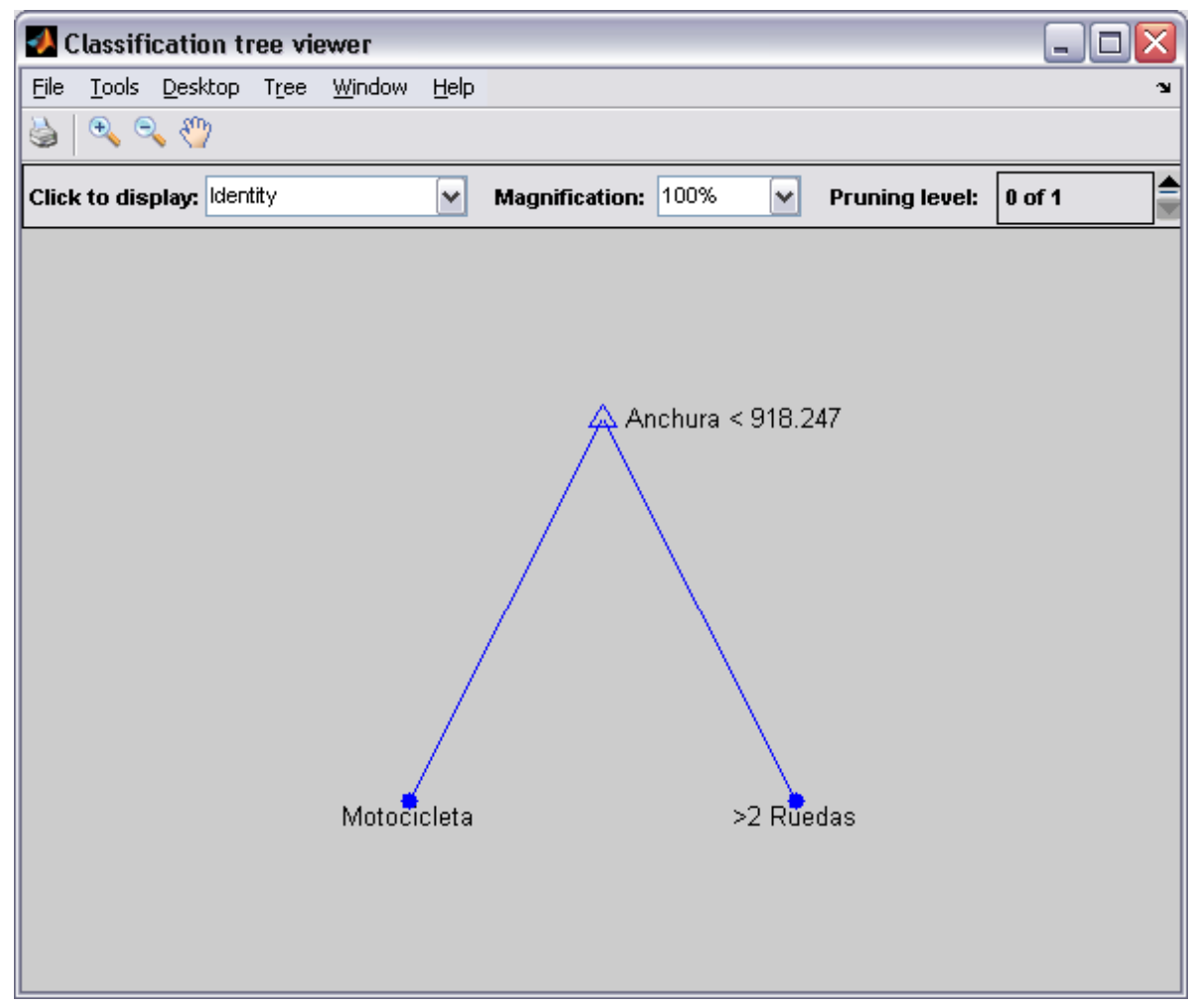

Figura 8.7 - Primera Discriminación: árbol de clasificación

nes correctas de la primera discriminación es de 1. El valor de otros parámetros se muestra en la tabla 8.10 .

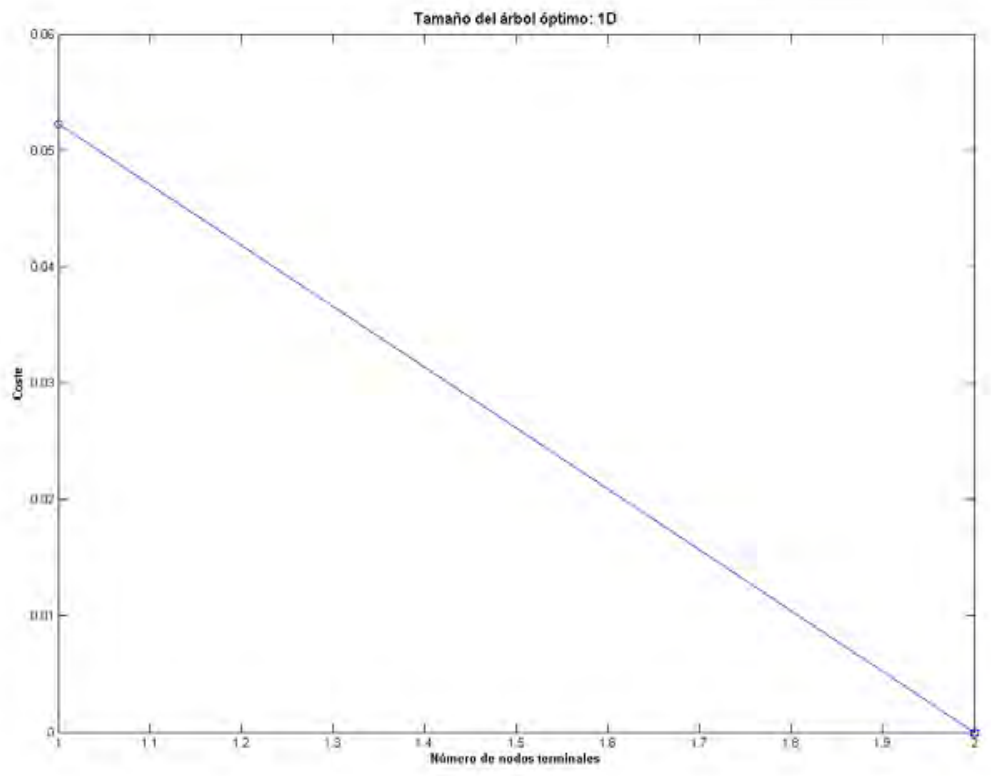

Figura 8.8 - Primera Discriminación: Tamaño óptimo del árbol 
Tabla 8.9 - Parámetros de la Primera Discriminación

\begin{tabular}{cccc}
\hline Nodo Terminal & $\begin{array}{c}\text { Clase } \\
(k)\end{array}$ & $\begin{array}{c}\text { Proporción de la clase } \\
\hat{p}_{m}\end{array}$ & $\begin{array}{c}\text { Coste de errores de clasificación } \\
r_{k}(m)\end{array}$ \\
\hline 1 & Motocicleta & 0,0523 & 0 \\
2 & $>2$ Ruedas & 0,9477 & 0 \\
\hline
\end{tabular}

\subsubsection{Segunda Discriminación}

La segunda discriminación tiene como objetivo diferenciar entre los nodos internos: "vehículos ligeros" y "vehículos pesados", (ver figura 8.6). Al tratarse de nodos internos, se sigue clasificando a partir de ellos en otras categorías. La rama de vehículos ligeros comprende las categorías: turismos, turismos con tráiler y furgonetas. Mientras, la rama de vehículos pesados abarca las categorías: camión, camión con tráiler, tipo articulado y autobús.

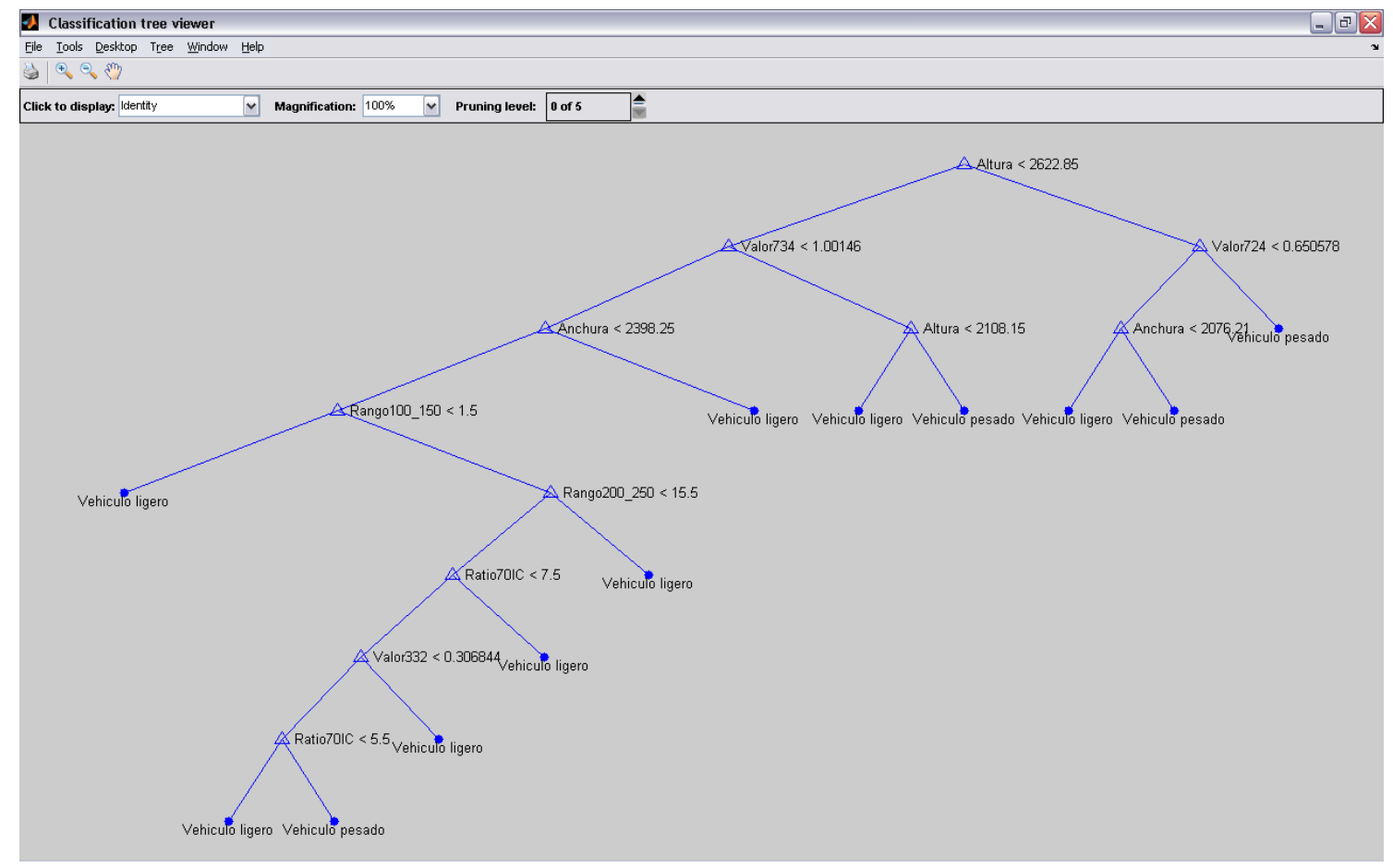

Figura 8.9 - Segunda Discriminación: árbol de clasificación

El árbol de clasificación de esta segunda discriminación, (ver figura 8.9), presenta 5 niveles diferentes y hace uso de 8 parámetros. Según el nivel en el que se encuentran, los parámetros son más o menos importantes. De este modo según orden de importancia, de mayor a menor, los parámetros son: altura, valor734, anchura, valor724, rango100_150, rango200_250, ratio70IC y 
valor332. Es decir, se analiza la parte delantera del vehículo mediante los parámetros valor734 y valor724, para saber si existe pendiente en esta parte del vehículo, si es así deriva en vehículos ligeros, sino da lugar a los vehículos pesados. El estudio es similar en la parte trasera mediante el parámetro valor332. La altura del vehículo se analiza mediante los parámetros: rango100_150, rango200_250 y ratio70IC. Valores que permiten conocer si el vehículo presenta valores de altura mayores de dos metros o entre 1 y 1,5 m. Los parámetros más importantes para la correcta discriminación son los que se encuentran en los nodos iniciales del árbol y en este caso son altura en el nivel 1 y valor734 en el nivel 2.

La gráfica 8.10 demuestra que los niveles del árbol son los óptimos. La línea continua muestra el coste estimado para cada nivel del árbol, la línea discontinua muestra el error estándar mínimo, y el cuadrado marca el nivel menor del árbol bajo la línea discontinua. En este caso aunque con 6 nodos terminales se obtiene el primer nivel que se encuentra por debajo del coste, se aprecia como este se reduce con 12 niveles presentando un valor de 0,0065 .

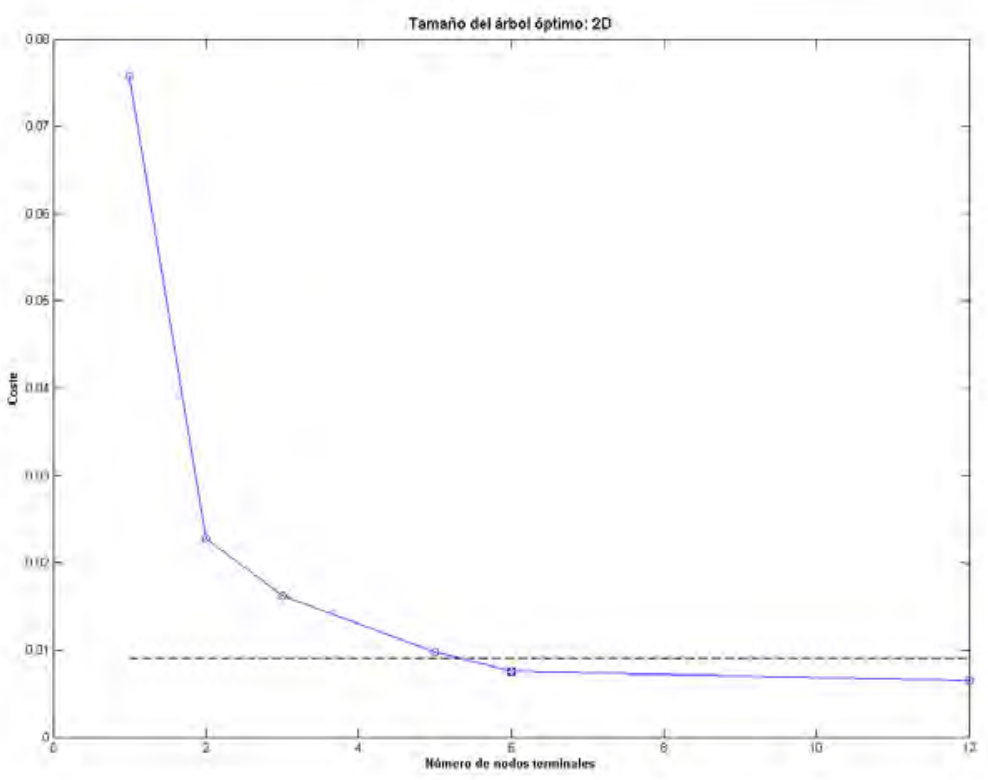

Figura 8.10 - Segunda Discriminación: Tamaño óptimo del árbol

La proporción de clasificaciones correctas de la segunda discriminación es 0,9935, y el coste debido a clasificaciones erróneas es de 0,0065. La tabla 8.10 muestra otros parámetros relativos a la segunda discriminación. 
Tabla 8.10 - Parámetros de la Segunda Discriminación

\begin{tabular}{cccc}
\hline Nodo Terminal & $\begin{array}{c}\text { Clase } \\
(k)\end{array}$ & $\begin{array}{c}\text { Proporción de la clase } \\
\hat{p}_{m}\end{array}$ & $\begin{array}{c}\text { Coste de errores de clasificación } \\
r_{k}(m)\end{array}$ \\
\hline 1 & V. Pesado & 0,0563 & 0 \\
2 & V. Ligero & 0,0054 & 0,4 \\
3 & V. Ligero & 0,0022 & 0 \\
4 & V. Pesado & 0,0087 & 0 \\
5 & V. Ligero & 0,0065 & 0 \\
6 & V. Pesado & 0,0054 & 0,2 \\
7 & V. Ligero & 0,0032 & 0,33 \\
8 & V. Ligero & 0,0054 & 0,2 \\
9 & V. Ligero & 0,0065 & 0,16 \\
10 & V. Ligero & 0,8885 & 0 \\
11 & V. Ligero & 0,0108 & 0 \\
12 & V. Pesado & 0,0001 & 0 \\
\hline
\end{tabular}

\subsubsection{Tercera Discriminación}

La tercera discriminación da lugar a la categoría de "furgoneta" y al nodo interno: "tipo turismo", (ver figura 8.6). Aún sin ser la de mayor número de vehículos involucrados esta discriminación es la más compleja debido a la gran diversidad de modelos de turismos y furgonetas. Dicha variedad en perfiles hace que los casos bajo estudio se multipliquen.

La categoría tipo turismo no comprende exclusivamente los modelos tipo berlina o los generalmente conocidos como turismos, sino que además incluye tipos como: sedan, micro coches, ejecutivos, gran turismos, coches deportivos, monovolúmenes e incluso todoterrenos 4x4, entre otros muchos. Se comprende así la complejidad y diversidad de esta categoría, algunos ejemplos de vehículos tipo turismo se pueden apreciar en el anexo A.

La discriminación tipo turismo incluye dos categorías: turismo y turismo con tráiler, (ver figura 8.6). Dado que en las pruebas de campo realizadas no se ha logrado encontrar ningún turismo con tráiler la quinta discriminación entre estas dos categorías no ha podido implementarse. A efectos reales la tercera discriminación se ha llevado a cabo entre dos categorías turismo y furgoneta, siendo los dos nodos terminales del árbol de clasificación.

Por otra parte la categoría furgoneta puede definirse como: vehículo de motor que es básicamente una "caja con ruedas" identificable por su área común de pasajero y/o de carga, piso 
elevado, y capó relativamente corto o inexistente, siguiendo la definición dada por el ANSI en su normativa D16.1-1996 [Ame96], (ver página 164).

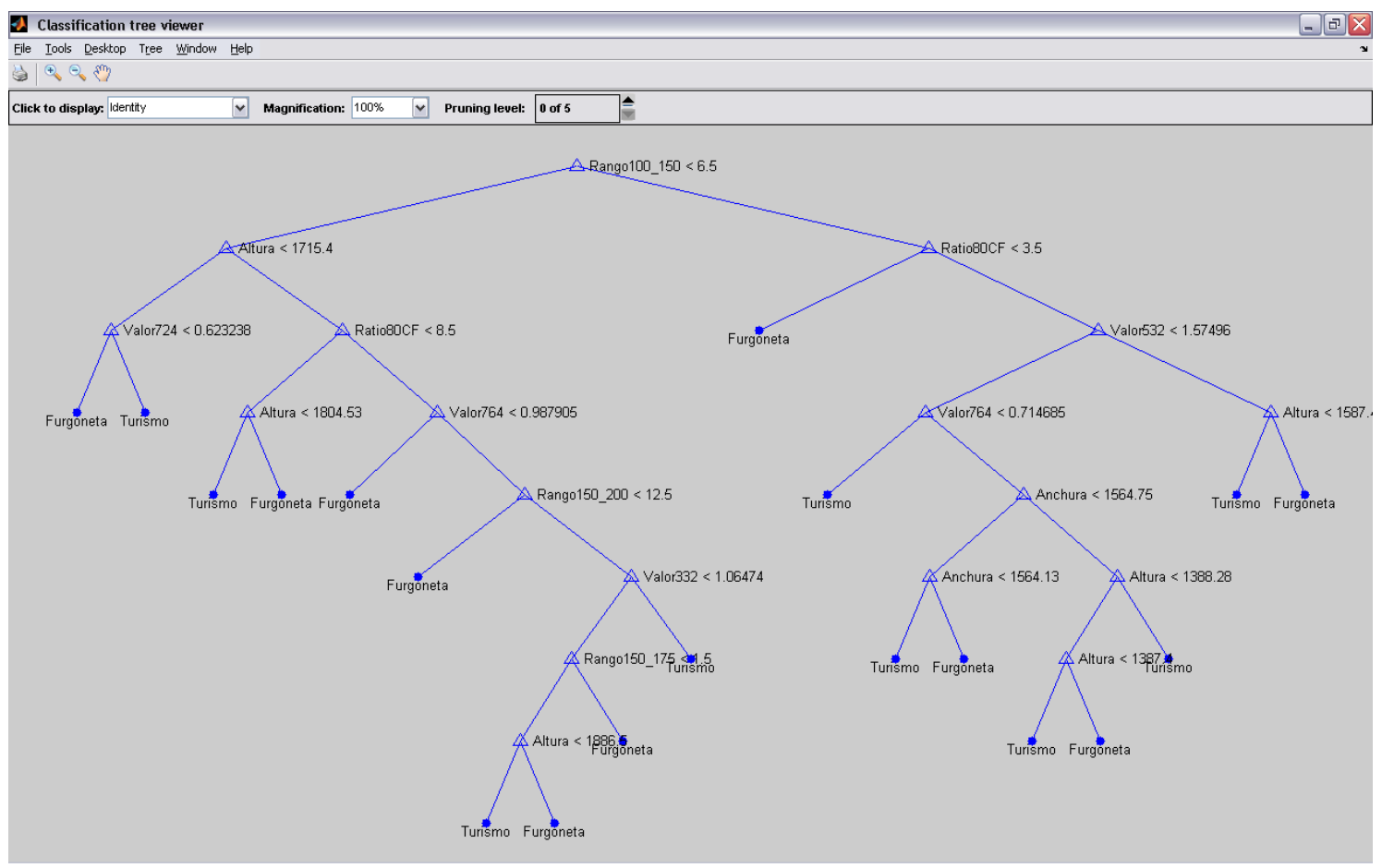

Figura 8.11 - Tercera Discriminación: árbol de clasificación

La tercera discriminación da lugar a un árbol de clasificación de 5 niveles, donde se usan 10 parámetros, (ver figura 8.11). Los parámetros usados son: Rango100_150, Altura, Ratio80CF, Valor724, Valor532, Valor764, Rango150_200, Valor332, Rango150_175 y Anchura. En este caso los más importantes son: rango100_150 de nivel 1, altura de nivel 2 y ratio80Cf, valor724 y altura de nivel 3. Mediante estos cinco parámetros se estudia principalmente la altura del vehículo y la pendiente de la parte delantera del mismo.

Al igual que la segunda discriminación, la gráfica 8.12 demuestra que los niveles del árbol son los óptimos. La línea continua muestra el coste estimado para cada nivel del árbol, mientras que la línea discontinua muestra el error estándar mínimo, y el cuadrado marca el nivel menor del árbol bajo línea discontinua. Con 19 nodos terminales se obtiene un coste de 0,0117.

La proporción de clasificaciones correctas de la tercera discriminación es 0,9883 y el error debido a clasificaciones erróneas es de 0,0117. La tabla 8.11 muestra otros parámetros relativos a esta discriminación. 


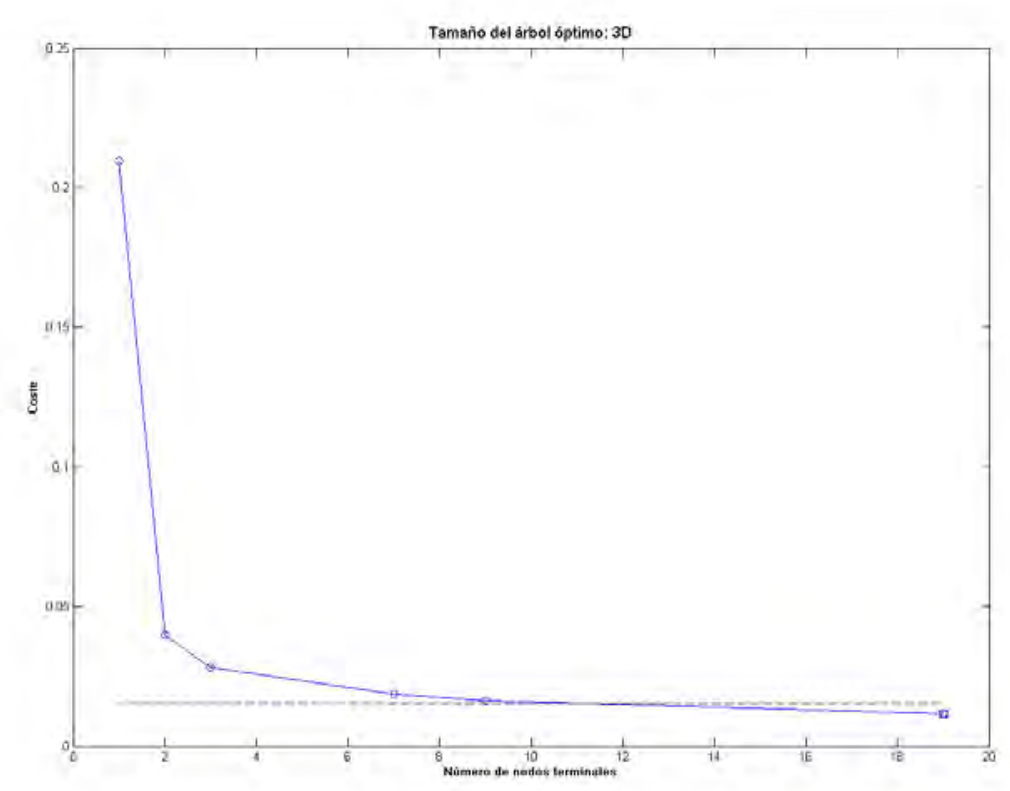

Figura 8.12 - Tercera Discriminación: Tamaño óptimo del árbol

Tabla 8.11 - Parámetros de la Tercera Discriminación

\begin{tabular}{|c|c|c|c|}
\hline Nodo Terminal & $\begin{array}{l}\text { Clase } \\
(k)\end{array}$ & $\begin{array}{l}\text { Proporción de la clase } \\
\qquad \hat{p}_{m}\end{array}$ & $\begin{array}{l}\text { Coste de errores de clasificación } \\
\qquad r_{k}(m)\end{array}$ \\
\hline 1 & Furgoneta & 0,0023 & 0 \\
\hline 2 & Furgoneta & 0,0047 & 0,2500 \\
\hline 3 & T. Turismo & 0,0141 & 0 \\
\hline 4 & T. Turismo & 0,0070 & 0,1667 \\
\hline 5 & Furgoneta & 0,0094 & 0,1250 \\
\hline 6 & Furgoneta & 0,0082 & 0,2857 \\
\hline 7 & T. Turismo & 0,0105 & 0,1111 \\
\hline 8 & T. Turismo & 0,0176 & 0 \\
\hline 9 & Furgoneta & 0,0023 & 0 \\
\hline 10 & Furgoneta & 0,1440 & 0,0081 \\
\hline 11 & T. Turismo & 0,0012 & 0 \\
\hline 12 & T. Turismo & 0,0656 & 0,0179 \\
\hline 13 & Furgoneta & 0,0012 & 0 \\
\hline 14 & T. Turismo & 0,6218 & 0 \\
\hline 15 & Furgoneta & 0,0234 & 0 \\
\hline 16 & T. Turismo & 0,0468 & 0 \\
\hline 17 & Furgoneta & 0,0012 & 0 \\
\hline 18 & T. Turismo & 0,0035 & 0,0333 \\
\hline 19 & Furgoneta & 0,0152 & 0,0769 \\
\hline
\end{tabular}

\subsubsection{Cuarta Discriminación}

El grupo “tipo camión” integra las categorías: camión, camión con tráiler y tipo articulado. 
Se consideran vehículos de la categoría "autobús" a los que cumplen la definición: automóvil que tenga más de 9 plazas incluida la del conductor, destinado, por su construcción y acondicionamiento, al transporte de personas y sus equipajes. Esta es la definición dada por el Ayuntamiento de Valencia es su “Anuario 2008” [Ayu08], (ver página 164).

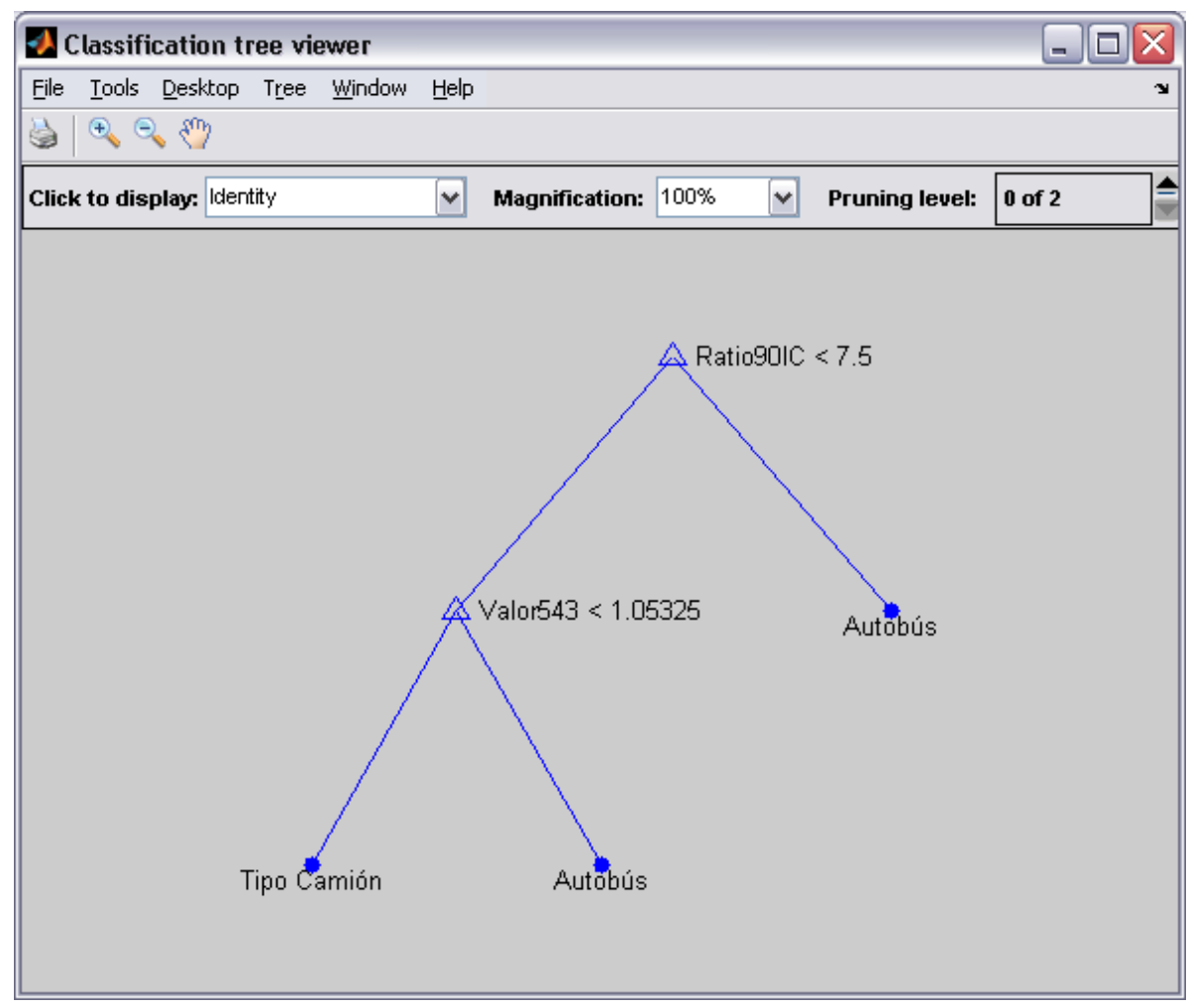

Figura 8.13 - Cuarta Discriminación: árbol de clasificación

La categoría autobús y el nodo intermedio tipo camión se obtienen en la cuarta discriminación, (ver figura 8.6). Dada la homogeneidad de la mayoría de los vehículos de estas categorías, el árbol de clasificación presenta sólo 2 niveles y se utilizan 2 parámetros: ratio90IC y valor543, (ver figura 8.13). Estos parámetros estudian la homogeneidad en la altura del vehículo y su parte central.

La gráfica 8.14 demuestra que los niveles del árbol de clasificación diseñado son los óptimos. Con 3 nodos terminales se obtiene un coste de 0,0286. La proporción de clasificaciones correctas de esta discriminación es 0,9714 y el error debido a clasificaciones erróneas es de 0,0286. La tabla 8.12 muestra otros parámetros relativos a la esta discriminación. 


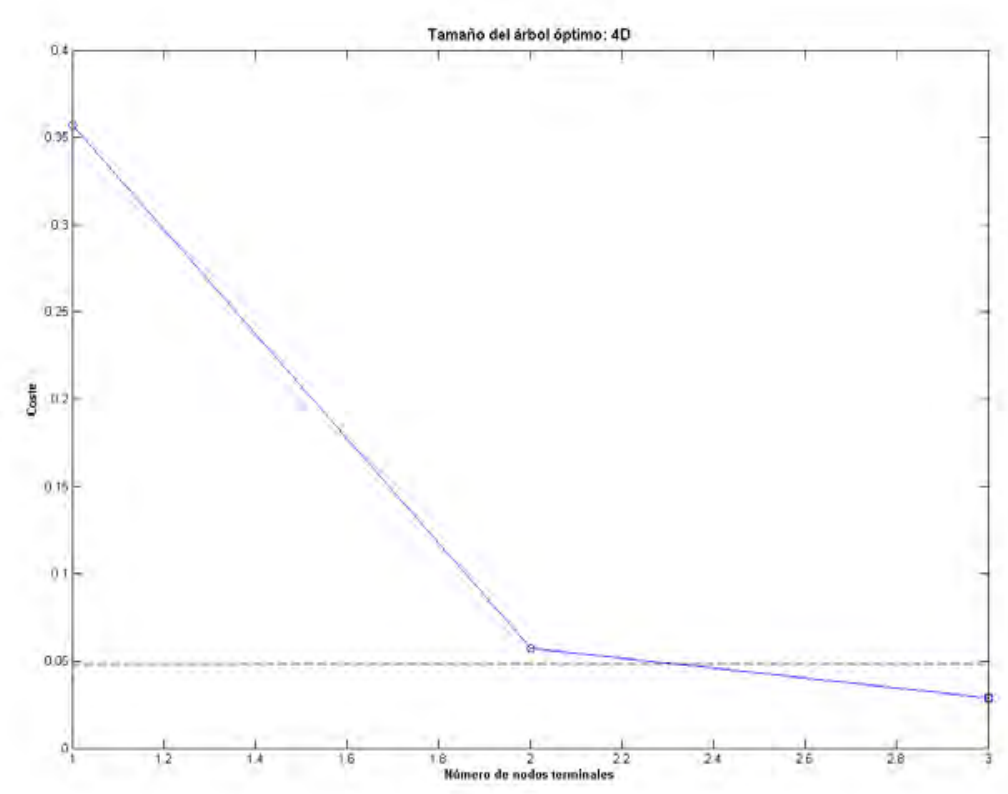

Figura 8.14 - Cuarta Discriminación: Tamaño óptimo del árbol

Tabla 8.12 - Parámetros de la Cuarta Discriminación

\begin{tabular}{cccc}
\hline Nodo Terminal & Clase & $\begin{array}{c}\text { Proporción de la clase } \\
\hat{p}_{m}\end{array}$ & $\begin{array}{c}\text { Coste de errores de clasificación } \\
r_{k}(m)\end{array}$ \\
\hline 1 & Autobús & 0,3286 & 0,0435 \\
2 & T. Camión & 0,6492 & 0,0222 \\
3 & Autobús & 0,0286 & 0 \\
\hline
\end{tabular}

\subsubsection{Sexta Discriminación}

Finalmente, el caso de la sexta discriminación es similar al de la tercera. El "tipo articulado", presente en la séptima discriminación, no ha podido detectarse al no circular ningún vehículo de esta categoría. Esta categoría representa a las cabezas tractoras únicamente, es decir, la parte delantera del camión con tráiler pero sin el mismo.

Justamente por ello, el tipo tráiler que forma parte de la sexta discriminación y agrupaba a esta categoría y a camión con tráiler, representa a efectos prácticos únicamente a vehículos de la categoría camión con tráiler. Este tipo de vehículos son automóviles que presentan una cabeza articulada que puede separarse del tráiler que remolcan. Así, la sexta discriminación se realiza entre las dos categorías y nodos terminales: camión y camión con tráiler, (ver figura 8.6). 
Se consideran vehículos de la categoría camión a los que cumplen la definición: automóvil con cuatro ruedas o más, concebido y construido para el transporte de mercancías, cuya cabina no está integrada en el resto de la carrocería. Esta es la definición dada por el Ayuntamiento de Valencia es su anuario 2008 [Ayu08], (ver página 164).

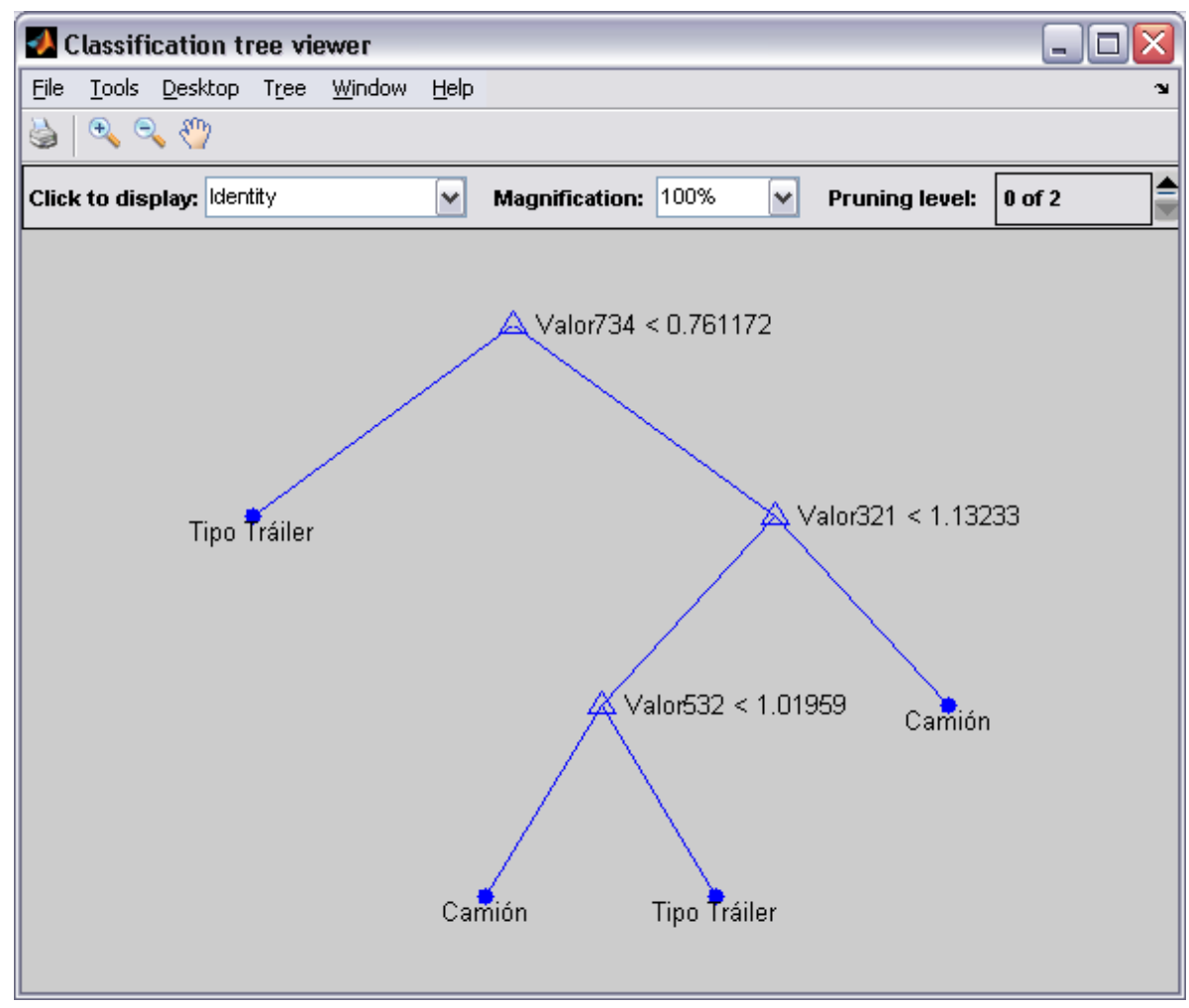

Figura 8.15 - Sexta Discriminación: árbol de clasificación

Finalmente, el árbol de decisión que da lugar a la sexta discriminación se muestra en la figura 8.15. Dicho árbol presenta 2 niveles y únicamente usa 3 parámetros. Estos son: valor734, valor321 y valor532. Evidentemente, todos ellos se centran en la búsqueda de la zona característica que existe entre la cabeza tractora y el tráiler que presenta valores de altura muy bajos.

La gráfica 8.16 demuestra que los niveles del árbol de clasificación diseñado son los óptimos. Con 4 nodos terminales se obtiene un coste de 0 . Esta discriminación es, junto a la primera, la más exacta debido a que la proporción de clasificaciones correctas de esta discriminación es de 1 y el error debido a clasificaciones erróneas es de 0 . La tabla 8.13 muestra otros parámetros relativos a la esta discriminación. 


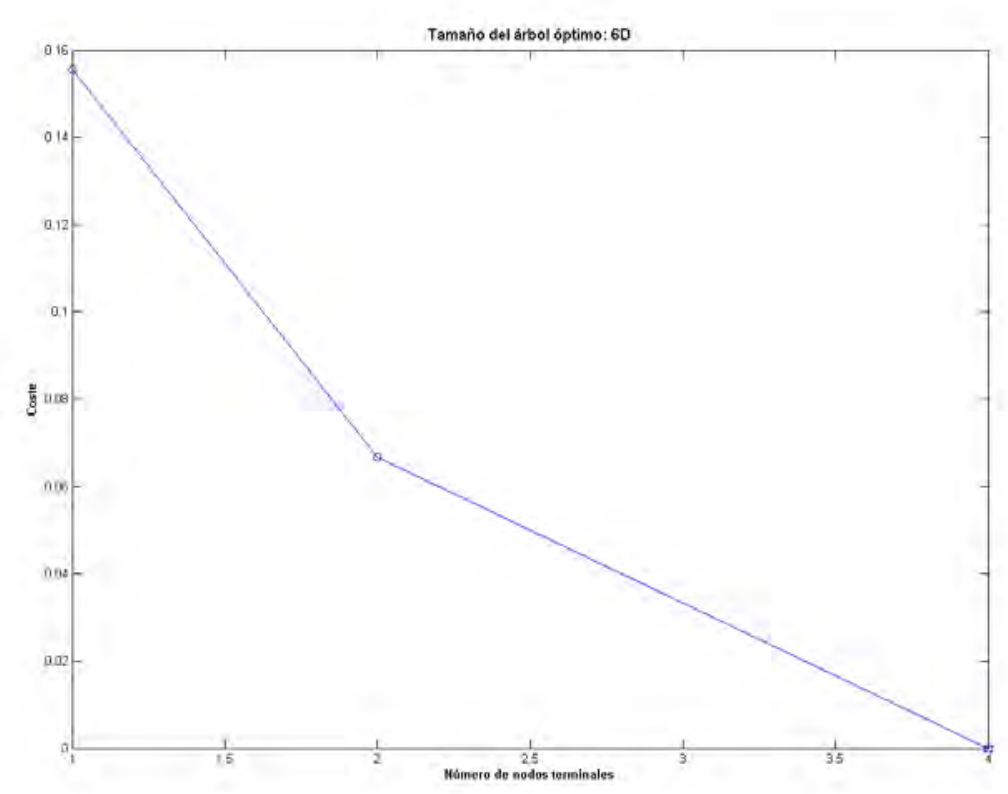

Figura 8.16 - Sexta Discriminación: Tamaño óptimo del árbol

Tabla 8.13 - Parámetros de la Sexta Discriminación

\begin{tabular}{cccc}
\hline Nodo Terminal & $\begin{array}{c}\text { Clase } \\
(k)\end{array}$ & $\begin{array}{c}\text { Proporción de la clase } \\
\hat{p}_{m}\end{array}$ & $\begin{array}{c}\text { Coste de errores de clasificación } \\
r_{k}(m)\end{array}$ \\
\hline 1 & T. Tráiler & 0,0889 & 0 \\
2 & Camión & 0,6667 & 0 \\
3 & Camión & 0,1778 & 0 \\
4 & T. Tráiler & 0,0667 & 0 \\
\hline
\end{tabular}

\subsubsection{Conclusiones}

De los 33 parámetros predictivos con los que se ha iniciado el proceso de aprendizaje, solo 16 han sido usados finalmente. Los parámetros utilizados han sido: anchura, altura, ratio80CF, ratio70IC, ratio90IC, valor321, valor332, valor532, valor543, valor724, valor734, valor764, rango100_150, rango150_175, rango150_200 y rango200_250.

El proceso de aprendizaje se ha llevado a cabo mediante una serie de programas desarrollados ex profeso para esta tesis. Se han realizado diferentes consultas sobre la base de datos, de forma que cada uno de los vehículos ha sido almacenado en un archivo de texto según su clase. Estos archivos contienen la anchura y el vector del perfil de todos los vehículos del grupo de aprendizaje para cada una de las clases. 
La extracción de características se ha realizado mediante un programa diseñado usando $M i$ crosoft Visual Studio llamado Clasicoche, (ver código en el anexo B pág. 291). Se ha ejecutado dicho programa sobre cada uno de los archivos de texto obtenidos con anterioridad, de modo que se producen otros tantos archivos tipo excel donde se han calculado todos los parámetros para cada uno de los vehículos. La figura 8.17 muestra el aspecto del programa Clasicoche tomando como ejemplo el caso de turismos. Como se aprecia en la figura el mismo programa permite ser utilizado para la obtención de estos parámetros y para realizar la clasificación del grupo de test con posterioridad. En ambos casos permite exportar los resultados a un archivo formato excel.

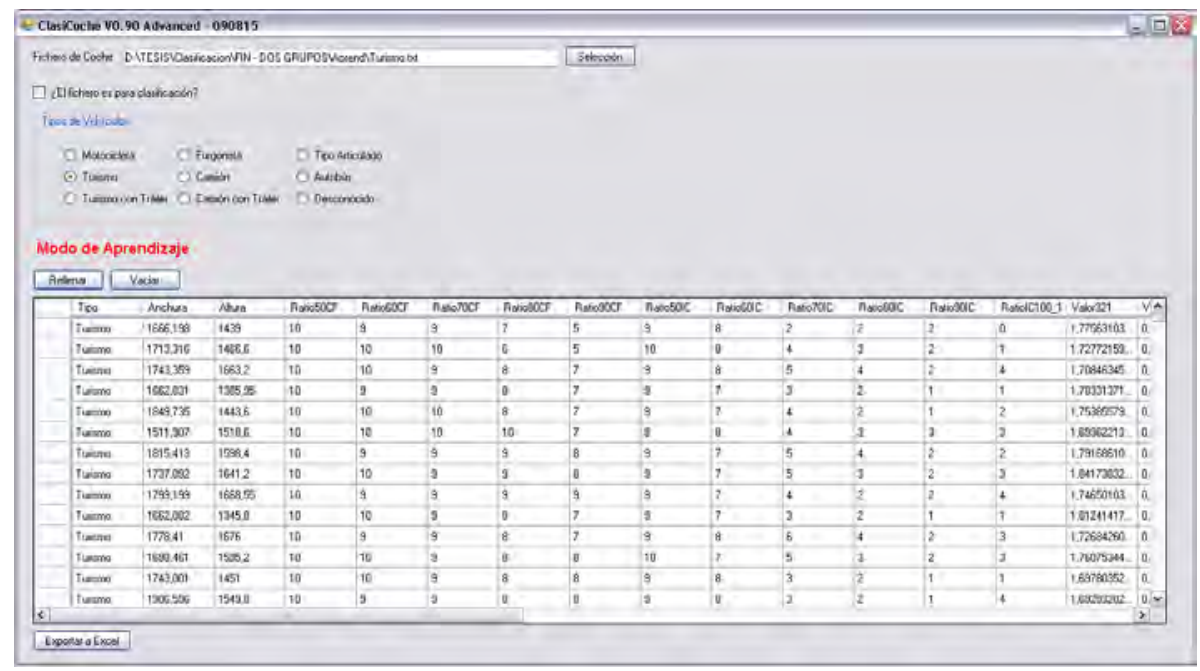

Figura 8.17 - Programa para la obtención de los parámetros

Tras la obtención de los parámetros significativos se ha procedido al diseño de los árboles de decisión para cada una de las discriminaciones. En este caso, la tarea se ha llevado a cabo mediante el programa $M A T L A B$ y ejecutando el archivo diseñado Generar_Arboles, (ver código en el anexo C pág. 303). De este modo se ha llegado a cada uno de los árboles de decisión para cada una de las discriminaciones presentadas en los anteriores apartados.

La figura 8.18 representa esquemáticamente el flujo llevado a cabo en el proceso de aprendizaje, con cada uno de los programas que se ejecutan en cada paso.

El árbol de clasificación debe ser capaz de predecir el resultado de nuevos casos a partir de lo aprendido con los datos del grupo de aprendizaje, generalizando, para poder resolver situaciones distintas a las acaecidas durante el entrenamiento. Sin embargo, cuando un sistema se entrena 


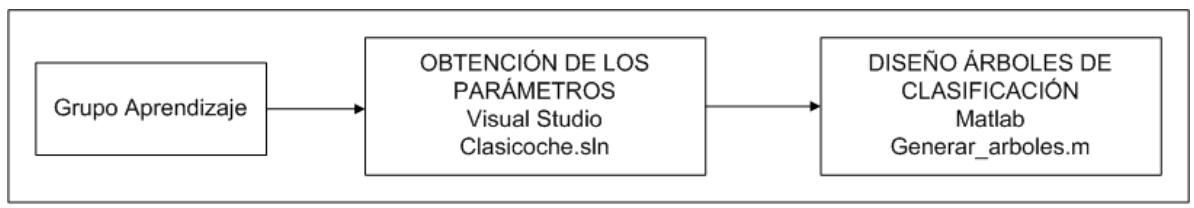

Figura 8.18 - Flujo del Proceso de Aprendizaje

demasiado o se entrena con datos extraños, el algoritmo de aprendizaje puede quedar ajustado a unas características muy específicas y anómalas que pueden no reproducir las características globales de la población. Ante estas situaciones de sobre-ajuste se puede tener éxito a la hora de responder con las muestras de entrenamiento mientras que, si se emplean muestras nuevas este acierto va empeorando. Se debe evitar estos casos realizando un diseño correcto de árbol y una selección apropiada de las muestras de entrenamiento. Así, en todas las discriminaciones ha sido realizado un análisis de poda demostrando que el tamaño del árbol es el correcto y que los nodos terminales minimizan el coste de diseño.

\subsection{Proceso de Test}

La evaluación se realiza aplicando la técnica de Bootstrap al grupo de test. Como se ha explicado anteriormente, en el capítulo Proceso de Clasificación: enfoque y metodología, dicha técnica de remuestreo se utiliza para aproximar la distribución en el muestreo de un estadístico y para reducir el sobre-optimismo que se produciría debido a clasificaciones calculadas sobre el grupo de aprendizaje.

Los pasos seguidos en base a la técnica Bootstrap han sido los siguientes:

- Crear un nuevo grupo de test con reemplazo, partiendo del grupo de test original con 972 elementos,

- Clasificar cada uno de los elementos del nuevo grupo en base a los árboles de clasificación desarrollados en el proceso de aprendizaje.

- Obtener los estimadores o indicadores que permiten evaluar la clasificación.

- Repetir el proceso 1.000 veces. 
- Calcular los estimadores bootstrap a partir de cada uno de los parámetros calculados en cada uno de los 1.000 grupos de test.

Los indicadores o estimadores empleados para evaluar cada clasificación son los parámetros estándar basados en una matriz de confusión. Dicha matriz ha sido calculada en cada uno de los 1.000 grupos de test obtenidos mediante reemplazo y ha permitido obtener los diferentes valores con los que se ha evaluado cada una de las discriminaciones.

La matriz de confusión presenta los datos de detección reales y los predichos, (ver tabla 8.14).

Tabla 8.14 - Matriz de Confusión

\begin{tabular}{lc|cc} 
& & \multicolumn{2}{c}{ Evento Real } \\
\cline { 2 - 4 } Evento & & $A$ & $B$ \\
Detectado & $A$ & TP & FP \\
\cline { 2 - 3 } & $B$ & FN & TN \\
\cline { 2 - 3 }
\end{tabular}

Esta matriz sirve, además de para demostrar la bondad del modelo, para evidenciar los detalles de dónde las cosas pudieron haber salido mal. Los valores que se usan en la tabla aplicados al caso de discriminaciones entre dos grupos A y B son, [TRA08]:

- TP (Verdadero Positivo) - número de vehículos A clasificados como tal, decisión correcta.

- FN (Falso Negativo) - número de vehículos A clasificados como B.

- FP (Falso Positivo) - número de vehículos B clasificados como A.

- TN (Verdadero Negativo) - número de vehículos B clasificados como tal, decisión correcta.

De la matriz de confusión se calculan los siguientes estimadores:

$$
\text { Exactitud }=\frac{T P+T N}{T P+F P+F N+T N}
$$

Ratio de Clasificación correcta de $\mathrm{A}=\frac{T P}{T P+F N}$

Ratio de Clasificación correcta de $\mathrm{B}=\frac{T N}{T N+F P}$ 


$$
\text { Precisión de } \mathrm{A}=\frac{T P}{T P+F P}
$$

$$
\text { Precisión de } \mathrm{B}=\frac{T N}{T N+F N}
$$

Ratio de Falsos Positivos $=\frac{F P}{T N+F P}=1-$ Ratio de Clasificación correcta de B

Ratio de Falsos Negativos $=\frac{F N}{T P+F N}=1-$ Ratio de Clasificación correcta de A

La exactitud presenta el ratio de las clasificaciones correctas sobre todas las clasificaciones, es decir, cuan cerca del valor real se está. Los ratios de clasificación presentan la relación entre el número de clasificaciones correctas de una clase y el número total de vehículos de dicha clase, es decir, se trata de los vehículos de una clase clasificados efectivamente como pertenecientes a dicha clase.

Por otra parte, la precisión muestra la relación entre las clasificaciones correctas de una clase y el número total de vehículos clasificados en dicha clase, es decir, presenta el ratio de vehículos clasificados como una clase que de hecho pertenecen a ella. Los falsos positivos sirven para acotar las áreas donde se debe trabajar para mejorar, además de indicar la relación entre los vehículos de una clase no detectados y los vehículos totales de la clase.

La forma gráfica seleccionada para la representación de los datos es el histograma, que muestra las frecuencias con las que se repiten los valores medidos identificando la distribución. Además, se han ajustado mediante una distribución gaussiana. 


\subsubsection{Primera Discriminación}

La primera discriminación se realiza con éxito en todas y cada una de las 1.000 submuestras de bootstrap realizadas como se demuestra en los resultados de la tabla 8.15. En esta clasificación se discrimina entre motocicletas y vehículos $>2$ ruedas.

Tabla 8.15 - Matriz de Confusión de la Primera discriminación

\begin{tabular}{rcc}
\hline \multicolumn{1}{l}{$\begin{array}{l}\text { Primera Discriminación } \\
\text { Exactitud (\%) } \\
\text { Ratio de Clasificación (\%) }\end{array}$} & Motocicletas & $>2$ Ruedas \\
Precisión (\%) & 100 & 100 \\
Ratio de Falsas Clasificaciones(\%) & 0 & 100 \\
\hline
\end{tabular}

La figura 8.19, que muestra el diagrama de dispersión de los vehículos clasificados según su tipo, en relación a la altura y anchura de los mismos, clarifica esta situación, que se debe fundamentalmente a las características intrínsecas de la discriminación.

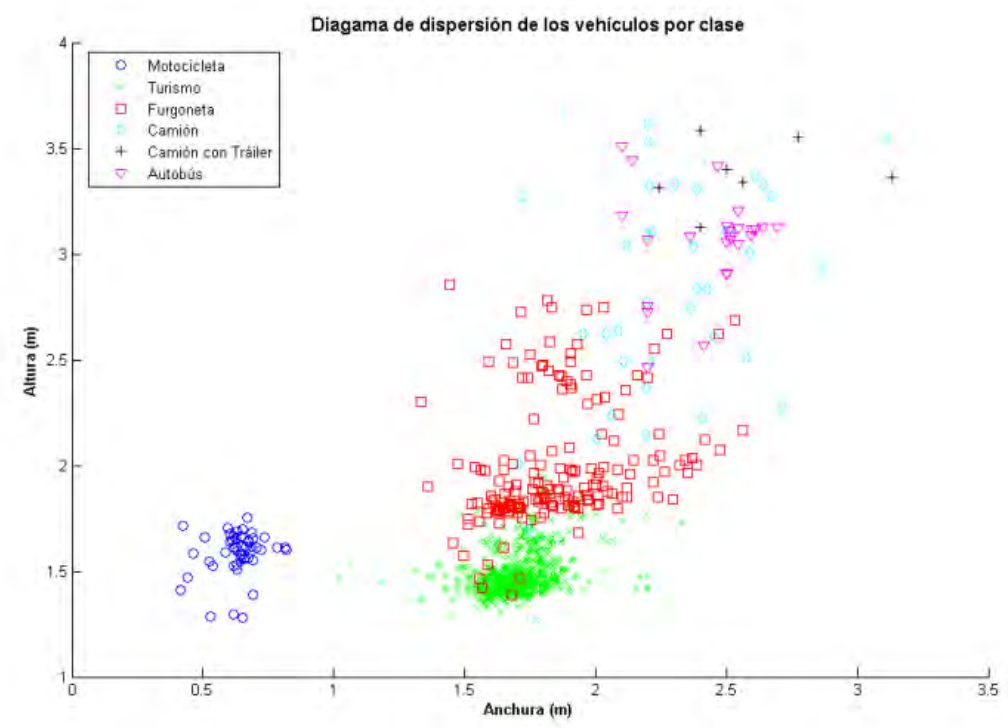

Figura 8.19 - Diagrama de dispersión

En dicha gráfica se puede apreciar como el grupo de motocicletas puede diferenciarse claramente del resto de vehículos si se discrimina por anchura, como ha sido el caso. Este hecho justifica la bondad de la clasificación realizada. 
Todos los estimadores presentan valores del $100 \%$ : exactitud, ratio de clasificación correcta y exactitud de motocicletas y de vehículos $>2$ ruedas.

\subsubsection{Segunda Discriminación}

En la segunda discriminación la clase de vehículos ligeros tiene 853 elementos, mientras que la clase de vehículos pesados presenta 68 elementos. La tabla 8.16 muestra los estimadores de dicha discriminación.

Tabla 8.16 - Matriz de Confusión de la Segunda discriminación

\begin{tabular}{|c|c|c|}
\hline \multicolumn{3}{|l|}{ Segunda Discriminación } \\
\hline Exactitud (\%) $\quad 98,02$ & & \\
\hline & Veh. Ligeros & Veh. Pesados \\
\hline Ratio de Clasificación (\%) & 98,47 & 92,44 \\
\hline Precisión (\%) & 99,39 & 82,95 \\
\hline Ratio de Falsas Clasificaciones( $\%$ ) & 1,53 & 7,56 \\
\hline
\end{tabular}

La exactitud en este caso presenta uno de los valores más altos siendo del 98,02\%, lo que significa que, además de producirse un elevado ratio de clasificaciones correctas, las falsas clasificaciones no son muy elevadas. Es decir, el número de vehículos de las clases A y B no clasificados correctamente no es significativo. La gráfica 8.20 muestra el histograma de la exactitud con su curva de ajuste.

Si se analizan los resultados en cada una de las clasificaciones, se observa que la discriminación de la clase vehículos ligeros presenta una mayor precisión que ratio clasificación correcta, situación que indica que se han detectado menos vehículos de la clase que los que realmente integran la misma. Con valores de precisión de 99,39\% y ratio de clasificación de 98,47\%, se trata de una de las mejores clasificaciones entre todas las discriminaciones entre clases.

En el caso de los vehículos pesados el ratio de clasificación baja hasta el 92,44 \% con una precisión del 82,95\%. El relativamente bajo valor que presenta el ratio de clasificación correcta de esta clase se debe principalmente a los falsos positivos. Es decir, los vehículos de esta clase que no han sido clasificados correctamente y que producen esta reducción en su valor. El ratio 


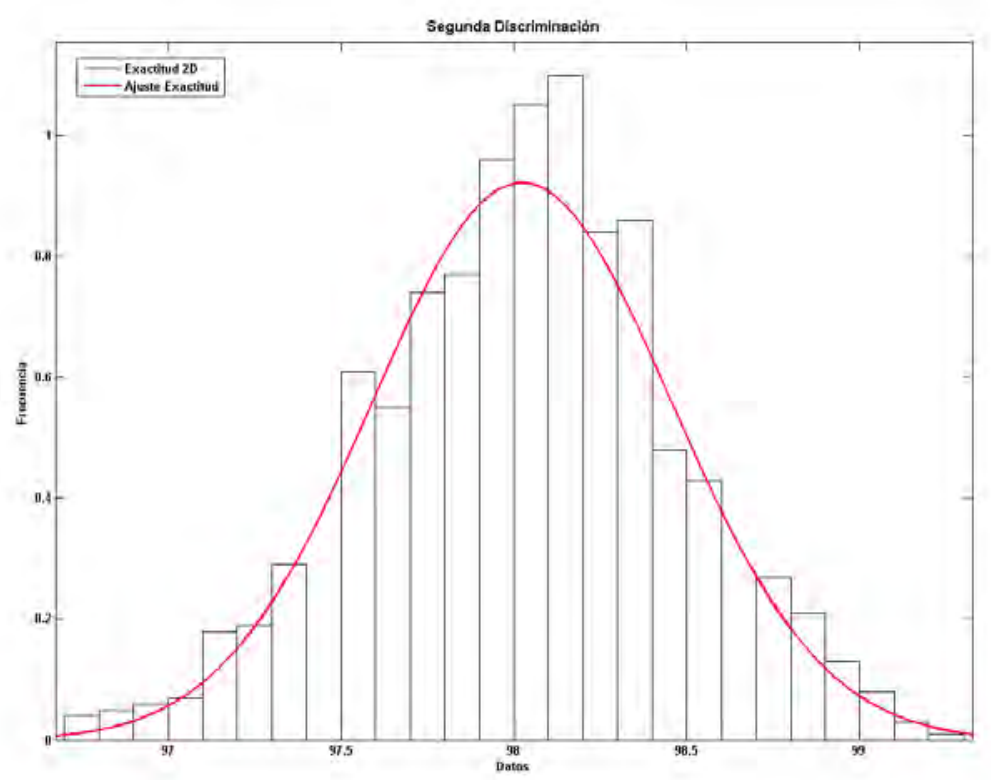

Figura 8.20 - Histograma de la exactitud en la segunda discriminación

de estos falsos positivos alcanza valores de 7,56\%. La gráfica 8.21 muestra los histogramas de ambas clases donde se puede apreciar todo lo comentado hasta ahora.

Estos datos demuestran que el número de falsos negativos es mayor que el de falsos positivos. Aunque pueda parecer a simple vista que este hecho deriva en que el ratio de falsos negativos sea mayor que el de falsos positivos, sucede todo lo contrario debido a la diferencia entre las poblaciones de cada una de las clases. Esta diferencia de número de vehículos de cada una de las clases deriva en un ratio de falsos negativos de $1,53 \%$ frente a un ratio de falsos positivos de $7,56 \%$.

\subsubsection{Tercera Discriminación}

La tercera discriminación se realiza entre las clases tipo turismo y furgoneta. La clase tipo turismo tiene 675 elementos y la clase furgoneta 37, diferencia de elementos entre clases similar a la acaecida en la segunda discriminación. Los estimadores calculados se muestran en la tabla 8.17 .

Esta discriminación presenta una exactitud de 96,41\% y, como se aprecia en la gráfica 8.22, se mueve en el rango [94,5 - 98], lo que son valores muy elevados. En la gráfica que muestra 


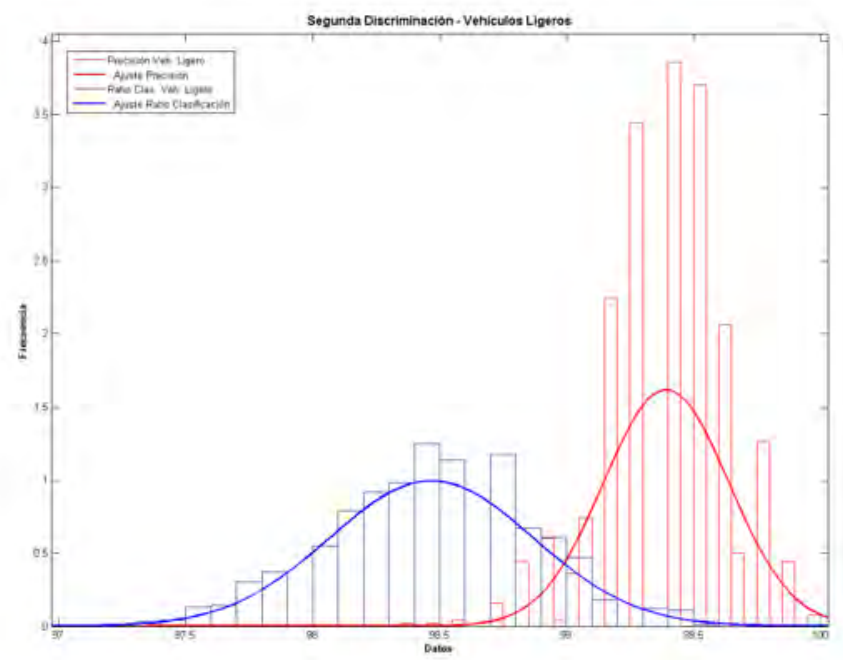

(a) Vehículos Ligeros

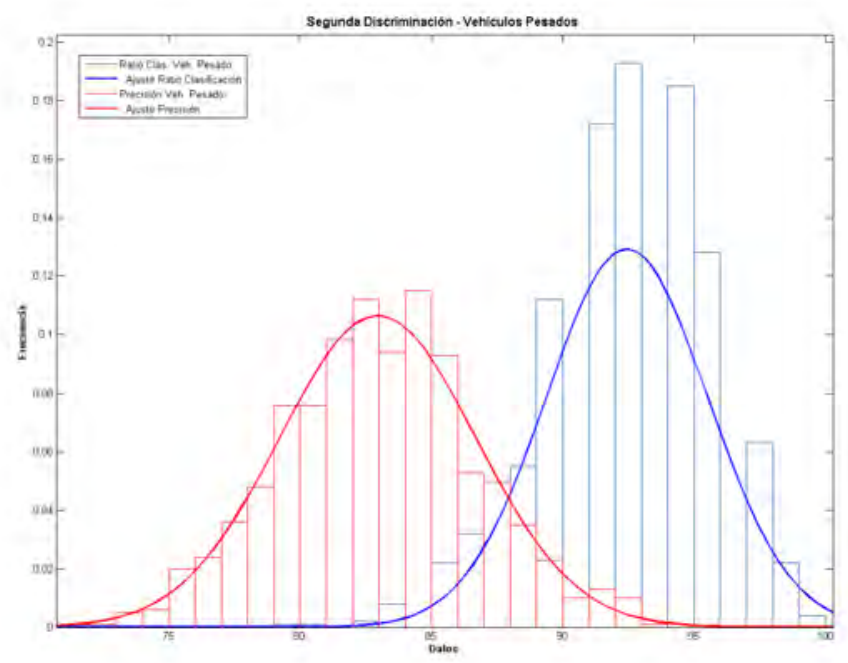

(b) Vehículos Pesados

Figura 8.21 - Histograma de la segunda discriminación por clases

Tabla 8.17 - Matriz de Confusión de la Tercera Discriminación

\begin{tabular}{|c|c|c|}
\hline \multicolumn{3}{|l|}{ Tercera Discriminación } \\
\hline Exactitud (\%) $\quad 96,41$ & & \\
\hline & Tipo Turismo & Furgoneta \\
\hline Ratio de Clasificación (\%) & 97,76 & 90,95 \\
\hline Precisión (\%) & 97,77 & 90,94 \\
\hline Ratio de Falsas Clasificaciones( \%) & 2,24 & 9,05 \\
\hline
\end{tabular}

el ratio de clasificación y la precisión de cada una de las clases, (ver figura 8.23), se observa como en ambos casos las curvas de ajuste y los histogramas son muy similares. Esta situación 


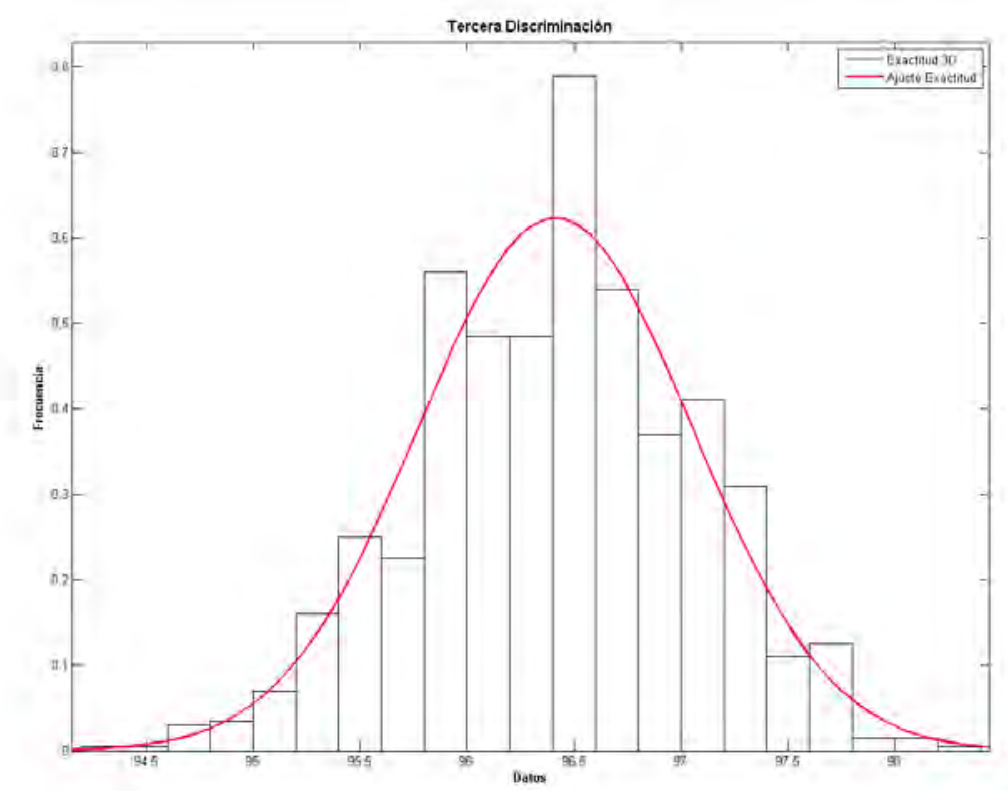

Figura 8.22 - Histograma de la exactitud en la tercera discriminación

se explica recurriendo a los valores de falsos positivos (FP) y falsos negativos (FN), al ser estos los únicos que difieren en ambas ecuaciones, (ver 8.10 y 8.12). En el caso de que estos dos valores sean muy similares los resultados que se obtienen de ratio de clasificación y precisión son idénticos. Así, en la clase tipo turismo se obtienen valores en el ratio de clasificación y precisión de $97,76 \%$ y 97,77\%; y en la clase furgoneta los valores que se obtienen son de $90,95 \%$ y $90,94 \%$.

Si bien los valores de los falsos positivos y los falsos negativos son idénticos, sus ratios no lo son al depender de la población de cada una de las clases, y como se comenta al inicio de este apartado existe una gran diferencia entre ellas. Entonces, se obtiene un ratio de falsos negativos de 2,24\% en relación con la población de tipo turismo, y un ratio de falsos negativos de 9,05\% en relación con la población de furgonetas. Es decir, los errores producidos en la clasificación de furgonetas como tipo turismos son mayores en relación con la población de furgonetas. 


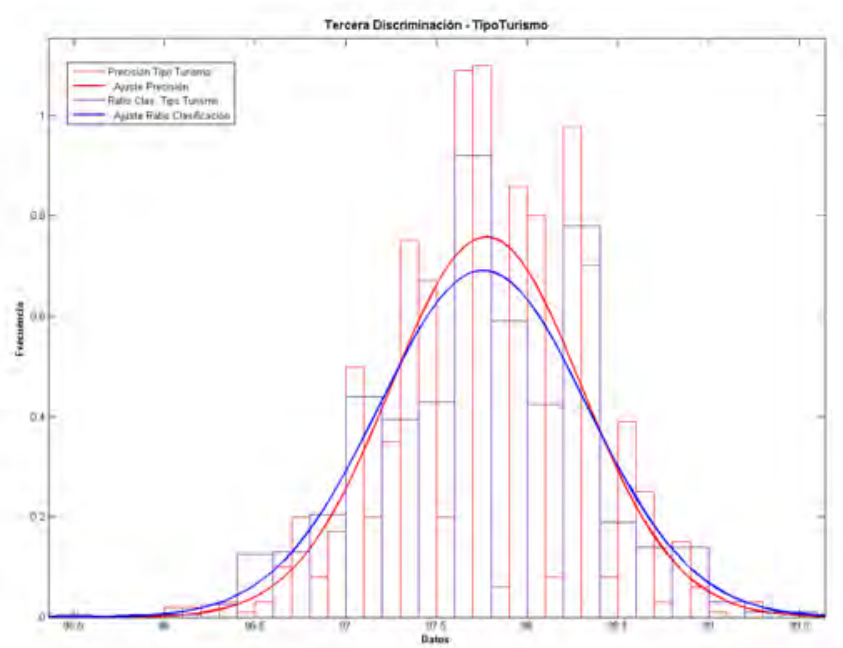

(a) Tipo Turismos

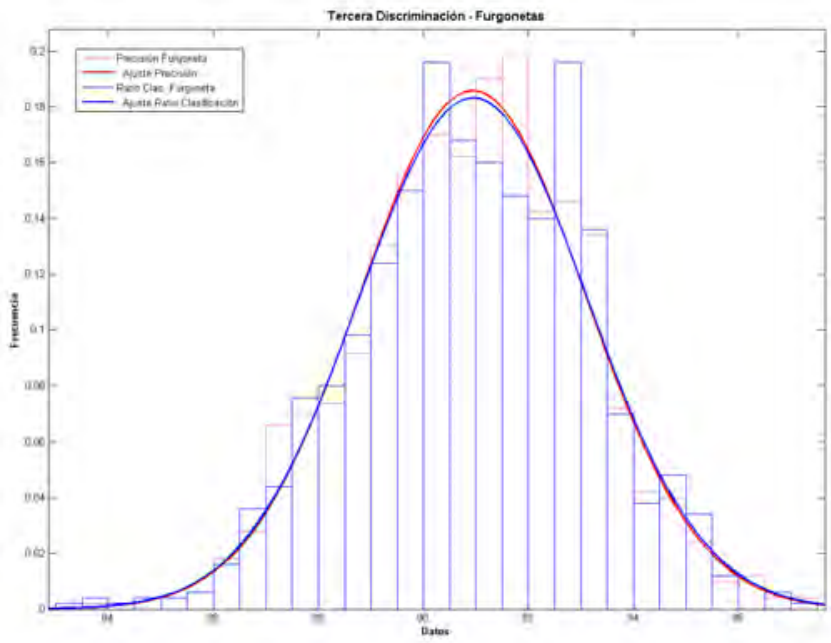

(b) Furgoneta

Figura 8.23 - Histograma de la tercera discriminación por clases

\subsubsection{Cuarta Discriminación}

La cuarta discriminación se efectúa entre el tipo camión y el tipo autobús, siendo la que presenta unas clases con el número de elementos más parejos, 44 y 24 respectivamente. En esta discriminación los estimadores obtenidos se muestran en la tabla 8.18.

La clase Tipo Camión presenta el valor más bajo del ratio de clasificación correcta aunque la precisión es similar a discriminaciones anteriores. Este hecho se debe al alto valor de vehículos 
Tabla 8.18 - Matriz de Confusión de la Cuarta Discriminación

\begin{tabular}{|c|c|c|}
\hline \multicolumn{3}{|l|}{ Cuarta Discriminación } \\
\hline Exactitud (\%) $\quad 90,05$ & & \\
\hline & Tipo Camión & Autobús \\
\hline Ratio de Clasificación (\%) & 86,81 & 95,67 \\
\hline Precisión (\%) & 97,27 & 81,10 \\
\hline Ratio de Falsas Clasificaciones( \%) & 13,19 & 4,33 \\
\hline
\end{tabular}

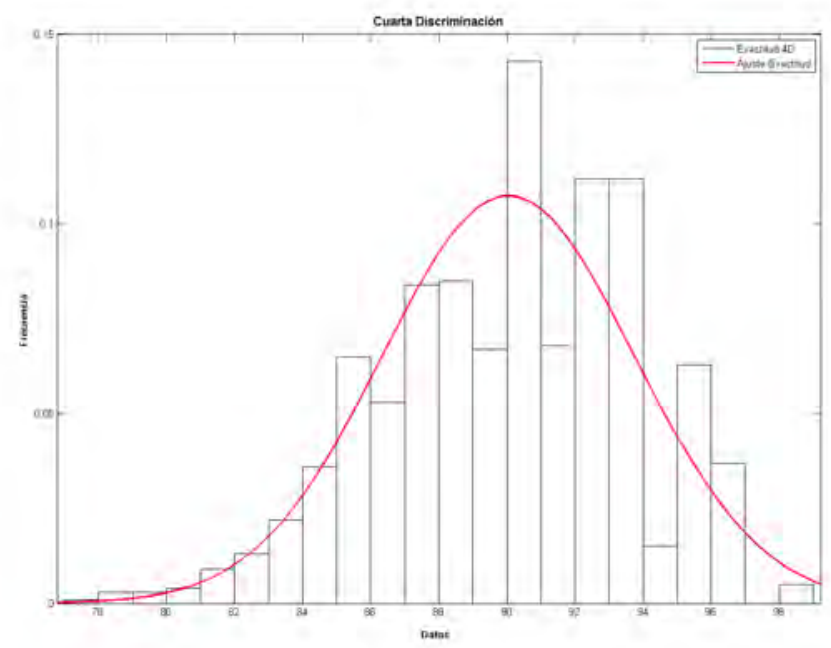

Figura 8.24 - Histograma de la exactitud en la cuarta discriminación

de la clase tipo camión detectados como autobús, lo que genera el ratio de falsos negativos más elevado de todas las discriminaciones con un valor del 13,19\%.

Este valor de falsos negativos también afecta a la precisión de la clase autobús penalizándola, por lo que presenta el valor más bajo de todas las discriminaciones, 81,10\%. El número de falsos positivos es significativamente menor que el de falsos negativos por lo que se obtiene un buen valor de clasificaciones correctas de la clase autobús, 95,67\%, y un bajo ratio de falsos positivos $4,33 \%$.

La diferencia existente entre los valores de ratio de clasificación y precisión en ambas clases se aprecia en las gráficas de la figura 8.25. Además, en los histogramas se muestra como el estimador con el valor más elevado, ratio de clasificación en la clase autobús y precisión en la clase tipo camión, presenta un gran número de repeticiones en el valor $100 \%$, aunque en el ajuste este valor se reduce significativamente. 


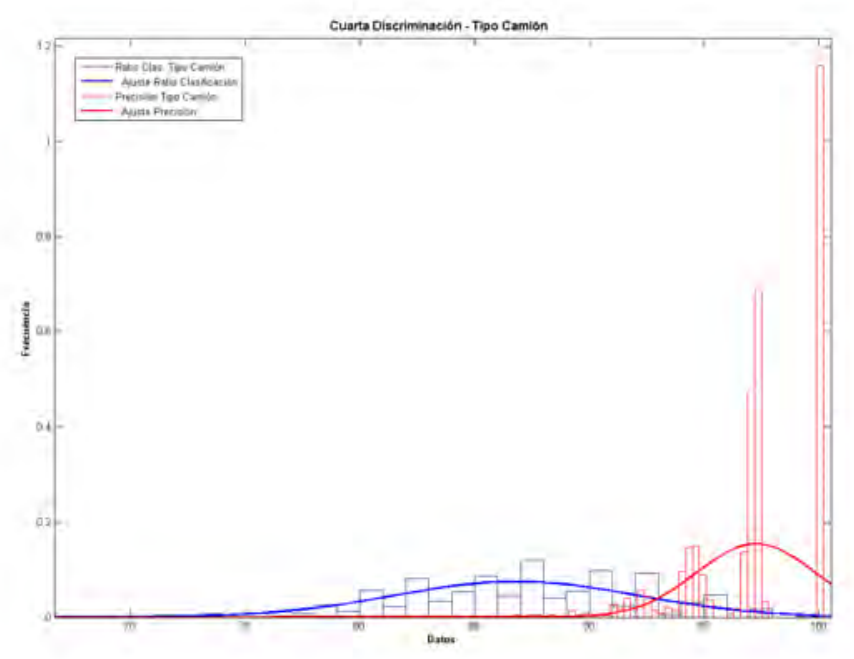

(a) Tipo Camión

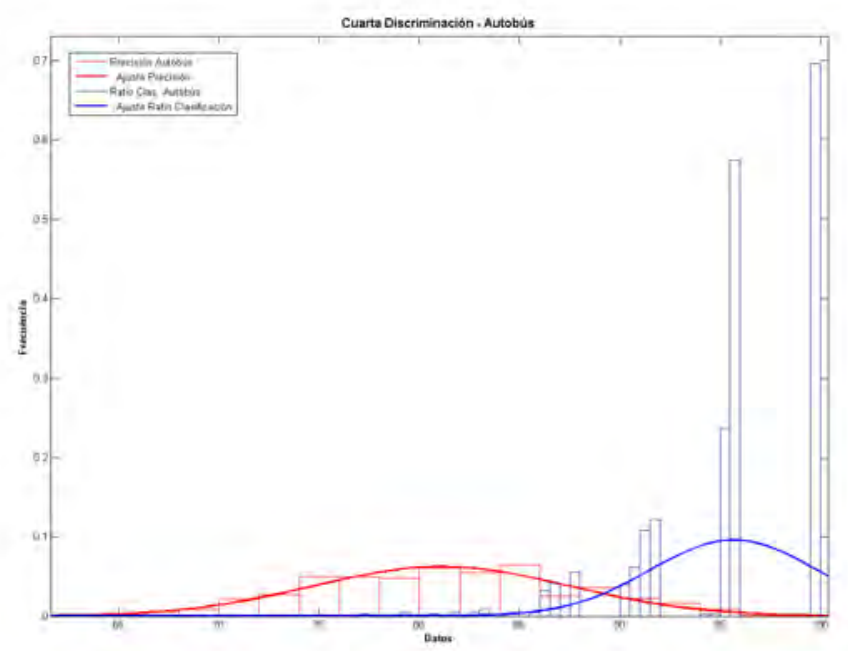

(b) Autobús

Figura 8.25 - Histograma de la cuarta discriminación por clases

\subsubsection{Sexta Discriminación}

Los estimadores de la sexta discriminación entre la clase camión, con 37 elementos, y la clase tipo tráiler, con 7 elementos, se muestra en la tabla 8.19.

La exactitud en la última discriminación es del 96,97 \% siendo un valor muy elevado. En el histograma de la figura 8.26 se puede apreciar como existe un elevado número de clasificaciones que han presentado un valor de exactitud del $100 \%$. Se trata del único caso entre todas las discriminaciones en las que se aprecia esta desviación en el ajuste de la curva de la exactitud. 
Tabla 8.19 - Matriz de Confusión de la Sexta Discriminación

\begin{tabular}{|c|c|c|}
\hline \multicolumn{3}{|l|}{ Sexta Discriminación } \\
\hline Exactitud (\%) & & \\
\hline & Camión & Tipo Tráiler \\
\hline Ratio de Clasificación ( \%) & 96,35 & 100 \\
\hline Precisión (\%) & 100 & 86,39 \\
\hline Ratio de Falsas Clasificaciones( $\%$ ) & 3,65 & 0 \\
\hline
\end{tabular}

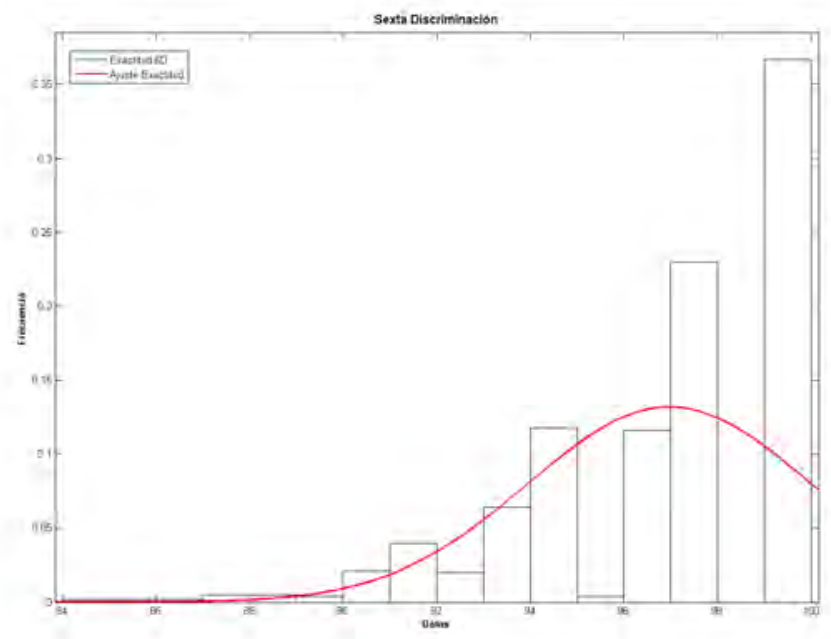

Figura 8.26 - Histograma de la exactitud en la sexta discriminación

El ratio de clasificación de la clase tipo tráiler y la precisión de la clase camión valen $100 \%$ al ser los falsos positivos 0 . Es decir, todos los vehículos de la clase tipo tráiler han sido clasificados correctamente y todos los vehículos clasificados como camión pertenecen asimismo a esa clase.

\subsubsection{Conclusiones}

La figura 8.28 representa esquemáticamente el flujo llevado a cabo en el proceso de test, con cada uno de los programas que se ejecutan en cada paso.

La clasificación se ha analizado en base a la técnica de remuestreo Bootstrap. La creación de cada uno de los nuevos grupos de test con reemplazo a partir del grupo de test original se ha realizado mediante un programa diseñado usando Microsoft Visual Studio llamado GruposTest, (ver código en el anexo D). Dicho programa además de crear los grupos, clasifica sus elementos y calcula los estimadores. Finalmente el programa permite exportar toda la información a un 


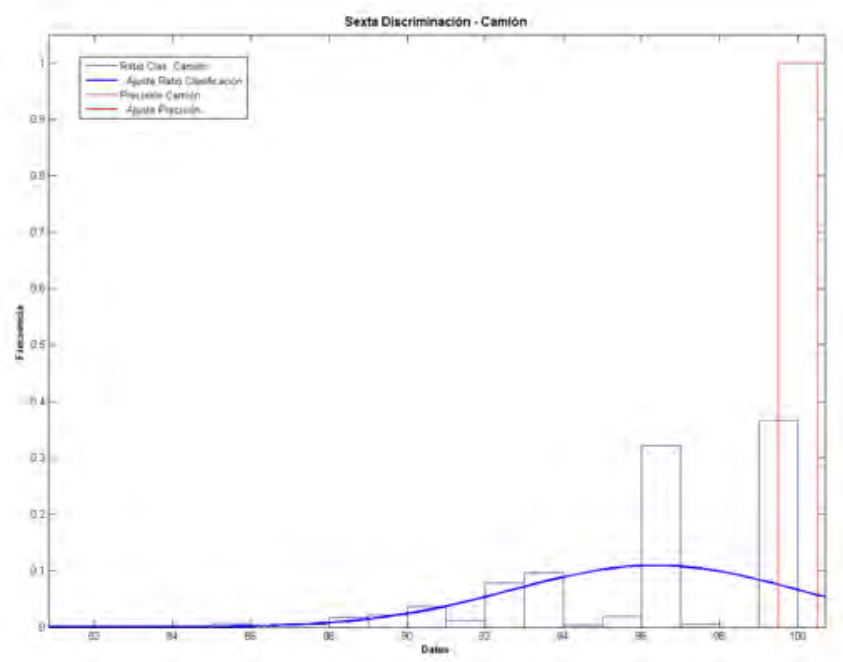

(a) Camión

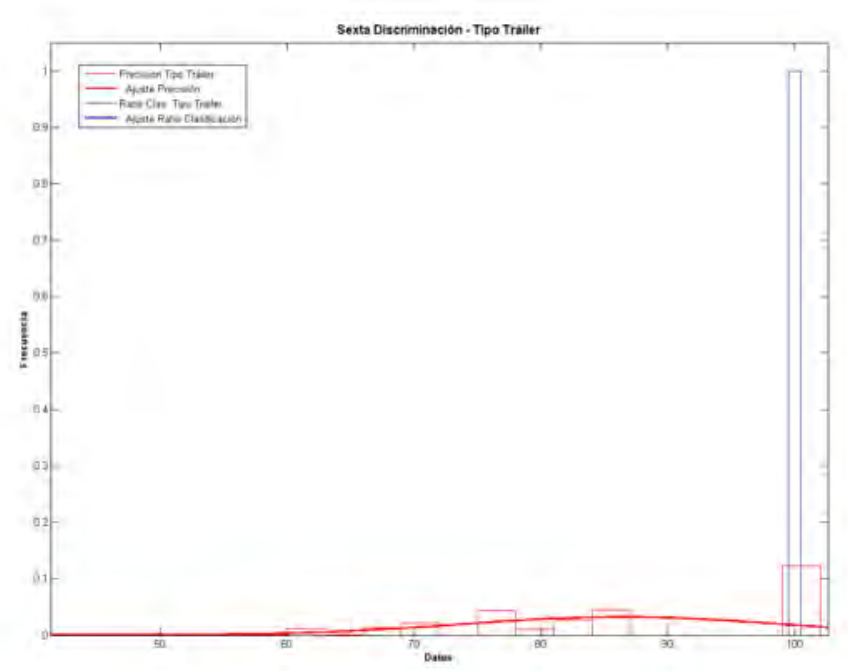

(b) Tipo Tráiler

Figura 8.27 - Histograma de la sexta discriminación por clases

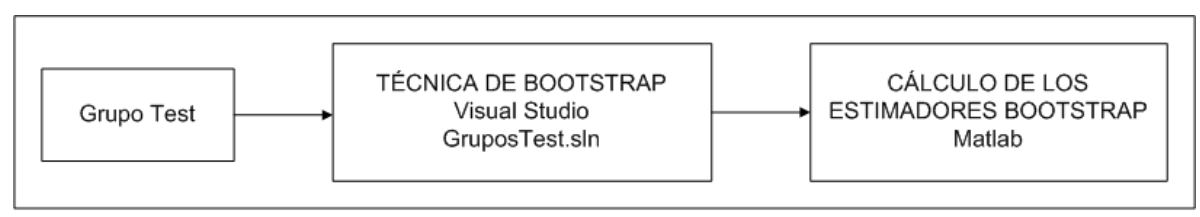

Figura 8.28 - Flujo del Proceso de Test

archivo tipo excel, como se muestra en la figura 8.29 , que ha permitido su tratamiento en MATLAB. 


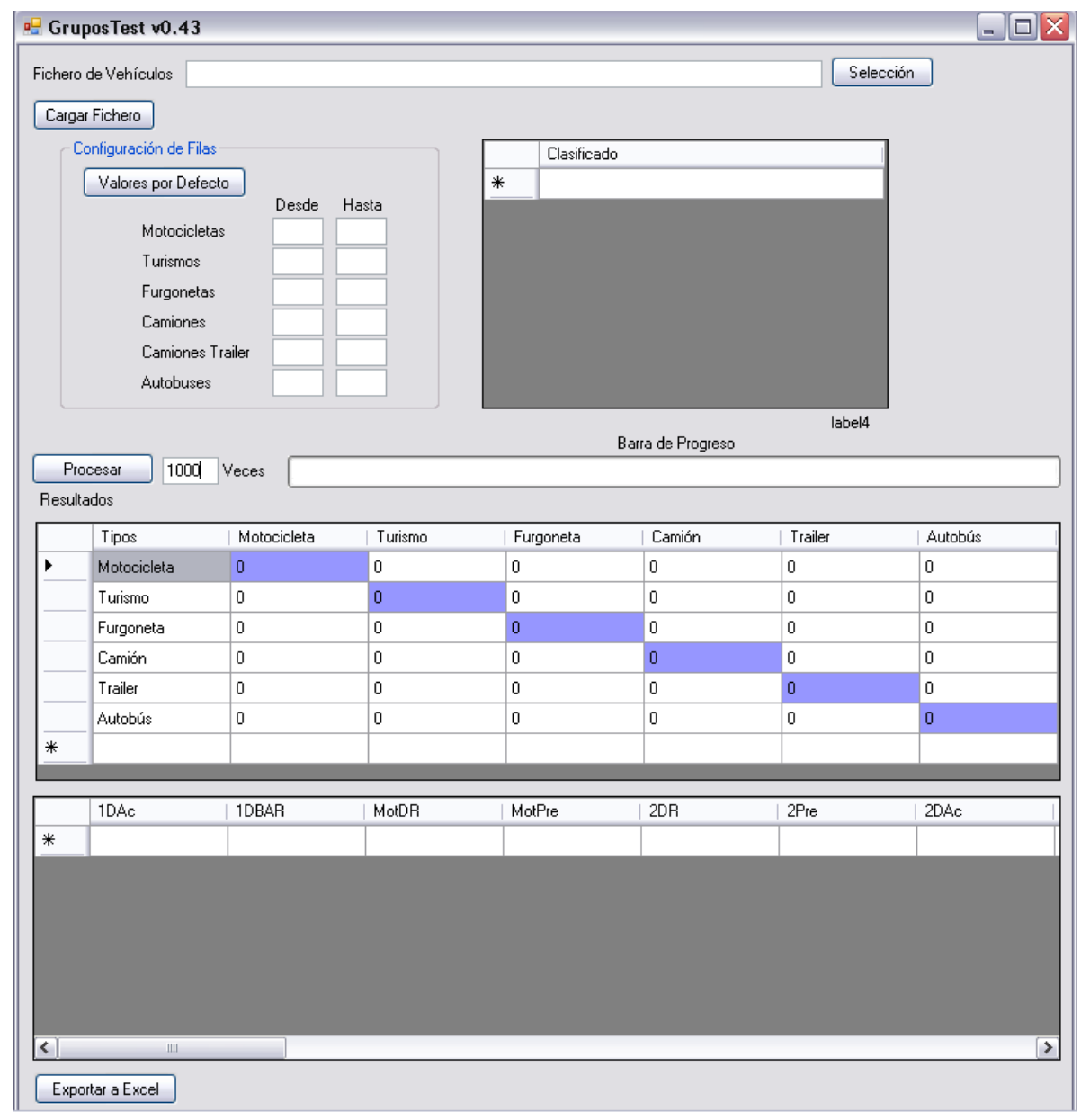

Figura 8.29 - Programa para la generación de los grupos de test

Los resultados de la clasificación por discriminación van desde una exactitud del $100 \%$ en la primera discriminación hasta un $90,05 \%$ en la cuarta. El ratio de clasificaciones correctas más elevado es el de las clase motocicleta y tipo tráiler, con un valor del $100 \%$; mientras el más bajo es el de la clase autobús con un 95,67\%. El valor de la precisión es de $100 \%$ en la clase motocicletas y camión, mientras que la clase autobús presenta el valor más bajo con un $81,10 \%$.

\subsection{Conclusiones}

Con las técnicas de reconocimiento de patrones como punto de partida se ha descrito la metodología y pasos a seguir para poder completar con éxito cada una de las etapas de recopilación de datos, proceso de aprendizaje y test. 
La recopilación de datos va más allá de una simple captura de información, es necesario conocer las medidas que van a ser usadas en la investigación para poder realizar una correcta captura de datos. Esta información, además de poder obtenerse de forma apropiada, debe ser almacenada para su evaluación, análisis y/o uso posterior en otros estudios. Esto, evidencia la necesidad de diseñar y estructurar una base de datos que cumpla las necesidades que marcan las características de la información que debe ser almacenada. Se ha realizado un estudio detallado de los estándares de clasificación para poder ajustarse a la realidad y poder aplicarse en cualquier sistema ITS con el que se combine.

El tamaño de la muestra es otra de las dudas que surgen antes de iniciar cualquier trabajo. ¿Cuántos datos se necesitan para que se considere un tamaño muestral correcto?. El hecho de trabajar con una población estratificada en grupos o clases derivaba en una nueva pregunta: ¿Cuántos datos de cada clase se necesitan? Todas estas dudas han sido tratadas y resueltas eficazmente gracias al muestreo estratificado proporcional seguido. Este muestreo valida estadísticamente el tamaño muestral usado al hacer que los datos capturados se parezcan a la población total.

Una vez capturada la muestra, con un tamaño estadísticamente válido, se divide en dos grupos: aprendizaje y test. En el proceso de aprendizaje se extraen las características del grupo que permiten la discriminación entre clases en base a determinados parámetros predictivos. Y se definen los patrones que se usarán en la clasificación mediante técnicas de árboles de clasificación. Finalmente, en el proceso de test mediante la técnica de remuestreo de Bootstrap se han calculado los estimadores usados para evaluar la bondad del sistema de clasificación. 


\section{Bibliografía}

[ADW98] Apte, C., Damerau, F. y Weiss, S., Text mining with decision trees and decision rules. C.M. University, ed., Conference on Automated Learning and Discovery, June 1998.

[Alu09] Aluja, T., Curso sobre árboles de decisión. 2009, URL http://www.Isi. upc.edu/ belanche/docencia/mineria/Apunts/Arbres.pdf.

[Online; Último acceso Agosto 2009].

[Ame96] American National Standards Institute. National Safety Council, Itasca, Illinois, ANSI D16.1-1996: Manual on classification of motor vehicle traffic accidents. Sixth edición, 1996.

[Ayu08] Ayuntamiento, Anuario 2008. Parque de vehículos. Informe técnico, Oficina de Estadística. Ayuntamiento de Valencia, 2008, URL http://www . valencia.es/ayuntamiento/anuario.nsf/fCategoriaVista? readForm\&nivel=6_2\&Vista=vListadoAnuario\&Categoria= Anuario_202008\&lang=1\&expand=4\&subexpandido= $1 \&$ bdorigen=ayuntamiento/estadistica.nsf. [Online; Último acceso Agosto 2009].

[BAS08] BAST, Description of the vehicle categories with code according to the tls. Bundesanstalt für Straßenwesen, 2008, URL http://www.bast.de/nn_ $43710 / \mathrm{EN} / \mathrm{e}-\mathrm{Home} / \mathrm{e}$-homepage_node.html?_nnn=true. [Online; Último acceso Octubre 2008].

[BFOS84] Breiman, L. et al., Classification and Regresion Trees. New York, NY: Chapman and Hall, 1984, ISBN 0-412-04841-8.

[Bis06] Bishop, C.M., Pattern Recognition and Machine Learning. Information Science and Statics, New York: Springer, 2006, ISBN 0-387-31073-8.

[CCM07] Cevher, V., Chellappa, R. y McClellan, J., Joint acoustic-video fingerprinting of vehicles, part $i$. Acoustics, Speech and Signal Processing, 2007. ICASSP 2007. IEEE International Conference on, tomo 2: págs. 745-748, April 2007, ISSN 15206149, doi:10.1109/ICASSP.2007.366343.

[CGSC07] Cevher, V. et al., Joint acoustic-video fingerprinting of vehicles, part ii. Acoustics, Speech and Signal Processing, 2007. ICASSP 2007. IEEE International Conference on, tomo 2: págs. 749-752, April 2007, ISSN 1520-6149, doi:10.1109/ ICASSP.2007.366344.

[Coc77] Cochran, W.G., Sampling Techniques. Wiley Series in Probability and Mathematical Statistics. Applied probability and statistics, New York: John Wiley and Sons, 3ª edición, 1977, ISBN 0-471-16240-X.

[Cor04] Correa, J.C., Método bayesiano bootstrap y una aplicación en la estimación del percentil 85 en ingeniería de tránsito. Revista Colombiana de Estadística, tomo 27 (2): págs. 99-107, Diciembre 2004. 
[CVP08] CVPR, Ieee computer society conference on computer vision and pattern recognition (cvpr). IEEE Computer Society, 2008, URL http://www . cvpr2009.org/previous-years. [Online; Último acceso Noviembre 2009].

[Día07] Díaz, Z., Predicción de crisis empresariales en seguros no vida, mediante árboles de decisión y reglas de clasificación. Colección: Línea 3000, Editorial Complutense, 2007, ISBN 8474918820.

[DGT07] DGT, Series históricas: Parque de vehículos. Dirección General de Tráfico, Diciembre 2007, URL http://www.dgt.es/portal/es/seguridad_ vial/estadistica/parque_vehiculos/series_historicas_ parque/. [Online: ?ltimo acceso Agosto 2009].

[EFK09] EFKON, Ae titan 3000. EFKON AG, 2009, URL http://www.efkon. com/docs/TD_si_AE_TITAN_01E03.pdf. [Online; Último acceso Agosto 2009].

[Ele09] Electronic, W., Classification detector mc2024. Weiss Electronic GmBH, 2009, URL http://www.weiss-electronic.de/englisch/03_ komponenten/03_03_03_mc-2024.htm. [Online; Último acceso Agosto 2009].

[EU04] EU, Directive 2004/52/ec of the european parliament and of the council. Oficial Journal of the European Union, 29 April 2004. L 166/124.

[Eur09] EuroNCAP, Euro ncap vehicle types. European New Car Assessment Programme, 2009, URL http://www. euroncap.com/. [Online; Último acceso Enero 2009].

[FHW01] FHWA, Traffic Monitoring Guide. Executive Summary. Informe técnico, US Department of Transportation. Federal Highway Transportation. Office of Highway Policy Information, May 2001, URL http://www. fhwa.dot. gov/ohim/tmguide/. Report Number: FHWA-PL-01-021.

[FHW08] FHWA, Fhwa vehicle types. Federal Highway Administration, 2008, URL http: //www. fhwa.dot.gov/policy/ohpi/vehclass.htm. [Online; Último acceso Octubre 2008].

[FK99] Friedman, M. y Kandel, A., Introduction to Pattern Recognition: statistical, structural, neural and fuzzy logic approaches, tomo 32 de Machine Perception and Artificial intelligence. Singapore: World Scientific, 1999, ISBN 9810233124.

[Gi105] Gil, J., Aplicación del método bootstrap al contraste de hipótesis en la investigación educativa. Revista de educación, págs. 251-265, 2005, ISSN 00348082 .

[Gil09] Ángel Gil, Muestreo. universitat oberta de catalunya, 2009. P03/75057/01005. 
[Góm05] Gómez, L.E., Contribución al diseño e implementación de un sistema de detección y clasificación de vehículos con tecnología láser, mediante método estadístico y redes neuronales. Tesis Doctoral, Departamento de Ingeniería Electrónica. Universidad Politécnica de Valencia, Valencia. España, 2005. Directores: Antonio Mocholí y José Millet.

[JDJ00] Jain, A.K., Duin, R.P.W. y Jianchang, M., Statistical pattern recognition: A review. Pattern Analysis and Machine Intelligence, IEEE Transactions on, tomo 22 (1): págs. 4-37, Jan 2000, ISSN 0162-8828, doi:10.1109/34.824819.

[Kis65] Kish, L., Survey Sampling. Wiley classics library, New York: John Wiley and Sons, published 1995 edición, 1965, ISBN 0-471-48900-X.

[KM06] Koch, M.W. y Malone, K.T., A sequential vehicle classifier for infrared video using multinomial pattern matching. Computer Vision and Pattern Recognition Workshop, 2006. CVPRW '06. Conference on, págs. 127-127, June 2006, doi: 10.1109/CVPRW.2006.21.

[LE04] López, A. y Elosua, P., Estimación bootstrap para el coeficiente de determinación: un estudio de simulación. Revista Electrónica de Metodología Aplicada, tomo 9 (2): págs. 1-14, 2004.

[Mar07] Martínez, C., Estadística básica aplicada. Colección Textos Universitarios, ECOE Ediciones, tercera edición, 2007, ISBN 9586484580.

[Mat09] The Mathworks, Inc., Natick, MA, Statistics Toolbox 7. User's Guide. Version 7.1 (released 2009b) edición, March 2009.

[MET09] METROCOUNT, Traffic executive software. MetroCount, 2009, URL http: / / www.metrocount.com/products/mte/index.html. [Online; Último acceso Agosto 2009].

[MGR02] Middlenton, D., Gopalakrishna, D. y Raman, M., Advances in Traffic Data Collection and Management, White Paper. Informe técnico, Office of Policy. Federal Highway Administration, Washington, DC, December 2002. Work Order Number BAT-02-006.

[MMP04] Martínez, A., Muñoz, J. y Pascual, A., eds., Tamaño de muestra y precisión estadística, tomo 23 de Monografías: Ciencia y Tecnología. Universidad de Almería, iii edición, 2004, ISBN 84-8240-711-2.

[MST94] Michien, D., Spiegelhalter, D. y Taylor, C., Machine learning, neural and statistical classification. February 1994.

[Ni196] Nilsson, N.J., Introduction to machine learning, December 1996. Early draft of a proposed textbook.

[NTC09] NTCIP, National transportation communications for its protocol. 2009, URL http://www.ntcip.org/info/. [Online; Último acceso Agosto 2009]. 
[Ott06] Otto, C.W., Development of a Mobile Vehicle Classification System. Bachelor of engineering electrical and electronic, University of Southern Queensland. Faculty of Engineering and Surveying, November 2006.

[Pha06] Pham, H., ed., Springer Handbook of Engineering Statistics. London: SpringerVerlag, 2006, ISBN 1-85233-806-7.

[Rip97] Ripley, B.D., Pattern Recognition and Neural Networks. Cambridge, UK: Cambridge University Press, 1997, ISBN 0-521-46086-7.

[RPA00] Ramsay, E.D., Prem, H. y Austroads., Development of an Austroads heavy vehicle nomenclature system: discussion paper. AUSTROADS publication; $\mathrm{n}^{\circ}$. AP-R174/00, Austroads, Sydney, N.S.W., 2000, ISBN 0855885602. Prepared by Euan Ramsay and Hans Prem.

[Sán09] Sánchez, A.C., Muestreo y tamaño de la muestra. 2009, URL http: / / www. monografías. com/. [Online; Último acceso Julio 2009].

[sR08] s, M. y Rodríguez, A., Clasificación automática de fuentes de ruido de tráfico. Acústica 2008, V Congreso Ibérico de Acústica, 39 Congreso Español de Acústica, Coimbra, Portugal, 20-22 Octubre 2008.

[SS99] Schapire, R.E. y Singer, Y., Improving boosting algorithms using confidence-rated predictions. Machine Learning, págs. 297-336, 1999.

[SS08] Schiattino, I. y Silva, C., Árboles de clasificación y regresión: Modelos cart. Ciencia \& Trabajo, págs. 161-166, December 2008.

[Tek09] Teknomo, K., Tutorial on decision tree. 2009, URL http://people. revoledu.com/kardi/tutorial/decisiontree/. [Online; Último acceso Agosto 2009].

[Tho02] Thompson, S.K., Sampling. Wiley Series in Probability and Mathematical Statistics, New York, NY: John Wiley and Sons, 2ª edición, 2002, ISBN 0-47129116-1.

[TRA06] TRACKSS, Technologies for road advanced cooperative knowledge sharing sensors. European Commission. DG Information Society Technologies. Esafety, January 2006, URL http: / /www.trackss. net/. [Online: Último acceso Enero 2009].

[TRA08] TRACKSS, D7.1 Evaluation Guidelines \& Plan. TRACKSS Consortium: Technologies for Road Advanced Cooperative Knowledge Sharing Sensors, 2008.

[Tro06] Trochim, W.M., Research methods knowledge base. 2006, URL http: / / www . socialresearchmethods . net/. [Online; Último acceso Julio 2009].

[Vil06] Ville, B.D., Decision Trees for Business Intelligence and Data Mining: Using SAS Enterprise Miner. SAS Publishing, 2006, ISBN 1590475674. 
[XOW $\left.{ }^{+} 07\right]$ Xiang, W. et al., Automated vehicle classification system using advanced noise reduction technology. Signal Processing and Communication Systems 2007. ICSPCS 2007. Conference on, December 2007.

[Xtr09] Xtralis, Traffic solutions. Xtralis, 2009, URL http: / / xtralis . com/p.cfm? $s=22 \& p=381$. [Online; Último acceso Agosto 2009].

[Ye04] Ye, N., ed., The handbook of data mining. Lawrence Erlbaum Associates, 2004, ISBN 0805855637. 


\section{Parte IV}

\section{Resultados y Evaluación}





\section{Capítulo 9}

\section{Resultados y Discusión}

En etapas anteriores se ha cubierto la definición de requerimientos y especificaciones tanto hardware como software, y se ha procedido a su implementación. Más tarde se han definido patrones mediante árboles de decisión y se han extraído las características necesarias para llevar a cabo la clasificación en categorías. En este punto se procede a la instalación del sistema, evaluación y validación. Así, en este capítulo:

- Se describen las condiciones en las cuales se ha obtenido la información y los datos: emplazamiento, equipos utilizados, condiciones de medida ...

- Se analiza la detección y clasificación de vehículos que ofrece el sistema: qué errores se obtienen, a qué son debidos y se plantean posibles soluciones. Estos análisis se realizan en dos situaciones distintas: pruebas de laboratorio y pruebas de campo.

\subsection{Instalación del equipo en la vía}

\subsubsection{Emplazamiento del sistema}

El emplazamiento seleccionado se encuentra en la ciudad de Valencia, España, en el cruce de la carretera de Malilla y la calle isla Formentera, en la zona sur de la ciudad. Tras el crecimiento urbano que dio lugar a la Ronda Sur, la carretera de Malilla se abrió como vía principal de salida del barrio de Malilla hacia la nueva Ronda. La importancia estratégica del cruce en el que se ha instalado el sistema radica en que es el primer cruce de los vehículos que circulan en sentido de 
entrada al barrio, o el último de los que circulan de salida. De este modo, es necesario realizar estadísticos de tráfico para poder diseñar un plan de circulación acorde a la nueva situación vial.

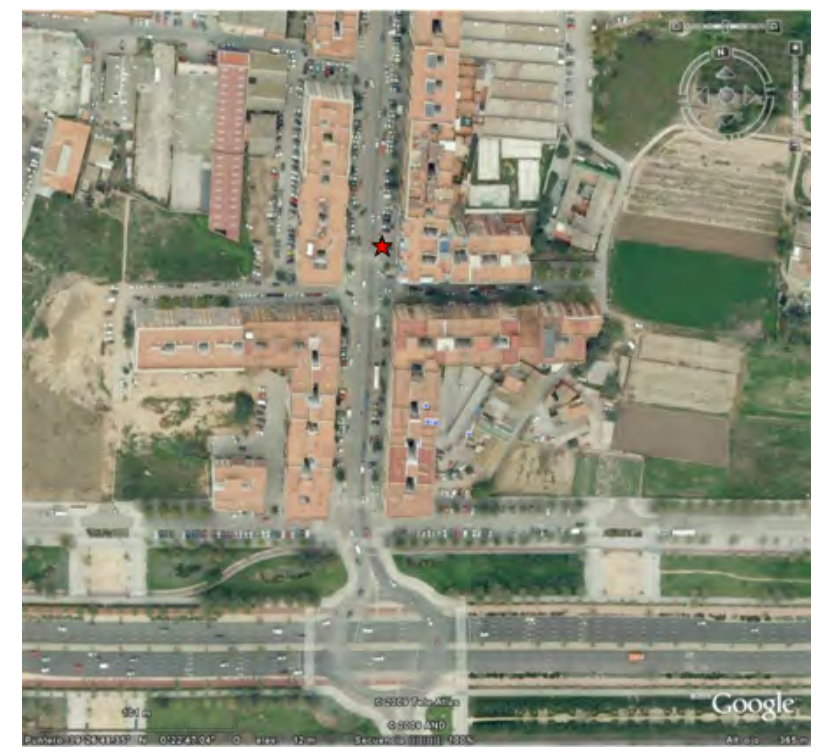

Figura 9.1 - Emplazamiento del sistema

La imagen 9.1 muestra la vista de satélite de la zona. La estrella indica la localización del báculo en el que se instaló el sensor láser escáner. En la zona de detección se controlan dos carriles en sentido salida del barrio, que de ahora en adelante se referencia como sentido A; y uno en el contrario o de entrada al barrio, que de ahora en adelante se referencia como sentido B. Al tratarse de un cruce entre una vía principal (Carretera de Malilla) con una vía secundaria (Calle isla Formentera) el emplazamiento presenta unas características determinadas:

- Las fases de verde del semáforo son más prolongadas en la vía principal, lo que le concede prioridad a la misma.

- Las incorporaciones desde las vías secundarias a la principal hacen que el carril de sentido B presente una ocupación casi constante.

- Los carriles de sentido A están controlados por un semáforo situado en línea con el sensor.

\subsubsection{Equipos: conexiones y características}

La instalación del sensor láser escáner fue realizado por los equipos de mantenimiento del Ayuntamiento de Valencia. Requirió del montaje de un báculo especial en el que colocar el 


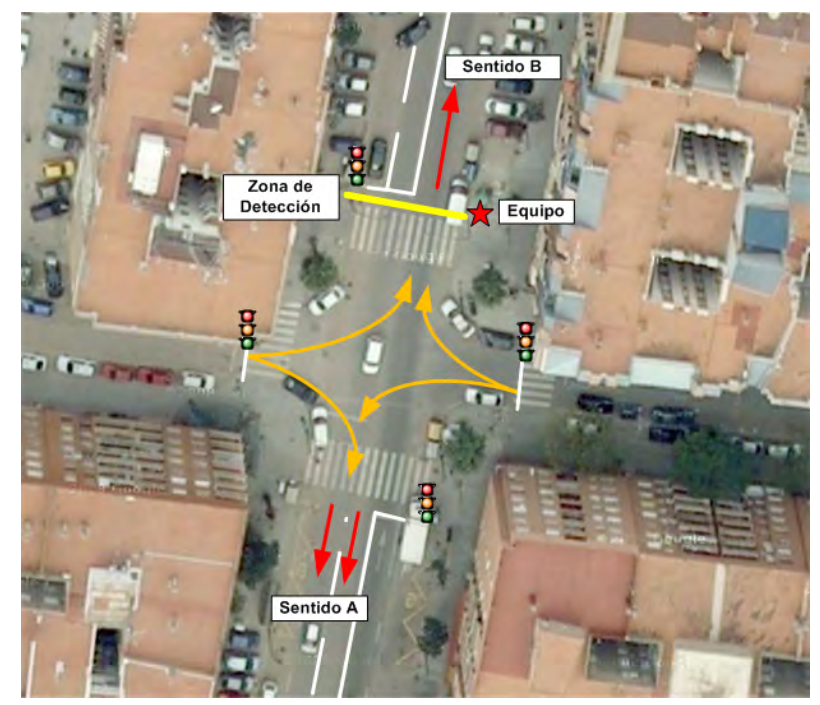

Figura 9.2 - Cruce bajo estudio

equipo junto a una videocámara, además de un armario en la base del mismo donde guardar equipos. La cámara permite obtener información vídeo de la zona de detección, que es utilizada para: verificar los resultados del sistema y almacenar en la base de datos las imágenes de los vehículos detectados y clasificados.

La imagen 9.3 muestra distintos momentos de la instalación de los equipos.

Si bien los sensores láser escáner permiten su instalación en postes de semáforos ya instalados, en este caso se consideró oportuno utilizar un báculo propio ante la previsión de instalaciones futuras de diferentes sistemas sensores. De hecho, más tarde se ha instalado un sistema radar en el mismo poste y una conexión WiMax para realizar las comunicaciones con el centro de control de tráfico.

Tras la instalación, se realizan los ajustes necesarios para adecuar el sistema a las características de la vía. El ajuste más importante consiste en la delimitación de la zona de detección evitando la detección de las aceras y otras zonas no deseadas. De este modo el sensor queda preparado para iniciar la toma de medidas. La tabla 9.1 muestra los equipos utilizados.

\subsubsection{Características de la captura de datos}

La captura de datos se realizó en base a dos premisas: verificar la dependencia o independencia del sistema ante variaciones de la intensidad luminosa en la vía; y comprobar el efecto 


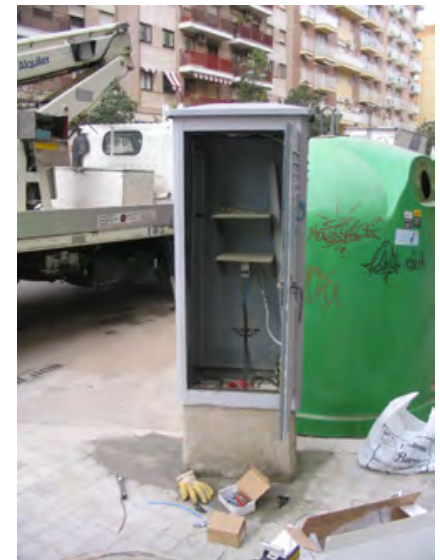

(a) Armario Metálico

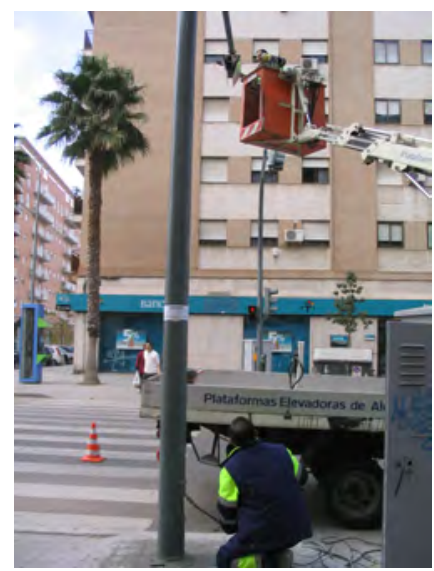

(c) Instalación sensor láser

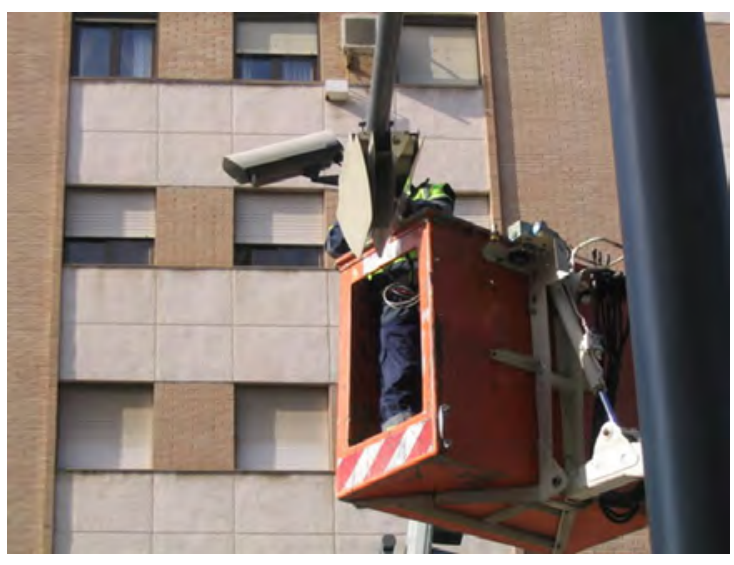

(b) Instalación de la cámara

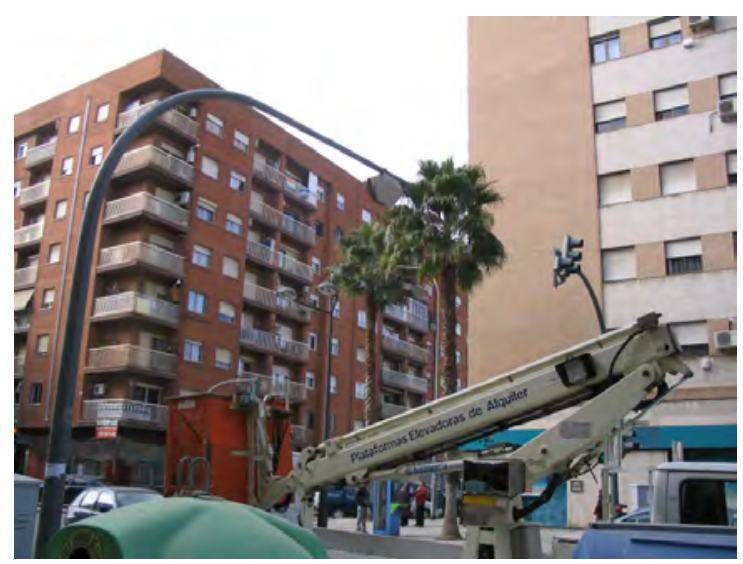

(d) Instalación finalizada

Figura 9.3 - Instalación en la vía

Tabla 9.1 - Equipos instalados y características

\begin{tabular}{|c|c|}
\hline Equipo & Características \\
\hline Sensor Láser & $\begin{array}{l}\text { Alimentación: DC } 24 \text { V. - } 2,5 \text { A. } \\
\text { OUT: conector DE9 hembra, salida de datos }\end{array}$ \\
\hline Videocámara & $\begin{array}{l}\text { Alimentación: DC } 12 \text { V. - } 1 \text { A. } \\
\text { OUT: cable coaxial RG59 con terminal BNC macho }\end{array}$ \\
\hline Etapas de alimentación & $\begin{array}{l}\text { Dos fuentes: una para el sensor y otra para la } \\
\text { videocámara }\end{array}$ \\
\hline Sistema Hardware & PCB diseñada + etapa alimentación \\
\hline Sistema Software & $\begin{array}{l}\text { Instalado en un ordenador portátil } \\
\text { Programa de adquisición de datos, tratamiento de la } \\
\text { señal y clasificación de los vehículos } \\
\text { Interfaz gráfico para la presentación de los datos }\end{array}$ \\
\hline Otros: & $\begin{array}{l}\text { Tarjeta capturadora de vídeo, videocámara extra, } \\
\text { trípode, programador ... }\end{array}$ \\
\hline
\end{tabular}


producido por la lluvia en las mediciones. Los primeros experimentos y ensayos se llevaron a cabo en dos periodos diferentes:

- Por la mañana temprano, entre las 8:00 am y las 11:30 am, cuando las condiciones de luz en la vía proporcionaban una intensidad luminosa baja. Bajo estas circunstancias el sistema debe ser preciso en sus medidas ya que la intensidad luminosa no le afecta.

- Mediodía, entre las 12:00 am y las 2:00 pm, intervalo durante el cual la intensidad luminosa aumenta ya que la luz incide directamente sobre la vía.

El largo periodo de tiempo en el que se ha realizado la captura de datos y toma de medidas ha permitido, además, realizar pruebas en todas las épocas del año. Se ha verificado que la detección y clasificación no se ve afectada en ningún caso por la estación del año, demostrando su inmunidad a las diferencias de temperatura. La verificación se ha realizado analizando diferentes capturas a lo largo de diferentes estaciones y comprobando que la clasificación se realizaba correctamente en todas ellas, independientemente de la estación. Hay que tener en cuenta que en la ciudad de Valencia los inviernos son suaves con una temperatura media mínima en el mes de enero de $7^{\circ} \mathrm{C}$; mientras que los veranos son calurosos con una temperatura media máxima de 29,6 $6^{\circ} \mathrm{C}$ en el mes de agosto [AEM09].

El caso del efecto de la intensidad luminosa sobre la vía es de otra índole. Precisamente, se ha podido comprobar que los días más soleados del mes de agosto donde la radiación es mayor, y por ello la intensidad luminosa, la detección de vehículos no se ve afectada, ni se produce un mayor número de reflexiones perdidas que en otros periodos diferentes. Queda de este modo descartada también la hipótesis de que la medida se puede ver afectada por la intensidad luminosa.

\subsection{Detección de vehículos: evaluación}

En este apartado se presentan los resultados obtenidos en la detección de vehículos tanto para las pruebas de laboratorio como para las pruebas de campo realizadas en el emplazamiento. 


\subsubsection{Pruebas de Laboratorio}

En el laboratorio se realizaron las primeras pruebas de detección usando prototipos a escala 1:60. Dichos prototipos se hacían circular por la zona de detección durante intervalos de dos segundos. Tras la realización de 500 medidas y bajo estas condiciones, se obtuvieron resultados muy positivos en la detección de vehículos. La duda planteada en este punto era saber qué sucedería cuando se incrementara la velocidad. Aunque los prototipos no podían circular a una velocidad constante, se hicieron pruebas donde circulaban a mayor velocidad que en el caso anterior. En esta situación los resultados también fueron muy favorables y positivos. Los resultados de estas medidas se muestran en la tabla 9.2 usando la matriz de confusión y los parámetros de evaluación estándar en el caso de detección de vehículos.

La matriz de la confusión presenta los datos de detección en el laboratorio frente a los predichos. Los valores que se usan en la tabla son:

- TP (Verdadero Positivo) - número de vehículos detectados $=495$.

- FN (Falso Negativo) - número de vehículos no detectados $=4$.

- FP (Falso Positivo) - número de objetos diferentes de vehículos detectados $=1$.

- TN (Verdadero Negativo) - número de objetos diferentes de vehículos no detectados $=0$.

Tabla 9.2 - Test de Laboratorio - Detección de Vehículos

\begin{tabular}{lccc}
\hline \multicolumn{3}{l}{ Evaluación de las pruebas de laboratorio } \\
\hline \multicolumn{4}{l}{ Matriz de confusión } \\
\hline \multicolumn{4}{c}{ Evento Real } \\
& $D$ & $\bar{D}$ \\
Evento & $D$ & 495 & 1 \\
Detectado & $\bar{D}$ & 4 & 0 \\
\hline Ratio de Detección: $99,198 \%$ & & \\
Precisión: $99,798 \%$ & & \\
Exactitud: $99 \%$ & \\
\hline
\end{tabular}

Analizando los resultados se puede apreciar que la mayoría de vehículos han sido detectados correctamente con una precisión del 99,798\%, es decir, el número de detecciones correctas 
frente al total de detecciones de vehículos es muy elevado. Además, es destacable el hecho que solo se detectara un falso positivo y cuatro falsos negativos frente al total de detecciones, lo que da un ratio de falsas alarmas del 0,80\%. Ratio que muestra la elevada fiabilidad en la detección de vehículos con un valor del 99,198\%. Las falsas detecciones hacen que la exactitud sea un poco menor que la precisión, aún así este valor presenta una mas que sobresaliente estimación de un $99 \%$, que representa el ratio de vehículos detectados correctamente sobre todas las detecciones.

Los resultados de laboratorio, aunque se han realizado en un entorno controlado y siguiendo un protocolo preestablecido, ofrecen resultados muy alentadores. Aunque era de prever que los resultados de detección en la vía presentasen ratios un poco más bajos, estos se mantienen en valores muy elevados lo que auguraba una correcta detección. En el laboratorio no se ha trabajado con objetos diferentes a vehículos con lo que no se han presentado casos de verdadero negativo. Evidentemente, es de esperar que en situaciones reales estos casos sucedan con lo que los valores de precisión y exactitud se verán modificados ligeramente.

Por último, es importante destacar que, aunque inicialmente se pensó que el hecho de trabajar con prototipos de vehículos y no tener el láser situado a escala pudiera haber afectado a las medidas, los resultados obtenidos tras las pruebas de campo en el emplazamiento (ver capítulo Resultados y Discusión) permitieron descartar estas hipótesis.

\subsubsection{Pruebas de Campo}

Los resultados de las pruebas experimentales de detección, una vez instalado el sistema en el emplazamiento final se muestran en la tabla 9.3. El protocolo seguido en este caso es bastante sencillo, se basa en el conteo de los vehículos que circulan por la zona de detección de forma presencial en el emplazamiento. Este proceso se realiza hasta contar un número de 1.000 vehículos, momento en el que se compara con los resultados de detección ofrecidos por el sistema.

A vista de los resultados obtenidos se puede verificar que la precisión en la detección de vehículos, en el laboratorio y en el emplazamiento experimental es muy similar. Las probabi- 
Tabla 9.3 - Test Experimental - Detección de Vehículos

\begin{tabular}{lccc}
\hline \multicolumn{3}{l}{ Evaluación de las pruebas experimentales } \\
\hline \multicolumn{4}{l}{ Matriz de confusión } \\
& \multicolumn{3}{c}{ Evento Real } \\
& $D$ & $\bar{D}$ \\
Evento & $D$ & 976 & 3 \\
Detectado & $\bar{D}$ & 21 & 0 \\
\hline Ratio de Detección: $97,894 \%$ & & \\
Precisión: $99,694 \%$ & & \\
Exactitud: $97,60 \%$ & \\
\hline
\end{tabular}

lidades de que un vehículo que circule por la zona de detección sea detectado correctamente presentan valores del 99,798 \% en el caso de laboratorio y 99,694\% respectivamente. Por otra parte, al aumentar las falsas alarmas tanto en falsos positivos como en falsos negativos, los valores de exactitud y ratio de detección se ven penalizados.

El ratio de detección se ve penalizado por los 21 vehículos no detectados, falsos negativos. Un estudio detallado sobre los falsos negativos permite apreciar que la mayoría de estos vehículos corresponden a motocicletas que circulan a elevadas velocidades y a vehículos solapados que no han sido separados en el proceso de eliminación de vistas laterales, (ver página 135).

Los tres falsos positivos corresponden a: dos vehículos detectados por duplicado, se trata de dos camiones con tráiler donde no se detectó correctamente la separación entre la cabeza articulada del camión y el remolque; y a una persona que cruzó bajo la zona de detección de forma indebida.

Los resultados obtenidos presentan valores muy elevados en ratio de detección, precisión y exactitud del sistema. También se puede afirmar que las falsas alarmas corresponden a casos conocidos y acotados. Aunque las modificaciones necesarias para su corrección son difíciles de diseñar, se puede hacer un esbozo de posibles soluciones a estos problemas:

- En el caso de peatones cruzando de forma indebida e invadiendo la zona de detección, se podría proponer la instalación de cintas o conos en la zona de modo que quedara 
delimitada. Sin embargo, no se puede asegurar la efectividad de este método ya que se ha comprobado que los peatones han hecho caso omiso a cualquier tipo de indicaciones que se han realizado de modo verbal durante la toma de datos en el emplazamiento.

- El caso de la incorrecta separación de los camiones con tráiler, se trata de un caso de difícil solución, al estar provocado por el funcionamiento del propio láser. Los datos enviados por el láser ya no contienen información sobre la parte más baja entre la cabeza articulada y el tráiler. Con lo cual, no se pueden implementar acciones correctoras posibles ante estos hechos, que no representan ni mucho menos la mayoría de esta categoría de vehículos.

- Por último, en el caso de las motocicletas que circulan a velocidades elevadas, no se detectan por el láser ya que no se capturan suficientes muestras de este tipo de vehículos. Para poder solucionar este caso sería necesario aumentar la velocidad de escaneo.

\subsection{Clasificación de vehículos: evaluación}

\subsubsection{Pruebas de Laboratorio}

Las pruebas de laboratorio para clasificación de vehículos han sido las más difíciles de verificar debido, fundamentalmente, al uso de prototipos a escala. Además de la falta de disponibilidad de prototipos a escala para todas las categorías de vehículos usados, existe el problema de que las ecuaciones de discriminación que se usan para la clasificación en categorías tienen que ser modificadas de forma proporcional al tamaño de los prototipos.

Las ecuaciones de discriminación y el árbol de decisión han sido diseñados en función de los valores obtenidos tras la captura de datos reales en el emplazamiento (ver página 182, capítulo Proceso de Clasificación: enfoque y metodología). Es decir, el perfil sobre el que se calculan los parámetros usados en la discriminación presenta valores que corresponden a vehículos reales. De modo que aunque los vehículos estén a escala y se pudiera modificar el perfil obtenido en el laboratorio por esa escala, sería necesario modificar los valores usados en la discriminación del árbol, lo que equivale a realizar un nuevo estudio y diseñar un nuevo árbol de decisión. 
Dado el trabajo que supone el diseño de nuevos árboles y la dificultad para la realización de las pruebas en el laboratorio, se decidió seguir los pasos de la metodología definida y se emplazó su estudio directamente a las pruebas experimentales de campo.

\subsubsection{Pruebas de Campo}

Los resultados de la clasificación en cada una de las discriminaciones se han analizado ya en capítulos anteriores (ver página 199, capítulo Proceso de Clasificación: enfoque y metodología). No obstante, en este apartado se analizan los resultados de cada una de las clases o nodos finales del árbol de clasificación. Se presentan nuevas gráficas y se intenta plantear una solución a los errores derivados de la clasificación en cada una de las clases. En base a los datos recogido sobre los 972 vehículos del grupo de test, sin recurrir a remuestreo en este caso, se obtienen los resultados que aparecen en la tabla 9.4.

Tabla 9.4 - Test Experimental - Clasificación de vehículos: Matriz de confusión

\begin{tabular}{|c|c|c|c|c|c|c|c|}
\hline \multicolumn{8}{|c|}{ Matriz de confusión } \\
\hline & & & & Evento R & & & \\
\hline & & Motocicleta & T. Turismo & Furgoneta & Camión & C. tráiler & Autobús \\
\hline \multirow{6}{*}{ 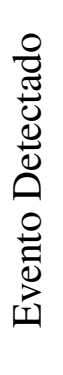 } & Motocicleta & 51 & 0 & 0 & 0 & 0 & 0 \\
\hline & T. Turismo & 0 & 659 & 15 & 0 & 0 & 0 \\
\hline & Furgoneta & 0 & 15 & 151 & 4 & 0 & 1 \\
\hline & Camión & 0 & 1 & 12 & 27 & 0 & 1 \\
\hline & Camión con tráiler & 0 & 0 & 0 & 2 & 6 & 0 \\
\hline & Autobús & 0 & 0 & 0 & 4 & 1 & 22 \\
\hline
\end{tabular}

En base a la matriz de confusión explicada en el capítulo anterior (ver Proceso de Clasificación: enfoque y metodología), se definen dos nuevos estimadores: ratio de falsos positivos y ratio de falsos negativos. Estos estimadores son el ratio de casos de una clase clasificadas como de otra. La matriz de confusión en este caso presenta más grupos que en el capítulo anterior, donde al trabajar con discriminaciones se trabajaba únicamente con dos grupos cada vez, por consiguiente los estimadores a utilizar presentan ecuaciones generalizadas a un mayor número 
de casos [TRA08]. En este análisis se trabaja con las siguientes ecuaciones: exactitud en la clasificación (9.1); ratio de clasificación correcta (9.2); y precisión para cada clase (9.3).

$$
\text { Exactitud de la clasificación }(\%)=100 \frac{\sum_{i=A \ldots C} N_{i i}}{\sum_{i=A \ldots C} \sum_{j=A \ldots C} N_{i j}}
$$

donde,

$N_{i j}$ es el número de vehículos de la clase i clasificados como vehículos de la clase j

$N_{i i}$ es el número de vehículos de la clase i clasificados correctamente en su clase

$$
\begin{aligned}
& \text { Ratio de Clasificación correcta para cada clase i }(\%)=100 \frac{N_{i i}}{\sum_{j=A \ldots C} N_{i j}} \\
& \text { Precision para cada clase i }(\%)=100 \frac{N_{i i}}{\sum_{j=A \ldots C} N_{j i}}
\end{aligned}
$$

Los estimadores de cada una de las clases son pues los mostrados en la tabla 9.5.

Tabla 9.5 - Test Experimental - Clasificación de vehículos: Evaluación

\begin{tabular}{lcc}
\hline \multicolumn{3}{l}{ Evaluación de las pruebas experimentales } \\
\hline & Ratio de Clasificación (\%) & Precisión (\%) \\
\hline Motocicleta & 100 & 100 \\
Tipo Turismo & 97,63 & 97,77 \\
Furgoneta & 84,83 & 88,30 \\
Camión & 72,97 & 65,85 \\
Camión con tráiler & 85,71 & 75,00 \\
Autobús & 91,67 & 81,48 \\
\hline Exactitud: $94,24 \%$ & & \\
\hline
\end{tabular}

El sistema presenta un elevado valor de exactitud del 94,24\%. La clase Motocicletas, como se ha demostrado en la primera discriminación, se clasifica siempre correctamente con ratios de detección y precisión del $100 \%$. La clase que presenta un mejor ratio de detección correcta 
(tras la clase motocicletas) es el Tipo Turismo, ya que de de todos los vehículos pertenecientes a esta clase, un $97,63 \%$ han sido clasificados correctamente. Los vehículos conocidos como todoterrenos son los que producen errores en esta clase al ser clasificados algunos de ellos como furgonetas, dado su perfil que se ajusta más a esta clase. Esta situación se puede solucionar decidiendo que este tipo de vehículos entren dentro de la clase furgonetas ya que al pertenecer a ese umbral dudoso entre clase, sería perfectamente aceptable. Las imágenes de la figura 9.4 muestran este tipo de vehículos donde queda en evidencia que la altura del capó y del techo son ligeramente superiores a los vehículos tipo berlina.
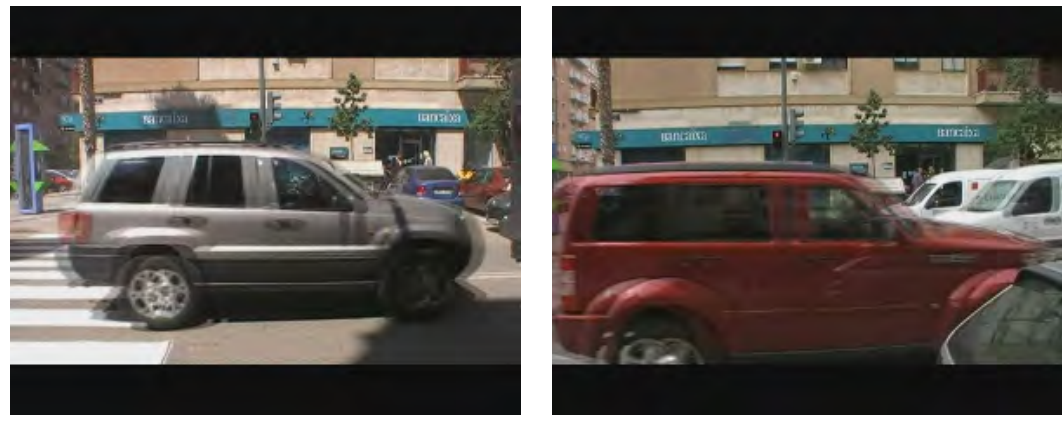

Figura 9.4 - Vehículos de la clase Turismo: Todoterrenos

Por otra parte, la clase que presenta un peor ratio de clasificaciones correctas es la clase Camión, donde únicamente un $72,97 \%$ de los vehículos de este grupo han sido clasificados correctamente. Estos errores se deben a las clasificaciones erróneas como furgonetas, camión con tráiler y autobuses. En el caso de camiones clasificados como furgonetas, la situación tiene difícil solución ya que existen vehículos que fácilmente podrían entrar en cualquiera de los grupos. La imagen 9.5 muestra dos de estos casos, donde ambos vehículos han sido clasificados como camiones ya que en la definición se decía que la parte delantera y trasera eran independientes, ver página 164. Evaluar este tipo de característica con los datos del perfil es complicado.

Los camiones clasificados como camión con tráiler se dan en un menor número de casos, y se deben a vehículos como los de la imagen 9.6, donde el hueco existente entre la cabeza y la parte trasera es interpretado como la clase camión con tráiler. Realmente no se pueden 


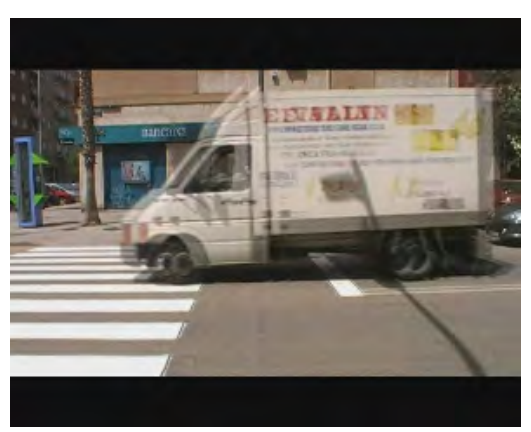

(a) Camión

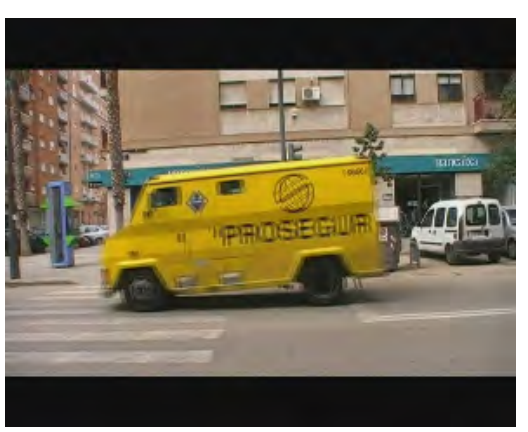

(b) Furgón Blindado

Figura 9.5 - Vehículos de la clase Camión

considerar en esta clase ya que no se trata de una cabeza articulada que se pueda separar del remolque, sino de un bloque compacto.

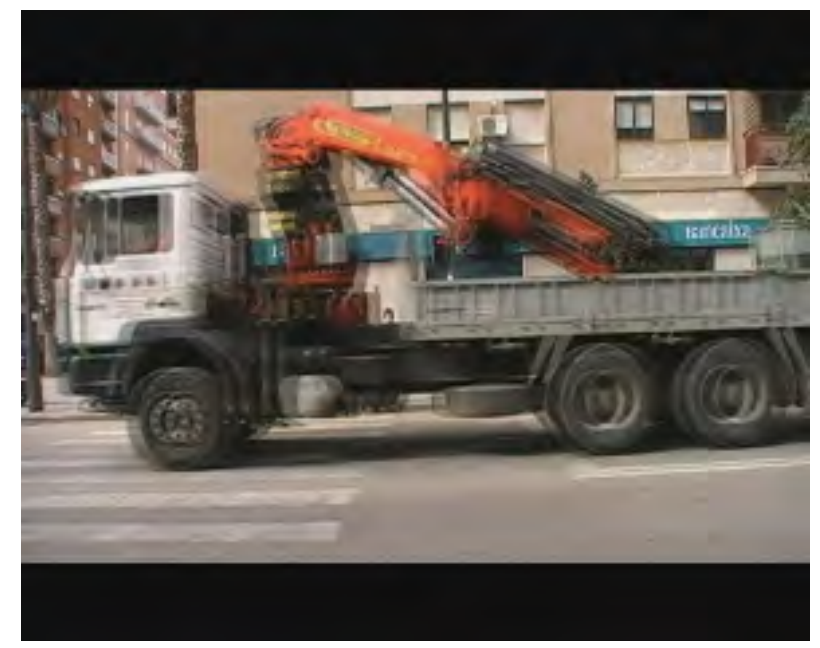

Figura 9.6 - Camión grúa

Los camiones clasificados como autobuses son los casos que presentan una solución más sencilla. Estos casos se deben a camiones muy altos por lo que se confunden con autobuses, pero se podría añadir un parámetro más específico para vehículos altos que buscara una continuidad en el perfil. La idea es la misma que la seguida en la definición de los parámetros ratio90ic y ratio90cf (ver página 182), pero parece que no ha sido suficiente, con lo que se deben buscar nuevos parámetros para solucionar este caso en el futuro.

En la clase Camión, la precisión se ve afectada por el número de furgonetas clasificadas como camiones. Este caso también es de difícil resolución. Se trata de vehículos que aunque 
por su altura podrían ser clasificados como camiones, la definición de camiones con las dos partes diferenciadas (ver página 164) no se ajusta a su caso, como se muestra en la imagen 9.7.
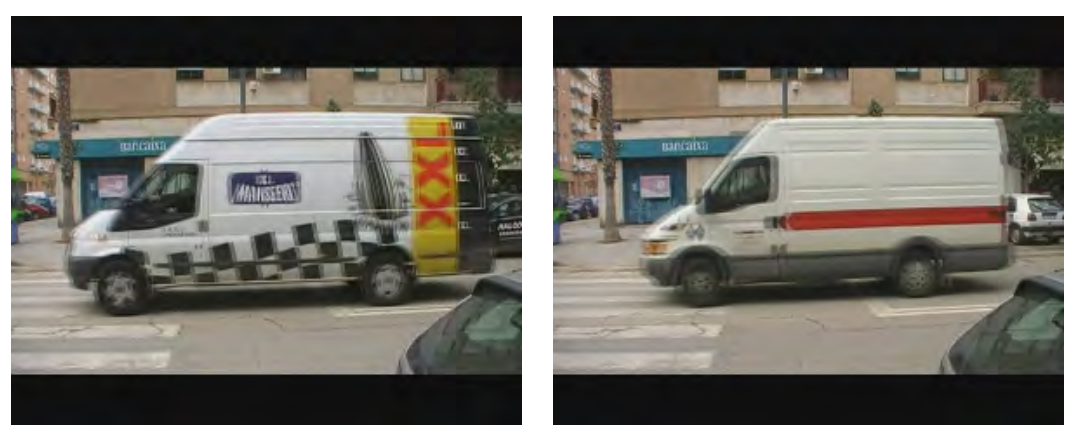

Figura 9.7 - Vehículos de la clase Furgoneta

Una solución ante las clasificaciones erróneas de camiones como furgoneta y viceversa se basa en la modificación de la definición de furgoneta. En lugar de basar la definición de furgoneta en dos módulos unidos, la cabina del conductor y la parte trasera, se podría definir por altura únicamente con lo que estos casos se podrían minimizar e incluso llegar a eliminar. Sin embargo, las modificaciones en las definiciones de vehículos conllevan un nuevo estudio y diseño de los árboles de clasificación.

La clase Camión con Tráiler presenta una pequeña población, de modo que pequeños errores de clasificación representan un porcentaje importante frente al total. Aún así, es interesante subrayar el hecho que de los 7 vehículos de esta clase del grupo de test, sólo uno se ha clasificado erróneamente, haciéndolo como Autobús. Lo más probable en este caso es que la cabeza articulada no haya sido detectada, con lo que el remolque, dada su uniformidad, ha sido clasificado como un autobús. Este error corresponde más a un fallo de detección que de clasificación.

Finalmente la clase Autobús tiene un buen ratio de clasificaciones correctas, si bien la precisión se ve afectada por el número de camiones clasificados como autobuses. La situación en este caso no consiste en mejorar la clasificación de autobuses clasificados como tales, sino la errónea de camiones clasificados como autobuses ya comentado con anterioridad. 


\subsection{Conclusiones}

En este capítulo se ha partido de la instalación del equipo en la vía para explicar cómo y bajo qué condiciones se ha realizado la toma de datos. Posteriormente se ha analizado por separado la detección y la clasificación bajo dos tipos de test: en laboratorio y experimentalmente mediante las pruebas de campo.

Las pruebas de campo han demostrado que el sistema presenta un ratio de detección del 97,89\%, con precisión del 99,69 \% y exactitud del 97,60 \%, lo que son valores muy elevados y demuestra la eficacia del sistema en el caso de detección. El estudio detallado realizado en el apartado Resultados y Discusión, ha analizado los errores y ha planteado su posible solución.

La separación por clases ha mostrado la necesidad de modificar las definiciones de algunas de ellas, especialmente furgonetas y camiones, para poder mejorar el ratio de detección de ambas. Aún así, la exactitud en la clasificación es del 94,24\%, valor ciertamente muy elevado y que demuestra el éxito de la discriminación realizada mediante árboles de clasificación. 


\section{Bibliografía}

[AEM09] AEMET: Valores Climatológicos Normales. Valencia. Agencia Estatal de Meteorología, 2009, URL http://www.aemet.es/es/elclima/ datosclimatologicos/valoresclimatologicos?l=8416 \&k=val, [Online; Último acceso Agosto 2009].

[TRA08] TRACKSS: D7.1 Evaluation Guidelines \& Plan. TRACKSS Consortium: Technologies for Road Advanced Cooperative Knowledge Sharing Sensors, 2008. 


\section{Parte V}

\section{Conclusiones y Trabajo Futuro}





\section{Capítulo 10}

\section{Conclusiones}

La motivación que ha llevado al desarrollo de esta tesis no ha sido sino el desarrollo de un detector ITS eficaz, eficiente y polivalente que sirva de plataforma a las entidades gestoras de las vías, proporcionándoles información en tiempo real, apoyando de este modo a la toma de decisiones, promoviendo una nueva gestión innovadora del tráfico, y el diseño de los planes de mejora de la seguridad vial.

Si la definición de objetivos supuso el punto de partida de esta tesis, delimitando y precisando la dirección hacia la que dirigir el estudio, el punto final es la justificación del logro de todos ellos. Precisamente este es el objetivo del actual capítulo; se repasan los objetivos definidos uno a uno, (ver página 75), y se describe como se ha llegado a su correcta consecución.

El primer objetivo pretendía realizar un listado y definición de requerimientos funcionales mínimos. Se persigue aportar una definición al estado del arte que sea válida para cualquier sensor de tecnología láser escáner para su aplicación en el área ITS. La respuesta a este objetivo se presenta en forma de tabla, (ver tabla 10.1), distinguiendo entre requerimientos hardware y software.

En el capítulo Arquitectura Hardware se ha especificado aquella en la que se basa la adquisición y pretratamiento de la señal proveniente de los sensores láser escáner. Independientemente de la señal que se reciba del sensor y el tipo de conector usado se han determinado las etapas necesarias para que la señal sea adquirida y analizada correctamente. Las etapas definidas han sido: 
- Etapas conversoras para la adecuación de la señal recibida por cualquier tipo de conexión: RS422-TTL/CMOS, RS232-TTL/CMOS, serie-USB ...

- Microprocesador, en este caso se ha utilizado un DSC, encargado de:

○ Configuración del láser escáner (baudrate, ángulo de escaneo, resolución... )

- Normalización de la trama del láser.

- Envío de la información al ordenador.

- Etapa de adaptación de la alimentación: protege el circuito ante variaciones de diferencia de potencial, descargas eléctricas y ruido existente, filtra la señal evitando posibles rizados y, sobre todo, garantiza la tensión constante de salida necesaria, $5 \mathrm{~V}$.

- Leds indicadores para la visualización de resultados de forma ágil y rápida.

- Diferentes conectores para dotar al hardware de la mayor versatilidad permitiendo conectar: DE9 tanto macho como hembra para las comunicaciones serie, conectores USB-B, conector de alimentación y conector RJ-11 para programación, pruebas y verificación del DSC.

La definición y especificación hardware ha permitido su implementación mediante el diseño de una placa de circuito impreso donde se incluyen todas las etapas anteriormente enumeradas, (ver figura 10.1).

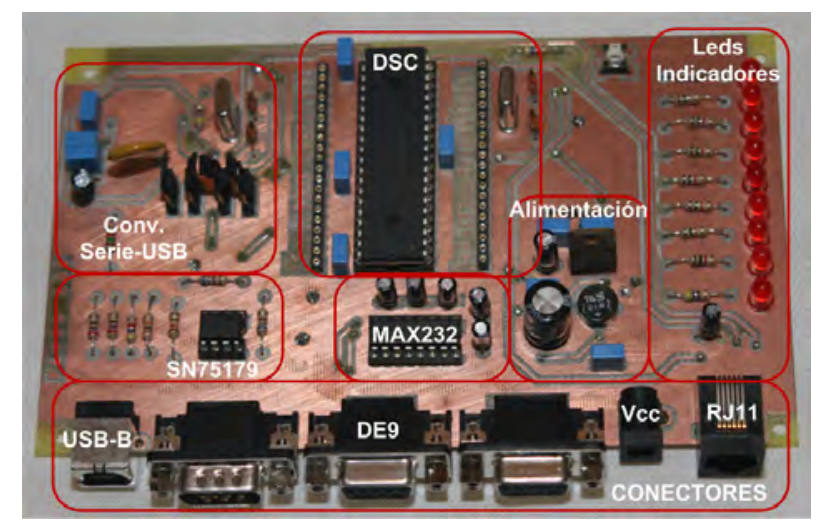

Figura 10.1 - Implementación de la Arquitectura Hardware

Dicha PCB ha sido utilizada en la etapa de validación con dos modelos de sensores comerciales diferentes: SICK LMS 221 y Acuity Accurange 4000. Se han elegido estos equipos porque, aunque el principio de operación es el mismo en ambos casos: escaneos perpendiculares 
a la vía, la información que envían presenta un formato diferente. Mientras que el modelo de SICK trabaja con un motor paso a paso y envía los datos asociados a cada una de las posiciones del motor; el modelo de Acuity, al trabajar con un motor de continua, envía los datos asociados a la posición de un encoder en cada momento. En la etapa de comunicación también difieren, ya que uno usa un interfaz RS422 y otro un RS485. Así se cumplió el tercero de los objetivos que se perseguía: "Implementar la arquitectura hardware y validarla mediante diferentes modelos comerciales de sensores láser escáner con el objetivo certificar su independencia del equipo usado, es decir, su condición de sistema multisensor”.

A la hora de especificar y detallar los algoritmos utilizados en la arquitectura software, se partía de unas definiciones de objetivos muy genéricas que se han visto concretadas en el desarrollo de los siguientes algoritmos:

- Algoritmos de tratamiento de las tramas: recepción y distribución.

- Algoritmo de reconstrucción de vehículos que incluye las siguientes etapas:

○ Eliminación de las vistas laterales permitiendo separar vehículos solapados.

- Tratamiento de Reflexiones Perdidas reconstruyendo partes del vehículo de las que no se posee información.

- Técnicas de Interpolación y Diezmado para la adecuación de la frecuencia de muestreo.

Así, el cuarto objetivo queda cumplido: "Especificar y detallar los requerimientos de la arquitectura software, es decir, los algoritmos necesarios para su correcto funcionamiento que deben ser íntegramente descritos". Además, estos algoritmos han dado lugar al desarrollo de dos programas de procesado denominados: Firmware $L S$, algoritmo de tratamiento de las tramas, y Procesado Sensor Laser, algoritmo de reconstrucción de los vehículos.

El quinto objetivo relativo a la base de datos exigía: "Crear una base de datos donde se guarde y recopile toda la información para su posterior análisis o uso en futuras aplicaciones”. El diseño de la base de datos, (ver figura 10.2(a)), cumple con las metas definidas al presentar una herramienta capaz de almacenar la información relativa a todos y cada uno de los vehículos detectados. Dicha información comprende: 
- tipo de vehículo,

- anchura,

- perfil,

- matriz 3D,

- e imagen.

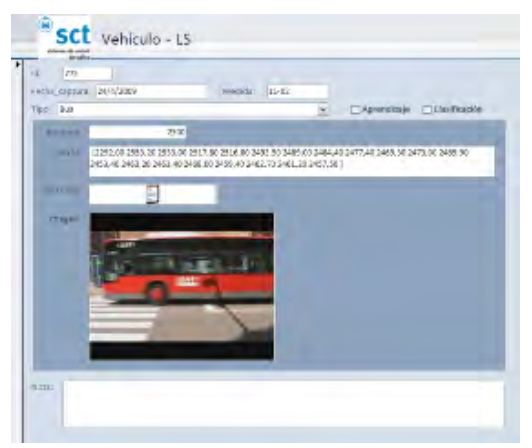

(a) Base de Datos

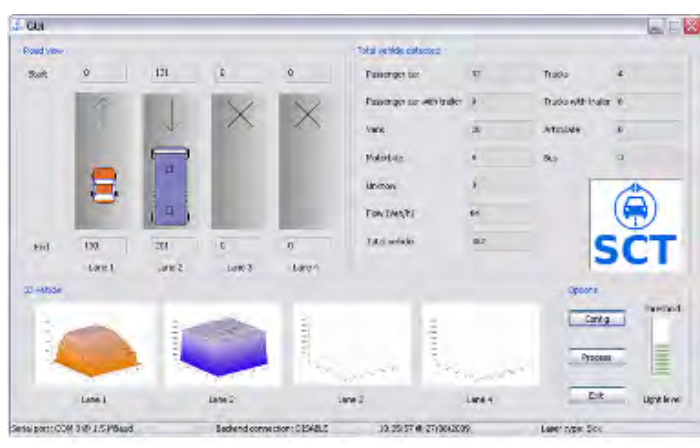

(b) Interfaz gráfico

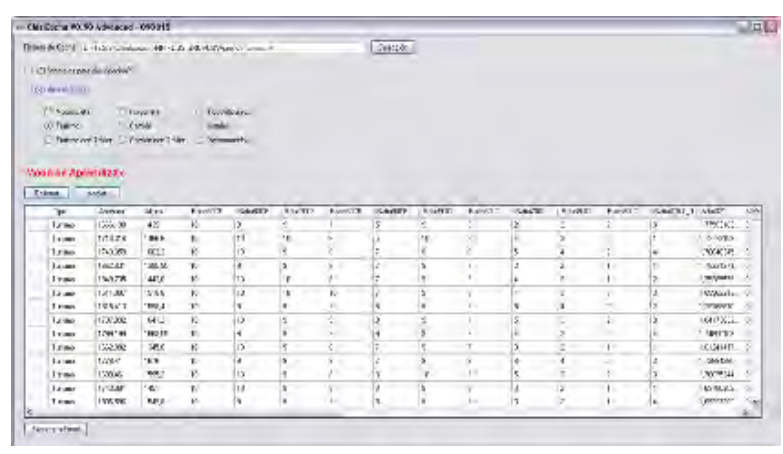

(c) ClasiCoche

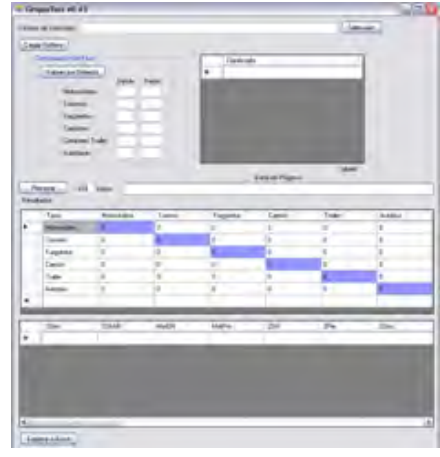

(d) GruposTest

Figura 10.2 - Diferentes Programas Desarrollados

"Determinar el enfoque y metodología a seguir en el proceso de aprendizaje y clasificación" era el sexto objetivo. El reconocimiento de patrones ha destacado como el mejor enfoque para atacar el problema ya que el objetivo principal de este tipo de técnicas es: clasificar patrones en base a un conocimiento a priori o información estadística extraída de los mismos que sirven para tomar diferentes acciones como clasificar datos en diferentes categorías.

La situación planteada era un caso típico de clasificación donde el objetivo es asignar cada valor de entrada a una de un número finito de categorías discretas. Nos encontramos ante una situación propia de caso de aprendizaje supervisado, resuelta mediante técnicas no paramétricas 
de modelización como son los árboles de decisión. Esta técnica es el método de aprendizaje inductivo supervisado más utilizado.

En las técnicas de reconocimiento de patrones se definen dos fases: proceso de aprendizaje y de test. En el proceso de aprendizaje se han extraído las características del grupo que permiten la discriminación entre clases en base a determinados parámetros predictivos, y se han definido los patrones para usar en la clasificación mediante técnicas de árboles de clasificación. Finalmente, en el proceso de test mediante la técnica de remuestreo de Bootstrap se han calculado los estimadores usados para evaluar la bondad del sistema de clasificación.

Se pueden relacionar los objetivos definidos con los siguientes resultados:

- Método de muestreo a seguir: muestreo estratificado proporcional.

- Procedimiento de extracción de características mediante el estudio del perfil de cada clase. Se ha diseñado un programa para la extracción de estas características llamado ClasiCoche, (ver figura 10.2(c)).

- Definición de patrones usando árboles de decisión en cada una de las discriminaciones. El programa desarrollado en este caso se denomina Generar_Arboles y trabaja en el entorno de Matlab.

- Análisis de los resultados mediante tests de hipótesis y técnica de remuestreo Bootstrap. En este caso, el programa diseñado se llama GruposTest, (ver figura 10.2(d)).

- Sistema de clasificación en diferentes clases en base al estándar alemán TLS 8+1, representado en la figura 10.3.

Los resultados de la clasificación en base a los algoritmos anteriormente especificados y diseñada en el programa Procesado Sensor Laser puede ser enviada a los centro de gestión de tráfico utilizando cualquier tipo de tecnología de comunicaciones: cable de fibra óptica, coaxial, GPRS, GSM, WiFi, WiMAX ... De hecho, durante las pruebas de campo se han utilizado tecnología WiMAX para comunicar desde el emplazamiento del sistema hasta la sala de control de tráfico del Ayuntamiento de Valencia. El objetivo séptimo queda de este modo concluido con éxito, siendo este "Comunicar con el centro de gestión de tráfico para enviar la información procesada”. 


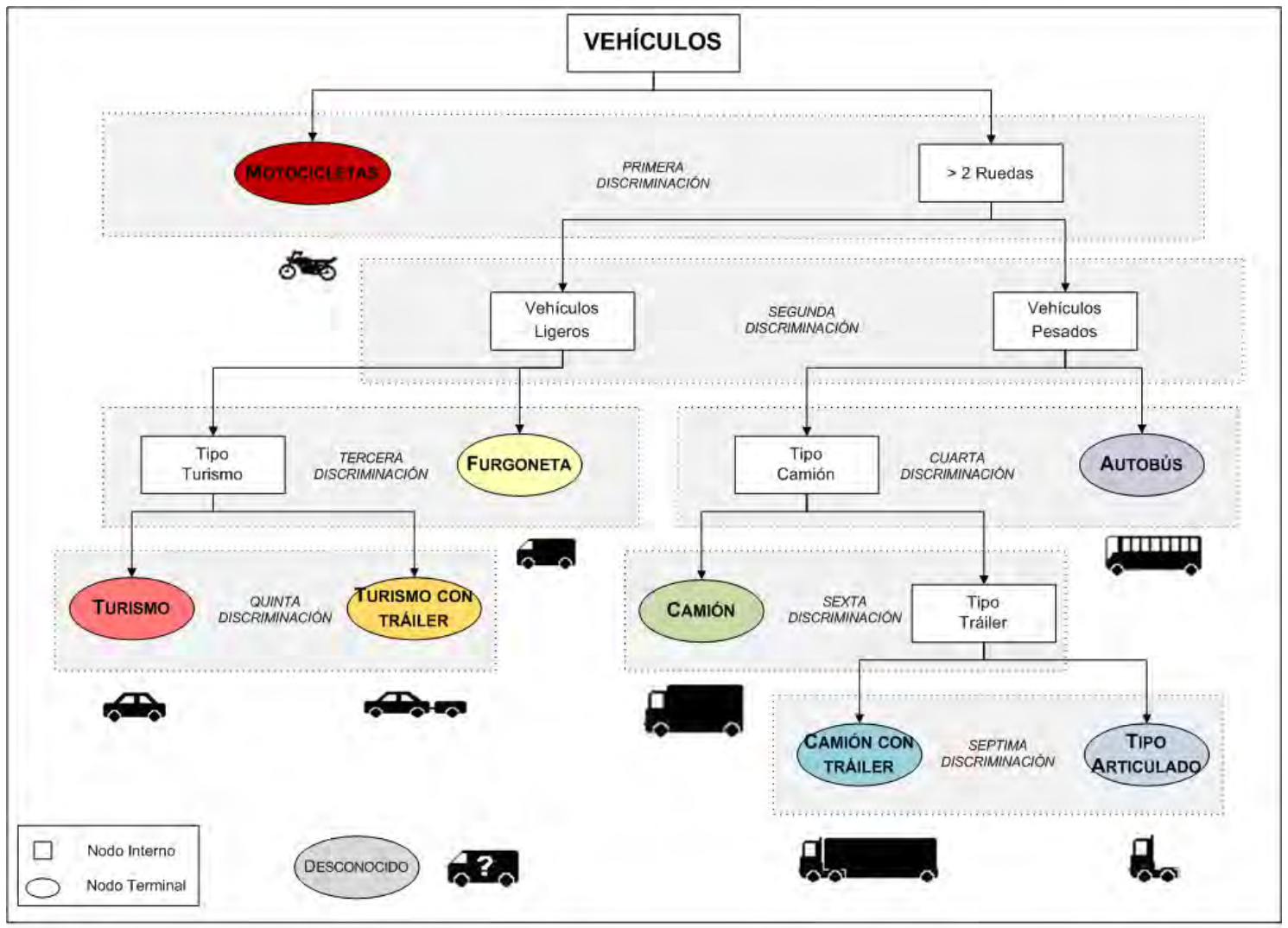

Figura 10.3 - Árbol de clasificación

El siguiente objetivo, octavo, demandaba una presentación de la "información obtenida de forma accesible, inteligible y fácil. El interfaz gráfico de usuario, o GUI, ha sido la respuesta a esta premisa, (ver figura 10.2(b)). El GUI permite visualizar de forma gráfica y numérica la información del estado del tráfico en tiempo real. Además de informar acerca de la la detección y clasificación de vehículos, envía información relativa a diferentes parámetros de tráfico interesantes para el CGT como pueden ser el volumen o la densidad. La ventana principal ha sido dividida en varios bloques según estén relacionados con la visualización de la vía y los vehículos, el cálculo de estadísticos o la configuración.

Uno de los objetivos más ambiciosos era el que exigía que la "información proporcionada fuera: cuantiosa, precisa, fiable y en tiempo real”. Los resultados obtenidos en la evaluación de detección y clasificación demuestran que los datos son cuantiosos, precisos y fiables. La detección, capaz de cubrir hasta cuatro carriles de una vía, presenta los siguientes valores: ratio de detección: 97,894 \%, precisión: 99,694 \% y exactitud: 97,60 \%. Mientras que la clasificación 
de vehículos presenta una exactitud global de $94,24 \%$. Se trata en todos los casos de valores innegablemente excelentes que no hacen más que confirmar la definición precisa y adecuada de los requisitos funcionales y la implementación apropiada de los mismos. Finalmente estos datos son proporcionados en tiempo real a medida que los vehículos circulan por la zona de detección.

Por último, se planteaba la capacidad de posibilitar futuras aplicaciones V2I o I2I. Las acciones enmarcadas en el proyecto TRACKSS son un claro ejemplo de este tipo de aplicaciones y de que la posibilidad de usar la arquitectura definida e implementada es más que una posibilidad, es una realidad. Las aplicaciones I2I en las que se ha utilizado el sistema basado en el sensor láser escáner han sido:

- Dentro del escenario "Establecimiento de comunicaciones entre sensores de infraestructuras inteligentes con fines de control y gestión de tráfico" se ha trabajado en la "modificación de los sensores afectados por la intensidad luminosa de la vía”.

- En el escenario "Centro de gestión de tráfico" se ha implementado la aplicación: discriminación de vehículos a la entrada a centros urbanos.

Partiendo de los sensores y las necesidades del CGT, la investigación desarrollada en esta tesis ha conseguido definir los requerimientos y la arquitectura del bloque intermedio que comunicará ambas áreas, para poder implementar y desarrollar las aplicaciones definidas con anterioridad enmarcadas en el ámbito del eSAfety y mejorando así la seguridad vial.

Finalizamos, afirmando que se ha definido un método que representa una opción válida, simple y con coste computacional reducido, que puede ser utilizado con cualquier sensor basado en el principio de detección de área de vehículos, con alta exactitud en la detección y la clasificación. Asimismo se trata de un sensor ITS que da respuestas a las necesidades de todos los agentes implicados en temas de seguridad vial (autoridades, entidades gestoras, usuarios y sociedad) y cuyas aplicaciones tienen incidencia directa sobre la mejora de la calidad de vida de los usuarios de la vía pudiendo ser utilizado en diversas aplicaciones ITS como pueden ser:

- Identificación vehículos en peaje en sombra. 
- Definición de planes para la reducción de emisiones contaminantes y otros aspectos medio ambientales.

- Información a los usuarios de la vía, bien sean peatones u otros vehículos.

- Control y gestión del tráfico en áreas urbanas:

○ Detectando posibles incidencias: atascos, accidentes ...

○ Planificando itinerarios alternativos.

- Restringiendo el paso a vehículos pesados.

- Controlando el acceso a determinadas zonas conflictivas de forma puntual debido a la celebración de eventos: deportivos, musicales ...

- Ayudando a la gestión urbanística mediante la planificación y ordenación de nuevas vías en zonas de crecimiento de las ciudades.

La figura 10.4 representa la filosofía de esta tesis y resume todo el trabajo realizado. 


\section{Requerimientos Funcionales}

\begin{tabular}{ll}
\hline & HARDWARE \\
\hline General & \\
\hline Altura mínima sobre la vía (m) & 5 \\
Consumo máximo (W) & 40 \\
Clase de láser & I (seguro) \\
Tipo de emisor & diodo láser IR \\
\hline Comunicaciones & \\
\hline Tipo interfaz & RS232 opcional RS485/422 \\
Baudrate, tasa de transferencia (KBd) & $9,6-500$ \\
Opción alta velocidad (MBd) & 1,5 \\
\hline Escáner & \\
\hline Frecuencia de escaneo (Hz) & $15-100$ \\
Tiempo respuesta (ms) & $53-10$ \\
Ángulo de Escaneo & $100^{\circ}-180^{\circ}$ \\
Resolución Angular & $0,25^{\circ}-1^{\circ}$ \\
\hline Especificaciones &
\end{tabular}

\section{Especificaciones}

- El sistema debe ser capaz de detectar los vehículos que circulan por la zona de detección.

- El sistema debe adquirir y almacenar los datos provenientes de los vehículos detectados.

- El sistema debe situarse en la perpendicular de la vía con visión directa a la misma.

- La comunicación entre el equipo sensor y la arquitectura hardware debe realizarse via RS232 o USB.

- La comunicación entre la arquitectura hardware y el ordenador debe realizarse via USB.

\section{SOFTWARE}

\section{Adquisición de la señal: Firmware}

- El sistema debe ser capaz de realizar el correcto tratamiento de la trama recibida del sensor láser escáner.

- El firmware tras la correcta detección de la señal y una vez realizado el pretratamiento debe enviar dicha información al ordenador vía USB a una velocidad de 1,5 MBd para su procesado.

\section{Tratamiento de los datos: Software}

- La información recibida ha de ser correctamente tratada para la obtención de los parámetros que se enviarán al CGT.

- Tras este proceso se debe obtener la siguiente información: detección de vehículos, discriminación por clases de los mismos y todos los estadísticos y valores que se puedan interferir de ellos: intensidad del tráfico (veh/h) y densidad principalmente.

- El tratamiento de la señal debe seguir los algoritmos definidos de tratamiento de las tramas (recepción y distribución) y reconstrucción de vehículos (eliminación vistas laterales, tratamiento de reflexiones perdidas y modificación de la frecuencia de muestreo).

- La información proporcionada tras estos procedimientos debe ser fiable e inteligible. 


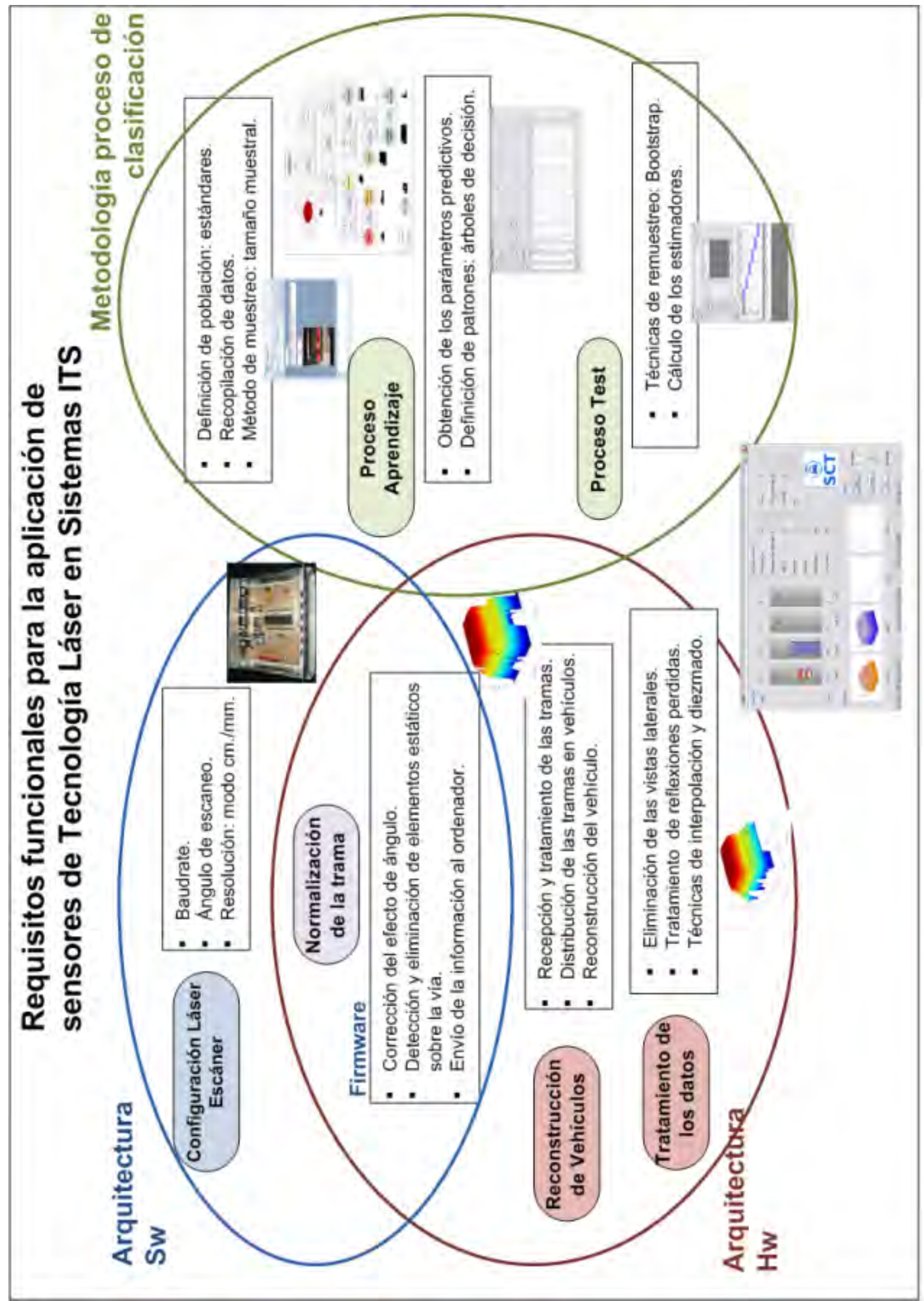

Figura 10.4 - Esquema de la tesis 


\section{Capítulo 11}

\section{Líneas Futuras de Investigación}

El estudio iniciado ha presentado una situación, definido y aportado soluciones y detallado una metodología de diseño que no pretende sino ser un punto de partida que sirva para el desarrollo de diferentes y nuevas aplicaciones en el área ITS mediante sensores IR, que ayuden en la mejora de la seguridad vial.

Las ramas de la actual investigación se extienden hacia diferentes áreas, de modo que abren el camino a posibles nuevos estudios y diseños. Entre las numerosas acciones que se pueden iniciar partiendo de esta tesis se procede a destacar las más importantes agrupadas en distintas áreas.

El Algoritmo de Clasificación definido en base a la clasificación TLS no se ha completado totalmente debido a dos clases que no se han encontrado presentes en la vía: turismos con tráiler y tipo articulado. En futuros trabajos se propone implementar estas dos clases mediante modelos descriptivos que permitan su simulación y estudio. También, para el caso de aplicaciones críticas en las que se requiera una mayor definición del grupo turismos se propone definir un rango de incertidumbre entre la clase turismos y furgonetas, en base al estudio de los tipos de vehículos que se puedan encontrar en el límite entre ambas como es el caso de los vehículos todoterreno $4 \times 4$.

En el caso de incidencias como: atascos, detenciones no prolongadas del tráfico, vehículos estacionados bajo el sensor ..., es posible que se de la situación que la información detectada desborde el sistema hardware y se entre en un estado de saturación que bloquee temporalmente el sistema. Aunque no se ha podido comprobar in situ esta situación, se contempla su posible 
existencia lo que deriva en el planteamiento de iniciar un estudio que analice y reflexione sobre esta posibilidad para poder plantear una solución acorde.

El estudio de la fiabilidad de la información del sistema bajo diferentes condiciones meteorológicas abre la vía a otra línea de investigación. Aunque en este estudio se ha comprobado la inmunidad del sistema definido, desarrollado e implementado ante variaciones de intensidad luminosa en la vía y diferentes situaciones meteorológicas (sol, nubes y lluvias) se propone realizar un trabajo más detallado basado en la influencia del viento, nieve o lluvia intensa.

No se ha contemplado el caso de posibles errores debidos a una mala instalación del sensor. A día de hoy, el láser se ha instalado perpendicularmente a la vía y con visión directa sobre la misma. Sería interesante estudiar el posible efecto debido a la instalación del sensor con un cierto ángulo sobre la vertical o a diferentes alturas. ¿Se ve modificada la forma en que la información es detectada?, ¿afecta a las medidas realizadas? Son preguntas que se han de plantear en futuros estudios.

Las necesidades de los usuarios de la vía aumentan cada día. El uso generalizado de las nuevas tecnologías en todos los ámbitos hace que los usuarios demanden más información. La respuesta en ITS se presenta mediante el uso de sistemas cooperativos de transporte, que exigirán nuevos sistemas de comunicación: V2V, V2I y I2I. En estos sistemas la inteligencia es distribuida y compartida entre la infraestructura de las redes y los vehículos.

Se trata de una nueva línea de trabajo para dotar a los sensores de la "inteligencia" necesaria para no solo comunicarse, sino interactuar entre ellos. En esta línea se debe investigar sobre el tipo de aplicaciones posibles, y en cada una de ellas, el tipo de información que es necesario comunicar entre los sensores. Imaginemos que se prohíbe el acceso al centro de las ciudades de un determinado tipo de vehículos, desviando su circulación por una determinada ronda exterior. La colocación de sensores láser escáner en los accesos estratégicos podría detectar si algún vehículo viola la prohibición y en su caso actuar enviando dicha información a diferentes fuentes: al CGT para que se actúe al respecto (pudiendo considerar el caso de avisar a la policía local), al PMV más cercano para informar al conductor del vehículo o incluso al propio vehículo si está dotado de los sistemas apropiados. 
Los sensores inteligentes son el inicio de una nueva familia de sensores cooperativos orientados a la aplicación final donde la tecnología queda en un segundo plano. Aunque se han realizado ya las primeras pruebas y demostraciones en este sentido, se sugiere trabajar en esta línea de investigación identificando posibles aplicaciones donde se puedan utilizar sensores láser escáner en combinación con otro tipo de tecnologías sensoras. 



\section{Capítulo 12}

\section{Aportaciones}

\subsection{Trabajos colaterales desarrollados}

\subsubsection{Sensores Inteligentes: Proyecto TRACKSS}

El proyecto europeo TRACKSS “Technologies for Road Advanced Cooperative Knowledge Sharing Sensors" (TRACKSS), [TRA06], enmarcado en el VI Programa Marco Europeo de Tecnologías para la sociedad de la información, ha servido de plataforma en la que validar y probar el sistema propuesto y diseñado.

Hoy en día, la seguridad se confía la mayor parte del tiempo a sistemas autónomos o independientes, que ofrecen sin ningún lugar a dudas lugar para mejoras. Para superar las limitaciones de esos sistemas, se necesitan otra clase de soluciones: Sistemas Cooperativos de Transporte, cuya inteligencia es distribuida/compartida entre la infraestructura de las redes viarias y los vehículos, llegando a un acuerdo entre innovaciones en la seguridad vial y eficacia del transporte. Indudablemente, las tecnologías disponibles actualmente, o en desarrollo, permiten la mejora no sólo en los sistemas de detección, sino también su filosofía de compartir información.

El punto de partida de este proyecto fue la premisa de que: "sistemas inteligentes requieren sensores inteligentes; sistemas cooperativos requieren sensores cooperativos". Afirmación que conduce a la definición de la siguiente meta estratégica: "Desarrollar nuevos sistemas de detectores cooperativos y que predicen el flujo, las infraestructura y las condiciones ambientales 
que rodean al tráfico, con objeto de mejorar la seguridad y la eficacia de las operaciones de transporte vial.”. Se pretende pasar de la situación de la figura 12.1(a) donde la información de la vía es enviada al CGT y los sensores no se comunican entre ellos, a la de la figura 12.1(b) donde se establecen comunicaciones V2I, V2V y I2I, de modo que la inteligencia se distribuye y comparte entre todos los elementos de la vía.

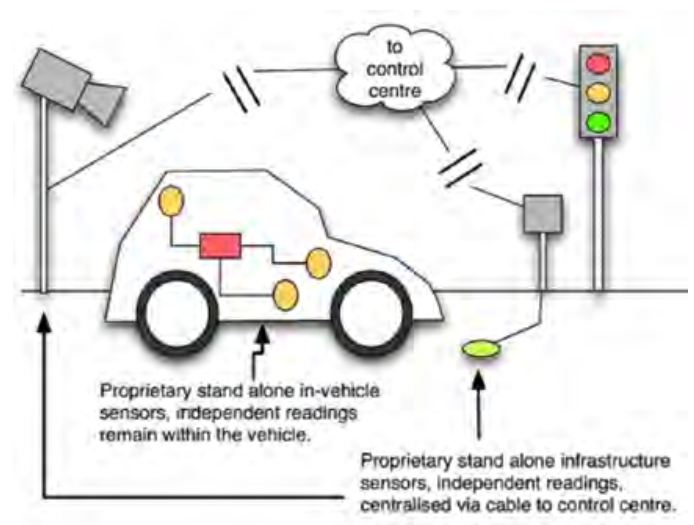

(a) Antes de TRACKSS

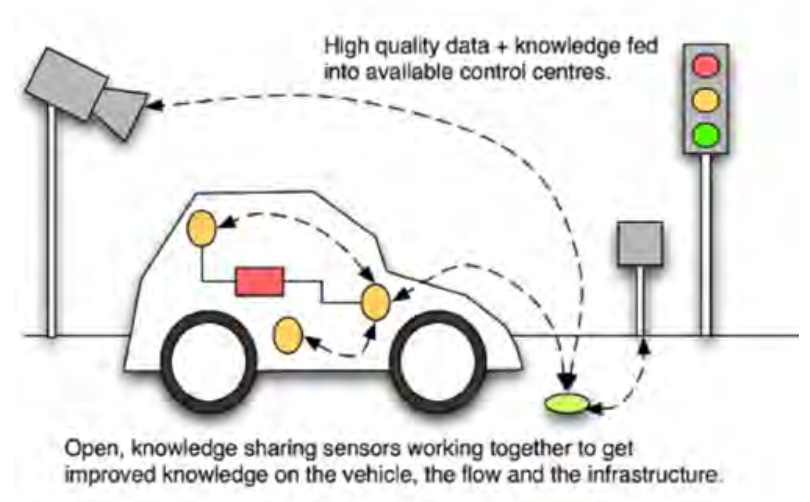

(b) Después de de TRACKSS

El proyecto mejora y desarrolla un número de novedosas tecnologías sensoras, al mismo tiempo que desarrolla un nuevo modelo para el intercambio de conocimiento entre sensores. Además, el consorcio ha contribuido en el diseño de una arquitectura pan-Europea para la eSafety juntos con los proyectos: CVIS, Coopers y Safespot, entre otros. Los resultados del proyecto han sido validados a través de 3 pilotos instalados en: París (Francia), Berlín (Alemania) y Valencia (España).

El proyecto, iniciado en enero de 2006 y con una duración de 3 años, ha sido desarrollado por un consorcio formado por 15 socios, incluyendo empresas industriales globales, innovadoras PyMES, e institutos de investigación de España, Reino Unido, Francia, Alemania, Italia, Hungría y la República Checa. Sus socios son: ETRA I+D, S.A.(España); Centro Recherche Fiat (Italia); University of Newcastle (UK); Institute for trsansport Sciences (Hungría); TRW Coneckt (UK); Moviquity (España); Ayuntamiento de Valencia (España); ITACA (España); DLR (Alemania); INRETS (Francia); Robert Bosch GMBH (Alemania); TRL (UK); CDV (República Checa); CITILOG (Francia) y LCPC (Francia). 
El cronograma que resume el trabajo realizado se muestra en la figura 12.1. Se puede apreciar como el trabajo desarrollado en relación con el Sensor Láser Escáner está enmarcado en la tarea 3 "Knowledge Sharing sensors in infrastructure" y en concreto se trata de la tarea 3.2 con una duración de un año para el desarrollo. También hay que contar con las tareas 6 y 7, relacionadas con la validación y evaluación de resultados, imprescindibles para demostrar la validez del desarrollo y el cumplimiento de los objetivos definidos inicialmente en el proyecto.

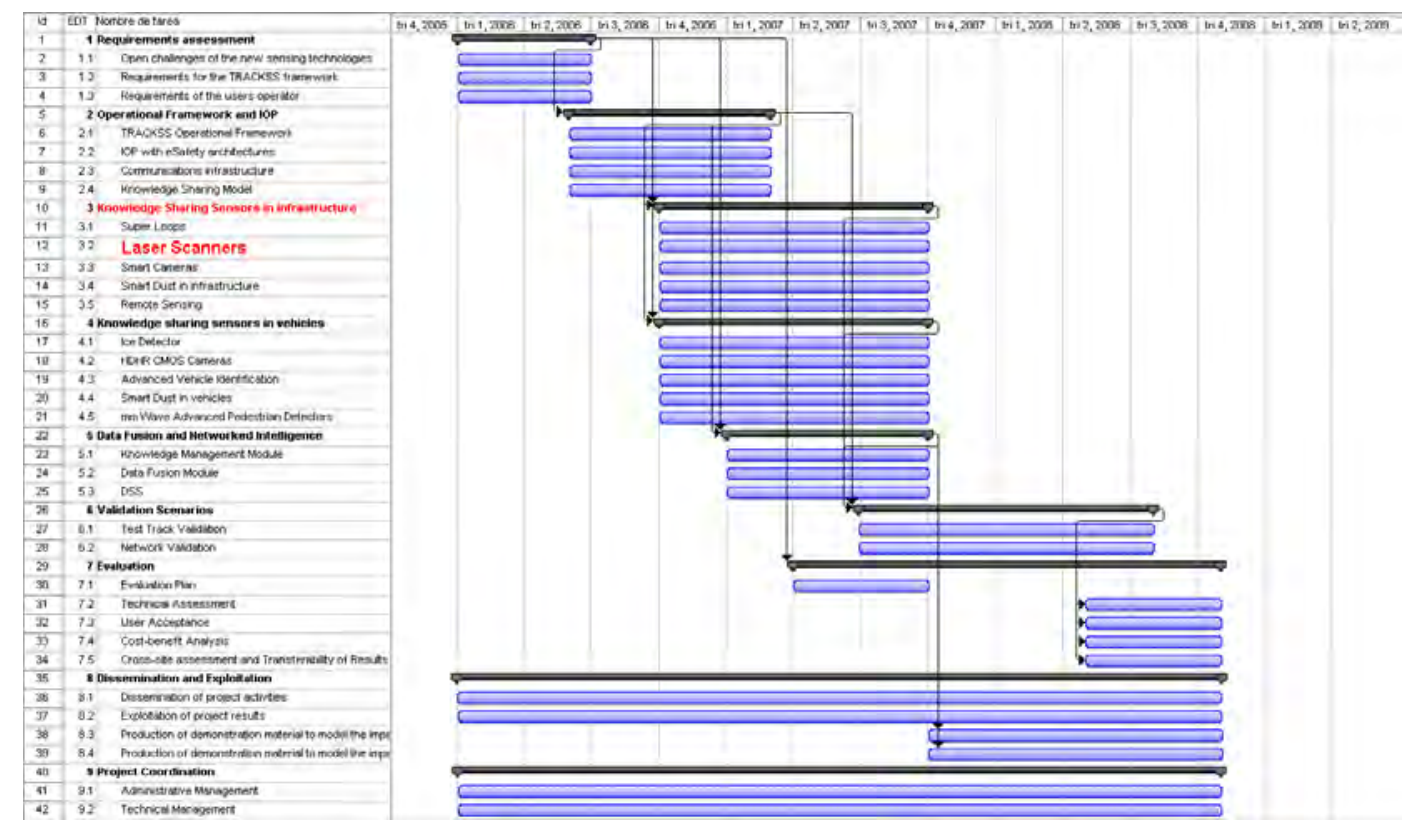

Figura 12.1 - Cronograma del proyecto TRACKSS

\subsubsection{Arquitectura Operacional}

La arquitectura operacional del sistema CTS especifica las decisiones estratégicas sobre la estructura y las funcionalidades del sistema, así como las colaboraciones entre los diferentes elementos del mismo. Además, define un centro de gestión de datos encargado de administrar la información y los mensajes enviados por los sensores denominado KMA (acrónimo del inglés Knowledge Manager Administrator).

El concepto de sensor en el proyecto, o KSS (acrónimo del inglés Knowledge Sharing Sensor), abarca no solo el sensor en sí sino que está formado por tres partes bien diferenciadas: 
- KSM (acrónimo del inglés Knowledge Sharing Model), es un modelo genérico y ampliable que permite un amplio rango de sensores heterogéneos cooperando a través de un simple interface.

- API (acrónimo del inglés Application Programming Interface) de comunicaciones, es el mecanismo que gestiona el intercambio de información entre los agentes involucrados: KSS y CTS.

- Sensor en si mismo.

La arquitectura operacional del sensor desarrollado en el marco de este proyecto se muestra en la figura 12.2, donde se aprecia cada una de las etapas y acciones que realiza el KSS. En este caso, el sensor comprende el hardware definido e implementado en esta tesis a lo largo del capítulo 6. Así mismo, el software de tratamiento y clasificación diseñado (ver capítulo 7) se ejecuta en el ordenador donde también se ejecuta el API. Es decir, queda perfectamente integrado en el KSS del proyecto TRACKSS la arquitectura definida e implementada a lo largo de la presente tesis, tanto el hardware para adquisición y pretratamiento como el software de tratamiento, análisis y clasificación.

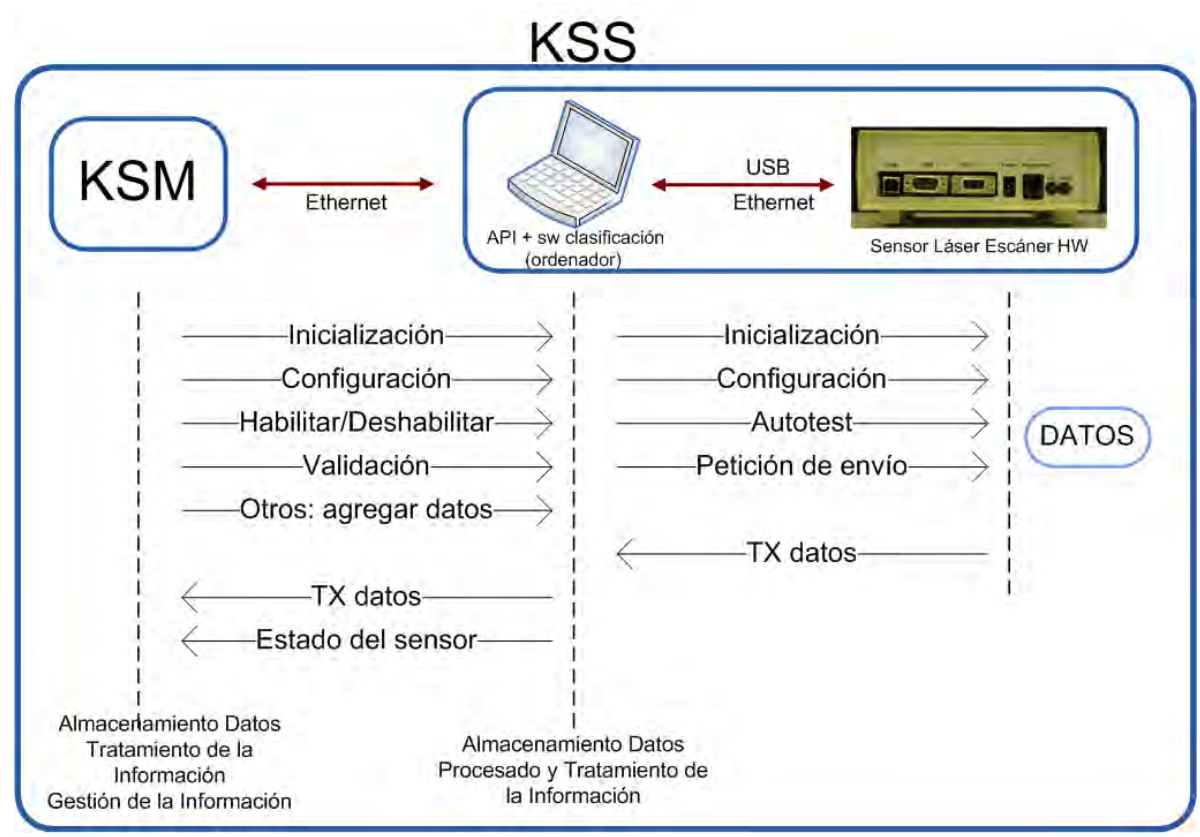

Figura 12.2 - Arquitectura del KSS Láser Escáner 
El KSM es el interfaz de comunicaciones que intercambia información basándose en la tecnología XML (acrónimo del inglés Extensible Markup Language). Al tratarse de un estándar de intercambio de datos, se eliminan los problemas inherentes al uso de diferentes formatos de intercambio de datos. Permite añadir elementos de forma transparente sin necesidad de modificar interfaces o esquemas de definición. Además, a nivel de seguridad y validación, todos los mensajes intercambiados son validados en origen y en destino. Cada uno de los sensores necesita una versión "personalizada" del KSM, dotando así al sensor de la inteligencia deseada y de la capacidad de interconectividad entre ellos.

La "personalización” del KSM consiste en la definición del tipo de información, llamado tipo de conocimiento, que puede enviar y la que está interesado en recibir. De este modo, los tipos de conocimiento definidos para el KSS Láser Escáner, KSS-LS, son detección y clasificación de vehículo. La información que envía/recibe el KSS-LS es la siguiente:

- Enviada:

○ Detección de vehículo: ksm_message_data_produced/observed/observable /measure_traffic/detection

- Clasificación de vehículo: ksm_message_data_produced/observed/observable /measure_traffic/measures_per_class/class

- Recibida:

- Iniciar colaboración con otro sensor.

○ Valores de Intensidad Luminosa: ksm_message_data_produced/observed /observable/measure_light_intensity/value/number

\subsubsection{Arquitectura Funcional}

El comportamiento lógico del sistema se basa en mecanismos de publicación/suscripción de datos. El consumidor, subscriber, es el actor interesado en determinada información a la que se abona indicando las características específicas que desea conocer. Las suscripciones pueden ser activas o pasivas, según se necesite o no en un determinado periodo dicha información, (ver figura 12.3(a)). Por otra parte, el editor, publisher, es quien produce la información. Los dife- 
rentes estilos de interacción entre sensores son: anuncio (de la disponibilidad de información), suscripción (un sensor demanda información) y publicación (un sensor envía información). Las publicaciones de información pueden darse de tres maneras diferentes: con cada evento, con cada fusión de datos o periódicamente, (ver figura 12.3(b)).

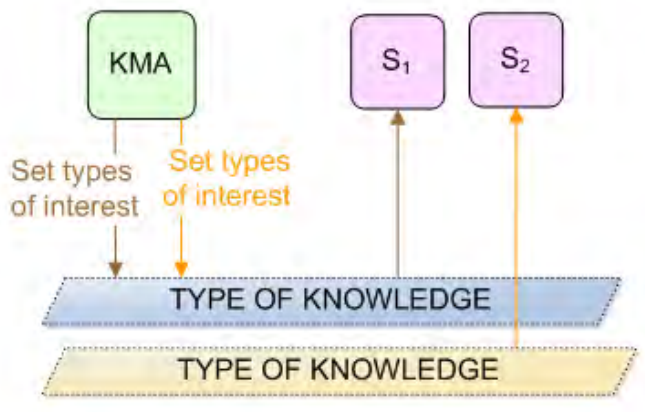

(a) configuración del consumidor

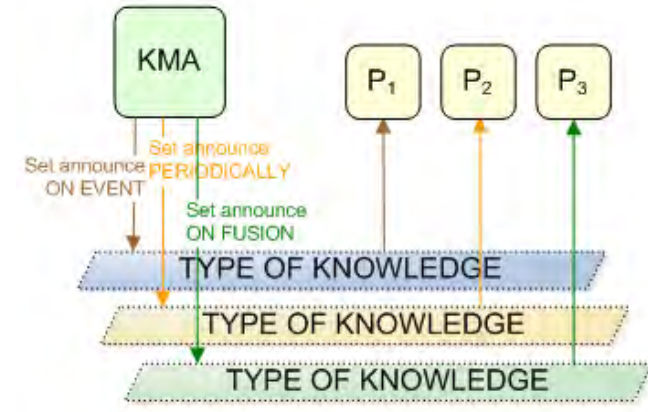

(b) configuración del editor

La iteración entre sensores producida por este tipo de arquitecturas se resume en la figura 12.3. El editor de información anuncia el tipo de conocimiento que va a proporcionar, el consumidor muestra su interés en ese tipo de conocimiento y se subscribe al mismo. Finalmente el editor publica dicha información que es recibida por el consumidor.

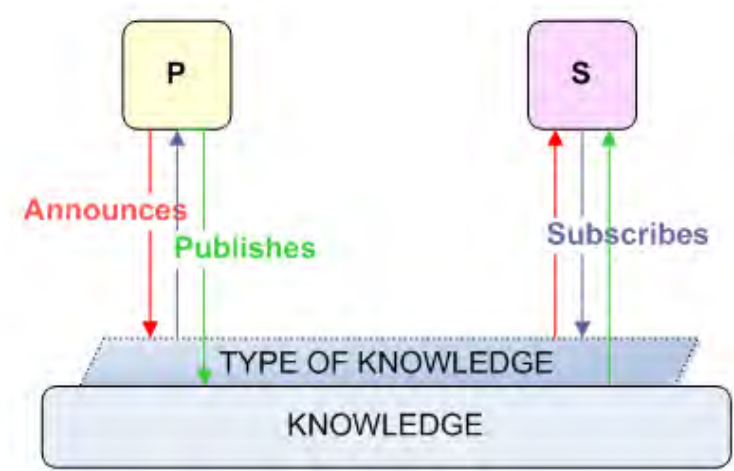

Figura 12.3 - Interacción: anuncio-subscripción-publicación

\subsubsection{Validación de resultados: Colaboraciones}

En el proyecto TRACKSS se han definido una serie de colaboraciones entre sensores para poder validar su inteligencia y su capacidad de intercomunicación. Así, se han definido tres escenarios de validación principales que cuentan con diversos sub-escenarios: 
- Escenario 1: Cooperación V2X.

- Escenario 2: Cooperación I2I.

- Escenario 3: Centro de Gestión de Tráfico.

Las colaboraciones en las que interviene el KSS-LS son dos:

- Escenario 2A: Modificación de los sensores afectados por la intensidad luminosa en la vía.

- Escenario 3B: Restricción de la entrada de vehículos al centro urbano.

En el escenario 2A se ha implementado la colaboración entre un sensor tipo smartdust y el KSS-LS y pretende demostrar la capacidad de comunicación I2I, es decir, entre dos sensores instalados en la vía, (ver figura 12.4). En este caso el smartdust realiza mediciones de la intensidad luminosa sobre la vía y se la envía al CGT. Cuando detecta un valor elevado, previamente definido, le envía esta información directamente al KSS-LS, que en base a esta modifica sus parámetros operacionales. Se puede llegar incluso a descartar las detecciones realizadas en este periodo en función del valor recibido. Nos encontramos ante una colaboración donde se demuestra el potencial de colaboración entre sensores. Ante la carencia de un sistema capaz de medir la intensidad luminosa por parte del KSS-LS, se recurre a la solución más sencilla que es solicitar la información a uno de los sensores de la vía que actualmente realiza estas mediciones. De este modo no es necesario recurrir a la instalación de nuevos equipos sino que se pueden reutilizar las infraestructuras existentes actualmente en la vía. Además, la comunicación se realiza directamente entre los sensores sin necesidad de nodos que concentren la inteligencia.

El escenario 3B resulta más complejo al intervenir el CGT. En esta aplicación la situación es la siguiente: el CGT detecta un atasco y en ese momento decide restringir el acceso de camiones al centro de la ciudad para mejorar el tráfico dándole más fluidez. Esta información se presenta a los vehículos antes de acceder a la vía mediante unos PMV, así los vehículos cuyo acceso ha sido restringido conocen la acción y seleccionan otra ruta. Desde el CGT se informa a los sensores instalados en la vía de la nueva situación para que actúen según su plan previamente definido en el caso de detectar una violación de la prohibición, es decir, un camión que acceda a la zona prohibida. 


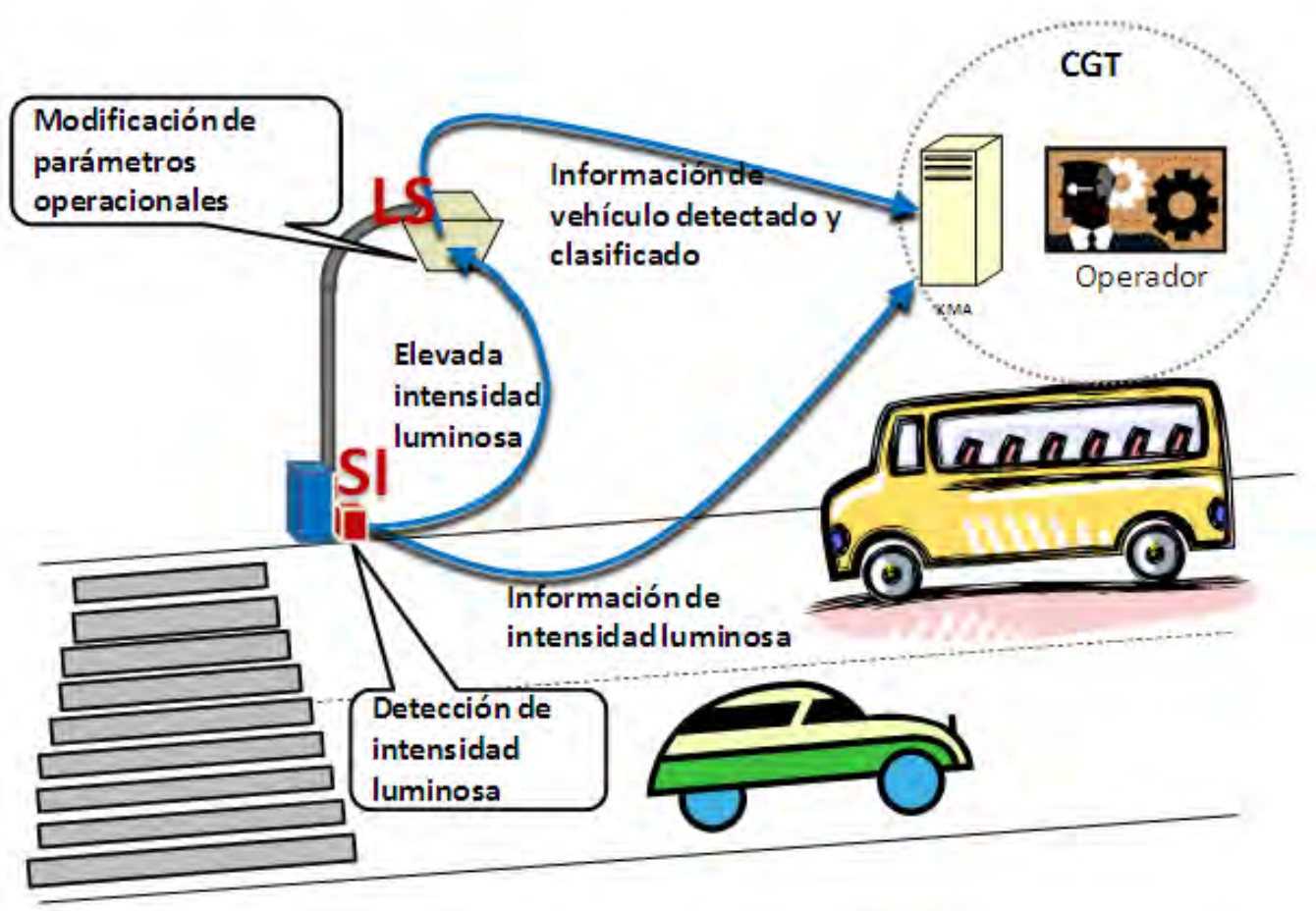

Figura 12.4 - Modificación de los sensores afectados por la intensidad luminosa en la vía

Supongamos el caso en el que un camión ha hecho caso omiso de la indicación y se encuentra circulando por la vía. En este momento el KSS-LS instalado en la vía detecta su paso y avisa a la cámara más cercana para que realice un seguimiento del vehículo. Esta, cuando detecte que el camión se encuentra cerca de un semáforo hará que éste pase a ciclo de rojo y enviará un mensaje al PMV situado cerca para que presente de nuevo la prohibición de circulación. El vehículo en este momento deberá salir de la vía. Una representación gráfica de este escenario se muestra en el figura 12.5 .

Ambos escenarios presentan la inteligencia y capacidad de interactuar que existe entre sensores. De este modo pasan de ser meros nodos de capturar de datos a centros capaces de realizar tareas de modo independiente sin la necesidad de acudir a un nodo central que gestione todas las comunicaciones y acciones con el coste que ello supone. La inteligencia se distribuye entre todos los actores de la vía y se realiza una mejor gestión del tráfico de un modo totalmente descentralizado. 


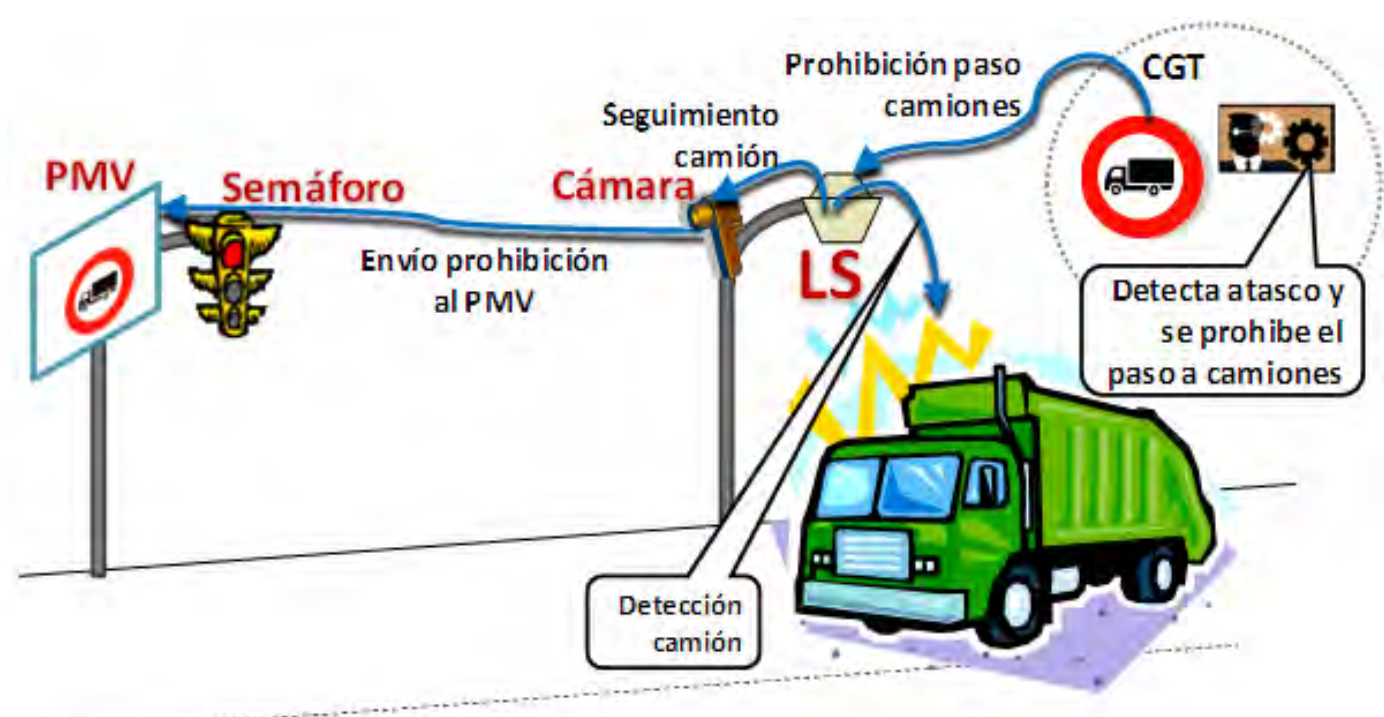

Figura 12.5 - Restricción de la entrada de vehículos al centro urbano

\subsubsection{Conclusión}

El trabajo que se ha desarrollado en el marco del proyecto TRACKSS va más allá del desarrollo del sistema sensor. Los escenarios anteriores ilustran algunas de las miles de aplicaciones posibles mediante el uso de sensores inteligentes. Se podría hablar de otras muchas como: detección y tratamiento de los atascos en condiciones climatológicas adversas, definición de rutas ante situaciones conflictivas, gestión de vehículos prioritarios, priorización de autobuses en intersecciones ...

En la mayoría de estos casos bastaría con adecuar los sensores actuales a la arquitectura funcional y operacional definida en el proyecto. Se ha demostrado así, que existen soluciones alternativas al desarrollo de nuevas y costosas infraestructuras y que la reutilización de los sensores actuales es posible y viable. Las autoridades competentes y los proveedores deben de ser conscientes de estas alternativas. Debido a la complicada y saturada situación de las ciudades hoy en día y a su previsible crecimiento, deben de ser soluciones a considerar.

Se trata del punto de partida de una generación de sensores inteligentes y cooperativos que ayuden a mejorar la seguridad vial y cambien radicalmente la forma que conocemos de 
gestionar y controlar el tráfico tanto urbano como interurbano. Se ha implementado el paquete software necesario para poder de un modo sencillo y a un coste reducido dotar de inteligencia y capacidad de cooperación a los sensores, diseñando una red completamente distribuida.

\subsubsection{Estudio del caso del equipo comercial Acuity Accurange 4000}

El objetivo principal que ha motivado el uso de otro modelo comercial ha sido realizar la verificación de algunas de las hipótesis establecidas en la tesis según las cuales se definía una arquitectura genérica capaz de implementarse con cualquier equipo comercial basado en láser escáner. De este modo se ha procedido a realizar un estudio mediante el cual se ha comprobado que la arquitectura definida es capaz de adecuarse a diferentes equipos comerciales como son los modelos LMS-221 de Sick y Accurange 4000 junto al AccuRange Line Scanner de Acuity.

El modelo comercial Accurange 4000 de la empresa Acuity ha sido presentado con anterioridad en el capítulo 2, apartado 2.5.2. Se realizó un estudio comparativo entre este modelo comercial y tres más, y se enumeraron sus características, prestaciones, ventajas e inconvenientes. En el caso de la empresa Acuity provee de modo separado el equipo láser (modelo Accurange 4000) y el motor de continua junto a un espejo utilizado desviar el haz y realizar el barrido sobre la vía (modelo AccuRange Line Scanner). Al tratarse de un motor de continua, se dispone de un encoder que proporciona información acerca de la posición del motor para cada una de las medidas (presenta 4.096 posiciones o cuentas por revolución). La figura 12.6 muestra el modelo Accurange 4000 junto al modelo AccuRange Line Scanner instalados en una caja hermética para su instalación en la vía.

La principal diferencia entre los dos equipos comerciales utilizados reside en que mientras el modelo LMS-221 trabaja con un motor paso a paso el modelo Accurange lo hace con un motor de continua. Este hecho afecta al modo en el que se realizan las medidas sobre la vía, ya que mientras que un motor paso a paso permite que las medidas se realicen sobre los mismos puntos de la vía en cada uno de los barridos, en un motor de continua estos puntos dependerán del momento en el que se inicie el barrido y la posición del motor proporcionada por el encoder. 


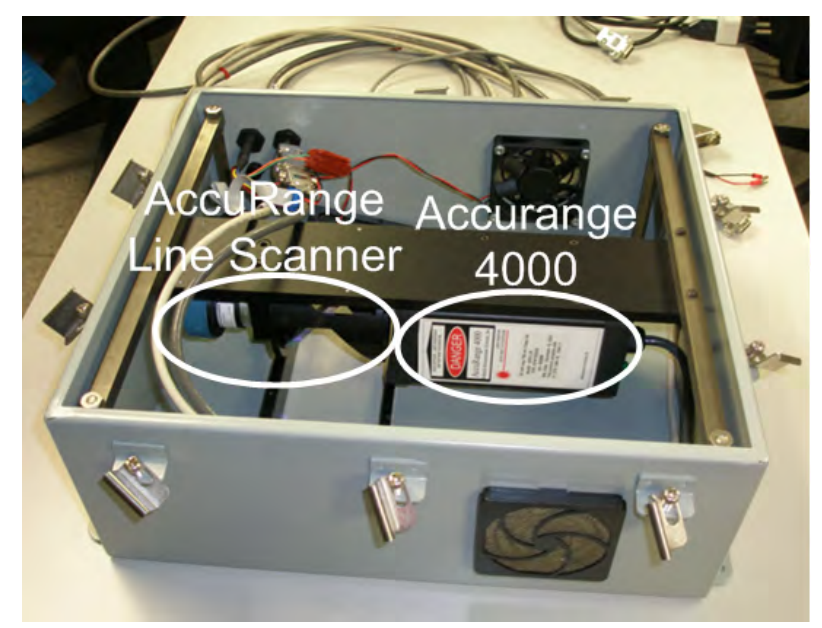

Figura 12.6 - Modelo Accurange y AccuRange Line Scanner

Por ejemplo, en el caso del LMS si se define un ángulo de escaneo de $100^{\circ}$ con resolución angular de $0,5^{\circ}$ se obtienen un total de 201 medidas sobre la vía que corresponden a las medidas para cada una de las posiciones del ángulo de barrido. En este caso, cada uno de los puntos de medida se toman con un ángulo idéntico en cada uno de los barridos. Es decir, por ejemplo la medida número 10 se realiza con un ángulo de medida de $4,5^{\circ}$ independientemente del barrido del que se trate. Por otra parte, en el caso de un motor de continua solo se conoce la posición del encoder para cada una de las medidas y esta posición depende del momento en que se haya pasado por el punto de origen que no tiene porqué coincidir en todos los casos. De hecho, es muy poco probable que coincida en diferentes barridos o escaneos.

Así, en el caso de un equipo se reciben únicamente los valores medidos sobre la vía ya que las posiciones son fijas (motor paso a paso), mientras que en el otro, se reciben además de los valores medidos la posición del motor en ese momento (motor de continua).

\subsubsection{Arquitectura Hardware}

La empresa Acuity proporciona los diferentes módulos que forman el sensor láser escáner: fuente de alimentación, Accurange 4000 (láser escáner propiamente dicho) y AccuRange Line Scanner (motor de giro, espejo giratorio y encoder). El sensor, motor y espejo giratorio se han instalado en una caja hermética que permita su instalación en entornos abiertos y susceptibles de sufrir las inclemencias del tiempo, como pueden ser báculos de semáforos, puentes, postes 
especiales, etc. Mientras, la fuente de alimentación se sitúa en un armario instalado al lado del báculo lo que permite un fácil acceso al mismo en caso de necesidad de reparación por ejemplo.

El sensor presenta la configuración por defecto [Acu03] que se muestra en la tabla 12.1.

\begin{tabular}{cc}
\hline Parámetro & Sensor AccuRange 4000 \\
\hline Baudrate & $9.600 \mathrm{Bd}$ \\
Intervalo de muestreo & 5 muestras/s \\
Ángulo de Escaneo & $360^{\circ}$ \\
Resolución Angular & $0,5^{\circ}$ \\
Rango de medida & $16,5 \mathrm{~m}$ \\
Resolución de medida & $12,5 \mathrm{~mm}$ \\
\hline
\end{tabular}

Tabla 12.1 - Configuración por defecto

En este caso el formato de los datos enviados por el sensor es 8N1, es decir, 8 bits de información, no parity bit, one stop bit. Cualquier modificación en estos valores de configuración se realiza mediante comandos predefinidos, telegrama, que se envían al láser a través del puerto serie. Estos, al igual que ocurría en el modelo LMS, permiten realizar diversas opciones de configuración, entre las que destacan: encender o apagar láser, periodo de muestreo, rango máximo, baudrate, temperatura, salida serie en ASCII o binario ... [Acu03]. La primera vez que se trabaja con este equipo se debe configurar mediante telegramas: periodo de muestreo, unidades de medida de distancias: mm o pulgadas, modo de salida calibrado o no y finalmente el rango de distancias de trabajo.

El sistema está formado, como se ha visto, por módulos separados que usan conectores diferentes para comunicarse con el exterior. De este modo la información de distancia y posición del encoder se recibe por separado mediante diferentes conectores. Las conexiones que presenta el sistema puede observarse en la figura 12.7 y se pueden resumir de la siguiente manera:

- La información relativa a las distancias medidas proveniente del láser escáner se transmite a través de un conector DE9 macho.

- La información relativa a la posición del motor en cada medida proveniente del encoder se transmite a través de un conector DB25 macho.

- Finalmente, existe un conector DE9 hembra que permite se conecta con el ordenador directamente para realizar diferentes configuraciones del sensor. 


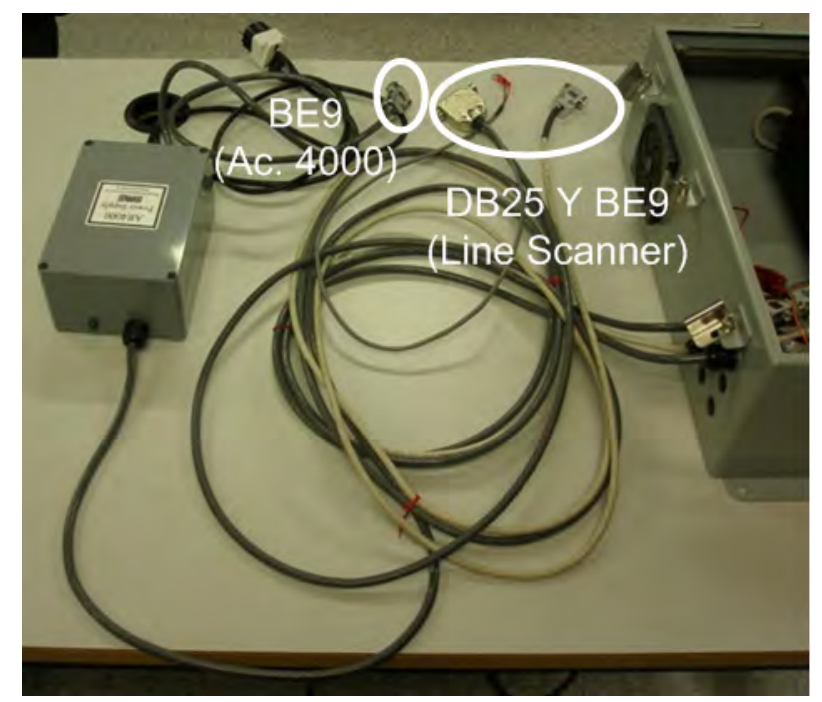

Figura 12.7 - Conectores: modelo comercial Acuity

La placa de circuito impreso a la que dio lugar la definición de las especificaciones hardware ha sido usada tal y como se diseñó en un principio funcionando de forma correcta con el nuevo equipo. Únicamente ha sido necesario añadir una etapa para amplificar la señal proveniente del sensor.

En este caso la información de la posición del motor se envía a través de un conector DB25, pero la placa de circuito diseñada no contaba con un conector de este tipo. De este modo las conexiones se han realizado directamente desde los conectores del sensor a los pines del DSC utilizado. A la hora de diseñar la placa PCB, para dotarla de la mayor versatilidad posible, además de añadirle diversos puertos serie, se instalaron diferentes pines que permiten el acceso directo al DSC. Estos pines son los que se han utilizado en esta ocasión para introducir tanto las medidas de distancia como las de la posición en el DSC. No se han utilizado así los puertos serie como en el caso del Sick.

La figura 12.8 muestra todos los equipos montados en una de las pruebas realizadas.

Las diferencias se producen a nivel de envío de datos y tratamiento de los mismos, lo que deriva en el desarrollo de un nuevo firmware para el DSC pero por coherencia con las especificaciones definidas anteriormente este tema se ha incluido en la arquitectura software. 


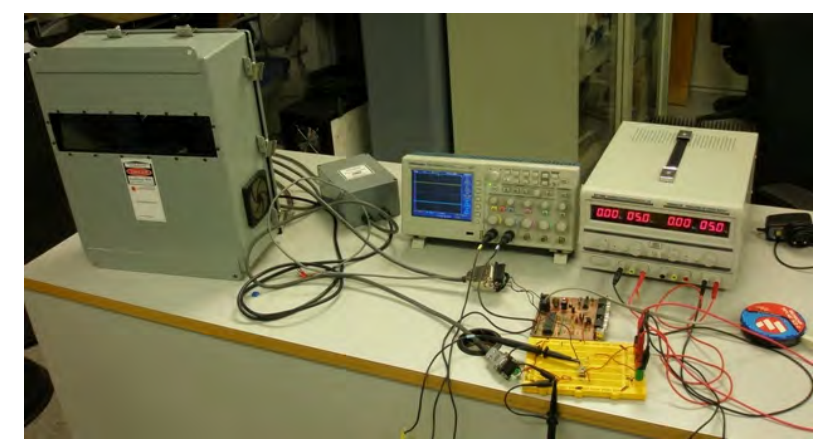

Figura 12.8 - Montaje realizado con el modelo comercial Acuity

\subsubsection{Arquitectura Software}

La información que proporciona el sistema es relativa tanto a la distancia medida como a la posición del motor en dicho instante, con lo que la cantidad de información a tratar se duplica en comparación con el caso de Sick. Para adaptarse al estas modificaciones la arquitectura general del sistema se modifica y queda como se muestra en la figura 12.9.

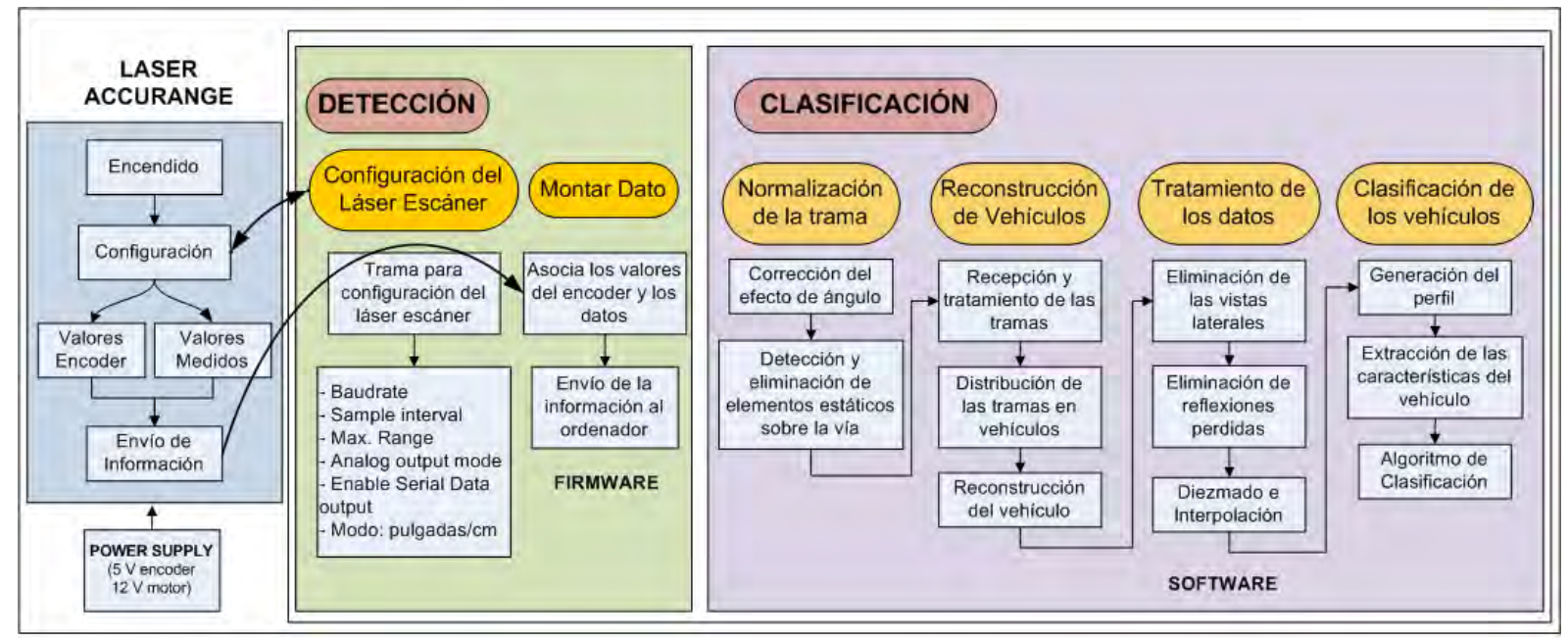

Figura 12.9 - Arquitectura general del sistema: modelo comercial Acuity

El equipo Accurange 4000 envía la información relativa a la distancia codificada según el tiempo a nivel bajo al que se mantiene la señal que envía. En este caso, es necesario poder “contar" la duración de ese periodo para poder conocer la distancia. El DSC seleccionado, dsPIC-30F4011, presenta un módulo de control de motor (PMW, acrónimo del inglés Pulse Width Modulated) [Mic05], que es usado para poder calcular la distancia medida. Aunque con anterioridad no había sido utilizado, se ha recurrido a dicho modulo en este caso al ser necesario 
realizar las cuentas de la distancia. De este modo, se ha tenido que programar en el firmware del DSC el modulo PWM de forma conveniente para medir los tiempos a nivel bajo de la señal de distancia.

Por otra parte, el equipo AccuRange Line Scanner envía la información relativa a la posición del motor. Esta información es leída por el encoder en función a las señales que recibe del motor: dos señales cuadradas desfasadas $90^{\circ}$ y una señal que marca el paso por cero del motor. Para conocer el ángulo se ha trabajado con las 4.096 posiciones (de $0^{\circ}$ a 4095 cuentas) con las que cuenta el encoder. Cada vez que se recibe una medida de distancia, se toma la cuenta del encoder y mediante unos cálculos se extrae el ángulo correspondiente, comprendido entre $0^{\circ}$ y $360^{\circ}$.

La diferencia principal entre este y el del modelo Sick, es que en este caso el DSC no posee memoria suficiente para llevar a cabo la normalización de la trama y el montaje de la misma. Esto es debido a que consume la mayor parte de sus recursos calculando la distancia mediante el módulo PWM. Por consiguiente, la etapa de normalización y montaje de la trama se lleva a cabo en el software desarrollado, mientras que la asociación entre la distancia medida y el valor del encoder correspondiente es realizada en el firmware.

El formato en el que se envían los datos, es decir la trama, en este caso presenta el formato que se muestra en la tabla 12.2, donde se incluye tanto la distancia medida como la posición del motor en ese momento.

\begin{tabular}{|c|c|c|c|c|c|}
\hline \multirow{2}{*}{ 0xFF } & \multirow{2}{*}{ 0xFF } & Datos & \multirow{2}{*}{ OxFF } & \multirow{2}{*}{ 0xEF } & Datos \\
& & Medidas de Distancias & & & Posición del motor \\
\hline
\end{tabular}

Tabla 12.2 - Formato de la trama: modelo comercial Acuity

Además de las etapas de normalización y montaje de la trama, el resto de etapas que se llevan a cabo en el ordenador son las mismas que se realizaban anteriormente con el equipo comercial Sick, sin modificar ninguna de ellas, se trata de:

- reconstrucción de los vehículos,

- tratamiento de los datos,

- y clasificación de vehículos. 


\subsubsection{Validación de resultados}

Una vez se han realizado las modificaciones mínimas necesarias debidas al funcionamiento del equipo, se procede a realizar las pruebas de validación del sistema. Estas permiten comprobar el correcto funcionamiento del equipo y que procede de modo similar al equipo comercial Sick, quedando demostrado de esta manera que los requerimientos especificados son independientes del equipo usado.

El primer paso consiste en verificar si se establece correctamente comunicación entre sensor y la PCB. Para ello se alimenta el sensor láser sin la parte del motor todavía, únicamente el modelo Accurange 4000, y se miden los datos que se reciben por el puerto serie. Se comprueba en este caso que las distancias medidas son correctas. Tras ello, se introduce un objeto en la zona de detección y se realiza una nueva medida. En primer lugar se comprueba que los datos enviados por el sensor no son los mismos que anteriormente como era de esperar. Posteriormente, para confirmar que los datos recibidos son correctos ya que al conocer la altura del objeto se pueden verificar que los datos recibidos son válidos.

En el segundo paso se conecta el motor, equipo AccuRange Line Scanner, para comprobar que: se realiza efectivamente el barrido sobre la zona de detección, y que además se envían datos correctos. Estas pruebas de laboratorio confirmaron que la PCB configuraba correctamente ambos equipos, y posteriormente que los datos se recibían correctamente. Se verificó no solo la correcta recepción de los datos, sino que la asignación a cada una de las distancia de su respectivo ángulo de medida era la adecuada.

Finalmente, se procede al ensayo del sistema completo, comprobando tanto el correcto funcionamiento de todas las comunicaciones, como el diseño firmware para el procesado de la señal. La primera prueba de laboratorio consistió en realizar un barrido sobre el suelo del laboratorio en ausencia de objetos sobre el mismo. La figura 12.10 muestra gráficamente la imagen 3D que se obtiene de la zona de detección tras la realización de varios barridos sobre la misma.

Introduciendo objetos en la zona de detección se comprueba que estos son detectados igualmente. La figura 12.11 muestra la detección de objetos tras la realización de un barrido sobre 


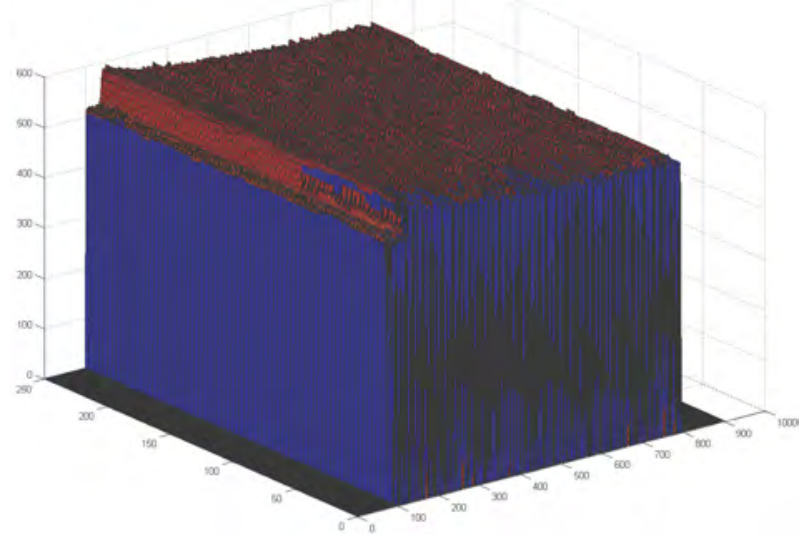

Figura 12.10 - Test Laboratorio: imagen 3D Equipo Acuity

la vía. Al ser las etapas de: reconstrucción de vehículos, tratamiento de los datos y clasificación idénticas a las realizadas con el equipo Sick, no se ha considerado necesario hacer pruebas de las mismas.

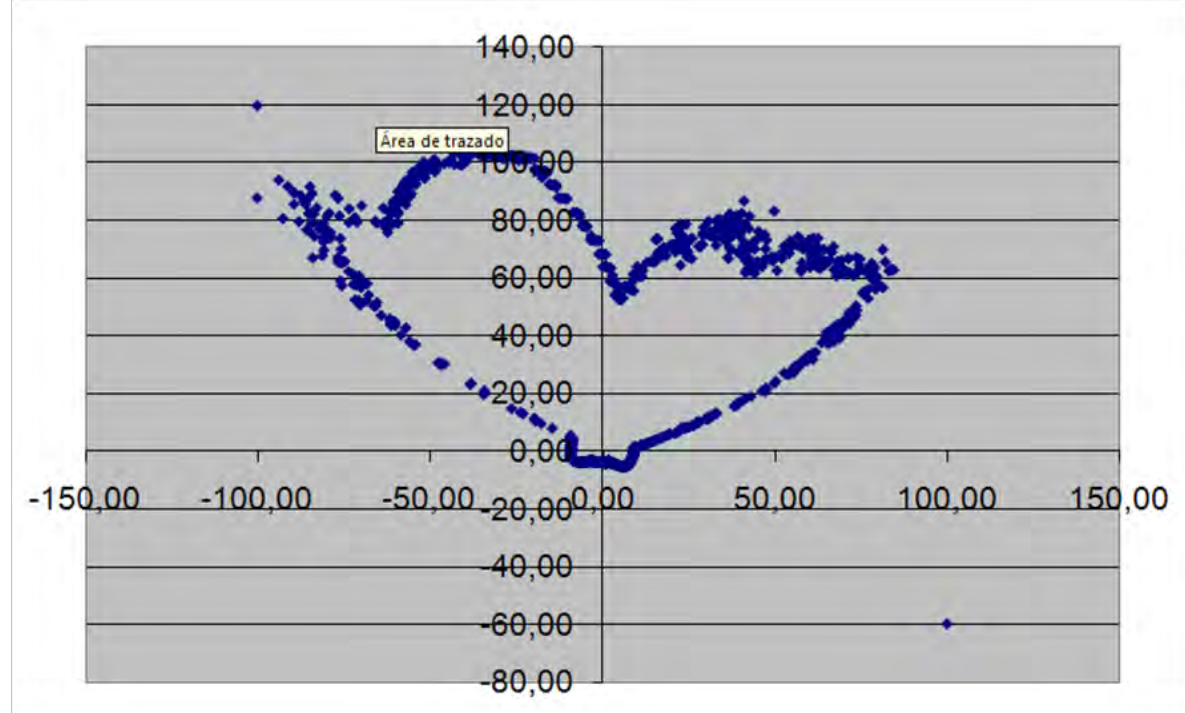

Figura 12.11 - Test Laboratorio Equipo Acuity

\subsubsection{Conclusiones}

En el caso del equipo comercial de la empresa Acuity se han superado satisfactoriamente todas las pruebas realizadas, demostrando así que la definición de especificaciones y requerimientos genéricos definidos a lo largo de la presente tesis son independientes de los modelos comerciales de láser escáner que se utilicen. 
La arquitectura definida inicialmente se ajusta al caso del modelo actual realizando pequeñas modificaciones debidas principalmente a la capacidad de procesado del DSC que queda limitada por la memoria que posee. Aún así, el DSC se ha justificado como la mejor opción posible al adaptarse a cualquier formato en el que se le envíen los datos. Se ha comprobado que en el caso del Sick su tratamiento era directo, mientras que en el caso del Acuity se ha ajustado perfectamente al formato de los mismos mediante el módulo PWM interno que posee.

El equipo se ha podido configurar; las comunicaciones se han realizado de forma esperada; y las pruebas realizadas han verificado su funcionamiento con y en ausencia de objetos sobre la vía. Pese a que estas pruebas se han realizado únicamente en un ambiente controlado como es el laboratorio, nada hace presagiar un mal funcionamiento tras su instalación definitiva en la vía. Aún así, ese no es objeto de esta tesis, sino de estudios que se realizarán posteriormente.

\subsection{Publicaciones}

El trabajo presentado y llevado a cabo a lo largo de la presente tesis ha dado lugar a las siguientes publicaciones científicas.

\subsubsection{Artículos en Congresos Nacionales}

- Nieves Gallego Ripoll, Miguel Menéndez Carrión y Antonio Mocholí Salcedo. Sistema Láser Escáner para aplicaciones ITS de gestión de tráfico urbano. XVI Seminario Anual de Automática, Electrónica Industrial e Instrumentación. SAAEI 09. Actas del SAAEI 2009, celebrado en la Universidad Carlos III, Leganés, Madrid, España. 01-03 Julio 2009. ISBN: 978-84-692-2596-7.

- Nieves Gallego Ripoll, Artur Cuñat Pellicer, Antonio Mocholí Salcedo y Miguel Menéndez Carrión. Arquitectura genérica de sensores láser escáner en aplicaciones de detección y clasificación de vehículos. XVI Seminario Anual de Automática, Electrónica Industrial e Instrumentación. SAAEI 09. Actas del SAAEI 2009, celebrado en la Universidad Carlos III, Leganés, Madrid, España. 01-03 Julio 2009. ISBN: 978-84-692-2596-7. 
- Miguel Menéndez Carrión, Nieves Gallego Ripoll y Antonio Mocholí Salcedo. Software de procesado y clasificación en tiempo real de un sensor láser para la detección y clasificación de vehículos. IX Congreso ITS Español. ITS 09. Actas del ITS 2009, celebrado en Andorra la Vella, Andorra. 02-04 Junio 2009.

- Artur Cuñat Pellicer, Nieves Gallego Ripoll, Antonio Mocholí Salcedo y Miguel Menéndez Carrión. Arquitectura genérica de sensores ITS para la de detección y clasificación de vehículos. IX Congreso ITS Español. ITS 09. Actas del ITS 2009, celebrado en Andorra la Vella, Andorra. 02-04 Junio 2009.

- Miguel Menéndez Carrión, Nieves Gallego Ripoll y Antonio Mocholí Salcedo. Frontend para aplicaciones de sistemas ITS: Interfaz Gráfico. XV Seminario Anual de Automática, Electrónica Industrial e Instrumentación. SAAEI 08. Actas del SAAEI 2008, celebrado en Cartagena, España. 9-11 Septiembre 2008. ISBN: 978-84-96997-05-9.

- Nieves Gallego Ripoll, Antonio Mocholí Salcedo, Alexander Arroyo Núñez, Raymundo Barrales Guadarrama y Miguel Menéndez Carrión. Explotación de las infraestructuras actuales en entornos urbanos para aplicaciones ITS. VII congreso español en Sistemas de Inteligentes de Transporte. Actas del congreso, celebrado en Valencia, España. 18-20 Septiembre 2007.

- Antonio Mocholí Salcedo, Alexander Arroyo Núñez, Nieves Gallego Ripoll, Gonzalo Penalva Torregrosa y Javier Ramos Atienza. Plataformas de ensayos de sistemas de control de tráfico para entornos urbanos: centrales de comunicación, reguladores y sensores. VII Congreso Español sobre Sistemas Inteligentes de Transporte (ITS). Actas del congreso, celebrado en Valencia, España. 18-20 Septiembre 2007.

- Alexander Arroyo Núñez, Antonio Mocholí Salcedo, Nieves Gallego Ripoll, Jose H. Arroyo Núñez y Anna B. Tortajada Celda. Sistemas sensores empleados en ITS. VII Congreso Español sobre Sistemas Inteligentes de Transporte (ITS). Actas del congreso, celebrado en Valencia, España. 18-20 Septiembre 2007.

- Nieves Gallego Ripoll, Luis E. Gómez Aguilera y Antonio Mocholí Salcedo. Sistema Láser para detección y clasificación de vehículos en múltiples carriles. XII Seminario 
Anual de Automática, Electrónica Industrial e Instrumentación. SAAEI 05. Actas del SAAEI 2005, celebrado en Santander, 28-30 Septiembre 2005. Pp.533-538. ISBN 848102-964-5.

\subsubsection{Artículos en Congresos Internacionales}

- Nieves Gallego Ripoll, Antonio Mocholí Salcedo y Miguel Menéndez Carrión. A RealTime Laser Scanner Intelligent Sensor for Traffic Management. $16^{\text {th }}$ Intelligent Transport Systems World Congress. ITS World 09. Proceedings del congreso, celebrado en Stockholm, Suecia. 21-25 Septiembre 2009.

- Nieves Gallego Ripoll, Antonio Mocholí Salcedo, Miguel Menéndez Carrión y Raymundo Barrales Guadarrama. Traffic Monitoring: improving Road Safety using a Laser Scanner Sensor. Electronics, Robotics and Automotive Mechanics Conference. CERMA 2009. Proceedings del congreso, celebrado en Cuernavaca, México, 21-25 Septiembre 2009

- Nieves Gallego Ripoll, Antonio Mocholí Salcedo y Miguel Menéndez Carrión. A RealTime Laser Scanner Intelligent Sensor for ITS applications. $6^{\text {th }}$ International Workshop on Intelligent Transportation. WIT 09. Actas del congreso Pp. 21-26, celebrado en Hamburg, Alemania, 24-25 Marzo 2009.

- Nieves Gallego Ripoll, Antonio Mocholí Salcedo, Miguel Menéndez Carrión y Alexander Arroyo Núñez. Sensores inteligentes cooperativos aplicados al sector de tráfico: El Láser Escáner. I Congreso Internacional de Mecatrónica y II Congreso Nacional de Universidades Politécnicas. Actas del congreso, celebrado en Tuxla Gutierrez, Chiapas, México, 2-4 Abril 2008.

- Miguel Menéndez Carrión, Nieves Gallego Ripoll y Antonio Mocholí Salcedo. Frontend de sistemas ITS: Interfaz Gráfico. I Congreso Internacional de Mecatrónica y II Congreso Nacional de Universidades Politécnicas. Actas del congreso, celebrado en Tuxla Gutierrez, Chiapas, México, 2-4 Abril 2008. 
- Alexander Arroyo Núñez, Antonio Mocholí Salcedo, Nieves Gallego Ripoll y Jose H. Arroyo Núñez. Plataformas de ensayos de sistemas de control de tráfico para entornos urbanos: Centrales de comunicaciones, reguladores y sensores. XIV Seminario Anual de Automática, Electrónica Industrial e Instrumentación. SAAEI 07. Actas del SAAEI 2007, celebrado en Puebla, México. 10-12 Septiembre 2007. Ed: Benemérita Universidad Autónoma de Puebla. ISBN: 978-968-9182-52-8.

\subsubsection{Artículos en Revistas}

- Nieves Gallego Ripoll y Antonio Mocholí Salcedo. Non-intrusive Urban Traffic Solution for ITS Applications. Transactions on Intelligent Transport Systems. Manuscrito ID: TITS-09-11-0295. En proceso de revisión.

- Nieves Gallego Ripoll, Antonio Mocholí Salcedo, Miguel Menéndez Carrión y Raymundo Barrales Guadarrama. Traffic Monitoring: Improving Safety Using a Laser Scanner Sensor. IEEE Computer Society. Proceedings of 2009 Electronics, Robotics and Automotive Mechanics Conference. Pp. 281-286. ISSN: 978-0-7695-3799-3.

- Nieves Gallego Ripoll, Antonio Mocholí Salcedo, Miguel Menéndez Carrión y Alexander Arroyo Núñez. Sensores inteligentes cooperativos aplicados al sector de tráfico: El Láser Escáner. Ed. "Ciencia y Tecnología en la frontera" del COCyTECH (Consejo de Ciencia y Tecnología del estado de Chiapas). Número Especial 2008. Pp. 166-174. ISSN: 1665-9775.

\subsubsection{Proyecto Europeo TRACKSS - 7PM}

- Knowledge Sharing Laser Scanner. D7.2 Technical Evaluation. October 2008. Pp. 27-32, 55-59, 93-95, 111-112.

- Knowledge Sharing Laser Scanner: Integration and Validation Tests. D6.2 Validation report for the Urban Road Network in Valencia, Spain. September 2008. Pp. 16-19, 30-32, 41-42, 50-53.

- D6.1 Validation report for the Test Track pilot in Berlin, Germany. April 2008. 
- Knowledge Sharing Laser Scanner. D3.1 Knowledge Sharing Sensors in Infrastructures. November 2007. Pp. 28-56.

- Operational Framework Requirements. D2.3 TRACKSS Knowledge Sharing Model. June 2007.

- Network pilot site. D1.2 Requirements of the TRACKSS operational framework. April 2006. Pp. 17-19.

- Laser Scanners for Infrastructure Applications. D1.1 Requirements of the TRACKSS sensors. April 2006. Pp. 12-16, 71.

- Sensing Technologies: Functional Requirements. Annex I - Description of work. November 2005. Pp. 28-31.

\subsubsection{Otros Artículos en el área ITS}

- Alexander Arroyo Núñez, Teresa Mengual Chuliá, Antonio Mocholí Salcedo, Jose H. Arroyo Núñez y Nieves Gallego Ripoll. Estudio teórico y práctico del comportamiento de sensores de espira magnética en sistemas de control de tráfico. Ed. "Ciencia y Tecnología en la frontera" del COCyTECH (Consejo de Ciencia y Tecnología del estado de Chiapas).Número Especial 2008. Pp. 108-115. ISSN: 1665-9775.

- Raymundo Barrales Guadarrama, Jose Humberto Arroyo Núñez, Antonio Mocholí Salcedo, Alexander Arroyo Núñez y Nieves Gallego Ripoll. Los sistemas RFID y WAVE para comunicaciones en entornos ITS. VII Congreso Español sobre Sistemas Inteligentes de Transporte (ITS). Actas del congreso, celebrado en Valencia, España. 18-20 Septiembre 2007. 


\section{Bibliografía}

[Acu03] Acuity: AccuRange 4000 Laser Rangefinder and AccuRAnge Line Scanner - User's Manual. Acuity a division of Schmitt Measurement Systems, Inc., revision 2.4 edón ., September 2003.

[Mic05] Microchip: Data Sheet: dsPIC30F4011/4012. Microchip Technology Inc., 2355 West Chandler Blvd., Chandler, AZ 85224-6199, preliminary ed ${ }^{\text {ón }}$., 2005.

[TRA06] TRACKSS: Technologies for Road Advanced Cooperative Knowledge Sharing Sensors. European Commission. DG Information Society Technologies. Esafety, January 2006, URL http://www.trackss.net/, [Online: Último acceso Enero 2009]. 



\section{Parte VI}

Anexos 

Apéndice A

\section{Imágenes de vehículos por clases}

A.1. Clase Motocicletas
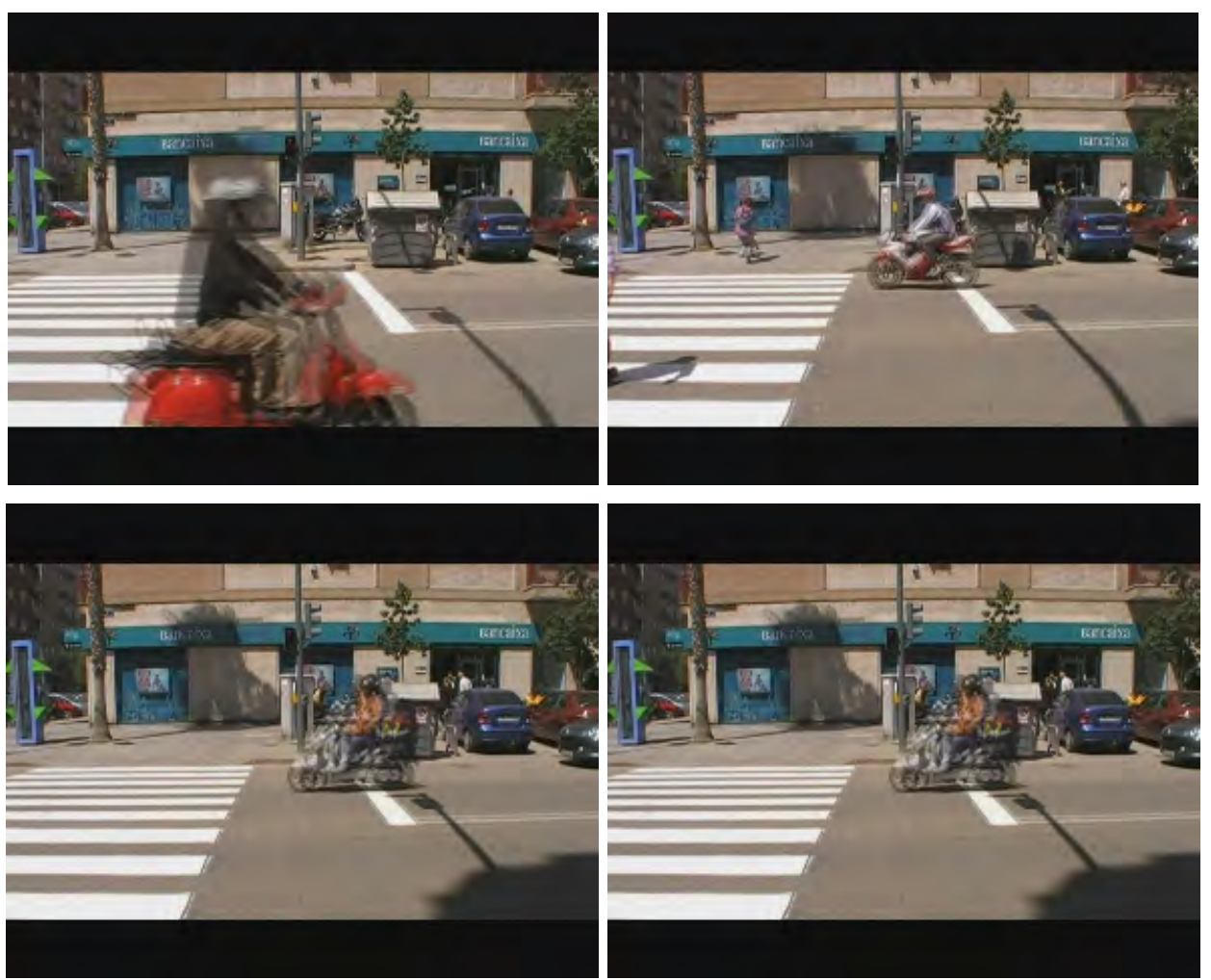

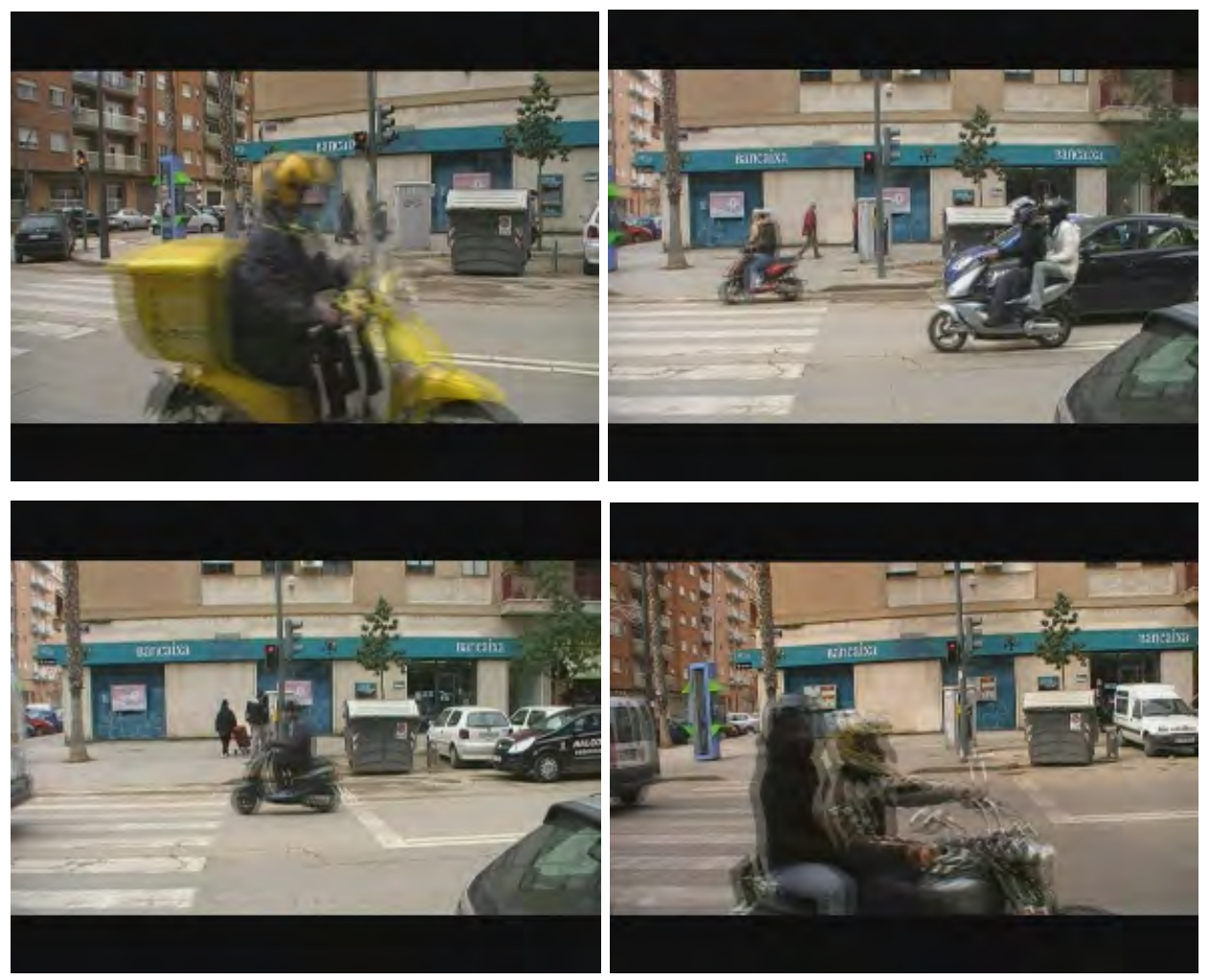

Figura A.1 - Vehículos de la categoría: Motocicleta

\section{A.2. Clase Tipo Turismo}
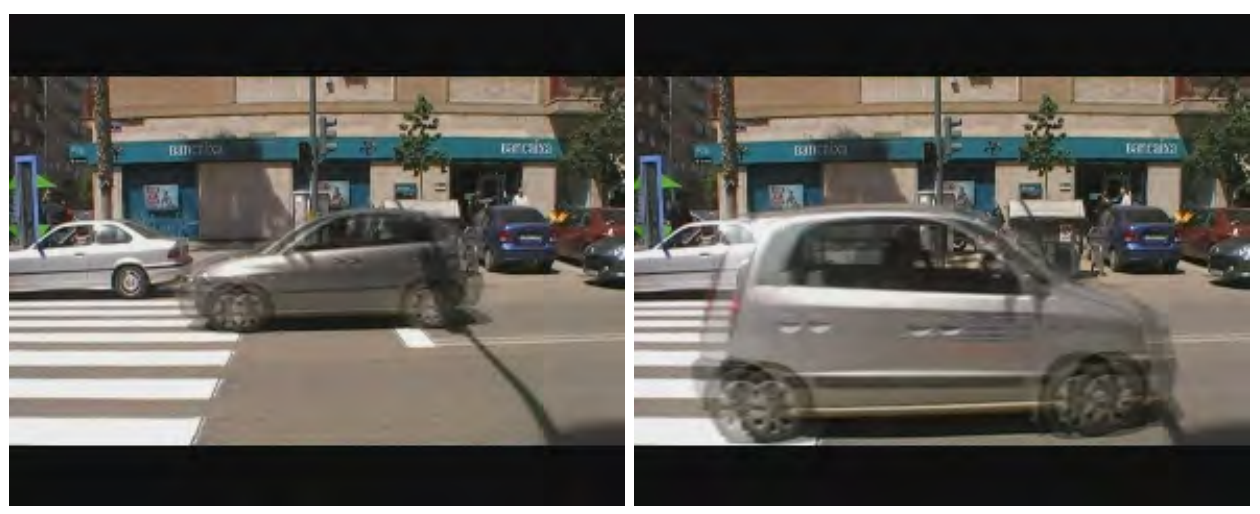

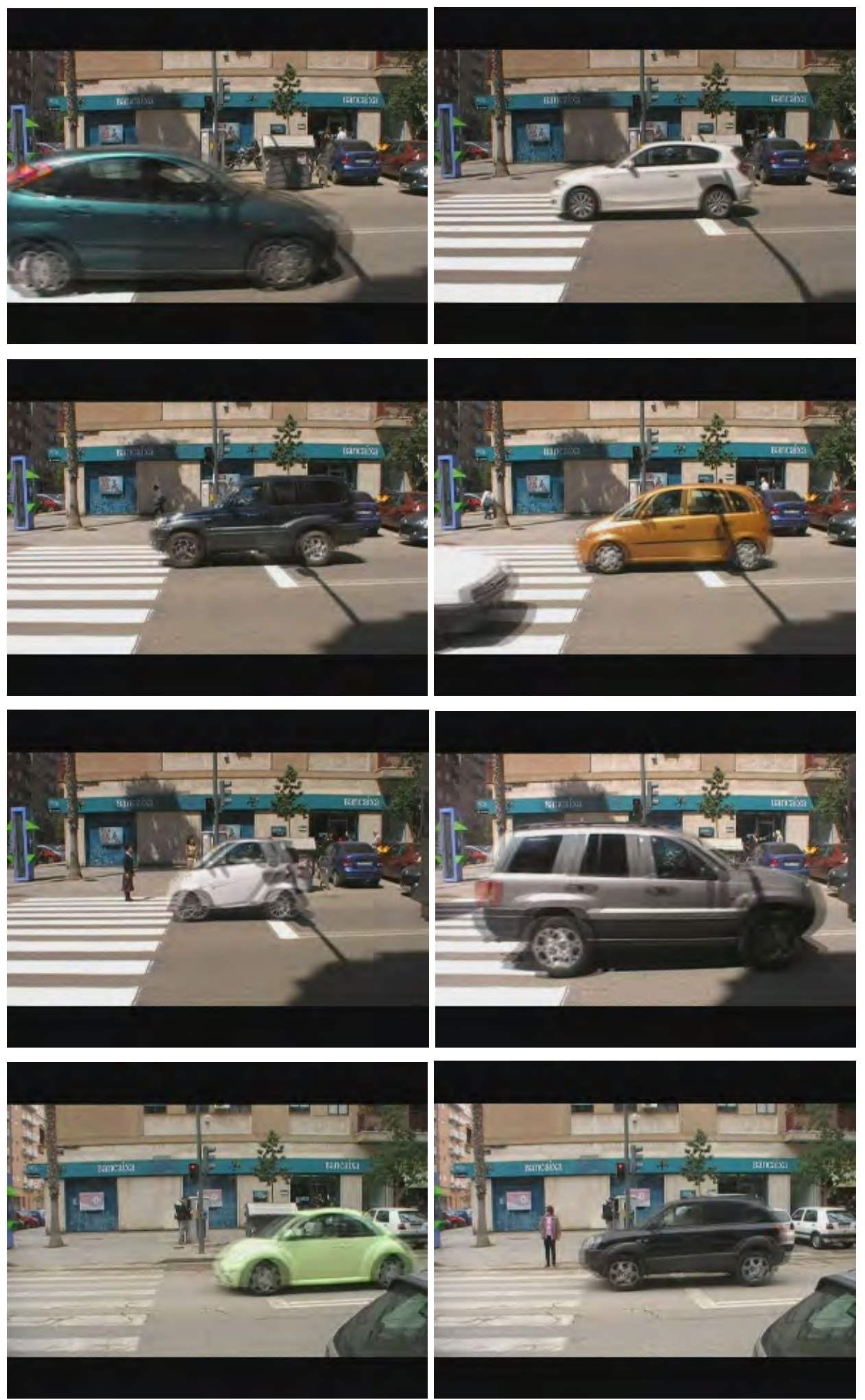

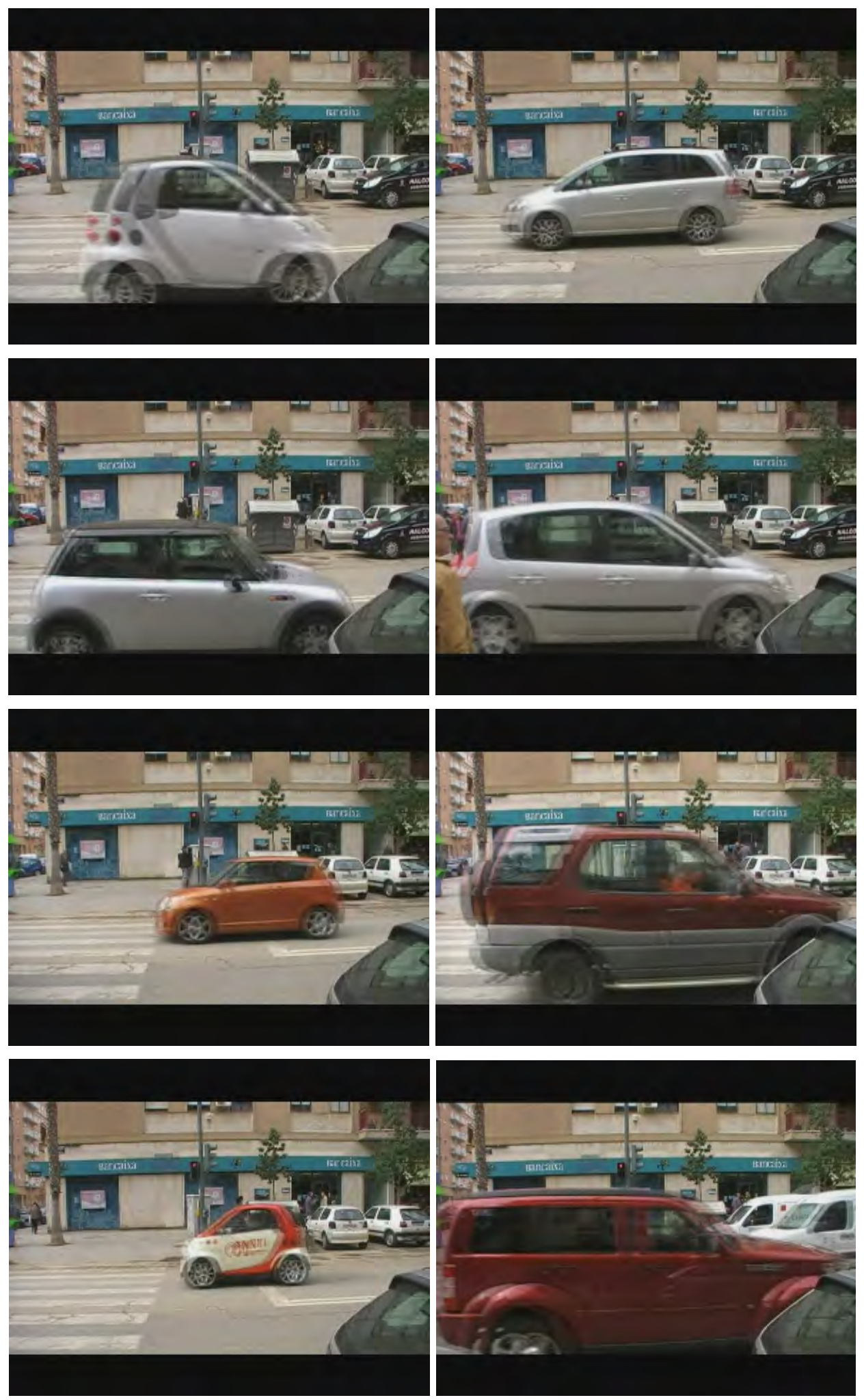

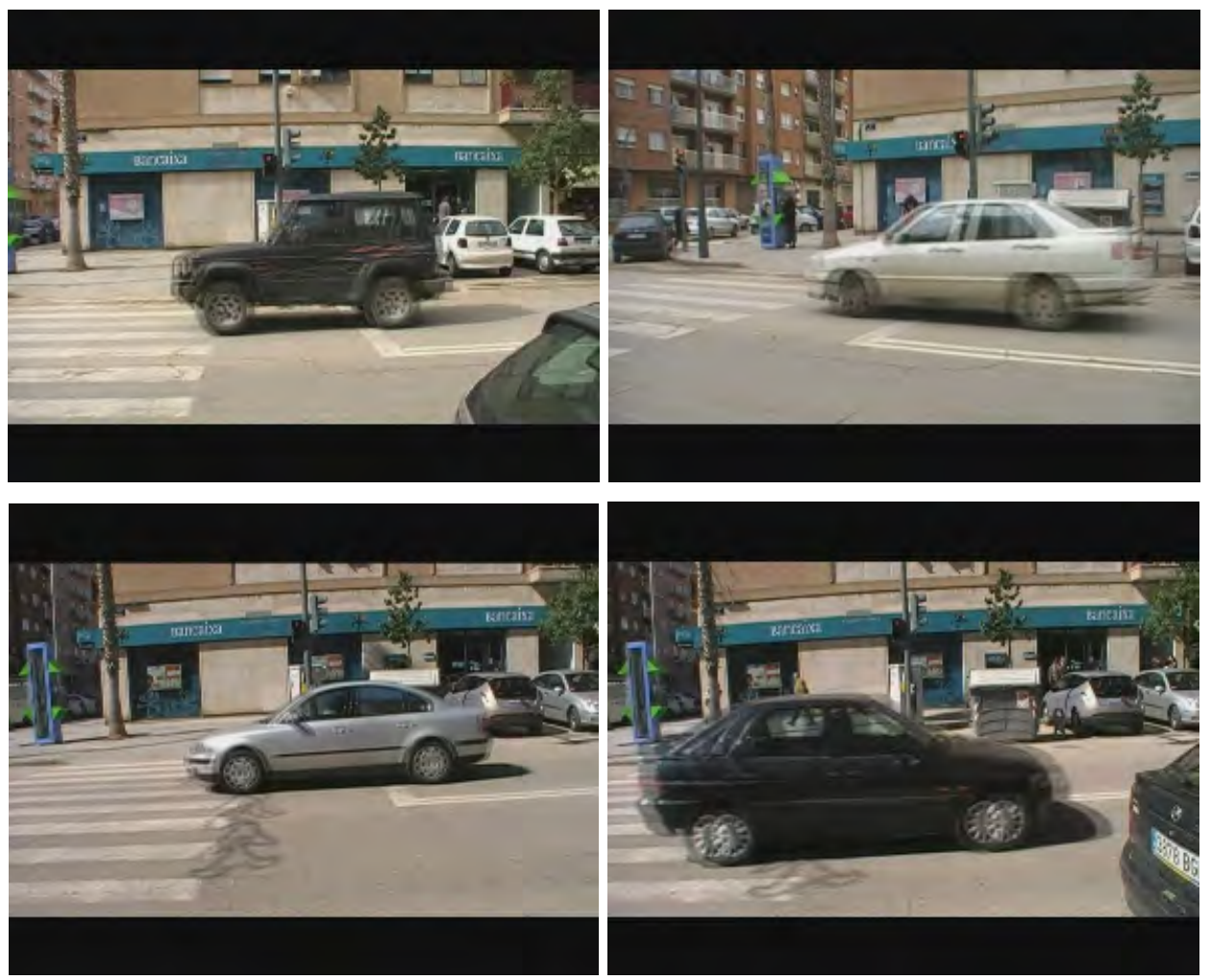

Figura A.2 - Vehículos de la categoría: Tipo Turismo

\section{A.3. Clase Furgonetas}
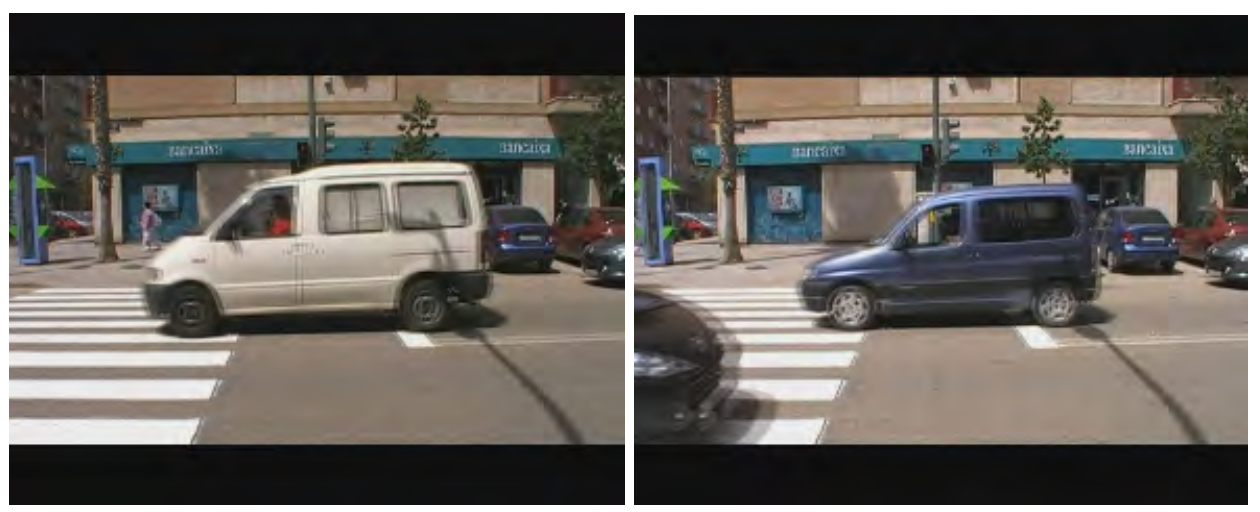

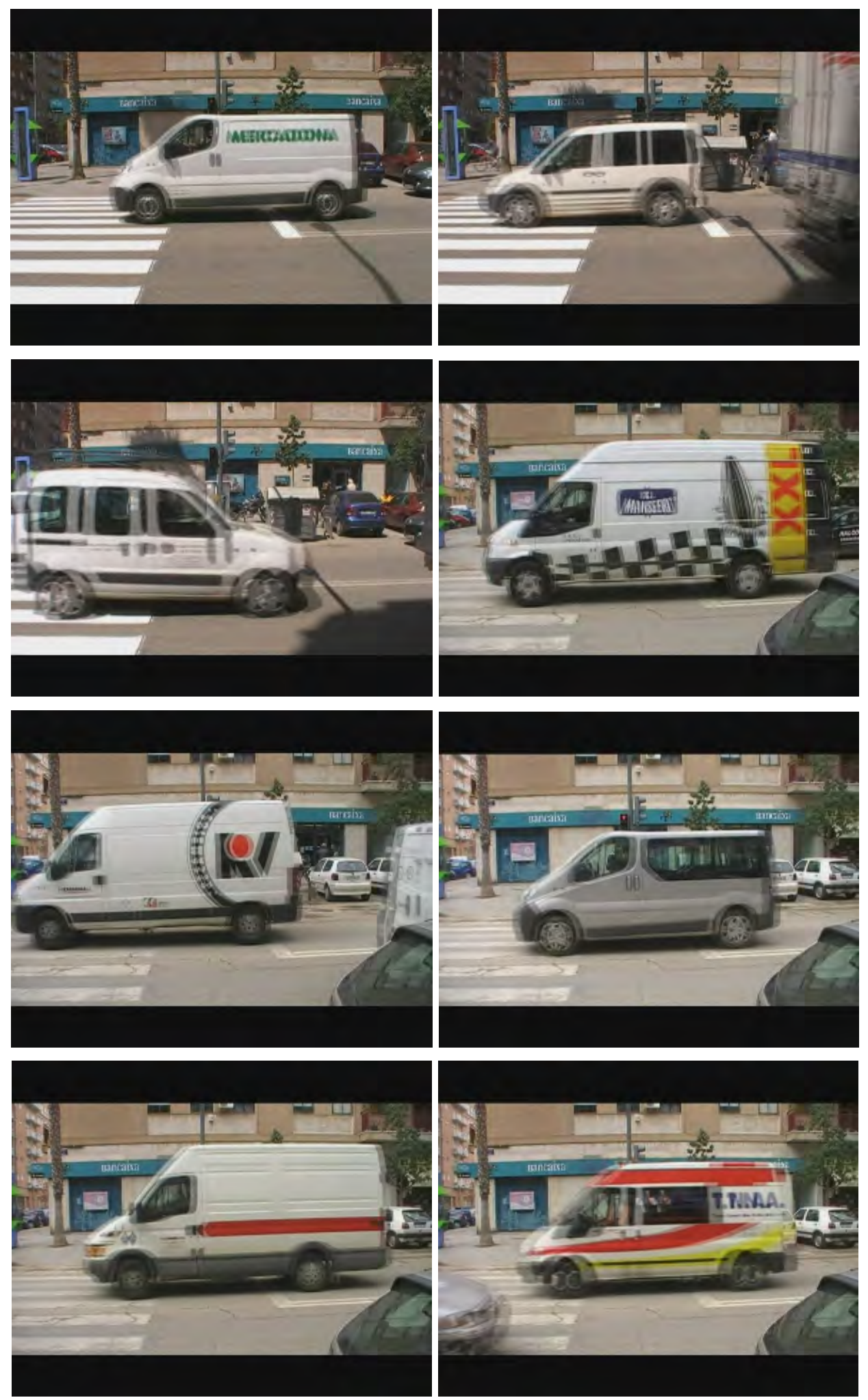

Figura A.3 - Vehículos de la categoría: Furgoneta 


\section{A.4. Clase Camiones}
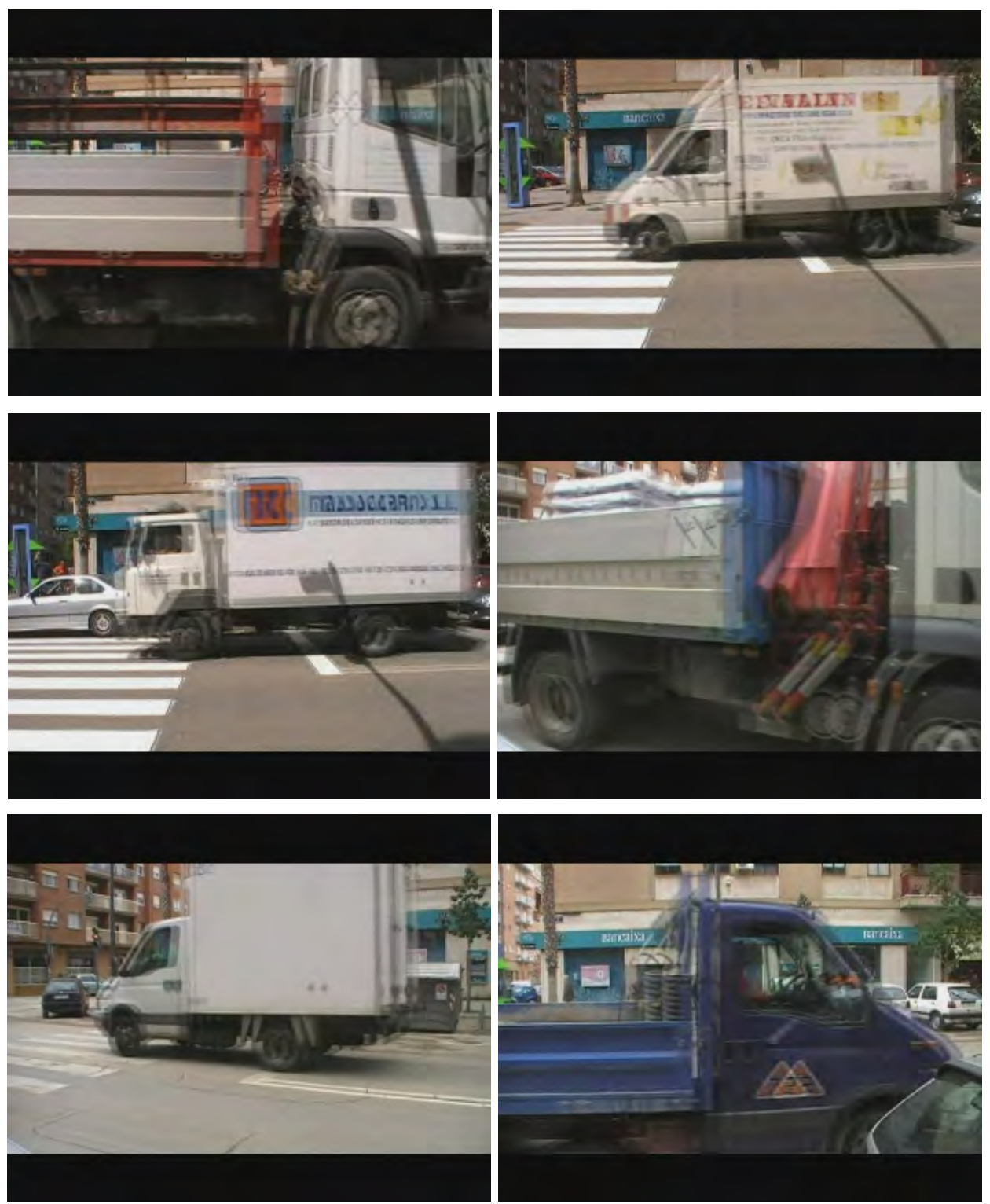

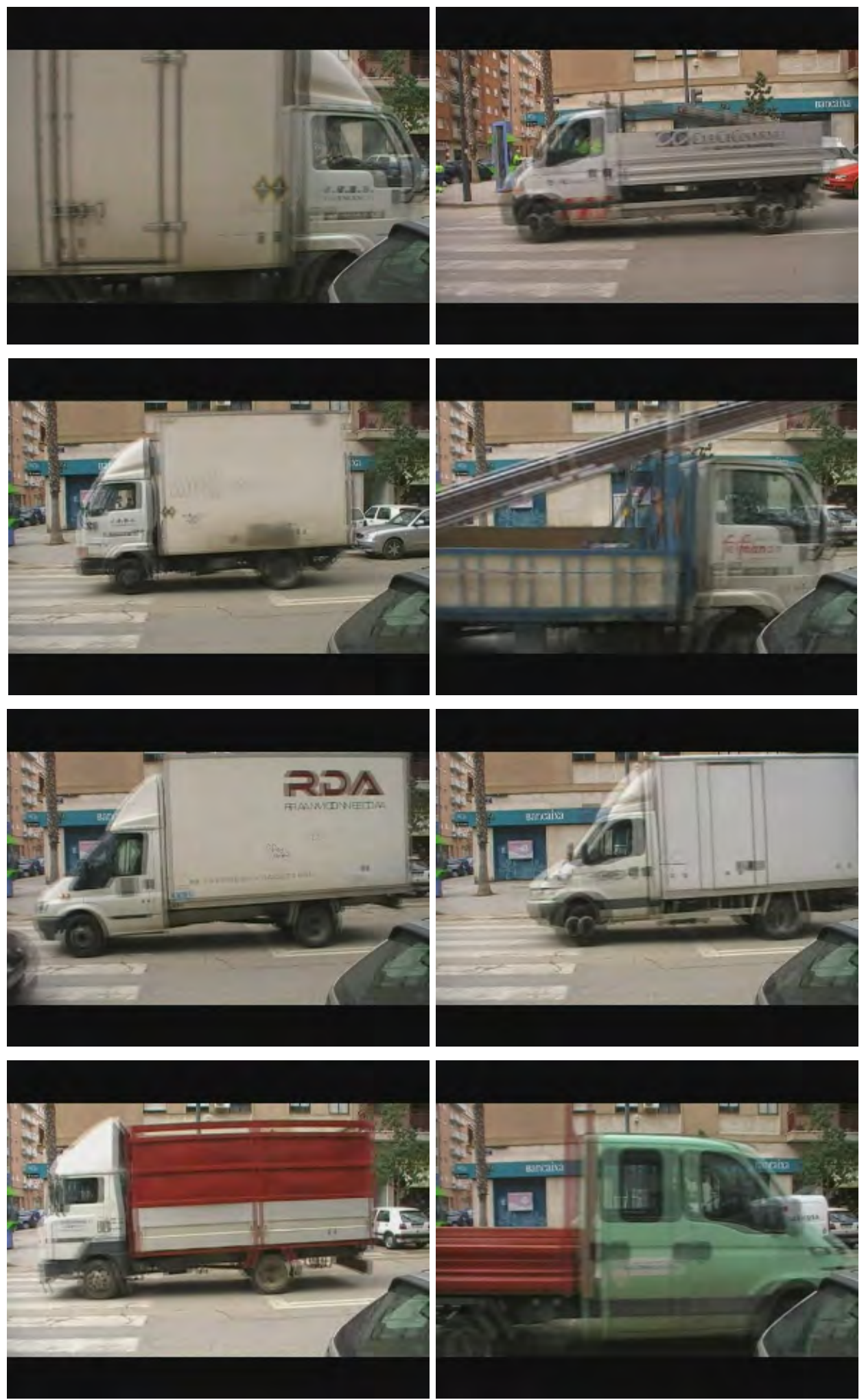

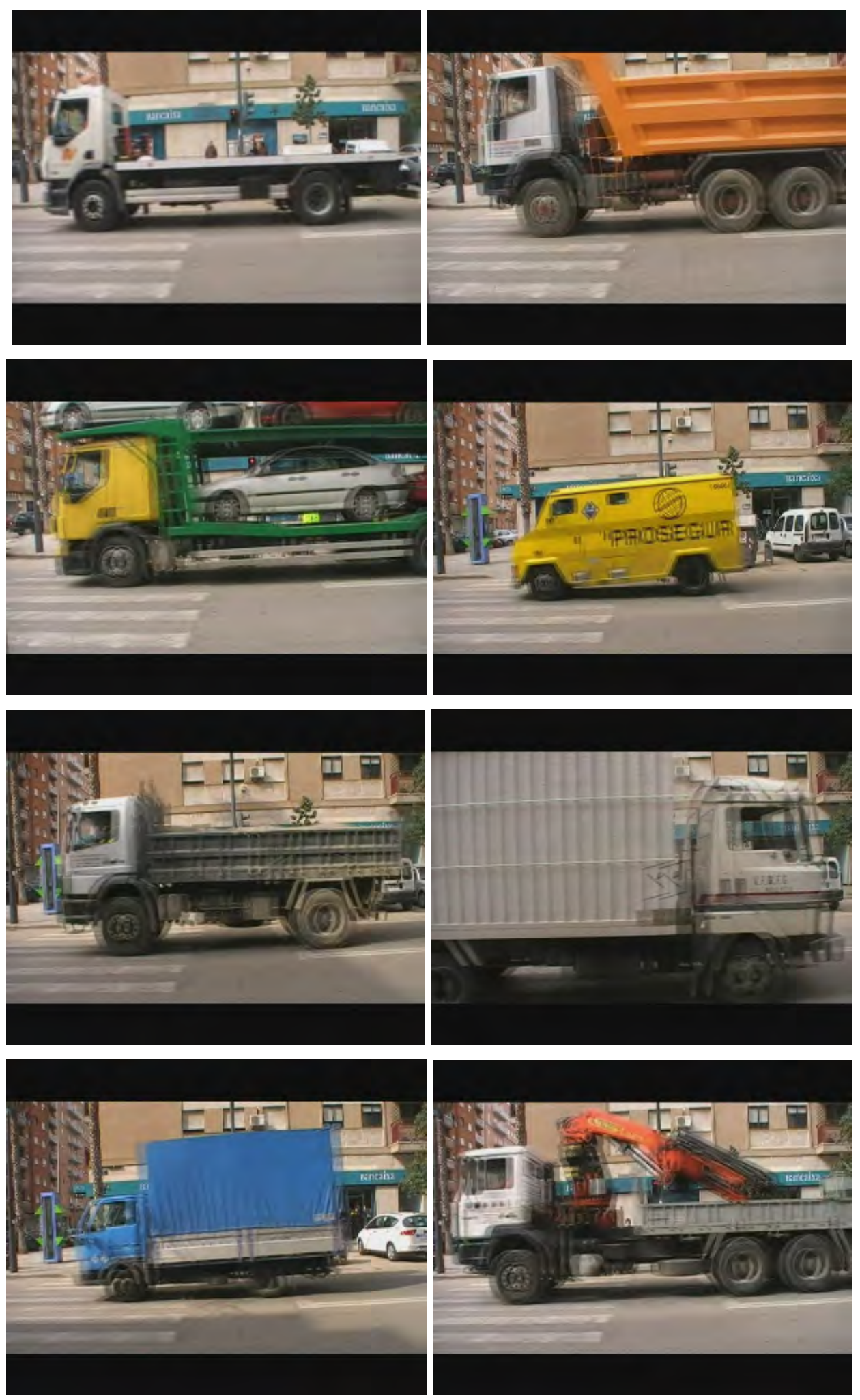

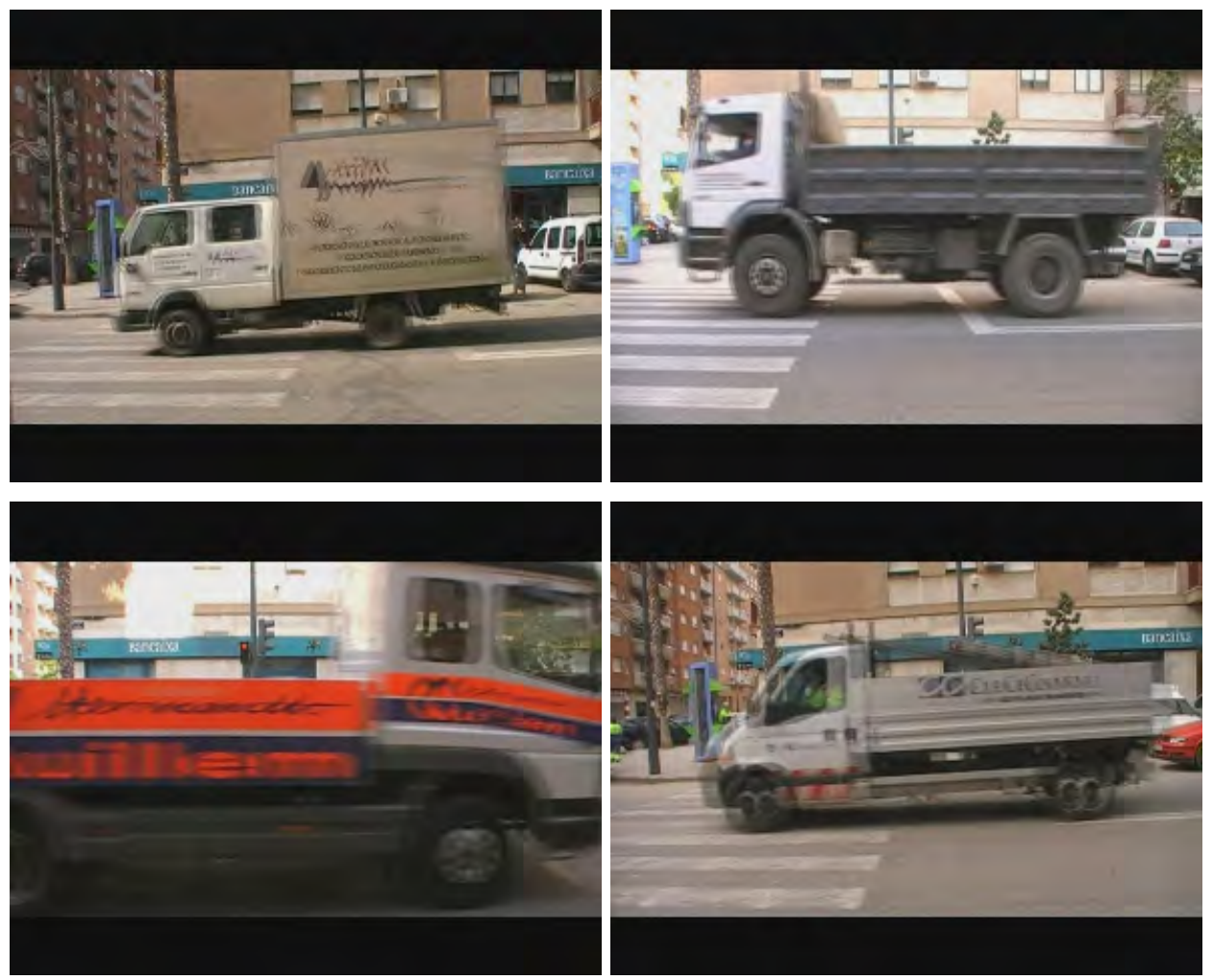

Figura A.4 - Vehículos de la categoría: Camión

\section{A.5. Clase Camiones con tráiler}
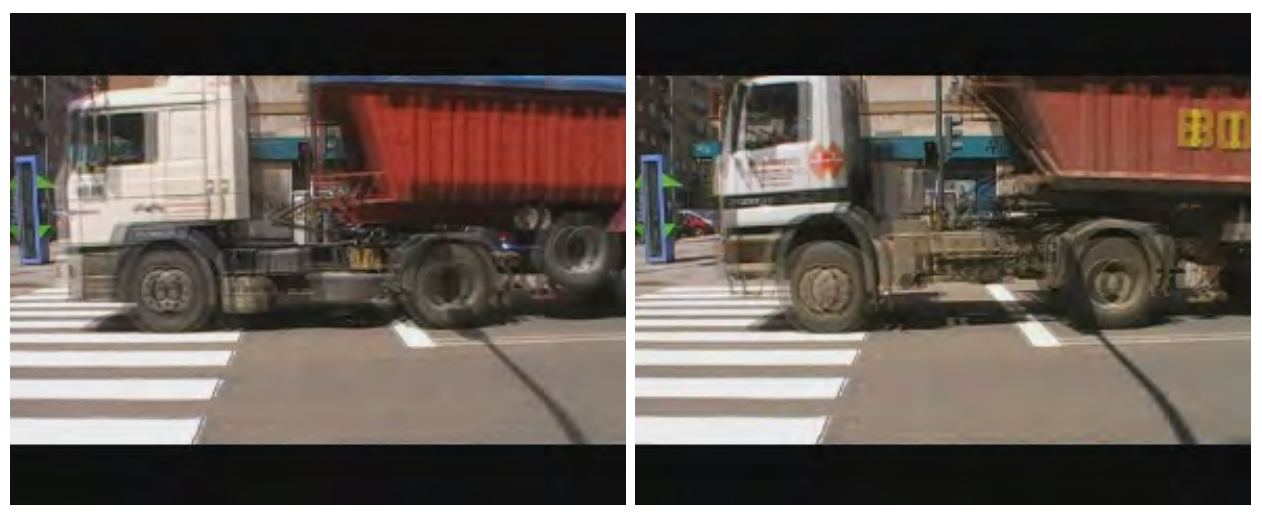

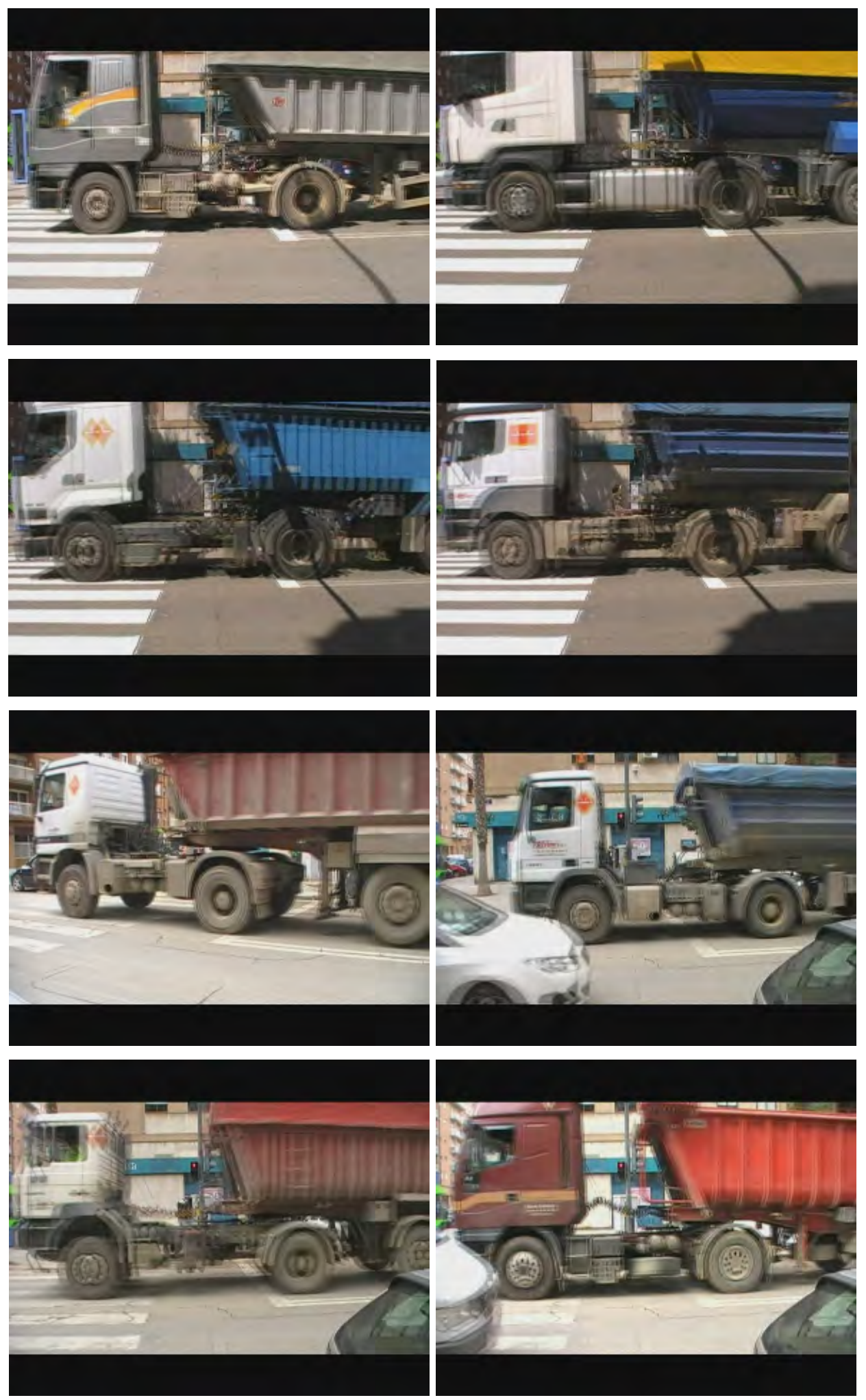

Figura A.5 - Vehículos de la categoría: Camión con tráiler 


\section{A.6. Clase Autobuses}
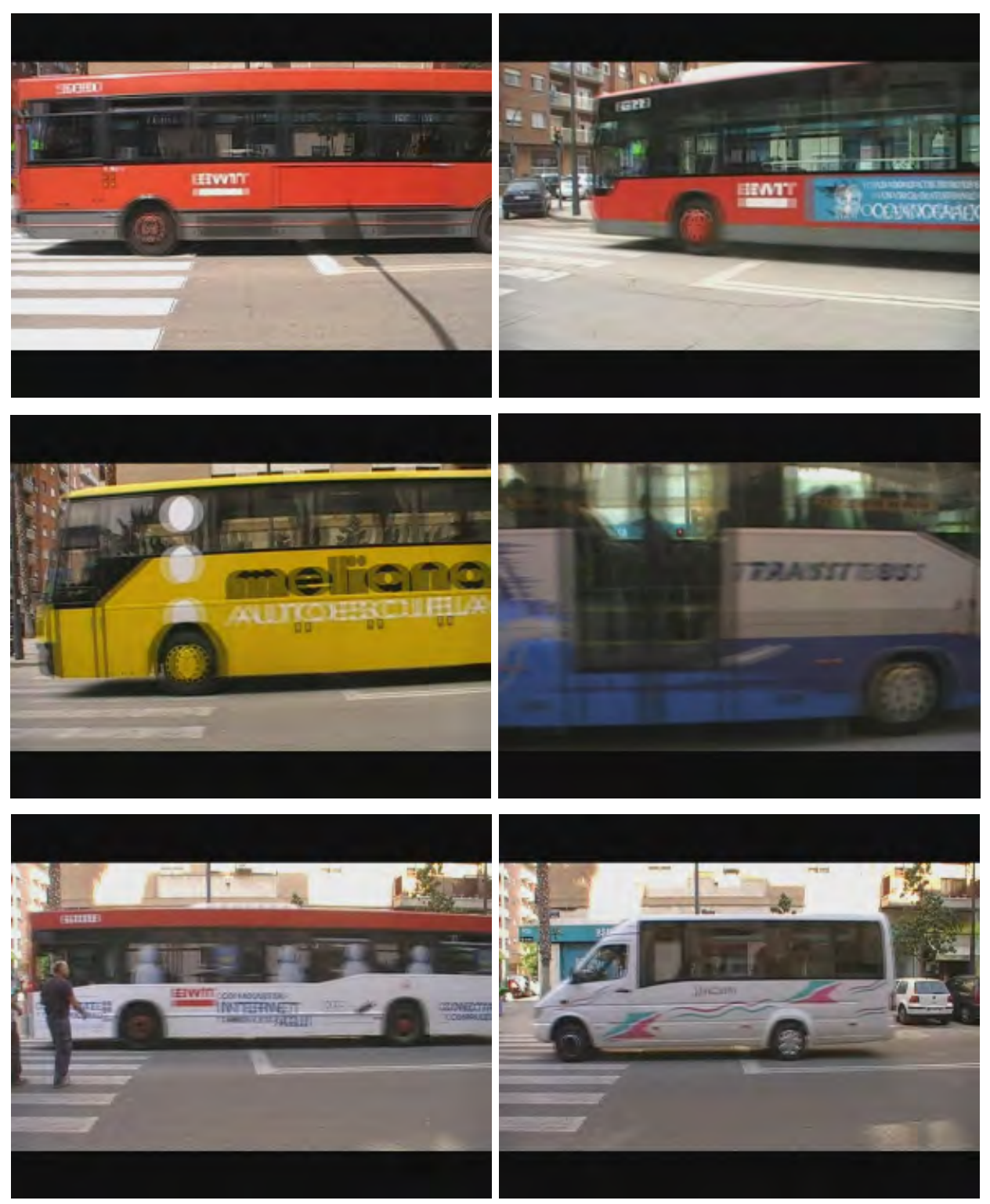

Figura A.6 - Vehículos de la categoría: Autobús 


\section{Código programa para la extracción de}

\section{características: ClasiCoche}

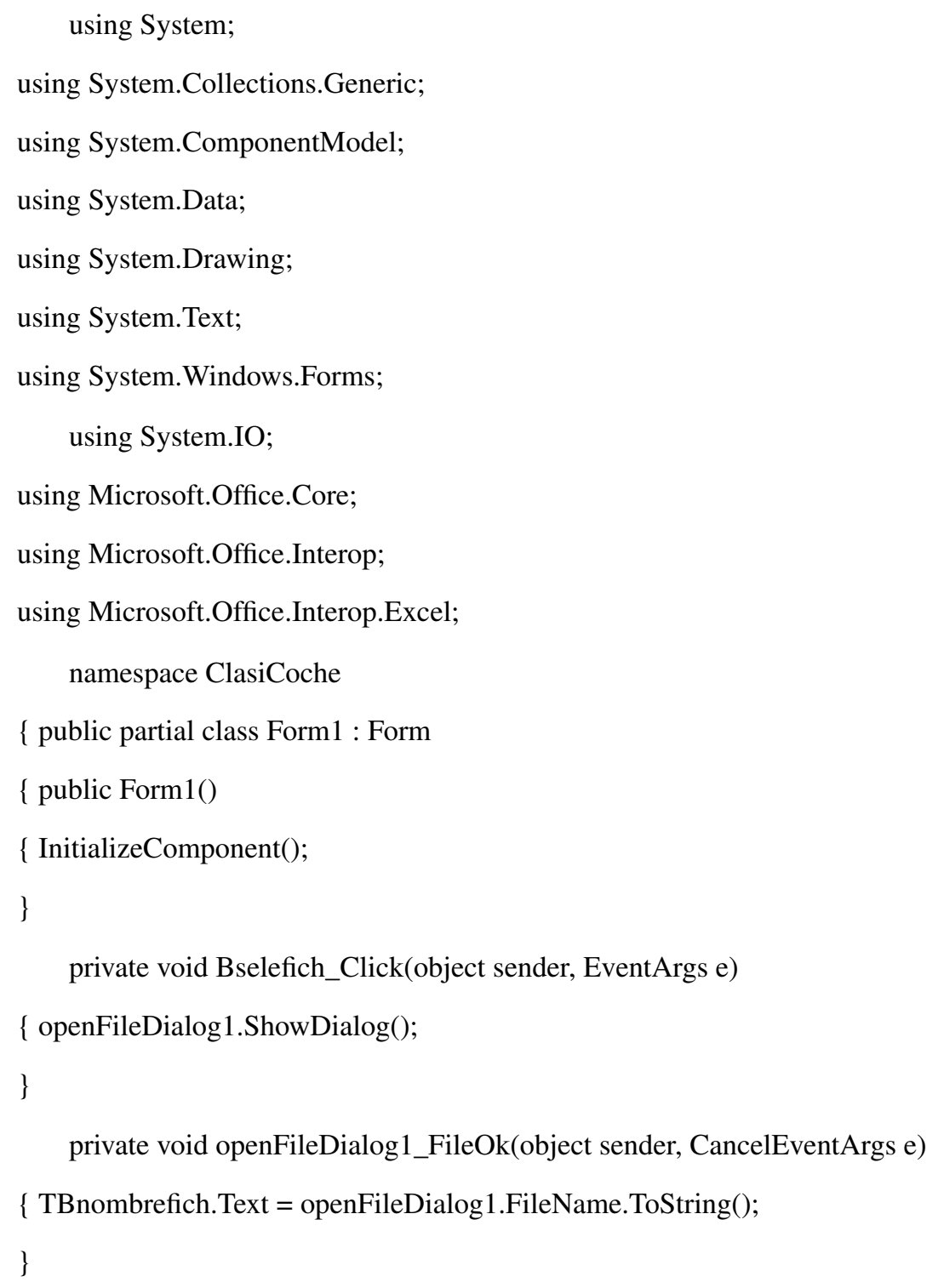


private void Brellenar_Click(object sender, EventArgs e)

$\{$ //Variables para las lineas

int $\mathrm{i}$;

Int32 contador;

string tipo = "',",",

Double intercambio;

//Delimitador para split

char[] deli $=\{,$,$\} ;$

StreamReader re $=$ new StreamReader(openFileDialog1.FileName);

string linea $=$ re. $\operatorname{ReadLine}()$;

bool final $=$ false;

while (final $==$ false $)\{$ if (re.EndOfStream)

$\{$ final $=$ true;

\}

if $\left(\right.$ linea $\left.[0]=={ }^{\prime} \sharp '\right)\{$ linea $=$ linea.Replace $(',,, ', ')$;

string[] valores = linea.Split(deli);

//Anchura es el primer valor despues del corchete

//Int32 anchura = Convert.ToInt32(valores[1]);

Double anchura = Convert. ToDouble $($ valores[1]);

//Altura es el maximo valor del perfil

Double altura $=0$;

for $(\mathrm{i}=2 ; \mathrm{i}<22 ; \mathrm{i}++)\{$ if $($ Convert.ToDouble (valores[i] $)>$ altura $)$

$\{$ altura $=$ Convert.ToDouble $($ valores $[\mathrm{i}])$;

\} \}

//Ratio50CF es el numero de valores entre el centro del vehiculo y el

//final que presentan un valor mayor del $50 \%$ del maximo del perfil

Int32 ratio50cf $=0$;

contador $=0$;

intercambio $=0$;

intercambio $=$ altura $* 50 / 100 ;$

for $(\mathrm{i}=12 ; \mathrm{i}<22 ; \mathrm{i}++)$

$\{$ if (Convert.ToDouble(valores[i]) >intercambio)

$\{$ contador $++;\}\}$ ratio50cf $=$ contador; 
//Ratio60CF es el numero de valores entre el centro del vehiculo y el //final que presentan un valor mayor del $60 \%$ del maximo del perfil

Int32 ratio60cf $=0$;

contador $=0$;

intercambio $=0$;

intercambio $=$ altura $* 60 / 100$;

for $(i=12 ; i<22 ; i++)$

$\{$ if (Convert.ToDouble(valores[i]) >intercambio)

$\{$ contador $++;\}\}$ ratio60cf $=$ contador;

//Ratio70CF es el numero de valores entre el centro del vehiculo y el //final que presentan un valor mayor del $70 \%$ del maximo del perfil

Int32 ratio $70 \mathrm{cf}=0$;

contador $=0$;

intercambio $=0$;

intercambio $=$ altura $* 70 / 100$;

for $(\mathrm{i}=12 ; \mathrm{i}<22 ; \mathrm{i}++)$

$\{$ if (Convert.ToDouble(valores[i]) >intercambio)

$\{$ contador $++;\}\}$ ratio70cf $=$ contador;

//Ratio80CF es el numero de valores entre el centro del vehiculo y el //final que presentan un valor mayor del $80 \%$ del maximo del perfil

Int32 ratio80cf $=0$;

contador $=0$;

intercambio $=0$;

intercambio $=$ altura $* 80 / 100 ;$

for $(i=12 ; i<22 ; i++)$

$\{$ if (Convert.ToDouble(valores[i]) >intercambio)

$\{$ contador $++;\}\}$ ratio80cf $=$ contador;

//Ratio90CF es el numero de valores entre el centro del vehiculo y el //final que presenta un valor mayor del $90 \%$ del maximo del perfil

Int32 ratio $90 \mathrm{cf}=0$;

intercambio $=0$;

contador $=0$;

intercambio $=$ altura $* 90 / 100$;

for $(i=12 ; i<22 ; i++)$ 
$\{$ if (Convert.ToDouble(valores[i]) >intercambio)

$\{$ contador++; $\}\}$ ratio90cf $=$ contador;

//Ratio50IC es el numero de valores entre el inicio del vehiculo y el //centro que presenta un valor mayor del $50 \%$ del maximo del perfil

Int32 ratio50ic $=0$;

intercambio $=0$;

contador $=0$;

intercambio $=$ altura $* 50 / 100 ;$

for $(\mathrm{i}=2 ; \mathrm{i}<12 ; \mathrm{i}++)$

$\{$ if (Convert.ToDouble(valores[i]) >intercambio)

$\{$ contador $++;\}\}$ ratio50ic $=$ contador;

//Ratio60IC es el numero de valores entre el inicio del vehiculo y el //centro que presenta un valor mayor del $60 \%$ del maximo del perfil Int32 ratio60ic $=0$

intercambio $=0$;

contador $=0$;

intercambio $=$ altura $* 60 / 100 ;$

for $(\mathrm{i}=2 ; \mathrm{i}<12 ; \mathrm{i}++)$

$\{$ if (Convert.ToDouble(valores[i]) >intercambio)

$\{$ contador $++;\}\}$ ratio60ic $=$ contador;

//Ratio70IC es el numero de valores entre el inicio del vehiculo y el //centro que presenta un valor mayor del $70 \%$ del maximo del perfil Int32 ratio70ic $=0$ intercambio $=0$;

contador $=0$;

intercambio $=$ altura $* 70 / 100 ;$

for $(\mathrm{i}=2 ; \mathrm{i}<12 ; \mathrm{i}++)$

$\{$ if (Convert.ToDouble(valores[i]) >intercambio)

$\{$ contador++;

\} \} ratio70ic $=$ contador;

//Ratio80IC es el numero de valores entre el inicio del vehiculo y el //centro que presenta un valor mayor del $80 \%$ del maximo del perfil Int32 ratio80ic $=0$;

intercambio $=0$; 
contador $=0$;

intercambio $=$ altura $* 80 / 100$;

for $(\mathrm{i}=2 ; \mathrm{i}<12 ; \mathrm{i}++)$

$\{$ if (Convert.ToDouble(valores[i]) >intercambio)

$\{$ contador++; $\}\}$ ratio80ic $=$ contador;

//Ratio90IC es el numero de valores entre el inicio del vehiculo y el

//centro que presenta un valor mayor del $90 \%$ del maximo del perfil

Int32 ratio90ic $=0$;

intercambio $=0$;

contador $=0$;

intercambio $=$ altura $* 90 / 100$;

for $(\mathrm{i}=2 ; \mathrm{i}<12 ; \mathrm{i}++)$

$\{$ if (Convert.ToDouble(valores[i]) >intercambio)

$\{$ contador $++;\}\}$ ratio90ic $=$ contador;

//RatioIC100_125 es el numero de valores entre el inicio del vehiculo y el //centro que presenta un valor del perfil entre 1000 y $1250 \mathrm{~m}$

Int32 ratioic100_125 = 0;

contador $=0$;

for $(\mathrm{i}=2 ; \mathrm{i}<10 ; \mathrm{i}++)$

$\{$ if $($ Convert.ToDouble $($ valores[i] $)>1000 \& \&$ Convert.ToDouble $($ valores $[\mathrm{i}])<=1250$ )

$\{$ contador++; $\}\}$ ratioic100_125 = contador;

//Valor321 tras dividir el perfil del vehiculo en 2 partes (3 lineas)

//este valor muestra el numero resultante de dividir el valor 2 entre el valor1

Double valor $321=0$;

valor321 = Convert.ToDouble(valores[11]) / Convert.ToDouble(valores[3]);

//Valor332 tras dividir el perfil del vehiculo en 2 partes (3 lineas)

//este valor muestra el numero resultante de dividir el último valor

//del perfil entre el valor central

Double valor $332=0$

valor332 = Convert.ToDouble(valores[21]) / Convert.ToDouble(valores[11]);

//Valor532 tras dividir el perfil del vehiculo en 4 partes (5 lineas)

//este valor muestra el numero resultante de dividir el valor 3 entre el valor 2 
Double valor $532=0$

valor532 = Convert.ToDouble(valores[11]) / Convert.ToDouble(valores[6]);

//Valor543 tras dividir el perfil del vehiculo en 4 partes (5 lineas)

//este valor muestra el numero resultante de dividir el valor 4 entre el valor 3

Double valor543 = 0

valor543 = Convert.ToDouble(valores[16]) / Convert.ToDouble(valores[11]);

//Valor724 tras dividir el perfil del vehiculo en 6 partes (7 lineas)

//este valor muestra el numero resultante de dividir el valor 4 entre el valor 2

Double valor724 =0;

valor724 = Convert.ToDouble(valores[5]) / Convert.ToDouble(valores[11]);

//Valor734 tras dividir el perfil del vehiculo en 6 partes (7 lineas)

//este valor muestra el numero resultante de dividir el valor 3 entre el valor 4

Double valor734 =

valor734 = Convert.ToDouble(valores[8]) / Convert.ToDouble(valores[11]);

//Valor754 tras dividir el perfil del vehiculo en 6 partes (7 lineas)

//este valor muestra el numero resultante de dividir el valor 5 entre el valor 4

Double valor754 =0;

valor754 $=$ Convert.ToDouble(valores[15]) / Convert.ToDouble(valores[11]);

//Valor764 tras dividir el perfil del vehiculo en 6 partes (7 lineas)

//este valor muestra el numero resultante de dividir el valor 6 entre el valor 4

Double valor764 = 0 ;

valor764 = Convert.ToDouble(valores[19]) / Convert.ToDouble(valores[11]);

//DerI50 calculo de la derivada entre el valor inicial y el central y cuento //los valores negativos que aparecen

Int32 deri50 = 0;

contador $=0$;

for $(i=2 ; i<11 ; i++)$

$\{$ Double derivada $=$ Convert.ToDouble $($ valores $[\mathrm{i}+1])-$ Convert.ToDouble $($ valores $[\mathrm{i}])$;

if (derivada $<0)$

$\{$ contador++; $\}\}$ deri50 = contador;

//Der50F calculo la derivada del perfil entre su valor central y el final

// y cuento los valores negativos que aparecen

Int32 der50f = 0;

contador $=0$; 
for $(i=11 ; i<21 ; i++)$

$\{$ Double derivada $=$ Convert.ToDouble $($ valores $[\mathrm{i}+1])-$ Convert.ToDouble $($ valores $[\mathrm{i}])$;

if (derivada $<0)$

$\{$ contador $++;\}\}$ der50f $=$ contador;

//Rango0_100 es el numero de datos del perfil que se encuentran entre

// 0 y 1,000 metros

Int32 rango0_100=0;

contador $=0$;

for $(\mathrm{i}=2 ; \mathrm{i}<22 ; \mathrm{i}++)$

$\{$ if $($ Convert.ToDouble $($ valores $[\mathrm{i}])>0 \& \&$ Convert.ToDouble $($ valores $[\mathrm{i}])<=1000)$

$\{$ contador++; $\}\}$ rango0_100=contador;

//Rango50_100 es el numero de datos del perfil que se encuentran entre

// 500 y 1,000 metros

Int32 rango50_100=0;

contador $=0$;

for $(\mathrm{i}=2 ; \mathrm{i}<22 ; \mathrm{i}++)$

$\{$ if $($ Convert.ToDouble $($ valores[i] $)>500 \& \&$ Convert.ToDouble $($ valores $[\mathrm{i}])<=1000$ )

$\{$ contador++; $\}\}$ rango50_100 = contador;

//Rango100_125 es el numero de datos del perfil que se encuentran entre

// 1,000 y 1,250 metros

Int32 rango100_125 =0;

contador $=0$;

for $(\mathrm{i}=2 ; \mathrm{i}<22 ; \mathrm{i}++)$

$\{$ if $($ Convert.ToDouble $($ valores[i] $)>1000 \& \&$ Convert.ToDouble $($ valores[i] $)<=1250$ )

$\{$ contador++; \}\} rango100_125 = contador;

//Rango100_150 es el numero de datos del perfil que se encuentran entre

// 1,000 y 1,500 metros

Int32 rango100_150=0;

contador $=0$;

for $(\mathrm{i}=2 ; \mathrm{i}<22 ; \mathrm{i}++)$

$\{$ if $($ Convert.ToDouble(valores[i]) $>1000 \& \&$ Convert.ToDouble(valores[i]) $<=1500$ )

$\{$ contador++; \}\} rango100_150= contador;

//Rango125_150 es el numero de datos del perfil que se encuentran entre

$/ / 1,25$ y 1,50 metros 
Int32 rango125_150=0;

contador $=0$;

for $(\mathrm{i}=2 ; \mathrm{i}<22 ; \mathrm{i}++)$

$\{$ if $($ Convert.ToDouble(valores[i]) $>1250 \& \&$ Convert.ToDouble(valores[i]) $<=1500$ )

$\{$ contador++; \} \} rango125_150= contador;

//Rango150_175 es el numero de datos del perfil que se encuentran entre

// 1,500 y 1,750 metros

Int32 rango150_175 =0;

contador $=0$;

for $(\mathrm{i}=2 ; \mathrm{i}<22 ; \mathrm{i}++)$

$\{$ if $($ Convert.ToDouble(valores[i]) $>1500 \& \&$ Convert.ToDouble(valores[i]) $<=1750$ )

$\{$ contador++; \}\} rango150_175= contador;

//Rango150_200 es el numero de datos del perfil que se encuentran entre

$/ / 1,500$ y 2,000 metros

Int32 rango150_200=0;

contador $=0$;

for $(\mathrm{i}=2 ; \mathrm{i}<22 ; \mathrm{i}++)$

$\{$ if $($ Convert.ToDouble(valores[i]) $>1500 \& \&$ Convert.ToDouble(valores[i]) $<=2000$ )

$\{$ contador++; \} \} rango150_200= contador;

//Rango200_250 es el numero de datos del perfil que se encuentran entre $/ / 2,000$ y 2,500 metros

Int32 rango200_250=0;

contador $=0$;

for $(\mathrm{i}=2 ; \mathrm{i}<22 ; \mathrm{i}++)$

$\{$ if $($ Convert.ToDouble(valores[i]) $>2000 \& \&$ Convert.ToDouble(valores[i]) $<=2500$ )

$\{$ contador++; $\}\}$ rango200_250 = contador;

//Rango250_300 es el numero de datos del perfil que se encuentran entre

$/ / 2,500$ y 3,000 metros

Int32 rango250_300 = 0;

contador $=0$;

for $(\mathrm{i}=2 ; \mathrm{i}<22 ; \mathrm{i}++)$

$\{$ if $($ Convert.ToDouble(valores[i]) $>2500 \& \&$ Convert.ToDouble(valores[i]) $<=3000$ )

$\{$ contador++; \} \} rango250_300 = contador; 
//Rango300 es el numero de datos del perfil mayores de 3,000 metros

Int32 rango $300=0$;

contador $=0$;

for $(i=2 ; i<22 ; i++)$

$\{$ if $($ Convert.ToDouble (valores[i] $)>3000$ )

$\{$ contador++; $\}\}$ rango $300=$ contador;

//Fin de entrada de parametros

//Selección entre Modo de Aprendizaje y de Clasificación

if $($ CBclasificacion.Checked $==$ false $)\{/ /$ Modo aprendizaje, sabemos el tipo de vehiculo

if (RBautobus.Checked) tipo = "Autobús";

if (RBcamion.Checked) tipo = "Camión";

if (RBfurgoneta.Checked) tipo = "Furgoneta";

if $($ RBcamtrailer.Checked) tipo = "Camión con Tráiler";

if (RBdesconocido.Checked) tipo = "Desconocido";

if $($ RBmotocicleta. Checked) tipo = "Motocicleta";

if (RBtipoarti.Checked) tipo = "Tipo Articulado";

if $($ RBturismo.Checked) tipo = "Turismo";

if $($ RBturistrailer.Checked) tipo = "Turismo con Tráiler";

\} else \{ //Modo clasificación, Para poder averiguar el tipo con el grupo de test

tipo $=$ obtener_tipo(anchura, altura, ratio80cf, ratio70ic, ratio90ic,

valor321, valor332, valor532, valor543, valor724, valor734, valor764,

rango100_150, rango150_175, rango150_200, rango200_250);

\}

Grid.Rows.Add(tipo, anchura, altura, ratio50cf, ratio60cf, ratio70cf,

ratio80cf, ratio90cf, ratio50ic, ratio60ic, ratio70ic, ratio80ic, ratio90ic,

ratioic100_125, valor321, valor332, valor532, valor543, valor724, valor734,

valor754, valor764, deri50, der50f, rango0_100, rango50_100, rango100_125,

rango100_150, rango125_150, rango150_175, rango150_200, rango200_250,

rango250_300, rango300);

\} linea $=$ re.ReadLine();

\}

Grid.Refresh();

\}

//Funcion que devuelve un string con el tipo de vehiculo 
private string obtener_tipo(double anchura, double altura, int ratio80cf, int ratio70ic, int ratio90ic, double valor321, double valor332, double valor532, double valor543, double valor724, double valor734, double valor764, int rango100_150, int rango150_175, int rango150_200, int rango200_250)

$\{$ string vehiculo $=" ” ;$

string tipo_vehiculo = "'”;

\section{//DISCRIMINACIONES}

//PRIMERA DISCRIMINACION (Motocicletas y $>2$ ruedas)

if $($ anchura $>1000)\{$ tipo_vehiculo $=$ ">2 ruedas";

else $\{$ vehiculo $=$ "Motocicleta"; $\}$

//SEGUNDA DISCRIMINACION (Veh. ligeros y pesados)

if (tipo_vehiculo == ">2 ruedas")

$\{$ if (altura $<2622.85$ )

$\{$ if (valor734 <1.00146)

$\{$ if (anchura $<2398.25$ )

$\{$ if $($ rango100_150 <1.5) \{ tipo_vehiculo = "Vehiculo Ligero"; $\}$ else

$\{$ if $($ rango200_250 $<15.5)$

$\{$ if $($ ratio70ic $<7.5)$

$\{$ if $($ valor332 $<0.306844)$

$\{$ if $($ ratio70ic <5.5) \{ tipo_vehiculo = "Vehiculo Ligero"; $\}$ else $\{$ tipo_vehiculo = "Vehiculo Pesado"; $\}$ \} else $\{$ tipo_vehiculo = "Vehiculo Ligero"; $\}$ else $\{$ tipo_vehiculo = "Vehiculo Ligero"; $\}$ \} else $\{$ tipo_vehiculo $=$ "Vehiculo Ligero"; \} \} \} else \{ tipo_vehiculo = "Vehiculo Ligero"; \} \} else

$\{$ if $($ altura $<2108.15)\{$ tipo_vehiculo = "Vehiculo Ligero"; $\}$ else $\{$ tipo_vehiculo = "Vehiculo Pesado"; $\}\}\}$ else $\{$ if (valor724 $<0.650578)$

$\{$ if $($ anchura <2076.21) $\{$ tipo_vehiculo = "Vehiculo Ligero"; $\}$ else $\{$ tipo_vehiculo = "Vehiculo Pesado"; $\}$ \} else $\{$ tipo_vehiculo = "Vehiculo Pesado"; $\}\}\}$

//TERCERA DISCRIMINACION (Tipo Turismo y Furgoneta)

if (tipo_vehiculo == "Vehiculo Ligero") //tipo vehículo ligero

$\{$ if (rango100_150<6.5)

$\{$ if (altura $<1715.4)$

$\{$ if $($ valor724 <0.623238) $\{$ vehiculo $=$ "VL - Furgoneta"; $\}$ else $\{$ vehiculo = "VL - Tipo Turismo"; $\}\}$ else

$\{$ if $($ ratio80cf $<8.5)$

$\{$ if (altura <1804.53) \{ vehiculo = "VL - Tipo Turismo"; $\}$ else $\{$ vehiculo = "VL - Furgoneta"; $\}\}$ else

$\{$ if $($ valor764 <0.987905) $\{$ vehiculo = "VL - Furgoneta"; $\}$ else 
$\{$ if (rango150_200<12.5) \{ vehiculo = "VL - Furgoneta"; $\}$ else

$\{$ if (valor332 <1.06474)

$\{$ if (rango150_175 <1.5)

$\{$ if $($ altura <1886.5) $\{$ vehiculo = "VL - Tipo Turismo"; $\}$ else $\{$ vehiculo = "VL - Furgoneta"; $\}$ \} else $\{$ vehiculo ="VL - Furgoneta"; \} \} else \{ vehiculo ="VL - Tipo Turismo"; \} \} \} \} \} \} else

$\{$ if $($ ratio80cf $<3.5)\{$ vehiculo $=$ "VL - Furgoneta"; $\}$ else

$\{$ if $($ valor532 <1.57496)

$\{$ if $($ valor764 <0.714685) $\{$ vehiculo = "VL - Tipo Turismo"; $\}$ else

$\{$ if $($ anchura $<1564.75)$

$\{$ if $($ anchura <1564.13) \{ vehiculo = "VL - Tipo Turismo"; $\}$ else $\{$ vehiculo = "VL - Furgoneta"; $\}$ \} else

$\{$ if $($ altura $<1388.28)$

$\{$ if $($ altura <1387.4) $\{$ vehiculo = "VL - Tipo Turismo"; $\}$ else $\{$ vehiculo = "VL - Furgoneta"; $\}$ else $\{$ vehiculo ="VL - Tipo Turismo"; \} \} \} \} else

$\{$ if $($ altura $<1587.45)\{$ vehiculo = "VL - Tipo Turismo"; $\}$ else $\{$ vehiculo ="VL - Furgoneta"; $\}\}\}\}\}$

//CUARTA DISCRIMINACION (Tipo Camión y Autobús)

if (tipo_vehiculo == "Vehiculo Pesado") //tipo vehículo pesado

$\{$ if $($ ratio90ic $<7.5)$

$\{$ if (valor543 <1.05325) \{ tipo_vehiculo = "Tipo Camión"; $\}$ else $\{$ vehiculo = "VP - Autobús"; $\}\}$ else $\{$ vehiculo ="VP-Autobús"; \} \}

//SEXTA DISCRIMINACION (Tipo Tráiler y Camión)

if (tipo_vehiculo == "Tipo Camión")

$\{$ if (valor734 <0.761172) \{ vehiculo = "VP - TC - Tipo Tráiler"; \} else

$\{$ if $($ valor321 $<1.13233)$

$\{$ if (valor532 <1.01959) \{ vehiculo = "VP - TC - Camión"; \} else $\{$ vehiculo = "VP - TC - Tipo Tráiler"; \} \} else $\{$ vehiculo = "VP - TC - Camión"; $\}\}\}$

return vehiculo;

\}

private void Bexcel_Click(object sender, EventArgs e)

$\{$ if (Grid.Rows.Count $>0$ )

$\{$ object oMissing $=$ System.Reflection.Missing.Value;

Microsoft.Office.Interop.Excel.Application apl = new Microsoft.Office.Interop.Excel.ApplicationClass();

Workbook libro = apl.Workbooks.Open("C:

exportado.xlsx”, oMissing, oMissing, 
oMissing, oMissing, oMissing, oMissing, oMissing, oMissing, oMissing, oMissing,

oMissing, oMissing, oMissing, oMissing);

Microsoft.Office.Interop.Excel.Worksheet sheet $=($ Microsoft.Office.Interop.Excel. Worksheet $)$ libro.Sheets[1];

for (int $\mathrm{i}=0 ; \mathrm{i}<$ Grid.Columns.Count; $\mathrm{i}++$ )

$\{$ sheet.Cells $[1, \mathrm{i}+1]=$ Grid.Columns[i].Name; $\}$

// Create an array to multiple values at once.

for (int $\mathrm{a}=0$; $\mathrm{a}<$ Grid.Rows.Count-1; $\mathrm{a}++$ )

$\{$ for (int aa $=0$; aa $<$ Grid.Columns.Count; aa++)

$\{$ sheet.Cells $[\mathrm{a}+2$, aa +1$]=$ Grid.Rows[a].Cells[aa].Value.ToString().Replace(',,,,,,."); $\}\}$

apl. Visible $=$ true;

apl.UserControl = true;

\} \}

private void Bvaciar_Click(object sender, EventArgs e)

\{ Grid.Rows.Clear(); \}

private void Grid_CellContentClick(object sender, DataGridViewCellEventArgs e)

\{\}

private void CBclasificacion_CheckedChanged(object sender, EventArgs e)

$\{$ if (CBclasificacion.Checked)

$\{$ groupBox 1.Enabled=false;

lmodo.Text = "Modo de Clasificación";

\} else

$\{$ groupBox 1. Enabled $=$ true;

Imodo.Text = "Modo de Aprendizaje";

\} \} \} \} 


\section{Código programa para diseño de los}

\section{árboles de decisión: Generar_arboles}

Descripción: A partir de los datos proporcionados por la BBDD en formato

excel genera un arbol de decisión dependiente de las clases definidas

Parámetros: 22. Comunes a todas las clases

Estructura:

- Valores_xx: Tabla de valores con los parámetros y los vehículos

- Textos_xx: Texto de la primera fila y la primera columna

- Tipo_xx: Tipo de vehículo almacenado en la base de datos

Autor: Nieves Gallego

Fecha: 08 de Agosto del 2009

Versión: 1.0

//VEHÍCULOS PESADOS

Discriminación 6D. Camión + Tipo Tráiler

[valores_ct ,textos_ct] = xlsread('Camión con trailer.xlsx')

num_ct $=$ length $($ textos_ct $(:, 1))-1$;

tipo_ct $=$ textos_ct(2:num_ct+1,1);

parametros $(1: 33)=$ textos_ct $(1,2: 34)$;

[valores_c ,textos_c] = xlsread('Camión.xlsx');

num_c $=$ length $($ textos_c $(:, 1))-1$;

tipo_c $=$ textos_c(2:num_c+1,1); 
$\operatorname{par} 6 \mathrm{D}=$ [valores_c; valores_ct $] ;$

tipo6D = tipo_c;

for $\mathrm{i}=1$ :num_ct,

tipo6D = [tipo6D;’Tipo Tráiler'];

end

num $\_6 \mathrm{D}=$ num_c + num_ct;

TREE6D = classregtree(par6D,tipo6D,'names',parametros);

view (TREE6D);

Discriminación 4D. Discriminación 6D + Autobuses

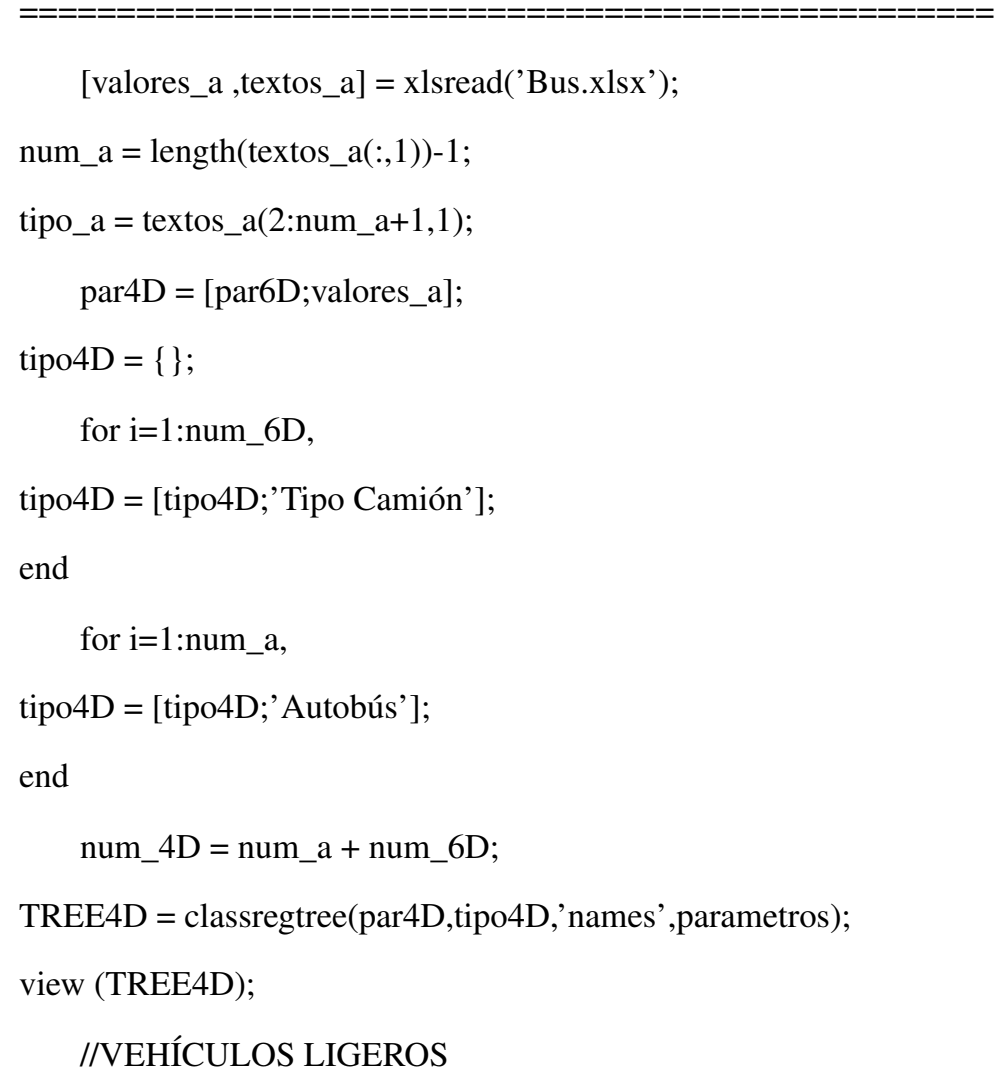

Discriminación 3D. Tipo turismo + Furgoneta

[valores_t ,textos_t $]=$ xlsread('Turismo.xlsx');

num_t $=$ length(textos_t $\mathrm{t}(:, 1))-1$;

tipo_t $=$ textos_t $(2:$ num_ $t+1,1)$;

[valores_f ,textos_f] $=$ xlsread('Furgoneta.xlsx');

num_f $=$ length $\left(\operatorname{textos} \_f(:, 1)\right)$ - 1 ;

tipo_f $=$ textos_f $\mathrm{f}\left(2: \mathrm{num} \_\mathrm{f}+1,1\right)$; 
$\operatorname{par} 3 \mathrm{D}=$ [valores_t; valores_f $]$;

tipo3D = tipo_t;

for $\mathrm{i}=1$ :num_f,

tipo3D = [tipo3D;'Furgoneta' $]$;

end

num_3D = num_f + num_t;

TREE3D = classregtree (par3D,tipo3D,'names',parametros $)$;

view (TREE3D);

// VEH. LIGERO Y PESADO

Discriminación 2D. Vehículo ligero + Vehiculo pesado

par2D = [par3D;par4D $;$

tipo2D $=\{\}$;

for $\mathrm{i}=1:$ num_3D,

tipo2D = [tipo2D;'Vehiculo ligero'];

end

for i=1:num_4D,

tipo2D = [tipo2D; 'Vehiculo pesado'];

end

num $\_2 \mathrm{D}=$ num $\_3 \mathrm{D}+$ num $\_4 \mathrm{D}$;

TREE2D = classregtree(par2D,tipo2D,'names',parametros);

view (TREE2D);

Discriminación 1D. Motocicleta $+>2$ ruedas

\section{// MOTOCICLETAS}

[valores_m ,textos_m] = xlsread('Motocicleta.xlsx');

num_m = length(textos_m(:,1)) - 1;

tipo $\_\mathrm{m}=$ textos_m(2:num_m+1,1);

par1D = [valores_m;par2D];

tipo1D $=\{\} ;$

tipo1D = tipo_m; 
for $\mathrm{i}=1$ :num_2D,

tipo1D = [tipo1D; '>2 Ruedas'];

end

num_1D = num_f + num_a;

TREE1D = classregtree $($ par1D,tipo1D,'names',parametros $)$;

view (TREE1D);

xlswrite('Aprendizaje.xlsx', parametros,'1D','B2')

xlswrite('Aprendizaje.xlsx', tipo1D,'1D','A3')

xlswrite('Aprendizaje.xlsx', par1D,'1D','B3')

xlswrite('Aprendizaje.xlsx', parametros,'2D','B2')

xlswrite('Aprendizaje.xlsx', tipo2D,'2D','A3')

xlswrite('Aprendizaje.xlsx', par2D,'2D','B3')

xlswrite('Aprendizaje.xlsx', parametros,'3D','B2')

xlswrite('Aprendizaje.xlsx', tipo3D,'3D', 'A3')

xlswrite('Aprendizaje.xlsx', par3D,'3D','B3')

xlswrite('Aprendizaje.xlsx', parametros,'4D','B2')

xlswrite('Aprendizaje.xlsx', tipo4D,'4D', 'A3')

xlswrite('Aprendizaje.xlsx', par4D,'4D','B3')

xlswrite('Aprendizaje.xlsx', parametros,'6D','B2')

xlswrite('Aprendizaje.xlsx', tipo6D,'6D','A3')

xlswrite('Aprendizaje.xlsx', par6D,'6D','B3') 


\section{Código programa para el análisis}

\section{mediante la técnica Bootstrap: GruposTest}

using System;

using System.Collections.Generic;

using System.ComponentModel;

using System.Data;

using System.Drawing;

using System.Text;

using System.Windows.Forms;

using System.IO;

using Microsoft.Office.Core;

using Microsoft.Office.Interop;

using Microsoft.Office.Interop.Excel;

namespace GruposTest

$\{$ public partial class Form1 : Form

$\{$ public int motocicletas $=0$;

public int turismos $=0$;

public int furgonetas $=0$;

public int camiones $=0$;

public int trailers $=0$;

public int buses $=0$;

public Form1() \{ InitializeComponent();

Gridresultados.Rows.Add("Motocicleta", 0, 0, 0, 0, 0, 0);

Gridresultados.Rows.Add('Turismo", 0, 0, 0, 0, 0, 0); 
Gridresultados.Rows.Add('Furgoneta", 0, 0, 0, 0, 0, 0);

Gridresultados.Rows.Add("Camión”, 0, 0, 0, 0, 0,0);

Gridresultados.Rows.Add('Trailer", 0, 0, 0, 0, 0, 0);

Gridresultados.Rows.Add("Autobús", 0, 0, 0, 0, 0, 0);

Gridresultados.Rows[0].Cells[1].Style.BackColor = System.Drawing.Color.FromArgb(150,150,255);

Gridresultados.Rows[1].Cells[2].Style.BackColor = System.Drawing.Color.FromArgb(150, 150, 255);

Gridresultados.Rows[2].Cells[3].Style.BackColor = System.Drawing.Color.FromArgb(150, 150, 255);

Gridresultados.Rows[3].Cells[4].Style.BackColor = System.Drawing.Color.FromArgb(150, 150, 255);

Gridresultados.Rows[4].Cells[5].Style.BackColor = System.Drawing.Color.FromArgb(150, 150, 255);

Gridresultados.Rows[5].Cells[6].Style.BackColor = System.Drawing.Color.FromArgb(150, 150, 255); \}

private void label1_Click(object sender, EventArgs e) \{\}

private void Bselefich_Click(object sender, EventArgs e)

\{ openFileDialog1.ShowDialog();

\}

private void openFileDialog1_FileOk(object sender, CancelEventArgs e)

$\{$ TBnombrefich.Text $=$ openFileDialog1.FileName.ToString () ;

\}

private void Bvaloresdefecto_Click(object sender, EventArgs e)

$\{$ TBmotoD.Text = "0";

TBmotoH.Text = "50";

TBturisD.Text = "51";

TBturisH.Text = "725";

TBfurgoD.Text = "726";

TBfurgoH.Text = "903";

TBcamionD.Text = "904";

TBcamionH.Text = "940";

TBtrailerD.Text = "941";

TBtrailerH.Text = "947";

TBbusD.Text = "948";

TBbusH.Text = "971";

private void Bcarga_Click(object sender, EventArgs e)

$\{$ StreamReader re $=$ new StreamReader(openFileDialog1.FileName);

string linea; 


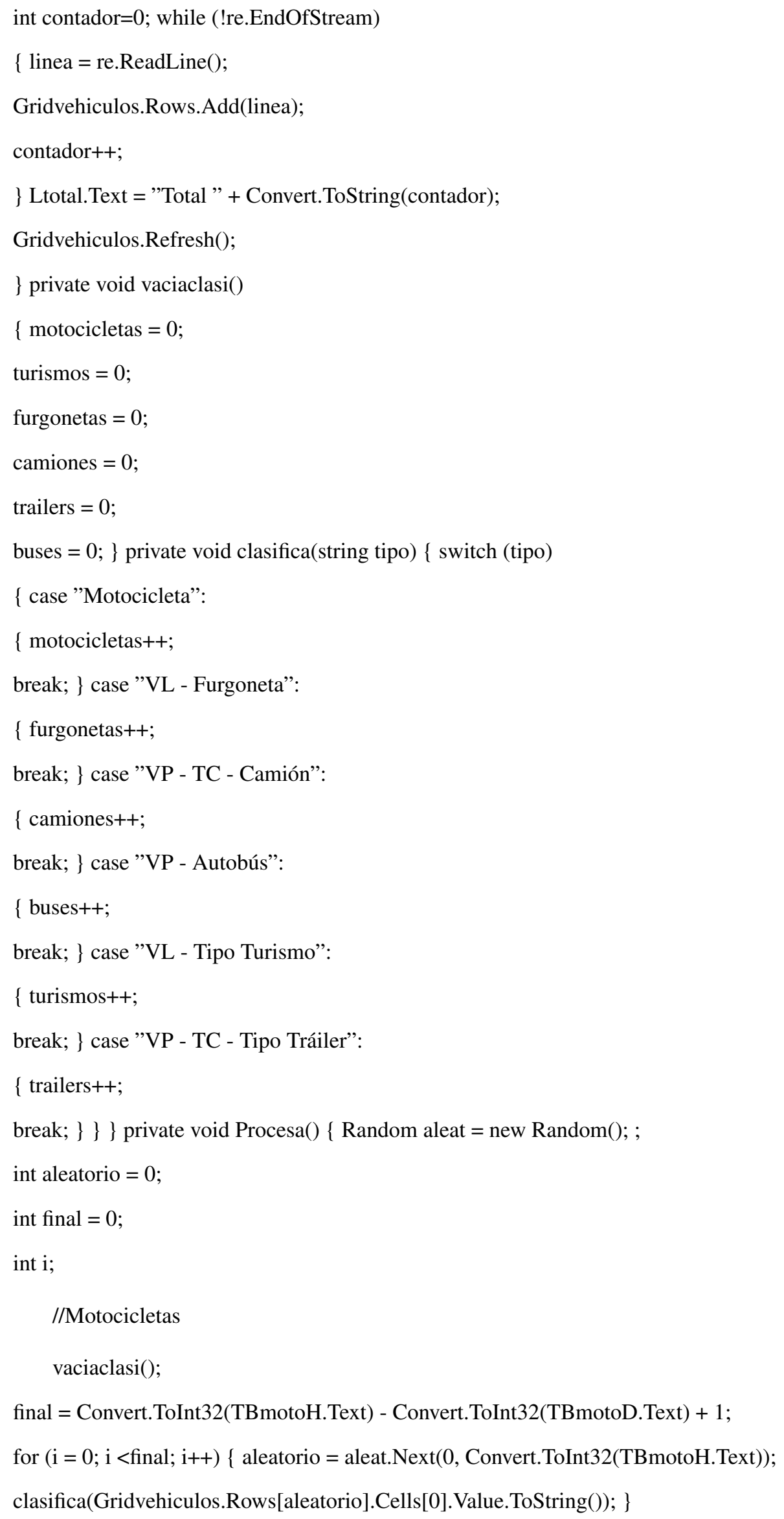


//Añado los resultados a grid de resultados

Gridresultados.Rows[0].Cells[1]. Value $=$ motocicletas.ToString () ;

Gridresultados.Rows[1].Cells[1].Value $=$ turismos.ToString () ;

Gridresultados.Rows[2].Cells[1].Value = furgonetas. ToString();

Gridresultados.Rows[3].Cells[1]. Value = camiones.ToString () ;

Gridresultados.Rows[4].Cells[1].Value = trailers.ToString();

Gridresultados.Rows[5].Cells[1].Value = buses.ToString();

//Turismos

vaciaclasi();

final $=$ Convert. ToInt32(TBturisH.Text $)-$ Convert.ToInt32(TBturisD.Text $)+1$;

for $(\mathrm{i}=0 ; \mathrm{i}<\mathrm{final} ; \mathrm{i}++)\{$ aleatorio = aleat.Next(Convert.ToInt32(TBturisD.Text), Convert.ToInt32(TBturisH.Text)); clasifica(Gridvehiculos.Rows[aleatorio].Cells[0].Value.ToString()); \}

//Añado los resultados a grid de resultados

Gridresultados.Rows[0].Cells[2].Value = motocicletas.ToString () ;

Gridresultados.Rows[1].Cells[2].Value = turismos.ToString () ;

Gridresultados.Rows[2].Cells[2].Value = furgonetas.ToString();

Gridresultados.Rows[3].Cells[2].Value = camiones.ToString () ;

Gridresultados.Rows[4].Cells[2].Value $=$ trailers.ToString ()

Gridresultados.Rows[5].Cells[2].Value = buses.ToString();

//Furgonetas

vaciaclasi();

final $=$ Convert. ToInt32(TBfurgoH.Text $)-$ Convert.ToInt32(TBfurgoD.Text $)+1$;

for $(\mathrm{i}=0 ; \mathrm{i}<$ final; $\mathrm{i}++)$

$\{$ aleatorio $=$ aleat.Next $($ Convert.ToInt32(TBfurgoD.Text $)$, Convert.ToInt32(TBfurgoH.Text $)$;

clasifica(Gridvehiculos.Rows[aleatorio].Cells[0].Value.ToString()); \}

//Añado los resultados a grid de resultados

Gridresultados.Rows[0].Cells[3].Value $=$ motocicletas.ToString () ;

Gridresultados.Rows[1].Cells[3].Value = turismos.ToString () ;

Gridresultados.Rows[2].Cells[3].Value = furgonetas.ToString () ;

Gridresultados.Rows[3].Cells[3].Value = camiones. ToString () ;

Gridresultados.Rows[4].Cells[3]. Value = trailers.ToString () ;

Gridresultados.Rows[5].Cells[3].Value = buses.ToString();

//Camiones 
vaciaclasi();

final $=$ Convert. ToInt32(TBcamionH.Text $)$ - Convert.ToInt32(TBcamionD.Text $)+1$;

for $(\mathrm{i}=0 ; \mathrm{i}<$ final $; \mathrm{i}++)\{$ aleatorio = aleat.Next(Convert.ToInt32(TBcamionD.Text), Convert.ToInt32(TBcamionH.Text));

clasifica(Gridvehiculos.Rows[aleatorio].Cells[0].Value.ToString()); \}

//Añado los resultados a grid de resultados

Gridresultados.Rows[0].Cells[4].Value $=$ motocicletas. ToString () ;

Gridresultados.Rows[1].Cells[4].Value $=$ turismos. ToString () ;

Gridresultados.Rows[2].Cells[4].Value $=$ furgonetas.ToString();

Gridresultados.Rows[3].Cells[4].Value = camiones. ToString( $)$;

Gridresultados.Rows[4].Cells[4].Value = trailers. ToString( $)$;

Gridresultados.Rows[5].Cells[4].Value = buses.ToString();

//Camión con Trailer

vaciaclasi();

final $=$ Convert.ToInt32(TBtrailerH.Text $)$ - Convert.ToInt32(TBtrailerD.Text $)+1$;

for $(\mathrm{i}=0 ; \mathrm{i}<\mathrm{final} ; \mathrm{i}++)$

$\{$ aleatorio $=$ aleat.Next $($ Convert.ToInt32(TBtrailerD.Text), Convert.ToInt32(TBtrailerH.Text) $)$;

clasifica(Gridvehiculos.Rows[aleatorio].Cells[0].Value.ToString()); \}

//Añado los resultados a grid de resultados

Gridresultados.Rows[0].Cells[5].Value $=$ motocicletas.ToString () ;

Gridresultados.Rows[1].Cells[5].Value $=$ turismos.ToString () ;

Gridresultados.Rows[2].Cells[5].Value = furgonetas.ToString();

Gridresultados.Rows[3].Cells[5].Value = camiones. ToString( $)$;

Gridresultados.Rows[4].Cells[5].Value = trailers.ToString () ;

Gridresultados.Rows[5].Cells[5].Value = buses.ToString();

//Autobuses

vaciaclasi();

final $=$ Convert. ToInt32(TBbusH.Text $)$ - Convert.ToInt32(TBbusD.Text $)+1$;

for $(\mathrm{i}=0 ; \mathrm{i}<\mathrm{final} ; \mathrm{i}++)\{$ aleatorio = aleat.Next(Convert.ToInt32(TBbusD.Text), Convert.ToInt32(TBbusH.Text));

clasifica(Gridvehiculos.Rows[aleatorio].Cells[0].Value.ToString());

\}

//Añado los resultados a grid de resultados

Gridresultados.Rows[0].Cells[6].Value = motocicletas.ToString () ;

Gridresultados.Rows[1].Cells[6].Value = turismos.ToString();

Gridresultados.Rows[2].Cells[6].Value = furgonetas.ToString () ; 
Gridresultados.Rows[3].Cells[6].Value = camiones. ToString () ;

Gridresultados.Rows[4].Cells[6]. Value = trailers.ToString () ;

Gridresultados.Rows[5].Cells[6].Value = buses.ToString();

\} private void Calcula() \{ int $\mathrm{i}$;

int ii;

Double a $1=0, \mathrm{~b} 1=0, \mathrm{a} 2=0, \mathrm{~b} 2=0$;

Double DAC1,DBAR1,MotDR,MotPre,DR2,Pre2;

Double DAC2, DBAR2, LigDR, LigPre, PesDR, PesPre;

Double DAC3, DBAR3, TurDR, TurPre, FurDR, FurPre;

Double DAC4, DBAR4, TcDR, TcPre, BusDR, BusPre;

Double DAC6, DBAR6, CamDR, CamPre, TtDR, TtPre; //PRIMERA DISCRIMINACIÓN

a1=Convert.ToInt32(Gridresultados.Rows[0].Cells[1].Value.ToString());

for $(\mathrm{i}=2 ; \mathrm{i}<7 ; \mathrm{i}++)\{\mathrm{b} 1=\mathrm{b} 1+$ Convert.ToInt32(Gridresultados.Rows[0].Cells[i].Value.ToString()); $\}$

for $(\mathrm{i}=1 ; \mathrm{i}<6 ; \mathrm{i}++)\{\mathrm{a} 2=\mathrm{a} 2+$ Convert.ToInt32(Gridresultados.Rows[i].Cells[1].Value.ToString());

\}

for $(\mathrm{i}=1 ; \mathrm{i}<6 ; \mathrm{i}++)$

$\{$ for $(\mathrm{ii}=2 ; \mathrm{ii}<7 ; \mathrm{ii}++)$

\{ b2=b2+Convert.ToInt32(Gridresultados.Rows[i].Cells[ii].Value.ToString());

\})

$\operatorname{DAC} 1=((\mathrm{a} 1+\mathrm{b} 2) /(\mathrm{a} 1+\mathrm{a} 2+\mathrm{b} 1+\mathrm{b} 2)) * 100 ;$

DBAR1 $=(0.5 *((\mathrm{a} 1 /(\mathrm{a} 1+\mathrm{b} 1))+(\mathrm{b} 2 /(\mathrm{a} 2+\mathrm{b} 2)))) * 100 ;$

$\operatorname{MotDR}=(\mathrm{a} 1 /(\mathrm{a} 1+\mathrm{a} 2)) * 100 ;$

MotPre $=(\mathrm{a} 1 /(\mathrm{a} 1+\mathrm{b} 1)) * 100$

$\mathrm{DR} 2=(\mathrm{b} 2 /(\mathrm{b} 1+\mathrm{b} 2)) * 100 ;$

Pre2 $=(\mathrm{b} 2 /(\mathrm{a} 2+\mathrm{b} 2)) * 100 ;$

\section{//SEGUNDA DISCRIMINACIÓN}

$\mathrm{a} 1=0 ; \mathrm{b} 1=0 ; \mathrm{a} 2=0 ; \mathrm{b} 2=0$

for $(\mathrm{i}=1 ; \mathrm{i}<3 ; \mathrm{i}++)\{$ for $(\mathrm{ii}=2 ; \mathrm{ii}<4 ; \mathrm{ii}++)$

$\{\mathrm{a} 1=\mathrm{a} 1+$ Convert.ToInt32(Gridresultados.Rows[i].Cells[ii].Value.ToString());

\} \}

for $(\mathrm{i}=1 ; \mathrm{i}<3 ; \mathrm{i}++)$

$\{$ for $(\mathrm{ii}=4 ; \mathrm{ii}<7$ ii ++$)$ 
$\{\mathrm{b} 1=\mathrm{b} 1+$ Convert.ToInt32(Gridresultados.Rows[i].Cells[ii].Value.ToString());

\} \}

for $(\mathrm{i}=3 ; \mathrm{i}<6 ; \mathrm{i}++)$

$\{$ for $(\mathrm{ii}=2 ; \mathrm{ii}<4 ; \mathrm{ii}++)$

$\{\mathrm{a} 2=\mathrm{a} 2+$ Convert.ToInt32(Gridresultados.Rows[i].Cells[ii].Value.ToString());

\} \}

for $(\mathrm{i}=3 ; \mathrm{i}<6 ; \mathrm{i}++)$

$\{$ for $(\mathrm{ii}=4$; $\mathrm{ii}<7$;i++)

$\{\mathrm{b} 2=\mathrm{b} 2+$ Convert.ToInt32(Gridresultados.Rows[i].Cells[ii].Value.ToString());

\})

$\mathrm{DAC} 2=((\mathrm{a} 1+\mathrm{b} 2) /(\mathrm{a} 1+\mathrm{a} 2+\mathrm{b} 1+\mathrm{b} 2)) * 100 ;$

$\operatorname{DBAR} 2=(0.5 *((\mathrm{a} 1 /(\mathrm{a} 1+\mathrm{b} 1))+(\mathrm{b} 2 /(\mathrm{a} 2+\mathrm{b} 2)))) * 100 ;$

$\operatorname{LigDR}=(\mathrm{a} 1 /(\mathrm{a} 1+\mathrm{a} 2)) * 100 ;$

LigPre $=(\mathrm{a} 1 /(\mathrm{a} 1+\mathrm{b} 1)) * 100 ;$

PesDR $=(\mathrm{b} 2 /(\mathrm{b} 1+\mathrm{b} 2)) * 100$;

PesPre $=(\mathrm{b} 2 /(\mathrm{a} 2+\mathrm{b} 2)) * 100 ;$

//TERCERA DISCRIMINACIÓN

$\mathrm{a} 1=0 ; \mathrm{b} 1=0 ; \mathrm{a} 2=0 ; \mathrm{b} 2=0 ;$

a1 = Convert.ToInt32(Gridresultados.Rows[1].Cells[2].Value.ToString());

b1 = Convert.ToInt32(Gridresultados.Rows[1].Cells[3].Value.ToString());

a2 = Convert.ToInt32(Gridresultados.Rows[2].Cells[2].Value.ToString());

b2 = Convert.ToInt32(Gridresultados.Rows[2].Cells[3].Value.ToString());

$\mathrm{DAC} 3=((\mathrm{a} 1+\mathrm{b} 2) /(\mathrm{a} 1+\mathrm{a} 2+\mathrm{b} 1+\mathrm{b} 2)) * 100 ;$

DBAR3 $=(0.5 *((\mathrm{a} 1 /(\mathrm{a} 1+\mathrm{b} 1))+(\mathrm{b} 2 /(\mathrm{a} 2+\mathrm{b} 2)))) * 100 ;$

$\operatorname{TurDR}=(\mathrm{a} 1 /(\mathrm{a} 1+\mathrm{a} 2)) * 100 ;$

TurPre $=(\mathrm{a} 1 /(\mathrm{a} 1+\mathrm{b} 1))^{*} 100$;

FurDR $=(\mathrm{b} 2 /(\mathrm{b} 1+\mathrm{b} 2)) * 100$

FurPre $=(\mathrm{b} 2 /(\mathrm{a} 2+\mathrm{b} 2)) * 100$;

\section{//CUARTA DISCRIMINACIÓN}

$\mathrm{a} 1=0 ; \mathrm{b} 1=0 ; \mathrm{a} 2=0 ; \mathrm{b} 2=0 ;$

for $(\mathrm{i}=3 ; \mathrm{i}<5 ; \mathrm{i}++)\{$ for $(\mathrm{ii}=4 ; \mathrm{ii}<6$; ii++)

$\{\mathrm{a} 1=\mathrm{a} 1+$ Convert.ToInt32(Gridresultados.Rows[i].Cells[ii].Value.ToString());

\} \} 


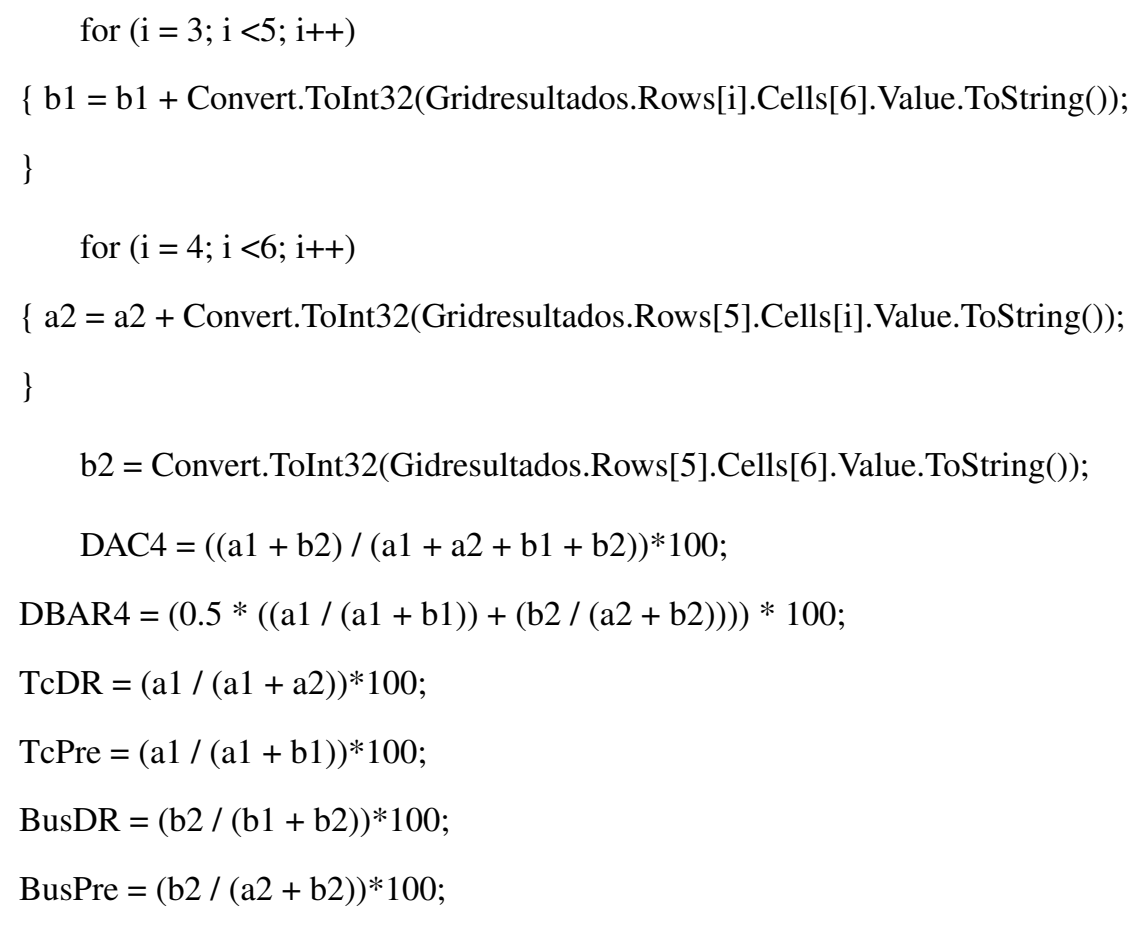

//SEXTA DISCRIMINACIÓN

$\mathrm{a} 1=0 ; \mathrm{b} 1=0 ; \mathrm{a} 2=0 ; \mathrm{b} 2=0 ;$

a1 = Convert.ToInt32(Gridresultados.Rows[3].Cells[4].Value.ToString());

b1 = Convert.ToInt32(Gridresultados.Rows[3].Cells[5].Value.ToString());

a2 = Convert.ToInt32(Gridresultados.Rows[4].Cells[4].Value.ToString());

b2 = Convert.ToInt32(Gridresultados.Rows[4].Cells[5].Value.ToString());

DAC6 $=((a 1+b 2) /(a 1+a 2+b 1+b 2)) * 100 ;$

DBAR6 $=(0.5 *((\mathrm{a} 1 /(\mathrm{a} 1+\mathrm{b} 1))+(\mathrm{b} 2 /(\mathrm{a} 2+\mathrm{b} 2)))) * 100 ;$

$\mathrm{CamDR}=(\mathrm{a} 1 /(\mathrm{a} 1+\mathrm{a} 2)) * 100 ;$

CamPre $=(\mathrm{a} 1 /(\mathrm{a} 1+\mathrm{b} 1)) * 100$;

$\mathrm{TtDR}=(\mathrm{b} 2 /(\mathrm{b} 1+\mathrm{b} 2)) * 100 ;$

$\operatorname{TtPre}=(\mathrm{b} 2 /(\mathrm{a} 2+\mathrm{b} 2)) * 100 ;$

Gridcalculos.Rows.Add(DAC1.ToString("\#\#\#.\#\#”),

DBAR1.ToString("\#\#\#.\#\#), MotDR.ToString("\#\#\#.\#”), MotPre.ToString("\#\#\#.\#\#”),

DR2.ToString("\#\#\#.\#\#”), Pre2.ToString("\#\#\#.\#\#), DAC2.ToString("\#\#\#.\#\#”, DBAR2.ToString("\#\#\#.\#\#”,

LigDR.ToString("\#\#\#.\#\#), LigPre.ToString(“\#\#.\#\#”), PesDR.ToString(”\#\#.\#\#”), PesPre.ToString("\#\#.\#\#”),

DAC3.ToString("\#\#\#.\#\#”), DBAR3.ToString("\#\#\#.\#\#”), TurDR.ToString("\#\#\#.\#\#”), TurPre.ToString("\#\#\#.\#\#”),

FurDR.ToString("\#\#\#.\#\#), FurPre.ToString("\#\#.\#\#”), DAC4.ToString("\#\#.\#\#”), DBAR4.ToString("\#\#.\#\#”),

TcDR.ToString("\#\#.\#\#”), TcPre.ToString("\#\#.\#\#”), BusDR.ToString("\#\#.\#\#”), BusPre.ToString("\#\#.\#\#”),

DAC6.ToString("\#\#\#.\#\#”), DBAR6.ToString("\#\#\#.\#\#”), CamDR.ToString("\#\#\#.\#\#), CamPre.ToString("\#\#\#.\#\#”), 


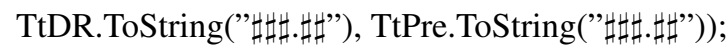

\} private void button1_Click(object sender, EventArgs e) $\{$ Barra.Value = 0;

Barra.Maximum = Convert.ToInt32(TBveces.Text);

Lbarra.Text = "Procesando...";

Lbarra.Refresh();

Gridcalculos.Rows.Clear();

for (int $\mathrm{a}=0 ; \mathrm{a}<$ Convert.ToInt32(TBveces.Text); $\mathrm{a}++$ ) \{ Procesa();

Gridresultados.Refresh();

Calcula();

Gridcalculos.Refresh();

Barra.Increment(1);

Barra.Refresh(); \} Lbarra.Text = "Fin de Proceso";

Lbarra.Refresh(); \}

private void Bexcel_Click(object sender, EventArgs e) $\{$ object oMissing = System.Reflection.Missing. Value;

Microsoft.Office.Interop.Excel.Application apl = new Microsoft.Office.Interop.Excel.ApplicationClass();

Workbook libro = apl.Workbooks.Open("C:

GruposTest.xlsx”, oMissing, oMissing, oMissing, oMissing, oMissing, oMissing, oMissing, oMissing, oMissing, oMissing, oMissing, oMissing, oMissing, oMissing);

Microsoft.Office.Interop.Excel. Worksheet sheet = (Microsoft.Office.Interop.Excel. Worksheet)libro.Sheets[1];

for (int $\mathrm{i}=0 ; \mathrm{i}<$ Gridcalculos.Columns.Count; $\mathrm{i}++$ )

$\{$ sheet.Cells $[1, \mathrm{i}+1]=$ Gridcalculos.Columns[i].HeaderText.ToString () ;

\}

// Create an array to multiple values at once.

for (int $\mathrm{a}=0 ; \mathrm{a}<$ Gridcalculos.Rows.Count-1; $\mathrm{a}++$ )

$\{$ for (int aa $=0$; aa $<$ Gridcalculos.Columns.Count; aa++)

$\{$ sheet.Cells $[\mathrm{a}+2$, aa +1$]=$ Gridcalculos.Rows[a].Cells[aa].Value.ToString().Replace(",,,,.’);

\} \}

apl. Visible $=$ true;

apl.UserControl = true; $\}$ \} $\}$ 



\section{Lista de acrónimos y símbolos}

$3 \mathrm{G}$

A/D

ACK

ADAS

ANSI

API

APD

ASCII

AVC

AVI

BBDD

BD

BIT

$\mathrm{BNC}$

BPS

BYTE

CAN

CCTV

CMOS

CRC
- Tercera Generación

- Analógico/Digital

- Acknowledge

- Advanced Driver Assistance Systems

- American National Standards Institute

- Application Programming Interface

- Avalanche Photodiodes

- American Standard Code for Information Interchange

- Automatic Vehicle Classification

- Automatic Vehicle Identification

- Bases de Datos

- Baudios

- Binary Digit

- Bayonet Neill-Concelman connector

- Bits Per Second

- Binary Tuple

- Controller Area Network

- Circuito Cerrado de Televisión

- Complementary Metal Oxide Semiconductor

- Cyclic Redundancy Checks 


\begin{tabular}{|c|c|c|}
\hline CTS & - & Cooperative Transport Systems \\
\hline CTV & - & Cámaras de Televisión \\
\hline CGT & - & Centro de Gestión de Tráfico \\
\hline $\mathrm{CPU}$ & - & Central Processing Unit \\
\hline $\mathrm{DAB}$ & - & Digital Audio Broadcasting \\
\hline DGT & - & Dirección General de Tráfico \\
\hline DSC & - & Digital Signal Controller \\
\hline DSP & - & Digital Signal Processor \\
\hline EEPROM & - & Electrically Erasable Programmable Read-Only Memory \\
\hline EETS & - & European Electronic Toll Service \\
\hline EM & - & Estación Meteorológica \\
\hline EIA & - & Electronic Industries Alliance \\
\hline EPROM & - & Erasable Programmable Read-Only Memory \\
\hline ETD & - & Estación de Toma de Datos \\
\hline ETSC & - & European Transport Safety Council \\
\hline ETX & - & End of Text \\
\hline ERU & - & Estación Remota Universal \\
\hline EURO NCAP & - & European New Car Assessment Programme \\
\hline FHWA & - & Federal Highway Administration \\
\hline FO & - & Fibra Óptica \\
\hline GPRS & - & General Packet Radio Service \\
\hline GSM & - & Global System for Mobile communications \\
\hline GUI & - & Graphical User Interface \\
\hline HW & - & Hardware \\
\hline $\mathrm{I}^{2} \mathrm{C}$ & - & Inter-Integrated Circuit \\
\hline I2I & - & Infrastructure to Infrastructure \\
\hline $\mathrm{I} / \mathrm{O}$ & - & Input/Output \\
\hline ID & - & Identifier \\
\hline
\end{tabular}




\begin{tabular}{|c|c|c|}
\hline IEEE & - & The Institute of Electrical and Electronics Engineers \\
\hline ILED & - & Infrared LED \\
\hline IMD & - & Intensidad Media Diaria \\
\hline IP & - & Internet Protocol \\
\hline IR & - & Infrared \\
\hline ITS & - & Intelligent Transport Systems \\
\hline ITU & - & International Telecommunication Union \\
\hline KMA & - & Knowledge Manager Administrator \\
\hline KSM & - & Knowledge Sharing Model \\
\hline KSS & - & Knowledge Sharing Sensor \\
\hline LED & - & Light Emitting Diode \\
\hline LS & - & Láser Escáner \\
\hline LWIR & - & Long Wavelength Infrared \\
\hline MCU & - & Microcontroller Unit \\
\hline MIPS & - & Million Instructions Per Second \\
\hline MPS & - & Multi Purpose Vehicle \\
\hline MUX & - & Multiplexor \\
\hline MWIR & - & Medium Wavelength Infrared \\
\hline NAK & - & Not Acknowledge \\
\hline NIR & - & Near Infrared \\
\hline NTCIP & - & National Transportation Communication for ITS Protocol \\
\hline OMS & - & Organización Mundial de la Salud \\
\hline ONU & - & Organización de las Naciones Unidas \\
\hline PCB & - & Printed Circuit Board \\
\hline PCMCIA & - & Personal Computer Memory Card International Association \\
\hline PLL & - & Phase Locked Loop \\
\hline PMV & - & Paneles de Mensaje Variable \\
\hline PIC & - & Programmable Intelligent Computer \\
\hline
\end{tabular}




\begin{tabular}{|c|c|c|}
\hline PIR & - & Passive InfraRed \\
\hline PWM & - & Pulse Width Modulated \\
\hline PyMES & - & Pequeñas y Medianas Empresas \\
\hline RAM & - & Random-Access Memory \\
\hline RDS & - & Radio Data System \\
\hline RDSI & - & Red Digital de Servicios Integrados \\
\hline RJ & - & Registration Jack \\
\hline SDH & - & Synchronous Digital Hierarchy \\
\hline SMS & - & Short Message Service \\
\hline SPI & - & Serial Peripheral Interface \\
\hline SPS & - & Samples Per Second \\
\hline SW & - & Software \\
\hline SWIR & - & Short Wavelength Infrared \\
\hline TA & - & Travel Announcements \\
\hline TCP & - & Transmission Control Protocol \\
\hline TDIDT & - & Top-Down Induction on Decision Trees \\
\hline TIA & - & Telecommunications Industry Association \\
\hline TIC & - & Tecnologías de la Información y las Comunicaciones \\
\hline TLS & - & Technical Delivery Terms for Route Stations \\
\hline TMC & - & Traffic Message Chanel \\
\hline TTL & - & Transistor-Transistor Logic \\
\hline ToF & - & Time of Flight \\
\hline UART & - & Universal Asynchronous Receiver Transmitter \\
\hline UIT & - & Unión Internacional de Telecomunicaciones \\
\hline UMTS & - & Universal Mobile Telecommunications System \\
\hline USB & - & Universal Serial Bus \\
\hline UVT & - & Unknown Vehicle Type \\
\hline V2I & - & Vehicle to infrastructure \\
\hline
\end{tabular}




$\begin{array}{lll}\text { V2V } & - & \text { Vehicle to vehicle } \\ \text { V2X } & - & \text { Vehicle to infrastructure/vehicle } \\ \text { VAO } & - & \text { Vehículos de Alta Ocupación } \\ \text { VLWIR } & - & \text { Very Long Wavelength Infrared } \\ \text { WAP } & - & \text { Wireless Application Protocol } \\ \text { WIFI } & - & \text { Wireless Fidelity } \\ \text { WIMAX } & - & \text { Worldwide Interoperability for Microwave Access } \\ \text { XML } & - & \text { Extensible Markup Language }\end{array}$





\section{Bibliografía}

[Acu03] Acuity, AccuRange 4000 Laser Rangefinder and AccuRAnge Line Scanner - User's Manual. Acuity a division of Schmitt Measurement Systems, Inc., revision 2.4 edición, September 2003.

[ADW98] Apte, C., Damerau, F. y Weiss, S., Text mining with decision trees and decision rules. C.M. University, ed., Conference on Automated Learning and Discovery, June 1998.

[AEM09] AEMET, Valores climatológicos normales. valencia. Agencia Estatal de Meteorología, 2009, URL http://www.aemet.es/es/elclima/ datosclimatologicos/valoresclimatologicos?l=8416 \&k= val. [Online; Último acceso Agosto 2009].

[AH05] Anant, V. y Hutchings, B., Digital signal controller applications. DSPFPGA.com Product Resource Guide, págs. 8-9, May 2005.

[AHG01] Abdelbaki, H., Hussain, K. y Gelenbe, E., A laser intensity image based automatic vehicle classification system. Intelligent Transportation Systems, 2001. Proceedings. 2001 IEEE, págs. 460-465, 2001, doi:10.1109/ITSC.2001.948701.

[AHS94] Ahmed, S.A., Hussain, T.M. y Saadawi, T.N., Active and passive infrared sensors for vehicular traffic control. Proceedings of IEEE Vehicular Technology Conference (VTC) VETEC-94, págs. 1393-1397, 1994.

[AJ99] Angelopoulou, E. y Jr., J.R.W., Laser Scanner Technology. Technical Report (CIS) MS-CIS-99-16, University of Pennsylvania. Department of computer and information science, 1999.

[Alu09] Aluja, T., Curso sobre árboles de decisión. 2009, URL http://www. Isi. upc.edu/ belanche/docencia/mineria/Apunts/Arbres.pdf. [Online; Último acceso Agosto 2009].

[Ame96] American National Standards Institute. National Safety Council, Itasca, Illinois, ANSI D16.1-1996: Manual on classification of motor vehicle traffic accidents. Sixth edición, 1996.

[Ame05] America, S.O.N., Installation Manual Tri-Tech TT 293, TT 295, TT 298. ASIM Technologies, Inc., 2005, URL http://www.asim-technologies . com/. Publication No. 19479800. 
[Arr08] Arranz, A., La gestión del tráfico. Jornada sobre la optimización en la gestión de carreteras, PROINTEC, 7 de Noviembre 2008.

[AYT08] AYTO, Sala de control de tráfico. Ajuntament de València. Regidoria de circulació, transports e infraestructures del transport, 2008, URL http://www.valencia.es/ayuntamiento2/ndprincipal. nsf/frtraficoc?openframeset. [Online: Último acceso Diciembre 2008].

[Ayu08] Ayuntamiento, Anuario 2008. Parque de vehículos. Informe técnico, Oficina de Estadística. Ayuntamiento de Valencia, 2008, URL http://www. valencia.es/ayuntamiento/anuario.nsf/fCategoriaVista? readForm\&nivel=6_2\&Vista=vListadoAnuario\&Categoria= Anuario_202008\&lang=1\&expand=4\&subexpandido= 1 \&bdorigen=ayuntamiento/estadistica.nsf. [Online; Último acceso Agosto 2009].

[Ban01] Bannatyne, R., The evolution of the digital signal controller. Embedded System Engineering, September 2001, URL http://www2 . electronicproducts.com/The_evolution_of_the_digital_ signal_controller-article-sepmot1-sep2001.aspx.

[BAS08] BAST, Description of the vehicle categories with code according to the tls. Bundesanstalt für Straßenwesen, 2008, URL http://www.bast.de/nn_ $43710 / \mathrm{EN} / \mathrm{e}-$ Home/e-homepage_node.html?_nnn=true. [Online: Último acceso Octubre 2008].

[BFOS84] Breiman, L. et al., Classification and Regresion Trees. New York, NY: Chapman and Hall, 1984, ISBN 0-412-04841-8.

[Bis06] Bishop, C.M., Pattern Recognition and Machine Learning. Information Science and Statics, New York: Springer, 2006, ISBN 0-387-31073-8.

[BKPS95] Balaguer, E. et al., Elementos de Ingeniería de Tráfico. Cátedra de Caminos y aeropuertos. Escuela Técnica Superior de Ingeniería de Caminos, Canales y Puertos. Universidad Politécnica de Madrid, 5ª edición, 1995, ISBN 847493091X.

[BMBL90] Butler, M.J.A. et al., Aplicación de la tecnología de percepción remota a las pesquerías marinas: manual introductorio. Documentos técnicos de pesca - T295 T0355/S, FAO, 1990. 9253026944.

[BOE00] BOE, Real Decreto 1947/2000, tomo 289, págs. 42.291-42.292. Boletín Oficial del Estado, 1 de Diciembre 2000.

[BOE03] BOE, Real Decreto 317/2003, tomo 80, págs. 12.847-12.851. Boletín Oficial del Estado. Ministerio de Administraciones Públicas, 3 de abril 2003.

[BOE04] BOE, Real Decreto 1599/2004, tomo 160, págs. 24.646-24.657. Boletín Oficial del Estado. Ministerio de Administraciones Públicas, 2 de Julio 2004. 
[BOE08] BOE, Real Decreto 11811/2008, tomo 171, págs. 31.041-31.054. Boletín Oficial del Estado, 11 de Julio 2008.

[BP01] Bargiela, A. y Peytchev, E., Intelligent transportation systems-towards integrated framework for traffic/transport telematics applications. Vehicular Technology Conference, 2001. VTC 2001 Fall. IEEE VTS 54 ${ }^{\text {th }}$, tomo 2: págs. 713-717 vol.2, 2001, doi:10.1109/VTC.2001.956863.

[Bui08] Buira, C., Los sistemas de gestión para la movilidad urbana. Boletic, págs. 6165, Junio 2008.

[CBU ${ }^{+97] ~ C a r v e l l, ~ J . D . ~ e t ~ a l ., ~ F r e e w a y ~ M a n a g e m e n t ~ H a n d b o o k . ~ I n f o r m e ~ t e ́ c n i c o, ~ U S ~}$ Department of Transportation. Federal Highway Transportation, Texas, August 1997. Report Number: FHWA-SA-97-064.

[CCM07] Cevher, V., Chellappa, R. y McClellan, J., Joint acoustic-video fingerprinting of vehicles, part $i$. Acoustics, Speech and Signal Processing, 2007. ICASSP 2007. IEEE International Conference on, tomo 2: págs. 745-748, April 2007, ISSN 1520-6149, doi:10.1109/ICASSP.2007.366343.

[CE94] CE, The fourth framework program 1994-98. Comisión Europea, 1994, URL http://ec.europa.eu/research/specpr.html. [Online: Último acceso Noviembre 2008].

[CE07] CE, The seventh framework program 2007-13. Comisión Europea, 2007, URL http://cordis.europa.eu/fp7/home_en.html. [Online: Último acceso Noviembre 2008].

[CGSC] Cevher, V. et al. Acoustics, Speech and Signal Processing, 2007. ICASSP 2007. IEEE International Conference on, April, ISSN 1520-6149, doi:10.1109/ ICASSP.2007.366344.

[Coc77] Cochran, W.G., Sampling Techniques. Wiley Series in Probability and Mathematical Statistics. Applied probability and statistics, New York: John Wiley and Sons, 3a edición, 1977, ISBN 0-471-16240-X.

[COO06] COOPERS, Cooperative systems for intelligent road safety. European Commission. DG Information Society and Media. Esafety, February 2006, URL http: / /www. coopers-ip. eu/. [Online: Último acceso Enero 2009].

[Cor04] Correa, J.C., Método bayesiano bootstrap y una aplicación en la estimación del percentil 85 en ingeniería de tránsito. Revista Colombiana de Estadística, tomo 27 (2): págs. 99-107, Diciembre 2004.

$\left[\mathrm{CSP}^{+} 01\right] \quad$ Cheng, $\mathrm{H}$. et al., A real-time laser-based detection system for measurement of delineations of moving vehicles. Mechatronics, IEEE/ASME Transactions on, tomo 6 (2): págs. 170-187, Jun 2001, ISSN 1083-4435, doi:10.1109/3516. 928732 . 
$\left[\mathrm{CSP}^{+} 05\right] \quad$ Cheng, H.H. et al., Development and field test of a laser-based nonintrusive detection system for identification of vehicles on the highway. Intelligent transportation systems, IEEE Transactions on, tomo 6 (2): págs. 147-155, 2005.

[CVI06] CVIS, Cooperative vehicle-infrastructure systems. European Commission. DG Information Society and Media. Esafety, January 2006, URL http://www . cvisproject. org//. [Online: Último acceso Enero 2009].

[CVP08] CVPR, Ieee computer society conference on computer vision and pattern recognition (cvpr). IEEE Computer Society, 2008, URL http://www . cvpr2009.org/previous-years. [Online; Último acceso Noviembre 2009].

[CZYH03] Chen, Q. et al., Self-triggering pulsed time-of-flight laser range-finding method. Optical Engineering, tomo 42 (12): págs. 3608-3611, 2003, doi:10.1117/1. 1621407.

[Día07] Díaz, Z., Predicción de crisis empresariales en seguros no vida, mediante árboles de decisión y reglas de clasificación. Colección: Línea 3000, Editorial Complutense, 2007, ISBN 8474918820.

[DGT03] DGT, Seguridad Vial en España: Informe 2003. Dirección General de Tráfico, 2003. NIPO: 128-05-122-1. ISSN: 1576-8708.

[DGT06a] DGT, Las principales cifras de la siniestralidad vial. Dirección General de Tráfico. Observatorio Nacional de la Seguridad Vial, 2006. NIPO: 128-06-083-4.

[DGT06b] DGT, Plan Estratégico de Seguridad Vial 2005-2008. Dirección General de Tráfico, 2006. NIPO: 128-06-012-6.

[DGT07] DGT, Series históricas: Parque de vehículos. Dirección General de Tráfico, Diciembre 2007, URL http://www.dgt.es/portal/es/seguridad_ vial/estadistica/parque_vehiculos/series_historicas_ parque/. [Online: ?ltimo acceso Agosto 2009].

[DGT08a] DGT, Centros de gestión de tráfico. Dirección General de Tráfico, 2008, URL http://www.dgt.es/portal/es/la_dgt/estructura_ organica/centros_gestion/funciones_cgt.htm. [Online: Último acceso Diciembre 2008].

[DGT08b] DGT, Plan de actuaciones de seguridad vial, 2008. Dirección General de Tráfico, Diciembre 2008, URL http://www.dgt.es/portal/es/seguridad_ vial/planes_seg_vial/. [Online: Último acceso Diciembre 2008].

[DGT08c] DGT, Series históricas: Parque de vehículos. Dirección General de Tráfico, Diciembre 2008, URL http://www.dgt.es/portal/es/seguridad_ vial/estadistica/parque_vehiculos/series_historicas_ parque/. [Online: Último acceso Noviembre 2009]. 
[DGT09a] DGT, Accidentes de tráfico en zona urbana en españa, 2008. Dirección General de Tráfico. Observatorio Nacional de Seguridad Vial, 2009, URL http://www.dgt.es/was6/portal/contenidos/ documentos/seguridad_vial/estudios_informes/Informe_ accidentalidad_urbana_2008.pdf. [Online: Último acceso Noviembre 2009].

[DGT09b] DGT, Portal de educación vial. Dirección General de Tráfico, Junio 2009, URL http://www.dgt.es/educacionvial/DGT_Home_Buscar_ .html.

[DGT09c] DGT, Resultados del programa pin sobre seguridad vial. Dirección General de Tráfico, Junio 2009.

[EC03] EC, Programa de acción europeo de seguridad vial. Comunicación de la Comisión. Comisión de las Comunidades Europeas, 2 de Junio 2003. $\operatorname{COM}(2003) 311$ Final.

[EC08] EC, European road safety day 2008. Comisión de las Comunidades Europeas, 2008, URL http://ec.europa.eu/transport/roadsafety/ road_safety_days/index_2008_en.htm. [Online: Último acceso Julio 2008].

[EFK09] EFKON, Ae titan 3000. EFKON AG, 2009, URL http: / / www . efkon. com/ docs/TD_si_AE_TITAN_01E03.pdf. [Online; Último acceso Agosto 2009].

[Ele09] Electronic, W., Classification detector mc2024. Weiss Electronic GmBH, 2009, URL http://www.weiss-electronic.de/englisch/03_ komponenten/03_03_03_mc-2024.htm. [Online; Último acceso Agosto 2009].

[EU02] EU, Libro Blanco: Política Europea de Transportes de cara al 2010: la hora de la verdad. Luxemburgo: Comisión Europea. Oficina de Publicaciones Oficiales de las Comunidades Europeas, 2002, ISBN 92-894-0337-3.

[EU04] EU, Directive 2004/52/ec of the european parliament and of the council. Oficial Journal of the European Union, 29 April 2004. L 166/124.

[Eur09] EuroNCAP, Euro ncap vehicle types. European New Car Assessment Programme, 2009, URL http://www. euroncap.com/. [Online; Último acceso Enero 2009].

[FD04] Fuerstenberg, K. y Dietmayer, K., Object tracking and classification for multiple active safety and comfort applications using a multilayer laser scanner. Intelligent Vehicles Symposium, 2004 IEEE, págs. 802-807, June 2004, doi: 10.1109/IVS.2004.1336487.

[FEZM05] Floreano, D. et al., Evolution of spiking neural circuits in autonomous mobile robots. International Journal of Intelligent Systems, tomo XX: págs. 100-123, February 2005. 
[FHW01] FHWA, Traffic Monitoring Guide. Executive Summary. Informe técnico, US Department of Transportation. Federal Highway Transportation. Office of Highway Policy Information, May 2001, URL http://www. fhwa.dot. gov/ohim/tmguide/. Report Number: FHWA-PL-01-021.

[FHW08] FHWA, Fhwa vehicle types. Federal HighWay Administration, 2008, URL http: //www. fhwa.dot.gov/policy/ohpi/vehclass.htm. [Online: Último acceso Octubre 2008].

[FK99] Friedman, M. y Kandel, A., Introduction to Pattern Recognition: statistical, structural, neural and fuzzy logic approaches, tomo 32 de Machine Perception and Artificial intelligence. Singapore: World Scientific, 1999, ISBN 9810233124.

[FM04] Friedman, E. y Miller, J.L., Photonics Rules of Thumb: Optics, Electro-optics, Fiber Optics, and Lasers. New York: USA: McGraw-Hill Professional, 2a edición, 2004, ISBN 0-07-138519-3.

[FMZW07] Fang, J. et al., A low-cost vehicle detection and classification system based on unmodulated continuous-wave radar. Intelligent Transportation Systems Conference, 2007. ITSC 2007. IEEE, págs. 715-720, 30 October 2007, doi: 10.1109/ITSC.2007.4357739.

[For00] Forum, U.I., Universal Serial Bus Specification. Recomendación USB Revision 2.0, Compaq Computer Corporation, Hewlett-Packard Company, Intel Corporation, Lucent Technologies Inc, Microsoft Corporation, NEC Corporation, Koninklijke Philips Electronics N.V., Abril 2000, URL http://www.usb. org/developers/docs/. [Online: Último acceso Marzo 2009].

[FR08] Fink, A. y Rothlauf, F., eds., Advances in Computational Intelligence in Transport, Logistics, and Supply Chain Management, tomo 144 de Studies in Computational Intelligence, capítulo Real time identification of road traffic control measures: I-4. Berlin: Springer, 1a edición, 2008, ISBN 978-3-54069024-5.

[Fre09] Freescale, Digital signal controller products. Freescale Semiconductor, 2009, URL http://www.freescale.com/webapp/sps/site/ overview. jsp? code=GS-MCUPRODOVDSC\&fsrch=1. [Online: Último acceso Febrero 2009].

[Gan04] Ganssle, J., The Firmware Handbook. Embedded Technology, Elsevier, 2004, ISBN 0-75067-606-X.

[Gar00] García, L.A., Diseño e implementación de una arquitectura multiagente para la ayuda a la toma de decisiones en un sistema de control de tráfico urbano. Tesis Doctoral, Departamento de Informática. Universidad Jaime I, Castellón de la Plana. España, 2000. Director: Dr. Francisco Toledo Lobo. 
[GGM05] Gallego, N., Gómez, L.E. y Mocholí, A., Sistema láser para detección y clasificación de vehículos en múltiples carriles. XII Seminario Anual de Automática, Electrónica Industrial e Instrumentación (SAAEI),2005. Congreso en., Septiembre 2005.

[Gib08] Gibson, D., Making signal systems work for cyclists. Public roads, tomo 71 (6), May/June 2008, URL http://www.tfhrc.gov/pubrds/08may/02. htm. [Online: Último acceso Septiembre 2008].

[Gil05] Gil, J., Aplicación del método bootstrap al contraste de hipótesis en la investigación educativa. Revista de educación, págs. 251-265, 2005, ISSN 00348082.

[Gil09] Ángel Gil, Muestreo. universitat oberta de catalunya, 2009. P03/75057/01005.

[Góm05] Gómez, L.E., Contribución al diseño e implementación de un sistema de detección y clasificación de vehículos con tecnología láser, mediante método estadístico y redes neuronales. Tesis Doctoral, Departamento de Ingeniería Electrónica. Universidad Politécnica de Valencia, Valencia. España, 2005. Directores: Antonio Mocholí y José Millet.

[Góm06] Gómez, N.R., Evaluación del uso de Autoscope para conteos automáticos de vehículos en intersecciones. Master en ingeniería, Universidad de Puerto Rico, Mayagüez, 2006.

[GMA $\left.{ }^{+} 07\right]$ Gallego, N. et al., Explotación de las infraestructuras actuales en entornos urbanos para aplicaciones its. VII congreso español en Sistemas de Inteligentes de Transporte, Valencia., 18-20 Septiembre 2007.

[GMMA08] Gallego, N. et al., Sensores inteligentes cooperativos aplicados al sector de tráfico: el láser escáner. Ciencia y Tecnología en la frontera, págs. 166-174, 2008, ISSN 1665-9775.

[GMMP02] Gupte, S. et al., Detection and classification of vehicles. Intelligent Transportation Systems, IEEE Transactions on, tomo 3 (1): págs. 37-47, March 2002, ISSN 1524-9050, doi:10.1109/6979.994794.

[GV04] Gobierno-Vasco, Sistema de gestión de tráfico interurbano y cgt de euskadi. Departamento de Interior, 2004, URL http://www9.euskadi.net/ o82 / o 82 WebServlet? accion=10\&id=24 \&ident $=168$ \&tag= PagDescProyecto. [Online: Último acceso Diciembre 2008].

[GV07] Gobierno-Vasco. Departamento de Interior, 2007, URL http://www . trafikoa. net/public/wps/portal/trafico. [Online: Último acceso Diciembre 2008].

[Har01] Harlow, C., Automatic vehicle classification system with range sensors. Transportation research. Part C: Emerging Technologies, tomo 9 (4): págs. 231247, August 2001. 
[HM05] Hussain, K. y Moussa, G., Automatic vehicle classification system using range sensor. Information Technology: Coding and Computing, 2005. ITCC 2005. International Conference on, tomo 2: págs. 107-112, April 2005, doi:10.1109/ ITCC.2005.96.

[HSA93] Hussain, T., Saadawi, T. y Ahmed, S., Overhead infrared sensor for monitoring vehicular traffic. Vehicular Technology, IEEE Transactions on, tomo 42 (4): págs. 477-483, November 1993, ISSN 0018-9545, doi:10.1109/25.260764.

[Ibe09] Ibeo, Ibeo lux. Ibeo Automobile Sensor, 2009, URL http: / / www . ibeo-as . com/english/products_ibeolux.asp. [Online: Último acceso Abril 2009].

[IJR04] Iske, B., Jager, B. y Ruckert, U., A ray-tracing approach for simulating recognition abilities of active infrared sensor arrays. Sensors Journal, IEEE, tomo 4 (2): págs. 237-247, April 2004, ISSN 1530-437X.

[Inc00] Incorporated, A.R., AccuRange 4000. User's manual. Acuity Research Incorporated, 2000, URL http://www. acuitylaser.com/spanish. htm. [Online: Último acceso Octubre 2008].

[Ind02] Indent, D.A., LMS 221. Laser Measurement Systems. Technical Description. SICK AG., Reute, Germany, 2002, URL http://www.sick.com/home/ en.html. 8008 970/01 2002 WU.Sm.

[Ins98] Instruments, T., Data Sheet: SN75179B. Texas Instruments Incorporated, Post Office Box 655303, Dallas, Texas 75265, review edición, June 1998.

[Ins04] Instruments, T., Data Sheet: MAX232. Texas Instruments Incorporated, Post Office Box 655303, Dallas, Texas 75265, review edición, March 2004.

[IRK02] Ivanov, B., Ruser, H. y Kellner, M., Presence detection and person identification in smart homes. International Conference in Sensors and Systems. St. Petersburg, 2002.

[ITS08a] ITS. ITS España. Ministerio de Ciencia y Tecnología, 2008, URL http: // www. itsspain. com/itsspain/. [Online: Último acceso Agosto 2009].

[ITS08b] ITS. Ertico. ITS Europe, 2008, URL http: / / www . ertico. com/. [Online: Último acceso Octubre 2009].

[ITS09a] ITS. ITS Japan, 2009, URL http://www.its-jp.org/english/. [Online: Último acceso Noviembre 2009].

[ITS09b] ITSA. Intelligent Transportation Society of America, 2009, URL http: // http: / / www . itsa. org/. [Online: Último acceso Noviembre 2009].

[ITU96] ITU, V.11 - Características eléctricas de los circuitos de enlace simétricos de doble corriente que funcionan con velocidades binarias de hasta $10 \mathrm{Mbit} / \mathrm{s}$. Recomendación UIT-T v.11 Serie V: Comunicación de datos por la red telefónica, Union Internacional de Telecomunicaciones. Sector de Normalización de las 
Telecomunicaciones, October 1996, URL http://www.itu.int/rec/ T-REC-V.11-199303-S/es. [Online: Último acceso Marzo 2009].

[ITU00] ITU, V.24 - Lista de definiciones para los circuitos de enlace entre el equipo terminal de datos y el equipo de terminación del circuito de datos. Recomendación UIT-T v.24 Serie V: Comunicación de datos por la red telefónica, Union Internacional de Telecomunicaciones. Sector de Normalización de las Telecomunicaciones, February 2000, URL http://www.itu.int/rec/ T-REC-V.24-200002-I/es. [Online: Último acceso Marzo 2009].

[JDJ00] Jain, A.K., Duin, R.P.W. y Jianchang, M., Statistical pattern recognition: A review. Pattern Analysis and Machine Intelligence, IEEE Transactions on, tomo 22 (1): págs. 4-37, Jan 2000, ISSN 0162-8828, doi:10.1109/34.824819.

[JLLM08] Jung, S. et al., Development of wireless interface signal control system for dynamic and optimal management based on dsrc. Networked Computing and Advanced Information Management, 2008. NCM '08. Fourth International Conference on, tomo 2: págs. 389-393, September 2008, doi:10.1109/NCM. 2008.109.

[JMS07] Jerbi, M., Marlier, P. y Senouci, S.M., Experimental assessment of V2V and V2I communications. Mobile Adhoc and Sensor Systems, 2007. MASS 2007. IEEE Internatonal Conference on, págs. 1-6, October 2007, doi:10.1109/MOBHOC. 2007.4428739.

[KEW94] Korba, L., Elgazzar, S. y Welch, T., Active infrared sensors for mobile robots. Instrumentation and Measurement, IEEE Transactions on, tomo 43 (2): págs. 283-287, April 1994, ISSN 0018-9456.

[KHY05] Kuo, C.H., Huang, F.C. y Yang, F.C., Development of active ir-based surgical marker tracking and positioning systems. Systems, Man and Cybernetics, 2005 IEEE International Conference on, tomo 3: págs. 2443-2448, October 2005.

[Kis65] Kish, L., Survey Sampling. Wiley classics library, New York: John Wiley and Sons, published 1995 edición, 1965, ISBN 0-471-48900-X.

[KKMKS02] Keßel, A. et al., A concept for coupling empirical data and microscopic simulation of pedestrian flows. Monitoring and management of Visitor Flows in Recreational and Protected Areas. Conference on, págs. 199-204, 2002. Bodenkultur University, Vienna, Austria.

[Kle01a] Klein, L.A., Sensor technologies and data requirements for ITS, capítulo Traffic Flow Sensor Technologies: 5. London: Artech House, 2001, ISBN 1-58053-077$\mathrm{X}$.

[Kle01b] Klein, L.A., Sensor technologies and data requirements for ITS, capítulo Sensors in modern Traffic Management Systems:1. London: Artech House, 2001, ISBN $1-58053-077-X$. 
[KM06] Koch, M.W. y Malone, K.T., A sequential vehicle classifier for infrared video using multinomial pattern matching. Computer Vision and Pattern Recognition Workshop, 2006. CVPRW '06. Conference on, págs. 127-127, June 2006, doi: 10.1109/CVPRW.2006.21.

[KMG06] Klein, L.A., Mills, M.K. y Gibson, D.R., Traffic Detector Handbook. Informe técnico, US Department of Transportation. Federal Highway Transportation, October 2006. Publication No. FHWA-HRT-06-108.

[KR09] Kauvo, K. y Roessler, B., Laserscanner data processing for motorcycle adas. $6^{\text {th }}$ International Workshop on Intelligent Transportation, 2009. Proceedings. WIT 2009, págs. 39-44, 24-25 March 2009.

[Las06] LaserScan, O., Autosense AS800. Series User guide. OSI LaserScan, Orlando, FL, USA., 2006, URL http://www.osi-ls.com/. Publication No. 19479800.

[LE04] López, A. y Elosua, P., Estimación bootstrap para el coeficiente de determinación: un estudio de simulación. Revista Electrónica de Metodología Aplicada, tomo 9 (2): págs. 1-14, 2004.

[LM75] Levinstein, H. y Mudar, J., Infrared detectors in remote sensing. Proceedings of the IEEE, tomo 63 (1): págs. 6-14, January 1975.

[Mar07] Martínez, C., Estadística básica aplicada. Colección Textos Universitarios, ECOE Ediciones, tercera edición, 2007, ISBN 9586484580.

[Mat04] Matthews, S.J., Thermal imaging on the rise. Laser Focus World, tomo 40 (3): págs. 105-109, March 2004, ISSN 1043-8092.

[Mat09] The Mathworks, Inc., Natick, MA, Statistics Toolbox 7. User's Guide. Version 7.1 (released 2009b) edición, March 2009.

[McC94] McClure, W.F., Near-infrared spectroscopy. the giant is running strong. Analytical chemistry, tomo 66 (1): págs. 43-, January 1994.

[MCG98] Cal-y Mayor, R. y Cárdenas Grisales, J., Ingeniería de Tránsito: Fundamento y aplicaciones. México: Alfaomega, 7ª edición, Octubre 1998, ISBN 958-682-103$\mathrm{X}$.

[MET09] METROCOUNT, Traffic executive software. MetroCount, 2009, URL http : / / www. metrocount. com/products/mte/index.html. [Online; Último acceso Agosto 2009].

[MFW03] Martin, P.T., Feng, Y. y Wang, X., Detector Technology Evaluation. Technical report, Department of Civil and Environmental Engineering University of Utah Traffic Lab, November 2003, URL http://www.mountain-plains. org/pubs/html/mpc-03-154/. MPC Report number 03-154. Last Access November 2008. 
[MGM08a] Menéndez, M., Gallego, N. y Mocholí, A., Frontend para aplicaciones de sistemas its: Interfaz gráfico. XV Seminario Anual de Automática, Electrónica Industrial e Instrumentación. SAAEI 08. Actas del SAAEI 2008, September 2008.

[MGM08b] Menéndez, M., Gallego, N. y Mocholí, A., Frontend para aplicaciones de sistemas its: Interfaz gráfico. I Congreso Internacional de Mecatrónica y II Congreso Nacional de Universidades Politécnicas. Actas del congreso, Abril 2008, ISSN ISSN: 1665-9775.

[MGM09] Menéndez, M., Gallego, N. y Mocholí, A., Software de procesado y clasificación en tiempo real de un sensor láser para la detección y clasificación de vehículos. IX Congreso ITS Español (ITS 09), junio 2009.

[MGR02] Middlenton, D., Gopalakrishna, D. y Raman, M., Advances in Traffic Data Collection and Management, White Paper. Informe técnico, Office of Policy. Federal Highway Administration, Washington, DC, December 2002. Work Order Number BAT-02-006.

[MHC05] Meier, R., Harrington, A. y Cahill, V., Framework for integrating existing and novel intelligent transportation systems. Intelligent Transportation Systems, 2005. Proceedings. 2005 IEEE, págs. 154-159, September 2005, doi:10.1109/ ITSC.2005.1520124.

[Mic01] Michalopoulos, P., Review of non-intrusive advanced sensor devices for advanced traffic management systems and recent advances in video detection. Proceedings of the Institution of Mechanical Engineers. Proceedings part L, Journal of materials, design and applications, tomo 215 (4): págs. 345-355, 2001, ISSN 1464-4207.

[Mic05] Microchip, Data Sheet: dsPIC30F4011/4012. Microchip Technology Inc., 2355 West Chandler Blvd., Chandler, AZ 85224-6199, preliminary edición, 2005.

[Mic09] Microsoft, Msdn library: Guidelines for applications. MSDN, 2009, URL http: / /msdn.microsoft.com/en-us/library/aa373651.aspx. [Online: Último acceso Marzo 2009].

[MK07] Mimbela, L.E. y Klein, L.A., A Summary of Vehicle Detection and Surveillance Technologies used in Intelligent Transportation Systems. Informe técnico, The Vehicle Detector Clearinghouse and US Department of Transportation. Federal Highway Transportation, August 2007.

$\left[\mathrm{MKH}^{+}\right.$06] McDonald, M. et al., Intelligent Transport Systems in Europe: Opportunities for Future Research. Singapore: World Scientific Publishing Co. Ltd., October 2006, ISBN 978-981-270-082-7.

[MKM99] Matsuo, T., Kaneko, Y. y Matano, M., Introduction of intelligent vehicle detection sensors. Intelligent Transportation Systems, 1999. International Conference on IEEE/IEEEJ/JSAI, págs. 709-713, 1999, doi:10.1109/ITSC.2005.1520124. 
[MMP04] Martínez, A., Muñoz, J. y Pascual, A., eds., Tamaño de muestra y precisión estadística, tomo 23 de Monografías: Ciencia y Tecnología. Universidad de Almería, iii edición, 2004, ISBN 84-8240-711-2.

[MnD97] MnDoT, Field Test of monitoring of urban vehicle operations using non-intrusive technologies. Technical Report FHWA-PL-97-018, Minnesota Department of Transportation and SRF Consulting Group, Inc. (SRF), May 1997.

[MPC98] Mocholi, A., Pérez, C. y Capilla, R., Optoelectrónica: Conceptos y componentes básicos. Valencia. España: Servicio Publicaciones de la Universidad Politécnica de Valencia, 1998. Ref.:2002.981.

[MSJ97] Middlenton, D., Shaffer, M. y Jasek, D., Initial Evaluation of the Existing Technologies for Vehicle Detection. Informe técnico, Texas Transportation Institute, College Station, Texas, TX, October 1997. Report Number: FHWA/TX99/1715-1.

[MST94] Michien, D., Spiegelhalter, D. y Taylor, C., Machine learning, neural and statistical classification. February 1994.

[Ni07] Ni, D., Determining traffic-flow characteristics by definition for application in its. Intelligent Transportation Systems, IEEE Transactions on, tomo 8 (2): págs. 181-187, June 2007, ISSN 1524-9050, doi:10.1109/TITS.2006.888621.

[Ni196] Nilsson, N.J., Introduction to machine learning, December 1996. Early draft of a proposed textbook.

[Noe08] Noergaard, T., Embedded board buses and i/o. Embedded Hardware: Know it all, capítulo 4, pág. 770, Amsterdam: Elsevier/Newnes, 2008, ISBN 0-75068-583-2.

[Nor06] Norma, N., El exceso de velocidad duplica la mortalidad. Tráfico y Seguridad Vial, tomo año XXII (177): págs. 24-25, Marzo-Abril 2006, ISSN 1886-3566.

[NPK03] Nissinen, J., Palojarviand, P. y Kostamovaara, J., A cmos receiver for a pulsed time-of-flight laser rangefinder. Solid-State Circuits Conference, 2003. ESSCIRC '03. Proceedings of the $29^{\text {th }}$ European, págs. 325-328, September 2003, doi:10.1109/ESSCIRC.2003.1257138.

[NTC09] NTCIP, National transportation communications for its protocol. 2009, URL http: / / www. ntcip.org/info/. [Online; Último acceso Agosto 2009].

[Oda07] Oda, T., Signal control by successive updating of control parameters based on prediction of traffic flow. Electrical Engineering in Japan, tomo 161 (3): págs. 49-57, July 2007, ISSN 1520-6416.

[ONU04] ONU, Resolución aprobada por la asamblea general en la 84a sesión plenaria. Organización de Naciones Unidas, 11 de Mayo 2004. A/RES/58/289.

[ONU07] ONU, Primera semana mundial de las naciones unidas para la seguridad vial. Organización de Naciones Unidas, 23-29 de Abril 2007, URL http: / /www . who. int/roadsafety/week/es/. [Online: Último acceso Julio 2008]. 
[ONU09] ONU, Primera conferencia global de ministros sobre seguridad vial. Organización de Naciones Unidas, 19-20 de Noviembre 2009, URL http://www.who.int/roadsafety/ministerial_conference/ en/index.html. [Online: Último acceso Noviembre 2009].

[Ott06] Otto, C.W., Development of a Mobile Vehicle Classification System. Bachelor of engineering electrical and electronic, University of Southern Queensland. Faculty of Engineering and Surveying, November 2006.

[Pha06] Pham, H., ed., Springer Handbook of Engineering Statistics. London: SpringerVerlag, 2006, ISBN 1-85233-806-7.

[PIA07] PIARC, Technical dictionary of road terms, validated by the members of the technical and terminology committees of piarc. World Road Association (PIARC), September 2007, URL http: / / termino . piarc . org/. [Online: Último acceso Octubre 2008].

[PPK06] Pehkonen, J., Palojarvi, P. y Kostamovaara, J., Receiver channel with resonancebased timing detection for a laser range finder. Circuits and Systems I: Regular Papers, IEEE Transactions on, tomo 53 (3): págs. 569-577, March 2006, ISSN 1549-8328, doi:10.1109/TCSI.2005.858758.

[PRK05] Palojarvi, P., Ruotsalainen, T. y Kostamovaara, J., A 250-mhz bicmos receiver channel with leading edge timing discriminator for a pulsed time-of-flight laser rangefinder. Solid-State Circuits, IEEE Journal of, tomo 40 (6): págs. 13411349, June 2005, ISSN 0018-9200, doi:10.1109/JSSC.2005.848022.

[PSS $\left.{ }^{+} 04\right]$ Peden, M. et al., World Report on Road Traffic Injury Prevention. Geneva, Switzerland: World Health Organization, 1- edición, 2004, ISBN 92-4-156260-9.

[Raz96] Razeghi, M., Long wavelength infrared detectors. Optoelectronic properties of semiconductors and superlattices ; 1, Amsterdam: Gordon and Breach Science Publishers, 1996, ISBN 2884492089.

[RC02] Rogalski, A. y Chrzanowski, K., Infrared devices and techniques. Opto-Electron. Rev., tomo 10 (2): págs. 111-136, 2002.

[Rip97] Ripley, B.D., Pattern Recognition and Neural Networks. Cambridge, UK: Cambridge University Press, 1997, ISBN 0-521-46086-7.

[RKS89] Rahkonen, T., Kostamovaara, J. y Saynajakangas, S., A cmos asic time-to-digital converter for short time interval measurements. Circuits and Systems, 1989., IEEE International Symposium on, tomo 3: págs. 2092-2095, May 1989, doi: 10.1109/ISCAS.1989.100787.

[Rod03] Rodríguez, J.I., Cómo ser un conductor bien informado. Tráfico y Seguridad Vial, tomo año XIX (158): págs. 38-39, Enero-Febrero 2003, ISSN 1886-3566.

[Rog00] Rogalski, A., Infrared Detectors, tomo 10 de Electrocomponent Science Monographs. Gordon and Breach Science Publishers, 2000, ISBN 90-5699-2031. 
[Rog03] Rogalski, A., Infrared detectors: status and trends. Progress in Quantum Electronics, tomo 27 (2-3): págs. 59-, 2003.

[RPA00] Ramsay, E.D., Prem, H. y Austroads., Development of an Austroads heavy vehicle nomenclature system: discussion paper. AUSTROADS publication; $\mathrm{n}^{\circ}$. AP-R174/00, Austroads, Sydney, N.S.W., 2000, ISBN 0855885602. Prepared by Euan Ramsay and Hans Prem.

[SAF06] SAFESPOT, Cooperative vehicles and road infrastructure for road safety. European Commission. DG Information Society and Media. Esafety, February 2006, URL http: //www. safespot-eu.org/pages/page.php. [Online: Último acceso Enero 2009].

[SBM04] Sun, Z., Bebis, G. y Miller, R., On-road vehicle detection using optical sensors: A review. Intelligent Transportation Systems, 2004. Proceedings. The $7^{\text {th }}$ International IEEE Conference on, págs. 585-590, October 2004, doi:10. 1109/ITSC.2004.1398966.

$\left[\mathrm{SCB}^{+} 06\right]$ Scanaill, C.N. et al., A review of approaches to mobility telemonitoring of the elderly in their living environment. Annals of Biomedical Engineering, tomo 34 (4): págs. 547-563, April 2006, doi:10.1007/s10439-005-9068-2.

[SG06] Sepulcres, M. y Gozálvez, J., Dimensionado de sistemas de comunicaciones móviles entre vehículos para aplicaciones de seguridad. Libro de Actas -URSI 2006. XI Simposium Nacional de la Unión Científica Internacional de Radio, 2006, págs. 1.158-1.161, September 2006.

[SGSSA08] Santa, J., Gómez-Skarmeta, A.F. y Sánchez-Artigas, M., Architecture and evaluation of a unified $\mathrm{V} 2 \mathrm{~V}$ and $\mathrm{V} 2 \mathrm{I}$ communication system based on cellular networks. Computer Communications, tomo 13 (12): págs. 2.850-2.861, July 2008, doi:10.1016/j.comcom.2007.12.008, URL http://www.sciencedirect.com/science/article/ B6TYP-4RDS 4 3D-2/2/2cfb 740205958 d1b85df688b 90429835. [Online: Último acceso Julio 2008].

[Sha04] Sharma, U.C., Infrared detectors. M. tech credit seminar report, Electronic System Group, EE Dept, IIT Bombay, October 2004.

[SIC02a] SICK, Quick Manual for LMS Communication Setup - Hardware setup and measurement mode configuration. Auto Indent. SICK AG, version 1.1 edición, March 2002.

[SIC02b] SICK, Quick Manual for MST Demo Setup - Software setup and configuration. Division Auto Indent. SICK AG, version 1.0 edición, August 2002. 8007 954/0000/04-04-2003.

[SIC02c] SICK, Technical Description: LMS 200/211/220/221/291. Laser Measurement Systems. Auto Indent. SICK AG, version 1.1 edición, January 2002. 8008 970/01-2002. 
[SIC06] SICK, Telegrams for Configuring and Operating the LMS 2xx. Laser Measurement Systems. Firmware Version v2.30/X1.27. Division Auto Indent. SICK AG, 2006. 8007 954/Q501/2006-08-01.

[Siz00] Sizov, S.S., Infrared detectors: outlook and means. Semiconductors Physics, Quantum Electronics \& Optoelectronics, tomo 3 (1): págs. 52-58, 2000.

[SMO06] Scheaffer, R.L., Mendenhall, W. y Ott, R.L., Elementary Survey Sampling. Thompson, sixth edición, 2006, ISBN 0-534-41805-8.

[Sán09] Sánchez, A.C., Muestreo y tamaño de la muestra. 2009, URL http: / / www. monografías . com/. [Online; Último acceso Julio 2009].

[Soc09] Society, I.T.S. IEEE, 2009, URL http://www.ewh. ieee.org/tc/its / index .html. [Online: Último acceso Noviembre 2009].

[sR08] s, M. y Rodríguez, A., Clasificación automática de fuentes de ruido de tráfico. Acústica 2008, V Congreso Ibérico de Acústica, 39 Congreso Español de Acústica, Coimbra, Portugal, 20-22 Octubre 2008.

[SS99] Schapire, R.E. y Singer, Y., Improving boosting algorithms using confidencerated predictions. Machine Learning, págs. 297-336, 1999.

[SS08] Schiattino, I. y Silva, C., Árboles de clasificación y regresión: Modelos cart. Ciencia \& Trabajo, págs. 161-166, December 2008.

[Sti63] Stirling, N.C., Detection range prediction for infrared detection systems. Proceedings of the IEEE, tomo 51 (10): págs. 1327-1336, October 1963, ISSN 0018-9219.

[STY04] Sawant, H., Tan, J. y Yang, Q., A sensor networked approach for intelligent transportation systems. Intelligent Robots and Systems, 2004. (IROS 2004). Proceedings. 2004 IEEE/RSJ International Conference on, tomo 2: págs. 17961801, September-2 October 2004, doi:10.1109/IROS.2004.1389657.

[Sut02] Sutter, E., Embedded Systems Firmware Demystified. Embedded Technology, Kansas: CMP Books, 2002, ISBN 1-57820-099-7.

[SYOC08] Seo, G. et al., An approach for data collection and traffic signal control in the futuristic city. Advanced Communication Technology, 2008. ICACT 2008. $10^{\text {th }}$ International Conference on, tomo 1: págs. 667-672, February 2008, ISSN 17389445, doi:10.1109/ICACT.2008.4493849.

[TA00] Turner, J.D. y Austin, L., A review of current sensor technologies and applications within automotive and traffic control systems. Institute of the Mechanical Engineers, 2000. Proceedings IMechE 2000, tomo 214 (D): págs. 589-614, 2000.

[Tec05] Technology, F., Data Sheet: FT245BL USB FIFO. Future Technology Devices Intl. Ltd., 373 Scotland Street, Glasgow G5 8QB, United Kingdom, version 1.7 edición, 2005. 
[Tec09] Technology, M., Dsc product tree. Microchip Technology Inc., 2009, URL http: / / www . microchip.com/. [Online: Último acceso Febrero 2009].

[Tek09] Teknomo, K., Tutorial on decision tree. 2009, URL http://people. revoledu.com/kardi/tutorial/decisiontree/. [Online; Último acceso Agosto 2009].

[Tho02] Thompson, S.K., Sampling. Wiley Series in Probability and Mathematical Statistics, New York, NY: John Wiley and Sons, 2ª edición, 2002, ISBN 0-47129116-1.

[TRA06] TRACKSS, Technologies for road advanced cooperative knowledge sharing sensors. European Commission. DG Information Society Technologies. Esafety, January 2006, URL http: / / www.trackss. net/. [Online: Último acceso Enero 2009].

[TRA08] TRACKSS, D7.1 Evaluation Guidelines \& Plan. TRACKSS Consortium: Technologies for Road Advanced Cooperative Knowledge Sharing Sensors, 2008 .

[TRB00] TRB, ed., Higway Capacity Manual, tomo II, capítulo Traffic Flow Parameters: 7. Washington, D.C.: National Research Council: Transportation Research Board, 2000, ISBN 0-309-06681-6.

[Tro06] Trochim, W.M., Research methods knowledge base. 2006, URL http: / / www . socialresearchmet hods . net/. [Online; Último acceso Julio 2009].

[TWM06] Tang, S., Wang, F.Y. y Miao, Q., Itsc '05: Current issues and research trends. IEEE Computer Science, págs. 96-102, March/April 2006.

[Uig95] Uiga, E., Optoelectronics. Englewood Cliffs: New Jersey: Prentice Hall, 1995, ISBN 0-02-422170-8.

[Ulz98] de Ulzurrum, J.D., Sistemas de control de accesos a valencia. Revista de Obras Públicas, págs. 55-70, Mayo 1998.

[Ulz02] de Ulzurrum, J.D., Red de transporte para los sistemas de gestión de tráfico de la dirección general de tráfico. BIT, tomo Especial: Sistemas de telecontrol (133), Junio 2002.

[UN03a] UN, Resolution adopted by the general assembly: Global road safety crisis. $56^{\text {th }}$ plenary meeting. United Nations, 19 November 2003. A/RES/58/9.

[UN03b] UN, Resolution adopted by the general assembly: Global road safety crisis. $86^{\text {th }}$ plenary meeting. United Nations, 29 May 2003. A/RES/57/309.

[UN04] UN, Resolution adopted by the general assembly: Improving road safety. $84^{\text {th }}$ plenary meeting. United Nations, 11 May 2004. A/RES/58/289.

[UN05] UN, Resolution adopted by the general assembly: Improving global road safety. $38^{\text {th }}$ plenary meeting. World Health Assembly, 26 October 2005. A/RES/60/5. 
[UN08] UN, Resolution adopted by the general assembly: Improving global road safety. $87^{\text {th }}$ plenary meeting. World Health Assembly, 31 March 2008. A/RES/62/244.

[UNF07] UNFPA, State of world population 2007.unleashing the potential of urban growth. United Nations Population Fund, 2007.

[Val88] Valdés, A., Ingeniería de Tráfico. Madrid: Bellisco, 3- edición, 1988, ISBN 8485198-22-0.

[VAVBB93] Van Arem, B. et al., Demonstration of a general european road data information exchange network - GERDIEN. Vehicle Navigation and Information Systems Conference, 1993., Proceedings of the IEEE-IEE, págs. 163-168, October 1993, doi:10.1109/VNIS.1993.585608.

$\left[\mathrm{VCK}^{+} 00\right] \quad$ Val, T. et al., Using télédomotis interface for a new multiservice network applied to monitoring the elderly. Universal Multiservice Networks, 2000. ECUMN 2000. $1^{\text {st }}$ European Conference on, págs. 433-438, 2000, doi:10.1109/ECUMN. 2000.880795 .

[Vil06] Ville, B.D., Decision Trees for Business Intelligence and Data Mining: Using SAS Enterprise Miner. SAS Publishing, 2006, ISBN 1590475674.

[Wan95] Wangler, R., Laser vehicle detector-classifier. Idea project - final report, Transportation Research Board. National Research Council, November 1995.

[WHA04] WHA, Resolution adopted by the 57th assembly: Road safety and health. World Health Assembly, 22 May 2004. WHA57.10.

[Wik09] Wikipedia, Firmware definition. Wikipedia, 2009, URL http://es. wikipedia.org/wiki/Firmware. [Online: Último acceso Febrero 2009].

[WN03] Wang, Y. y Nihan, N.L., Can single-loop detectors do the work of dual-loop detectors? Journal of Transportation Engineering, tomo 129 (2): págs. 169-176, March/April 2003, doi:10.1061/(ASCE)0733-947X(2003)129:2(169).

[Won06] Wong, J.Y., Ultra low power ndir gas sensor fire detector. US Patent and Trademark Office, 2006. Patent number: 7335885. Filing date: 3 March 2006. Issue date: 26 February 2008.

[WZ85] Wolfe, W.L. y Zissis, G.J., The infrared handbook. Arlington: Office of Naval Research, Department of the Navy, 1985, edited by Wolfe, William L.; Zissis, George J., 1985.

$\left[\mathrm{XOW}^{+} 07\right] \quad \mathrm{Xiang}, \mathrm{W}$. et al., Automated vehicle classification system using advanced noise reduction technology. Signal Processing and Communication Systems 2007. ICSPCS 2007. Conference on, December 2007.

[Xtr09] Xtralis, Traffic solutions. Xtralis, 2009, URL http://xtralis.com/p. Cfm? $s=22 \& p=381$. [Online; Último acceso Agosto 2009]. 
[Ye04] Ye, N., ed., The handbook of data mining. Lawrence Erlbaum Associates, 2004, ISBN 0805855637.

[YSJ07] Yoo, J.J., Sung, K.B. y Jang, J.A., Intelligent non-signalized intersections based on magnetic sensor networks. Intelligent Sensors, Sensor Networks and Information, 2007. ISSNIP 2007. $3^{\text {rd }}$ International Conference on, págs. 275280, December 2007, doi:10.1109/ISSNIP.2007.4496856.

[Zam06] Zambon, A., Thermally sensitive array device for presence detection around automatic doors. EPO, European Patent Office, 2006. European Patent number: EP1619342. United States Patent number: 7362224. Filing date: 22 July 2004. Publication date: 25 January 2006. Bulletin 2006/04.

[ZGBW07] Zhang, Z. et al., Moving targets detection and localization in passive infrared sensor networks. Information Fusion, $200710^{\text {th }}$ International Conference on, págs. 1-6, July 2007, doi:10.1109/ICIF.2007.4408178. 